\title{
MADE IN CHINA YEARBOOK 2017 GILDED AGE
}

Edited by

Ivan Franceschini and Nicholas Loubere

with the Made in China Editorial Board

Kevin Lin, Elisa Nesossi, Andrea E. Pia, and Christian Sorace

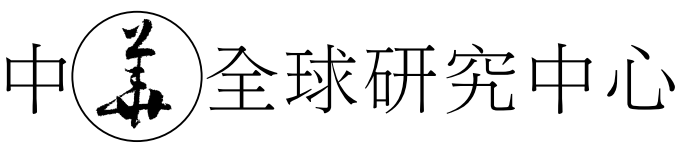

AUSTRALIAN CENTRE ON CHINA IN THE WORLD
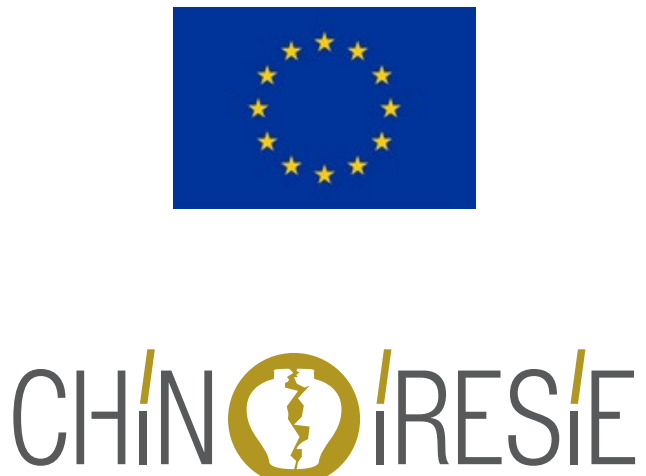

mismatched shards of China

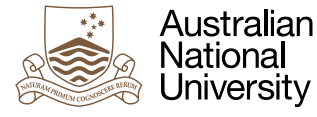

PRESS 


\section{( ) The Australian National University}

(as represented by the the Australian Centre on China in the World)

First published 2018 by ANU Press

The Australian National University

Acton ACT 2601, Australia

Email: anupress@anu.edu.au

This title is also available online at press.anu.edu.au

\begin{tabular}{|c|c|}
\hline$\prod_{r \pi n}$ & A catalogue record for this \\
\hline $\begin{array}{l}\text { NATIONAL } \\
\text { LIBRARA } \\
\text { OF AUSTALII }\end{array}$ & National Library of Australia \\
\hline
\end{tabular}

ISBN: 9781760461980 (paperback) 9781760461997 (ebook)

This title is published under a Creative Commons Attribution-NonCommercialNoDerivatives 4.0 International (CC BY-NC-ND 4.0).

\section{(c) $(1)$}

The full licence terms are available at creativecommons.org/licenses/by-nc-nd/4.0/ legalcode

Note on Visual Material

All images in this publication have been fully accredited. As this is a non-commercial publication, certain images have been used under a Creative Commons licence. These images have been sourced from Flickr. Wikipedia Commons and the copyright owner of each original picture is acknowledged and indicated in the source information.

Design Concept \& Typesetting by Tommaso Facchin; Illustrations by Marc Verdugo. Proofreading by Sharon Strange.

The Australian Centre on China in the World is an initiative of the Commonwealth Government of Australia and The Australian National University.

This project has been produced with the financial assistance of the Australian Centre on China in the World (CIW), Australian National University, and the European Union Horizon 2020 research and innovation programme under the Marie Skłodowska-Curie grant agreement No 654852. The views expressed are those of the individual authors and do not represent the views of the European Union, CIW, or the institutions to which the authors are affiliated. 


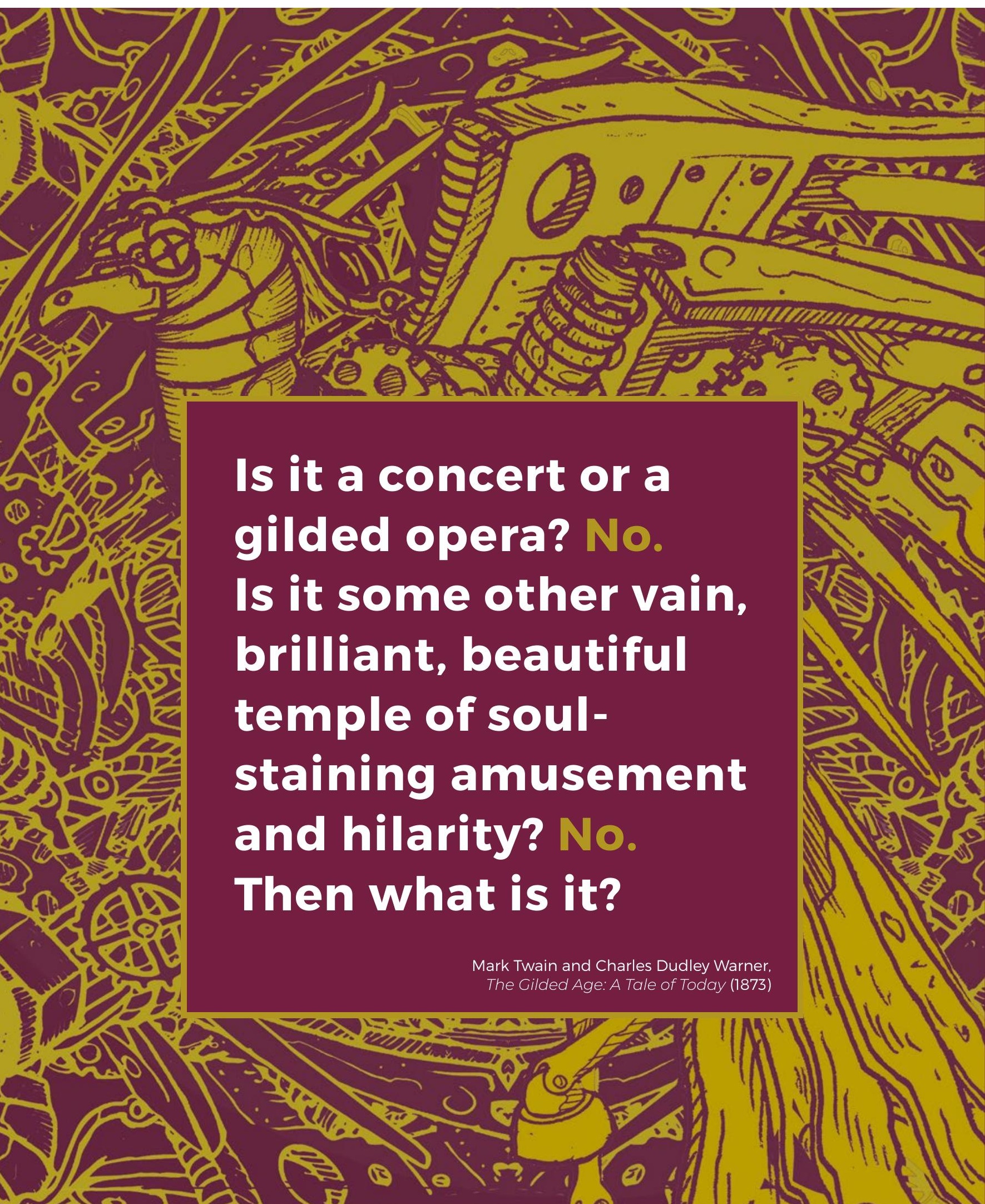




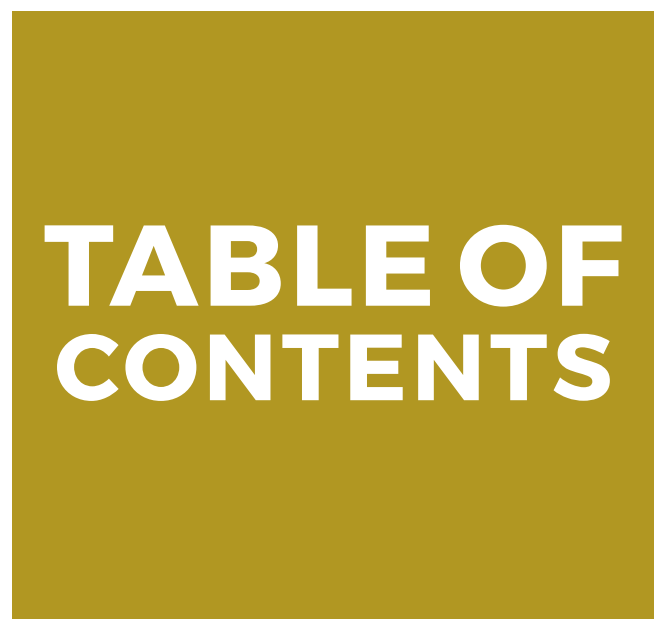

INTRODUCTION (PP. 8-12)

GILDED AGE (P. 8)

\section{BRIEFS (PP. 13-27)}

JANUARY-MARCH 2017 (P. 14)

APRIL-JUNE 2017 (P. 17)

JULY-SEPTEMBER 2017 (P. 21)

OCTOBER-DECEMBER 2017 (P. 24)

\section{CLASS AND PRECARITY IN CONTEMPORARY CHINA}

(PP. 28-71)

A GENEALOGY OF PRECARITY AND ITS

AMBIVALENCE (P. 30)

Francesca Coin

WORK PRECARISATION AND

NEW INEQUALITIES: THE ROLE OF MIGRATION (P. 34)

Fabio Perocco

MAKING CLASS AND PLACE IN CONTEMPORARY CHINA (P. 40)

Roberta Zavoretti

CLASS AND PRECARITY IN CHINA: A CONTESTED RELATIONSHIP (P. 44)

Chris Smith and Pun Ngai
FROM DORMITORY SYSTEM TO CONCILIATORY DESPOTISM:

CHANGING LABOUR REGIMES IN

CHINESE FACTORIES (P. 48)

Kaxton Siu

THE PRECARITY OF LAYOFFS AND STATE COMPENSATION: THE MINIMUM LIVELIHOOD GUARANTEE (P. 52)

Dorothy J. Solinger

COLLECTIVE BARGAINING IN CHINA IS DEAD: THE SITUATION IS EXCELLENT (P. 56)

Eli Friedman

COLLECTIVE BARGAINING OR UNIVERSAL BASIC INCOME: WHICH WAY FORWARD FOR CHINESE WORKERS? (P. 60)

Kevin Lin

COUNTING CONTENTION (P. 64)

Manfred Elfstrom

MIGRANTS, MASS ARREST, AND RESISTANCE IN CONTEMPORARY

CHINA (P. 68)

Ma Tian

\section{CHINESE LABOUR IN GLOBAL PERSPECTIVE (PP. 72-111)}

CHINESE MULTINATIONAL

CORPORATIONS IN EUROPE: RACINC TO THE BOTTOM? (P. 74)

Zheng $\mathrm{Yu}$ and Chris Smith

LIQUID LABOURSCAPE: AD HOC EXPERIMENTATION IN A CHINESE SPECIAL ECONOMIC ZONE IN LAOS (P. 80)

Antonella Diana 
OUTSOURCING EXPLOITATION:

CHINESE AND CAMBODIAN GARMENT WORKERS COMPARED (P. 84)

Ivan Franceschini

TRADE UNION REFORM IN ONE-

PARTY STATES: CHINA AND VIETNAM COMPARED (P. 90)

Anita Chan

PROSPECTS FOR US-CHINA UNION RELATIONS IN THE ERA OF XI AND

TRUMP (P. 96)

Katie Quan

\#iSLAVEAT10 (P. 102)

Jenny Chan

TREATING WHAT AILS THE STUDY OF CHINESE POLITICS (P. 106)

William Hurst

\section{THE END OF CHINESE CIVIL SOCIETY? (PP. 112-143)}

CONCEPTUAL CONFUSION IN THE RESEARCH ON CHINESE CIVIL

SOCIETY (P. 114)

Taru Salmenkari

CHINA'S SOCIAL ORGANISATIONS

AFTER THE CHARITY LAW (P. 118)

Karla W. Simon and Holly Snape

THE RISE OF FOUNDATIONS: HOPE FOR GRASSROOTS CIVIL SOCIETY IN CHINA? (P. 122)

Jessica $C$. Teets

WHAT FUTURE IS THERE FOR HUMAN RIGHTS LAWYERING IN CHINA? (P. 126)

Fu Hualing

THE MENTAL HEALTH COSTS OF

REPRESSION (P. 130)

Nicola Macbean
SNAPSHOTS OF CHINA'S 'UNCIVIL

SOCIETY' (P. 134)

Bфrge Bakken

SLAVING AWAY: THE 'BLACK BRICK

KILNS SCANDAL' TEN YEARS ON

(P. 138)

Ivan Franceschini

\section{CHINESE ENVIRONMENT AND THE COMMONS (PP. 144-171)}

A WATER COMMONS IN CHINA?

(P. 146)

Andrea E. Pia

AMATEURISM AND OUR COMMON CONCERN FOR BIODIVERSITY (P. 150)

Timothy McLellan

COMMONS AND THE RIGHT TO THE

CITY IN CONTEMPORARY CHINA

(P. 154)

Carlo Inverardi-Ferri

BURNING COAL IN TANGSHAN:

ENERGY RESOURCES AS COMMONS

(P. 158)

Edwin Schmitt

PROTECTING SACRED COMMONS:

BALANCING COMMODITY

VITICULTURE ECONOMIES WITH

ECOLOGICAL HEALTH IN SHANGRI-LA

(P. 162)

Brendan A. Galipeau

CHINA'S ENVIRONMENTAL

CRACKDOWN: THE CASE OF

CHENGDU (P. 166)

Daniel Fuchs and Edwin Schmitt 
WINDOW ON ASIA

(PP. 172-193)

IN THE ABSENCE OF A PEASANTRY,

WHAT, THEN, IS A HONG KONG

FARMER? (P. 174)

Loretta leng Tak Lou

BURMESE CIVIL SOCIETY CHALLENGES

CHINA'S DEVELOPMENT ASSISTANCE

IN MYANMAR (P. 178)

Jennifer Y.J. Hsu

BOOM OR BUST IN CHINA'S JADE

TRADE IN MYANMAR? (P. 182)

Henrik Kloppenborg M $\phi \mid l e r$

INDIAN LABOUR MOVEMENTS UNDER

MODI (P. 186)

Tom Barnes

IN THE SHADOW OF KEM LEY: IS

CIVIL SOCIETY THE SOLUTION TO

CAMBODIA'S WOES (P. 190)

Astrid Norén-Nilsson

WORK OF ARTS (PP. 194-233)

AI WEIWEI'S \#REFUGEES: A

TRANSCULTURAL AND TRANSMEDIA

JOURNEY (P. 196)

Giorgio Strafella and Daria Berg

REN HANG: BODIES WITHOUT

REDEMPTION (P. 200)

Chen Shuxia

LOSING THE WORLD: AFTER THE

MOOSE HAVE GONE AWAY (P. 206)

Christian Sorace
DATONG, FOREVER IN LIMBO (P. 210)

Jonathan J. Kinkel

CHINA'S INDUSTRIAL HERITAGE

WITHOUT HISTORY (P. 214)

Maris Boyd Gillette

INDUSTRIAL LANDSCAPES OF

SOCIALIST REALISM (P. 219)

Craig A. Smith

COLLECTING THE RED ERA IN

CONTEMPORARY CHINA (P. 224)

Emily Williams

RESURRECTING THE DEAD (P. 230)

Ivan Franceschini

CONTRIBUTORS (PP. 234-239)

BIBLIOGRAPHY (PP. 240-271) 


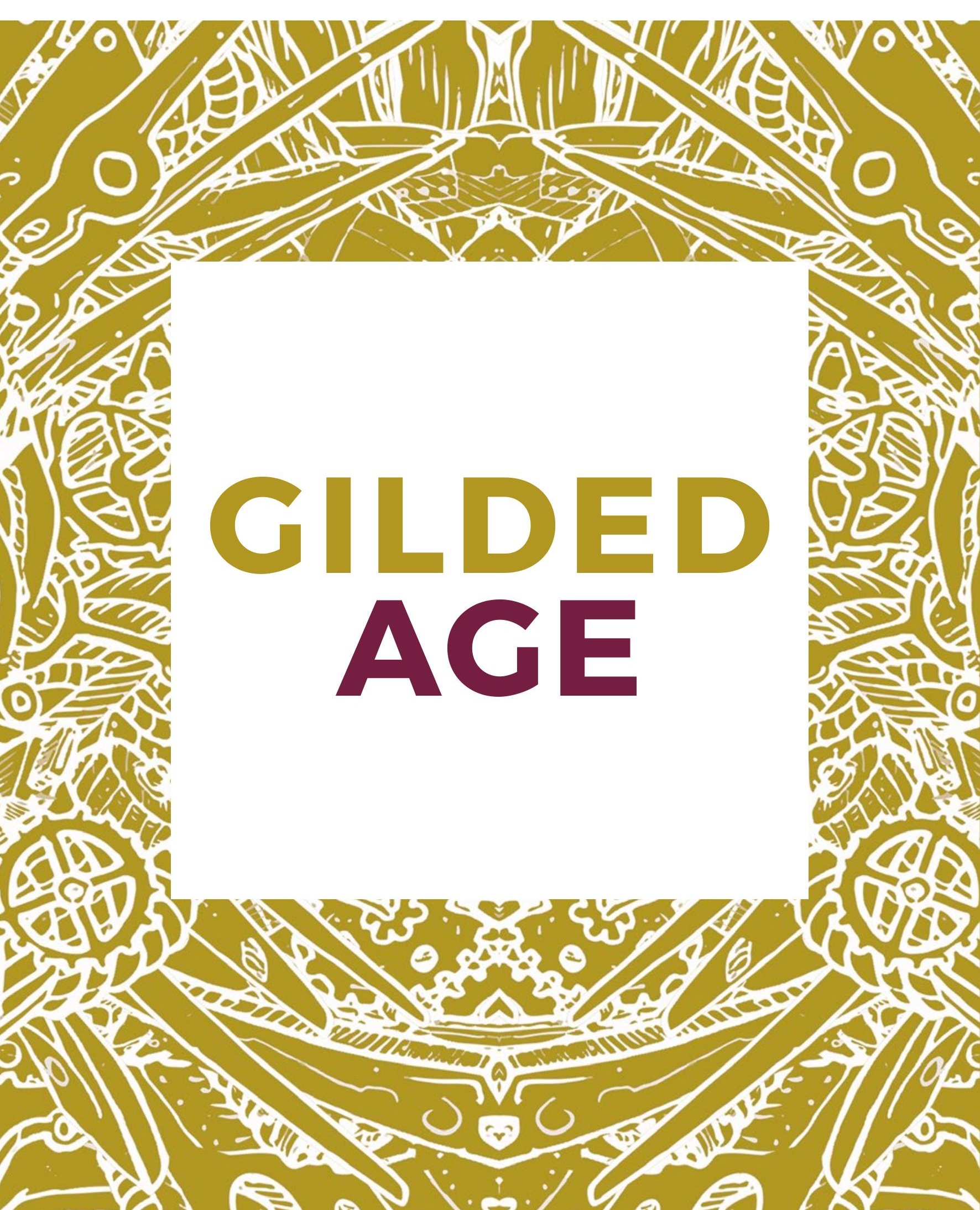




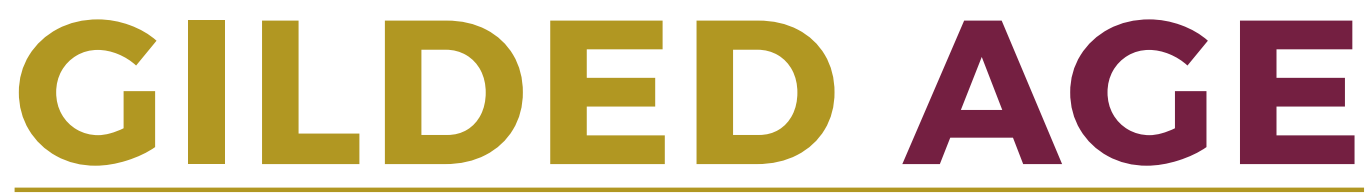

According to the Chinese zodiac, 2017 was the year of the 'fire rooster', an animal often associated with the mythical fenghuang, or 'August Rooster' (kunji). According to Chinese legend, the fenghuang is a magnificently beautiful bird whose appearance is an auspicious sign, as it marks the beginning of a new era of peaceful flourishing-such as in 1368, when the bird was allegedly last sighted on the grave of the father of the founder of the Ming dynasty. This legendary creature represents a moment of great hope and potential: it only remains during the harmonious reign of a righteous ruler, and disappears during times of unrest and chaos. It is worth noting that the previous year of the fire rooster began in 1957-a period marked by the unleashing of new freedoms and the hope for a new society defined by collectivism, followed quickly by repression and ultimately resulting in tragedy.

Considering the auspicious symbolism surrounding the fenghuang, it is fitting that on 18 October 2017, President Xi Jinping took to the stage of the Nineteenth Party Congress to proclaim the beginning of a 'new era' (xin shidai) for 'socialism with Chinese characteristics' (zhongguo tese shehuizhuyi). In his words:

This new era will be an era of building on past successes to further advance our cause, and of continuing in a new historical context to strive for the success of socialism with Chinese characteristics. It will be an era of securing a decisive victory in building a moderately prosperous society in all respects, and of moving on to all-out efforts to build a great modern socialist country. It will be an era for the Chinese people of all ethnic groups to work together and work hard to create a better life for themselves and ultimately achieve common prosperity for everyone. It will be an era for all of us, the sons and daughters of the Chinese nation, to strive with one heart to realise the Chinese Dream of national rejuvenation. It will be an era that sees China moving closer to centre stage and making greater contributions to mankind.

$\mathrm{Xi}$ also made a point of reiterating that the reverberations of this change would go far beyond the boundaries of China, insisting that this 'new era' presents 'a new option for other countries and nations who want to speed up their development while preserving their independence; and it offers Chinese wisdom and a Chinese approach to solving the problems facing mankind.'

It did not take long to discover that, in spite of such ecumenical proclamations, not all would be able to partake in this 'new era' of Chinese socialism. Migrant workers, for one, remain disposable. Barely one month after Xi's speech, on 19 November, a fire broke out in a popular housing block inhabited mostly by migrant workers in Beijing's Daxing district, killing nineteen. Citing the need to ensure safety, in a matter of days the local authorities forced thousands upon thousands of 'low-end people' (diduan renkou) to abandon their dwellings in the suburbs of the Chinese capital, showing absolutely no regard for their livelihoods. Families who had moved from all over China-and had, in some cases, lived in Beijing for years-were effectively thrown out on the street and left to their 
own fate in the freezing northern winter. In just a few days they lost everything, a cruel reminder of the precarity inherent to the life of the Chinese migrant. Lawyers, activists, and even ordinary citizens who dare to express critical views also hardly find a place in Xi's brave new world. In the past year, they have been silenced one after another through disappearances, arrests, and forced public confessions, as a newly revamped public security apparatus gears into motion. They have been labelled as disturbers of the public order, betrayers of the Chinese dream, mere tools in the hands of 'hostile foreign forces' always eager to wreak havoc in an otherwise harmonious society.

It is in this increasingly repressive context marked by rapid economic growth, uneven wealth creation, and China's expanding global reach, that we have titled this second volume of the Made in China Yearbook 'Gilded Age', alluding to the classic novel by Mark Twain and Charles Dudley Warner that satirises the endemic contradictions underpinning the rise of the United States of America at the end of the nineteenth century. There are many parallels that could be noted between that era and the one we now find ourselves in. The most relevant for our purposes is the fact that in both of these ages dramatic economic and technological advancements have been underpinned by the exploitation of workers, and the violent silencing of those who advocate for the subjugated and marginalised segments of society.

In this Yearbook we trace China's stark new 'gilded age' through the articles that appeared in our open-access Made in China journal in 2017. We have regrouped the essays into six thematic sections. The first, entitled 'Balancing Acts', examines different declinations of precarity. We open with two chapters that frame precarity in general terms-'A Genealogy of Precarity and Its Ambivalence', in which Francesca
Coin presents a brief conceptual history of precarity, and 'Work Precarisation and New Inequalities', in which Fabio Perocco looks at the vicious circle that links precarity and migration. In 'Making Class and Place in Contemporary China', Roberta Zavoretti contends that in China today, the statesponsored discursive production of migrant labourers as a homogeneous social group sustains the promotion of the hegemonic social model of an ideally emerging 'middle class'. In 'Class and Precarity in China', Chris Smith and Pun Ngai question the nexus between class and precariousness, demonstrating that the boundary between regular and non-regular work is far from static. In 'From Dormitory Regime to Conciliatory Despotism', Kaxton Siu adopts a long-term view to probe the new social, technical, and gendered divisions of labour inside Chinese garment factories. In 'The Precarity of Layoffs and State Compensation', Dorothy Solinger looks into the policy processes that have led to the emergence of urban poverty in China and at the prospect of poverty alleviation. These pieces are followed by two essays that consider the situation of collective bargaining in China-first, in 'Collective Bargaining Is Dead: The Situation Is Excellent', Eli Friedman argues that the recent decline in discussions about collective bargaining in China is not necessarily bad news, as it paves the way for public debate about other meaningful policies, such as universal basic income. This is followed by a response from Kevin Lin with 'Collective Bargaining and Universal Basic Income', in which he compares the two strategies in relation to the empowerment of Chinese workers. Moving on to the realm of worker protests, in 'Counting Contention', Manfred Elfstrom explains why it is so difficult to find accurate data about strikes in China. To conclude, in 'Migrants, Mass Arrest, and Resistance in Contemporary China', Ma Tian looks into how Chinese migrants 
are commonly perceived as criminals and assesses how this bias is reflected in mechanisms of crime control, as well as in the judicial and correctional systems.

Since in today's globalised and interconnected world, Chinese labour issues have become much more than merely a local matter, we have dedicated the second section-'Chinese Labour in Global Perspective'-to a series of essays that either frame Chinese labour comparatively or examine its transnational implications. In 'Chinese Multinational Corporations in Europe', Zheng $\mathrm{Yu}$ and Chris Smith challenge the widespread perception that Chinese investments are undermining labour standards in Europe. In 'Liquid Labourscape', Antonella Diana looks into the governance experimentations in a Chinese special economic zone in Laos. In 'Outsourcing Exploitation', Ivan Franceschini compares the wages, expectations, and needs of Chinese and Cambodian garment workers, examining how these factors are likely to impact labour activism. In 'Trade Union Reform in Two One-Party States', Anita Chan assesses the prospects for union democracy in China and Vietnam. In 'Prospects for US-China Union Relations in the Era of Xi and Trump', Katie Quan reconstructs the bumpy history of exchanges between American and Chinese unions, and suggests possible ways to foster mutual engagement in the current political climate. Finally, in '\#iSlaveat10', Jenny Chan reviews ten years of struggles at the infamous Taiwanese-owned Apple supplier, Foxconn: a company that transcends all national boundaries. To conclude, in the spirit of adopting a 'global' line of inquiry, we include 'Treating What Ails the Study of Chinese Politics', an essay in which William Hurst makes an argument for freeing political studies of China from isolation by engaging in comparative research.
The year 2017 saw the implementation of the Foreign NGOs Law and other regulations, which the Party-state has used to claim back control over civil society. In the past, there has been great eagerness to salute every small victory by Chinese NGOs and activists over the powerful Party-state as evidence that the authoritarian tide was finally receding, and that grassroots forces were stepping up to take a new role in Chinese politics and society. Now, with the arrest of yet another activist, the airing of yet another public confession, the closure of yet another NGO working for the weak and disenfranchised, and the passing of yet another repressive law, the world has come to view Chinese civil society as if it were on its deathbed. For sure, the ideal of Chinese civil society is ailing. But, if we consider the swiftness with which the Party-state has tamed these forces (at least for the time being), we wonder whether this civil society was ever there in first place. Could it be possible that we were simply projecting our hopes onto a handful of Chinese grassroots organisations and activists? Mourning the death of an ideal, in the third section'The End of Civil Society?'-we overcome our sorrow to look at the momentous changes that are currently taking place in the realm of Chinese civil society. In 'Conceptual Confusion in the Research on Chinese Civil Society', Taru Salmenkari highlights the biases and lack of clarity that undermines much of the discussion of Chinese civil society. In 'Chinese Grassroots Organisations after the Charity Law', the late Karla Simon and Holly Snape consider how the new legislation is likely to break down the old order and establish a new system of governance. In 'The Rise of Foundations', Jessica Teets examines the role of Chinese foundations in providing financial assistance to local NGOs now that foreign sources of funding are drying up. Shifting the focus from the realm of legislation to activism, in 'What Future 
Is There for Human Rights Lawyering in China?', Fu Hualing analyses the practices of Chinese human rights lawyers and examines the prospects for their survival in Xi Jinping's new era. In 'The Mental Health Costs of Repression', Nicola Macbean looks at the toll that the latest crackdown is taking on the psychological wellbeing of human rights lawyers in China. In 'Snapshots of China's “Uncivil Society”, Børge Bakken describes how the attempt by the Party-state to prevent a civil society from organising itself has led to the emergence of a rather uncivil type of society. Finally, in 'Slaving Away', Ivan Franceschini looks back at the 'black brick kilns scandal' that took place in China ten years ago and attempts to draw some lessons from those horrific stories of forced labour.

In June 2017, the government of the United States announced its intention to withdraw from the Paris Accord, severely undermining the global effort to contain climate change. Since then, China has attempted to portray itself as a world leader on environmental issues. Considering that China is currently the largest emitter of greenhouse gases, this development might appear paradoxical. Nevertheless, in recent years the Chinese authorities have become increasingly concerned with the toll that the many environmental catastrophes are taking on the health of the country's citizens, as this has the potential to spark unrest that could negatively affect governmental legitimacy. While global attention has focussed on China's top-down environmental efforts, in the fourth section-'The Good Earth'-we consider the engagement of Chinese citizens with state policies on the environment, and look into their potential for articulating workable grassroots alternatives. In particular, we examine the management of public resources-the so-called 'commons'. In 'A Chinese Water Commons?', Andrea Pia argues that there are places in rural China where water is already being managed as a common resource. In 'Amateurism and Our Common Concern for Biodiversity', Timothy McLellan outlines his experience with a project aimed at introducing biologically diverse agroforestry in a county in southwest China, and puts forward a critique of professionalisation in the realm of international environmental cooperation. In 'Commons and the Right to the City in Contemporary China', Carlo InverardiFerri tells the story of an urban village on the outskirts of Beijing, providing insights into the process of land commodification in today's China. In 'Burning Coal in Tangshan', Edwin Schmitt traces the history of coal mining in China, highlighting the nexus between the physical characteristics of energy resources and the development of the rules that govern them. Finally, in 'Protecting Sacred Commons', Brendan Galipeau explores how some Tibetan communities engaging in viticulture in northwest Yunnan province pursue an ecologically friendly agenda meant to protect 'common' sacred Buddhist landscapes. In this section we also include 'How China's Environmental Crackdown Is Affecting Business Owners and Workers', an essay in which Daniel Fuchs and Edwin Schmitt describe the human consequence of China's intensified environmental crackdown in Chengdu.

The fifth section-'Window on Asia'offers a series of perspectives on the latest developments in the field of labour and civil society across Asia. In 'In the Absence of a Peasantry, What, Then, is a Hong Kong Farmer?', Loretta Lou ponders the reasons for, and implications of, the absence of a discourse about peasantry in the former British colony. In 'Burmese Civil Society Challenges China's Development Assistance in Myanmar', Jennifer Hsu analyses how Burmese civil society has reacted to the challenges posed by Chinese aid and investment in the country. In 'Boom or Bust in China's Jade Trade with Myanmar?', Henrik 
Møller outlines the history of commercial exchanges of jade between China and its southern neighbour, and gauges the impact of the recent anti-corruption drive on this market. In 'Indian Labour Movements under Modi', Tom Barnes looks at the development of the worker movement in India under the right-wing government of Narendra Modi. Finally, 'In the Shadow of Kem Ley', Astrid Norén-Nilsson considers the politicisation of Cambodian civil society and the implications of this process in light of the latest authoritarian turn in Cambodian politics.

We wrap up the volume with a particularly rich cultural section titled 'Work of Arts'. In 'Ai Weiwei's \#Refugees', Giorgio Strafella and Daria Berg offer their take on the latest endeavours of the Chinese artist. In 'Bodies without Redemption', Chen Shuxia retraces the life of the late photographer Ren Hang, who committed suicide earlier in 2017. In 'Losing the World', Christian Sorace reviews Gu Tao's documentary The Last Moose of Aoluguya, about the forced relocation of the Evenki people in Northern China. In 'Datong, Forever in Limbo', Jonathan Kinkel reviews The Chinese Mayor, a documentary about a politician and a very ambitious plan. In 'China's Industrial Heritage without History', Maris Boyd Gillette examines the public memory of China's socialist industrial heritage. In 'Collecting the Red Era in Contemporary China', Emily Williams looks into the archival practices of Chinese collectors of Maoist memorabilia and how they relate to historical memory. In 'Industrial Landscapes of Socialist Realism', Craig Smith surveys the fate of a very peculiar form of socialist art in China and North Korea. Finally, in 'Resurrecting the Dead', Ivan Franceschini ponders the contemporary relevance of Old Tales Retold, Lu Xun's final oeuvre of fiction.

This volume recaps the second year of our Made in China journal. Since the journal's launch in 2016, the publication has grown beyond our wildest expectations, and we are grateful not only to all the contributors who have taken time out of their busy schedules to write for us, but also our readers, who have read and shared widely. The aim of Made in China is to create a bridge between academia and a wider audience, to make the research and work of our authors accessible to everybody, especially to those who might make use of their findings and ideas. For this reason, we strongly believe in open access. As the Chinese authorities step up their attempts to censor academic publications and to influence global public discourse on China-and as commercial academic publishers all over the world capitulate to the demands coming from Beijing-we are convinced that open access publishing remains key to academic freedom and integrity. Take the profit motive out of the equation, and it will be much harder for anybody to influence the decision of an editor or a publisher regarding what can and cannot be published. It will also be truly possible to reach out to (almost) everybody, not only to the members of a limited elite who are still entitled to access now largely unaffordable academic publications. It is this belief that motivates us to keep Made in China going, and it is with this conviction that we have now entered our third year of activity. We believe that the conformity and sycophancy that are increasingly underlining the debate in and on China can only be fought through critical engagement and inclusion. It is from this standpoint that we look back on the dramatic events of 2017, hoping that they represent an auspicious new awareness of our shared challenges, and that the fiery August Rooster does not end up betraying its promise by burning everything to the ground.

Ivan Franceschini and Nicholas Loubere 12 February 2018 


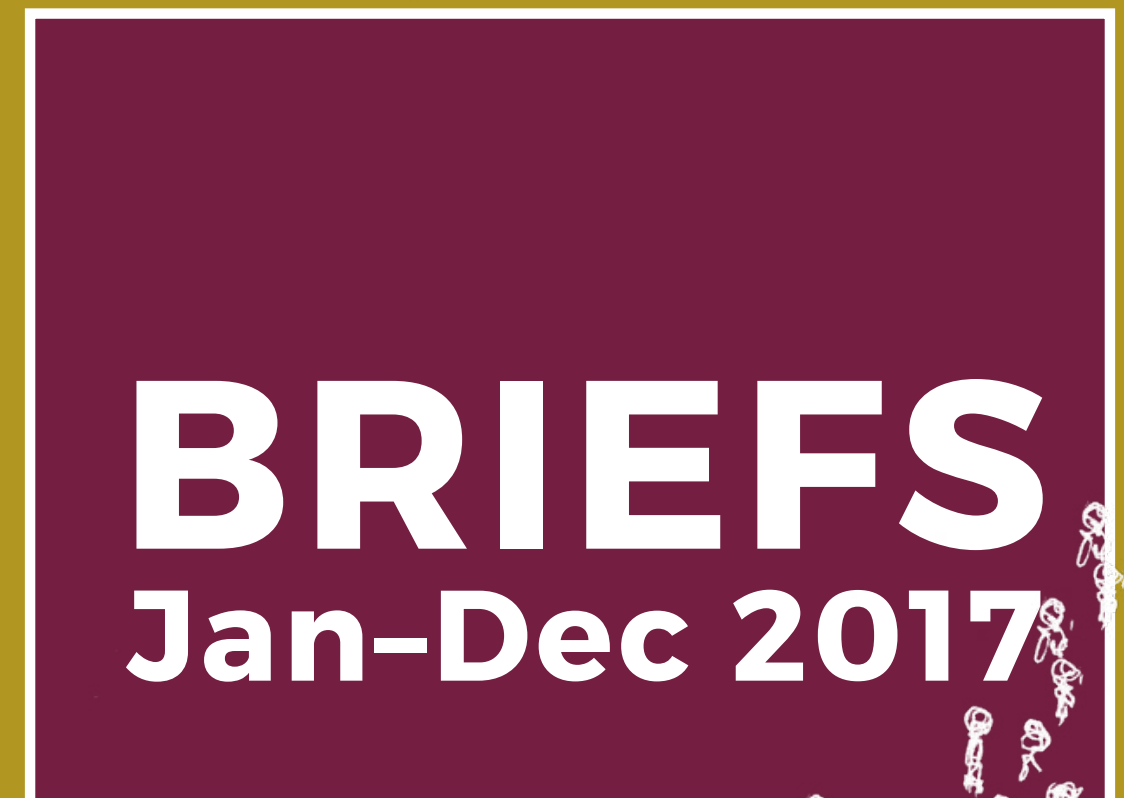

$88^{8}$ के

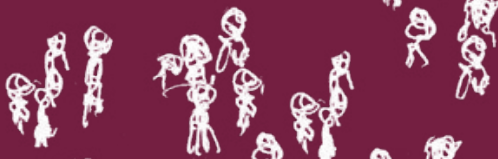
हैं की

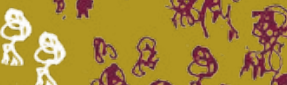
का

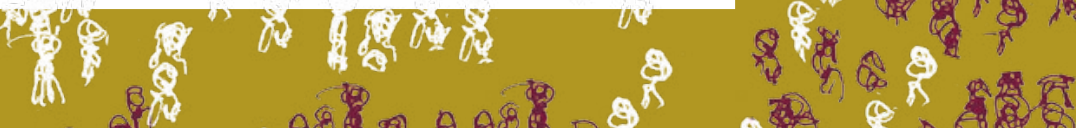

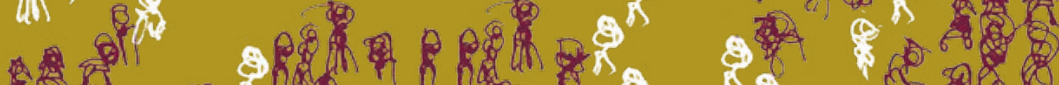
F.

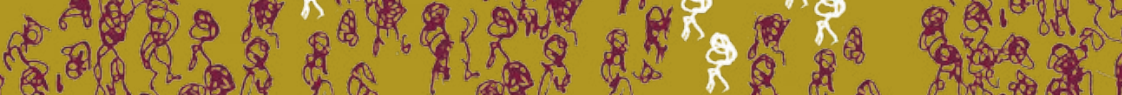
(2)

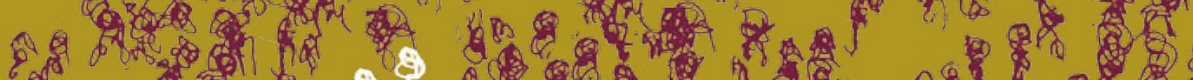
क्ष

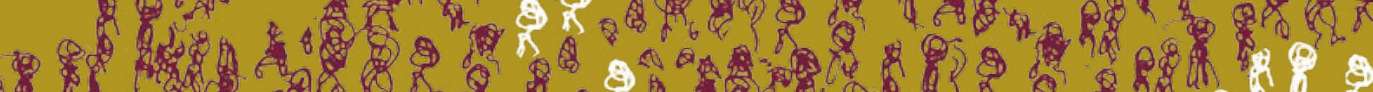

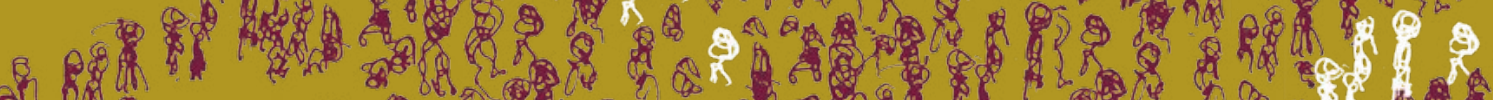

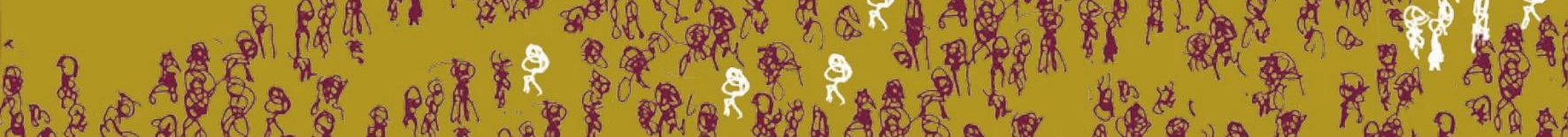
8.

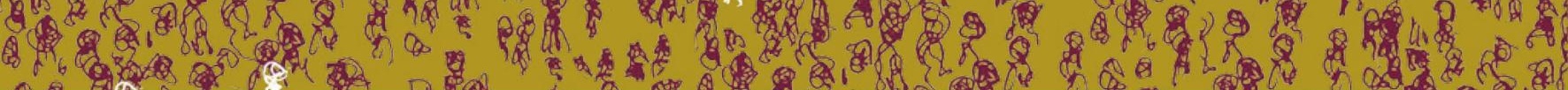




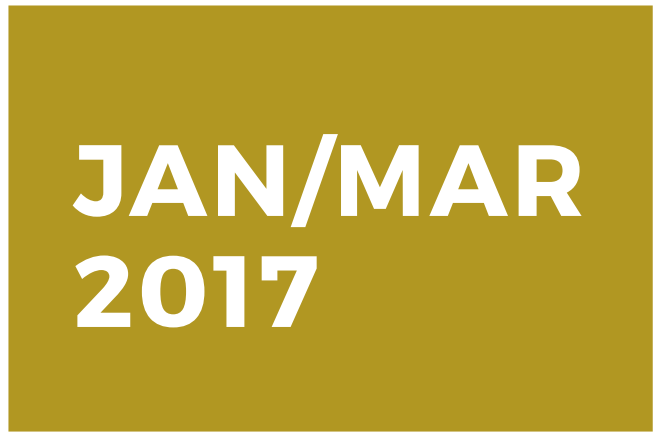

Foreign NGOs Law Enforced

On 1 January, the controversial Law on the Management of Foreign NGOs' Activities within Mainland China came into force. To clarify matters in the midst of legal and procedural uncertainty-the list of agencies allowed to supervise foreign organisations and the areas these organisations can work in was only released at the end of December-in early January the Ministry of Public Security (MPS) published an online manual in Chinese on how to register foreign NGOs. Roughly at the same time, thirty-six Chinese lawyers formed a legal service group to advise foreign NGOs and their local partners on matters related to the new legislation. Still, in early March only three dozen organisations had been able to complete the registration process. These included the World Economic Forum, Save the Children, the Bill and Melinda Gates Foundation, as well as several chambers of commerce. Many foreign NGOs simply adopted an attitude of wait and see, suspending their activities in China until they could observe how other organisations would fare in the registration process. Still, according to some observers, this difficult start did not warrant excessive pessimism. In the words of civil society scholar Shawn Shieh: 'In my experience working with Chinese and foreign NGOs in China is that both are quite creative and persistent and as long as there are pressing social needs for their work, they will find ways to work through or around the NGO Law.' IF

(Sources: China Development Brief; China Law Translate; The Diplomat; NGOs in China; South China Morning Post)

\section{Further Job Cuts in the Coal and Steel Industry Announced}

China's annual economic growth in 2016 reached the expected target of 6.7 percent, with the creation of more than thirteen million new jobs in cities and towns. Still, at the beginning of 2017 the employment prospects remained worrying, as China continued to rein in its overcapacity in heavy industries such as steel and coal. In a press conference held on 1 March, Yin Weimin, the Chinese Minister of Human Resources and Social Security, explained that arrangements were made in 2016 for 726,000 workers who had lost their jobs in the steel and coal industry. Moreover, he announced that an extra 500,000 workers would need similar arrangements in 2017. To facilitate this process, the authorities proposed four approaches: workers whose skills are applicable to other positions within their factories would be reassigned internally; workers with skills incompatible to other roles in the same factory would be relocated to other places, with the government providing them with job training and guidance; workers within five years of retirement would be encouraged to retire early; finally, a special effort would be made to ensure the livelihoods of disadvantaged and older workers who did not belong to the first three categories. $J L$

(Sources: Caixin 1; Caixin 2; Renminwang)

\footnotetext{
Authors can be identified by their initials at the end of each brief: Ivan Franceschini (IF), Kevin Lin (KL), Jamie Liu (JL), Nicholas Loubere (NL), and Elisa Nesossi (EN). The content of the briefs is based on news that has been widely reported on in various media outlets and on social media. Below each brief we list some of the outlets that have published on the topic, and in the electronic version of the volume we provide links to some of the articles.
} 


\section{Talks about Migrant Workers at the Two Sessions}

In early March, the annual 'Two Sessions' of the National People's Congress (NPC) and the Chinese People's Political Consultative Congress (CPPCC) convened in Beijing. On 5 March, Prime Minister Li Keqiang addressed the NPC. In his speech he reiterated once again the determination of the government to tackle the issue of wage arrears besetting migrant workers. The beleaguered situation of migrant workers also drew much attention from representatives. Some delegates contended that inadequate legislation on wage payment, lenient punishment for companies violating laws, and weak law enforcement are some of the main reasons for the persistence of wage arrears in China. They thus suggested that the government should reinforce its supervision of the labour market-for instance by creating a blacklist of law-violating companies and imposing stiff penalties on them. Wage arrears aside, a special personal income tax scheme was proposed, which would take into consideration the seasonal fluctuations in migrant workers' wages and therefore help increase their disposable income. Moreover, it was recommended that the government, in cooperation with firms, provide more vocational training to migrant workers to help them survive in the era of automation. $J L$

(Sources: Gongren Ribao; Xinhua 1; Xinhua 2; Zhonggongwang)

\section{Supreme People's Court Boasts about Arrest of Lawyer}

During the 'Two Sessions', Zhou Qiang-the President of the Supreme People's Courtpresented his annual report about developments in the work of the courts over the past year and plans for the year to come. In the very first section of the speech-entitled 'ensuring state security, punishing crime, and protecting human rights'-Zhou Qiang singled out the sentencing, 'according to the law', of weiquan lawyer Zhou Shifeng to seven years in jail as one of the key achievements in the protection of state security in 2016. This happened in concurrence with media reports about the issue of torture in relation to Chinese lawyers caught up in the '709 incident'-the crackdown against the 'rights protection' (weiquan) community that took place in July 2015. In January, the legal team of human rights lawyer Xie Yang, who was detained in Hongjiang, Hunan, on 11 July 2015, released the transcript of a conversation they had with their client to protest the decision of the authorities not to release him. In it, Xie described the details of the physical and mental abuse he had been subjected to while in detention. The transcript resonated with other similar incidents, particularly human rights lawyer Li Chunfu, who emerged from nearly seventeen months in police custody on 21 January in a shattered state, suffering from violent bouts of paranoia and with a diagnosis of schizophrenia. In an unprecedented move, on 1 March, China's official media responded to Xie's allegations, claiming that his torture was a story fabricated in order to attract international attention. State media accused disbarred lawyer Jiang Tianyong-himself detained since November 2016-of making up 'fake news', and featured interviews with him admitting to fabricating Xie's claims of torture. Chinese media reported that an 'independent' investigation by the authorities found that Xie had not been tortured. $E N$

(Sources: South China Morning Post; The New York Times; Global Times; Minnan Network; The Independent; Guanchazhe; Xinhua) 


\section{Grisly Murder Brings Back Haunting Memories}

In March, the Chinese media reported that in December 2016 a court in Beijing handed a suspended death sentence to two migrant workers from a village in Sichuan province, while three others were given jail terms ranging from fifteen years to life imprisonment for the premeditated murder of a colleague in August 2014. They had killed him on a construction site in Shunyi district, Beijing, and then used his corpse to stage a fake accident in order to claim compensation from the construction company by posing as relatives of the victim. Such grisly deeds are not unheard of in China. In May 2016, prosecutors in Inner Mongolia announced the indictment of seventy-four people for the killing of seventeen mine workers in order to blackmail mine owners running unlicensed operations into paying reparations. In 2009, the police discovered that several residents of a village in Leibo county, Sichuan province, were involved in buying or kidnapping people with severe mental problems to sell them as slaves or to kill them in mines to get compensation by posing as relatives. A similar situation was famously portrayed few years earlier in Li Yang's haunting movie Blind Shaft. IF

(Sources: Caixin English; The New York Times)

In 2009, the police discovered that several residents of a village in Leibo county, Sichuan province, were involved in buying or kidnapping people with severe mental problems to sell them as slaves or to kill them in mines to get compensation by posing as relatives."

\section{Chinese-Born Australian Scholar Prevented from Leaving China}

Over the weekend of 25 March, Feng Chongyi, a Chinese-born professor who has been teaching for over a decade at the University of Technology Sydney, was stopped at immigration checkpoints in Guangzhou while he was attempting to board a flight back to Australia. For a week, he was prevented from leaving China and remained in a hotel room, subject to interrogation by state security agents because of his alleged involvement in a threat to national security. He was allowed to leave the country on 1 April. Professor Feng, who is known for having repeatedly expressed critical views about the Chinese government and its political dealings in Australia, was in China to conduct research on weiquan lawyers during one of the worst crackdowns in years. The 'incident' happened while Prime Minister Li Keqiang was on an official visit in Australia to negotiate several trade deals, and when the Australian Parliament was on the verge of ratifying an extradition treaty long in the making with China. On 28 March, facing rising public concerns about China's record of abuse of national security charges to quash political dissent, Australian Prime Minister Malcolm Turnbull called off the vote on the extradition treaty. This incident followed the disappearance of Lee Ming-cheh, a Taiwanese human rights activist, the week before. According to friends and relatives, on 19 March, Lee had boarded a flight from Taipei to Macau, but he never emerged from the arrivals gate. $I F$

(Sources: The Guardian; Reuters; The New York Times 1; The New York Times 2; The New York Times 3) 


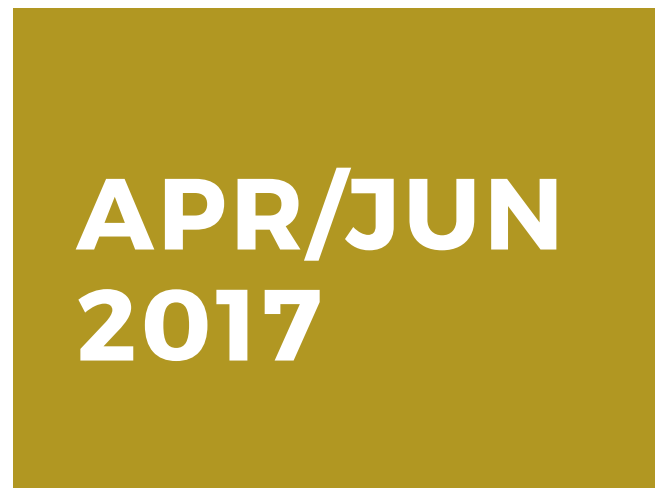

\section{Amnesty International Releases Report on Death Penalty in China}

In April, Amnesty released a report on the death penalty in China entitled 'China's Deadly Secrets'. In spite of the near absolute secrecy over the Chinese death penalty system, Amnesty estimated that in 2016 China carried out more executions than all other countries combined. The Report also objected to the unverifiable claims by the Chinese government that the country has been 'killing fewer, killing cautiously' (shaosha shensha). To The Guardian, Amnesty International East Asia Director Nicholas Bequelin explained that without concrete statistics there is no way to verify such claims, and demanded that China 'stop being a rogue state in the international community with respect to the death penalty and finally allow the Chinese people to have a proper, informed debate about capital punishment in the country.' Commenting on the Report for The New York Times, Professor Susan Trevaskes, an expert on the death penalty in China, claimed that the number of people executed annually is probably in the 'low thousands' and that the Chinese government has significantly reduced the use of capital punishment since the mid-2000s. According to the Report on China released by Amnesty International, a partial dataset of cases shows that farmers and the unemployed constitute the majority of people given death sentences. $E N$

(Sources: Amnesty International Global Report; Amnesty International China Report; The Guardian; Quartz; The New York Times)

\section{Beijing Offers Rewards for Reporting Spies}

On 10 April, the Beijing State Security Bureau released a set of Measures on Rewards for Citizens Reporting Leads on Espionage Conduct. These regulations promised informants who reported on spies rewards ranging between 10,000 and 500,000 yuan, depending on the relevance and usefulness of the information provided. The new regulations were accompanied by the online publication of a cartoon in which a young boy donning the red scarf of a Communist Young Pioneer reports a bearded foreigner wearing a bandit's mask. This was not the first sign of an increasing concern with matters of national security among the Chinese leadership. Back in 2013, President Xi Jinping established a new, secretive National Security Commission of the Communist Party of China in an apparently successful attempt to consolidate the political leadership of all the components of the country's fragmented security apparatus. In November 2014, the Chinese government passed a Counterespionage Law, followed a few months later by a National Security Law. In November 2015 , Jilin province was the first to introduce a hotline for residents to report possible spies. Since the passing of the National Security Law, the Chinese government has declared 15 April 'National Security Education Day', i.e. a day for raising public awareness of national security issues. That these concerns remain paramount to the Chinese leadership was also highlighted by the unusually brief round of discussions that preceded the adoption of the new National Intelligence Law-which regulates the activities of state security bodies-on 27 June. IF

(Sources: China Law Translate 1; China Law Translate 2; Reuters; The New York Times 1; The New York Times 2; The Paper) 


\section{Salaries of Executives in State- Owned Enterprises Linked to Party-Building Effort}

On 17 April, Premier Li Keqiang told a meeting of top state-owned enterprise (SOE) executives at the State-owned Assets Supervision and Administration Commission in Beijing that the government was reconsidering a 2015 policy capping their pay, and promised more competitive rates tied to performance. According to a Xinhua report, executives' pay and other rewards or punishments will be linked to how well individuals carry out 'Party building' work. This was part of the government's attempt to reform SOE management in order to restructure, modernise, and internationalise the state sector. At the time, the news was seen as an effort to re-establish the role of the Party in China's state industry, and retain loyal and talented managers. Since 2013, President Xi Jinping has been pushing for China's state sector-whose worth is estimated at twenty trillion USD-to embrace structural reforms while reining in state sector managers' pay. In 2017, China once again pushed forward state-enterprise reform, with ten large state-owned enterprises started selling stakes in their units. However, the pace of the reform has remained slow, and concern over unrest by laidoff state workers has similarly stalled reforms of state-owned steel and coal enterprises. $K L$

(Sources: Bloomberg; Reuters; South China Morning Post; Xinhua News)

\author{
In 2017, China once again \\ pushed forward state- \\ enterprise reform... However, \\ the pace of the reform has \\ remained slow, and concern \\ over unrest by laidoff state \\ workers has similarly stalled \\ reforms of state-owned steel \\ and coal enterprises."
}

\section{National Bureau of Statistics Releases Annual Report on Migrant Workers}

At the end of April, China's National Bureau of Statistics (NBS) released its latest annual report on Chinese migrant workers. According to the NBS, in 2016 there were $281,710,000$ migrants in China-1.5 percent more than the previous year. Chinese workers appeared to be increasingly reluctant to migrate far away from their hometowns. In 2016, 112,370,000 workers migrated within the boundaries of their town (xiangzhen) of permanent residence-3.4 percent more than the previous year-compared to $169,340,000$ who moved away, an increase of barely 0.3 percent. Significantly, 88.2 percent of the new migrant workers did not leave their towns of permanent residence. Inter-provincial migration was also dropping: 76,660,000 workers migrated to another province in 2016, 1 percent less than the previous year. Other significant trends included: a) an increase in the percentage of female migrants, who constituted 35.5 percent of the total migrant workforce in 2016 ; b) the progressive aging of migrant workers, with the average age in 2016 being thirty-nine, 0.4 years older than the previous year; and c) an improvement in the educational level, with the percentage of migrant workers holding a high school diploma-17 percentgrowing by 1.2 percent. Data related to the protection of labour rights were mixed. In 2016, migrants worked an average of 24.9 days a month and 8.5 hours a day, with 64.4 percent working more than eight hours a day, a decrease of 0.4 percent compared to the previous year. The contractualisation rate was 35.1 percent-1.1 percent less than the previous year. 2,369,000 migrant workers were owed back wages-a drop of 14.1 percent compared to 2015. In general, salaries were still on the rise. In 2016, migrant workers received an average of 3,275 yuan-or 203 yuan more than the previous year-a growth rate of 6.6 percent. However, the growth rate for wages slowed by 0.6 percent. IF

(Sources: Caixin; National Bureau of Statistics; Sixth Tone) 


\section{Fan Yusu Highlights Plight of Domestic Workers}

In late April, Fan Yusu, a forty-four-year-old female migrant worker from Hubei province, was propelled to literary stardom when her essay entitled 'I am Fan Yusu' went viral. Fan's writing recounted a life marked by patriarchy, domestic abuse, and raising children singlehandedly. She detailed her feelings of isolation, and the challenges she faced living as a domestic migrant worker in Beijing. Fan also reflected on her experiences of exploitation at the hands of employers, and the unequal treatment she had faced as a migrant due to government policies, stressing the need for solidarity between marginalised and exploited people. In the wake of her success, Fan was offered book deals and media appearances, but she shunned the spotlight, reportedly leaving Beijing and going into hiding until the unwanted attention subsided. $N L$

(Sources: China Digital Times; Los Angeles Review of Books; Sixth Tone; The Paper)

\section{My life is a book that's}

unbearable to read, and my fate has made the binding on that book extremely clumsy. I am from Xiangyang, Hubei. When I was twelve, I started teaching at the village school. If I never left my hometown, l'd have continued, and would have become a formal teacher there. But I couldn't bear to stay in the countryside viewing the sky from the bottom of a well, so I went to Beijing. I wanted to see the world. I was twenty that year."

Fan Yusu (translated by China Digital Times)

\section{Li Heping Is Sentenced, Lee Ming-cheh and Lu Yuyu Face Trial}

At the end of April, the ordeal of Li Heping, a prominent lawyer who was caught up in the '709 crackdown' against the weiquan community that took place in July 2015, came to an end. After being detained for almost two years, Li, who is well known to the international community for his overt rights activism, was convicted of 'subversion of state power'. In a secret trial, a court in Tianjin sentenced him to three years in prison with a four-year reprieve, meaning that he was to be released but could still be arrested again at any time. The court ruled that since 2008, Li Heping repeatedly used the Internet and foreign media interviews to discredit and attack China's state power and the legal system. The court also accused $\mathrm{Li}$ of accepting foreign funding and employing paid defendants. For many others the ordeal continued. On 26 May, the Chinese authorities formally announced that Lee Ming-cheh, the human rights advocate from Taiwan who had disappeared on arrival to Macao Airport in March, was under arrest on a charge of 'subverting state power'. Finally, on 23 June former migrant worker and blogger $\mathrm{Lu}$ Yuyu-who was detained in Yunnan province in June 2016 along with his partner Li Tingyu for his work of meticulously recording details of public protests online (see Manfred Elfstrom's chapter in the present volume)-stood trial for 'picking quarrels and provoking troubles', facing three to five years in jail. Li Tingyu was tried in April and later released without a verdict. $E N$

(Sources: BBC; Hong Kong Free Press; The Guardian; The New York Times; The Wall Street Journal; Weibo) 


\section{Undocumented Chinese Workers Protest in Saipan}

On 22 March, a Chinese construction worker died from a fall at the Imperial Pacific Casino construction site in the American Pacific island of Saipan. Soon after, Federal Bureau of Investigation agents raided the construction site and discovered hundreds of undocumented Chinese construction workers employed by a company named Suzhou Gold Mantis Construction and Decoration. They had been brought to Saipan illegally under a tourist visa programme, after being enticed by the false promises of the labour contractors. In April, United States prosecutors filed criminal charges against individuals connected to the Chinese labour contractors for illegally employing these workers, and the construction projects soon stalled. Investigators also discovered substandard working and living conditions. Out of job since early April, the undocumented workers fought for unpaid wages, staging public protests in front of the casino. On 16 May, over ninety unpaid workers received their salaries and placement fees, and flew back to China. On 1 June, another group of thirty-five Chinese workers staged a protest at the construction site to demand unpaid wages and reimbursement for medical fees for workplace injuries. Again on 22 June, forty-three unpaid workers protested at the same place against unpaid wages. After rejecting an offer of five thousand USD each from the company, the protesting workers insisted that unless all workers are paid the full wages owed to them, they will not return to China. Only in March 2018, following persistent efforts by the workers and as part of the investigation of the US Department of Labour, four Chinese construction companies agreed to pay 13.9 million USD in back wages and damages to 2,400 Chinese workers employed for the construction of the casino. $K L$

(Sources: Saipan Tribune 1; Saipan Tribune 2; Saipan Tribune 3; The New York Times; The Paper)

\section{Labour Activists Detained While Investigating Ivanka Trump's Manufacturer}

In late May, Hua Haifeng, Su Heng, and Li Zhao-three labour activists working for the New York-based advocacy group China Labor Watch (CLW)-were detained by the police in Ganzhou, Jiangxi province, while investigating labour conditions at factories making designer shoes for global brands. In particular, they were inspecting a supplier of Ivanka Trump's fashion brand. Earlier in May, CLW had issued an interim report that alleged forced overtime and a monthly salary of 2,500 yuan in this factory. The three investigators were charged on suspicion of illegal eavesdropping, and given limited access to lawyers. According to Li Qiang, the organisation's Executive Director, CLW had been conducting investigations in China for seventeen years, but this was the first time that its investigators have been detained. Ivanka Trump's brand has sought to distance itself from its Chinese supplier. On 5 June, Alicia Edwards, a spokeswoman for the US State Department, declared that the American government was concerned by the arrests, and added that the investigations carried out by Chinese labour activists help American companies to understand conditions in their supply chains in order to hold manufacturers accountable. In response, on 6 June Hua Chunying, spokeswoman for the Chinese Ministry of Foreign Affairs, said that the activists were being investigated on suspicion of using illegal 'professional surveillance equipment'. She added that the case was being dealt with according to the law and that no foreign country had the authority to interfere in China's judicial process. Relatives of the activists reported being harassed by the public security. On 27 June, the three investigators were released on bail. $K L$

(Sources: Associated Press; BBC; Bloomberg; The New York Times; The Paper) 


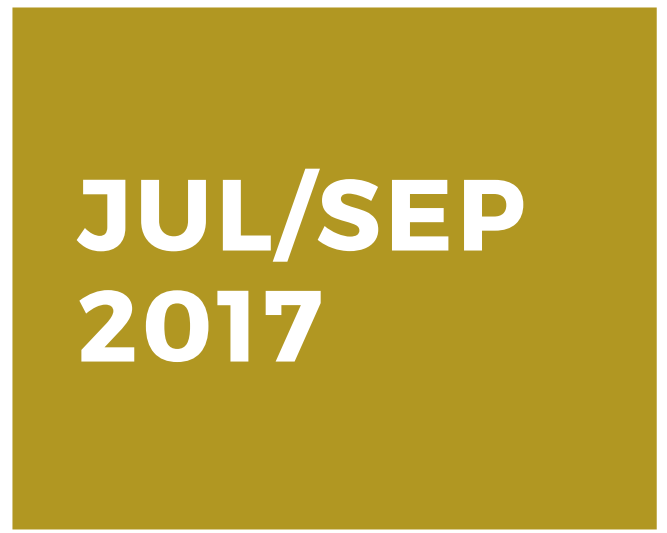

\section{Liu Xiaobo Passes Away and Liu Xia Goes Missing}

On 13 July, the activist and Nobel laureate Liu Xiaobo passed away at the age of sixty-one in the First Hospital of China Medical University in Shenyang. Much to the anger of his friends and supporters, his ashes were buried at sea, off the coast of Dalian. Liu had been imprisoned since 2009 for 'inciting state subversion', but in June was paroled to receive treatment for advanced liver cancer. Requests from Liu and his family to receive medical treatment outside of China were denied. After the funeral, Liu's wife-the artist Liu Xia-went missing for over a month, only appearing in a Youtube video to say she was mourning her husband's death outside of Beijing. The disappearance of Liu Xia, who has been under house arrest since 2010, sparked further international condemnation of the Chinese government. Chinese authorities denied detaining Liu Xia, claiming that she was a 'free citizen', and suggesting that she had not communicated with family or friends due to her grief. In early September, Liu Xia was reported to have returned to her Beijing home. However, her supporters remained concerned about her mental health, as she was reportedly suffering from depression induced by years of captivity, surveillance, and the death of her husband. NL

(Sources: BBC; South China Morning Post 1; South China Morning Post 2; The Guardian; The Washington Post)

\section{Continuing Repression of Human Rights Lawyers and Activists}

During the summer, the Chinese government continued its repression of human rights activists and lawyers. During a conference at the National Judges College in Beijing at the end of August, Minister of Justice Zhang Jun called on lawyers to refrain from engaging in protests, criticising judges and courts, and speaking or acting for personal gain or to boost their reputation. A couple of weeks later, the Ministry of Justice launched investigations into the conduct of several lawyers and law firms across China, including the firm of prominent human rights lawyer Mo Shaoping. In August, human rights lawyer Jiang Tianyong and online activist 'Super Vulgar Butcher' Wu Gan went on trial for their crimes of 'subversion of state power'. On 11 September, Taiwanese activist Lee Ming-cheh went on trial and pleaded guilty to charges of subversion in a televised confession. Lawyer Gao Zhisheng, under house arrest since 2014, was once again reported as missing and was believed to be in police custody. Labour activists did not fare any better. After initially being detained in May 2015, labour activist Liu Shaoming was sentenced to four and a half years in prison for 'inciting subversion of state power' in July. Similarly, in August, Lu Yuyu was sentenced to four years in prison on charges of 'picking quarrels and provoking trouble'. On a more positive note, human rights lawyer $\mathrm{Xu}$ Zhiyong and labour activist Meng Han were both released from prison, after serving sentences of four years and twenty-one months respectively for 'gathering crowds to disturb public order'. EN

(Sources: BBC; China Labour Bulletin; Front Line Defenders; Human Rights Watch; Ministry of Justice; Radio Free Asia 1; Radio Free Asia 2; South China Morning Post; The Australian; The New York Times) 


\section{University Apologises for Forced Internships}

In July, Shenyang Urban Construction University offered a public apology to a secondyear student pressured by the university into a three-month internship at a Foxconn factory in Yantai, Shandong province. The university had told her that, had she refused to comply, she would not have been able to graduate. To deal with rising labour costs, in recent years Taiwanese electronics manufacturer Foxconn has struck several deals with Chinese secondary vocational schools and universities to hire students as paid interns in its factories. This young workforce has often voiced dissatisfaction about cramped accommodations, inadequate meals, and a type of work that they consider to be unrelated to their studies. Since the apology, the Department of Education in Liaoning province-the area where the University is located-has ordered an investigation and halted such internships at public universities. Foxconn has also issued a statement, saying that the company had fully complied with the existing laws and regulations, and that interns had been fully informed about the programme and had the right to leave at any time. However, the company has a history of hiring interns that goes back at least a decade (see Jenny Chan's chapter in the present volume). Back in 2012, the Taiwanese manufacturer was criticised by labour rights groups for exploiting forced internship labour, but the company denied all allegations of wrongdoing. Only one year later, in 2013, as more evidence from investigations emerged, Foxconn was forced to admit that student interns worked overtime and night shifts at its Yantai factory. Even at that time, students reported that they had no choice but to take part in the factory internship programme if they wanted to graduate. $K L$

(Sources: Financial Times; Ministry of Education; South China Morning Post; The New York Times; Sina)

\section{Village in Beijing Charges Migrant Workers}

In July, the rural village of Qiuxian in Beijing's Daxing district announced plans to start charging migrant residents 2,000 yuan (about 295 USD) per month. The document released by the village leadership stated that the fees collected would be used to pay for public sanitation, tap water, public security, and electricity, but also made it clear that the levy would 'fulfil the target of having zero migrants in our village'. Those who did not pay would be denied services and evicted. As would become evident with the mass eviction of migrant workers from Beijing later in the year, the village's decision is best understood in the context of the government's policy to place further restrictions on the migrant population in the Chinese capital. In April, the authorities indicated their intention to cap the city's population-now at twentytwo million-at twenty-three million 'longterm residents' by 2020 . In recent years, the capital has also started moving its secondary bureaucracies and university campuses to cities in neighbouring Hebei province. Moreover, in 2016 alone, thirty million square metres of small shops, restaurants, and fruit stands considered to be 'illegal constructions' were dismantled, with plans to dismantle another forty million square metres in 2017. Schools for migrant children on the outskirts of Beijing have been forced to close, and car-sharing services have been restricted to local drivers, thus excluding migrants. While China is pursuing migrants' integration and urbanisation as an engine for economic growth in the transition away from low-end manufacturing, rural migrants are encouraged to stay away from mega-cities like Beijing and Shanghai, and instead settle in second-tier and provincial cities. $K L$

(Sources: Caixin Global 1; Caixin Global 2; Caixin (Chinese); Financial Times; South China Morning Post) 


\section{Maternal Leave Extended in Thirty Provinces}

Since the amended Population and Family Planning Law in January 2016 universally allowed married couples to have a second child, in September 2017 thirty provinces and regions required employers to extend paid maternity leave. In these areas, on top of the nationally mandated ninety-eight days, female employees are now entitled to an additional leave of one to three months. In more prosperous municipalities such as Beijing and Shanghai, as well as provinces like Zhejiang and Jiangsu, female employees are now given 128 days paid leave after the birth of a child. A number of provinces such as Hebei, Liaoning, Sichuan, and Shandong allowed female employees 158 days of paid maternity leave. While Henan and Hainan provinces saw the largest increase, from ninetyeight days to 190 days, the longest leave can be found in the Tibet Autonomous Region where female employees are now given one year of paid maternity leave. While this was good news for millions of female workers, Beijing News reported that many women still face difficulties in claiming this right, as many companies have adopted internal policies aimed at restricting the frequency and timing of pregnancies, and have imposed hefty financial penalties for violators. $K L$

(Sources: Beijing News (Chinese); Los Angeles Times; Shanghai Daily; SupChina)

\section{Beijing Attempts to Censor Foreign Academic Publications}

In mid-August, Cambridge University Press (CUP) conceded that it had acted on a request from Chinese authorities to block 315 articles from the Chinese website of The China Quarterly, one of the most prestigious and long-running international China Studies journals. CUP's decision prompted outrage in the academic community and beyond. After a few days of petitions and threats of an academic boycott, CUP reversed its decision and agreed to make all the censored articles available free of charge worldwide. While the scholarly community was successful in pressuring CUP, this incident exposed the serious challenges facing academic publishers operating in the lucrative Chinese market. It was subsequently revealed that LexisNexis, a provider of legal, regulatory, and business information, withdrew content in China at the request of the authorities. Moreover, in anonymous interviews at the Beijing International Book Fair in late August, other commercial publishers admitted to engaging in self-censorship in order to retain access to the Chinese market. Meanwhile, other disturbing revelations showed that censors were systematically deleting historical articles from Chinese journals that did not toe the current ideological line. Beijing responded defiantly to the international condemnation, inviting Western institutions to leave China if they did not want to follow Chinese rules, and warning that all imported publications 'must adhere to Chinese laws and regulations'. $N L$

(Sources: Global Times; Reuters 1; Reuters 2; South China Morning Post 1; The China Collection; The Guardian 1; The Guardian 2)

\section{In anonymous interviews at the Beijing International Book Fair... other commercial publishers admitted to engaging in self-censorship in order to retain access to the Chinese market. Meanwhile, other disturbing revelations showed that censors were systematically deleting historical articles from Chinese journals that did not toe the current ideological line."}




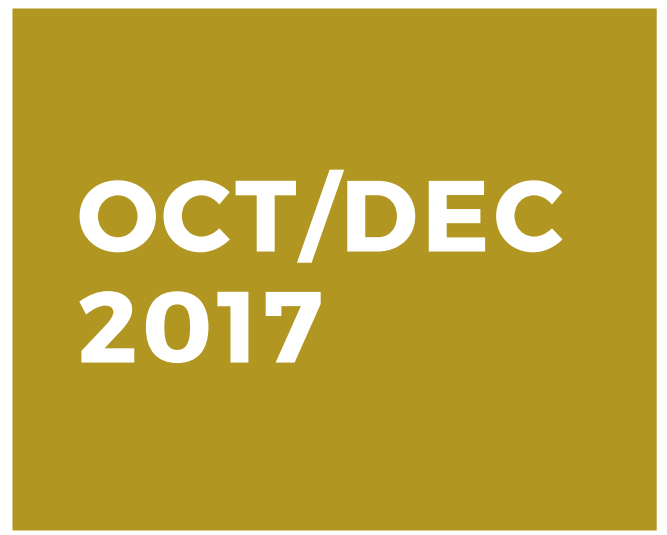

\section{Chinese Communist Party Holds Nineteenth National Congress}

Between 18 and 24 October, the Chinese Communist Party (CCP) held its Nineteenth National Congress. In his three-hour-long Report, General Secretary Xi Jinping heralded the dawn of a new era for socialism with Chinese characteristics, an age in which the contradiction between 'unbalanced and inadequate development and the people's evergrowing needs for a better life' has replaced that between the ever-growing material and cultural needs of the people and backward social production'. While not directly referring to workers, the Report went to great lengths to highlight the many achievements of the CCP in improving people's livelihoods (minsheng). Xi cited as evidence of these improvements the fact that government policies have lifted sixty million people out of poverty. He also recognised that employment is key to people's livelihoods, citing the steady creation of thirteen million urban jobs per year. The Report recommended policies to facilitate and improve the quality of employment, including expanding skills training and encouraging entrepreneurship. Since urban citizens have seen their incomes increase at a faster rate than China's economic growth, with the 'middle-income' group continuing to expand, the CCP called upon the government to play a role in income redistribution to narrow income disparity. Furthermore, Xi pointed to the success of establishing a better social security system, with efforts to expand the coverage of healthcare, pensions, unemployment insurance, and affordable housing. Xi concluded this section of the Report by pointing out that because of these efforts, society is stable and national security is strengthened as a result.

Despite the Report's claim that China is led by the working class in alliance with the peasantry, references to workers were few and far between. In the entire text, 'migrant workers' (nongmingong) were mentioned only once, in a passage that encouraged migrants to maintain multiple avenues for finding employment. The Report also made no mention of the household registration system (hukou or huji), a fundamental issue for rural migrants. References to 'workers' (gongren) were only made to state that the country is led by the working class, and to call on the CCP to expand membership among many groups, including workers. There was one further, brief reference to 'employees' (zhigong) in relation to improving the old-age pension system for urban employees.

The most explicit reference to labour relations came in a section on the tripartite collective negotiation mechanism. This tripartite system has been promoted since the 1990s, but has only taken on a sense of urgency in the last decade, as more and more workers have organised to demand higher pay and better conditions. The Report stated that a tripartite mechanism in which the government, official union (representing workers), and enterprises negotiate wages and labour conditions will contribute to a more just and orderly income distribution, as well as to more harmonious industrial relations. However, it must be noted that the push for tripartite collective negotiation has stalled in recent years and that the Report made only one reference to trade unions, where it demanded that mass organisations became more political, progressive, and mass-based, in order to more effectively serve as transmission belts between the Party and workers. In sum, it appears that even in the new era there will be very little that is new for China's working class. $K L$

(Sources: Party Congress Report in Chinese; Party Congress Report in English) 


\section{The Good Samaritan Law Comes into Effect}

On 1 October, the General Rules of Civil Law-a collection of general principles of Civil Lawcame into effect. Article 184 is generally referred to as the 'Good Samaritan Law', stating that those who attempt to aid others in emergency situations will not be liable under any circumstances. This clause aims at solving the dilemma of people who, after helping an injured person, end up falsely accused by the victim of having caused the injury in the first place. The scope of the article was the subject of numerous discussions that have resulted in Chinese legislators producing different drafts of the rule over the years. The core of the controversy concerned the definition of gross negligence in the process of rescue, and the general tendency of Chinese law to look at anyone connected to a loss to share that loss, regardless of their level of fault. The provision came in the wake of a number of incidents widely reported by the Chinese media, in which either bystanders showed egregious indifference to suffering, or victims who had received assistance sued their helpers. One of the most iconic cases took place in Nanjing in 2006. That year, a young man named Peng Yu helped an old woman to get to the hospital after she was injured while getting off a bus. In return, he was sued for his troubles. In that case, the court decided against him, stating that "no one would in good conscience help someone unless they feel guilty', causing a public furore (although in 2012 it turned out that Peng was actually guilty). In 2011, China was shocked by the case of Wang Yue, a twoyear-old toddler who passed away after having been run over by two vans while being ignored by passersby. More recently, in June 2017, a video went viral in China, in which a woman was hit by a vehicle and was then left unaided until a second vehicle killed her. $E N$

(Sources: BBC; Caixin; China Digital Times; National People's Congress; The China Collection; The New York Times; Xinhuanet;)

\section{Human Rights with Chinese Characteristics?}

On 7 December 2017, about three hundred participants from over fifty mostly developing countries gathered in Beijing for the 'SouthSouth Human Rights Forum'. In his opening address, President Xi Jinping reiterated that 'human rights must and can only be promoted in light of specific national conditions and people's needs.' The initiative took place after another string of harrowing events. In early November, the police in Liaoning province formally arrested human rights lawyer $\mathrm{Li}$ Yuhan for 'picking quarrels and provoking trouble'. On 7 November, dissident writer Yang Tongyan, who had been in detention since 2006 and had nearly completed a twelve-year sentence for subversion, died from a brain tumour barely three months after having been released on medical parole. Later the same month, two more activists-lawyer Jiang Tianyong and Taiwanese human rights activist Lee Ming-che-were respectively sentenced to two and five years imprisonment on subversion charges. At that time, there was little reaction from the international community. In late October, foreign media reported that a human rights panel at the United Nations had called on China to release and compensate three prominent human rights activists-Christian church leader $\mathrm{Hu}$ Shigen (condemned to seven and half years in detention), and lawyers Zhou Shifeng (condemned to seven years in detention) and Xie Yang. On 10 December, international Human Rights Day, the European Union Delegation and United States Embassy to China both released statements expressing concern about 'China's ongoing denial of human rights and fundamental freedoms'. IF

(Sources: China Change; China Digital Times; China News Service; EU Delegation to China; South China Morning Post 1; South China Morning Post 2; The Guardian 1; The Guardian 2; The New York Times) 


\section{China Continues to Extend Influence over Foreign Publishing and Universities}

In the months following the uproar caused by the Cambridge University Press censorship fiasco, the Chinese government continued to exert pressure on foreign publishers operating in the country. In late October, it was revealed that Springer Nature, one of the largest commercial academic publishers in the world, had capitulated to the Chinese censors, blocking access to at least one thousand 'politically sensitive' articles on their Chinese website. The publisher defended the decision by saying that only 1 percent of total content had been 'limited', and claiming that it was necessary to comply in order to avoid wider restrictions. In mid-November, Australian academic Clive Hamilton went public saying that Allen \& Unwin withdrew his forthcoming book Silent Invasion: How China Is Turning Australia into a Puppet State, due to fears of defamation litigation. In late November, SAGE Publishing warned that they might be required to censor content or be pushed out of the Chinese market. The increasing assertiveness of Chinese censors and their zeal to push foreign publishers to self-censor in order to access the large Chinese market resulted in numerous headlines and petitions. However, despite the high-profile coverage, the response from the wider academic community outside of China-focussed social sciences remained largely apathetic. Beijing's efforts to influence foreign academia were not limited to the publishing sphere. In mid-November, over two thousand foreign-funded joint venture universities in China were instructed to set up party units and give the new party secretaries a role in decision making through seats on institutional boards. This decision came at the end of a year filled with continuous controversy about Chinese influence in higher-education institutions abroad. $N L$

(Sources: BBC; Financial Times 1; Financial Times 2; Financial Times 3; Reuters; The New York Times)

\section{Beijing Evicts 'Low-end Population'}

On 18 November, a fire broke out in the basement of an apartment block inhabited mostly by migrant workers in Beijing's Daxing district, killing nineteen and injuring eight. Around four hundred people lived in cramped conditions in the two-story structure. In the aftermath of the tragedy, the city authorities launched a fortyday campaign to inspect and demolish buildings that unlawfully mixed residential and industrial facilities, as well as overcrowded apartments. This led to a wave of evictions that mostly affected the migrant population of the Chinese capital, with thousands of migrants forced out of their residences and left homeless in spite of the cold temperatures. As part of the campaign, officials also shut down small plants, shops, and restaurants, in some cases going as far as to cut electricity and water without any notice. While state censors were quick to take control of the media narrative, for a few days Chinese social media was abuzz with discussions and denunciations of how the crackdown was targeting Beijing's 'low-end population' (diduan renkou), a term that first appeared in official debates a few years ago referring to those who work in low-end service and manufacturing jobs, and that more recently has come back in vogue in relation to plans to cap the capital's population at twenty-three million by 2020. From the beginning of the campaign, the crackdown drew widespread condemnation from the Chinese public. Some migrant communities took to the streets in an attempt to resist, and more than one hundred intellectuals signed an open letter demanding an end to the evictions. Even some state media were unusually critical. On 27 November, Beijing Communist Party Chief Cai Qi declared that the campaign should not have been carried out in a simplistic and hasty manner, and that those evicted should have been given time to move out. IF

(Sources: BBC; Caixin Global; China Digital Times; China Media Project; People's Daily; Quartz; Reuters; South China Morning Post 1; South China Morning Post 2) 


\section{Foxconn Entangled in Another Scandal}

On 21 November, Foxconn came once again under the spotlight following a media investigation into its forced use of seasonal student interns. The Financial Times uncovered that three thousand high school students from the local Urban Rail Transit School had been forced to work eleven-hour shifts at the company's plant in Zhengzhou, Henan province, to produce the new iPhone $\mathrm{X}$. While admitting the violation of the rules regarding overtime, the company insisted that student internships were voluntary, a fact that was contradicted by the Financial Times investigation. The next day, on 22 November, Foxconn announced it had taken immediate action to address the violations. However, by that time, as the busy season from August to December was coming to an end, the use of student interns had already become unnecessary. Such practices have been found across electronics manufacturers. In October, the Hong Kong-based labour rights group, Students and Scholars Against Corporate Misbehaviour (SACOM), reported that vocational school students were forced to work also at Quanta Computer, which supplies global brands such as Apple, Acer, Hewlett-Packard, and Sony. Local governments have been complicit in allowing such practices to prevent businesses from relocating to other regions where labour is cheaper and more flexible. $K L$

(Sources: Financial Times; Sina News; The Guardian)

\section{New Implementation Rules for the Counter-espionage Law Released}

On 6 December, the State Council released the Implementation Rules for the Counterespionage Law that had come into force earlier in November 2014. The new Rules significantly enhance the powers of the State Security, which had already gained significant clout under the original legislation. In particular, Article 8 grants the State Security the power to investigate acts of subversion that are not necessarily related to espionage, including situations involving 'fabricating or distorting facts, publishing or disseminating text or information that endangers national security, or creating, transmitting, or publishing $\mathrm{a} / \mathrm{v}$ products or other publications that endanger national security'; 'using religion to carry out activities endangering national security'; and 'foreign individuals [violating] the relevant provisions, not [heeding] discouragement, and, without authorisation, [meeting] with mainland persons who have conduct endangering national security or who are strongly suspected of having conduct endangering national security'. Article 6 also expands the concept of 'funding' espionage to include providing funding to those who engage in espionage even if the money is not used for that aim and the funder is not aware of the illegal conduct. This significantly reinforces the hand of the State Security in dealing with activists and NGOs working in politically sensitive areas, and also serves to intimidate their foreign donors. $I F$

(Sources: China Law Translate 1; China Law Translate 2; South China Morning Post 1; South China Morning Post 2)

\section{The new Rules significantly enhance the powers of the State Security, which had already gained significant clout under the original legislation. In particular, Article 8 grants the State Security the power to investigate acts of subversion that are not necessarily related to espionage."}




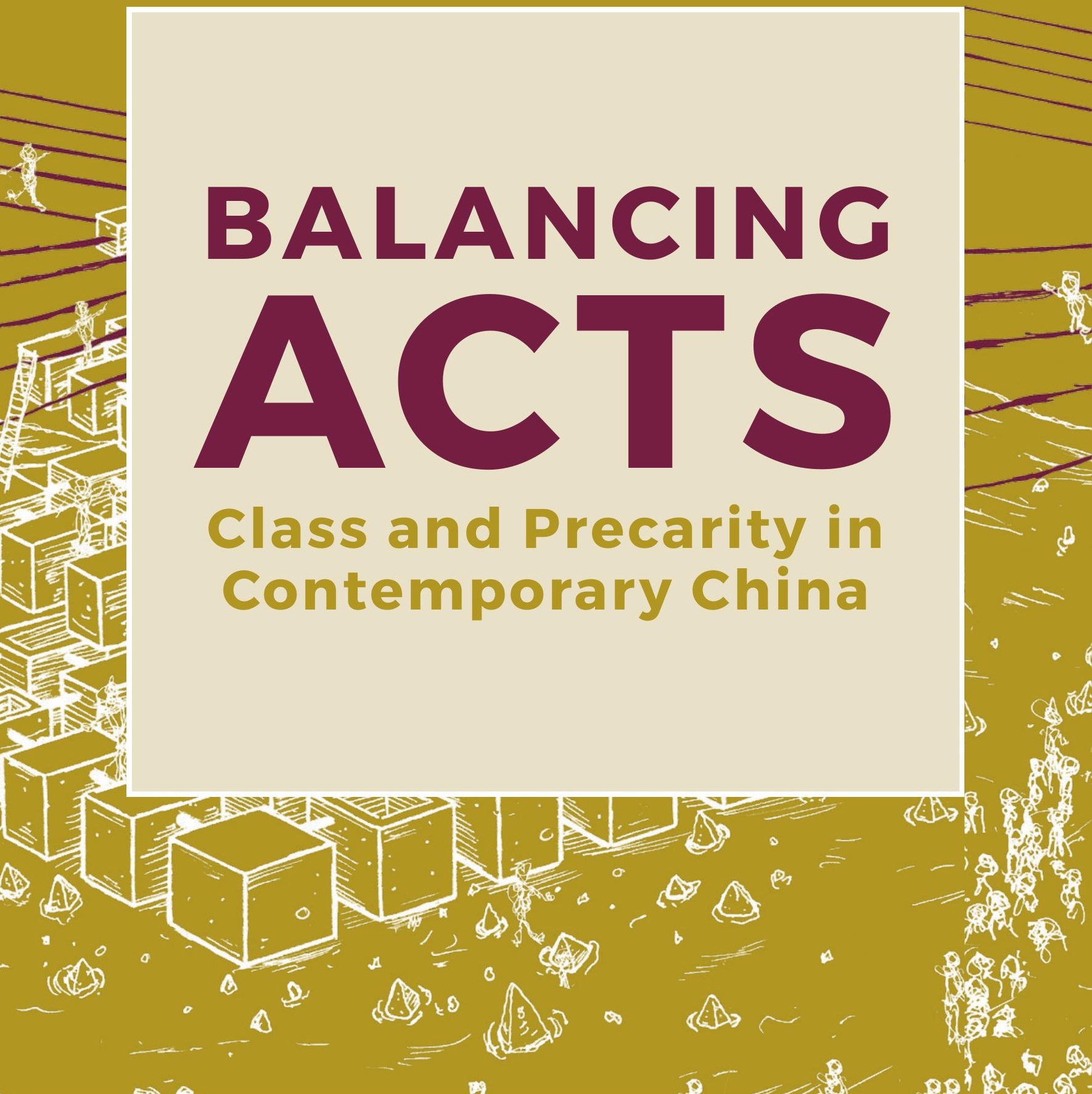



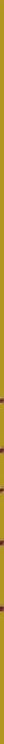
TEP
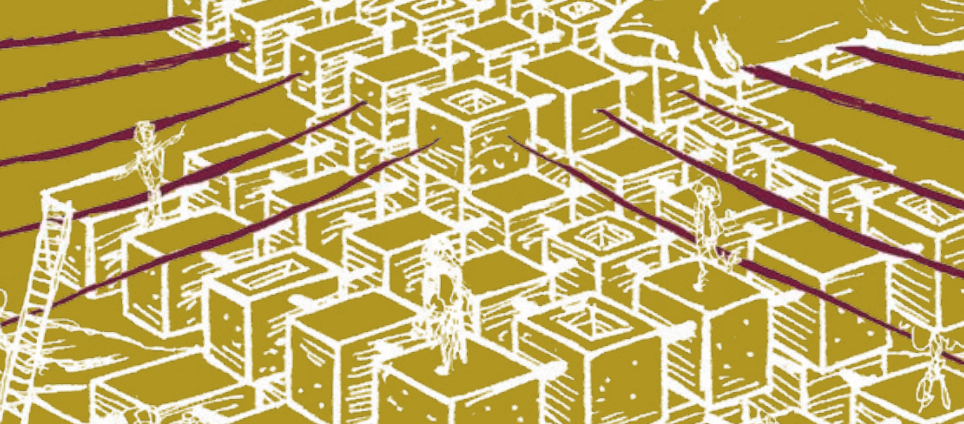

4 E

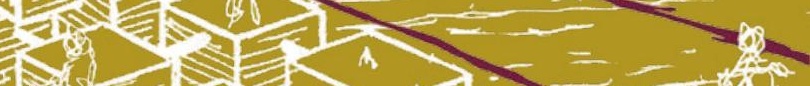

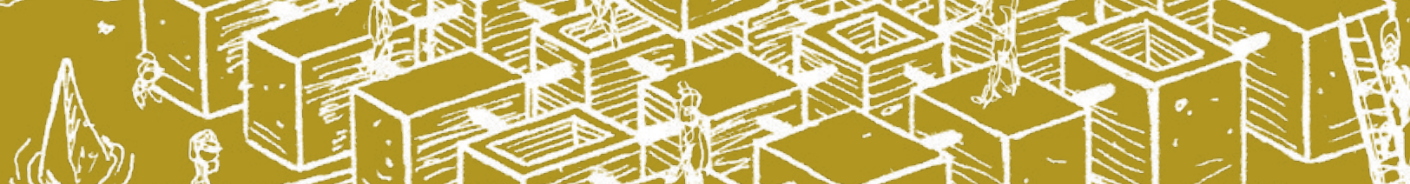

...
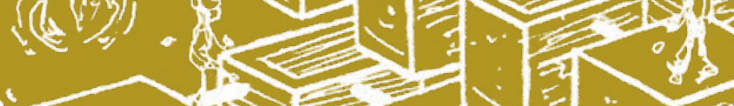

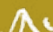

a

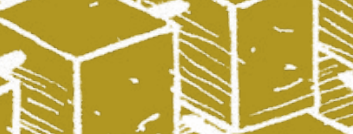

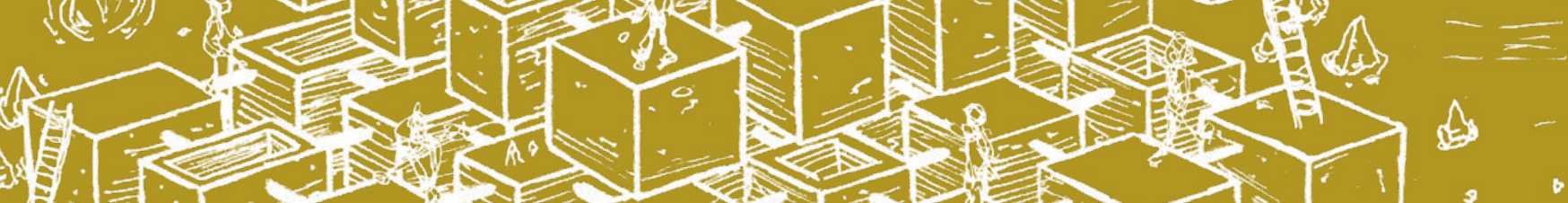

(4)

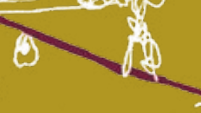
(2)

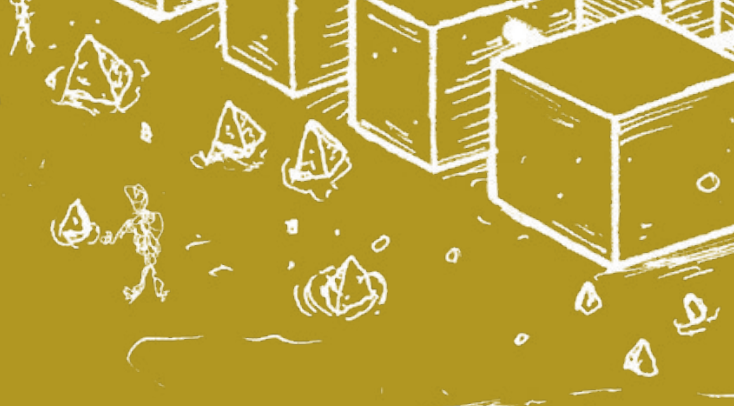

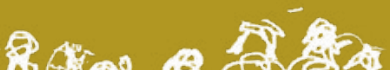

G $\Delta \sin _{\infty}$

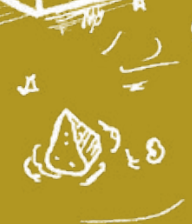

$\circ$

(B)

$+$

$\underline{=}$

(A) 


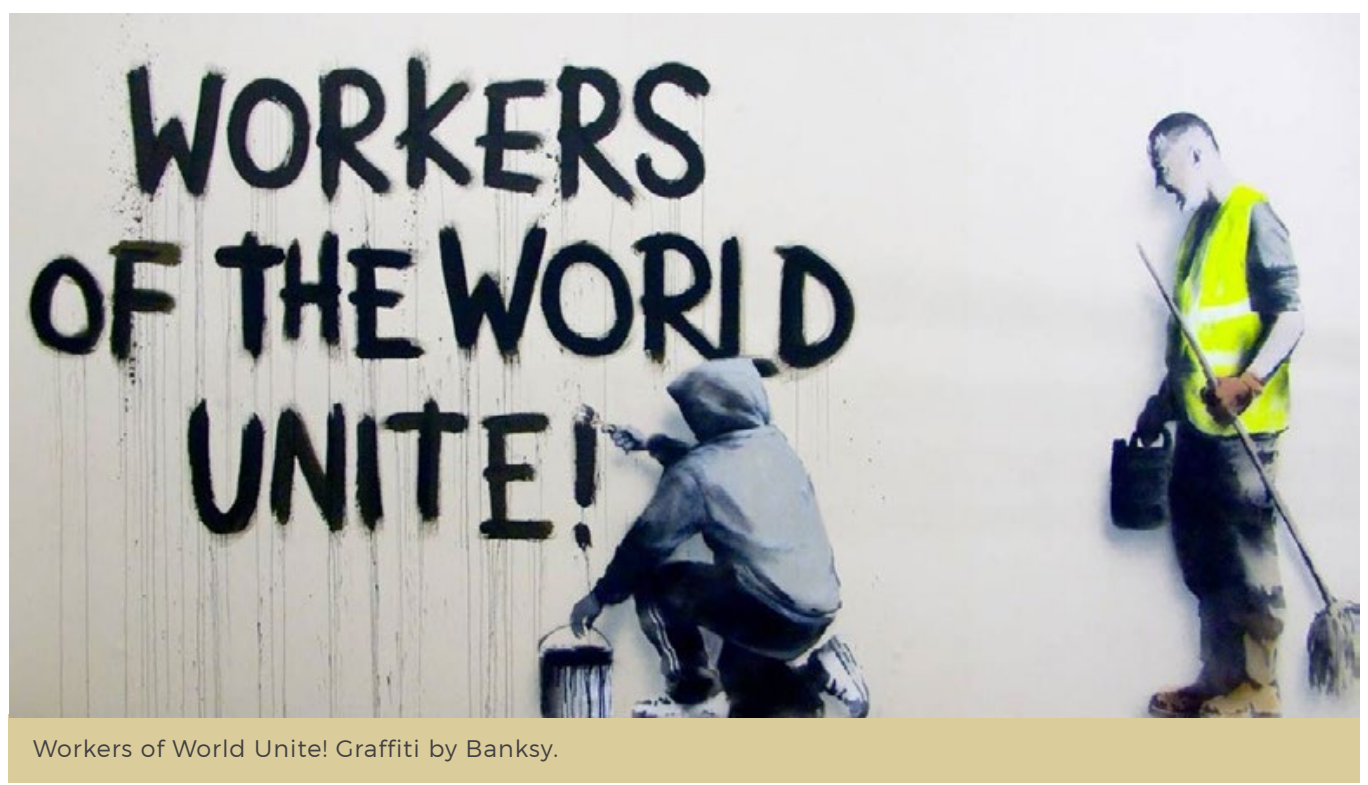

\section{A Genealogy of Precarity and Its Ambivalence}

\section{Francesca Coin}

Focussing on the conceptual evolution of precarious labour over the past three decades, this essay provides a genealogy of the notion of precarity. On the eve of the fourth industrial revolution, when precarity has become the norm and fears of a jobless society have alimented a dystopian imaginary for the future, this historical reconstruction seeks to identify those elements that have shaped the material conditions of workers as well as influenced their capacity for endurance in times of growing uncertainty.
My generation-or probably most individuals who were born since the late 1970s-has often perceived precarity as a generational curse, and looked at Fordism as a time of social and labour stability. On the contrary, Brett Neilson and Ned Rossiter's article Precarity as a Political Concept, or, Fordism as Exception (2008) reminds us that for us to understand precarity, we must move beyond such approaches to see Fordism as an exception and precarity as the norm. In fact, the 1960s and 1970s were decades of uncertainty. The Federal Reserve's monetarist experiment in 1979 transformed labour into an adjustment variable of its monetary policy. In this context, the de-standardisation of salaries and the individualisation of contract relationships came with an overall transformation of governance and labour management that tied income to profit and transformed labour into the shock absorber for capital risk. Since then, casualisation of employment, insecure income, and labour dislocation became the defining traits of labour relations (Marrazzi 2008). Time softens the hard edges in our memories, but accounts from those years 
provide descriptions of a society in turmoil, mired by plant foreclosures and rampant job losses.

In the United States, the monetarist experimentsuddenlybrought unemployment to levels unseen since the Great Depression. In several cities, manufacturing plants that had been the symbol of industrial growth either shut down, introduced severe cuts in the workers' salaries, or started laying off employees (Toland 2012). Modernity seemed to be going downhill rapidly. In several industrial cities, unemployment peaked at over 20 percent in the early 1980s, often leading people to flee to other places to find work. In some instances, manufacturing jobs vanished into obsolescence due to technological changes; in others, they drifted overseas in the search for cheaper labour. In retrospect, we know that what was happening was a major global restructuring of labour relations (Toland 2012). Over the past decades, the increase in productivity allowed by science and innovation became the catalyst for a transformation in labour relations characterised by a growing distance between emerging clusters of high-tech industries and the Global South's dependency on technologically advanced multinational corporations. Inequality was not limited to macroeconomics but was reflected in the growing cleavage between a higher rank of high-tech specialists and a growing reserve of low-skilled precarious workers.

\section{The Experience of the Italian Autonomia}

During the 1960s and 1970s, the Italian leftist movement autonomia turned to Marx's Grundrisse (1973) to define this transition. In this work, Marx foresaw that innovation and technology would become a direct force of production and allow employers to become relatively independent of the labour force. In other words, capital could use 'the inanimate limbs' of science and technology to restrict necessary labour, hence transforming innovation into a curse likely to increase unemployment and social insecurity. At the same time, the purpose of technology would not only be the limited to the accumulation of wealth. On the contrary, the general intellect could use technology to improve the conditions of production and liberate time-what Marx defined as 'the general reduction of the necessary labour of society to a minimum, which then corresponds to the artistic, scientific etc. development of the individuals in the time set free.' The fact is that the 'inanimate limbs' of science are not outgrowths of nature, Marx warned. 'They are organs of the human brain, created by the human hand, and in this sense 'they are the material conditions to blow this foundation sky-high'.

During the 1960s and 1970s, these prophetic words became the distinctive tune of a generation. The diffuse intellectuality that took to the streets turned to the Grundrisse to decipher the historical transition they were enduring. No longer wanting to be constrained within the space and time of the plant, Italian autonomia posited itself as an embodiment of the 'general intellect' that felt an urge to liberate society from its chains. The simplicity of their slogans beautifully explains the complexity of their interpretation.

'Zero work for income

Automate all production

All power to living labor

All work to dead labor'

'The revolution is over, we've won'

A/traverso, 1977 (Berardi 2009, 25-26)

Despite the cultural distance that separates us from those years, it must be said that recent literature has rediscovered 
those perspectives. From Nick Srnicek and Alex Williams' Inventing the Future: Postcapitalism and a World without Work (2016) to Paul Mason's Postcapitalism: A Guide to Our Future (2015), intellectuals have turned to these interpretations in order to compensate for today's social and political impasse. Liberation from labour and the 'struggle to be human and educated during one's free time', emerge in Mason's analysis as the vision of a post-capitalist society that can grow inside the old one.

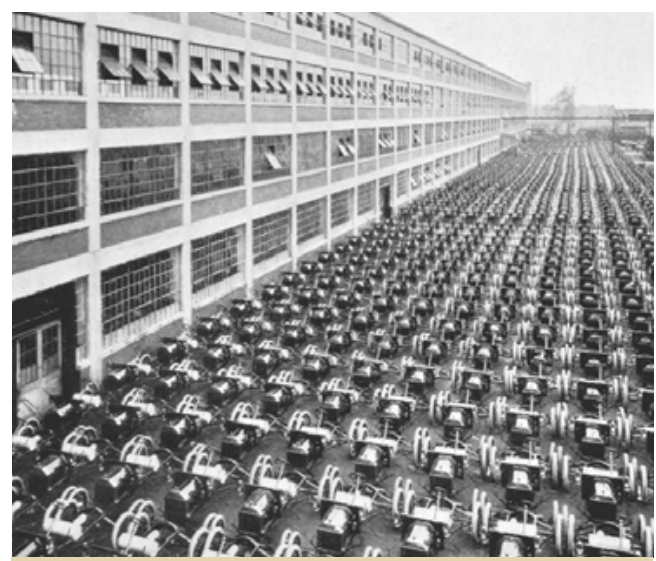

Highland Park Ford Plant, the first factory in history to assemble cars on a moving assembly line. Photo: AutoTraderClassics.com

\section{From Utopia to the Race to the Bottom}

The problem in these visions is that they never came true, and the enchanting idea of a world free from work left room for a generalised race to the bottom where labour was often not only unfree but unpaid. The transition to post-Fordism could be defined as a general dismantling of the time and space boundaries established by Fordism. According to Antonio Negri (1984), the mass worker that characterised the years of Fordism gave way to the 'social worker'an individual whose life was entirely put to work. While industrial capitalism was founded on large factories, specialised in the production of mass, standardised goods and marked by a clear separation between the time of production and the time of consumption, post-Fordism annihilated such divisions (Vercellone 2005). In the social factory, the creation of value extended beyond the factory walls to embrace the whole of society.

In this context, the question became what type of organisational mechanisms of control could be used to supervise a labour force that was ever more fluid and free to move beyond space and time constriction. In 1978-1979, Michel Foucault's course at the Collège de France, La naissance de la biopolitique (Foucault and Senellart 197879), analysed how the breakup of time and space constrictions that was typical of a disciplinary society transformed governance and management. In a postFordist society, governance became micropolitical and used new techniques to enforce discipline. Deleuze spoke of a 'society of control' characterised by the use of salaries to justify the coercion of individuals into a new relation of dependence (1992). In this context, precarity became 'the growing insecurity brought on by the flexible management of the global work force within post-Fordist capitalism' (Brophy 2006, 622). Today's Uber drivers or social media 'prosumers', in some instances, embody this shift. The notion of the 'prosumer' refers to the 'progressive blurring of the line that separates producer from consumer' (Toffler 1980, 267), a definition that is often used to describe 'prosumer capitalism' and the management's attempt to outsource informal labour to consumers-a mechanism that defines both corporations such as Ikea and the political economy of social media. The progressive blurring of the line that separates leisure and work, as well as production and consumption, have come to define a type of capitalism 
marked by precarity-as manifested in the proliferation of temporary and casual labour, delocalisation and subcontracting, occasional labour, labour on demand, and unpaid work.

\section{The New Dangerous Class?}

Over the past ten years, the representation of precarity has been ambivalent. In his widely discussed book, Guy Standing describes the precariat as 'the new dangerous class' and maintains that the precariat is not merely a distinctive socioeconomic group but rather a neologism that combines an adjective 'precarious' and a related noun 'proletariat', to describe 'a class-in-the-making, if not yet a class-foritself, in the Marxian sense of that term' (2011, 19). Standing's representation of precarity refers to the early 2000s. During the 2005 May Day protest in Milan, for example, over one hundred thousand people took to the streets to voice the needs of the global precariat. These very assemblies and moments of collective action were considered pivotal in globalisation politics and crucial for the precariat to find its own voice. In her genealogy of precarity, Maribel Casas-Cortés looks at the activist networks that emerged in those years as 'a Deleuzian politics of unfixed alliances' that transformed the precariat into a political subject capable of intertwining identities and demands $(2014,220)$. In this sense, she drafts a set of concepts that could agglomerate social groups-from immigrants to young, educated locals-and a set of demands to be posed to governments. Intertwining the struggles of migrants, women, and precarious workers, Maribel Casas-Cortés argues that precarity seemed to represent a strategic political proposal intended to use Deleuze's 'tool box' to change society, as maintained by a EuroMayDay organiser that she interviewed (2014, 221). At the same time, it is absolutely evident that there is a tremendous distance between those empowered accounts of precarity and the conditions of social insecurity that have continued to afflict labour over the years.

Today, employment insecurity has evolved into conditions even more challenging. The widespread use of unpaid labour in the 'internship economy' and the prospects of uncertainty accelerated by the gig economy, obscures the idea of the precariat as a dangerous class and emphasises the raising insecurity facing it. As I look at the labour market from the rotten heart of Southern Europe, I wonder whether the artificial description of precarity as a political subject did us any good. The bitterness of an unfulfilled revolution during the 1970s probably found comfort in representations of the precariat as a dangerous subject, but at the same time such narratives permitted a general underestimation of the violent forces confronting labour. It is going to take a very different sense of urgency and determination to reverse the conditions of exploitation that have become the new normal. 


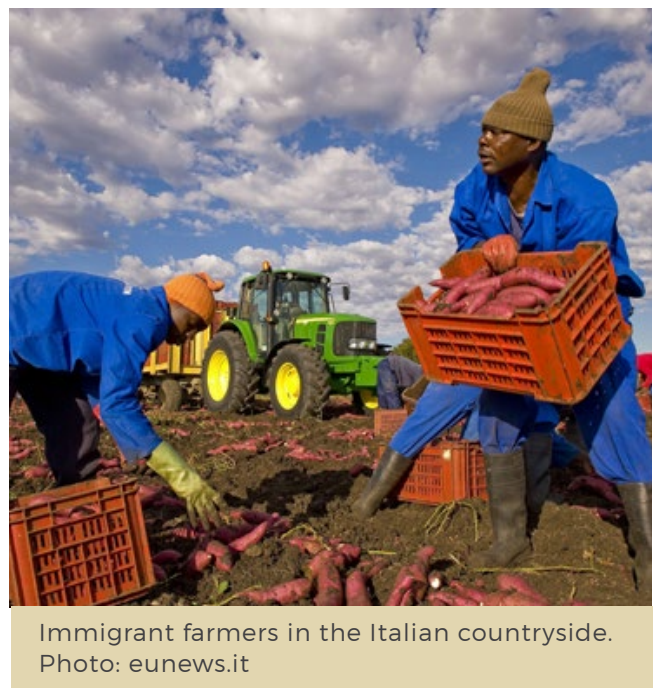

\section{Work}

\section{Precarisation and New Inequalities The Role of Migration}

\section{Fabio Perocco}

In the neoliberal era, precarity has become a general condition in the life of workers. The structural precarisation of labour is a global process, which has taken place heterogeneously according to national contexts, sectors, qualifications, and labour market stratifications. This essay looks at precarity from two angles: the impact of it on migrant workers and the role of migration in the exacerbation and extension of it.
Turning precarity into a general condition in the life of workers is one of the most important social transformations of the neoliberal era. The structural precarisation of labour is a global process, which has taken place heterogeneously according to national contexts, sectors, qualifications, and labour market stratifications. Besides young people, low-skilled older workers, and women, it has mainly affected migrants, who have suffered from labour precarity combined with the weakness of their legal and social status. At the same time, immigration is also involuntarily an agent of spreading and widening precarisationoften a testing ground where new forms of precarity are trialled before being extended to other groups of workers.

In this essay, I look at precarity from two angles: the impact of it on migrant workers and the role of migration in the exacerbation and extension of it. I first analyse the process of structural precarisation of labour, highlighting how it has become even more extreme in recent years. I then examine the precarisation of migration in Europe over the past two decades and its role in paving the way for a wider enlargement of precarity. Finally, I consider the Italian context as a striking example of this two-fold process. This analysis is highly relevant if we wish to better understand what has been happening in China since the onset of the reform era. In fact, while the Chinese context has arisen from a specific set of conditions (economic, social, political, and cultural), it nevertheless presents many similarities with the Italian context regarding the social transformations, the new inequalities, and the conditions of migrant workers.

\section{Precarity $\mathbf{2 . 0}$}

One of the cornerstones of the great social restructuring of the past three decades is the widespread and intense 
transformation of the organisation of work and of the labour market-a composite yet unitary process (Head 2003; Doogan 2009; Art 2011; Antunes 2013). The features of these transformations may be summed up as follows: 1) organisational flexibility, i.e. the set of methods-from lean production to outsourcing, from just-in-time to new management-which have produced the fragmentation and acceleration of production processes; 2) the systematic application of informatics and robotics to the production process, which has increased the polarisation of work and the de-skilling of a number of workers; and 3) the structural precarisation of labour.

As one of the cores of neoliberal policies, the precarisation of labour is a prerequisite and a carrier of the intensification of labour exploitation required by the rules of the global economic order in response to the constant decrease of accumulation rates and recurring economic crisis. The fracture in the unity of the labour contract, the restructuring of labour law, the introduction of a plethora of contract types with different conditions and rights, are all part of a process which is broader and deeper than a mere reduction of guaranteed work spaces. Following a few decades in the wake of the Second World War, which saw the attainment of relatively stable and secure jobs, a radical and extreme commodification of labour has taken place.

The structural precarisation of labour has several consequences-including new stratifications, the growth in wage inequalities, the impoverishment of many groups of workers, the increase in the army of reserve workers (with the creation of a reserve of the reserve), the unconditional adaptation of workers' lives to the organisational needs of private companies and public bodies, the alteration of social rights which have been readjusted for the benefit of companies, and the deterioration of psychological and physical health as precarity gradually destroys people. Atypical contracts, at first applied among migrants, have fragmented and disconnected the labour force, enabling the general devaluation of labour, denying the role of workers in the process of production. The consequences have been so dire that rather than describing this as simply commodification of labour, in extreme cases we can actually conceptualise it as the nullification of labour and of the worker, who does not have and does not need to have anything guaranteed, who-exactly as migrant workers in racist representationshave zero rights.

With the recent economic crisis and the consequent radicalisation of neoliberal policies, labour precarisation has further expanded and deepened, going beyond precarity as it was known in the recent past. Now, precarity 2.0-typified by vouchers, meal tickets instead of wages, serial internships, volunteering, unpaid work, zero-hour contracts, temporary work, posted workers, fake cooperativeshas transcended the original boundaries of precarious labour, replacing a segment of the 'first generation' precarious jobs and becoming the norm.

The precarisation of labour, both in its old and new versions, has been unleashed on workers unevenly. The first, most affected, were migrants, young people, low-skilled and low-educated female workers with children, older workers affected by company restructuring, and then other low-skilled workers more generally-i.e. those who constitute the most vulnerable segment of the European working class. These groups, which do not constitute an individual class of their own, have experienced increased impoverishment and marginalisation, and their foreign components have also been the subjects of racist campaigns (Flecker 2007; Art 2011). 


\section{Precarisation of Migration in Europe}

Across the majority of mainland Europe, the precarisation of labour has markedly affected migrants. There are at least three primary reasons for this: the migration policies of many European countries; the role attached to migration in European capitalisms and in the operation of the labour market; and the rise of anti-migrant racism in the $2000 \mathrm{~s}$.

In several European countries, migrant workers are subject to a double precarisation, both in the work and legal sphere (Morris 2002; Schierup et al. 2015). With regard to the legal sphere in particular, the migration policies of many countries subordinate the migrants' right of abode to the existence of a work contract, and also tie their social rights to their migration status, thus stratifying social rights. These principles have contributed to the return of the 'guest worker', which has taken place in a context of flexible capitalism with all its fragmentation and polarisation. The generalisation of the bond between the residence permit and the work contract during a period of structural economic crisis and casualisation puts migrants in a perilous and blackmail position, forcing them to accept any work conditions. The interaction between these two dimensions has produced, compared to the previous decades, a larger and deeper precarisation of migrants' conditions. These migrants, torn between the rigidity determined by migration laws and the flexibility produced by labour laws, have found themselves as 'guest workers' attempting to navigate a context of economic stagnation, characterised by atypical contracts and the general weakening of the workers' movement. Thus, if for the 1960s and 1970s we may talk about a relatively stable work regime, in the following decades the reality is that of a precarisation of the very process of work insertion and, on the social part, the enhancement of exclusion or segregation factors.

Historically, migration has been allocated the role of a reserve army and social buffer against possible crises within European capitalisms (Castles 2000; Schierup et al. 2006). In the last decade, this has intensified, so that migrant workers have been the first group experimented on with regard to the shift to precarious work and to the most extreme forms of precarity. In the meantime, the operating mechanisms of the labour market-selection, concentration, and specialisation-have continued to channel a good share of migrant workers into the most precarious and less paid sectors. This means that, in Europe, their working conditionsfrom access to work to unemployment, from tasks to wages, from classification to mobility-still present disparities compared to national workers. There are large swaths of unemployment, underemployment, 'overeducation', and atypical contracts-all of which have become higher in percentage over time, and which have grown alongside crises (OECD 2013 and 2015).

The rise of institutional racism has increased precarisation and reduced social rights. The anti-migration offensive has supported migration policies characterised by a mix of identity and security elementsaimed at curbing social rooting, and at supporting temporary and fluctuating migration, following the requests for a just-in-time workforce. The return of assimilationism, both in policy and rhetoric, has required maximum social adaptation by migrants to the conditions to which they are subjected. Mass media, in creating a racialised depiction of society, has served to produce a differentiation in the public representations of migrants which is functional to the differentiated exploitation deriving from their stratified precarity. Slogans and discourses focussed on a necessarily temporary presence, preference 
for national workers, and on a subordinated integration of migrants in the name of social inferiority, have paved the way for the precarisation affecting a vast majority of migrants as a racialised class segment of the European working class.

At the same time, the role of migration as a carrier of precarisation must be highlighted. The labour market is segmented, but the spreading of precarity among migrant workers has been a factor of the multiplication and enlargement of precarity that has affected a remarkable share of workers. In this framework, migration policies have played an important general role in paving the way and anticipating comparable labour laws (Basso 2004; Morice and Potot 2010).

The process of downward convergence of migration policies-starting slowly in the 1970s and 1980s, and gaining momentum in the 1990s and 2000s-has affected a fair share of European states and has seen the confluence of the different migration policies into one single migration policy, which is selective, restrictive, and repressive, and which balances new migrant arrivals according to the needs of the labour market (Basso 2014). Such processes have been accompanied by unceasing denigration campaigns targeting different groups of migrants, which have ended up affecting migration as a whole and, subsequently, a large share of the world's labour, dividing it along distinct lines of differentiation.

In this context, where migration is encouraged by the market and discouraged by institutions-according to a role play aimed at the social and political exploitation of migrants-the real purpose of this downward migration policy is not a complete stop to immigration, but rather an unstable, vulnerable immigration, which serves as a general devaluation of labour. Historically, the use of a migrant labour force has been one of the main leverages for the devaluation of the labour force as a whole. By lowering the cost of labour and by offering an ultra-flexible workforce, migrants are forced into a subordinated position, and are liable to blackmail by migration policies and institutional discrimination (Potts 1990). Today, this specific situation has turned migration into a laboratory where the manufacturing system has experimented with new forms of organising work-conceived of as a means of increasing profitability and productivitywhich have led to replacing secure jobs with precarious ones.

Migration and labour policies increasingly aimed at precarity have gone hand-in-hand. The creation of an institutionally weak and precarious proletariat, of an underclass of temporary workers replacing each other in constant rotation and circulation, has not only allowed the experimentation with new forms of labour exploitation to spread, but has also favoured a new global regulation of work relations and contracts in the name of stable precarity. The production of undocumented migrants, for instance, is an integral part of the structural precarisation of labour.

\section{The Italian Case}

The hectic pace of labour market reformation, which has taken place in Italy over the past two decades, has legalised all forms of precarisation, many of which were first trialled on migrant workers. From the July 1993 agreement between the Government and trade unions, which paved the way for fixed-term and temporary employment, to the Jobs Act in 2014, which has institutionalised precarity by turning it into the norm rather than the exception, the task of creating a precarious labour market has been carried out in a bipartisan fashion through the promulgation of a long list of laws and provisions that have affected both 'work flexibility' and 'employment flexibility'. 
Simultaneously, immigration law has gradually established the connection between residence permits, work contracts, and housing-institutionalising a migrant work model based on forced illegality and social precarity. Law 40/1998 has explicitly legitimised the existing social practices, confirming that undocumented migration is unavoidable for migrants and that regularisation can only happen afterwards (with amnesties or specific decrees) according to the will of the employers. Law $189 / 2002-$ which dictates that residence is strictly subordinated to employment-has redefined, restrictively, the prerequisites to right of abode with the introduction of a 'stay contract', thus creating a form of immigration that is extremely susceptible to blackmail. This has placed the vast majority of migrants in a condition of structural, legal, and social precarity solidified by the labour law itself. The creation of an unbreakable bond between employment, residence permits, and housing guarantees means that migrants' destinies are, to a large extent, in the hands of the employer-the only person who may legitimately ask for a working permit for migrants and who has the subjective right to ask for a residence permit. Law 94/2009 has further worsened migrant conditions by introducing a pointbased residence permit, articulated in credits. As in a game of snakes and ladders, during the validity of the residence permit, migrants can obtain or lose points that will count towards the permit's renewal.

The fragmentation of residence permits types and the multiple durations of residence permits stipulated by immigration laws-combined with the different kinds of atypical contracts stipulated by labour lawshave determined a marked stratification of the legal and social status of migrants. In other words, different types of migrants are granted, with several categories with different rights and conditions, which trigger a hierarchy of precarity within the very same migrant populations.

\section{Pedagogy of Precarity and New Forms of Casualisation}

Throughout the 1990s migrants have been channelled into the worst jobs, especially in labour-intensive sectors, with a high rate of irregular work. The shift to the industrial sector of the 2000 s has entailed an improvement in the condition of migrant workers, yet they still take up proportionally more low-skilled and low-paid jobs. Migrant participation in the official labour market has increased, but the racial segmentation of the labour market has grown, and is matched by labour segregation and ethnicisation in the manufacturing processes. The manufacturing system, characterised by small and medium units, drawing on the more unstable or marginal segments in the labour market, has had a permanent reserve of cheap workers with which it could support the new forms of organisation of work. The working experience of migrantswith regard to tasks, classification, wages, accidents, and social security-presents severe disparities in comparison with national workers (Centro Studi e Ricerche IDOS 2012). Among them, we encounter the highest rates of unemployment (16.2 percent for migrants versus 11.4 percent for national workers), underemployment (11.7 percent versus 4.2 percent), over-education (40.9 percent versus 21.6 percent), contract precarity, and intermittent work (Centro Studi e Ricerche IDOS 2016).

This situation results in mass socialisation to precarity. As migrants enter the labour force, running the gauntlet of irregular work and undocumented migration before reaching a minimally stable situation, they 
often spend a long period experiencing the most exploitative labour practices in the country. In a sense, this can be considered a sort of 'warming-up' phase for permanent uncertainty and social inferiority. This stage, which affects migrants differently according to various factors, prepares them for a lifetime of precarious work. This is the cornerstone of Italy's labour migration regime. This pedagogy of precarity is a pillar of the subjugation of migrants that began in the 1980s and 1990s, and was institutionalised in the 2000s. In terms of socialisation, it has enlarged to create a sort of halo effect that has affected other groups of workers, who at first had witnessed the precarisation of migrants thinking it would only be limited to them.

In this context, migrants have been the 'guinea pigs' for new forms of precarisation. Work paid with vouchers-used in Italy until March 2017 and currently under reform-is just one example. This is a remuneration arrangement for accessory occasional work that entails a remuneration of ten euros per hour before tax. Vouchers have no relation to a work contract, do not guarantee a day off, paid leave, sick leave, unemployment benefits, maternity or marriage leave, family benefits, nor loss-of-job indemnities. At first, in 2003, they were used for a few occasional activities carried out by specific categories (after-school tutoring, side jobs for students, and retired people), but later found wide application in sectors featuring a high rate of migrant labour-including domestic work, care work, and seasonal work in agriculture (harvesting). In 2015, 115 million vouchers were sold, corresponding to 1.1 billion euros, a third of which were used in the construction sector, and half in trade, tourism, and services (Bombelli et al. 2016). Vouchers then became a 'universal' tool, across all sectors, used for several jobs and for activities that are not necessarily occasional, and has partly replaced fixed-term precarious contracts. From a remuneration arrangement, it transformed into an employment arrangement, but in such evolution cases, the work relation no longer exists, channelling workers into a situation of extreme precarity.

\section{Advocating a Global Social Citizenship}

There is a close connection between work transformations and alteration of social rights, between labour precarisation and social rights stratification. The effects of organisation flexibility and of contract precarity are not only visible in the hyper segmentation of the labour market and the rapid growth of under-employed people, but can also be seen in the erosion of labour rights and the restriction of social citizenship. In the case of migrants, labour precarity entails a considerable exclusion or segregation factor, as the exercise of social rights is often subordinated to the work contract or the residence permit. The return of the 'guest worker' and the preference by states and markets for temporary migration, have favoured-in an era of structural precarity-a limited and conditional acquisition of social rights, generating new forms of inequality and a framework of stratified rights. All of this is supported by a strong xenophobia in the name of the welfare state (Spire 2013; Burnett 2015). The attack on the social rights of the citizen has been going on for at least two decades as a fully-fledged state policy aimed at altering the very structure and functions of these rights. Even though it started in the migration sphere, it has not been confined there, and has expanded to other segments of the population. For this reason, it is high time to consider the idea of a global social citizenship that may curb this downward slide into a future defined by structural precarity. 


\section{Making Class and Place in Contemporary China}

\section{Roberta Zavoretti}

Rural-to-urban migrants in China are often depicted as being poor, uncivilised, and having a lower level of 'human quality' than those with urban household registration. Policy-makers carefully strategise in order to produce rural-to-urban migrants as a homogeneous category. However, the use of this term obscures more than it illuminates, as it homogenises complex social realities.
In the People's Republic of China the media, official state policies, and propaganda, as well as the policies of market organisations, define rural-to-urban migrants (nongmingong) as essentially lacking 'human quality' (suzhi). They are depicted as being poor, uncivilised, backwards, and hopelessly bound to their rural roots. In China, the nongmingong paradigm also evokes the spectre of Maoist egalitarianism. This implicitly reminds Chinese people that post-Mao inequality should be recognised as the motor of 'development', and that it has allowed people to get rich or, to paraphrase Deng Xiaoping, it has allowed some to 'get rich first'. Western media and academia have largely drawn on the paradigm of the rustic, plain, and hopelessly marginalised nongmingong, identifying them with a specifically Chinese 'underclass' (Fan 2002; Alexander and Chan 2004; Vermeer 2006; Wu 2006; Day 2008). As Michael Stewart has observed in his study of the plight of Romany people of Eastern Europe, the use of this term, however, may

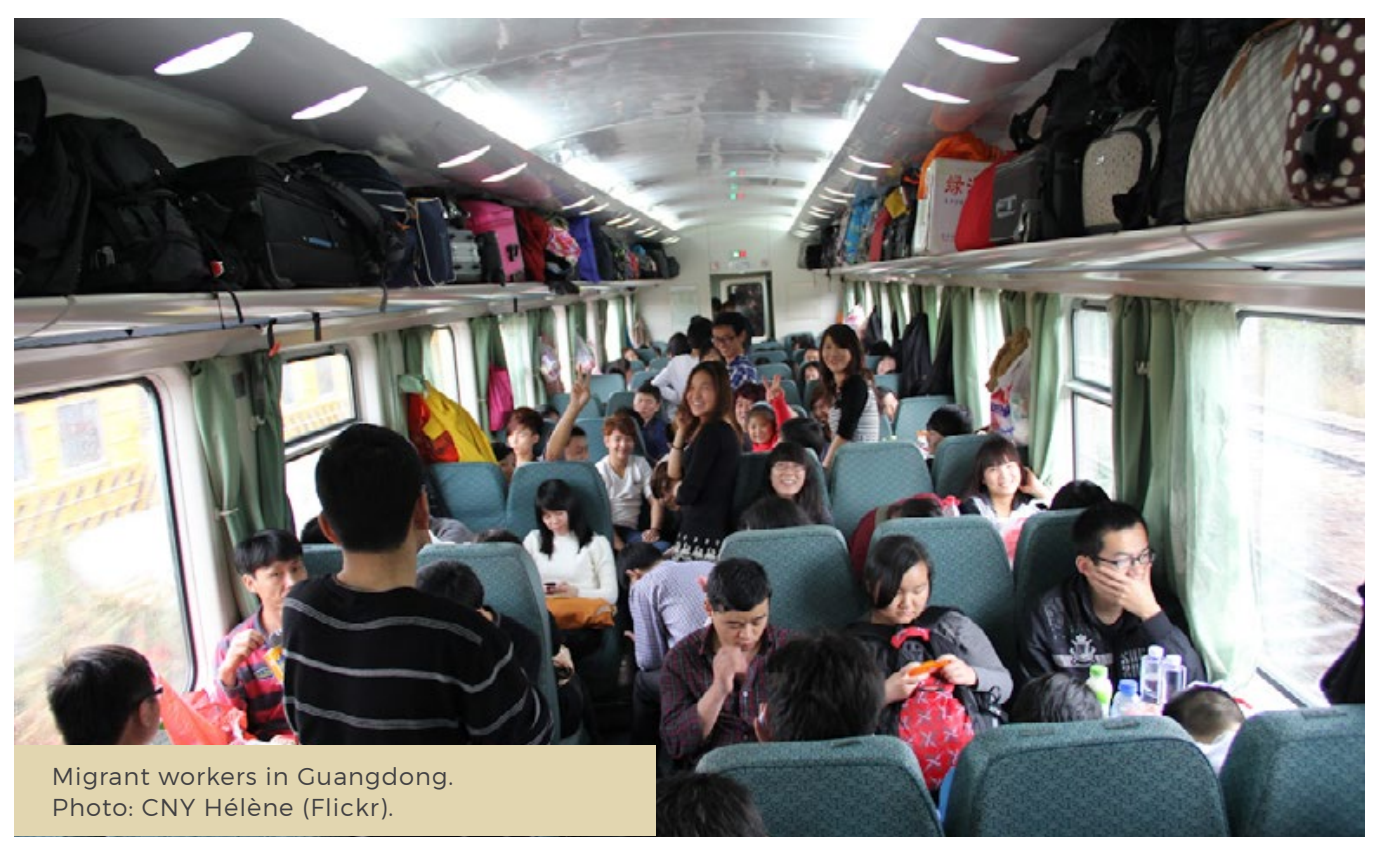


obscure more than it illuminates in terms of social exclusion, as it homogenises complex social realities $(2002,139)$.

\section{Displacements of Class Meanings}

Since the 1990s, ethnographers have devoted much attention to the predicament of migrant factory workers in South China. Pun Ngai (2005), for example, argues that this group constitutes a new working class whose subordinate position is determined by the interplay of ethnicity, gender, and residence status. These sensitive and influential ethnographies, however, portray the specific experiences of life and labour in Guangdong-based factories, rather than providing a general picture of migrant labour in China. General depictions of China's nongmingong as a socially homogeneous group are constantly confronted with the ever-growing heterogeneity and presence of migrants in the labour force. The phenomenon of labour migration in China involves people who differ by local origin, employment sector, income, educational level, gender, and age, to mention just a few factors (Pieke 1999).

In present-day China, the state-sponsored discursive production of migrant labourers as a 'real' and homogeneous social group sustains the promotion of the egemonic social model of an ideally emerging 'middle class' (Zhou 2005a, 2005b, and 2006; Anagnost 2008; Guo 2008; Ong and Zhang 2008; Zhang 2008; ). This trope implies high disposable income and home ownership, as well as publicly recognised professional status, top-level education and the highly valued quality of taste. In other words, it embodies the ability to compete and to choose as a high-quality consumer. Yet the discursive opposition between the nongmingong paradigm and the trope of middle classness must be produced without mentioning 'class' (jieji), a term that China-based policy, media, and academic production routinely avoid, and replace with the less conflictive term 'social stratum' (jieceng). To quote Sherry Ortner (1999), the use of the policy category of nongmingong contributes to the continuous 'isplacement of class meanings' into other discursive fields, such as gender, geographical background, ethnicity, and sexuality, in order to produce a class-based order without mentioning class.

\section{Household Registration Today}

The household registration (hukou) system has long allowed administrative institutions to identify rural-born city dwellers as a group. However, following the social and economic changes of the last forty years, as well as the various reforms of hukou at the local level, a debate has emerged about the link between residence status and the reproduction of social inequality (Solinger 1999a and 1999b; Lei 2003; Pun 2005; Jacka 2006; Kipnis 2008; Whyte 2010). Following the radical Reformled changes in urban-based employment and social security provision, the hukou system is no longer used to stop rural residents from moving into the cities. Urban residence status is increasingly being commoditised through policies linked to the opening up of the housing and employment markets (Solinger 1999a and 1999b; Wu 2006; Wang 2010; Whyte 2010). Four decades of marketoriented policies have brought about a profound redefinition of social relations and a rapid process of social segmentation in the countryside as well as in the city (Zhang 2001, 2008).

Some scholars have associated urban hukou status with the idea of 'citizenship' (Solinger 1999a and 1999b; Fong and Murphy 2006; Kipnis 2008), thus echoing a larger debate on migration, citizenship, 


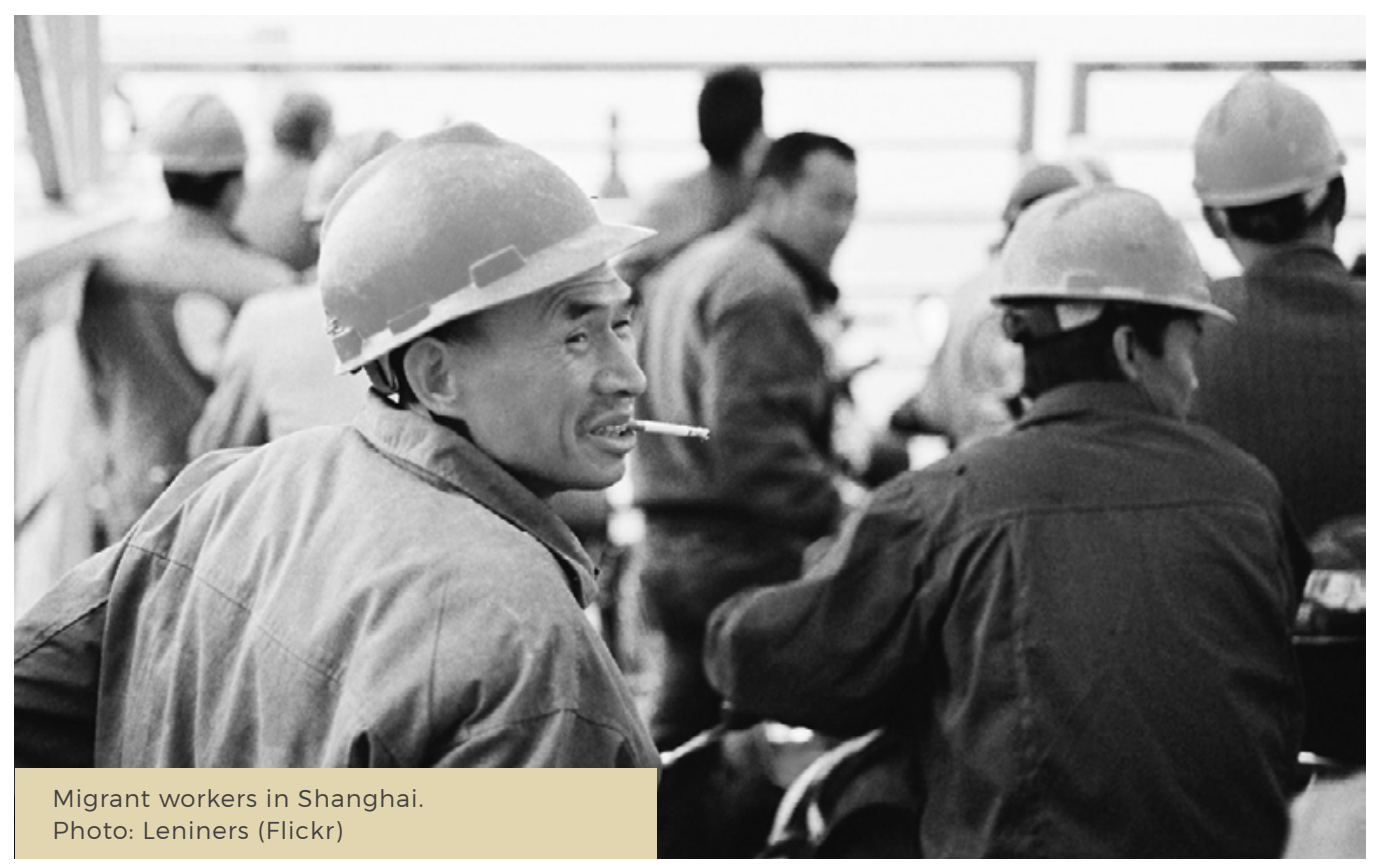

and globalisation. This debate illuminates the dynamics of state-market relations at a global level, while being relevant to China as well. Saskia Sassen's analysis of migrant service sector workers in 'global cities' (1998) distinguishes between a top end of high-flying 'global managers' and a bottom end of low-status service workers whose existence is the bedrock of the current global economic system. This latter group is denied full citizen rights and is therefore, by definition, vulnerable to exploitation and to specific forms of state policing. Notably, the state's policing role survived the rolling back of nation-states prescribed by the current neoliberal policy trend. The neoliberal state is thus not antagonistic to, but rather complicit with global market forces and transnational institutions (Sassen 1998 and 2003; Harvey 2007). This synergy between state and market in neoliberal times implies an altered idea of the citizen as a self-regulating, self-promoting competitor and consumer, and thereby a noticeable redefinition of the value of citizenship. In this view, Sassen ultimately suggest that citizenship may gradually lose importance in the lives of migrants due to the neoliberal restructuring of state-market relations.

\section{Governing Inequalities}

In post-Mao China the restructuring of state-market relations-and accordingly of the relationships of both state and market with citizens-brought about a specific form of governance that reconciles the state's promotion of neoliberal subjectivities with the perpetuation of socialist discursive practices and political structures (Ong and Zhang 2008). The persistence of the household registration system allows state policy to cast hukou status-rather than class, for example-as a proxy for social positionality. While residence status still plays an important role in the definition of social positionality, however, urban residence is gradually ceasing to represent 
a guarantee of economic and social rights, as Solinger anticipated in her study of the work unit in the early 1990s (1995).

Following the gradual dismantlement of the work unit, the state has increasingly made access to resources and services not a matter of residence, but of individual responsibility towards the family. According to this model of governance, each individual should compete to secure jobs and invest sensibly in his/her family's long-term security, and also by participating in market-mediated insurance schemes. In this context, identifying 'urban residence status' with citizenship-based full civil, social and economic rights obscures the role that equally important variables play in the formation of social inequality, such as class, connections, gender, education, etc (Wacquant 2008). These assets may be far better guarantees in terms of securing social and economic rights, including the right to be recognised as an 'urban citizen'.

\section{Nongmingong as a Strategic Discourse}

The development of China's state-led capitalism and the dramatic increase of inequality witnessed in Chinese society has led to the emergence of unprecedented forms of social exclusion-even among the once protected urban residents. During the Maoist era, urban residence status guaranteed the provision of a large array of services, including employment and housing. The main channel for rural to urban mobility was supposed to be higher education. Rural youngsters, however, faced enormous challenges to get a formal education in their villages, and only few determined and lucky ones were able to access universities. Four decades of economic reforms fundamentally changed the nature of social inequality and the role that residence status plays in it. During the pre-reform era, holding urban residence enabled citizens to claim housing (although often of poor quality) from the state; nowadays it is the ability to purchase property on the housing market that allows many, if not all, to access urban residence. Purchasing housing is also a strategy to situate oneself in a highly unequal and segmented society.

Local authorities throughout the country have been gradually reforming hukourelated provisions, leading to a de facto commoditisation of residence (Wang 2010; Whyte 2010). However, the nongmingong remain a central category in state policy and media discourse. Local policy-makers carefully strategise in order to produce and maintain the social order. Policies that produce rural-to-urban migrants as a homogeneous category remind urban residents that these 'outsiders' may constitute a social problem; they also prompt both rural and urban residents to see each other as competitors rather than as possible allies on the basis of overlapping socioeconomic positions. In addition, grouping citizens according to the rural/urban binary allows the state to deflect attention from the increasing complexity and deepening of inequality in the city as in the village. 


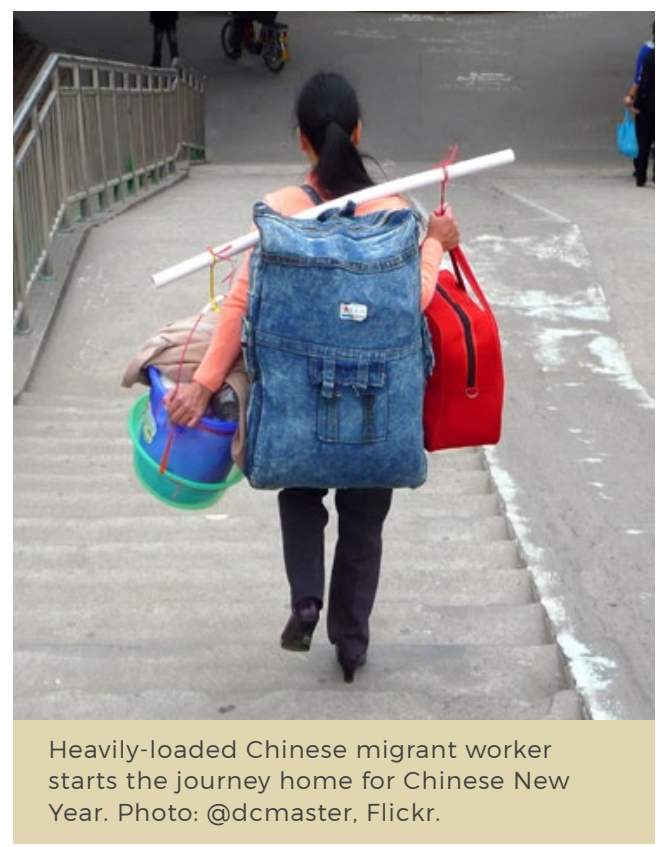

\section{Class and}

Precarity in China A Contested Relationship

\section{Chris Smith Pun Ngai}

The increasing precariousness of labour forces globally has prompted some to argue that a new 'precariat' is emerging to challenge the privileges of the securely employed 'salariat'. This divergence within the working class has been depicted as more significant than the traditional conflict between labour and capital. This essay examines these discussions in China, where precarity is increasingly being employed as a theoretical tool to explain the fragmentation of labour in the country.
There is a general trend in capitalist societies with regard to the nature of employment contracts and relations. The old promise of formal or continuous employment following a probationary period is no longer the norm (Liu and Ouyang 2016). It is increasingly harder to get into work, with competitive selection tournaments and rotating internships; and when employed, the length and security of contracts are changing, with zero hour contracts and agency work growing, and direct employment by the firm diminishing for new workers. These trends have prompted some to argue that a new class of precariously employed workers (the precariat) is emerging to challenge the 'privileges' of those who are securely employed (Standing 2011). This internal conflict within the working class has been projected as more important than conflicts between labour and capital. This essay looks at these debates in China, where some writers are beginning to apply these ideas to argue that there is a structural bi-furcation in the Chinese working class.

\section{The Precariat Thesis and China}

In his conceptualisation of the rise of precarious work, Guy Standing (2011) suggests that internal divisions within the working class, between those in regular/ standard employment, judged as being a privileged 'salariat', and those excluded from standard employment contracts, considered as a disadvantaged 'precariat', forms the main 'class divide' in contemporary capitalism. However, as Jane Hardy has pointed out, the problem with arguing that regular workers 'are a privileged group' is that it 'completely denies the realities of life in the public sector, which has faced commodification, marketization and taken 
the brunt of austerity' (2015, 13). Looking back at the history of capitalism, welldefined and comprehensive employment security was only enjoyed by labour for a relatively short period of time (from the 1950 s to the 1970s) and only in advanced economies. In fact, the category of precariat is extremely diverse, including students, temporary and contract workers, elderly workers, migrant and immigrant workforces, as well as workers with very different skill and educational levels. Thus, members of the precariat are defined by their lack of secure contracts. The thesis stresses divisions between the two groups, or empirical examples of collaborations between workers on different contracts. Standing provides no empirical evidence that people in insecure employment identified themselves as part of a separate class. This hints at the fact that 'precariat' is an academic term with little traction in people's lives and selfidentification in class terms.

The employment situation in China follows some of these generic trends, but also has distinctive characteristics that allow close examination of the claim that the precariat is a separate new class. According to official data, in 2014 China had 772.5 million employed persons, 274 million of whom were rural 'migrant workers' (nongmingong). These migrants are excluded from many basic social benefits because of the country's restrictive household registration system (hukou), which is used by employers to segment workers by different contracts, even though they generally perform similar types of work.

In the case of China, we find that there is a contradictory movement with regard to regular and insecure work. On the one hand, legislation has increased security for regular workers in mass production and mass service industries, where more regular forms of employment have been recognised and protected by law. On the other, the very same legislation has also created incentives for employers to use agency or dispatched workers and bring in non-regular workers (Smith and Chan 2015; Chan 2017). Additionally, many self-employed rural migrants are involved in the informal sector, or are employed in the formal sector but appear to have informal working conditions. Increasingly, urbanised migrant workers continue to be denied equal citizenship and welfare rights, and hold rural hukou in perpetuity. The hukou system 'makes' workers, but not stable urban working class communities. Proletarianisation is separated from urbanisation, and working class community development, which is a typical process in most modernisation projects, is highly fractured in China.

\section{Student Interns, Agency Workers, and Formal Workers}

In a recent attempt to apply the precariat concept to China, Chunsen Yu offers a more detailed empirical assessment of the value of the idea ( $\mathrm{Yu}$ 2017). While we are critical of some of his argument, what his work shows is that the boundary between regular and non-regular work is often crossed. Against a static view of classes of employee, the China case is dynamic and the inflexible concept of the precariat singularly unhelpful. In particular, Yu focuses on the objective conditions of insecurity of rural migrants and uses three indicators of precariat status-non-signing of long-term labour contracts, irregular payments of wages, and non-provision of social security. These conditions are looked at through three elements of 'precariat migrant worker class'-student interns, agency workers, and regular workers, which are explored in an empirical study of these workers in seven multinational companies operating in two 
regions of China: the Liangjiang New Area in Chongqing, and the Longhua and Futian districts in Shenzhen.

In Chongqing the local government promoted 'school-enterprise cooperation' but according to Yu's findings-which contradict official data that says formal workers are the majority of employees -60 percent of the assembly line workers he interviewed were student interns. Reinforcing the findings of others (Smith and Chan 2015), student interns in his sample performed unskilled regular work that bore no relation to their studies. They also worked for less pay, facing the double burden of factory work and school supervision. Yu documents that student interns in Chongqing had no choice but to comply with their schools' internship arrangements with hi-tech factories and other types of manufacturing factories.

Categorising students as part of the precariat because of their insecure employment means ignoring the major element of their status, i.e. the fact that they are undergoing vocational training and hence work only for the shortterm. Although they often do not receive specialist training in their chosen field, this does not change the fact that they are structurally temporary workers who plan to pursue their career elsewhere. This is a constrained, transitional labour force. Yu bemoans their lack of commitment to work and the struggle by this section of the socalled precariat, but this is largely due to the abuse of the internship system by colleges and employers, and it is hardly surprising to find members of this group wishing to leave employment that does not match their area of study or their career aspirations.

Due to this mismatch, student interns show a high level of dissatisfaction with factories, and are disengaged with both labour processes and collective action. Yu's research reveals that the majority of his student interns were confused about their identities, as they saw themselves as students, not full-time workers. At the same time, though, they were engaged in hi-tech factories and treated as full-time workers doing assembly line work.

Agency workers face a different set of problems. Working through an agency sets up a triangular relationship between workers and employers. This can add complexity to these relations, as well as fraud, as bogus employment agencies can easily dupe young migrants, taking fees without providing work. Problems can also arise in the event of a labour controversy, as employers and agencies dispute responsibility for health and safety failings. In Yu's research, some companies used a limited number of agencies, generally just the larger ones, while others had a more diverse approach, hiring workers through several commercial labour agencies. Some companies maintained that they offered a temporary-to-permanent pattern of work, with workers having the opportunity to become formal workers after a probationary period, but when $\mathrm{Yu}$ spoke to agency workers, they disputed this easy transition. Instead, for them an 'agency labour regime' meant little control over work allocation and schedules, as well as regular reassignments to different types of jobs and easy dismissal.

Still, this and other accounts that stress the negative effects of agencies in forming barriers to secure work ignore the fact that workers possess labour mobility power and they can change agencies if things don't turn out well. Given the large number of agencies in China, there is fierce competition between them for labour, a situation that creates bargaining power for workers. While agencies may try to avoid recruiting workers who change jobs frequently, the high levels of turnover mean this rule is difficult to apply.

Finally, regarding formal workers, while they have regular employment, they also face specific problems. For instance, they 
are forced to change their jobs frequently, due to factors that include variations in production seasons; the practice of loaning employees (zhiyuan) to other departments or factories; the tradition of changing workers' job specifications and labour relationships (fenliu); as well as an abusive labour regime that involves the use of 'constructive dismissal', active pressure to take on unwanted tasks, and limited job security. Posted workers often lose out financially. For example, enrolment at Foxconn was effectively compulsory, with formal workers being punished with reduced overtime if they did not participate. According to Yu, factories routinely violate labour contracts to change formal workers' work, content, and locations, effectively 'selling' labourers from the original factories to other factories or firms.

\section{Problems with the Precariat in China}

The idea central to the precariat thesis, that there is a class divide in terms of the employment conditions of the salariat and precariat, falls at the first hurdle. All workers are insecure in China, and precariousness is not evidence of a separate class, but part of the general condition of waged labour in the country. Take the issue of high labour turnover, seen as indicative of precarity. In fact, labour turnover is high for all groups and in part expresses the mobility power of labour (Ariga et al. 2012)-and, as such, it has been a central mechanism for improving wages and conditions. Jobs were more precarious in the 1980s and the 1990s than in the new millennium when precariousness acquired structural significance. More recent protection, if not standardisation of employment relations, due to state labour policy and legislation, has coincided with more labour resistance and collective actions. More importantly, precarity has been the fate of two generations of migrant workers, but in terms of labour disputes and collective actions, we witness much more in the new or second generation, as indicated by numerous empirical studies (Leung and Pun 2009; Pun and Lu 2010a and 2010b). For instance, Pringle notes that in the 2010 dispute at a Honda transmissions factory in Foshan, agency workers were a critical part of the action (Pringle 2016).

The official categorisation of peasant workers-wage labourers with rural household registration-keeps their social status and class identities ambiguous. Taking a specific path of proletarianisation, the new generation of migrant workers has gradually become aware of their class position and participated in a series of collective actions. The migrant workers are now experiencing a deeper sense of anger and dissatisfaction than that of the first generation, accompanied by the realisation that the return to their hometowns is more problematic (Pun 2016).

To conclude, precariousness as a process is a useful concept, 'precariat' is not. At different times, precariousness is a more or less important attribute of being a worker. The idea that security is fixed and settled is unhelpful as is the idea of a new class called the 'precariat'. The processes of creating non-standard forms of employment are recognisable across work with different forms of status, from unskilled to more white collar and professional occupations. More importantly, we need to look at interactions between workers on different contracts in production relations, and not invent employment differences that confuse employment status and social class. Class is about ownership relations, and structural class relations between labour and capital. 


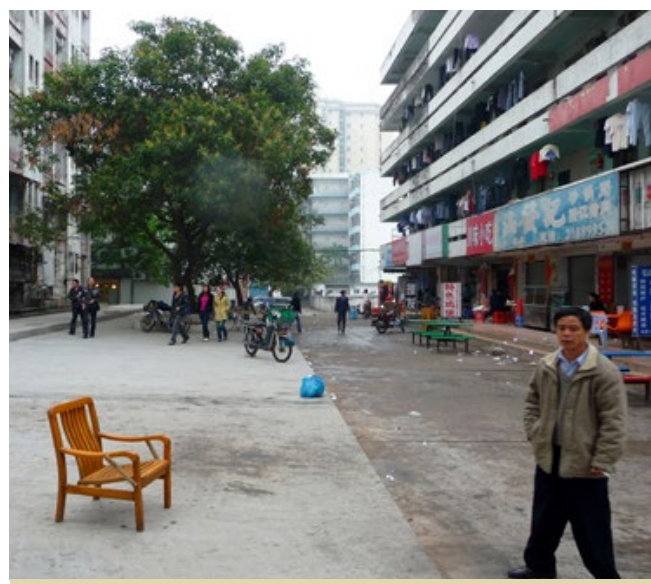

Dormitory buildings, Shenzhen. Photo: DcMaster.

\section{From Dormitory}

System to

Conciliatory

Despotism

Changing Labour

Regimes in Chinese

\section{Factories}

\section{Kaxton Siu}

China's manufacturing model has been built on the exploitation of migrant workers under a despotic labour regime. But is that still the case? Based on extensive research in the Chinese garment sector, this essay argues that while draconian controls persist up to this day, the situation of China's migrants has undergone dramatic transformations that encompass not only changes in the workers' demographic profile and everyday life practices, but also new social, technical, and gendered divisions of labour inside factories.

This article draws substantially on the author's forthcoming article 'Labor and Domination: Worker Control in a Chinese Factory,' in Politics \& Society, DOI: 10.1177/0032329217714784
For the past three decades, China's export-led manufacturing model has been built on extensive exploitation of its migrant workforce under a despotic labour regime. Draconian controls persist, and it is easy to view both Chinese migrant workers and the ways employers subordinate them as static and unchanging. Yet the situation of China's migrants has undergone a dramatic transformation-a shift that encompasses not only changes in their demographic profile and everyday life practices, but also new social, technical, and gendered divisions of labour inside factories.

This transformation presents a formidable challenge for any conceptual understanding of how factory regimes and management controls have changed under global capitalism. How do managers exert control in Chinese factories? What are the characteristics of China's current labour regime? To examine these changes, in 2010, I lived with several young male migrant workers for six months in a small apartment near a garment factory in the Pearl River Delta (PRD).

Focussing on labour-intensive, foreignowned factories where tens of millions of migrant workers have worked since the early 1990s, in this essay I trace the changes embodied by reform policies and practiced by managers and workers. My findings reveal that since the mid-2000s new modes of domination-crystallised into a new labour regime that I call 'conciliatory despotism'-have combined coercive power with new workplace tactics and production strategies.

\section{Breaks and Continuity}

While extant studies have noted how the emphases of labour regimes shift in line with changing patterns in the capitalist economy and society (Sturdy et al. 2010), the emerging Chinese labour regime of 
'conciliatory despotism' has had a unique developmental trajectory. On the one hand, it incorporates new measures of control that allow factory managements to adapt to changing global production environments and to a domestic economy marred by labour shortages. On the other, it inherits a series of despotic disciplinary measures that were developed during the first exploitative wave of capitalist manufacturing in China during the 1990s, when foreign companies took advantage of the vulnerability of rural migrants under an apartheid-like urban household registration system that was itself a legacy of the Maoist period.

My research highlights the coexistence of institutional continuity and a change in the labour-intensive factories of postsocialist China. While the Chinese state still engages in labour law non-enforcement and employers still rely on strong disciplinary measures to reinforce their managerial practices, in the past few years the Chinese state has relaxed the major institution that determined migrant workers' lives in urban areas in the 1990s: the discriminatory, restrictive household registration system (hukou). At the same time, real wages have risen substantially and, consequently, workers are no longer financially desperate and vulnerable. For instance, in response to workers' capacity to afford to live outside factory dormitories, away from the constant control of their employer, local residents have constructed apartment buildings that enable migrant workers to find alternative accommodation outside factory compounds. Labour shortages have also compelled employers to recruit more young male migrants, resulting in new gendered divisions of labour and workplace politics on the shop floor. As a result of these new changes, managers and policy-makers have had to devise new mechanisms of 'soft control' to conciliate workers' grievances.

\section{Beyond the Dormitory Labour Regime}

A great deal of China's export industry is clustered in Guangdong province. Until recently, the Chinese authorities tightly implemented the hukou system to control the mobility of migrant workers in much the same way as the South African government used the pass system in the days of apartheid (Alexander and Chan 2004). By restricting peasants to the countryside, the state could control not only urban growth but also the status and identity of individuals.

Without an urban registration, rural migrants needed a permit to remain away from home, and they could only secure this if they had an employer. Police in the Pearl River Delta (PRD) regularly checked their permits on the streets, a situation that not only intensified migrants' fear of unemployment but also pushed them to get factory jobs at any condition in order to become registered 'workers' and remain in the region. Taking advantage of this situation, factory management drew up shop floor and dormitory rules alongside physical punishments to discipline and penalise migrant workers in order to transform them into docile and disciplined subjects (Lee 1998; Chan 2001; Pun 2005).

Outside factories, in the public sphere, the state wielded the power to control the inflow of migrant workers; inside, managers held sway over their lives. Workers from the countryside were normally required by their employers to reside inside the factory grounds, in crowded dormitories that often accommodated eight people in a single room. Factory dormitories and production lines were interlinked, in what Chris Smith and Pun Ngai have defined the 'dormitory labour regime' (Smith and Pun 2006; Pun and Smith 2007; Chan and Pun 2009). The dormitory was an extension of the point of production, and factory management could 
flexibly utilise and prolong work hours, thus maintaining a great breadth of control over the working and non-working time of the employees.

But this despotic dormitory factory regime no longer prevails today, as employers have lost their monopoly over the housing of the workers. In the early 2000 s, local villagers in the PRD began to demolish their old houses to construct cheap, ugly apartment buildings. They did so in order to profitably rent out rooms to migrants who did not want to live in factory dormitories. Still, if workers were finally able to escape the dormitories, this was only because of major changes in their own standing vis-à-vis management (Siu 2015).

\section{Labour Famine and Worker Empowerment}

A fundamental change that occurred is that today migrant workers are no longer desperate to keep their jobs. As the factories in China relentlessly expanded in number and size year after year, the stream of young rural migrants no longer exceeds the evergrowing need for workers. Since 2003, factory jobs have been readily available, and employers have been competing to find workers. Facing labour shortages, local governments in industrialised districts no longer seek to control the movements of the workers. Migrant workers today do not need to obtain work permits to stay in the PRD region, though they still are supposed to obtain temporary residence permits, which are seldom checked in the streets.

In the 1990s and early 2000s, for most types of production work, factory managers were willing to employ only young women between the ages of eighteen and twentythree, on the ground that they have nimbler hands, are more obedient, and easier to manage. The factories were not interested in older rural women in the belief that by the age of twenty-four most of them would return to their home village to get married and have a child. But the number of young rural women in China was not limitless, and as the number of factories kept expanding, labour shortages of young women became evident. For this reason, since around 2003, employers could no longer allow themselves to be too choosy and had to start employing women in their early thirties, as well as young men (Chan et al. 2009; Chan and Siu 2010).

The competition to recruit workers has had at least one other effect: over the past 12 years, the real wages of migrant workers have more than tripled in Shenzhen, China's leading centre for the export industry. By the late 2000 s, migrant workers in the southern metropolis could afford to regularly eat meals with vegetables and meat, to snack regularly at fast-food outlets, and to eat sometimes at small cheap restaurants; they could afford smartphones; could afford to dress attractively-and could afford to talk back or quit work if harassed. This needs to be put into context, though. They were still very poor, and by urban Chinese standards their hourly wages were considered quite low. Moreover, urban residents still refused to engage in blue-collar work in factories where migrants worked. In their shared rental apartments, double-decker beds were crowded together. When I lived with a group of male migrants, my housemates decided to save even more money by sharing the same mattress with another worker, each sleeping in shifts.

\section{Towards Conciliatory Despotism}

My study of a garment factory in the PRD reveals that all control mechanisms are embedded in a wide array of factory rules, regulations, practices, customs, production hierarchies, divisions of labour, and systems 
of production. Each of these modes of domination assumes different forms, with mechanisms ranging from despotic to the tactical and strategic. Coercive power includes punishment, disciplinary measures, and restrictive resignation and leave policies. Workplace tactics and strategies include affective personal ties and face-giving, (collective) bargaining, and encouragement of competition among workers. Over time, social, technical, and gendered divisions of labour and the production hierarchy have been altered.

The use of punishment and disciplinary tools, affective personal ties, face-giving tactics, hidden collective bargaining, and competition among workers jointly determine the extent to which workers are dominated. The ways these mechanisms combine and the extent to which each of them has been brought into play has changed over the past decade. Extracting extra work time is one of the major aims of the despotic apparatuses, and exploitation is evident to workers who are forced, for instance, to do unpaid overtime. In a changing labour environment, though, a new shop-floor culture comprising of new strategies to control workers' emotions, dispositions, and rationalities, seemingly speaks against the literature in Chinese labour studies from an earlier decade which emphasised the blatant coercion of a despotic labour regime (Chan 2001).

How does all this change our understanding of contemporary Chinese practices? My research has shown that despotic controls alone are no longer able to maintain factory order, and that a new regime of 'conciliatory despotism' has been taking shape to replace the older dormitory labour regime. 'Conciliatory' refers to the incorporation of new mechanisms of soft control in normative forms of shop-floor tactics and production strategies, aimed at creating a shop-floor culture which mediates direct confrontations, gives workers a sense of give-and-take over the production process, and boosts individual productivity through competition.

of particular importance to this conciliatory approach is the fact that line leaders and supervisors have to invest in affective ties with rank-and-file workers, and to devise effective interactive tactics whenever there are emotional outbursts. Different from the situation in the 1990s when despotism prevailed and management had no interest in appeasing workers, these affective ties-though thin, fragile, and still based mostly upon cold market relations and coercive power-are part of a new stage of development in China's labour-management relations. Such ties are strategically activated by low-level members of management to mediate workers' discontents in a context where coercive power alone is not effective enough to control employees.

Workers today can readily find jobs elsewhere and thus are able to respond to excessive coercion by leaving the factory. Thus, low-level managers, in dealing with emotional outbursts, invoke Chinese cultural norms through face-giving tactics to maintain factory order. Giving workers 'face' entails temporarily considering workers not as subordinate tools for production, but as human beings to be respected (at least nominally). Unlike the situation in the 1990s, where management in Chinese factories considered rural migrants to be 'uncivilised' subjects in need of disciplining by modern factory rules and practices, the unequal power relationship between managers and migrants is slowly shifting towards a more 'humanised' social bond through which both rank-and-file workers and low-level management are increasingly able to influence the outcomes of the labour process in China. 


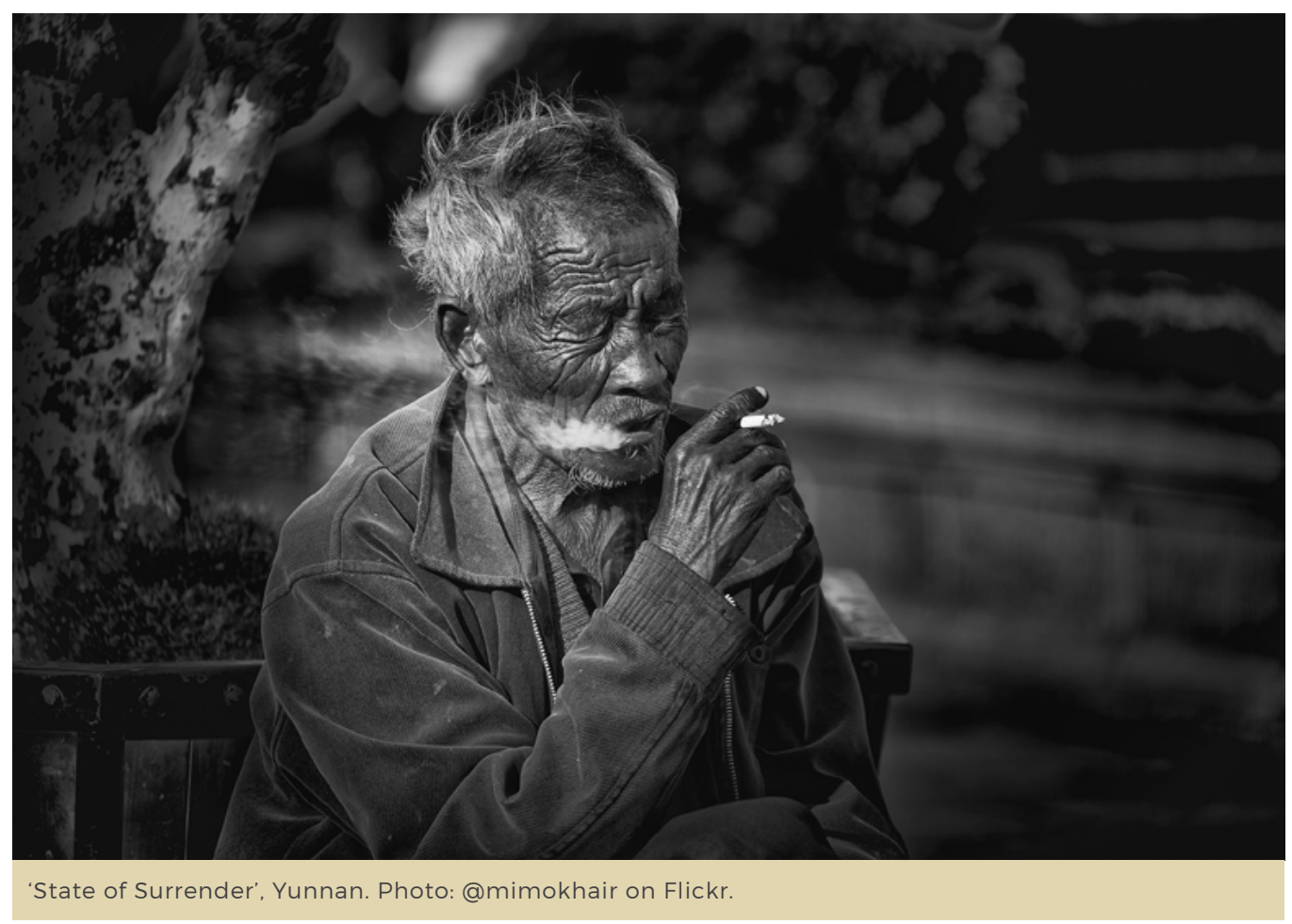

\section{The Precarity of Layoffs and State Compensation The Minimum Livelihood Guarantee}

\section{Dorothy J. Solinger}

When discussing the outcomes of China's economic development, the poverty that can still be found in Chinese cities is seldom mentioned. While the Party-state is indeed making a token effort to sustain the victims of this destitution, these people and their offspring will never be able to escape this manufactured poverty. This essay looks at the policy process that led to this outcome and at the prospects for poverty alleviation in Chinese urban areas.
When discussing the results of China's 'miracle' development over the past four decades, it is common enough to hear about the large numbers of rural Chinese citizensespecially those residing in designated poor counties-who have been 'lifted out of poverty' by the policies of the government, or about the surging numbers of the 'new middle class', or else, often enough, about the infamous urban-rural income dividewhich suggests that all those in urban areas are well off if they have the good fortune to hold an urban household registration. But, by contrast, we hear almost nothing about the poverty and attendant precarity found in the cities, which the state itself has engendered. The state makes a token effort to sustain the victims of this destitution, but it is clear they will never be able to escape this manufactured poverty, nor will their offspring. How many of them are there and how did this transpire? 


\section{Manufacturing Precarity in the State Sector}

It is easier to document the regime choices and the process that produced this outcome, and to describe the programme intended to maintain the status quo, than to estimate the number of people affected. But tens of millions would be a fair guess. The choices of the Chinese leadership had much to do with China's aim for a type of modernity characterised by participation in global competition, spurred on by the country's preparation to enter the World Trade Organisation (WTO) in the late 1990s. The lot of China's laid-off workers, therefore, rightly fits within the rubric of the types of precarity attending the life of labourers around the world. This shift towards integration into the global economy overlapped with an official diagnosis of the failure of the planned economy and of its unsuitability for participation in the modern world market, which was ultimately responsible for driving huge numbers of state-owned firms into the red by the mid1990s.

As a consequence of those glances both ahead and into the past, on the eve of China's accession to the WTO the decision makers at the helm of the state determined that firms losing money were not just a significant drain on the state budget, but also-and perhaps even more critically-incapable of competing in the world market, due to their unskilled workforces and obsolete technology. For this reason, they had to be shut down, with their workers dismissed from their jobs in droves. Figures vary, but in recent years most observers agree that the total of those let go may well have exceeded sixty million (Hussain 2003).

So a project termed 'enterprise restructuring' (qiye gaizhi) was set into motion from 1997 to 1999, following the principle of 'grasping the big and letting go the small' (zhuada fangxiao). This amounted to allowing the smaller firms, and those in non-strategic sectors, to fail; it also meant permitting the more successful enterprises to take over anything of value from the weaker ones-primarily by way of mergers or buyouts. Complex arrangements sometimes ensued, but the upshot for my argument here is to highlight the emergence of mass unemployment for many millions of olderthat is over the age of thirty-five!-state workers, whose education was deficient because of the closure of schools during the Cultural Revolution. Deemed worthless, these people were often forced to make do on their own. Certainly, a huge increase in urban poverty occurred at that time, affecting perhaps some 15 to 20 percent of the urban population if dependents of the laid-off workers are included, and nothing serious has been done to remove this blight.

A hastily assembled plan called the 'Reemployment Project' (zaijiuye gongcheng) was put into action in 1998. It was supposed to be underwritten by enterprises, localities, and 'society', with the aim of supplying training, finding jobs, and distributing 'basic livelihood allowances' (jiben shenghuofei) for the furloughed. But in fact, many workers received no funds, and even for those who did, the amount they were given was grossly inadequate. Moreover, indebted or bankrupt firms were not able to contribute to the collections, and the rate of re-employment even after a few years fell below 20 percent (Wu and Huang 2007).

\section{Minimum Livelihood Allowance as a Tranquiliser}

\footnotetext{
Workers responded by protesting vociferously in many cities, causing disruptions (Hurst 2009). Central leaders understandably became anxious, first about the instability itself, and then about what
} 
they deemed to be the likely impact on their visions of enterprise 'reform', and what such disorder might spell for discouraging foreign investment. The judgment of the political elites was that a 'tranquiliser', in the form of a 'minimum livelihood allowance' (zuidi shenghuo baozhang, or dibao), was to be provided to all urban citizens whose families' average household income fell below a locally set poverty line. Thus, the leadership expanded a scheme pioneered in Shanghai in 1993, decreeing that it was to be adopted in every city by the fall of 1999 . The sums dispensed were trivial, whether considered as a percentage of gross domestic product (GDP), or as compared with average levels of disposable income in the various localities.

The programme is means tested, meagre, and stigmatising. It entails cash transfers, requiring no contributions, but it also sets no conditions, such as demanding that mothers ensure that their children see doctors and go to school (as is the case for other social relief plans elsewhere in the world). Thus, it seems indifferent as to whether it lays out a path to eventual, inter-generational departure from penury.

As of the mid-2000s, soon after the birth of the programme, about 4 percent of the urban populace was being served, a percentage that remains pretty much the same today nationally. But at that time researchers figured that something like twice that percentage of the people had net incomes below the poverty line in their own cities (Lou and Wang 2008). More than that, yesterday as today, a frequently bemoaned 'preference for friends and relatives' has placed the allotments into hands that do not deserve it, overlooking often enough those who do need assistance.

In addition, as the years passed, by the end of the decade able-bodied unemployed people were advised to find work for themselves, even as the labour market was decidedly unfriendly to these 'aged', under- educated, and sometimes disabled or ill former workers. Many of them were unable to leave their homes, as they had no choice but to tend to their own sick, infirm, and young, since their scant incomes prohibited them from hiring any help.

\section{Perspectives from the Beneficiaries}

How do the recipients of this assistance experience their situation? The following excerpt reveals how they struggle to get along. When asked what they would like to see the government do for them, here is what a recipient said:

Recipient: First, supply some regular jobs; second, when you do a little business, shouldn't the government's policy tilt to you? If the government doesn't help, we certainly don't have the strength to assist ourselves.

Interviewer: To help the recipients of dibao throw off poverty, are jobs the root cure?

Recipient: Yes. Otherwise, just give more money, but it's not possible, giving us one third of the average wage is not possible. If the state's finance really has this ability, why can't it adjust employment policy? I feel that at the present stage the state should raise [our allowance] a little, price inflation now is so severe! The prices of so many things have risen, how can this be tolerated? The recipients of dibao are already very low on money, you could give them a little more. Public officials and government cadres don't care about inflation, if you give them two hundred yuan [at the time of the interview, that would have been about twenty-five USD], or five hundred yuan, it won't count for much. But for the recipients of dibao, if you give them ten yuan or twenty yuan it has a function. But the state can't simply give you more money, so I say it's employment. Really getting rid of the dibao would be good. Having some stable work instead, wouldn't that be even better? 
The programme often comes under suspicion because people assume that it enables laziness and a reluctance to work. And yet other interview subjects agreed with the sentiments of the interviewee quoted above. In 2010, a beneficiary of the programme in Guangzhou-a man who was half-paralysed and had both high blood pressure and diabetes-still wished to work. In his words: 'Because I'm too old and sick, if you were a boss you wouldn't look for a forty-year-old sick person, it's this simple.' Similarly, another recipient in the same city at the same time declared that: 'Everything requires a high educational background, but I only have primary school education, so naturally they won't hire me. Talented people are numerous; they won't take me. You say go to sell things, but that needs startup money (benqian). Private businesspeople won't hire us, and private bosses have no reason to ask a sick, old person to work, right?'

\section{A Cultural Explanation}

Once laid off from enterprises, older workers are seen as of no use. So it is felt that it is best to keep them barely alive, but not as a part of society. It is better to leave them unemployed and stuck in their homes, out of sight. Do not waste resources, let them die off, is the implicit message. So let's view the laid-off, sick, and older urban people as metaphors for Mao's society. It seems that those people, along with that society, should be obliterated. The market is modern, and it cannot absorb them. Modern is middle class - a state that is impossible to reach for these laid-off workers and their children.

And there has been no real effort to help them break out of their impoverishment, as an inter-generational cycle of poverty gears into motion. True, Party leader Xi Jinping promises an end to poverty in the near future, but it is only rural poverty to which he alludes, which, as noted above, can be addressed by targeting funds and services to whole areas of the countryside. There has been almost no mention of the urban poor. Thus, while the future of China can be viewed as a beautiful dream, the past remains depicted as a nightmare, filled with poverty, backwardness, and obsolescence. The poor are the antithesis of the dream, of the market, of economic growth, of progress, and glory. When multitudes of the old 'masters' of society (as state workers were labelled in the past) raged in the roads, the dibao was established to calm them down. But a policy devised mainly for stability waned as the beneficiaries went back home, out of sight. So as the project achieved its political purpose, its funds have diminished, relatively speaking. This is a tale of poverty and of precarity that never gets told. 


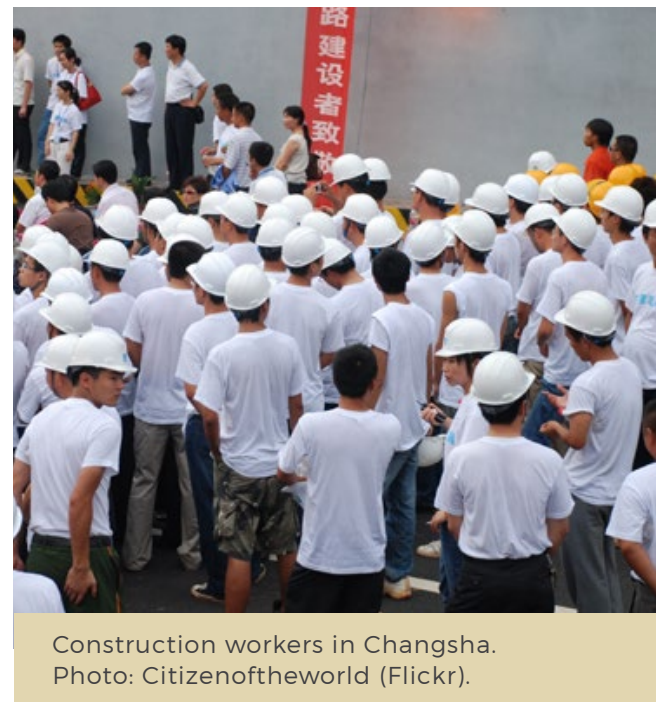

\section{Collective} Bargaining in China is Dead: The Situation is Excellent

\section{Eli Friedman}

As the Chinese government under Xi Jinping has turned in a markedly anti-worker direction, attempts to establish a genuine collective bargaining system in China have been smothered. If collective bargaining is dead, what might Chinese workers and their allies advocate? The time might be ripe to shift our focus to a demand for a rapid expansion of universal social services, not least for a universal basic income.
For many years reform-oriented labour activists and scholars working in China have seen collective bargaining as the cure for the country's severe labour problems. The logic underlying this was often unstated, but straightforward: collective bargaining was crucial for twentieth century labour movements in capitalist countries in giving workers a voice and creating a more equitable social distribution of wealth. With growing levels of labour unrest in China over the past twenty years, collective bargaining seemed like a logical next step. Hopeful reformers-both within the official unions as well as labour NGO activists and academics-envisioned rationalised, legalised bargaining between labour and capital as a central pillar in the construction of a more just workplace and society.

The challenges to institutionalising a robust collective bargaining system in the People's Republic of China (PRC) have always been profound. Fundamental to labour relations theory is that collective bargaining rights must be accompanied by the right to strike and freedom of association-capital has no reason to take workers seriously without labour possessing some coercive power. But independent unions have long been an anathema to the Communist Party. From the Lai Ruoyu debacle of the 1950s (Franceschini 2015) to the crushing of the Beijing Workers Autonomous Federation in 1989 (Walder and Gong 1993), the Party has made it clear time and again that independent worker organisations are forbidden. Although workers have never enjoyed the right to strike in practice, the right was formally included in the Chinese constitutions of 1975 and 1978. It was Deng Xiaoping who removed it from the constitution just as private capital began pouring into China in the early 1980s.

Nonetheless, with no signs of articulated worker movements since 1989, many wellintentioned people thought it was worth 
trying to advance worker rights within the system. Especially from the mid 2000s on, academics (myself included) launched research projects, NGOs held training sessions, and foreign unions engaged with the All-China Federation of Trade Unions (ACFTU). Many assumed that the state would eventually decide that worker insurgency was exacting too high a cost, and that serious labour reforms were therefore necessary. And indeed, beginning in the late 2000s the ACFTU made collective negotiations (xieshang)-rather than the more antagonistic sounding 'bargaining' (tanpan)-a high priority, investing time and resources into expanding the coverage of collective contracts.

At its best, collective bargaining in China has been woefully inadequate. The state and the ACFTU have been very cautious about controlling workers' aspirations, and have insisted on the fundamental harmony of interests between labour and capital. Experiments with bargaining have been almost exclusively restricted to single enterprises, thereby preventing workers from constituting cross-workplace ties. The overwhelming majority of collective contracts are formulaic: actual bargaining rarely occurs, and enforcement is largely nonexistent. The few shining examples where employers have made real compromises during collective bargaining have followed autonomously organised wildcat strikes. The best-known case is the 2010 strike from a Honda transmission plant in Guangdong province, which resulted in major wage gains as well as an (ultimately unsuccessful) effort to reform the enterprise union. It is not coincidental that substantive worker-led bargaining is much more likely in Japanese or American firms, where the state must be cautious not to inflame patriotic sentiments. State-sanctioned economic nationalism is a shaky foundation for a robust collective bargaining system.

\section{The Death of Collective Bargaining under $\mathbf{X}$}

Even these timid efforts have been smothered in recent years, as the central government has turned in a markedly antiworker direction under Xi Jinping. There was a brief moment in 2010 when discussion about the right to strike emerged from hushed whispers into the public discourse. But this opening was ephemeral, and union reformers in Guangdong who had pushed gentle reforms in the mid-late 2000s were replaced with typical Party apparatchiks. The country's pre-eminent centre for labour studies at Sun Yat-sen University in Guangzhou was shuttered (Wong 2015). The academic study of employment has now been left almost entirely to business schools, as the government has stymied further expansion of labour relations programmes. Labour NGOs in Guangzhou were subjected to a brutal crackdown in December 2015, with the government specifically targeting those groups that had been helping workers to engage in collective negotiations to resolve strikes. And the ACFTU has seemingly given up on advancing collective negotiations altogether. The Chairman of the ACFTU Li Jianguo does not even mention the term in his speeches anymore. Under the 'work developments' section of the ACFTU's website, a lonely single report on collective contracts for the entirety of 2016-which is not even available online anymore-is a stark indication that the union has almost totally forsaken this agenda.

Collective bargaining is not dead in the sense that it will disappear from China's labour-capital relations. It is almost certain that official unions will continue to pursue bargaining in its current vacuous, bureaucratic, and worker-exclusionary form. Collective contracts will continue to be signed, tabulated, and then hidden from view from workers. Somewhat less 
pessimistically, workers will continue to force management to bargain with the collective via wildcat strikes. This latter form will still be an important means by which workers can attempt to ensure their most basic rights, and these efforts are absolutely worth supporting. But collective bargaining is dead as a political aim. It is not going to be the cornerstone of twentieth century-style class compromise in China, it is not generative of worker power, and it certainly does not herald broader social transformation. To the extent that legal bargaining does develop, it will be as a mechanism for the state to deprive workers of autonomous power.

What then might Chinese workers and allied intellectuals and activists aim for? At the risk of stating the obvious, the working class needs more power. The question is, how to foster proletarian power in the face of a highly competent authoritarian state that views organised workers as an existential threat? In the absence of independent organisations, the only option is an intensification of already widespread worker insurgency. The more wildcat strikes, mass direct action, and worker riots, the more the state and capital will be forced to take worker grievances seriously. Of course such forms of collective action come at great risk for workers, and many have already paid a high price. In any particular case, the risks may certainly outweigh the benefits. But in the aggregate, expansive unrest is just what the working class needs. With the institutions firmly oriented towards advancing the inter-related goals of state domination and exploitation by capital, disruption on a large scale is the only chance workers have of forcing change. Ungovernability will be the necessary prelude to any institutional reform worthy of the name.

\section{The Quest for UBI}

Let's now imagine a scenario-a fantastic one, admittedly, but one for which we should be prepared: worker unrest hits some inflection point, and the state comes begging for compromise. If collective bargaining is dead on arrival, what might Chinese workers and their allies advocate? The time has come to shift our focus to a demand for a rapid expansion of universal social services, not least of which should be universal basic income (UBI).

UBI has been hotly debated in North America and Europe in recent years. There are numerous excellent accounts of various ways of structuring UBI (Van Parijs 2004), which I cannot rehash in detail here. But the fundamental idea is that all members within some given political jurisdiction receive a certain income by virtue of their citizenship-there are no means tests, and everyone receives the same amount regardless of employment status or existing wealth.

Perhaps the most frequently cited reason for implementing UBI is that technological development is increasing productivity while undermining the stability of jobs. A somewhat more expansive version of this argument recognises the diverse ways that people contribute to capital accumulation outside of wage labour-if the traditional wage is an increasingly unreliable measure of value production, perhaps it should be abandoned altogether. Another important point is that UBI would have the advantage of freeing up time for more socially constructive activities (Weeks 2011). Liberated from the daily struggle for survival, people will have the space to do what they will-including engaging in politics. In this sense, UBI is not merely an end in itself but also a means for developing the political energies of the dominated. 
UBI is by no means a panacea, and at worst it could be a Trojan horse for austerity (Ikebe 2016). Many conservatives have come to embrace UBI, as they see it as an efficient replacement for all other social programmes. An additional concern is that it is unlikely that elites will endow society with the right kind of UBI in the absence of vigorous, organised demands from below. A technocratic approach will likely serve the interests of elites, or will be unenforceable.

A few exceptions notwithstanding (Ding 2016), UBI has aroused little discussion within China. There are a variety of reasons for this, not least of which has been thirty years of nearly unbroken economic development and job growth. Industries such as manufacturing and construction have absorbed huge volumes of labour, and automation has only just begun chipping away at this growth in employment. Ideologically, UBI has resonances with the state socialist 'iron rice bowl', and runs counter to dominant meritocratic discourses that valorise hard work. Advocates of UBI would likely encounter repression, as the state is constitutionally opposed to any politics that could articulate the aspirations of a broad constituency. Given all of this, UBI has not yet gained widespread currency in China, and workers have not put it forward as a demand.

Nonetheless, the moment seems ripe to raise the topic for debate. Economic growth is slowing, automation is accelerating, and greater numbers of people are dependent on highly informal, contingent, and irregular forms of work to survive. Minimum wages increased significantly from 2010 until last year, but have more recently been frozen in many provinces. The growing informal workforce does not enjoy minimum wage rights, and even formal workers with a labour contract often have to protest just to have basic laws enforced. Furthermore, the minimum wage has never been a liveable wage, particularly for migrant workers excluded from state-subsidised health care, education, and housing. The contradiction between China's highly uneven economic geography and localised system of social welfare provision on the one side, and its unified national labour market on the other, is only likely to intensify. UBI cannot be realised without widespread working class support and mobilisation-now is the time to plant the seed.

\section{Crucial Questions}

There are important details that would need to be worked out for UBI to be effectively implemented, especially in a place as large and complex as China. Crucial questions about how to fund such a programme, how much citizens would receive, and the administrative arrangements could determine success or failure. But even in advance of having a perfectly worked out plan, the demand serves an important political purpose: it proposes that all humans have a right to subsist, irrespective of their utility to capital. Particularly given China's highly fractured welfare regime, the demand could serve to unify people across region, ethnicity, and hukou status. If linked to demands for universalising other forms of social protection such as healthcare, education, and housing, it could lay the foundation for meaningful human autonomy from the dictates of the market.

Is the demand for UBI in China utopian? Perhaps. But based on the past two decades of experience, we know for a fact that collective bargaining is a chimera. As China's wealth and social inequalities yawn ever wider, factories relocate to cheaper locales, automation expunges workers from the labour process, and the old state socialist institutions continue to rot in irrelevance, it is time to change tack. The death of collective bargaining may yet be a gift to China's workers. 


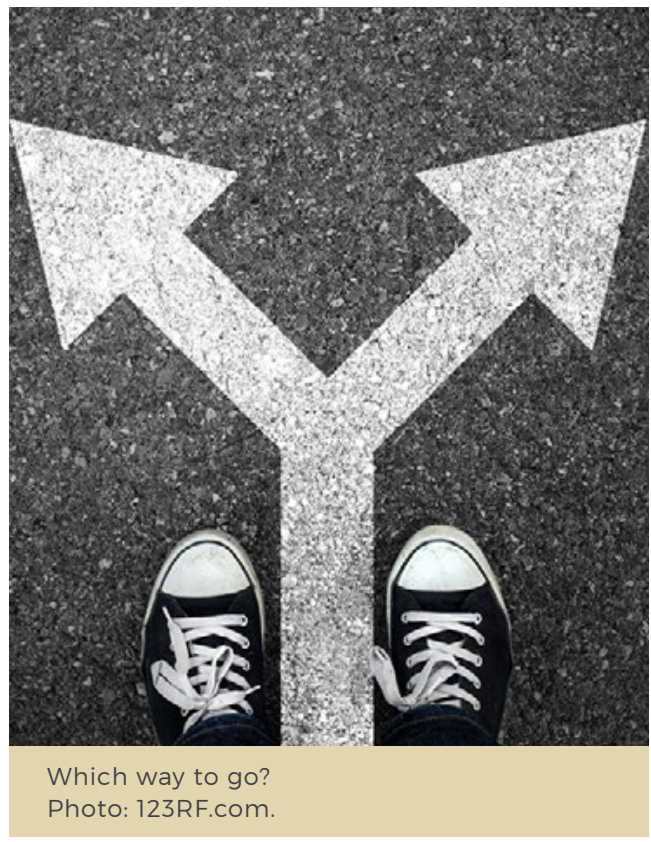

\section{Collective} Bargaining or Universal Basic Income Which Way Forward for Chinese Workers?

\section{Kevin Lin}

The loss of political support for collective bargaining has stripped the Chinese labour movement of one of its few unifying forces. In light of this decline, in a recent essay Eli Friedman has argued that collective bargaining should be replaced with universal basic income (UBI) as a common goal of the movement. But would UBI be able to play such a role? What may be gained or lost by mobilising around UBI? To respond to these questions, this essay compares the two strategies with regard to a number of crucial aspects.
In the previous chapter, Eli Friedman analyses the state of the labour movement in China, focussing in particular on the failure of the institutionalisation of collective bargaining. Given the loss of political support that collective bargaining seems to have experienced in China in recent years, Friedman makes an argument for replacing it with universal basic income (UBI) as a political goal of the labour movement. This is not to say that in his opinion collective bargaining will disappear or will no longer be useful, or that UBI is on the immediate horizon; rather, he believes that in the current circumstances alternative political goals and projects such as UBI should be seriously considered, even if they may seem utopian for now.

\section{An Impasse in the Chinese Labour Movement}

Friedman's essay provides an occasion for serious reconsideration of the goal and strategy of the Chinese labour movement. This is particularly necessary at a time when the activism of Chinese workers seems to have reached another impasse due to the double challenges of political and economic tightening. The movement led by Chinese migrant workers is autonomous in two senses: it is autonomous in relation to the official trade union-the All-China Federation of Trade Unions (ACFTU) - and it is also autonomous in that workplacebased industrial actions are independent of each other. The result is an independent, unco-opted, but also fractured movement. The notion of collective bargaining, one of a few clearly articulated goals that are widelyshared by worker-activists, grassroots labour organisations, industrial relations scholars, the government, and the ACFTU, has provided this highly fragmented movement with a sense of direction, bringing together 
the efforts of a diversity of individuals, groups, and institutions.

While there is near consensus on the importance of collective bargaining for Chinese workers, not everyone is in complete agreement about the goals of collective bargaining or the forms that it should take. Some advocate for it to contain labour conflicts, others see it as a convenient tool to resolve labour disputes, while some hope to empower workers. In other words, collective bargaining has always been a contested idea, but differences have generally not been publicly voiced for strategic reasons. Herein lies the continual appeal of this strategy in debates on Chinese labour over the last decade, whether they are among workers, scholars, policy-makers, or activists. In this sense, the replacement of collective bargaining as a legitimate goal may strip the movement of one of the few unifying forces. Would UBI be able to play a similar or even more strategically sound role? What may be gained or lost by mobilising around UBI as the goal? To respond to these questions, I compare the two strategies with regard to a number of crucial aspects.

\section{Workers (Dis)Empowerment}

How to build workers' power should be at the heart of any strategic consideration. Is collective bargaining furthering this goal? Scholars have identified two forms of collective bargaining: 'collective bargaining by riot' and 'Party-state-led wage bargaining' (Chan and Hui 2014). These two strategies have divergent goals: the former emerges only after workers stage collective actions and demand direct negotiation with management, and it thus contributes to building workers' collective power, confidence, and capacity; the latter is an effort led by the Party-state to pre-emptively institutionalise wage bargaining, primarily aimed at containing labour conflict. While 'Party-state-led wage bargaining' seems reactive at best, and its institutionalisation is rarely successful, 'collective bargaining by riot', beyond the immediate goal of resolving workers' grievances, is a critical practice of workers' self-organisation and self-governance.

In contrast, the ability of UBI to build workers' power is less direct. As Friedman argues, it may require labour unrest leading to ungovernability to bring forward UBI as a political compromise, but this does not necessarily presuppose worker selforganisation and self-governance, nor does it present obvious opportunities to exercise collective power. There is no doubt that UBI, if designed and administered well, will provide employees with economic security and more bargaining power to negotiate working conditions, as well as with increased freedom and capacity to pursue other social and political goals outside employment. However, such security and freedom will still be threatened by the thorny issues of freedom of association and assembly, things that will not necessarily be brought forward by UBI. In fact, it is not impossible that UBI may actually preclude these possibilities. In terms of empowering workers, collective bargaining seems to hold an advantage over UBI.

\section{Sources of Support}

Any goal, if it is to be accepted by the movement, will firstly need to be discussed, understood, and broadly supported. Collective bargaining was able to gain acceptance for a number of reasons. First, collective bargaining, in the simplest form of negotiating with employers, is often a logical demand of workers in collective disputes; second, it is seen as an inevitable component in the mature industrial relations system toward which China should be moving; and 
finally, it is broad and ambiguous enough as a concept and practice to attract the interest of different constituencies. However, as Friedman has described in his essay, belief in the adequacy and plausibility of collective bargaining has perceptively declined in China. At the same time, due to the lack of better alternatives, it has been difficult to register opposition to it.

In comparison, UBI, while gaining momentum globally, is little known and discussed in China. Whereas collective bargaining has a long history-both positive and negative-in industrialised and industrialising countries, UBI does not have a lot of historical precedents, nor current instances of successful adoption beyond early local-level experimentations. A recent article looking for any UBI-type programme in China, cites the example of the minimum income guarantee (dibao) (Green 2017). Dibao is a welfare scheme that is extremely selective in the target population of disabled and elderly people, and which provides only a very modest income supplement. It is unlikely to be expanded in the near future, nor, given these limitations, is it likely to serve as a good model for UBI. Proponents of UBI may thus have to look for inspiration elsewhere. This uncertainty over what form a Chinese UBI could take, and what the effects and consequences would be, present a large hurdle for its advocates.

However, while China's social welfare system is fragmented and unevenly enforced (Carrillo 2017), there has been impetus in the last decade and a half to improve and expand welfare, in contrast to decades of cuts and ideological assault in the West. For this reason, an extension of the current system to include UBI may encounter less resistance in China, and could, in fact, even galvanise a movement behind it. However, while China should still be able to provide a fiscal basis for expanded social welfaredespite its slowing economy-even a small amount per person would be a gigantic undertaking for the government, with any future debt-crises risking to undermining the UBI project altogether. Furthermore, the country currently has a low unemployment rate and wages have been growing, albeit more slowly than in the last decade. Lack of employment, which prompts a lot of the debate on UBI, is thus arguably not the most urgent issue for workers.

\section{Building Momentum}

Finally, where would the momentum come from? The practice of collective bargaining takes place at the workplace, and its momentum stems from workers' collective actions within the factories, where the pressure is most direct and concentrated. Here, workers have the capacity to play a direct role in shaping the bargaining process, even though the pressure from management is enormous. This bottom-up drive is the most important reason that ensures the legitimacy and longevity of collective bargaining as a movement goal. But today, as Friedman observes, such momentum seems to be slowing down. The manufacturing industry is offering less space for industrial workers to negotiate wages, and we often see workers simply demanding severance pay due to factory closure or relocation, without getting a chance to negotiate for better salaries or labour conditions. The political tightening over civil society organisations, lawyers, individual labour activists (Franceschini 2017b), and even people who were merely documenting protests (Ramzy 2017), constrains the transfer of experience and knowledge, undermining the very foundation of the support for collective bargaining.

In comparison, UBI is a policy instrument that is designed by and negotiated at the highest echelons of the Party-state, where workers cannot exercise direct power or influence. In the past, the ACFTU might have 
played a role in lobbying for the protective Labour Contract Law, and it is still possible that under the right circumstances it may choose to advocate for better welfare policies or even UBI. In these scenarios, would workers be able to have any say in a UBI initiative, or would they have to rely on the official union or other bureaucratic actors? Moreover, we are no longer simply talking about migrant workers in industrial workplaces: UBI will and must necessarily be a national debate, encompassing broad sections of the population, across sectors, regions, and employment categories. It may take a social movement broader than only workers to advocate for UBI, the building of which is a task as exciting as it is challenging.

\section{A Golden Age Remnant}

Where does this leave us? Faith in collective bargaining is evidently in crisis. Enterprise bargaining, if it happens at all, is rarely sustained over time. Any attempt to move beyond enterprise bargaining, toward sectoral or regional wage setting and bargaining, has not seen much success besides in a few celebrated cases-for example in Zhejiang province (Friedman 2014). Recently, there also has been a more radical rethinking of workingclass formation in Asia (Chang 2015). It may be argued that the kind of trade union movement under which collective bargaining is institutionalised is unique to the golden age of post-war capitalism in the early-industrialised countries. At a time when trade unionism and collective bargaining have been in serious decline for decades in the West, it is reasonable to reconsider this strategy.

Still, collective bargaining remains relevant. For the foreseeable future, industrial workers in China will surely continue to demand to bargain collectively with management, whatever form these negotiations may take. While it should not be the only goal, it should still serve as a legitimate instrument in industrial relations, particularly in order to build collective capacity. There is also a distinct possibility that interest in collective bargaining will be rekindled, with the issue returning to the political agenda, in the event of a successful bargaining after an unexpected, socially significant strike-and almost all prominent strikes of the last decade in China have been unexpected.

However, the limit of enterprise bargaining is clear, and at best this should only be an intermediary goal. It may be useful to revisit sectoral and industry-wide collective bargaining as an alternative, or as the next step in a wider collective action strategy. Or, it may be strategic as a movement to combine such goals with advocacy for specific legal changes, such as strengthening antiretaliation measures to protect workers who complain about illegal working conditions, or imposing criminal sanctions and personal liability for employers (Halegua 2017). No single goal is likely to be sufficient, nor is it likely to gain the approval of all participants in the movement. In fact, collective bargaining, UBI, and the other approaches outlined here may well be complementary to one another. At the current impasse, critical engagement with a range of goals and strategies will better inform the labour movement's strategies, providing it with coherence and direction. 


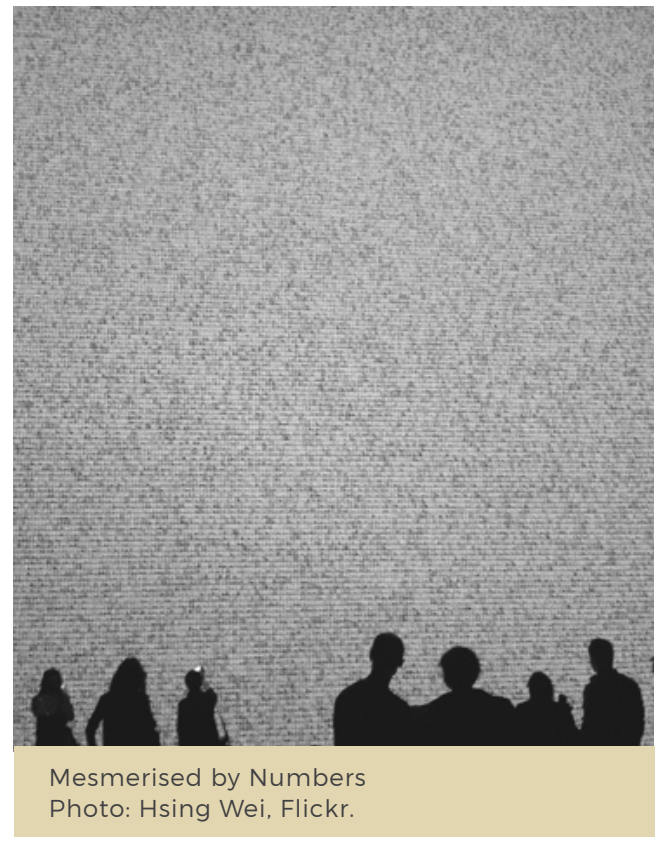

\section{Counting Contention}

\section{Manfred Elfstrom}

In the past few years, a growing number of academics and activists have launched projects aimed at counting contention in the realm of Chinese labour. This essay explores the power and limitations of such efforts, detailing the inevitable data problems involved in any quantitative approach to documenting protests in China. It also examines the ethics involved in how we collect such data and the questions we ask of it.
In August 2017, activist Lu Yuyu was sentenced by the Dali City People's Court to four years in prison for 'picking quarrels and stirring up trouble' (xunxin zishi zui). Together with his partner Li Tingyu, who was detained but then eventually released, $\mathrm{Lu}$ had collected information on thousands of 'mass incidents' (qunti shijian). These incidents encompassed a broad range of Chinese contentious politics, from pitched battles between farmers and thugs hired by development companies, to taxi drivers parking en masse along roadways in protest against high fuel prices; and from migrant workers threatening to jump from bridges, to retirees gathering to condemn pollution. $\mathrm{Li}$ and $\mathrm{Lu}$ posted the information they gathered on social media and blogs under the name Wickedonna (also known as feixinwen, non-news). Their reports usually took the form of short, two- or threesentence descriptions of confrontations, paired with photos or videos. But the activists also calculated monthly and yearly totals of periods of unrest, accompanied by brief analyses.

It is impossible to know what, exactly, triggered the initial detention of the pair in June 2016. Drawing data of this sort together in one place was clearly unsettling for authorities. But what exactly was so troubling about it? One possibility is that making individual stories of conflict so accessible was dangerous. The activist Huang Qi was detained half a year earlier because of his work curating similar tales on his website 64 Tianwang. Most likely, though, the sheer number of incidents $\mathrm{Lu}$ and $\mathrm{Li}$ recorded undercut government narratives related to the creation of a 'harmonious society' (hexie shehui) and bringing about the 'great revival of the Chinese people' (zhonghua minzu de weida fuxing). After all, the government itself used to sporadically make public annual incident counts, but it stopped doing so in 2005 , 
presumably because the numbers conveyed a negative impression of where the country was headed.

Wickedonna represented a particularly dedicated and courageous effort at counting Chinese unrest. However, a growing number of academics and activists have launched similar projects-albeit mostly from the safety of universities and non-governmental organisations located outside the mainland. These projects include an extensive dataset covering all types of disturbances put together by Chen Chih-Jou of the Academia Sinica (2009); my Ash Center colleague Li Yao's dataset of all the mass incidents reported in Boxun between 2001 and 2012 (2017); the 'China Environmental Protests \& Accidents' map covering 2005 to present (https://chinaenvironment.crowdmap. com); China Labour Bulletin's (CLB) strike map of workplace unrest from mid2011 to present (http://maps.clb.org.hk/ strikes/en); my own China Strikes dataset covering the $\mathrm{Hu}$-Wen decade (https:// chinastrikes.crowdmap.com); and the Global Labour Conflicts collection hosted by the International Institute of Social History in the Netherlands, which combines the maps from CLB and myself for its China section (https://datasets.socialhistory.org/ dataverse/labourconflicts).

In this essay, I will explore the power and limits of such efforts with regard to Chinese labour issues. I will begin by contrasting the practices of digging deep (qualitative research) versus counting (quantitative research), and posit that both have their virtues. Then, I will detail the inevitable data problems involved in any quantitative approach to documenting protest in China, while arguing that these problems, although serious, should not deter researchers. Finally, I will examine the ethics involved in how we collect such data and the questions we ask of it.

\section{Digging Deep versus Counting}

Research about Chinese labour politics to date has tended to involve in-depth fieldwork (digging deep). Scholars have worked on production lines themselves or interviewed strikers in cafes outside factory gates. They have also put in less adventurous, but sometimes equally demanding, time navigating the Chinese bureaucracy to buttonhole labour officials and trade union leaders. This is as it should be. To a certain extent, you have to physically be 'there' to 'get it'. There are also good reasons to be suspicious of statistics in labour studies. Quantitative data introduces the temptation, often subconsciously, to begin to make the sorts of assumptions about rational individuals and limited options that have led mainstream economics astray. Numbers, moreover, necessarily omit the voices of workers themselves. No econometric take on the industrial revolution, for example, will ever have the humanity of E.P. Thompson's exploration of the many forces that 'made' the English working class (1966). And most basically, with regard to China in particular, reliable quantitative data is simply not available for many aspects of the country's economy and society.

Nevertheless, counting unrest, where it is possible, serves at least two important purposes. First and most importantly, it can give us a sense of the general trends that underlie individual cases and how those trends interact-an imperfect sense to be sure, but a sense all the same. While a close analysis of a single strike at a single factory can challenge our ideas of how things 'work' in China and provide us with important clues as to the mechanisms of change at the grassroots level, we should not use a single case-or five or ten or twenty cases-to make claims about how most conflicts play out. Labour scholars generally include in their qualitative work various asides about limited 
external validity, but they nonetheless too often leave the distinct impression that they are really talking about where China as a whole is headed, caveats notwithstanding. You simply cannot do this with a country so big and complex.

Second, and this is maybe not so obvious, the process of counting itself is illuminating. Reading strike report after strike report can help you develop a rough sense of what the norms are for conflicts, something which is hard to come by if you are not yourself involved in activism on the ground. At the very least, you develop a feel for the norms of reporting a conflict. Thus, for example, I have noticed that coverage of public bus strikes in Chinese state media tends to take the following form: 'Today, many people waited for their buses for hours but none came. This reporter went to the bus station to investigate. Drivers were standing around. They had several important complaints. When asked about the issue, the transportation bureau said that they were putting together a team to investigate....' Then, when you read something that deviates from the expected story arc, it makes you take notice. You know that it is an outlier-and you wonder what has changed.

Counting contention has yielded useful findings in other labour contexts. For example, sociologist Beverly Silver's Forces of Labor (2003), which describes how worker militancy chases particular industries around the globe, continues to be a touchstone for many scholars (and has been translated into Chinese, winning it a new circle of readers there). Edward Shorter and Charles Tilly's examination of the size and frequency of strikes in France from approximately the mid-nineteenth to mid-twentieth centuries draws together national politics and shop floor dynamics in an illuminating manner (1971). Graeme Robertson's study of Russian labour protests under Yeltsin and Putin similarly documents fascinating interactions between workers and elite actors in a hybrid regime (2010). Works like these do not rely on perfect data (Silver's World Labor Group dataset uses articles from The New York Times and The Times of London to cover unrest the world over), but they are nonetheless revealing. There is no reason this work should not be extended to the world's second largest economy and largest working class. However, any quantitative approach to China must be balanced by extra close attention to the data problems and ethical issues involved in how we go about gathering and using numbers. I turn to these next.

\section{Data Problems}

If we are to begin counting, we must address the problems with the data available to us upfront. The most obvious problem is with totals. Everyone naturally wants to know how often, and in what numbers, workers are protesting in China. However, it is unlikely that any individual or institution actually has this information-not even the Chinese government. CLB has tried to be clear that their strike map likely only represents a small sample of the full 'population' of unrest occurring. Nonetheless, media outlets have repeatedly treated the CLB map as a more or less accurate measure of yearto-year changes in contention. This problem has sometimes extended to scholars. At one point in a thought-provoking 2016 article in the Journal of Asian Studies, Ching Kwan Lee contrasts CLB figures with numbers she obtained from the Shenzhen City Labour Bureau and Ministry of Public Security in the 1990 s and early 2000 s, concluding that 'the current period is actually witnessing a decline, not a rise, in strikes' (Lee 2016, 325). But surely the government sources Lee cites, while themselves imperfect, convey a more complete picture than CLB. Although her broader point stands-there was a lot of protest before, too, and academics are 
overstating today's conflict-the precise comparison made is thus inappropriate.

Other problems relate to more subtle issues of bias. Although a surprising amount of information is reported from poorer and more remote parts of the country, more data will always be available for a place like Guangdong than Gansu. Guangdong, in particular, is home to a relatively open press (especially the Southern Media Group), scores of bloggers and social media gadflies, and foreign journalists-and it abuts Hong Kong. Whether the imbalance in reports from different places is wildly out of sync with the imbalance in actual instances of unrest is a question that is important but almost impossible to answer. There are also biases in terms of sources. Dissident media outlets are unsurprisingly better at documenting violence against workers by police or thugs, whereas state media makes sure to always describe the steps taken by officials to resolve a dispute. There may also be biases that manifest themselves over time, as censorship tightens and slackens, and news cycles come and go. Statistically, these issues can be dealt with by using only one source for all reports (so that the biases are predictable), by including fixed effects, by zeroing in on dynamics in a particular region, or by seeing what happens when all observations with more than a certain number of incidents are dropped (to ensure that the story is not just related to one of the hotspots). The main thing, though, is to be honest about the data's limitations.

\section{The Questions We Ask}

Not all the dangers of counting relate to issues of samples versus totals or bias in terms of sources or cycles of reporting. We should also consider the real-world impact of what we are trying to learn with quantitative data. As with qualitative research, sometimes the easiest questions to answer are not the ones that matter most. Moreover, focussing on certain issues over others means serving certain interests over others. Traditional studies of strikes by labour economists have focussed on the number of incidents, number of participants, or the number of workdays lost. These figures are tracked by many governments (although not China's) and obviously have a big impact on an economy. But why not put more energy into rigorously documenting the different types of worker claims made (Franzosi 1989)? Claims may matter more to discussions of class consciousness. When you have thousands of 'dots' representing disputes marked on a map-the default of software programs like the one I use for my China Strikes map-it is natural to wonder why they cluster in some places and not in others. However, workers and their allies may not need lessons about what causes mobilisation. Instead, they may be more interested in its consequences: which tactics are effective and which are not, where in the country breakthroughs are possible, etc. In contrast, state authorities and businesses have an intense interest in understanding the roots of contention: they just want to stop protests! As has been well-documented in the media, big data is now being harnessed to track individuals and groups in China in disturbing ways, such as via the country's proposed new social credit system. The American military, meanwhile, is devoting substantial sums to predicting social upheavals with its Minerva grants. The protest maps assembled by labour researchers are unlikely to be as comprehensive as these projects and so should not raise the same level of concern. But research can always be turned to multiple purposes. It is important for scholars to ponder what purposes their research most easily serves. This sort of awareness is the least we owe people like Lu Yuyu and $\mathrm{Li}$ Tingyu who have sacrificed their freedom to document what is happening. 


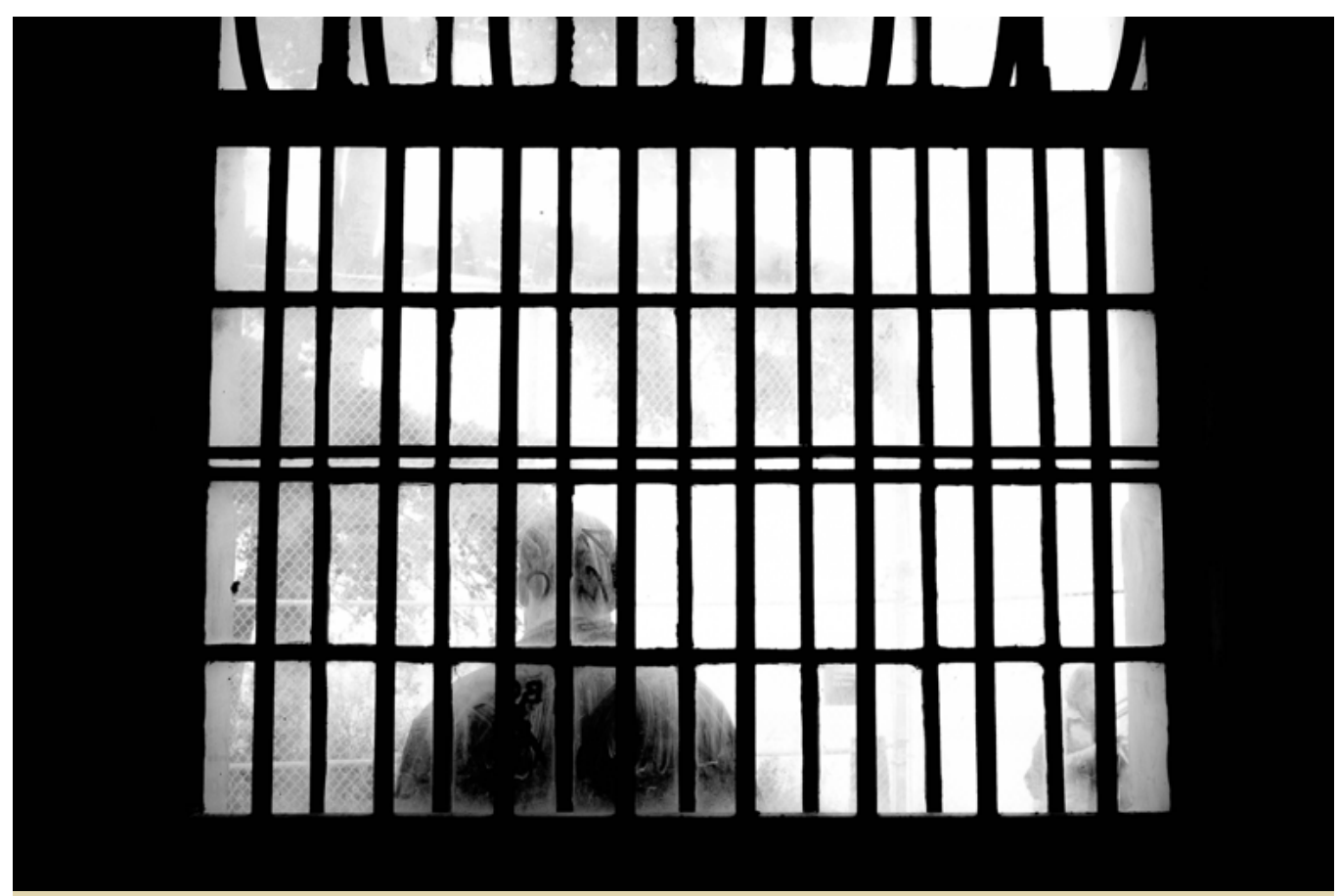

\section{Migrants, Mass Arrest, and Resistance in Contemporary China}

\section{Ma Tian}

In today's China, migrant workers are commonly perceived as criminals. This essay examines how this bias is reflected in mechanisms of crime control, as well as in the judicial and correctional systems. It also looks into the strategies adopted by migrants to cope with this kind of discrimination by the law enforcement bodies.
In Chinese society today, migrant workers are commonly perceived as criminals. This can be clearly seen in various mechanisms of the crime control regime, with the migrant population being stopped and searched more frequently than local populations, and experiencing a disproportionately high rate of police arrests and pre-trial incarceration. Migrants are also more likely to receive longer sentences, to be denied parole and probation, and to receive discriminatory treatment in the correctional system.

To address existing biases in the arrest rate of migrant suspects, between 2011 and 2015 more than twenty first-tier cities in China initiated legal reforms. Still, when I was doing fieldwork in major cities in the Yangtze River Delta back in 2015, prosecutors explicitly acknowledged that in their daily work they simply followed the principle of 'arresting all' (yilü shiyong jiyaxing qiangzhi cuoshi) when it came to migrant 
suspects. In their opinion, the reforms were 'totally infeasible, contradictory, and utterly ridiculous.' Similarly, policemen I interviewed in Ningbo during that period affirmed that they had never even heard of the new legislation. Apparently, the ambitious reform programme outlined in official legal documents had essentially come to naught. This failed reform highlights how hukou status still plays a fundamental role in determining how the police and judicial bodies in China deal with different types of suspects.

\section{Hukou Disparity in Arrest Decisions}

It is a fact that prosecutors in China are more prone to issue or approve an arrest warrant for migrant suspects. For instance, according to internal documents of the local Procuratorate, in Ningbo in 2010, the arrest rate for the migrant population was 368 arrests per 100,000 people-7.36 times higher than the rate for local residents. In light of this, the police find it easier to target migrants, as their arrest is more likely to be officially sanctioned. This dynamic of mutual reinforcement not only engenders discrimination against migrants, but also leads to a disproportionate arrest rate within this social group-in fact, we can talk about this phenomenon as being a form of 'mass arrest'.

Far from being simply the result of the personal preferences of individual police officers, this bias has been systematised, rationalised, and legalised. Article 5.6 of the Quality Standards for the Examination of Arrest Requests by People's Procuraturates provides specific procedural instructions to legal professionals, mandating that if the criminal suspect has no fixed residence, or commits crimes from place to place or in different places, and does not possess the conditions for bail or residential confinement', he shall be arrested (Supreme People's Procuratorate 2010). One of my interviewees, a prosecutor from a district procuraturate in Shanghai, confirmed that it was this link between the absence of a 'fixed residence' to a 'non-local hukou' that resulted in the establishment of standardised arrest guidelines in China. In this way, the creation of a causal link between migration and criminality has resulted in a major bias in the approval rate of arrest warrants targeting migrants.

Besides being legalised and institutionalised, this logic is also enshrined in routine everyday practice. Migrants are discursively equated with crime, and thus with instability and danger. Given the risk that migrants could 'run away', positive arrest decisions targeting this kind of suspect are justified as essential to ensure the defendant's return for subsequent proceedings. However, this apparent necessity is, in actuality, based on an illogical assumption formalised through the law.

\section{Coping with Police Discrimination}

My research shows that the benefits of the judicial reforms of the early 2010s have not trickled down to migrants. When suspected of a crime, they still found themselves stuck in the Kafkaesque position of being subject to relentless interrogations and arrests due to their hukou status rather than actual misbehaviour. In such recurring circumstances, migrants have no choice but to cope with the police strategically.

Article 10 of the Regulations on Detention Centres of the People's Republic of China (State Council 1990) stipulates that criminals have to go through a health check prior to detention, and lists three medical conditions under which they cannot be detained: a) Mental illness or acute infectious disease; b) Other serious illnesses that may be life- 


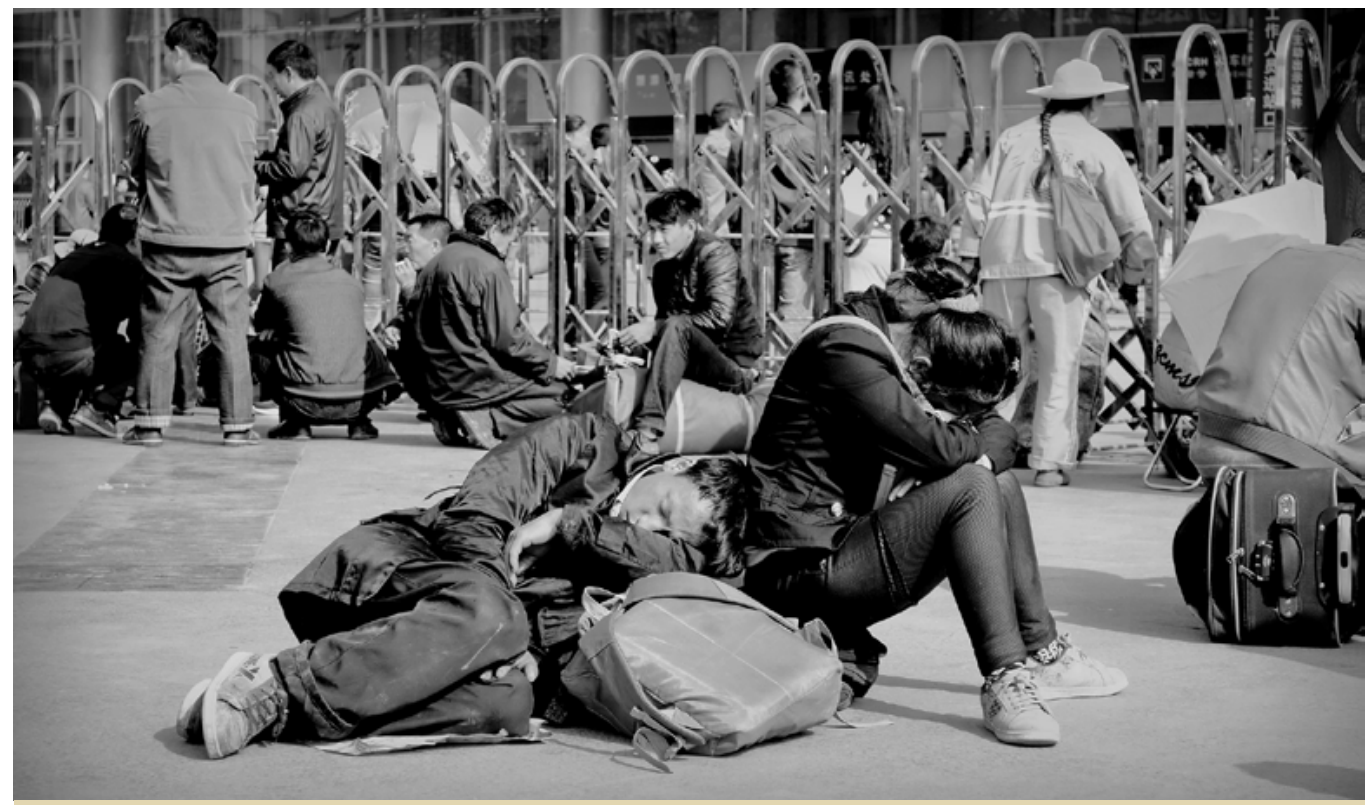

Chengdu, North Train Station. Photo: Phoootoooos, Flickr.

threatening while in custody or for which they can not take care of themselves (this does not apply to those who are extremely dangerous to society); and c) Pregnancy or breastfeeding of children less than one year old. Taking advantage of these legal guarantees, many migrants attempt to place themselves into these scenarios in order to evade arrest and detention. The most common coping strategies include putting oneself in a life-threatening situation for male migrants ( $\mathrm{Li}$ 2016), and pregnancy or simply cuddling a baby for female migrants.

In my interviews, the police continually complained about how 'crafty' (jiaohua) migrant suspects are nowadays. They vividly described their encounters with migrants who, in order to avoid arrest, swallowed blades, coins, keys, zips, screws, nails, nail clippers, and even saws. These occurrences were regarded as complicated and difficult to resolve. A policeman told me a story about a migrant 'thief' who used to carry nails with him at all times. 'After we caught him, he swallowed the nails instantly. The detention centre (kanshousuo) carries out $\mathrm{X}$-ray checks for all incoming detainees before taking them into custody. If they see things like these in their stomach, they will not accept them.' Under these circumstances, he continued, 'We had to let him go... After being released, he continued to steal. Then he went through prosecution and trial. Although the court sentenced him to prison, the jail still did not want to take him. What can we do? He continues to steal, but our hands are tied. There is nothing we can do.'

This process of 'othering' was repeated in encounters between the police and suspects, enhancing the discursive framing of migrants as having violent and irrational tendencies. In some cases, this discourse overlaps with other narratives and concerns related to specific ethnic minorities. For instance, Muslims from Xinjiang are often marked out for their 'savageness and aggression'. As one police officer told me: 'We caught several people from Xinjiang. Once he put some blades into his mouth, and 
then chewed the blades. Lots of bloods came out of his mouth, I was frightened to death, we just let him go.'

Female migrants often use motherhood to avoid arrest. In his master's dissertation, Li Weiming (2013) found that in Shanghai numerous organised crime groups from Hunan province recruit women who are pregnant or have a small baby. A woman told Li how she came to join the group: 'My townsfolk told me that nowadays pregnant women are all doing this. They said: "You are pregnant. What a pity if you don't do this!" Sometimes, women have abortions after months of pregnancy, and then get pregnant again just to stay out of jail.

\section{Blurred Morality and Resistance}

This essay certainly does not intend to glorify migrant coping strategies, or suggest that migrant suspects are activists leading a non-violent life in a context of apartheid. However, their actions cannot only be understood as a devious way to avoid criminal charges. From feigning illness to skipping a class, to soldiers deliberately harming themselves in order to escape the war; from espionage agents taking a cyanide pill to avoid torture, to people grabbing a baby at the very last minute to gain a seat on a lifeboat, it is never easy to distinguish between courageous acts and irresponsible cowardice. These examples all demonstrate that resistance is a complex set of actions that go against an established order. In other words, resistance-or the act of saying nois, by its very nature, contentious.

Facing the real possibility of arrest and pre-trial incarceration, migrant suspects look for alternatives for self-redemption. There are two layers of 'resistance' in the coping strategies outlined in this essay. The first layer lies within the offender's noncompliant behaviours during his or her interactions with the police. In this case, rather than being verbally or physically aggressive, the resistance is actually nonviolent. It is a tangible, subtle, even silent act. The second layer resonates with the idea of resistance or rebellion in cultural criminology. As Jock Young pointed out in The Criminological Imagination, 'resistance is always there' (2007, 77). Self-harm and pregnancy should also be seen as 'forms of resistance' against discriminative policing. At a disadvantage in the criminal justice system, migrant suspects change their own bodies to resist the asymmetrical power relationships between themselves and those administering 'justice'. For these subversive migrants, nails in the stomach and foetuses in the womb become a type of protection from discriminatory incarceration. 
$\rightarrow$

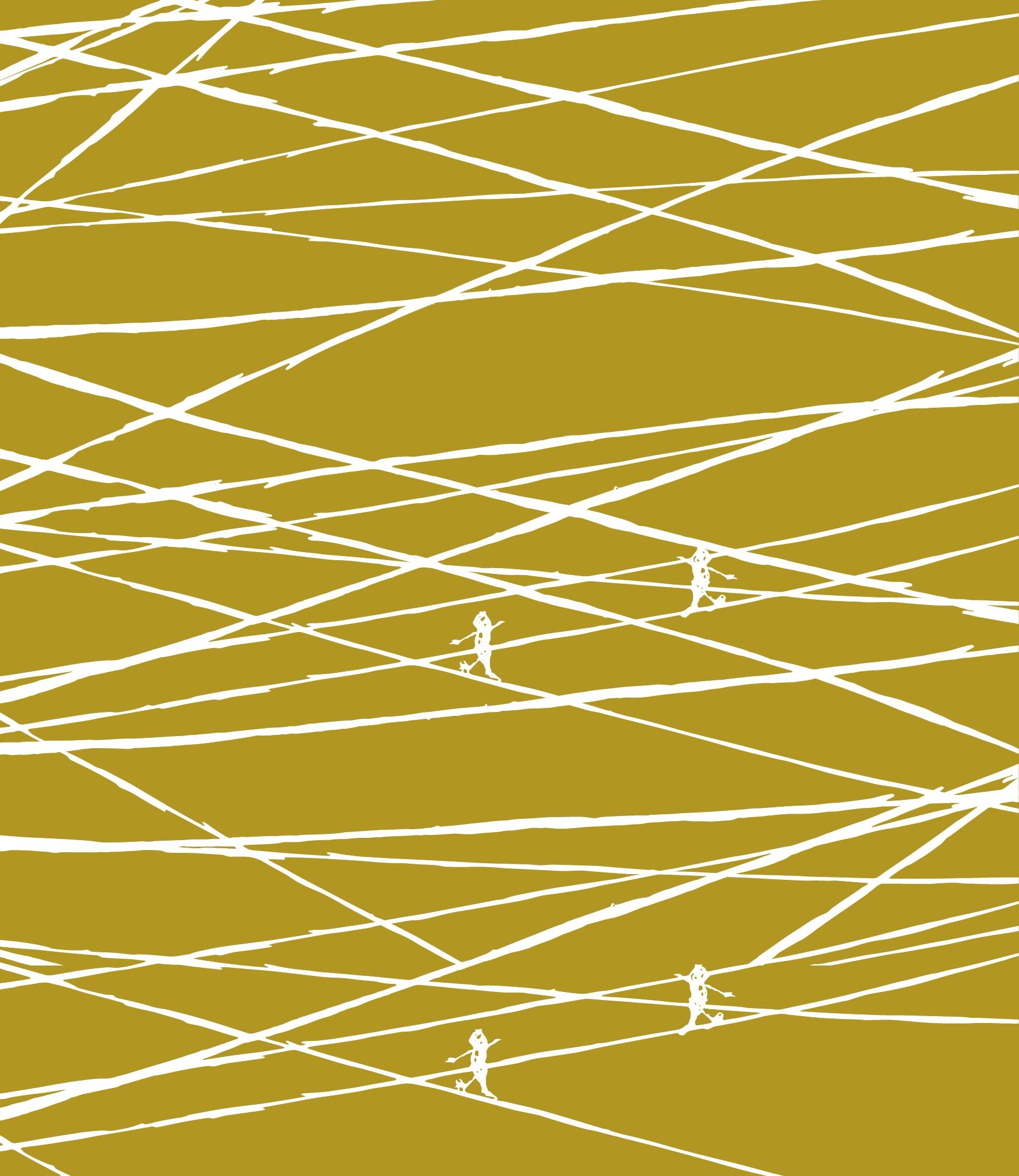




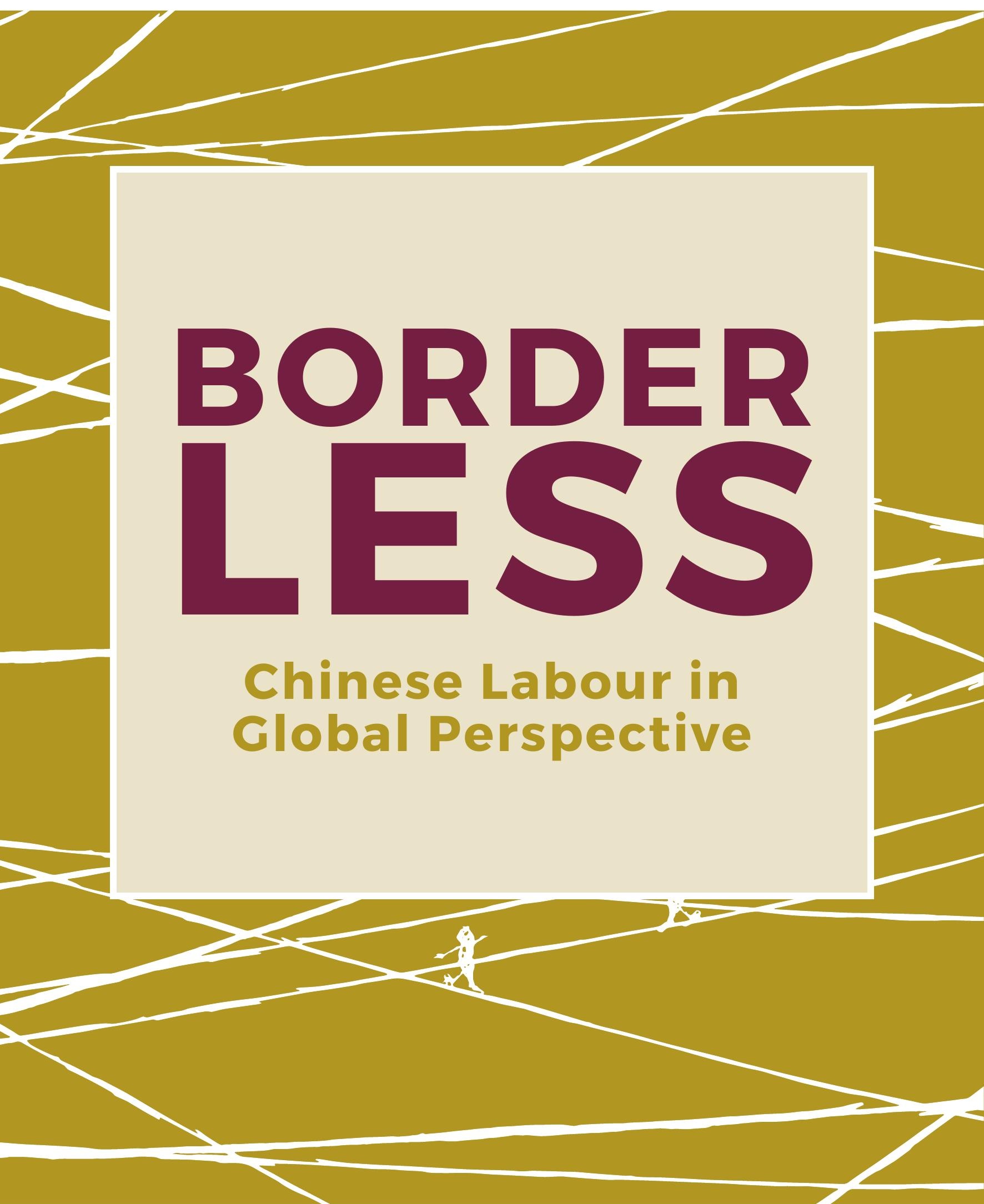




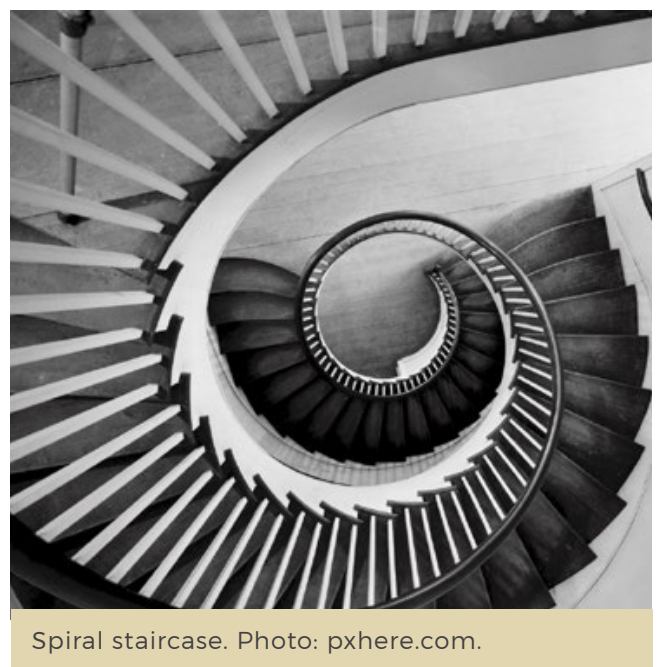

\section{Chinese}

Multinational

Corporations in

Europe

Racing to the Bottom?

\section{Zheng Yu \\ Chris Smith}

As the scale and scope of Chinese investment in Europe increases, it is important to understand how Chinese multinational corporations organise their workplaces on the continent, and what this entails for their workforce. This essay examines three key issues: the level of Chinese investment in comparison to investment from other countries; the extent to which employment models developed in China are transferable to European workplaces; and whether or not Chinese firms prefer using home practices to manage their workforce in Europe.
The arrival of Chinese firms in Europe has elicited both excitement and anxiety. New investors with funding from the Chinese state present a challenge to an open market in crisis and to Europe's faltering welfare capitalism model. A typical narrative depicts Chinese multinational corporations (MNCs) as exploiting institutional loopholes, and undermining local laws, regulations, and norms. In terms of employment relations, a widespread concern is that labour standards may be lowered by those Chinese MNCs that break rules on working hours and health and safety; use coercive forms of labour control, including withholding wages to inhibit mobility, and taking deposits to control migrant workers; ignore or suppress trade unions; and pay wages below subsistence levels, including through the employment of prison labour on construction and civil engineering projects. A further concern is that employment practices adopted by Chinese firms will influence the way that non-Chinese MNCs and local firms manage their workforce, with the fear that Europe will see a deterioration in working conditions across the board. However, despite such negative speculation, we actually know very little about what it is like to work in Chinese MNCs. As the scale and scope of Chinese investment increases, we need to better understand how Chinese MNCs organise their workplaces in Europe, and what this means for labour on the continent.

To avoid an over-simplistic reading of the impact of Chinese investment on work and employment in Europe, this essay will examine three key questions. First, we ask how influential Chinese investment is in comparison to investment from other countries. Focussing on this question allows us to evaluate the ability of firms to introduce employment practices from their home country to the host society. Second, we ask to what extent employment models developed in China are transferable to the European workplaces. Addressing 
this question will help determine the appropriate methods for studying Chinese firms overseas. Third, we question whether Chinese firms prefer using home practices to manage their workforce in Europe. Exploring this final issue prompts us to consider the various options Chinese firms have when it comes to deciding employment practices to be adopted in foreign countries.

\section{Debating Foreign Direct Investment}

The debates on how foreign direct investment (FDI) may reshape employment relations in Europe are nothing new. In the 1960s and 1970s, there were similar speculations over the 'Americanisation' of European businesses. Likewise, in the 1980s and early 1990s, when Japanese firms challenged American firms in becoming the main source of FDI, there was intense discussion about the 'Japanisation' of the manufacturing industry in Europe. In both previous waves of FDI, the perceived transformation of employment relations was at heart of the debates. Although there were criticisms of the intensification of work pressure, there was also a sense that
European companies needed to learn from the much more celebrated employment models that contributed to the American and Japanese companies' success overseas.

Compared to American and Japanese companies, Chinese firms have never been the single dominant force of capital expansion. According to data by the United Nations Conference on Trade and Development, the total stock of Chinese outward foreign direct Investment (OFDI) accounts for just 4.9 percent of the worldwide OFDI stock and one fifth of American OFDI stock by end of 2016. It is true that the scale of Chinese investment overseas has grown rapidly in the past ten years, at an average rate of 40 percent, and that the outward flow of FDI from China as a proportion of the total OFDI flow worldwide has expanded at a steady pace (see Figure 1). Together with American OFDI (light blue line) and the Japanese OFDI (green line), Chinese OFDI (dark blue line) has become one of the major sources of capital flow worldwide. Within the European Union's (EU) twenty-eight countries, however, China accounted for just over 2 percent of the FDI inflow in 2015 and 1 percent of total FDI stock by the end of 2015 (see Figure 2). Given that the scale of Chinese investment in Europe remains

Figure 1

Country-based OFDI as a Percentage of World Total OFDI (flow, three-year average)
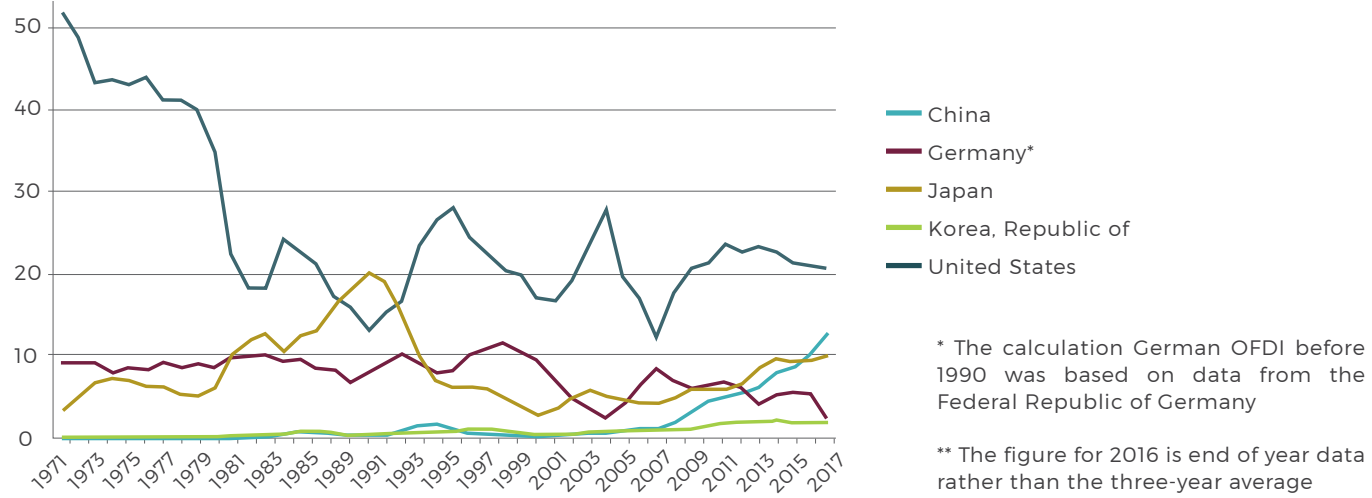

Source: Compiled from UNCTAD's statistical data on global outward FD 
Figure 2

Top Ten Countries as Source of FDI into the EU (flow, three-year average)

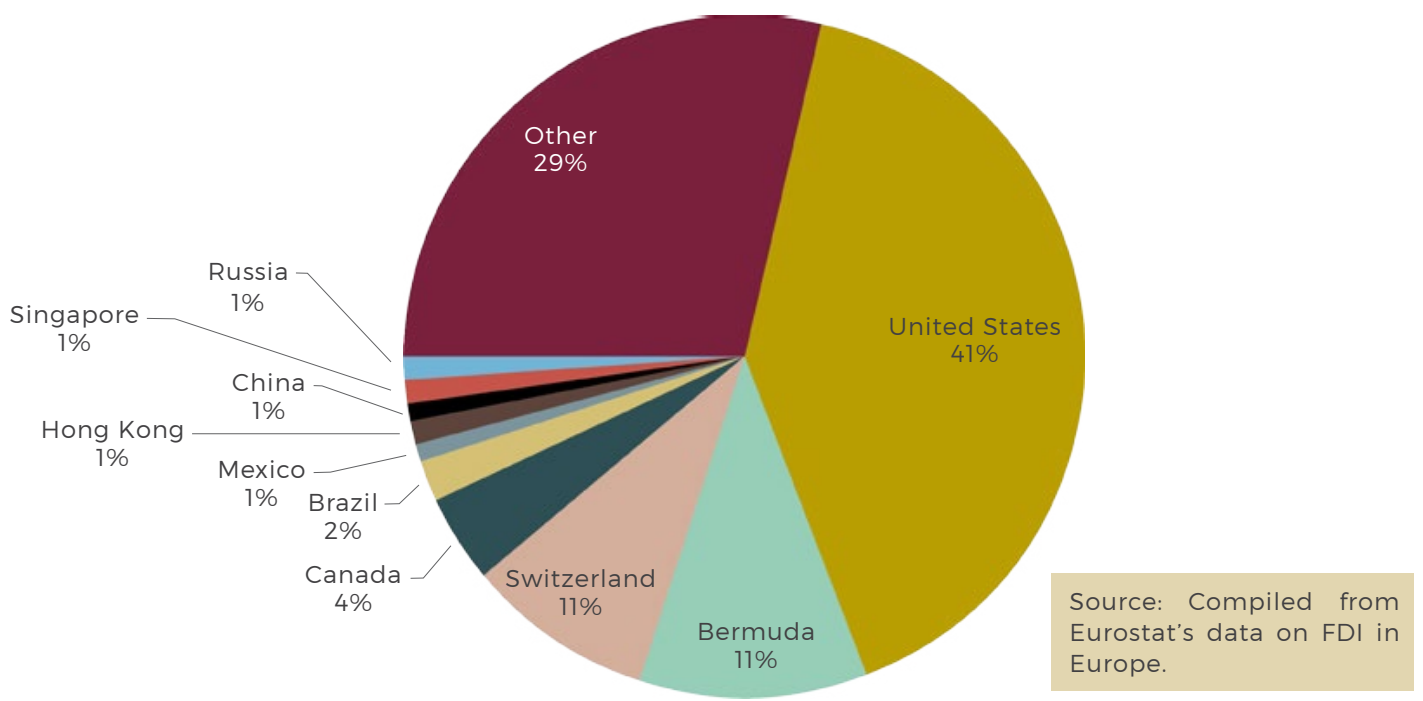

relatively small, we would expect Chinese firms to exercise control and influence over employment practices at workplace level, rather than having large scale impact on employment relations at national or crossnational level.

\section{Differentiated Foreign Employment Practices}

It must be assumed that any new employment practices introduced by Chinese firms will be contested by local workers and their representatives by referring to the local 'norms' of employment relations (Kostova 1999). Moreover, given that China is a less advanced economy with a smaller collective force of investors in Europe, employment practices exercised by rival MNCs from other countries may be used by Chinese firms as key references to effectively manage the local workforce. Therefore, studying the impact of Chinese investment on local employment relations will need to take into account the application of established practices, as well as experimentation with emergent practices in the new regional spaces of differentiated European labour markets.

This prompts the question of whether there is a set of Chinese indigenous employment practices that could potentially be used as a model for Chinese MNCs moving into the European market for the first time. China's move from a socialist to a capitalist state has passed through several experimental stages, and has embraced a number of developmental models. As a result, there are significant differences in the way Chinese firms manage their workforce. Many stateowned companies have maintained some legacy of the old Chinese socialist personnel system, which means that the terms of employment are based on a mixture of permanent, contractual, and ad hoc labour relations. Private companies and foreign investment companies have developed their employment practices in response to transitions in labour markets. For this reason, employment practices of Chinese MNCs are typically fragmented, adopting 
elements of modern human resource management, continued paternalism, and coercive labour control.

In addition to ownership-based differences, geographical differences in labour market conditions have facilitated sub-national employment models to emerge (Peck and Zhang 2013). For example, the 'Guangdong model' is based on manufacturing contractors employing mainly migrant workers and supplying owners of international brands. Firms adopting this model engage in OFDI by acquiring supplier or client firms in the global production network. In contrast, the 'Wenzhou model' has relied on small family ties and personal networks to generate growth and to accumulate funds for investing overseas. We cannot really say that there is a single or dominant model that has been adopted by Chinese MNCs abroad. For this reason, a firm-focussed approach is more likely to offer insights on why certain employment practices were adopted, modified, or abandoned.

\section{The Myth of National Models}

Whenever a new player enters the international space we should avoid overemphasising the employment models employed by their compatriots and instead focus more on the choices made by the individual firms themselves. Among Chinese firms in Europe, we can see that certain firms may be in favour of adopting some of their home practices especially those firms that are under wage, labour supply, or consumer market pressures in China. However, it is also true that some Chinese firms' internationalisation is of a more hybrid nature, aiming to perpetuate employment practices which prevail in China, as well as replicating 'successful' experiences of other firms in the new host territory. In particular, when firms are able to secure continued access to a pool of inexpensive and well-trained Chinese workers, they can bring much of their workforce overseas through an intra-firm transfer system allowed by some European countries' immigration policy. For instance, Huawei, a major Chinese telecommunications firm and a forerunner in terms of investment in Europe, demonstrates the benefits of sourcing a young labour force from China. Controlled by a performance reward system administrated and remunerated by the parent firm, the workforce is hardworking, motivated, and efficient (Lai 2016).

However, firms like Huawei are exceptional cases, and employing a Chinese workforce in Europe may be a temporary phase. Changes in labour costs, productivity, and other labour market conditions in the future will undoubtedly trigger reassessment of such employment practices. Additionally, pressure from local trade unions, the media, and the general public has the ability to force Chinese firms to rethink their employment policies and assess the possibility of targeting alternative sources of labour.

New entrants into a country can also operate in a space where employment practices can be implemented with less local pressure. This is particularly true in some special economic zones, where exceptions are given by the host country as an incentive to attract foreign investors. However, employment terms may or may not be included in such exceptions and can be subject to change, requiring firms to search for viable alternatives to the practices they are used to. This point can be illustrated by the case of China Shipping Group's investment in upgrading two container terminals in the Greek port of Piraeus (Zheng and Smith 2017). At the beginning of the rebuilding project, the firm recruited Chinese construction workers. However, the local dockworkers union organised several 
rounds of strikes, demanding the termination of any hiring practices that denied local workers' access to work (Reuters 2016). In response, the firm withdrew the majority of Chinese workers, replacing them not with local Greek workers, but instead with migrant workers from within the EU hired through employment agencies. The aim was to maintain a flexible supply of labour and to exclude local union members from the workforce. This example points to the fact that on-going industrial conflict might lead to further changes in employment practices. Firms operating in a space created outside local norms can change the 'rules of the game' and their ability to transcend such norms cannot be overstated. In regional labour markets, targeting EU migrant workers is a common practice of firms in sectors characterised by intense cost competition-such as construction, logistics, and services.

It is also possible that some Chinese firms invest in Europe in an attempt to move away from home-country practices and thus develop new ways of working in host societies. Especially in more developed economies, the incentives for investment from Chinese MNCs are often linked to upgrading technological and management capabilities, seeking novelty in products and services, and improving the way work is organised. Because of this, they try to maintain subsidiary autonomy and some stability by focussing on organisation, development, and learning. This trend is reflected in the composition of Chinese MNC investments in Europe, with merger and acquisition (M\&A) having become in recent years a major mode of Chinese MNCs entering Europe (see Figure 3 below).

For instance, Volvo Cars, a Swedish automobile manufacturer acquired by Geely, is one of the cases where most existing employment practices have been maintained as the Chinese acquirer attempts to improve

\section{Figure 3}

\section{Entry Modes of Chinese Investment in the EU}

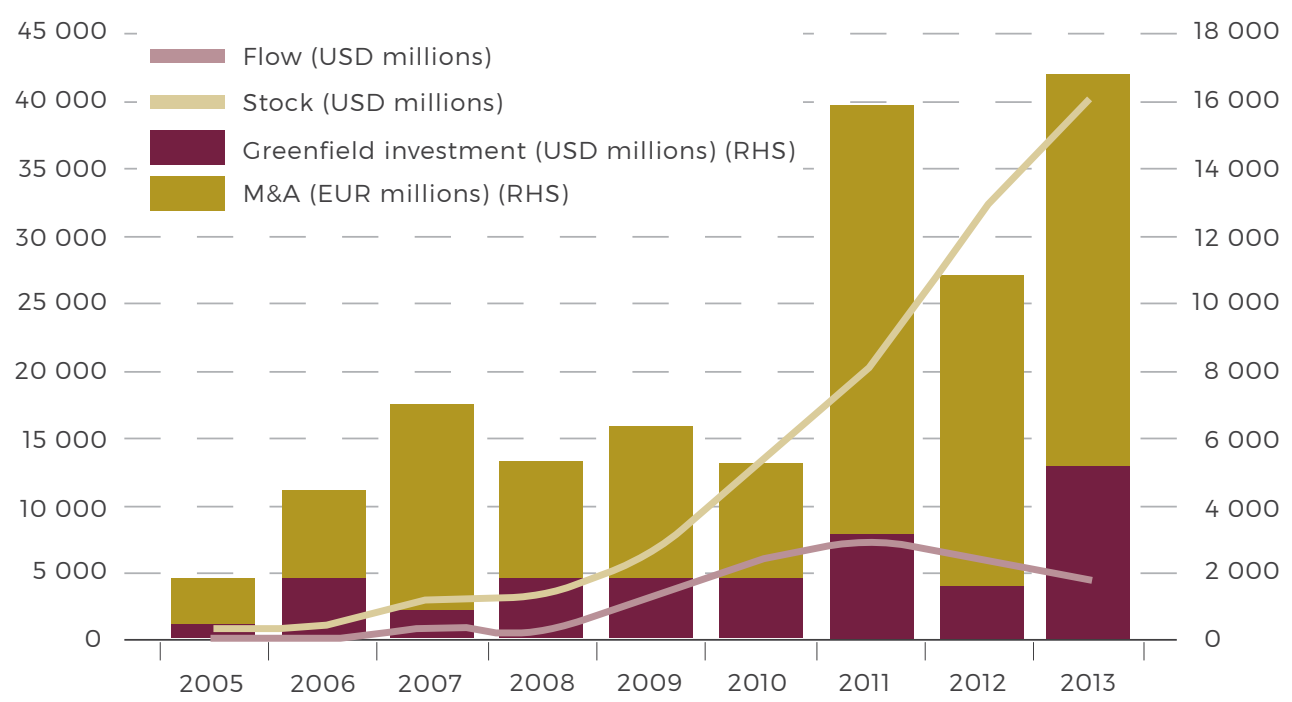


their market position, productivity, and management know-how by learning from the more developed subsidiary firm (Russo et al. 2010). For Chinese MNCs undertaking large-scale M\&As, it makes sense to incorporate existing employment practices, at least in the short-term-particularly if they see the acquired European subsidiary as having the potential to be key contributor to future revenue, a source of advanced technology, or a model management system.

\section{Rethinking the 'China Model' of OFDI}

The examples highlighted in this essay suggest that it is misleading to depict Chinese MNCs as being exporters of lower labour standards from China to Europe. In fact, Chinese firms in Europe are diverse in the way they engage with the local workforce. This is because Chinese firms have followed multiple routes of developments and their motives for internationalisation vary. Employment practices that seem to have been brought in by the Chinese firms evolve and transform in workplaces in Europe. Against a background of casualisation of employment relations with the resurgence of neo-liberalism across European labour markets, new entrants (Chinese firms) have found more space to negotiate with existing institutional players (national states, trade unions, employment agents) to develop divergent employment practices.

Research elsewhere shows that Chinese firms are extremely pragmatic, adaptive, and willing to work with local institutions. For example, Chinese firms are found to take a practical approach in resolving industrial confrontations in some developing countries, changing remuneration policies in response to local workers' opposition to practices such as continuous overtime and flexible working (Cooke 2014; Lee 2014a). While Chinese managers are often seen as championing 'job insecurity, hard-work and self-sacrifice' as key to China's economic success, they show strong sensitivity to the country conditions as well (Lee 2014a). When engaged in engineering and construction projects in developing countries, Chinese firms tend to emphasise the relevance of management practices and applicability of past experiences to new situations (Rui et al. 2017).

To understand the complex impact of Chinese investment in Europe, future research would do well to examine more fully the dynamics and diversity in the way Chinese firms manage their overseas workforces. Much more research is needed to see how Chinese MNCs negotiated with various institutional players for workforce composition, working conditions, and employment terms. Ethnographic case studies are most likely to enrich our understanding on this front. In addition, comparative case studies across a range of sectors and countries will also be useful to allow us to uncover what underpins the Chinese firms' ability to access labour and mobilise workers. 


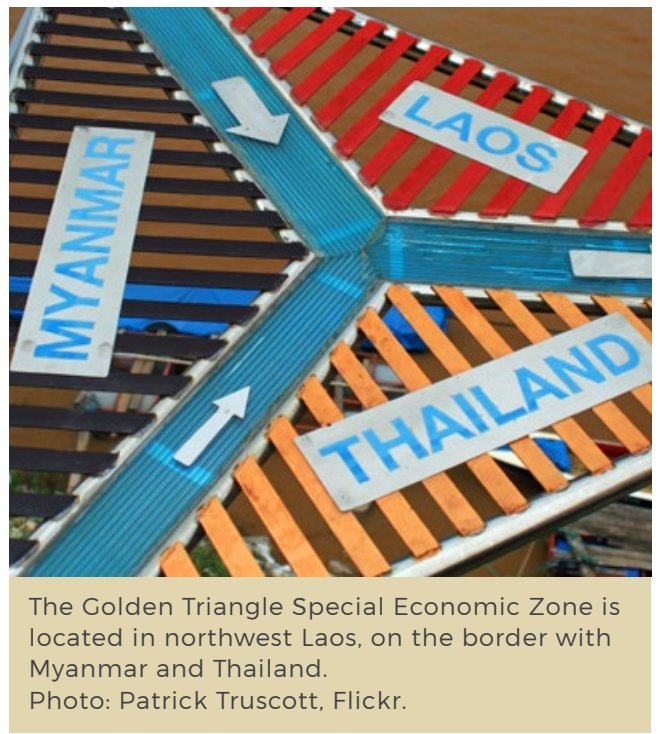

\section{Liquid}

Labourscape

Ad Hoc Experimentation

in a Chinese Special Economic Zone in Laos

\section{Antonella Diana}

Chinese-established Special Economic Zones (SEZ) in Laos have been criticised as being sites of neoliberal exception, sustained by a Chinese logic of self-entrepreneurship and selfdetermination-or a soft version of colonialera extraterritoriality. This essay argues that such areas are, in fact, a frontier space of post-socialist ad hoc experimentation, within which the Lao state haphazardly tests new socioeconomic and governing mechanisms under authoritarian rule in order to produce revenue and perpetuate its power over Lao citizens and territory.
In the northwest corner of Laos, where the confluence of the Ruak and the Mekong rivers marks the border with Myanmar and Thailand, lies the Golden Triangle Special Economic Zone (GTSEZ). This is one of twelve special and specific economic zones across Laos, all of which are areas where Chinese investments feature prominently (2017). The GTSEZ was established in 2007 on a ninety-nine-year land concession of three thousand hectares granted by the Lao government to Golden Kapok, a private Chinese firm owned by Mr. Zhao Wei, a casino tycoon from Heilongjiang province. Amounting to 700 million USD as of 2015, the firm's investment resulted in the construction of a new conurbation whose economy revolves around the casino business. The Lao government and the foreign company jointly rule the area. In this essay I will draw on ethnographic fieldwork undertaken in 2010 and 2015 in order to explore how this new governance model has affected labour dynamics in the zone, and to shed new light on the alliance between Chinese capital and the Upper Mekong states.

\section{A Frontier Space of Post-Socialist Ad Hoc Experimentation}

Chinese-established SEZs in Laos have recently been at the centre of media and scholarly debate. Two main analyses have emerged in academic literature. One, put forward by Santasombat (2015), draws on Aihwa Ong's previous work (2006) and defines the GTSEZ as a site of neoliberal exception, sustained by a Chinese logic of self-entrepreneurship and selfdetermination. This is coupled with 'state socialism from afar' (Yos 2015; Li and Ong 2008), which has caused deprivation and disempowerment of Lao people through a 
process of 'accumulation by dispossession' (Harvey 2005, 116). The other, represented by Pál Nyíri (2009), sees the land concessions granted to Chinese companies for SEZs in Laos as a soft version of colonial-era extraterritoriality, and criticise them for eroding 'the boundaries of citizenship'.

My research suggests that neither the neoliberal nor the crypto-colonial soft-extraterritoriality view fully captures the current political and socioeconomic dynamics of the GTSEZ. The former arbitrarily applies a universal neoliberal framework to the Lao and Chinese authoritarian post-socialist contexts; the latter, underestimates that shared sovereignty has been an on-going governance pattern in the Upper Mekong since pre-colonial times. Drawing on interviews with different actors within the GTSEZ, participant observation of the lived labour experiences of residents, and an analysis of official documents from the Lao government, I argue that the GTSEZ is, in fact, a frontier space of post-socialist ad hoc experimentation (Diana 2009). In it, the Lao state haphazardly tests new socioeconomic and governing mechanisms under authoritarian rule in order to produce revenue, and renew and perpetuate its power over Lao citizens and territory.

Evidence of this post-socialist experimental approach is demonstrated in the ways in which SEZs are used as sites for testing a new modernisation and industrialisation mode by attracting both domestic and foreign investment with the aim of integrating Laos into the regional economy. SEZs are subjected to special investment promotion policies and have autonomous economic, financial, and legal systems. In the GTSEZ, the experimental policies are implemented by a Management Board and an Executive Board, each constituted by Lao state officials at different levels and representatives from the Chinese firm. The boards are charged with jointly planning development interventions, issuing and enforcing regulations, as well as managing the zone on a daily basis. However, the zone's administration and management remain under the ultimate supervision of the Lao national government (DOASLNCSEZ; DOALNCSEZ) .

However, both a 2012 official report by the Lao government (DSSEZb) and later indiscretions from employees in the zone's administration during my fieldwork in 2015, reveal that the zone's experimentation was dysfunctional and ad hoc when put into practice. More than the subjugation of Laos to Chinese interests, the operation of the GTSEZ was tinged with illiberal and authoritarian undertones from the Lao state, a situation that belied the 'neoliberal' and 'crypto-colonial' views described above. Day-to-day co-ruling unfolded through on-going frictions over decision-making between the Chinese and Lao counterparts, as well as through obstruction by the Lao government of the Chinese firm's plans. It was rumoured that high-level Lao officials kept Mr. Zhao in check by constantly asking for money in return for concessions on project advancement. The committees' lack of administrative capacity contributed to casual and chaotic governance. This kind of ad hoc rule allowed the Lao government to secure its sovereignty over the zone.

\section{Liquid Labourscape}

The inconsistency between political rhetoric and socio-economic reality was also manifested in the labour sphere. SEZs are intended to create employment for zone residents, and in theory the Lao Labour Law should guarantee labour rights and regulate investor activities. However, my empirical research found that in the unstable administration of the GTSEZ, these legal resolutions were arbitrarily or barely enforced. Ad hoc experimentation 
produced what I call a 'liquid labourscape', a labour scenario characterised by inequality, casualisation, and lack of regulationespecially on matters concerning rights and safety.

In the GTSEZ's liquid labourscape, Chinese investors' treatment and remuneration of labourers was unequal and informed by a discourse of productivity that reflected an evolutionary view of socioeconomic development, tinged with racism, whereby nationals from 'more developed' countries were framed as more productive and therefore more-deserving than nationals from 'less developed' states (see also Nyíri 2016). At the top of the wage-labour hierarchy stood the twenty-seven Ukrainians and one Russian who worked at the casino as VIP room managers, supervisors, and, in one case, as a receptionist. By virtue of being Europeans-and thus being presumed to have a higher level of civilisation and skillsthey received salaries that ranged between 1,000 to 1,200 USD. Below them were around 1,000 to 1,500 mainland Chinese. Considered to be the most hard-working, rule-abiding, smartest, and civilised among the Asian employees, they were employed as skilled labourers in the casino, taking care of hospitality, recreation, or administration. Given their perceived higher 'quality' (suzhi), they received monthly salaries that varied between 600-800 USD. Lower in the hierarchy were the Thai employees, considered to be rule-abiding and relatively civilised, followed by the Lao, who were regarded as lazy, uncivilised, and stupid. Finally, at the bottom were the Burmese, viewed as hard-working and submissive, yet coming from a poor country and having dark skin. Only 40 Lao, a dozen Thai, and a couple of hundred Burmese workers were employed at the casino as croupiers, receiving wages of about 100 USD a month. A dozen of the Lao employees, who worked as interpreters, middlemen, or clerks in the zone's administration or in the casino, earned between 200-300 USD per month. About 400 Burmese performed unskilled jobs, such as gardening, cleaning, waitressing, and construction, for salaries ranging between 70-100 USD a month.

Although the Lao Labour Law sets the daily working time limit to eight hours and guarantees one day of rest per week, most employees worked for ten to twelve hours a day and had only two unpaid days of leave per month. With the exception of the Europeans, none of the employees in the casino or in other service sectors in the zone had employment contracts. Most worked short-term, without life or health insurance. Many interviewees complained about being mistreated and forced to work overtime by their Chinese employers. Indeed, labour conditions within the zone did not differ much from those found elsewhere in Laos. The Lao state officials' loose or lack of control contributed to reducing the gap between the GTSEZ and the rest of the country. These dynamics confirm that Laos' SEZs are not zones of neoliberal exception, but rather spaces of 'normalised' postsocialist inequality and lack of rule of law.

\section{Resistance, Resilience, and Reinvention}

Paradoxically, the liquid nature of the zone's labourscape enabled residents to devise creative modes of survival. These took the form of resistance, resilience, and reinvention. Expressions of resistance to the Chinese-Lao joint rule came from many Lao citizens who resided in or around the Zone. One such case can be seen in the actions of the residents of Khuam, a village that had been relocated in 2008 in order to make space for the construction of the Zone's business neighbourhood-a move that left a few without land and jobs. In 2014, residents gathered on the streets to demonstrate against the committees' proposal to take 
more land for the construction of an airport. Although the Lao Army cracked down on the demonstrators, the protest was successful in halting the airport plan. The government's backlash notwithstanding, dissent continued in a concealed way in virtual and real life. A Lao man showed me a Facebook page where netizens exchanged satirical pictures and posts that contested Chinese investments in Laos, and even mentioned an uprising being organised by overseas Lao to free Laos from the yoke of Chinese investment. In general, except for the few Zone employees mentioned above, Lao residents refused to work for the Chinese due to the long working hours and discrimination that this involved.

Additionally, several locals demonstrated their resilience to land and labour deprivation. Many started to learn Chinese language or send their children to study in China, in order to accrue a 'cultural capital' that could help them profit from the newcomers (Bourdieu 1985). A few established social connections with the Chinese, which in some cases resulted in love affairs or marriages, and in others turned into business collaborations. A few other Lao locals ventured into independent small business to capitalise on the Chinese presence. For instance, Sai, a Lao middleaged woman from Khuam village, responded to the Chinese taking away her farmland by opening a food stall in the market across from the casino in 2015, serving both Lao and southern Yunnan style noodles for employees and visitors. Within a short time Sai's entrepreneurial effort was rewarded with a booming business and considerable revenue.

Many Burmese migrant workers found social redemption in the Zone by reinventing themselves. Some turned to metaamphetamine smuggling from across the Mekong. This illegal activity allowed them to earn five to ten times as much as they would have in the more repressive and unequal context of Myanmar. A few young Burmese were able to save money not only to support their families back home, but also to pursue their studies at the university in Yangon. Some others became businesses owners. This was the case of Phon, a young man from the Shan States who had worked as a kitchen hand in a Chinese restaurant. In two years he had learned how to cook Chinese food and become fluent in the Chinese language. After his employer returned to China, Phon took on his former boss's business with his sister, and opened a restaurant across from the casino. Marketing his cuisine as ChineseBurmese fusion, within a short time Phon's business had become quite profitable. Much like for the resilient Lao and other creative Burmese, for Phon the Chinese presence in the zone had paved the way for upward social mobility.

\section{Winds of Change?}

This article has unravelled the political and labour contradictions born out of the partnership between Chinese capital and the Lao state in the GTSEZ. It has suggested that rather than being a site of neoliberal exception or cryptocolonial extraterritoriality, the GTSEZ is a frontier space of ad hoc experimental governance and liquid labour. Paradoxically, experimentation and liquidity have allowed many Lao and foreign residents to devise a new creative SEZ existence. A recent article in the Vientiane Times has denounced the lack of protection and precarious conditions for many Lao workers in sites where foreign companies operate (Sengpaseuth 2017). There is some hope that, under the rule of the allegedly progressive Lao Prime Minister Thongloun Sisoulith, elected in 2016, political rhetoric may be turned into an actual upholding of worker's rights. This could be a good opportunity for the Lao state to use Chinese capital to construct a more equitable SEZ labourscape. 


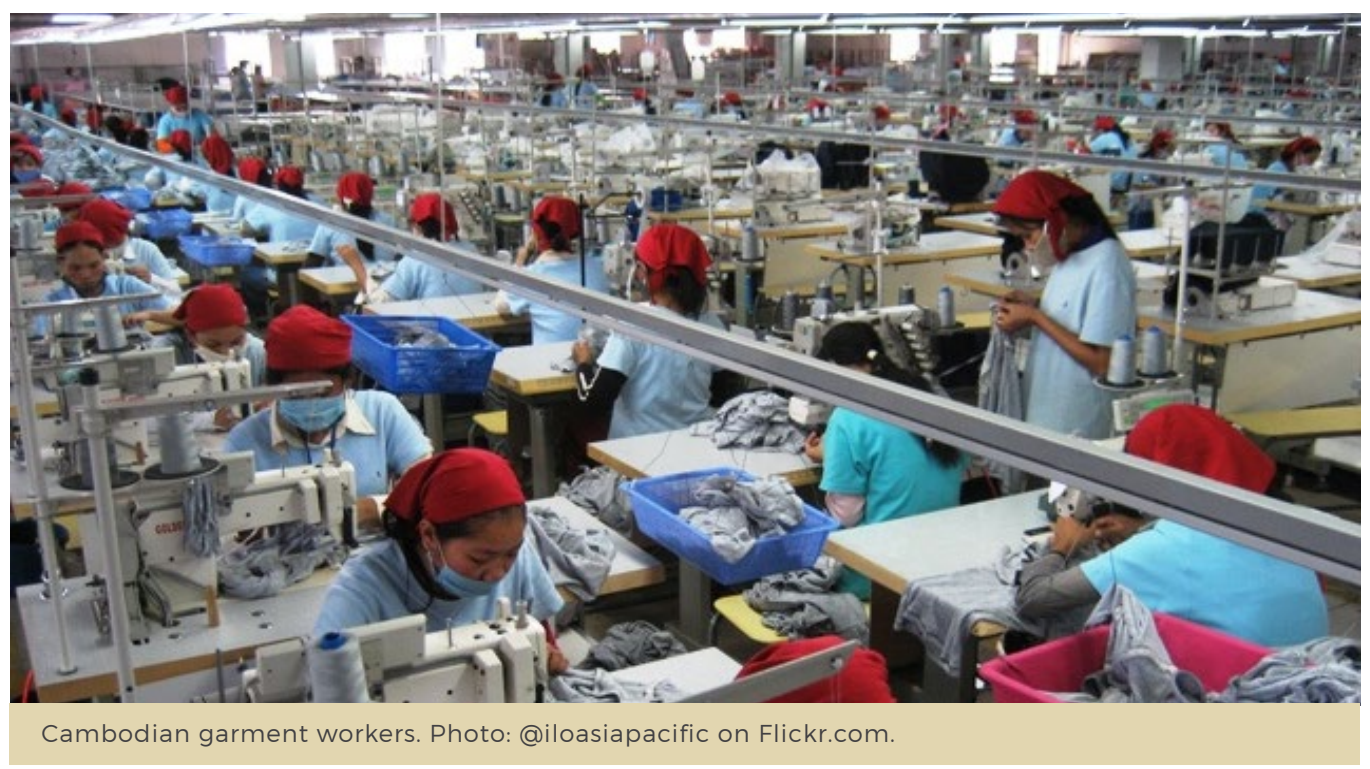

\section{Outsourcing Exploitation Chinese and Cambodian Garment Workers Compared}

\section{Ivan Franceschini}

In recent years, much has been written about how increasing labour costs in China are pushing investors to move labour-intensive production to other countries where wages are still low. But what does this shift in global capital trends entail for workers? How do the workforces in these new outsourcing destinations fare compared to their Chinese counterparts? In order to gain a better understanding of the human cost of this latest capital flight, this essay compares garment workers in China and Cambodia, considering the wages they receive in relation to the context of their expectations and needs.
In recent years, much has been written about how increasing labour costs in China-among other factors-are pushing investors to move labour-intensive production to other countries where wages are still low. Due to its moderate capital requirements, low level of automation, and minimal demands in terms of skills, the garment industry is one of the sectors in which China's loss of competitiveness is felt most acutely-especially as other countries, such as Bangladesh, Vietnam, Myanmar, and Cambodia, adopt policy after policy to entice foreign investors. But what does this shift in global capital trends entail for workers? How do the workforces in these new outsourcing destinations fare compared to their Chinese counterparts? There is no easy answer to these questions. Indeed, while the past two decades have seen a broad theoretical debate about the consequences and extent of the global 'race to the bottom' in labour standards, not much attention has yet been paid to the human costs of the wave of capital flight that is taking place in the wake of China's industrial upgrade. To address this gap, in this essay I will compare 
garment workers in China and Cambodia, considering the wages they receive in the context of their expectations and needs.

The choice of these two countries is dictated by the fact that the garment industry in China and Cambodia is at two different stages of development. While China remains the undisputed global leader in the industry, with its 2015 exports worth approximately 274 billion USD, there are already signs that the Chinese garment sector is unravelling due to rising labour costs, as the country embarks on an ambitious path of industrial upgrading (Van Der Kamp 2016). The Cambodian garment industry, on the other hand, was only established in the mid-1990s, when Cambodia finally emerged from more than two decades of chaos, and maintains a positive outlook. Having started from barely 80 million USD of exports in 1996, in 2015, the Cambodian garment sector had become a 6.8 billion USD industry, the ninth largest in the world (ILO 2017). Of course, the weight of the two industries within their respective local economies is very different. While the garment industry today plays a relatively minor role in China-in 2015 only 12 percent of the Chinese merchandise exports were in the garment sector-Cambodia's economic growth remains heavily dependent on garment production, with about 610,000 workers employed in the sector in 2016 and as much as 80 percent of the country's total merchandise exports in the same year being garment and footwear products.

To explore these different contexts, during the summer of 2016 I undertook two surveys. The first was conducted in June and July 2016 at three Hong Kong-owned garment factories in Dongguan, Guangdong province. These factories employed 2,000, 1,000 , and 800 workers respectively, and I was able to collect a total of 250 completed questionnaires. The second survey was carried out from July to September 2016 in three Hong Kong-owned garment factories in Phnom Penh, where most of the Cambodian garment industry is concentrated. In this case, the factories employed 5,700, 2,100, and 1,100 workers, and I collected a total of 291 questionnaires. To avoid interference from the management and possible biases in the responses of the workers, all respondents were approached outside the factory without prior knowledge of their employer. Most often, the meetings took place in the safety of their accommodation after their shift had ended or in restaurants around the factory during their lunch break. The quantitative data were supplemented with forty semi-structured interviews with garment workers employed in the sampled

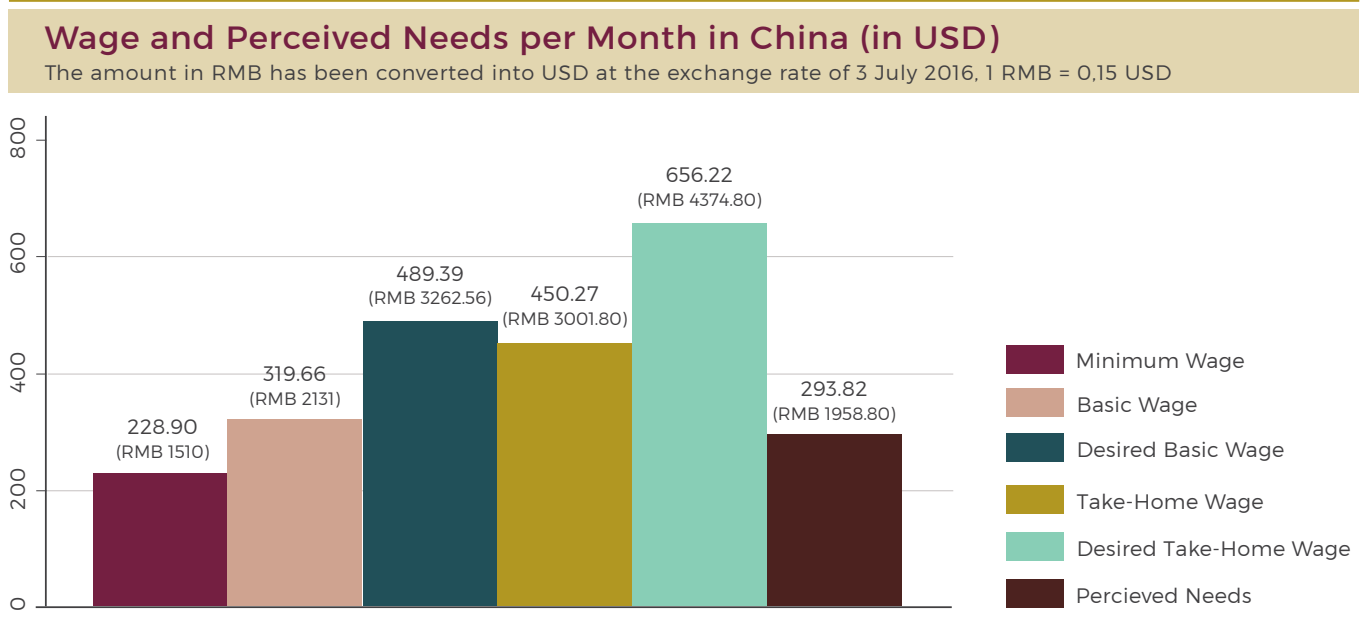




\section{Wage and Perceived Needs per Month in Cambodia (in USD)}

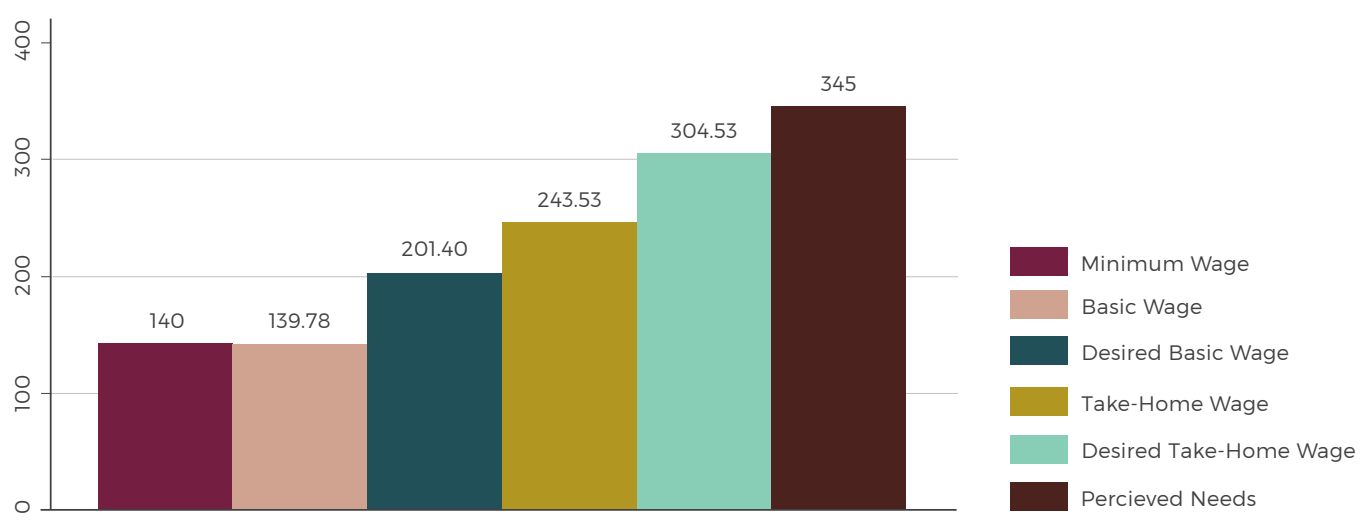

factories in both countries, plus additional interviews with local lawyers specialising in labour disputes, union leaders, and labour activists.

\section{Basic Guarantees}

The two graphs that accompany this essay summarise my findings. The first aspect to consider when comparing the two countries is the level of wages guaranteed by law, i.e. the local minimum wage. This is depicted in the first column in both graphs. According to the Chinese labour legislation, local governments in China are allowed to decide their own minimum wage through a process of tripartite consultation between local labour departments, the official trade union, and business associations. In setting the amount, these actors have to consider several factors, including the cost of living, the percentage of social security contributions paid by the workers, the average salary in the area, the unemployment rate, and the local level of development. At the time of the survey, the minimum wage in Dongguan was set at 1,510 RMB (roughly 229 USD) per month. In Cambodia, in 2016, authorities announced their intention to pass a Minimum Wage Law that would lay the foundations for a 'universal minimum wage' to be determined every year through 'tripartite consultation' (Bun and Davis 2016). However, currently only the garment and footwear sector is covered by a minimum wage, which is the same for the whole country. The amount is decided every year by the central government on the basis of the recommendation coming from a tripartite Labour Advisory Committee composed of 28 representatives. Of these, 14 come from the government, 7 from the employers associations, and 7 from the unions (5 of which are considered progovernment). At the time of the survey, the Cambodian minimum wage was set at 140 USD per month.

While in China there are no reported strikes related to minimum wage, in Cambodia the issue is at the centre of much controversy. In early January 2014, massive strikes and demonstrations of garment workers protesting over the government's refusal to raise the minimum wage ended in a bloodbath after the intervention of the military police (AMRC 2014). Due to the increasing repression of civil society and independent unions by the Cambodian authorities (see also NorénNilsson's chapter in the present volume), the following years have seen no more 
mass demonstrations during the minimum wage negotiations. Nevertheless, the raises that were granted by the government have continually fallen short of the expectations of independent trade unions and workerswith the exception of 2017, when the ruling party, concerned about its performance at the impending national elections, actually granted a minimum wage rise in line with the demands of the unions, which went into effect in January 2018 (Sineat and Baliga 2017). In 2016, for instance, independent unions pushed for a new monthly minimum wage of no less than 171 USD, but the government settled on a figure of 153 USD, far closer to the 147 USD proposed by the garment employer association (Baliga and Samean 2016). This was far lower than the 177 USD that some local and global trade unions and advocacy groups had been demanding as a 'living wage' for Cambodian garment workers since 2014 (Clean Clothes Campaign 2015). In light of these controversies, it is unsurprising that the draft Minimum Wage Law mentioned above introduces severe restrictions on the ability of independent unions to negotiate for higher minimum wages. One example of this is the inclusion of clauses that allow for fines of up to 1,250 USD for those 'creating obstacles or putting illegal pressure on discussions to determine the minimum wage', or up to 2,500 USD for anyone who 'incites activities against the declaration of the minimum wage' (Bun and Davis 2016).

Why do negotiations about the minimum wage elicit such different responses from Chinese and Cambodian workers? The reason can be found in the second column of both graphs, which depicts the basic wage, i.e. the monthly amount that the factories guarantee to the workers regardless of their actual workload. While the Cambodian factories offered a basic wage that coincided with the minimum wage, in China the basic wage was significantly higher (41.1 percent more) than the legal minimum.
The explanation for this disparity can be found in the cyclical 'labour famines' (mingonghuang) that have hit coastal areas in China, including Guangdong province, since the early 2000s (Zhang and Liu 2012). With many young Chinese rural women deciding to stay home to raise a family or to look for a job in townships closer to their hometowns, companies in labour-intensive sectors such as the garment industry have no other choice than to offer salaries higher than the legal minimum in order to attract workers. This means that while increases in the minimum wage in Cambodia have a direct impact on the income of the workers, in China workers already receive higher basic salaries and therefore do not have a large stake in the government's decisions on the matter. Most importantly, it shows that due to reasons related to demography, as much as to local development, Chinese workers have much more bargaining power than their Cambodian counterparts-a much more threatening prospect for investors than a difference of a few dozen dollars in the minimum wages.

\section{Expectations and Perceived Needs}

Minimum wages are simply a bottom line that is somehow supposed to protect workers from extreme exploitation, providing them with the guarantee of an income at times when production slows down due to the paucity of orders. As such, they do not reflect the actual level of remuneration that the workers receive, which in both China and Cambodia largely depends on the amount of overtime work. The Chinese workers in my sample worked an average of 10.3 hours a day from Monday to Friday, plus an average of 9.9 hours on Saturdays, with only Sundays off. This is a clear violation of the national labour law, which states that workers should work no more than 8 hours a 
day and 44 hours a week, with a maximum of 36 hours of overtime a month. In Cambodia, the workers worked 9.7 hours a day from Monday to Saturday and got only one day off every two weeks, another clear violation of the national legislation, which allows for 48 hours a week, with no more than 2 hours of overtime a day.

Due to the large amount of overtime, workers in both countries were able to earn more than the local minimum wage. This can be seen clearly from the fourth column of both graphs, which depicts the take-home wage, i.e. how much the workers were actually paid after taxes and other deductions for social security. In absolute terms, Chinese garment workers received much higher take-home wages compared to their Cambodian counterparts. While the Chinese workers in my sample were given an average take-home wage of 3,001.76 RMB (roughly 450.30 USD) a month, Cambodian workers were paid only 243.53 USD, a gap which would most likely widen if the survey also included the costs born by the companies for social insurance and other welfare-related expenses, burdensome in China and almost non-existent in Cambodia. In this sense, the assumption that rising labour costs underscores industrial relocations from China to other countries indeed has a strong foundation.

Significantly, both workforces were not satisfied with their remuneration levels. The third column of both graphs shows the desired basic wage, i.e. the response to the question in a situation in which you have to work only 40 hours a week [ 48 hours in Cambodia] and do not have to work overtime, how much do you think a reasonable salary would be?' Comparing the desired basic wage with the actual basic wage highlights that workers in both countries thought it reasonable to receive much higher wages for working only ordinary hours, with the Chinese workers wanting 53.1 percent more and the Cambodian workers wanting 44.1 percent more. The same frustration emerged when the workers were asked about their desired take-home wage. The question, depicted in the fifth column of both graphs, was formulated as such: 'Considering your current workload, how much do you think would be a reasonable salary for you?' While Chinese workers considered 4,374.80 RMB (roughly 656.20 USD) to be a reasonable amount, 34.1 percent more than their takehome wage, Cambodian workers desired 304.53 USD, that is 'only' 25 percent more than what they were currently making.

Still, the roots of this dissatisfaction cannot be understood without considering the perceived economic needs of the two workforces, which are displayed in the sixth column of the graphs. As mentioned above, international advocacy groups and Cambodian independent unions have been campaigning since 2014 for a living wage of 177 USD per month. An unpublished survey undertaken by several unions and NGOs in Cambodia in June 2016 found that workers in Phnom Penh needed around 142 USD a month for their living expenditures. Yet, as Dennis Arnold has noted, 'workers' politics and livelihood concerns [in Cambodia] include and extend beyond the (peri-) urban factory floor to rural households' $(2017,26)$. For this reason, in my survey I decided to go beyond basic living expenses and ask: 'On average, how much do you think you need every month to cover the basic living expenses of yourself and your immediate family (your partner, children, parents, or other people whom you have to support)?'

The responses were surprising, considering that living costs are much higher in Dongguan than in Phnom Penh. Cambodian workers felt they needed an average of 345 USD per month, more than the 1,958.80 RMB (roughly 293.80 USD) required by the Chinese workers. One initial explanation for this counterintuitive finding is that most Cambodian workers came from extended families-besides their parents, 
84.2 percent of them had three siblings or more-with most family members remaining in the countryside to engage in agricultural work. A second reason is that while 82.4 percent of the Chinese workers in my sample lived in a dormitory provided by the factory-evidence of the persistence of the so-called 'dormitory labour regime' in today's China (Smith and Pun 2006)-and thus paid only a symbolic fee for water, gas, and electricity averaging 122 RMB (roughly 18.30 USD) a month, Cambodian workers had to find private accommodation outside the factory, paying an average of 34.40 USD monthly. Chinese workers also had access to much cheaper food, paying $311.57 \mathrm{RMB}$ (approximately 46.70 USD) for their meals on average, compared to the 71.66 USD paid by Cambodian workers. This disparity in expenses clearly affected the amount of funds sent home. While Chinese workers were able to remit 1,724.90 RMB (roughly 258.70 USD) a month, i.e. 57.5 percent of their take-home wage, Cambodian workers could only send 67.55 USD, i.e. 22.2 percent of their take-home wage.

\section{A Matter of Survival}

What does this comparison tell us about the implications of the decline of the garment industry in China? First, it says that labour costs-as shown by the data on minimum wages and take-home wages - are indeed much higher in China than in Cambodia. This situation is further compounded if we consider the likely impact of the various costs related to social security and welfare that the companies must bear-costs which are substantial in China and almost nonexistent in Cambodia. Even more important, in order to face the challenges posed by demographic trends and local development, garment factories in China today often have no other choice than to offer better conditions than the legal minimum wage in order to attract workers. This is in stark contrast to Cambodia, where most employers have no incentive whatsoever to provide anything more than to what they are legally bound. In such a context, although China still offers advantages in terms of infrastructure and the availability of raw materials, investments in labour-intensive industry are likely to continue to desert the country.

Second, my survey demonstrates that by relocating from China to Cambodia, investors perpetuate dynamics of exploitation. This emerges clearly from the data regarding the expectations and perceived needs of the workers in the two countries. While the Chinese workers in my sample were finally able to earn wages higher than what they felt they needed, their Cambodian counterparts still earned much less than their perceived needs. It was definitely not a coincidence that wages were never at the top of the list of the workers' concerns during my interviews in China, while they regularly came up in my conversations in Cambodia. This does not mean that Chinese garment workers are happy with their remuneration-on the contrary, as we have seen, they still deem wages 'unreasonable' in light of their workload. Still, there is a fundamental difference between dissatisfaction due to the perceived unfairness of the economic treatment experienced in the workplace, as I found in China, and a deeper concern about the ability to provide a basic level of subsistence for oneself and one's family, as I encountered in Cambodia. It is this kind of human cost that employers should bear in mind when deciding to relocate from one country to the next in their unending quest for lower costs and higher profits. 


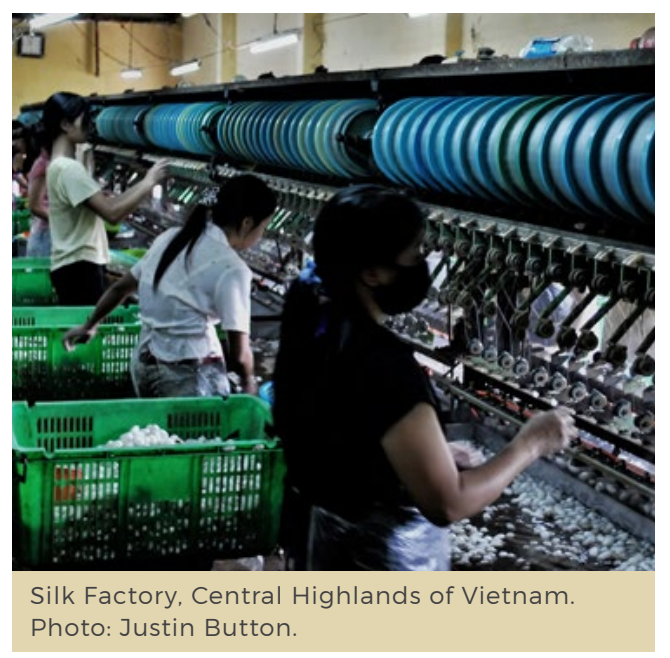

\section{Trade Union Reform in One- Party States China and Vietnam Compared}

\section{Anita Chan}

This essay compares the prospects for union reform in Vietnam and China. In Vietnam, heated debates about how to reform the trade union and the industrial relations system have been ongoing for more than a year, ever since the government signed the now defunct Transnational Pacific Partnership Agreement. That the debate continues among the top leadership and within government bureaucracies indicates that there is no lack of willingness to reform. In China, on the contrary, the Chinese Party-state and the official unions are taking the route of suppression of labour activism, indicating grim prospects for union reform.
As I understand it, the new President of the Vietnam General Confederation of Labour is enthusiastic about continuing efforts to 'renovate' grassroots unions even if the Trans-Pacific Partnership Agreement does not go forward... In addition, I understand that the Ministry of Labour

has moved forward with creating a new division of industrial relations that will administer the registration of independent unions.

An ILO Consultant 2 March 2017

From the [Chinese] trade union's standpoint we do not welcome labour NGOs. We even feel antagonistic towards them. My own feeling is about the same.

The union has always taken them as a serious enemy.

An informal employee of the Chinese trade union 4 January 2017

These two comments embody the current concerns over the problems that the Vietnam General Confederation of Labour (VGCL) and the All-China Federation of Trade Unions (ACFTU) are facing in their respective countries. In Vietnam, heated debates about how to reform the trade union and the industrial relations system have been going on for more than a year, ever since the government signed the now defunct Transnational Pacific Partnership Agreement (TPP) with the United States in February 2016 (USTR 2016). Vietnam's eagerness to become a member of the TPP was due to the promising prospect of quick economic gains connected to the membership. In light of this, there was consensus in the government and the VGCL on the need to enter into this international pact despite the TPP's Chapter 19, which required Vietnam to ensure freedom of association. If the TTP had been implemented, workers would have been permitted to set up their own unions and affiliate themselves to union federations of their choice. This would have meant a fundamental change in Vietnam's political 
structure necessitating relevant laws to be revised and new institutions created. In order to support this complicated process, the United States government had already earmarked four million USD to fund the International Labour Organisation (ILO) and the Vietnamese Ministry of Labour, Invalids, and Social Affairs (MOLISA) in the development of a plan for the reform of industrial relations in the country within five years (ILO 2016).

Sceptics, die-hard critics of oneparty states, and those who would have been losers in the new deal-such as the American trade unions (AFL-CIO 2016)believe that Vietnam signed the TPP for purely economic reasons, and that genuine freedom of association for Vietnamese workers is unlikely to materialise. When Donald Trump withdrew from the TPP in February 2017, scepticism heightened. Indeed it seems that the factions within the Communist Party of Vietnam (CPV) and the VGCL that have not been so supportive of dismantling the monopolistic trade union system are now backtracking. At the time of writing, freedom of association is still under discussion in Vietnam, albeit not as urgently as before. Still, as the quote from the ILO Consultant indicates, the issue is not yet dead and drawing up a programme for trade union reform is now seen as the more urgent task. Had Vietnam been motivated only by economic interests, then these initiatives would have been dropped entirely. That the debate continues among the top leadership and within government bureaucracies indicates that the willingness to reform is also self-motivated. This essay points to the fact that signing the TPP was not a decision solely made on the spur of the moment with economic gains in mind, but also has deeper historical roots.

To strengthen my argument, I will compare Vietnam with China. As many other scholars, including myself, have already discovered, China is an excellent comparator for Vietnam (Chan et al. 1999; Nguyen 2016; Chan 2015a). Both countries are Asian, socialist, one-party states steeped in market socialism, and they are both often criticised as being authoritarian. The countries' ossified political structures share many common characteristics borne from their Marxist-Leninist origins, but in as much there are varieties of capitalism (Hall and Soskice 2001), there are also varieties of socialism. Having recognised their similarities, identifying their differences and tracing the root causes of their divergences allows us to understand both systems better.

The second quote at the beginning of this essay is taken from an interview with a young university graduate hired by a citylevel trade union in Guangdong province. Only one year earlier, for the first time the local government had launched a massive crackdown that saw the arrest and interrogation of some twenty labour NGO activists (Franceschini 2017b). The quote-as well as those arrests-shows that, while the Vietnamese are debating how to liberalise the trade union system, the Chinese Partystate and the ACFTU are taking the route of suppression. Thus, the prospects for trade union reform in the two countries are very different. But before analysing these prospects, we need to examine the historical roots of why these two one-party states are not equally authoritarian.

\section{Historical, Political, and Structural Differences}

While both the Vietnamese and Chinese unions have been conceived of as Leninist 'transmission belts' between the higher echelons of the Party-state and the masses (Franceschini 2015), with an additional role as dispensers of social welfare, in many respects the ACFTU is much weaker than the VGCL. The ACFTU has been in a subservient status under Party-state domination since 
1949 , bereft of any élan of resistance. For eleven years, from 1967 to 1978, it was even disbanded. After Deng Xiaoping came back to power in 1978, he re-established the ACFTU and gave it some magnitude of autonomy, but to this day it remains no more than a very weak bureaucracy. The VGCL, on the other hand, has a history of militancy, first against French colonialism and then against American invasion (Tran 2014). As Gabriel Kolko has written, 'all wars more or less transcend the control of those leading them' (Kolko 1995, 4). Because of the war, the union had stronger ties with its constituency. In the South, trade unions battled against American and Vietnamese capitalism (Chan 2011). After the war ended in 1975, a legacy of militancy remained, so much so that when I interviewed quite a high-level trade unionist in the mid-1990s, I had the feeling I was talking to a trade union official who still possessed some revolutionary commitment, unlike those Chinese union officials who tended to just spout the Party line. South Vietnam had never been totally absorbed into the fold of the socialist bureaucratic subservient structure when doi moi-that is 'renovation', an expression equivalent to China's 'reform and opening up' (gaige kaifang)-began in the mid-1980s.

Both the ACFTU and VGCL tried to wrest more power from their respective Party-states in the late 1980s. While the ACFTU failed to gain anything following the suppression of the Tiananmen Uprising in 1989 (Franceschini 2015), the VGCL, in contrast, achieved some independence a year earlier at its 1988 Congress (Chan and Norlund 1998). The then secretary general of the CPV declared that union cadres might voice their ideas independently of the Party and management. Thus, when I first began doing research on Vietnam I was surprised to discover that Lao Dong (Labour), the official newspaper of the VGCL, carried articles in which the union openly staked positions that were different from those of the Party and of MOLISA. One consistent public debate up to this very day has been the VGCL's argument that the minimum wage is set too low for workers' needs. Never has such kind of public discussion appeared in the Chinese Workers' Daily, the ACFTU's mouthpiece, where all Chinese bureaucracies speak with one voice-that of the Chinese Communist Party (CCP). If there were any internal debates on these issues in China, they took place behind closed doors. This difference in the trade union publications alone indicated that in Vietnam there was some room for transparency, and that the VGCL had some space to act independently.

One reason why the VGCL could enjoy this space is partly related to the trade union's organisational structure. The Chinese and Vietnamese administrative systems are similar. In both countries, the Party has control over the appointment of leading union cadres at each level. Leading cadres are also subjected to two management systems, what the Chinese authorities call 'branch dictates' (tiaotiao zhuanzheng) and 'area dictates' (kuaikuai zhuanzheng), with 'branch' referring to ministerial hierarchical chain of commands, and 'area' referring to a command system under the Party at the same hierarchal level (Unger 1987). However, while the Chinese bureaucracy is dominated by 'area dictates', Vietnam is more inclined towards 'branch dictates'. In other words, the VGCL's line of command from the top to various lower level unions can override the interests of the Party at the same levels. This permits the VGCL to carry out its assigned mission to represent and protect workers' rights without being trumped by the priorities of the local Partystate for economic development. In China, in contrast, local unions are under the control of the local Party-state and thus tend to collude with employers, a situation that makes it difficult for them to help workers even if they are so inclined. The difference 
is further amplified by Vietnam's traditional sectoral trade unions that have a vertical line of command (Chan and Norlund 1998). In China, sectoral industrial unions do exist but they are so weak that they are almost irrelevant.

\section{Different Attitudes and Ways of Handling Strikes}

Since the mid-2000s, both countries have been plagued by wild-cat strikes, especially in the labour-intensive export sector. None of these strikes is organised by official grassroots trade unions, and they are thus 'leaderless' strikes. China has chosen to be silent on the legal status of strikes and, without functioning formal channels to resolve their grievances, going on strike has become the only possible strategy for workers to call attention to their plight. Vietnam, in contrast, recognises the right to strike on condition that workers follow a cumbersome application procedure. However, the process is so laborious that out of the several thousands of strikes that broke out in the past two decades not even one can be considered legal. This situation may lead one to conclude that the concession of a legal right to strike is irrelevant in preventing strikes from breaking out.

The difference, therefore, is not in the law but in the authorities' attitude to strikes. Since strikes in Vietnam are officially recognised as a right of the workers-even if they do not comply with the pre-strike procedures-when a strike breaks out, the local Department of Labour and the local trade union immediately arrive on the scene, lambast the management for violating the laws, and negotiate on behalf of the workers. The police too rush to the scene, but they just stand by in case the strikes descend into violence. Once workers' demands are metusually this happens in a couple of daysproduction returns to normal.

As for China, since the Party-state does not recognise strikes as a right of the workers, the local authorities' attitude towards strikes is generally hostile. They are seen as potentially socially and politically destabilising, and thus anathema to capital

Vietnamese and Chinese Workers' Attitudes towards Factory Trade Unions

Do you think the trade union in your workplace represents workers' interests?

\begin{tabular}{|l|l|l|}
\hline & Vietnam & China \\
\hline Yes & $894(85 \%)$ & $100(10 \%)$ \\
\hline No & $58(6 \%)$ & $203(20 \%)$ \\
\hline Don't know & $100(9 \%)$ & $672(67 \%)$ \\
\hline Missing & $2(<1 \%)$ & $33(3 \%)$ \\
\hline Total & $1054(100 \%)$ & $1008(100 \%)$ \\
\hline
\end{tabular}


investment and economic development. The local union arrives on the strike scene to quell the disturbance rather than to act as a representative of the workers. The police is apt to use force, especially if workers take to the streets. In such a context, Chinese workers see the union, local government, and management as colluding against them. In fact, the attitude of Chinese workers towards the union is not only one of mistrust, but antagonism. Vietnamese workers on the other hand see the primary union as representative of their rights despite its weakness. The table illustrates the surprising results of a survey that Wang Hongzen and I undertook in 2007 (Siu and Chan 2015).

In other words, though their union is weak, the vast majority of Vietnamese workers still tend to think of the union as an ally rather than an antagonist.

\section{Different Countries, Different Systems}

To summarise, though their workplace union is weak, the two countries are quite different historically, politically, and culturally. On the whole Vietnam is more pluralistic while China is more monolithic. These fundamental preconditions lead to a divergence in the formation of the system of industrial relations. The situation in Vietnam is much more conducive to learning from and working with foreign countries and organisations. For many years, the MOLISA and VGCL have been working closely with international organisations, the most important of them being the ILO, which played an important role in helping and advising Vietnam to revise the strike regulations included in the 2012 Labour Code. They have also been partnering with two trade union support and solidarity organisations: the German Friedrich Ebert Stiftung (FES) and the Australian Union Aid
Abroad (APHEDA). The Australian Public Sector Union also helped the VGCL when it was setting up its public sector union in the early 1990s.

Vietnamese trade unionists, unlike their Chinese counterparts, are used to addressing foreign trade unionists and labour activists as brothers and sisters. It reflects their selfidentity as comrades in the international trade union community. The TPP, therefore, should not be seen as the root cause, but as a trigger of Vietnam's decision to reform its industrial relations system, including setting up a system that recognises freedom of association. In fact, it was the VGCL that proposed to the Party-state to accept this demand of the American government. The VGCL felt confident enough in its own ability to compete for the loyalty of Vietnamese workers with emerging new trade unions. In mid-2016 during our field research, we saw the relevant Vietnamese bureaucracy stakeholders, in collaboration with the ILO, rolling out programmes of social dialogue and collective bargaining at various administrative levels. There was open discussion that some workers had already agitated to set up new independent unions and the urge was not to suppress them, but to revise the relevant laws to make them reflect this new reality. At the behest of the ILO, Vietnam is consolidating a peak tripartite system. Minimum wage and other labour standards are now set at the national level after intense debate between the three parties-government, employers, and unions. The emphasis of the programme is on strengthening the trade unions' power and their ability to negotiate at different levels. Training on social dialogue techniques is aimed at instructing union officials to identify themselves as representatives of the workers and dissociate themselves from management domination. The ILO's tripartite system is beginning to take shape in Vietnam. However, it seems that the VGCL is on the losing end. After the new minimum 
wages for various regions were announced in June 2017 (VNA 2017), the VGCL openly complained that they were too low to meet workers' needs.

In the past two years, the ACFTU has also been in the midst of reforms. Programmes to reform the union in China are not unprecedented, but time and again not much has changed. Direct elections of workplace union committees (Chan 2015b), campaigns to establish workplace collective bargaining, and the setting up of amalgamated unions at the district or village level for scattered small workplaces have all failed to effect any noticeable changes, except in isolated cases. With strikes breaking out unabated, particularly in Guangdong province, the ACFTU has been blamed for its incompetence in keeping the labour peace.

Meanwhile under Xi Jinping the Chinese authorities have intensified their repression of labour activism; labour NGOs have been harassed and some of their staff have been arrested. Foreign contacts are controlled and closely monitored. According to authoritative internal sources, $\mathrm{Xi}$ has lambasted the ACFTU, blaming it for having alienated itself from the workers. The unions are criticised for four types of 'ossification'-they are said to have become bureaucratised, hedonistic, behaving like royalty, and acting like functionaries. A new round of reform has been ordered-union officials are to be at one with the people, with more grassroots and amalgamated unions to be set up to provide workers with more services. At the same time, the role of the CCP at the grassroots is also being strengthened, with the Party being cast as the overseer of the union reform.

In January 2017, we had a chance to observe how this programme is being carried out in an industrial zone in Guangdong province. The city union has used its own resources to recruit a dozen or so young university or college graduates to staff one of the zone's community centres.
From here they provide social services, run social club activities, and disseminate some labour law knowledge to the workers in the neighbourhood. The office is open until late at night, unlike a regular trade union office that only opens during normal work hours. It is hoped that workers who are active in organising social activities will ultimately become labour activists. If a strike involving more than one hundred workers breaks out in the neighbourhood, it is not the task of the office staff to intervene. They have to wait for the local union and authorities to come to resolve the problem by themselves. The reason why this type of work cannot be taken care of by a regular grassroots trade union office, we were told, is because the union is held back by its own organisational inertia. For all intents and purposes, these grassroots union outposts resemble youth centres and community centres. It is through these services that the city union hopes to be able to satisfy the assigned responsibility of being at one with the masses. But it is not the regular trade union staff who is tasked to do this-it is their surrogates. At best, one can characterise this programme as social work trade unionism. 


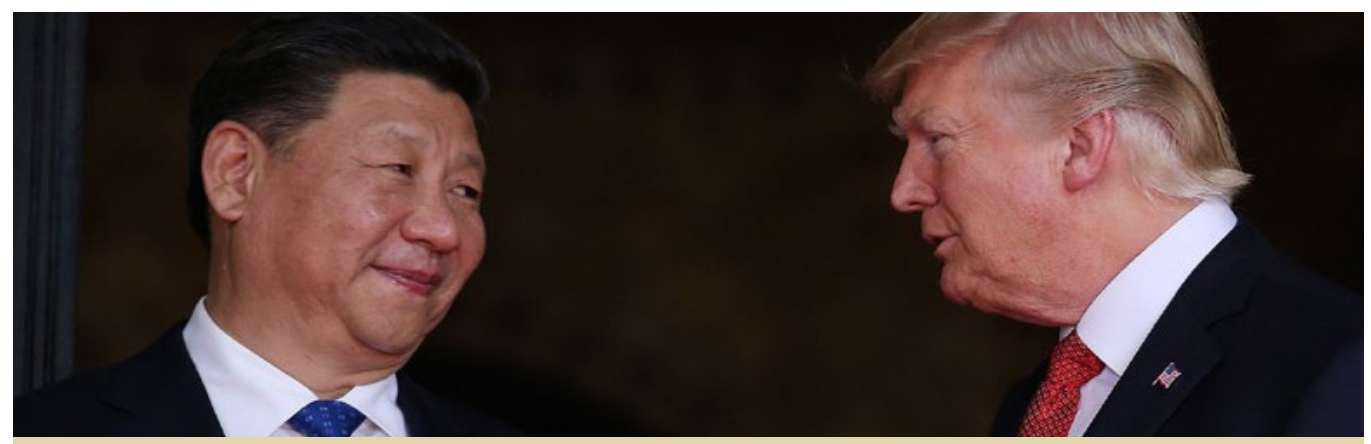

Xi Jinping and Donald Trump during one of their first official meetings. Photo: Businessinsider.com

\section{Prospects for US-China Union Relations in the Era of $X i$ and Trump}

\section{Katie Quan}

Under the presidency of Xi Jinping and Donald Trump, relations between trade unions in the United States and China have come to a virtual standstill. To understand how we arrived at this point, and what can be done to break the impasse, this essay briefly reviews the historical development of union relations between the two countries. In order to achieve this, it draws on voices of those labour leaders in the United States who have been direct participants in efforts to develop early contacts with their Chinese counterparts.
In October 2013, Richard Trumka, President of the American Federation of Labour and Congress of Industrial Organisations (AFLCIO), visited the All-China Federation of Trade Unions (ACFTU) to establish formal bilateral relations between unions in China and the United States (DePillis 2013). This visit signalled an historic shift in labour policy, from Cold War-style hostility to normalisation of relations. Some American labour activists hoped that it might further lead to collaboration on joint activities, such as collective bargaining. That collaboration would be a significant step forward in labour solidarity and building a global labour movement.

However since then progress towards building relations has been decidedly slow. There have been only a couple of official exchanges with the AFL-CIO, and activities sponsored by Change To Win (CTW), the splinter group of the AFL-CIO that first began relations with the ACFTU a decade ago, have decreased. Some American labour leaders have noted that the ACFTU has become less interested in collective bargaining since Xi Jinping's campaign against corruption began. Now, given Donald Trump's election as US President with his agenda to weaken the American labour movement and start a trade war with China, it is fair to ask whether there are any prospects for progress in relations between unions in China and the US, and if so where. 
To understand the American perspective on the relationship between the US and Chinese unions, I will briefly review the historical development of relations between workers in the two countries. Then, I will address more recent union relations based on information obtained through semi-structured interviews with a dozen labour leaders in the US who have been direct participants in efforts to develop those relations. Finally, I will discuss the challenges and opportunities laid out by my informants and draw conclusions.

\section{A Troubled History}

The root of American attitudes towards Chinese labour have been shaped by race, class, and ideology. Since the nineteenth century there have been xenophobic fears of the 'Yellow Peril' represented by Chinese workers, as well as arguments that workers of European ancestry should cast their lot with American business and shut out Chinese workers (Tchen and Yeats 2014). These fears were compounded in 1949, when China became a communist state and an ideological enemy, resulting in antipathies that linger to this day.

After World War II, the Cold War set in, and the world was divided into two main ideological camps: the communist and the 'free world'. In 1949, American unions led a split in the World Federation of Trade Unions (WFTU) - a global union that aspired to bring together unions from all over the world into a single organisation-to form the International Confederation of Free Trade Unions (ICFTU), an alliance of free world unions. Meanwhile, the WFTU came to be known as the federation of communist unions, to which the ACFTU was affiliated. Back then, divisions in the international working class mirrored ideological debates among nation-states. The ICFTU consistently criticised the ACFTU for not being a free and independent trade union, and therefore declared that it was not an 'authentic' voice of Chinese workers.

However, in 1979, when China opened its doors to foreign investment and diplomatic relations with the US were established, the material basis for this divide changed. Multinational corporations raced to China to take advantage of the low-cost labour. Factory conditions were appalling and workers were exploited, causing outcry among international consumer and human rights activists, and drawing criticism of the Chinese government and its unions for not protecting workers. At a time when international labour solidarity might have meant American workers reaching out to workers in China, American unions continued to refuse to have anything to do with Chinese unions, repeating the Cold War rhetoric that they were neither independent nor authentic. Meanwhile, some leftleaning labour organisers worked quietly in the background to coordinate worker-toworker exchanges between US and Chinese workers, hoping to build solidarity.

The Tiananmen Incident in 1989 proved to be a setback for these budding relations. The crackdown on the protests was viewed worldwide on cable news in real time, and its brutality reinforced what many American labour unionists had believed all along-that despite capitalist markets and openness to meeting foreigners, China was still an authoritarian state that did not respect human rights. The AFL-CIO response was to support a few Chinese labour activists in exile, and to continue to boycott relations with Chinese unions.

At that time, American unions supported campaigns targeting international brands, pressuring these companies to accept corporate social responsibility in their supply chains. The theory was that the brands had power to control labour conditions in factories that manufactured their products. In Latin America, Africa, and Southeast 
Asia, these cross-border campaigns, mostly led not by unions but by non-governmental organisations (NGOs), had modest success in supporting worker organising. However, with respect to China-where an increasing share of the world's export manufacturing was taking place, and where supply chain organising strategies might have had an impact on the global economy-no NGO ever figured out how to get brands to pressure the Chinese government to allow workers to organise themselves.

Another response of American unions was to push for trade sanctions against China. Arguing that the low labour standards in China undercut American jobs, the AFLCIO sought to block China from entering the World Trade Organisation (WTO) and from receiving Most Favoured Nations status under Permanent Normal Trade Relations (PNTR) with the US. Using the race card once again, the AFL-CIO's petition against PNTR painted a dehumanised picture of Chinese workers as willing slaves who were willing to work for practically nothing, thus undermining the standards of American workers (Wong and Bernard 2000). It argued that sanctions would force the Chinese government to improve conditions for Chinese workers. So at the turn of the twenty-first century, racist stereotypes of Chinese workers that were common over a century before were still being used, and policies from the Cold War era that ended nearly half a century before still kept Chinese and US workers divided.

\section{First Engagements}

Meanwhile, global labour activists continued to organise worker-to-worker exchanges. In 2002, Andy Stern, president of the Service Employees International Union (SEIU), participated in an exchange that was facilitated by Kent Wong for the Asian Pacific American Labour Alliance (APALA), a constituency group of the AFL-CIO that was formed in part to break through racial stereotypes of Asian workers. Stern was later criticised by AFL-CIO leaders for having visited China, but he was firmly convinced that China was important to the global economy, and he was determined to develop relationships with the ACFTU. Importantly, he was an activist union leader, so he was looking not just to have fraternal affiliations, but also to find concrete ways to collaborate. One of the issues that SEIU continuously raised with the ACFTU was its concern about Walmart. In 2005, SEIU was heavily involved in the American labour campaign against Walmart, and Stern hoped that there was a way for US and Chinese unions to collaborate (Moberg 2015).

In 2005, when SEIU and other unions broke away from the AFL-CIO to form the CTW federation, Andy Stern persuaded other CTW leaders to go to China to see things for themselves and to propose joint action. One of these leaders was James Hoffa, president of the Teamsters union, and an active opponent of PNTR for China. Staffed by veteran international labour activist Tim Beaty, Hoffa's approach to relations with Chinese unions was open but cautious. As Beaty told me in an interview in February 2017:

I did have an idea that by going to China, talking directly to folks, even in formal contexts, about leadership elections, how we collectively bargain, that maybe there would be an opportunity to see an alternative way. We might get discussion, contribute to the process of change inside the ACFTU, and create a different consciousness, broaden alternatives and possible reforms. Maybe this would legitimise people who had more democratic idea of getting workers involved. I have no idea that that has happened. Maybe I was naïve. 
Another CTW leader who travelled to China, United Food and Commercial Workers (UFCW) President Joe Hansen, was interested in the connections that Chinese unions had with the same employers. Early on he was concerned about the impact of Chinese companies selling pork to the US, and later in 2013, he became concerned when the Chinese company Shuanghui International purchased Smithfield Food, an American meat processor where the union had won an organising campaign after a long and bitter battle. Shuanghui, now known as WH Group, recognised the union, added 38,000 workers to the payroll, and has continued the collective bargaining relationship (Bloomberg 2016).

In other words, from the early 2000 s, CTW unions stepped into uncharted territories to try to get to know the ACFTU and find out what kind of relationship and joint action was possible. The Teamsters hoped that engagement would lead to labour solidarity as they practice it with other countries, but repeatedly found that the ACFTU side was not interested in providing information or writing letters of solidarity. UFCW also hoped that there could be joint work with the ACFTU on mutual employers, but found little interest at the regional level, though a proposal for a research survey sent ripples that were felt worldwide. SEIU built deep relationships that made important headway in the Walmart campaign, but found that unionising China's Walmart workers did not give them a voice. These unions discovered that their concepts of solidarity, and goals for developing relationships and activities were quite different from those of the ACFTU.

\section{AFL-CIO and China}

In 2011, the ACFTU made a bid for a seat on the governing body of the International Labour Organisation (ILO), which placed the AFL-CIO in the middle of an international debate. Many American and international unions opposed the bid on the grounds of the old ICFTU arguments that it was not independent and not authentically representatives of Chinese workers. On the other hand, other labour movements supported the bid, on the grounds that the ACFTU is the official union of China and it represents the largest working class in the world. In this path-breaking vote, the AFL-CIO abstained, paving the way for the ascendance of ACFTU to the ILO governing body.

The AFL-CIO decision was advanced by its International Affairs Director, Cathy Feingold, who in an interview I had with her in January 2017 rationalised: 'We thought constructive engagement was important, but we could not fully endorse, because of human rights and other issues.' In the end, the decision paved the way for Feingold to begin a process of building relationships with ACFTU leaders at the ILO, and making plans for AFL-CIO President Richard Trumka to visit China. Her efforts bore fruit in September 2013, when Trumka and a small group of AFL-CIO staff made the first official AFL-CIO visit to China (ACFTU 2013). Though this visit was relatively lowkey, it was nevertheless historic, given the hostile relations that had existed between US and Chinese workers in the previous decades.

In spite of the goodwill expressed during Trumka's visit, progress in building relationships between Chinese and American unions has been slow, for both AFL-CIO and CTW unions. Both federations say that exchanges are cordial, though veteran China labour hands like Josie Mooney and Kent Wong in interviews I had with them in January and February 2017 say that frank conversations are more difficult since there have been many changes in union leadership in both countries, and trust relationships have to be rebuilt. According to my interviewees, in recent years there 
have been some tensions, like with the Chinese government's 2014 criticism of the AFL-CIO's decades-long support for the Hong Kong Confederation of Trade Unions, through its international education arm, the American Center for International Labour Solidarity. The ACFTU has also voiced displeasure with the City University of New York's grant from the US State Department to do labour education in China.

One new development involves union relations at Chinese firms investing in the US (Sheng 2016). In 2016, Chinese companies invested nearly 54 billion USD in the US in various industries, which was up 359 percent from the previous year. There is no systematic data on how these investments are affecting labour relations, but there are at least some cases, like the Smithfield Foods case mentioned earlier, which appear to indicate that Chinese employers are not necessarily anti-union. In such a context, once again attempts have been made to build relationships between Chinese and American unions vis-a-vis a common employer. Instead of building the relationships by building union-to-union ties, this strategy relies on the employer as the bridge between the unions, at least initially.

\section{The Larger Picture}

Relations between unions in the US and China are one aspect of the larger picture of global capital and global labour. Presumably, if the labour movements in the US and China were strong, and relations between the two countries were strong, they could muster a countervailing force against multinational capital. Towards this end, some American unions have attempted to establish relations with unions in China to work on joint campaigns against common employers. While in the process they have broken through some stereotypes and misconceptions about China and Chinese workers, in general they have found the ACFTU to be welcoming and cordial, but perhaps not so interested in joint campaigns against common employers aimed at worker empowerment. In spite of this, American unions remain committed to searching for ways to work with Chinese unions.

Under the current presidencies of $\mathrm{Xi}$ Jinping and Donald Trump, it is possible that these fledgling attempts at building relationships will be further set back. Under $\mathrm{Xi}$, the Chinese government has cracked down on human rights and labour activists, and has put NGOs under the administration of the Public Security Bureau, its domestic security agency. This may make the ACFTU less interested in sharing information with American unions about activating workers, particularly with regard to coordinating collective bargaining and strategic campaigns. Meanwhile, Trump's current agenda includes a myriad of threats to lower labour standards, eliminate collective bargaining rights, and substantially weaken union influence. American unions are currently preparing for major defensive battles, and have already announced substantial staff layoffs and financial cutbacks. Given these challenges to their survival, they may have little resources left for international solidarity.

One area that might have complex consequences is international trade. Donald Trump has already announced that the US will withdraw from the Trans-Pacific Partnership (TPP), decrease its role in the World Trade Organisation, and hold China accountable for currency manipulation. He has even hired Peter Navarro-producer of the fervently anti-China film Death by China (http://deathbychina.com)-as his chief trade adviser and many observers are concerned that they intend to start a trade war with China. Some US unions, like the autoworkers and steelworkers, are cheering Trump's positions on trade (even as they face 
decimation from Trump's domestic labour policies), because they believe that trade barriers will bring back jobs to American workers. It is hard to say at this point if trade barriers will cause American firms to reinvest in the US, without knowing what the specific policies and comparative costs will be. In any case, it will be important to watch out for racial stereotyping that has been used to advance support for protectionist trade in the past.

Meanwhile, Xi Jinping has stepped into the vacuum left by Trump's retreat from global trade, and is proposing that China lead the world's new economic order. Among many concerns, this raises the question as to whether China would consent to a labour clause as a core chapter in these international trade agreements, something that global labour activists have spent many years fighting for, and have actually achieved in cases like the TPP. These labour clauses have varied in effectiveness, but in some cases they have provided the basis for workers to advance rights, like freedom of association in Vietnam. Given China's poor record on labour standards enforcement domestically, it would be a surprise if it agreed to a labour clause in international trade agreements. Of course, the ACFTU would be bound to support Xi's position because it is subordinate to the Chinese Communist Party, but this position would also be consistent with views that were expressed to American trade unionists on numerous exchange visits.

In an era when relations between unions in the US and China do not progress or even regress, what is to be done? According to veteran labour activist Apo Leong, whom I interviewed in January 2017, 'Over the years we've seen political windows open and close, and during the closed periods labour organisers need to continue foundational work that will put them in a better position to advance when the political window opens.' For American and Chinese unions, this might mean that both sides should continue to have official exchanges, while understanding that the pace of engagement may not accelerate. It also suggests the need to evaluate where some gains can be made, perhaps in areas of mutual interest other than strategic campaigns, like health and safety or labour law. Aside from high level official exchanges, US and Chinese unions might also consider increasing lower level dialogues among union members and staff aimed at strengthening friendship-such as member-to-member visits, staff internship exchanges, and technical and research exchange. After all, US-China union relationships will continue to be critical to labour power in the global economy, but given the current political climate, organisers need to be more strategic than before and ensure that the one step forward is not undone by two steps backwards. 


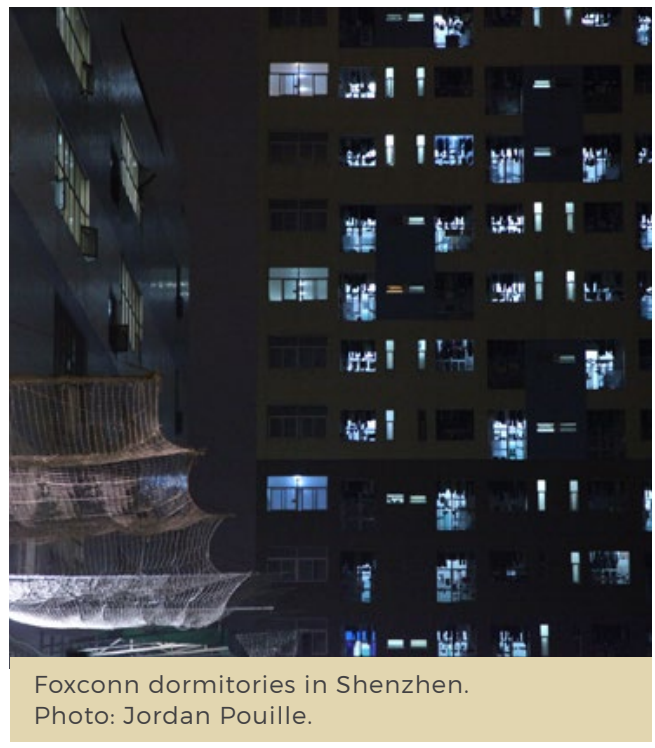

\section{\#iSlaveat10}

\section{Jenny Chan}

In January 2017, Apple celebrated the tenth anniversary of the launch of the first model of the iPhone. After a decade, has Apple's extraordinary profitability been coupled with any greater social responsibility? Are the Chinese workers who produce the most lucrative product in the electronics world seeing improved working and living conditions? This essay provides some answers by focussing on two issues: freedom of association and the situation of student interns.
On 9 January 2017, Apple celebrated the tenth anniversary of the iPhone's debut with an event entitled 'iPhone at Ten: The Revolution Continues'. Since its launch in 2007, the iPhone has remained the company's flagship product and biggest income generator. In 2016, nearly two-thirds of Apple's revenue came from sales of the smartphone. The iPhone is supposed to be revolutionising not only mobile phones, but also corporate social responsibility (CSR). In 2015, when Time magazine crowned Apple CEO Tim Cook as one of the world's one hundred most influential people, writer John Lewis hailed Cook's ability to push Apple to 'unimaginable profitabilityand greater social responsibility' (2015). What he did not mention was the reality of social irresponsibility confronting Chinese workers who make Apple products.

When discussing the labour rights abuses associated with the production of the iPhone, the name that continually resurfaces is that of the Taiwanese-owned Foxconn Technology Group (hereafter Foxconn). Its collaboration with Apple started back in 2002, as the company was on its way to becoming China's leading exporter of high-tech electronics. Initially, Foxconn was contracted to build Macs and iPods. Then, in 2007, the contract was extended to include the first-generation of iPhones. In 2010, when Foxconn was confronted by a spate of worker suicides in its factories in Shenzhen (Chan 2011), the company was the sole maker of iPhones. After this, however, Apple-following the common practice of pitting suppliers against each other to maximise profit-shifted some of its production to Pegatron, another Taiwaneseowned supplier where labour costs are allegedly even lower.

Since 22 September 2017, Apple has been selling iPhone 8-'a new generation of iPhone', as they market it-on the global markets. Has Apple's 'unimaginable profitability' been coupled with any 'greater 
social responsibility'? Are the Chinese workers who produce the most profitable product in the electronic world seeing improved working and living conditions? In this essay, I will attempt to provide some answers with a specific focus on two issues: freedom of association and the situation of 'student interns'.

\section{Freedom of Association Denied}

The Apple Supplier Code of Conduct explicitly highlights the rights to freedom of association and collective bargaining (Apple Inc. 2017). Unfortunately, although codes of conduct produced by many multinational companies and industry associations pledge to honour workers' rights to form trade unions, in China the process is dominated by management in the workplace, and is ultimately controlled by the state through the branches of the only trade union whose existence is allowed in the country, the AllChina Federation of Trade Unions (ACFTU).

Foxconn's resistance to any call for union democracy emerged in several instances. This was particularly evident in the wake of a riot that erupted at a Foxconn plant in Taiyuan, Shanxi province, at the end of September 2012. In that case, the fury of the workers was triggered by their exasperation with company policies. In the months leading up to the release of the iPhone 5 , they had only one day off a month. Also contributing to their grievances was the militaristic security imposed by the company at the male workers' dormitory. When company guards beat two workers for failing to show their staff IDs, and kicked them until they fell to the ground, the workers reached a breaking point. To deal with the fallout, Foxconn announced 'a special day off' for all eighty thousand workers and staff at the facility. On the same day that the riot occurred, Tim Cook assured the world that retail stores would "continue to receive iPhone 5 shipments regularly and customers [would be able to] continue to order online and receive an estimated delivery date' (Apple Inc. 2012). But as international news media published articles with blaring headlines like 'Riot Closes China Foxconn Factory' (Al Jazeera 2012) and 'Riot Reported at Apple Partner Manufacturer Foxconn's iPhone 5 Plant' (Apple Insider 2012), Apple was compelled to reassure consumers around the world that it was not running sweatshops. It was then, amidst the factory-wide riot, that a twenty-one-year-old worker wrote an open letter to Foxconn's Chief Executive (Drahokoupil et al. 2016). The letter ended with the following words: 'Please remember, from now on, to reassess the responsibilities of the company union so that genuine trade unions can play an appropriate role'. Still, even on that occasion, this bottomup demand was completely ignored by the company management (Chan et al. 2013).

While over the years there have been union elections at Foxconn, these initiatives have been mostly a formality to demonstrate Foxconn's supposed commitment to Apple's CSR principles. In an interview with a Foxconn worker in March 2015, I asked about the union election that had taken place earlier that year:

Not many workers knew about the company union elections. The promotional posters were placed in the dark corners in the factory. The management did not do it for our information. They did it to complete the standard process only.

On several occasions, supervisors manipulated the elections by explicitly instructing workers to cast their votes for designated candidates. Out of fear of retaliation, workers followed the managerial instructions. As one worker candidly admitted to me: 
We're asked by our supervisors to check the right box. What's laughable is that all the candidates are complete strangers to me. Afterwards, I checked the information about the winner, and found out that he's a senior manager from the same department [as me]! But I've never heard of him. I believe that all the winners were handpicked by the senior management.

In the words of another worker: 'After all, we have no idea who's running for the elections. Perhaps only our boss knows about them!' This does not mean that workers are not aspiring to have their own organisations. In the course of my multi-year research project, Foxconn workers have repeatedly made calls for democratising the company union. I argue that having a democratic, representative trade union, instead of a management-dominated one, is critical to ensure workers' rights.

\section{Student Workers at Foxconn}

Without independent labour representation, for years Foxconn has been able to get away with using 'student interns' who are not legally recognised as employees, and are often forced by their schools to work at the company's plants. In 2010, following China's economic recovery from the global financial crisis, 28,044 student interns from over two hundred technical and vocational schools all over China were assigned to the integrated Digital Product Business Group (iDPBG)-a Foxconn business group that exclusively serves Apple-to work alongside Foxconn employees in Shenzhen. This was a six-fold increase from the 4,539 interns who, according to Foxconn's internal magazine, had been assigned to Foxconn's Shenzhen plants in 2007 (Chan 2017). During the summer of 2010, Foxconn employed 150,000 student interns nationwide-15 percent of its entire million-strong Chinese workforce (Foxconn 2010).

In recent years, China's leaders have sought to boost labour productivity through expanded investment in vocational training. The number of vocational high school students doubled from 11.7 million in 2001 to 22.4 million in 2010, even as regular high schools still enrolled a larger number of students than vocational high schools nationwide. Vocational schools follow a work-study model that emphasises the integration of education with production, as stated in China's 1996 Vocational Education Law (Ministry of Education 1996). They offer employment-oriented courses for eligible applicants who have completed nine years of schooling. The official goal for 2020 is to recruit 23.5 million students -50 percent of the nation's senior secondary student population-into three-year vocational programmes (State Council 2010).

In this, Foxconn saw an opportunity to exploit student interns. A 2011 company statement claimed: 'Foxconn cooperates with vocational schools to provide students with practical skills training that will enable them to find employment after they graduate from these programmes' (Foxconn 2011). But Foxconn has said nothing either about the contents of its training programmes, nor about its skill evaluation methods. Working hand in glove with local governments, Foxconn has simply violated China's internship regulations designed to protect students and assure that their career needs are served (Chan 2015c).

In the words of a sixteen-year-old Foxconn student intern whom I interviewed in 2011:

Come on, what do you think we've learned standing for more than ten hours a day manning machines on the line? What's an internship? There's no relation to what we study in school. Every day is just a repetition of one or two simple motions, like a robot. 
To this day, the company not only recruits students regardless of their field of study, it also routinely recruits them much earlier than is legally allowed, while they are still in their first or second year, rather than their final year of vocational school. Even worse, these so-called internships are often extended from three months to a full year to meet production needs, with scant regard for the students' training needs.

Under mounting pressure, in 2016, the central government finally took some measures to protect the basic rights of student interns. Vocational schools were instructed to manage student internships in accordance with new regulations that came into force on 11 April 2016, superseding the 2007 Administrative Measures (Ministry of Education 2016). Under this new regulatory regime, the duration of workplace-based internships should not exceed six months. Moreover, the regulations not only require that student internships provide substantial educational content and work-skill training, but also mandate comprehensive labour protections for student interns, such as eight-hour working days, no overtime and no night shifts. Above all, no more than 10 percent of the labour force at 'any given facility', or no more than 20 percent of the workers in 'any given work position', should consist of student interns at any point in time.

However, in spite of these legal improvements, the government has left intact incentives for corporations to continue to prioritise internship programmes as sources of cheap labour. With the passage of the 2016 Regulations, the statutory minimum level for paying interns is clearly specified: 'Wages shall be at least 80 percent of that of employees during the probationary period'. In other words, employers are still permitted to give student interns only 80 percent of the income offered to full employees on the job, whether or not students' productivity is less.

\section{Ten Years On, the Campaign Continues}

Global supply chains are not benign spaces of transnational trade. While rooted in local terrains, proliferating labour struggles in China have to simultaneously confront forces of global capitalism and the Chinese state. Workers are protesting and striking, labour rights groups are issuing statements demanding that corporations accept responsibility for worker abuses, and engaged scholars are analysing the structures of domination that drive labour control and eventually spark resistance. In solidarity with Chinese workers and student interns, and in an attempt to focus the spotlight on the ongoing illegal practices of Foxconn, Hong Kong-based advocacy group Students and Scholars Against Corporate Misbehavior (SACOM) has marked 2017 as the year of the global anti-sweatshop campaign '\#iSlaveat10-No More iSlave'.

However, in spite of these transnational initiatives, the most important driving force for change remains the workers themselves. The current protests in localised and dispersed sites of resistance across China need to develop further through intra- and inter-class lines and across the urban-rural divide, growing into a more broadly based social movement. It is the evolving consciousness and praxis of the new generation of Chinese workers that will shape the future of China and global capitalism. 


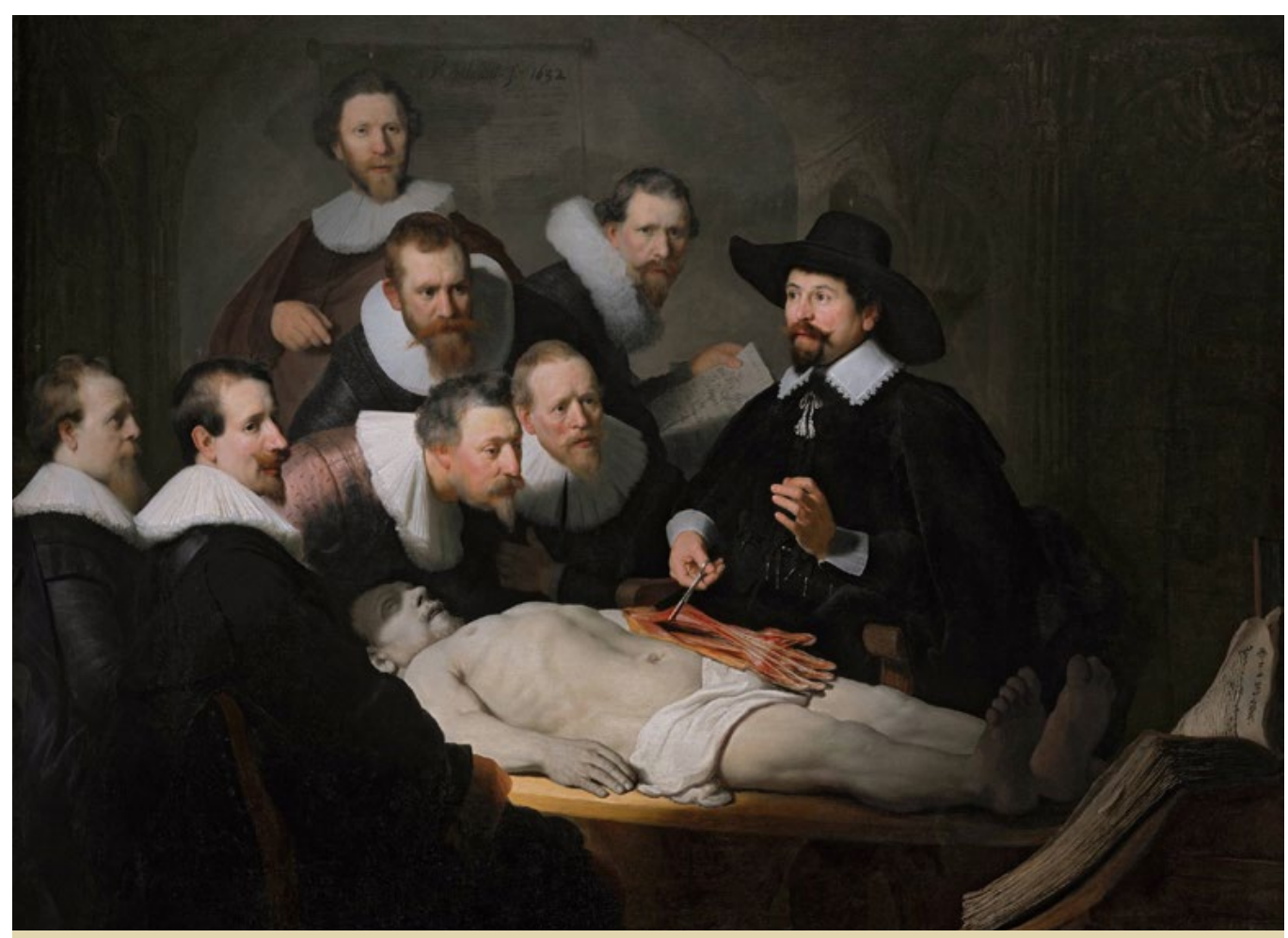

The Anatomy Lesson of Dr. Nicolaes Tulp, by Rembrandt van Rijn, 1632.

\section{Treating What Ails the Study of Chinese Politics}

\section{William Hurst}

For almost as long as political science has existed as a discipline, the study of Chinese politics has been afflicted with a chronic disease. Depending on one's perspective, this malady's manifestations have amounted to either neglected isolation or arrogant exceptionalism. To treat this illness, it is important to set aside any rigid orthodoxy and to encourage and celebrate diversity and bold experimentation.
For almost as long as political science has existed as a discipline, the study of Chinese politics has been afflicted with a chronic disease. Depending on one's perspective, this malady's manifestations have amounted to either neglected isolation or arrogant exceptionalism. At root has been a tendency of China scholars to recount everything they could learn about one village or neighbourhood, one leader, or one army group, without context or comparison, assuming the wider world would care simply because their research was about China; and then the wider world took little notice. Regardless of whom one believes may have been to blame, students of Chinese politics have been searching for curative remedies for at least the past forty-five years.

During the 1970s and 1980s, it was en vogue to deploy macro-models of Chinese politics, both to compensate for our 


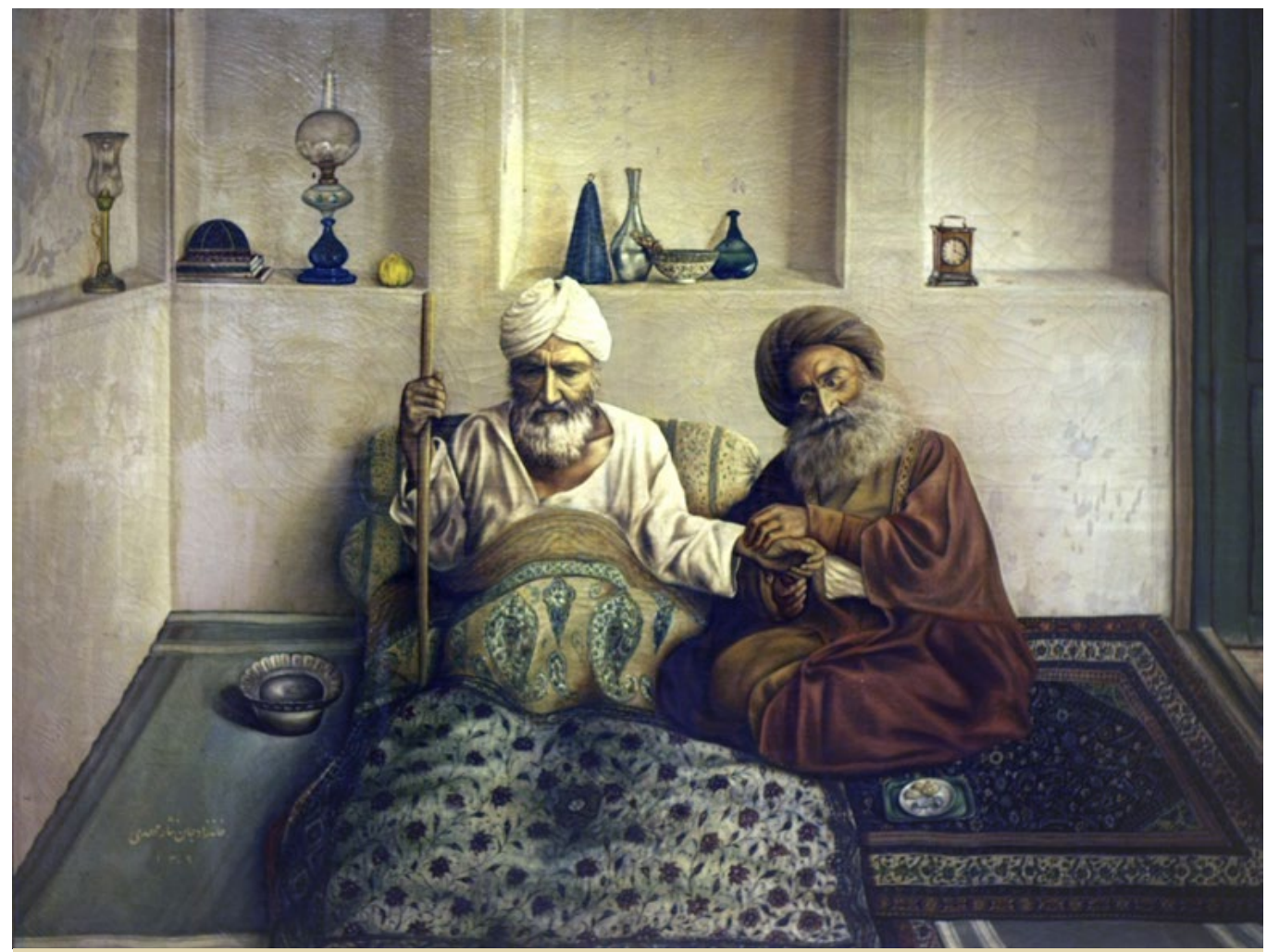

Iranian Physician and Patient, Mehdi Mosavarolmolk, 1891.

field's relative data paucity and to make findings more readily intelligible to nonarea specialists. Even when such models had names like 'Mao in Command', they still represented first attempts to 'replace proper names with variables'. Yet, just as the last of these older-style model debates was raging (between proponents of 'civil society' and 'corporatism' perspectives), a number of scholars sought to introduce greater methodological rigor and better demonstrate the validity of their findings by making use of dramatically more advanced survey techniques and quantitative analysis than had ever before been common in the China field. From about 1990-2005, this trend did indeed bring some greater visibility to at least some parts of the field, though it began to bump up against some limits of data availability, research costs, and political strictures and risks. Survey research remains important, but it proved not to be a panacea.

Roughly contemporaneously, from around 1995-2010, some other scholars (including this writer) tried to make the study of Chinese politics more systematic, accurate, and ultimately generalisable by advocating for a new emphasis on subnational comparative analysis within China. Whether they compared regions, elements of the bureaucracy, social groups, or even time periods, these colleagues hoped that stepby-step disaggregation and more careful attention to China's internal diversity might refine the specification of hypothesised causal processes and mechanisms and enable testable claims about their scope of 
generalisability. As with the survey tradition, this had the potential to allow concepts and theories to travel more readily, not only into China from other parts of comparative politics but also in the opposite direction. Yet, Chinese politics never became anything close to a net exporter of theory or concepts during this period.

\section{Racing for a Cure}

Faced with the ongoing relative otiosity of prior therapies, alongside the stress of an ever more competitive and vagarious job market, a new generation of students has gravitated toward a different approachone that is predicated on a sea change in the China field. Over more or less the past decade, Chinese politics has gone from a data-poor field to one overflowing with all manner of observable phenomena that can be examined, counted, aggregated, or analysed. In part, this has been driven by a technological revolution in both the output of content and techniques for 'scraping' or otherwise 'mining' it, allowing the endless torrent of terabytes produced by and for the Internet to be converted into useful sets of 'big data'. In part, it has also been based on other innovations, such as the use of field experiments and a greater propensity than among most of their predecessors for today's graduate students and junior scholars to collaborate closely with leading quantitative researchers based in Mainland China. The preferred regimen of the new generation is thus to play in what could be called the discipline's methods arms race, deploying ever more stunning technical tools and operations in hopes of impressing the discipline as a supreme virtuoso after the current fashion (or fad), outshining all others, landing a good job, and then making one's mark.

Yet, while the shiny object so many are reaching for may be a brass ring, it is no silver chalice. Today's younger scholars are certainly landing jobs, but the Holy Grail of bringing Chinese politics into the core of political science remains elusive and the concentration and compression of new research into increasingly small-bore methodological debates and frameworks risks the perverse effect of rendering the field even more marginal and less relevant. At its worst, scholarship in the new mould can amount merely to taking up concepts or hypotheses uncritically from American politics or haphazard corners of comparative politics and testing them out with bigger and bigger Chinese datasets and fancier and fancier methods. Such research can end up asking the wrong questions, cutting itself out of the most essential conversations even before it has settled on findings. All of the current emphasis, for example, on discerning through experiments how mayors or other local officials in China's consultative authoritarian system respond to claims from different social groups has produced some impressive, even virtuosic, articles. But all such work is predicated on the assumption that China's is indeed a consultative authoritarian system. Of course, the really important question is whether consultative authoritarianism describes China very well at all (I do not think it does, but I would welcome a healthy debate). The obsessive focus on methods occludes the fact that a great deal of research can be misguided (and thus at best trivial and at worst wrong) from the get-go. Unfortunately, if such work predominates, Chinese politics can appear from the outside as mundane, epiphenomenal, or even vapidly irrelevant. China specialists are relegated still further toward the edges of the discipline, even as they loose their area studies moorings, and slowly drift toward abject obscurity.

Even at its very best, embracing the methods arms race constitutes but one candidate sanative treatment. The mad dash toward it since about 2010, however, has left 
other potential contenders neglected. There are many other ways we might bring the study of China's rich historical experience, internal diversity, unique institutional landscape, and dynamic economy and society into conversation with the rest of political science. It is high time we pay attention to one of these: cross-national comparative analysis.

\section{Cross-National Comparison: A Refreshing Therapy}

When I speak of cross-national comparison, I do not mean the type that was popular several decades ago and sometimes amounted to throwing hundreds of countrycase (or even worse country-year) scores into a statistical package and seeing which broad claims might stick (e.g.: democracies do not fight, unions strike less under leftleaning governments, etc.). Rather, I wish to advocate for careful paired comparison of China with other individual countries or small sets of countries. Combining this with careful, historically and contextually informed, work on China's domestic politics-whether quantitative, qualitative, subnationally comparative, or other-has the potential to let us export ideas and arguments at least as well as brandishing the latest technical tools to test others' hypotheses.

Broadly speaking, there are four ways to undertake the kind of cross-national work I am advocating. I call them: shadows, mirrors, partners, and apples. I have listed these in increasing order of both their risks and difficulty and of their potential dividends. Shadow comparisons are the sort that one finds in the concluding chapters of old books-not only the ones about China, but also many with titles like 'XXX's Party System in Comparative Perspective'. After offering the reader a study of politics in a single country (e.g. China), authors would pad a last chapter full of vignettes about how the arguments might be applied to another country or set of countries, almost always based entirely on a very superficial reading of a thin set of secondary sources. This is not useless (I have done it), but it is of limited utility. Still, it remains all too rare in the writing of China specialists. Mirror comparisons involve a much more nuanced look at one or two countries that in some important way reflect China's political reality as analysed or explained in the main body of a work. This might involve at least a chapter or two, also likely (but not necessarily) drawn from secondary sources, that delve into considerable detail to examine how causal processes and mechanisms uncovered in the rest of a book play out in a critical case or set of cases for testing whether they might travel beyond China's borders. This has become popular in recent work on India and other large countries, but has remained largely unexploited by students of Chinese politics. More common in studies of international relations, partner comparisons revolve around the study of China's relationships with a particular other country or set of countries (e.g. Japan or the Soviet Union). Such comparisons usually become the main focus of the books based on them and often (but not always) can require relatively in-depth and extensive, though tightly focused, fieldwork and/or primary source research in a country other than China. Apples comparisons carry by far the highest costs and risks, but also the greatest potential rewards.

In an apples comparison, a researcher endeavours to compare China and some other country (or set of countries) side-byside as co-equal units; that is, to compare 'apples to apples'. Doing so in a way that remains faithful to the immense internal diversity and complexity of politics in China requires nothing short of training up 
fully in the language, history, and politics of another country (or multiple other countries), to at least a roughly similar level of expertise that the researcher had acquired on the China case. This means many years of language study, at least a small library's worth of reading, and even more time spent on the ground in the field in a new country. There is thus little chance that any single scholar can cultivate more than one or a very small number of apples to compare with China during his or her career. Apple comparisons can be tricky and are often complicated by uneven access to data, vastly divergent political strictures or economic contexts, or the absence of key actors or events in either China or the apple comparator; furthermore, not every apple will be suitable for comparison with China on all possible research questions or areas. Nevertheless, investment in developing apple comparisons can be incredibly fruitful. Such a method enables one to deploy mostsimilar and most-different systems designs simultaneously (one within each case and the other between), for example, to compare subnational units or phenomena across national boundaries, and to test the limits and scope of generalisability not only in terms of broad causal arguments but also very precisely of specific causal mechanisms. Concepts developed to characterise elements of Chinese politics can be refined in the full light of another case before being offered as wares for export to a broader comparative politics audience.

\section{Comparing China with Southeast Asia: A Modest Proposal}

When China scholars have attempted comparisons-of any of the four types just discussed-they have often selected India or Russia as comparators. These are certainly not bad choices, but they are difficult in important ways and lacking in a certain kind of comparative advantage. With secondary literatures and area studies scholarly traditions as vast or even larger than those on China, Russia and India require an especially large amount of up-front investment to get up to speed. Research on these countries has also tended to favour a similar sort of disaggregation, close-tothe-ground fieldwork, and a 'splitting' (as opposed to 'lumping') approach to that which has classically characterised much work on Chinese politics. In this, they lack any comparative advantage that might be conferred by having strengths complementary to the China field's. Thus, adding new innovation or knowledge through comparative analysis is particularly difficult. Though one could certainly look elsewhere (from Mongolia to Mexico) with excellent results, I propose that many countries of Southeast Asia (Myanmar, Thailand, Cambodia, Laos, Vietnam, the Philippines, Indonesia, and Malaysia) can be especially apt comparator cases for the kinds of cross-national work on China I am advocating.

The study of politics (as opposed to culture, history, or society) in Southeast Asia has suffered from an opposite pathology to that which has plagued the China field. Rather than assuming the wider field would care about their findings because they were rooted in the study of Southeast Asian countries, specialists on that part of the world have too often tended to assume the field would never care about their findings because they were derived from the study of Southeast Asia. This has led a lot of scholarship to focus tightly on what is generalisable or exportable about Southeast Asian countries' experiences or outcomes, rather than what is unique; never to miss the forest for the trees, but often to emphasise the broad shape of the landscape without even naming the tree species present. In sum, 
Southeast Asian politics offers a comparative advantage as a comparator area because it has focused on exactly the areas the China field has neglected or been weak in and has tended too often to neglect exactly the areas (e.g.: local variation, subnational politics, etc.) on which the China field has done well. Also, none of the countries of Southeast Asia have area studies or secondary literatures of similar volume to those associated with Russia or India (indeed, other than those on Vietnam, Thailand, the Philippines, and Indonesia, secondary literatures on Southeast Asian countries' politics and history are comparatively quite small). The costs are thus relatively low, the comparative advantages obvious, and the payoffs potentially very high for using Southeast Asian countries as comparison cases to bring the study of Chinese politics into closer dialogue with the rest of political science. I very much hope more students and colleagues will heed this call to consider delving into these and other country cases seriously for this purpose.

\section{All Hands Needed on Deck}

To conclude, I do not intend this essay to be any sort of definitive or final statement. Rather, I hope it may spark important conversations. I am more than happy to be corrected or invited to rethink any and all aspects of what I have said here. My greatest aspiration is to motivate colleagues and students to think more expansively and daringly about what is possible and desirable in terms of Chinese politics research. There is nothing wrong with technical sophistication in one's methods and there is absolutely a rightful place for research using 'big data', experiments, and other new tools. But we must prevent the stifling homogeneity of the methods arms race from becoming completely ensconced and crowding out all other work (especially by younger or emerging scholars). Diversity and bold experimentation must win out over any rigid orthodoxy if we have any chance to put our patient's illness fully into remission. 

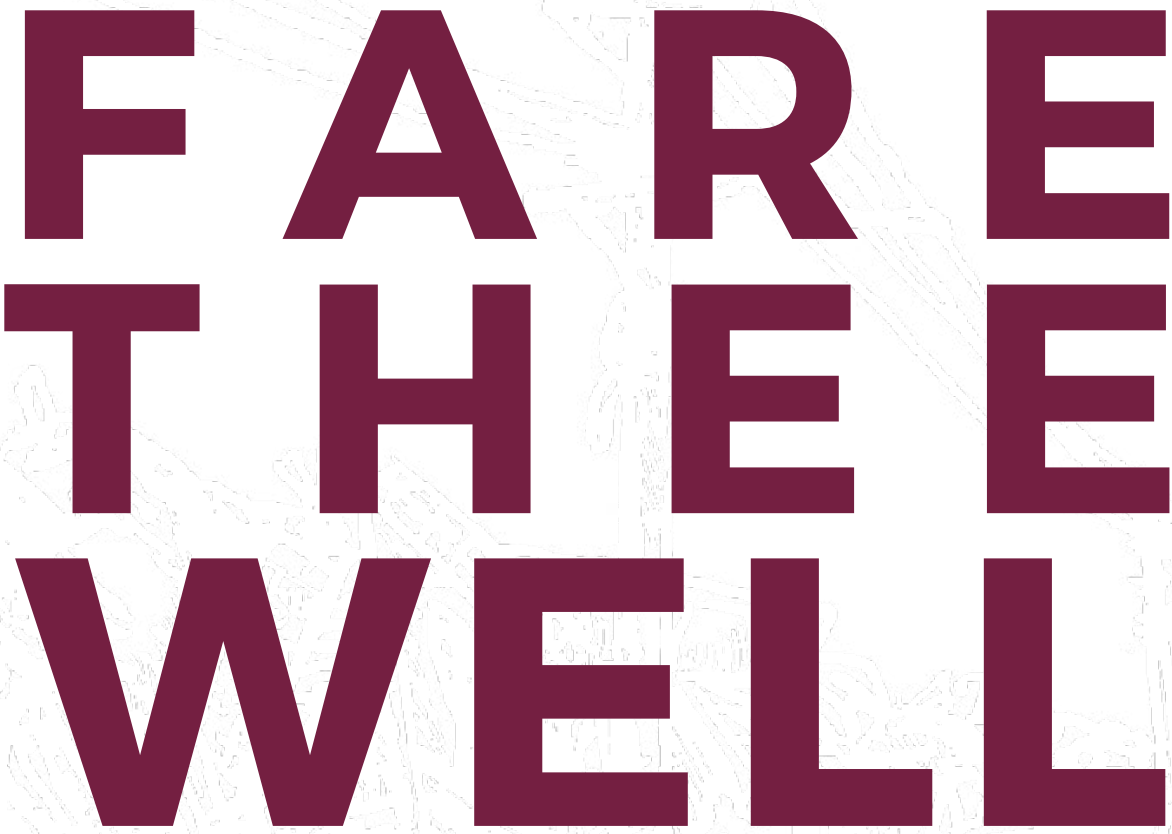

(il) 13 The

$$
\begin{aligned}
& \text { End of Chinese } \\
& \text { Civil Society? }
\end{aligned}
$$

$=$

$-5$

$2 y=9$

(E)

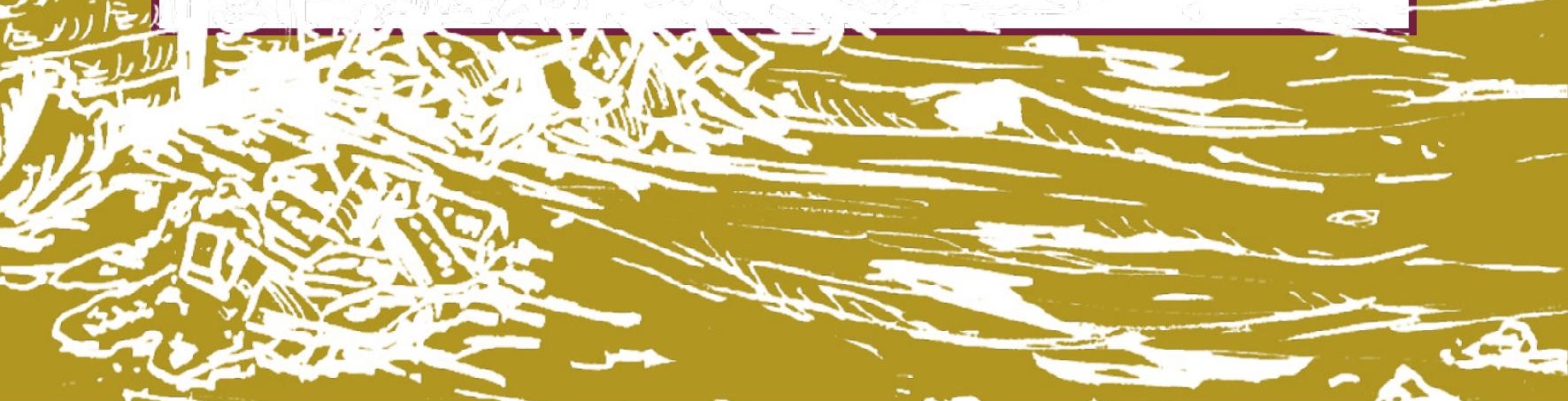




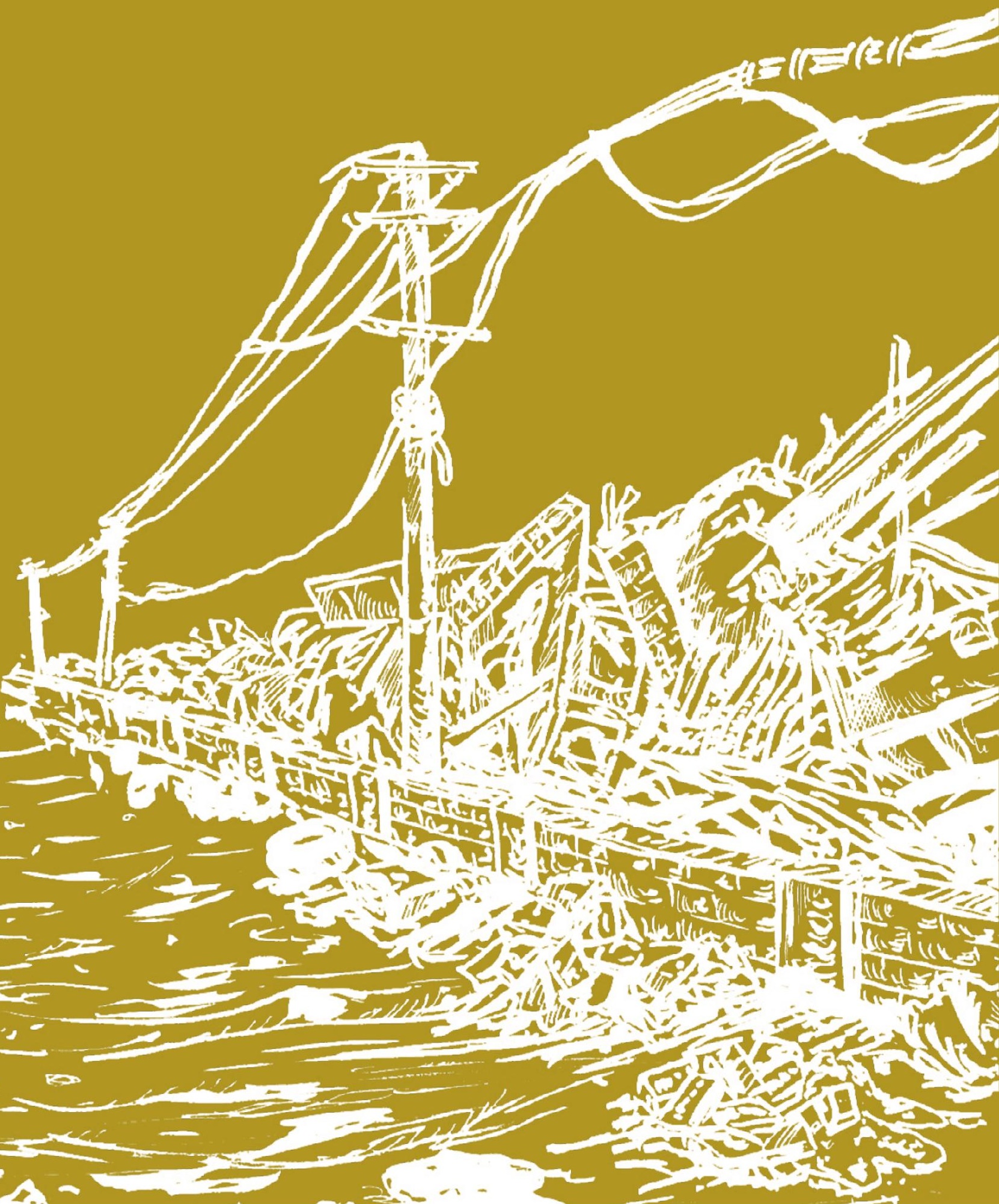




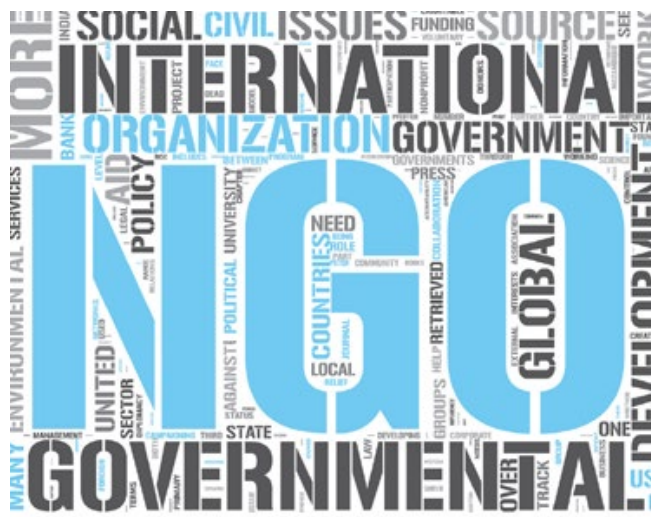

\section{Conceptual Confusion in the Research on Chinese Civil Society}

\section{Taru Salmenkari}

Chinese civil society research is obsessed with finding non-governmental organisations. In this search, different types of civil society organisations are conflated, and nongovernmentality becomes the sole factor that matters. Analytical accuracy is lost when too many things are fused under one term, especially when more accurate and nuanced terminology is available.
Research on Chinese civil society is consumed with the obsession of finding non-governmental organisations (NGOs). In this search, non-governmentality becomes the sole factor that matters in civil society. As a consequence, all civil society organisations and functions have been lumped together, perhaps with the expectation that any organisation that is non-governmental will be conducive to facilitating all the positives associated with civil society. This is evidence of conceptual confusion. Analytical accuracy is lost when too many things are fused under one term, especially when more accurate and nuanced terminology is available. In China studies, this conceptual bloating concerns both civil society organisations and civil society itself.

\section{Making Sense of the Diversity in Chinese Civil Society}

The field of China studies often conflates different types of civil society organisations. For instance, the term 'NGO' is used to refer to a wide range of organisations, regardless of whether they are political or not. Elsewhere, NGO is usually reserved for associations engaged in advocacy or participating in developmental projects. In particular, in the West NGOs constitute a self-proclaimed category used for advocacy and for demanding inclusion in policy-making processes. The category is not politically neutral, but mostly comes with a liberal or leftist worldview. Some other organisations, such as 'think tanks', often hold more rightist stances but may occasionally engage in activities similar to what NGOs do. In Japanese parlance, the term NGO is used to refer to those organisations engaged in developmental aid, 
while those that work on domestic arenas are usually called non-profit organisations (NPOs).

Instead of NGO, a number of other terms are available for voluntary organisations engaging in societal service production and its private funding. Others include NPOs, philanthropic organisations, charities, aid organisations, foundations, cooperatives, social enterprises, and selfhelp groups. 'NPO', in particular, is a legal category employed in relation to specific tax regulations reserved for voluntary associations. The official Chinese category'citizen-initiated non-enterprise units' (minban feiqiye danwei)-conveys the same meaning. Because many civil society organisations are actually registered within this category, Chinese scholars, correctly, use 'NPO' at least as often as 'NGO'. In addition to NGOs and NPOs, civil societies are populated by other types of organisations such as interest groups, professional associations, sports clubs, support groups, academic societies, syndicates, cooperatives, and many others.

Furthermore, civil society includes more fluid and less organised forms of associating. Civil societies contain social movements, campaign networks, community assemblies, voluntary projects, and temporary gatherings and forums inspired by public issues. These less formal platforms and networks are even closer to civil society ideals than formal associations are. Besides, the fall of communism in Eastern Europe and the Arab Spring demonstrated that these non-organised or loosely organised forms of public activity have more potential than registered associations for mobilising social pressure for democratisation.

\section{Conceptual Mistakes}

China studies would benefit from using more specific terms for different types of organisations because different organisations do dissimilar things and fulfil particular attributes of civil society in distinct ways. The use of the term 'NGO' for many analytically diverse types of organisations in society suggests that NGOs can do it all just by the virtue of their nongovernmentality.

'NGOs' are expected to defend interests, channel developmental aid, give voice to society, produce social services for the needy, protect rights, empower the marginalised, self-regulate industries, offer opportunities for popular participation, advocate liberal causes, and, eventually, demand a democratic political system. This list should make it evident that an individual NGO can hardly do everything and that some kind of division of labour is needed to fulfil these promises of civil society. This division of labour should be recognised and highlighted conceptually.

Conflating too many aspects together blurs analytical clarity and results in misinterpretations. Because terminology makes no distinctions between causes and roles in civil society, conclusions based on one specific type of civil society organisation have been expanded to cover them all. Conceptual confusion has contributed to consensus that Chinese NGOs are mainly service providers. Had service-providing organisations been classified as NPOs, attention could have been focused on political NGO activities as such. In fact, China is no exception. Nowhere in the world do advocacy NGOs make up the majority of civil society organisations.

Currently, analytical approaches that suit one type of civil society organisation are expected to suit them all. It makes complete sense to analyse as an epistemic community a global advocacy network that produces and spreads new knowledge and vocabulary in order to make violence against women a political issue. Chinese feminist NGOs campaigning against domestic violence are part of this epistemic community (Milwertz 
and $\mathrm{Bu}$ 2007). However, non-profit service providers hardly form such an epistemic community (Hsu and Hasmath 2017).

Orally, I have heard my colleagues suggest even wilder ideas, such as using the One Foundation, a private philanthropic foundation, to discuss NGO advocacy, while still opining that there is no connection between charity and civil society. Using the term 'NGO' for all privately established associations makes it non-transparent when they are philanthropic and when they engage in more political activities, such as policy advocacy and interest promotion.

This type of conceptual confusion has caused a major theoretical confusion in China studies. Only China studies uses the theory of corporatism about interest groups for analysing NGOs, as if all associations automatically equal intermediary organisations and interest groups (Zhang 2015). Those who introduced the term 'corporatism' to Chinese studies used it correctly to analyse labour union activities and business associations (Lee 1991). Corporatism is a form of interest representation delegating regulatory functions to interest groups in civil society. Hence, it has been described as a mixed mode of policy-making, private interest government, and self-regulation (Streeck and Schmitter 1985).

However, NGOs are not the kinds of organisations that could participate in corporatism. They do not represent any sector and cannot make agreements on behalf of a sector. Many NGOs have only a few members. Thus, they are not intermediary organisations able to talk to the state or other interest groups in the name of a coherent social group. Furthermore, corporatism does not contain a comprehensive vision about the regulation of civil society as a whole. Corporatist compacts regulate only the relevant parties, such as relations between the labour and the employers, usually under the auspices of the state. Apart from these interest groups, all corporatist countries have voluntary associations not connected to this system.

\section{Macro Consequences}

Different types of organisations fulfil the promise of civil society in different ways. NPOs by definition emphasise voluntariness; advocacy NGOs monitor the government and demand a more inclusive political system; the philanthropic sector solicits non-state resources for causes determined as being important by society; interest groups engage in social mediation of interests. All of these attributes and functions are characteristics or forms of self-organising in society.

Using different terms for various organisations in civil society, and even for diverse visions of civil society, is advisable because these differentiated terms imply different relations to the state. Liberals see that advocacy NGOs offer policy alternatives in the public sphere. In more leftist interpretations, NGOs and social movements epitomise anti-hegemonic organising to demand inclusion and voice for the marginalised. Special-interest groups, which derive from the theory of pluralism rather than of civil society, lobby the government. In corporatism, certain intermediary groups participate in social mediation of interests in civil society, nowadays often through tripartite arrangements involving the state. Non-profit service production is present in most societies, but is theoretically emphasised in the neoliberal strategy for the state to reduce its social service burden by outsourcing services to civil society. Communitarianism wants to reclaim faceto-face social life and cultivate social capital in everyday life. For acquiring social capital, any form of association that brings people together is fine, recreational associations and self-help groups included. In the communitarian vision, associational life is a school for citizenship and political 
participation. Theoretically speaking, none of these relationships equal categorical separation from the state.

Civil society itself is a vast container of associative activities and 'occasional' and 'episodic publics', which together constitute public life (Habermas 1996). As a whole, it seldom promotes any particular political opinion, supports any particular form of activity, or holds any united stance in regards to the government. In civil society, hegemonic groups associate alongside with anti-hegemonic forces.

Due to different contributions to civil society by different types of associations, just to show that civil society is there tells us little about what is happening within civil society or the political consequences of what is occurring. The developments are neither linear nor similar to associations of all types. For example, after the crushing of the massive protests in Beijing in 1989, the first independent aid organisations rocketed to fame, according to their own understanding because the state media needed positive news in gloomy times. Developments in different fields and between different types of civil society organisations can be contradictory. For example, some Chinese advocacy NGOs I have interviewed find that the opportunities emerging with the growth of the third sector contradict activists' own ideals about NGO work.

\section{Using Correct Terminology}

Conceptual confusion in naming organisations leads to a poor understanding of civil society itself. The use of more accurate terms is not only beneficial for semantic clarity, but makes visible the unevenness of forces and growth trends within civil society.
Hence, it may be advisable to use more confined terms which focus on some aspects of civil society only. 'Associational society' suffices if the purpose is to research formal associational activity without complex networks and causes that make these associations, ideally, contribute to nationallevel publics and to a community of citizens. Other terms used far too little in China studies are 'third sector', or its equivalents, 'non-profit sector' and 'voluntary sector'. This omission is particularly surprising considering the fast development of this sector in China. Not only would analytical nuance be gained if third sector service production was distinguished from political aspects of civil society, but using these terms would treat China more equally than current civil society research does. Although Chinese associations are not always fully 'autonomous' (whatever that means), the existence of three separate sectors is evident. China observably has a public sector, a private sector, and a third sector.

Conceptual clarity is needed to understand what happens in Chinese civil society. Consequences are hardly the same if the number of political advocacy groups or the number of third sector service providers grows. These types of organisations answer to very different social needs, have different relations to the government, and contribute differently to politics and democratisation. One part of civil society can be growing even if others are not or even if its growth happens at the expense of another part.

For gaining a more comprehensive, nuanced and meaningful understanding about Chinese civil society, researchers should do what social sciences have always taught them to do: use accurate and exact terminology to specify what is being referred to and what is expected of the research objects. 


\section{China's Social Organisations after the Charity Law}

\section{Karla W. Simon \\ Holly Snape}

The passage of the Charity Law in May 2016 has made the legal environment for charities in China more complex. The new Law does represent an initial breakthrough in the transformation of the regulatory system for social organising and, on a deeper level, in the relations between society, government, Party, and market. However, it does not equalise the rules for all Chinese non-profit organisations and, crucially, it does not provide a basic social organisation law applicable to all types of non-profit entities. Why does this matter?
Many commentators have sought to simplify the legal environment in China after the passage of the Charity Law in May 2016 (National People's Congress 2016). But in our view that Law has made the legal environment more complex. The new Law does represent an initial breakthrough in the transformation of the regulatory system for social organising, and on a deeper level in the relations between society, government, Party, and market. However, it does not equalise the rules for all Chinese non-profit organisations (NPOs), and crucially it does not provide a basic social organisation law applicable to all types of non-profit entities. But why does this matter?

\section{What is a Social Organisation?}

To understand the need for a basic law for social organisations, first we need to get straight what social organisations are, and what charitable organisations are not. 'Social organisation' (shehui zuzhi)

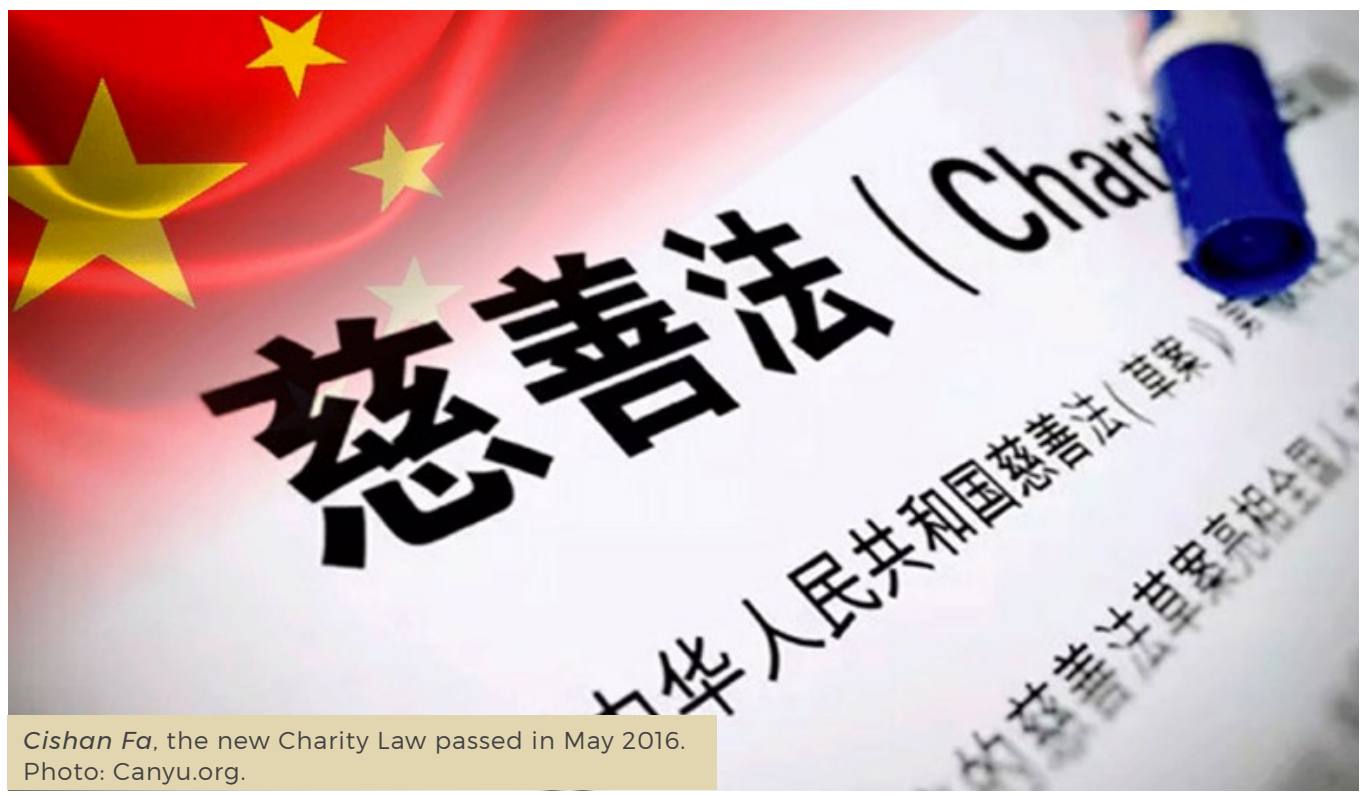


(hereafter SO) can be understood as a kind of blanket term used in official policy for all kinds of non-governmental NPOs. It covers the three legal forms that Chinese citizens are obliged to choose from to establish such an organisation: foundations (jijinhui), social groups (shehui tuanti), and social service organisations (NPC 2017) (shehui fuwu jigou). At present, it also covers citizeninitiated non-enterprise units (widely known by their abbreviated Chinese name 'minfei' (minban feiqiye danwei). The latter continues to be a legal form even though the Charity Law and the newly modified General Provisions of Civil Law (GPCL), passed by the NPC on 15 March 2017, replace it with 'social service organisations'. There are currently over three hundred and twenty thousand minfei already with legal status that have been placed in limbo since the passing of the Charity Law (State Council 2016). This is partly because the relevant administrative regulations are currently being revised-the latest draft of the new minfei regulations was released publicly in May-June 2016 to solicit comments (MCA 2016), but revisions have been ongoing for years and there is uncertainty as to when and what revisions will be made.

The term 'SO' also covers a new category'charitable organisation' (cishan zuzhi)created by the Charity Law. While the new GPCL makes the watershed adjustment of dividing legal persons into 'non-profit' and 'for-profit', charitable organisations are not among the four categories of organisations referred to as NPOs. 'Charitable organisation' does not represent a legal category in its own right. Instead it can be thought of as being a hallmark of an SO's ability to adhere to legal requirements related to accounting, transparency, and so on. To become a charitable organisation, a group must register as one of the legal forms of non-profit SOs, then apply for charitable accreditation. In other words, if we tier the new system ('new' after the GPCL), the
GPCL is the threshold system, a basic law on SOs would be the second tier (this does not yet exist), and the Charity Law would be the third tier.

The GPCL treats public service institutions (shiye danwei), foundations, social groups, and social service organisations as NPOs. The first of these, public service institutions, differ significantly from the others. They are not SOs, although it is intended that some will morph into them. Born of the socialist system built after the establishment of the People's Republic of China, public service institutions formed the public service arm of the government structure that all but subsumed society. With their deep links to government and their ability to monopolise resources and opportunities, their reform is essential to creating a competitive nonprofit market in which diverse and genuinely non-governmental organisations can thrive.

China's SOs work in education, healthcare, culture, science and technology, and sports and fitness, which are among the many fields covered explicitly in the broad definition of charity used in the Charity Law. But they also work in a vast range of other areas, on labour issues, in advocacy, legal services, and so on, none of which are covered by the Charity Law. While legislators and scholars involved in the legislative process for the Charity Law underlined the 'big' definition of charity as a legislative success and an important fundamental feature of the Law, many SOs cannot be squeezed into the definition of charitable organisations, no matter how 'big' that definition may be.

In implementation, while the Charity Law offers the opportunity to gain charitable status through accreditation to SOs that do fit its definition, there is already anecdotal evidence of SO leaders being reluctant to seek this charitable status for their organisations (Jin xia shuo shenme da shihua 2017). Thus, for myriad SOs, there is a gaping legislative hole. 


\section{Breaking Down the Old System of SO Regulation}

There is no doubt that the Charity Law is a landmark step toward breaking down the old system for regulating social organising. That system was characterised by a lack of clear boundaries between society, state, and the market, and the use of administrative powers to meddle in and control SOs combined with a failure to regulate effectively. At the Eighteenth National Congress of the Chinese Communist Party (CCP) in 2012, it was announced that China was to build 'an SO system in which government and SOs are separate, powers and obligations are clear, and autonomy is practiced in accordance with law' (Hu 2012, part seven). This is a powerful statement of intent, which has often been quoted in the Chinese literature to suggest that $\mathrm{SOs}$ will gain greater autonomy and be freed from government intervention (see, for example, Wang 2014). The Charity Law, if implemented fully, is a significant move in this direction, to a certain extent delineating boundaries and replacing administrative control with law-based regulation. In this sense, it is an important step in building a new model of governance.

The Charity Law moves toward direct registration for some SOs in a step that is basically a nationwide adoption of rules that had already been put into practice in a large number of provinces. It moves away from ex ante regulation to a system of ex post oversight connected to report filing, transparency, and accountabilityplacing new demands on organisations in these regards. These responsibilities do not come accompanied automatically with new rights. The Charity Law and its ancillary regulations make the right to fundraise from the public a possibility for SOs that gain charitable organisation status, albeit only through a further process of accreditation. This is a major step in levelling the playing field for some genuinely non-governmental organisations to compete in the non-profit market.

The new Law begins to swap opaque administrative management for a greater reliance on public oversight, and new ways of making this possible, such as with analysis of big data. There continue, however, to be exceptions and strong traces of the old way of thinking about how to achieve regulation. This is apparent for example in the Provisional Regulations on the Work of SO Registration and Management Bodies Related to Administrative Law Enforcement Using Talks (yuetan) released days after the passage of the Charity Law. Also, interestingly, some of the ancillary regulations that followed the passage of the Charity Law are actually related to all SOs and not just those with charitable organisation status, such as the Provisional Measures on SO Registration and Management Bodies' Receipt and Handling of Complaints and Accusations passed in August 2016, and the Guiding Opinion on Strengthening and Improving the Management of Pay in SOs issued in July of the same year. This shows the need to regulate all SOs and not just charitable organisations.

\section{Building a New System of Governance}

The Charity Law goes further toward enabling SOs to provide public services to the Chinese people in lieu of government. This means that government must delegate and outsource service provision through instruments set up at the local level (Simon 2013). Some provinces and municipalities will find it more comfortable to do this by contracts or grants, while others may wish to use vouchers, and other methods (Simon and Teets 2014). 
Allowing SOs to provide almost everything but the most basic of public services forms one part of the transformation of China's system of governance. Back in 2013, the Resolution of the Third Plenary Session of the Eighteenth Central Committee of the CCP announced that the 'overall aim of comprehensively deepening reform is to push ahead with the modernisation of China's governance system and capacity for governance' (Central Committee of the CCP 2013). But using law as a means to do this will only go so far unless the law itself goes further. A basic law for charities is not enough.

Two areas of reform given attention in Premier Li Keqiang's 2017 Government Work Report illustrate this well ( $\mathrm{Li}$ 2017). The first is the 'profound reform of government' as government steps up efforts to transform its own functions and delegate roles and powers to others. SOs, not just charitable organisations, are a key group to 'receive' these new roles and powers. A crucial top level policy document issued jointly in 2016 by the general offices of the CCP Central Committee and the State Council (2016)-an unprecedentedly high level document for the non-profit sectorlinks the government's transformation of functions directly to SO development. The 'Two-Office Opinion' (liangban yijian) as this document is known in Chinese, tells us that government will give priority to SOs in purchasing services related to safeguarding people's welfare, social governance, and industry regulation, and states the need for SOs to make innovations in social governance.

The second, directly related to the first, is the continued reform of public service institutions, the so-called shiye danwei. This reform goes back many years, but was underlined early in Xi Jinping's first term in office as an important task in transforming the functions of government. Looking back at the Resolution of the Third Plenary Session of the Eighteenth Central Committee, the stated intention was to "push publicly run public service institutions to clear up their relationships with their managing bodies and de-governmentalise (qu xingzhenghua), and 'push those public service institutions in the position to do so to transform into enterprises or SOs.'

What kind of SOs are these public service institutions supposed to transform into? Surely they cannot all be transformed into charities? And yet there is no basic law for SOs. This is not an easy issue as these institutions have complicated relationships with the state, involving a tangled web of different interests. Perhaps an even more knotty issue is that of the mass organisations (renmin tuanti), such as the All-China Federation of Trade Unions and the AllChina Women's Federation. But, these are critical reforms. In the market, state-owned enterprise reform is needed to level the playing field for businesses. In the third sector, public service institution reform is needed to allow the fair competition necessary to develop healthy SOs able to take on the roles and responsibilities of a transforming and downsizing government. 


\section{The Rise of Foundations \\ Hope for Grassroots Civil Society in China?}

\section{Jessica C. Teets}

Over the past decade, the not-for-profit foundation sector has grown rapidly in China. This expansion has occurred as international foundations and organisations were withdrawing funding from Chinese grassroots NGOs, causing many civil society leaders to put their hopes into domestic foundations as a way to close their deficit of funding. But can the rise of foundations in China really replace the evaporating foreign grants for domestic NGOs?
After the new Regulations on Administration of Foundations were promulgated by the Ministry of Civil Affairs in 2004, foundations (jijinhui)-that is not-for-profit organisations that promote public benefit undertakings through grants and donations-experienced rapid growth in China. In light of this, some observers considered private foundations to be the hope of China's third sector (China Development Brief 2011). The rapid expansion of the foundation sector indeed occurred as international foundations and organisations were withdrawing funding from Chinese grassroots NGOs, and many civil society leaders hoped that foundations would replace the international funding deficit. According to a report by the China Development Brief, 'NGOs cannot rely solely on international foundations. In the future, international foundations will move on to other countries. Even now you see international foundations will not use the majority of their funding on a country like China that is developing so fast' (2011, 12). In fact, the Global Fund withdrew funding from China in 2013, the Ford Foundation changed its funding profile so that less than one third of its funding went to grassroots NGOs (Spires 2011), and the new Foreign NGOs Management Law

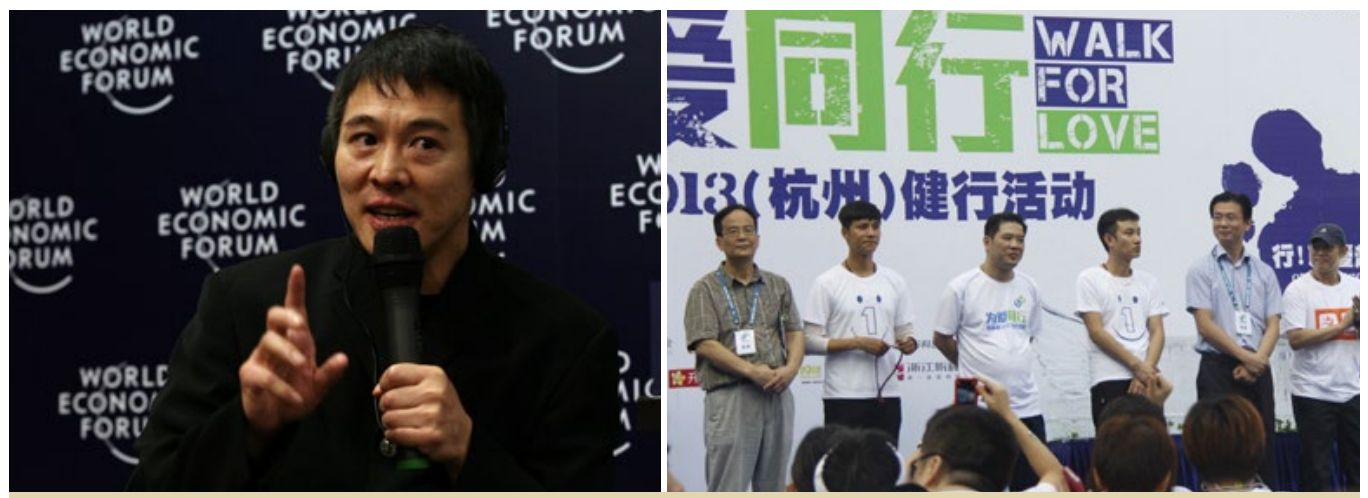

(Left) Jet Li, movie star and President of the One Foundation; (Right) Supporters of the One Foundation during a charity event. Photo: Wikimedia Commons; One Foundation. 
passed in 2016 restricts foreign funding of domestic social organisations (Hsu and Teets 2016; Franceschini and Nesossi 2017). In this essay, I explore whether the rise of foundations in China could serve as a potential funding source to replace foreign grants for domestic NGOs.

Despite the promise of the rise of Chinese foundations, I find that they function differently from their counterparts in the United States, in that very few foundations make grants to other nonprofit organisations. This might be a result of differences in the identity (or missions) of Chinese foundations, or simply due to their relatively early stage of development. Regardless of the reason, since foundations mostly finance their own projects rather than funding other organisations, they often compete with, rather than support, NGOs. If this trend continues after the implementation of the Foreign NGOs Management Law further restricts foreign funding, grassroots NGOs will depend entirely on private donations and government-awarded service contracts for funding. Government contracts do not help grassroots NGOs build capacity in the same way that grants often do, in that most contracts prohibit the use of funding for salaries or restrict other administrative costs to ten percent of the total value of the contract. In order to promote a more diverse and active civil society sector, foundations in China should partner more with grassroots NGOs to build civil-society capacity and replace lost international funding. For example, the Narada Foundation provided ten million yuan to NGOs for over sixtytwo projects related to disaster relief and to aid reconstruction after the 2008 Sichuan earthquake (China Development Brief 2011). This undoubtedly had a large impact on the groups receiving funding, and arguably helped them build capacity.

\section{The Rise of the Foundations Sector in China}

Although the first foundations were established in 1981, the rapid expansion of this sector did not occur until after the 2004 Regulations were passed, reducing capital barriers to two million yuan. The earliest were public foundations, mostly funded and managed by the government, and the 2004 Regulations distinguish between 'public fundraising foundations' (gongmu jijinhui) which are allowed to raise funds publicly, and non-public fundraising foundations (feigongmu jijinhui), which are not allowed to raise funds publicly. Before 2004, over eighty percent of all foundations were government-initiated public foundations; but after 2004, private foundations increased to forty percent (China Foundation Center 2013). Although private citizens started some of these private foundations, many are established by companies, especially those in real estate. In 2010, the number of private foundations overtook public ones, and by 2013 the total number of foundations reached 3,082-1,753 private and 1,329 public (Feng 2013). At the latest count, 5,209 foundations were registered in China (data from the China Foundation Center). Education is their most common focus, with fifty-three percent of all foundations focusing on education as a key area. By 2013 , there were 422 education foundations, with net assets, income and charitable spending accounting for nearly half of the total spending of private foundations (China Foundation Center 2013).

Why is the emergence of a foundation sector so important? According to Joel Fleishman (2007), in the United States, foundations represent 'the operational secret of America's civic sector' by playing 'the priming role ... in starting new civic- 

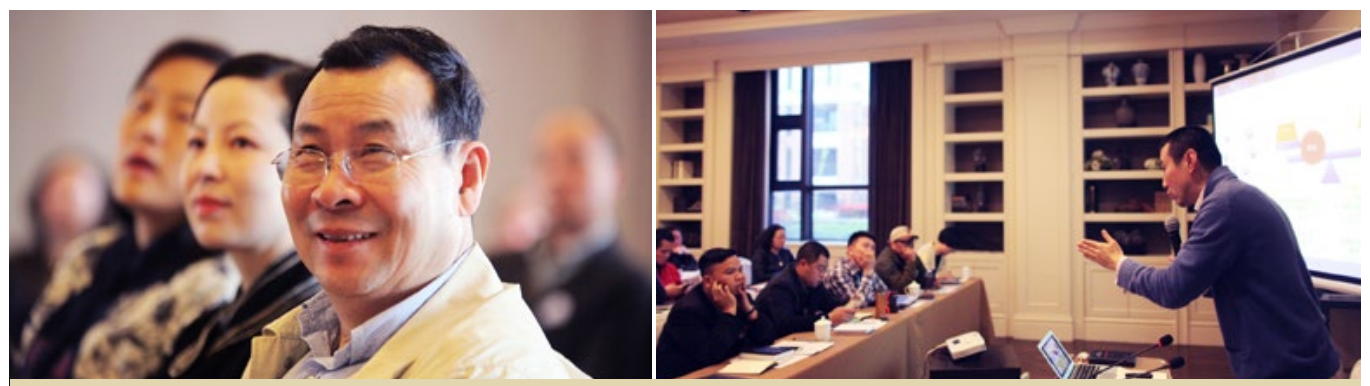

(Left) Xu Yongguang, President of the Narada Foundation and Emeritus Chairman of the China Foundation Center. (Right) Members of the Narada Foundation during a meeting. Photos: Narada Foundation.

sector organisations, they nurture them into self-sustainability, and provide a continuous supply of social venture capital to the civic sector.' While almost eighty percent of the foundations in the United States are grantmaking, private Chinese foundations mostly operate their own projects; one study found that only 1.6 percent of all public foundations and 13.2 percent of all private foundations could be categorised as grant-making (Kang et al. 2012). Thus, despite the promise of private foundations becoming "the hope of China's third sector', very few foundations currently make grants to other non-profit organisations: 43.5 percent provide some grants to grassroots organisations, but only nine percent are solely grant-making foundations (Feng 2015). As Xu Yongguang, the President of the Narada Foundation and Emeritus Chairman of the China Foundation Center, notes, private foundations that fund NGOs are still in the minority (China Development Brief 2011). This results in insufficient support for grassroots NGOs-a situation that will take time to change.

Despite its growing number of wealthy citizens, China has also been criticised for having little charitable giving. For example, the 2015 'World Giving Index' ranked China 144 out of 145. Furthermore, while many foundations have been established, indicating the potential for an expanded charity sector, the China Foundation Ranking-a survey of grassroots Chinese
NGOs that looks at their experiences with funders-criticised these organisations for not engaging in promoting the development of the sector or supporting the work of local NGOs. In the words of Chen Yimei, the Executive Director of the China Development Brief, '[the China Foundation Ranking] helps to make foundations realize that they should treat NGOs with more equality in their partnerships, rather than just assume a top-down relationship.... It's a critical moment, a time when foundations are thinking about their operating model and the philanthropy sector is contemplating whether we should have more grant-making foundations' (Bannister 2014).

\section{Sources of Change?}

The lack of NGO support on the part of Chinese foundations might be due to a number of reasons, including legal impediments, habits of donors and foundations, or just an early stage of development. For example, over 85 percent of foundations have been registered with low levels of initial capital, under eight million yuan (Kang et al. 2012). As regulations and habits change, will we see that more Chinese foundations assume a grant-making role, similar to the foundations in the United States? Or, as these foundations continue to develop, will we see persistence along a unique path of 
development, i.e. 'foundations with Chinese characteristics'?

Regarding legal impediments, there is a great deal of change in the regulations governing this sector. The 2004 Regulations promoted the expansion of the foundation sector due to changes in tax laws, as well as the formation of private foundations. More recently, the 2016 Foreign NGOs Law restricts the ability of international foundations to fund grassroots NGOs in China. This means that Chinese NGOs will need to depend more on domestic sources of funding. In addition to increasing services contracted by local governments, the 2016 Charity Law allows any registered charity to apply for permission to seek public donations (see also the chapter by Simon and Snape in the present volume). This major change might provide more funding sources for NGOs, in addition to funding from foundations which, Shawn Shieh notes, is slowly increasing through mechanisms like 'special funds' and 'joint fundraising' (2014). The regulations governing registration and management of the three types of 'social organisations' (shehui zuzhi) are currently under revision, and amendments are expected to be issued related to the Regulations on the Registration and Administration of Social Associations (1998); the Interim Regulations on the Registration and Administration of Civil Non-Enterprise Institutions (1998); and the Regulations on the Management of Foundations (2004) (Simon and Snape 2017).

In addition to legal changes that seem to encourage philanthropic giving and the expansion of the foundation sector, there is also a shift in habits of both donors and foundations regarding willingness to fund NGOs. This began in 2008 after the Sichuan earthquake. In 2016 the top one hundred Chinese philanthropists donated 37.9 billion yuan, up nearly twenty-five percent from the record 30.4 billion yuan given in 2014, underscoring the philanthropic potential in China (Simon and Snape 2017). Since, as $\mathrm{Xu}$ Yongguang notes, public foundations control most of the public donations in China, it may be more important to convince these types of foundations to support NGOs, as when the Chinese Red Cross offered funding to grassroots NGOs for the first time in the wake of the 2008 Sichuan earthquake (China Development Brief 2011). Xu and other foundation leaders are also creating initiatives like the China Private Foundation Forum and the China Foundation Center to encourage greater cooperation between foundations and NGOs.

These changes in the laws supporting foundations and philanthropy, shifting norms around charitable giving, coupled with the continued development of the foundation sector in China, might encourage foundations to take on more of a grant-making role similar to foundations in the United States. However, becoming a grant-maker is not inevitable, and is instead a decision that the founder must make. In this way, the unique path of development for Chinese foundations might influence whether foundations choose a grantmaking mission over a project-based one. As Shawn Shieh contends: 'In our interviews, a surprising number of foundations who did commit to grant-making did so either because their founders had participated in or were in some way influenced by international philanthropic approaches' (Shieh 2014). If the American model of grant-making influences the development of Chinese foundations, this would provide an invaluable source of funding for Chinese NGOs, especially as these grants might allow for a stronger focus on capacity building, unlike government service contracts. Although there remain many obstacles, the collaboration between an increasingly vigorous foundation sector and Chinese NGOs would thus end up reinforcing the continued development of each. 


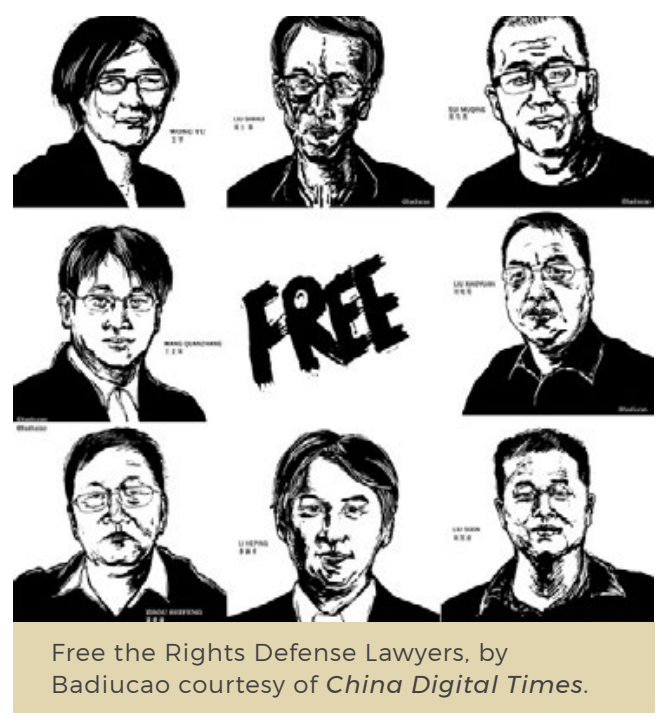

What Future is there for Human Rights Lawyering in China?

\section{Fu Hualing}

In the aftermath of the latest wave of repression, Chinese human rights lawyers have started to reflect on their past successes and failures. They also began to express anxiety, frustration, and confusion about their work. Ultimately all the soul searching boils down to one question: is there a future for human rights lawyering in China as we know it? To answer this question, this essay analyses the practices of human rights lawyering, and examines the circumstances in which socio-legal mobilisation may fail or succeed.
Eighteen months after the Chinese crackdown on human rights lawyers started on 9 July 2015 (the so-called '709 Crackdown'), a debate took place within the communities of China's human rights lawyers (weiquan lüshi). It was a brief, yet passionate and provocative, discussion on some fundamental questions about the limits of the law in seeking justice and protecting rights in an authoritarian state, and on the limited role that lawyers can play in this endeavour. A pointed question that has been raised is whether the traditional case-focused and law-centred strategy of legal mobilisation, moderate or aggressive, is still a feasible approach to bring structural changes to the political system, incremental or otherwise. In the aftermath of the latest wave of repression, lawyers started to reflect on their past successes and failures, casting doubts on the potential of their own profession in catalysing political transformation. They also began to express deeply-seated anxiety, frustration, and confusion about human rights lawyering. Ultimately all the challenging questions boil down to this: is there a future for human rights lawyering in China as we know it?

This essay addresses this question by analysing the practices of human rights lawyering, and by examining in broad strokes the process through which human rights discourses are translated into practices and the circumstances in which a socio-legal mobilisation may fail or succeed. In particular, the article focuses on the collective and sustained endeavours in which human rights lawyers and other citizen activists advocate the rights of specific communities through a relatively stable organisational structure. The primary concern here is not with the exceptional successes, nor with the notable failures in rights practices manifested in individual cases. Instead, the point is to take a close look at institutionalised routines in which legal cases are used as entry points to 
mobilise support from popular opinion, and bring those pressures to bear on decisionmakers.

\section{Human Rights Ideas as an External Shock}

To change a stagnant system, an external shock through the challenge of fresh and even 'subversive' ideas is necessary. Most of the human rights ideas, as practiced in China, originated outside of China and were then appropriated by Chinese reformers. Given that China is a late-comer in the construction of its legal system, importation and appropriation of foreign ideas has proved crucial for the seeding, incubation, and growth of rights discourses and practices.

Since legal activism is guided by a moral vision of social change for the better, ideas that are appropriated are often regarded as progressive with some liberating and emancipatory impact. As such, they serve multiple functions. Ideas have an enlightening power: they educate, raise awareness, allow people to look at their world in alternative ways, and, in general, they lift up people's spirit. Ideas also have the instrumental value of empowering people to re-frame their grievances and claims, enabling them to articulate and assert their positions in more effective and forceful ways.

The appropriation of human rights discourses has always been a contentious issue. Some concepts have been quickly accepted and entered the mainstream. Others remain lofty ideas at a philosophic level, but have not been meaningfully put into practice. Yet others have been rejected firmly at an ideological level. In general, to become part of the mainstream, a rights discourse has to be politically acceptable or at least tolerated. In addition, we can say that if a discourse is merely property of the elites or vanguards, and the masses cannot claim ownership and make use of it in their daily life, it will not be effective.

Legal activism is a top-down process in which elite members of a community-and those with visions, resources, and leadership ability-can, in the right circumstances, translate rights discourse into practices that will eventually catalyse a rights movement. China is not short of heroes or heroines in the legal field who have the courage and wisdom to fight alone. But what makes China's rights practice enduring is the alliance making in the rights complex, capacity building in the NGO sectors, and the development of a critical citizenship among stakeholders and constituents.

\section{No Leaders, No Rights Movements}

China's rights movement is closely associated with a small group of individuals who often single-handedly trigger and then lead rights mobilisation in their respective fields. Few would deny the significant contributions that a limited number of individuals have made in organising and leading China's rights practices. No leaders, no rights movements.

Leaders in China's rights movement share many core characteristics. A key quality of an effective rights leader is their credibility among the constituents they seek to represent. Leaders are not only embedded in the communities they work with, but are also able to develop common interests through their advocacy. An idea may be foreign, but organisation must be indigenous, and activism that is resilient and effective must be bottom up and inside out. In that sense, successful leaders are insiders. What is crucial, in the end, is the common identity, developed through frequent interpersonal connections, that binds leaders and constituents. Leaders who 
are embedded in, part of, and supported by the respective physical and cultural communities are able to make their ideas enter the mainstream, empower and energise communities, and translate their ideas into practice. A shared identity, such as that of gender, sex orientation, disability, or social status, generates a strong sense of internal solidarity which, in turn, motivates members to strive for a collective endeavour.

There exist different strategies based on different positioning of the leaders and the demands of their constituents. There are also significant fault lines, which divide rights movements in various subfields. First of all, there is a divide based on agenda setting and prioritisation of issues between elitists who aim at policy change and political impact, and grassroots campaigners who are principally concerned with welfare and short-term interests. Second, there is a fault line between those who focus on individual cases and those who prioritise institutional and structural changes. The main question in this case is whether the limited resources should be spent on addressing some immediate concerns or on raising more structural issues targeting a root cause. Finally, there is differentiation between those who work for and within the system, and those who challenge it. Traditional human rights lawyering is suspicious of legal institutions, and treats courts as adversaries rather than partners to work with and rely on. However, many lawyers insistently rely on the system to achieve larger policy objectives. Instead of challenging or bypassing the courts, there is now a more critical engagement between judges and lawyers in the courtroom, as well as in the court of public opinion.

For instance, the celebrated $\mathrm{Mr} \mathrm{Lu}$ Jun, a key leader in China's civil society, argues persistently and forcefully that organisation matters the most in socio-legal activism. By organisation, Lu means coordinated and sustained socio-legal mobilisation that is case-focused and rights-based. This requires the active participation of lawyers, NGOs, and media, aiming simultaneously at influencing the immediate legal decision, shaping public opinion, and lobbying institutions for certain legal and policy changes. Under Lu Jun's leadership, the NGO Yirenping excelled in public interest advocacy, but this was prior to the tightening of space for legal mobilisation and, indeed, Lu himself has become a victim of the crackdown (Fu 2012; Chin 2015). Can this style of public interest lawyering continue in these new and visibly more hostile circumstances?

\section{Lingering Spaces for Socio-Legal Mobilisation}

While the world's attention is directed to the persecution of lawyers and activists in the wake of the 709 Crackdown, there remains in China a resilient form of sociolegal mobilisation with a sharp focus on equality rights. Yes, there is much less political space for activism and street action, but while this new hostile environment has halted the flash mob type of street action, a court-centric mobilisation is still feasible. This is a familiar story in which human rights lawyers work closely with the respective NGOs and use litigation as an entry point to shape and influence public opinion with the ultimate goal of achieving certain legal or policy changes.

A key difficulty in launching public interest litigation today is the absence of plaintiffs. Suffering and grievances abound, but victims who are willing to step up to confront their bullies are a rare occurrence. Once a plaintiff is identified and prepped, a campaign has to be designed and implemented. A suitable team of public interest lawyers is retained, law professors in the respective fields are consulted, and journalists are notified. Once a case is in court, the event is widely publicised and 
circulated in the media-including in official media-whose involvement may have been reduced but has not been prohibited. In these cases, all the parties in the rights arena have a common goal, that is to make the case educational for the general public and a deterrent for offending parties. The media landscape remains a significant battleground for public interest cases. Through a strategy of combining legal action through social media mobilisation and civil society capacity building, underpinned by continuous legal reform to strengthen professionalism, lawyers are able to move forward-inch by inch-knowing the potential setbacks and risks that lie ahead.

Without a meaningful political process, legal mobilisation that is case-focused and court-centric is bound to be 'petty'-soft in the approaches taken, incremental in objectives to achieve, and negligible in challenges to pose. Ten years ago, lawyers went to court to challenge discriminatory rules and practices; now the same lawyers have to restart, literally from scratch, similar litigation. Now, however, they have less political space while continuing to experience a similar degree of ignorance, insensitivity, and hostility. Even if they win, as they occasionally do, their actions do little to moderate political power or to hold the repressive arm of the state accountable.

\section{Two Answers to the Challenges Ahead}

Activist lawyers have offered two answers to the challenges. A 'weak' answer relies on remedial justice. That is, while well aware of the structural constraints placed on sociolegal activism, lawyers can still choose to do whatever they are allowed to do in order to make a contribution. As long as there is space-no matter how limited this space is-and as long as there are cases-no matter how petty they are-lawyers will continue.
A 'strong' answer points to the fact that public interest law survives a brutal political repression thanks to the resilience and strength of a rebellious sector in the legal profession and in civil society. Public interest litigation is not mainly about winning a case, but is about persuading power holders and educating the general public. Education and persuasion are necessarily slow paced and incremental in their processes. In addition, cases and the battles surrounding them serve as boosters for all stakeholders in the rights complex as, one by one, they strengthen the resolve of the forces of civil society and enhance their capacity in their on-going negotiations with the Party-state.

More specifically and pointedly, individual cases do trigger systemic or structural changes. There are many examples of case-driven changes that have happened in the past. While one can argue that legal advocacy in authoritarian states cannot lead to transformative political change-and that, as some human rights lawyers insist, legal battles in court rooms do not have a democratisation potentialone can argue with equal force that, as long as the regime embraces a degree of legality and promulgates laws to protect a range of legal rights, those rights-friendly laws can be enforced more or less effectively, and rights can be protected more or less rigorously. Legal and political opportunities are there, and it depends on civic leaders, professionals, and civil society at large to seize the opportunities to empower their human agency and to maximise their rights and freedoms through socio-legal action. 


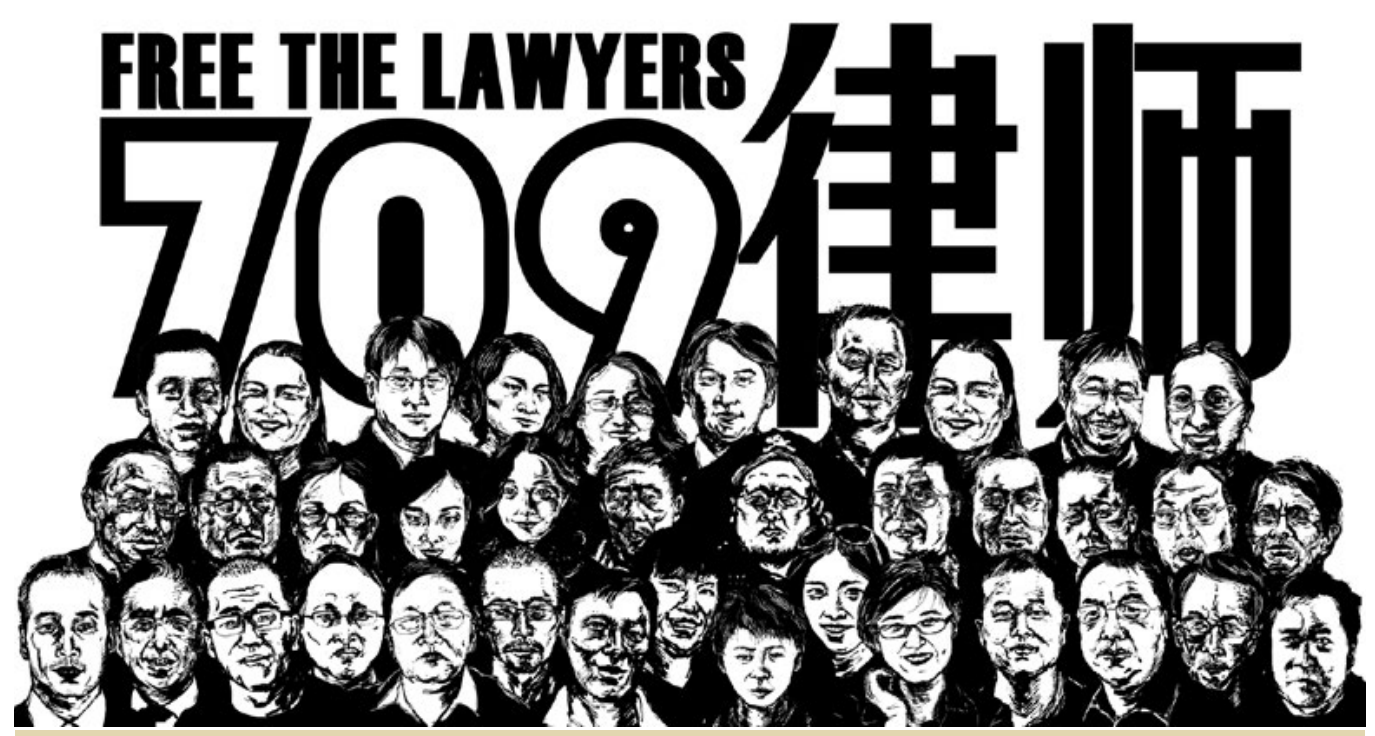

Free the Rights Defense Lawyers, by Badiucao courtesy of China Digital Times.

\section{The Mental Health Costs of Repression}

Nicola Macbean

Chinese civil society activists and human rights lawyers are experiencing unprecedented levels of repression. The relentless pressure, as well as the acts of police violence and torture, has made many fearful of the consequences of their work. This is, inevitably, taking a toll on the mental health of activists. While psychological counselling services in China have expanded in recent years, most counsellors are reluctant to work with politically sensitive clients. This essay examines the need for the human rights community in China to develop the skills to address the mental health challenges of activism.
Early in the morning of Thursday 9 July 2015 police hammered on the door of Wang Yu's apartment in Beijing and took her away. Within days, hundreds of Chinese lawyers were called in for questioning by the police or the local lawyers' association. While the majority of lawyers were released within hours, many were detained for days, months and, for some, now years. The '709' incident, as it became known, is the most high profile systematic hounding and prosecution of Chinese human rights defenders in recent years.

For over a decade, feminists, democracy activists, workers' representatives, human rights lawyers (weiquan lüshi) lawyers and NGO staff have endured the threat of crackdowns and imprisonment as a deterrent to their activism. The authorities also deploy less high-profile measures to intimidate, harass, and punish activists: parents are bullied, old boyfriends approached, children are prevented from attending school, landlords are pressured into rescinding rental contracts, and high 
profile activists are not allowed to travel overseas (Franceschini 2017a). The police periodically step up the pressure on human rights defenders with unscheduled visits to offices and homes, monitoring meetings, photographing visitors or installing surveillance cameras. Almost anyone working in the civil rights field has been invited by the police 'to drink tea' (he cha), a euphemism for an interview or a rebuke. More insidious is the unseen surveillance: the monitoring of social media and the hacking of email and private messaging.

\section{The Psychological Toll of State Repression}

Disappearances and the fear they induce have long been a governance tool of the Chinese Communist Party. Yet, the current level of repression appears unprecedented. The authorities seem to hope that relentless pressure will deter activists while the new Overseas NGO Management Law cuts off the main source of funds to civil society (Franceschini and Nesossi 2017). As domestic NGOs disband or are closed down, activism and the continued defence of human rights increasingly takes place on an individual or small scale. While this seems to offer some protection, working from home cuts off individuals from the conviviality and support of colleagues. Although social media partially offsets the physical isolation and need for social interaction, the constant stream of news detailing incidents and related calls for support can themselves be a source of stress.

Human rights defenders share many of the same concerns as other over-burdened families in China: unsafe food and air pollution, school and job insecurity, and the costs of medical care. On top of this they must deal with shifting Party attitudes to their work. Considerable time and effort are dedicated to analysing the local and national situation to determine whether a particular case, report or activity will cross an invisible red line bringing a knock on the door late at night.

For the human rights community, increased levels of repression pose three significant mental health challenges: managing day-today anxieties; anticipating and preparing for the possibility of detention; and responding to the use of torture and ill treatment. Individuals face varied levels of risk and will also react differently to the impact of pressure by the authorities. Human rights defenders can learn to improve their personal security and build their confidence in handling police harassment and abuses. Courage and preparation, however, will not be enough. To sustain the work of the human rights community, the mental health costs of activism should be understood and addressed.

\section{Access to Psychological Support}

A number of NGO staff have turned to China's growing ranks of psychological counsellors for help in addressing feelings of stress and anxiety. For some the experience has been unsatisfactory. In the words of one young woman, the counsellor was unable to understand her fear of the police. To the counsellor such a fear was not only outside her realm of experience, but seemed irrational. Some counsellors are unwilling to help human rights defenders, seemingly worried that 'political sensitivity' may be contagious. There is equally a lack of trust on the part of many human rights defenders towards mainstream psychologists. Moreover, as a service to the wealthier middle classes, counselling in China does not come cheap. On an NGO salary it would be difficult to afford regular sessions. 
In recent years small peer support groups have started to meet. These gatherings provide participants with a psychologically safe space to share and work through their feelings and experiences. Peer support groups are a cost-effective response to the need for counselling. They have the added benefit of building stronger relationships within the human rights community. Although peer support groups lack expertise, by bringing people together who have shared experiences, they provide an opportunity for participants to learn from each other. Several groups now integrate attention to mental wellbeing into their broader human rights work.

Experience suggests that peer support groups are most effective when group facilitators have the chance to continue developing their own skills. These include not only logistical skills to arrange meetings in the current climate, but also how best to respond to the varied needs of the group and individual members. A simple, but very valuable, skill is helping participants learn relaxation techniques to help manage stress, including deep breathing and visualisation. Some activists need to learn to take time off and introduce small pleasures into their weekly routines.

Many human rights defenders have tried to keep their activism separate from family life. They believe this will stop spouses or parents from worrying and protect their family from police pressure. Several years ago, the wife of a prominent imprisoned activist described a young woman she had met who had no knowledge of her husband's activism. When he was detained she was completely unprepared. She knew none of his friends, had not met any weiquan lawyers and had no idea what to do. Peer support groups have encouraged human rights defenders to become more open with their families and seek their understanding, even if they cannot always enjoy their full support.
The '709' wives have shown immense courage demanding accountability from the authorities for the detention of their husbands (BBC Beijing Bureau 2016). Together with the Feminist Five (Fincher 2016), these wives have challenged gender stereotypes among activists and opened up new opportunities for the participation of family members. Strong and open relationships among close friends and family are needed to sustain activism for the long haul. They are also important when the frustration experienced by frontline human rights defenders may be expressed in anger or violence in the home. Support group leaders also need to recognise when professional help is needed.

Observation suggests that fostering active listening is one of the most important skills for facilitators. While activists routinely use social media to report threats, beatings or other abuses, there are few opportunities to talk about the experience and how they felt being treated in this way. The development of active listening skills has helped survivors of police brutality to be able to tell their stories in their own words and at their own pace. Reflecting on one such conversation, a lawyer shared the relief he felt describing in detail, for the first time, his experience of being detained and beaten by the police: 'No one asked me before how I felt.'

\section{Surviving Torture and Violence}

Active listening skills are not only important in peer support groups, but also among those lawyers whose clients have been tortured or subject to other forms of ill treatment. Working within the constraints of a brief meeting in the detention centre, lawyers are often quick to interrupt a conversation and offer their opinion. A former detained activist, while grateful for several visits from lawyers during his thirty- 
day detention, nevertheless complained that the lawyers never really listened to him. Improved communication skills among lawyers are essential where traumatised clients have difficulty recounting their experience in the logical manner that the law expects. As human rights lawyers have become targets of police abuse, forging increased mental health awareness is helpful on both a professional and personal level.

Engaging with survivors of torture is a particular challenge for support groups. Many released prisoners and other human rights defenders have been subjected to torture, but there are no specialist rehabilitation services in China. Many survivors are also prevented, by public security, from travelling abroad to meet with psychologists based outside mainland China. Members of peer support groups can, therefore, be at the forefront in engaging with survivors. Sensitisation training on the impact of torture, the symptoms of post-traumatic stress disorder, and the risk of re-traumatisation is starting to help lawyers and other human rights defenders develop more psychologically aware communication skills. Survivors require sufficient time to heal and process their traumatic experience before they are encouraged to speak out.

Human rights lawyers have helped to raise awareness of the use of torture (Buckley 2017). The apparent increase in the use of 'clean', particularly psychological, torture is a direct response to growing public disquiet at police violence. New legal measures, such as the exclusion of illegally obtained evidence (Xinhua 2017a), are of little use if procurators and judges ignore allegations that unbearable psychological pressure was applied to secure a confession. Increased understanding of the impact of torture will help challenge the impunity with which interrogators use violence and threats to secure the cooperation of detainees.

\section{Overcoming the Divided Self}

Increased mental health awareness, and better skills to handle stress and fear, enhance the resilience of human rights communities to endure unprecedented repression. Recognising the toll on mental health experienced by many human rights defenders does not 'pathologise' dissent. Nor is fear of the police in China irrational. And greater psychological resilience to withstand repression does not normalise police brutality. On the contrary, it helps ensure that human rights defenders have the inner strength to continue challenging police abuse and illegality by the authorities.

Many ordinary citizens in China display a divided self in which politically sensitive opinions are repressed to allow the individual to get on with their life. With their commitment to universal values, human rights defenders challenge this tension between the true self and a public persona that supports an increasingly repressive Party. Attention to mental wellbeing has encouraged greater emotional honesty among human rights defenders, and their friends and family. It is helping strengthen the human rights community through building stronger interpersonal networks. Talking about feelings helps human rights defenders articulate a language of optimism and human values in the face of a destructive repression. It is the belief in the rightness of their cause that helps sustain their work. Those of us outside China should ensure that they can continue to develop these essential skills and support each other at a difficult time. 


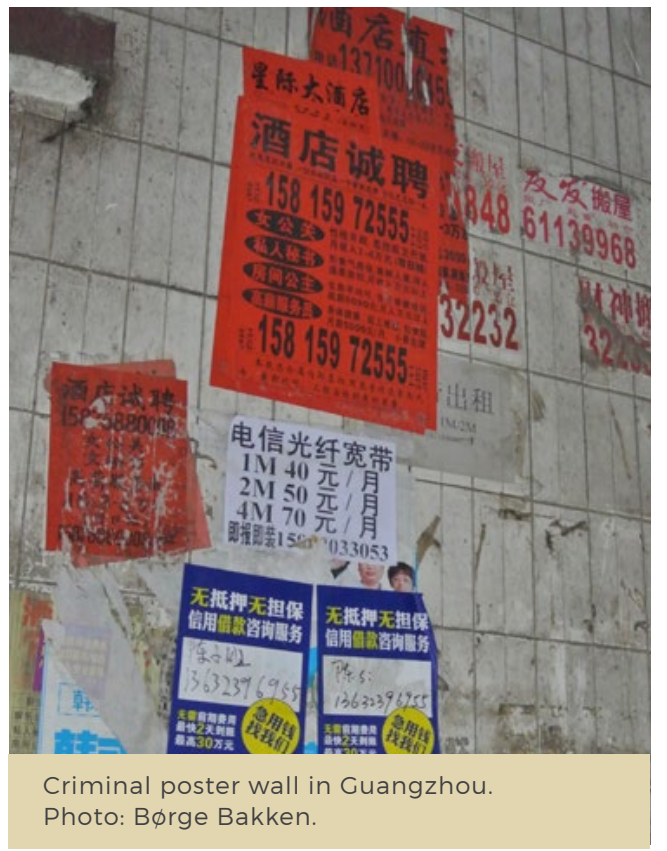

\section{Snapshots of China's 'Uncivil Society'}

\section{B $\phi$ rge Bakken}

Under the leadership of Xi Jinping, the Chinese Communist Party has reinvigorated attempts to eradicate detrimental 'Western ideas', resulting in the assertion that civil society is nothing more than a concept, if not a trap set by the West. In practice, however, these attempts by the Chinese government to prevent a civil society from organising itself has led to the emergence of a very differentuncivil-type of society.
It has now been thirty years since former British Prime Minister Margaret Thatcher gave voice to her famous and equally senseless idea that: 'There is no such thing as society.' In the Chinese Communist Party's quest to eradicate 'Western ideas' from the realm of discourse in China through the 'seven prohibitions' ( $q$ i bu jiang), Xi Jinping is likewise denying the existence of a society, by arguing that a civil society is nothing but a mere concept, and even a trap set by the West. Thatcher and Xi's ideas are equally senseless and equally ideological in their quest to deny the obvious. While the denial of the very existence of a civil society is not new in China, and Xi Jinping is not the first to have devised this type of propaganda (it was already referred to as a 'trap' by the former $\mathrm{Hu}$ Jintao administration), the 'trap theory' today is closely linked to the propaganda surrounding the 'Chinese Dream' (zhongguo meng).

\section{Dreams of Exclusion}

In the myth of the American Dream, it was once said that: "What is good for General Motors is good for America and good for you.' In February 2013, the People's Daily made a direct reference to the American Dream when stating that the Chinese Dream promotes the idea that what is good for the nation will also be beneficial for the individual. While holding to the assumption that the Chinese Dream diverges from its American counterpart, the Party-state basically promoted the same myth about the dream's alleged benefits for 'the people'.

Ideological references to 'individualism' and 'collectivism' aside, the respective 'Dreams' are, of course, the dreams of the rich and the beautiful. Like in America, many Chinese fall outside the dream with no chance to 'get rich first', as was the original slogan put forward by Deng Xiaoping. The present propaganda texts emphasise 
that the Chinese Dream is the dream of all Chinese, in particular the 'Dream of the laobaixing'-the 'old one hundred surnames', or the people themselves. Of course it is all basically an emperor's dream, and very much as is the case in America, the people who fall outside the grand dream tend to organise themselves in ways outside the legal rules and accepted norms in an attempt to reach the overarching cultural norm of prosperity that ultimately underpins the dream in the first place. In many such cases we are not even speaking of getting rich, but merely of getting by.

The sociologist Robert Merton wrote about those excluded by the American Dream as far back as the late 1930s (1968). One of his main findings was precisely that people who could not achieve the dream of personal prosperity by the restricted avenues of legal means and norms would simply try to achieve that aim by illegal means. And why shouldn't this be the case in a China that has moved from one of the most equal to one of the most unequal societies in the world in just a few decades? According to recent World Bank statistics, China has seen the Gini coefficient-the statistical estimate of relative equality and inequality-moving up from an equal 0.21 in 1978 to an estimated highly unequal 0.61 (AFP 2016). The Chinese people and their ways of organising themselves in the face of this reality is tangible and no imagined theoretical 'trap'.

\section{Underworld Countryside}

The paradox of trying to prevent a civil society from organising itself from the grassroots in any legal manner has seen the unintended consequence of a rather uncivil type of society emerging from the bottom of contemporary Chinese society. The examples of such phenomena are too many to describe here, but let me take just a couple of examples from my new book Crime and the Chinese Dream (Hong Kong University Press 2018).

In the countryside, we see the emergence of a virtual criminal economy among the excluded. Earning money by illegal means has become common as the only way to 'get rich' or even just get by, and many parts of the countryside have come to be described as an 'underworld countryside'. So-called 'criminal villages' (fanzui cun) and criminal towns have emerged as people on the margins are struggling to fulfil the dream of relative prosperity in the only way available to them (Wu 2014). In Fang Village in the south-east, so-called 'cake-uncles' (bingshu) are running grand scams by carrying out sales with falsified account booksextending their fraudulent activities across China and making the village prosperous. The new mansions in the village are all built and owned by the fraudsters. The village girls all want to marry a 'cake-uncle' instead of a toiling peasant. The story is one where the village struggled with all kinds of legal means to gain prosperity before they found their criminal and profitable trade. Fang Village is not alone.

A map of criminal villages in China shows a diversity of criminal activities from fraud, organised large-scale shoplifting, car theft, and burglary. In one much publicised example, a robbery village in Guangxi specialised in hand-cutting as a means of creating chaos and then utilised that chaos to rob people in the panic after their bloodletting attacks. The village robbers typically attacked crowded places like train stations or other locations where many people had gathered. The culprits then robbed and fled in the mayhem created by the incident. Other examples we can read about include drug-producing villages where the whole local economy is based on drug production and transportation, typically in poor provinces like Yunnan and Guangxi in the south-western drug belt areas. There 
are also weapon-making villages trading in illegal firearms. The list of criminal entrepreneurialism is diverse and wide ranging.

I have recently been involved in a project that looks at child kidnapping. The project has identified villages that base their local economy on the kidnapping of children for profit. We found that the children are typically under three years of age, and that there is a clear 'division of labour' among traffickers. The last link in the on-the-spot act of kidnapping is often an old woman who may look like the grandmother of the screaming kidnapped child, not creating any suspicion about the crime being committed. After the kidnapping, other perpetrators stand for the storage, transport, and final sale of the kids. The entire process is extremely well organised, with the police involved occupied looking in other directions. In this example it is worth noting that impunity is the rule for the kidnappers, and that the civil society occupied with organising and petitioning activities among parents is cracked down upon far more readily and effectively than the 'uncivil' organisations and networks in the criminal villages. The few solved child-kidnapping cases are shown on a special national TV show as 'proof' of the effectiveness of the police. Parents, however, are not able to have the TV station run any unsolved cases, as the show only allows happy stories to be aired.

\section{Criminal Advertisement}

A snapshot from the 'uncivil' reality of the cities can be illustrated by a short stroll over a narrow footbridge in Guangzhou. I counted no less than two hundred and fifty illegal posters and stickers offering everything from false documents and stolen goods, to sexual scams and job ads for prostitutes. This is typical for many public spaces in the city-in the outlaying rural areas, the suburbs, and the central business districts. All posters, stickers and painted messages come with a mobile phone number that is impossible to trace by the police, and the high-ranking policemen I spoke with said they do nothing about this unless there is a genuine complaint from the public, and even then is there is not much that can be done. The regular police even blame the urban management teams (chengguan) for being responsible for the criminal posters problem. The chengguan on their side believe that it is the duty of the police to take down the posters, so they simply let it pass and refuse to do anything about the problem. The uncivil society, thus, has free advertisement walls all over the city and with a nearly one hundred percent chance of impunity.

If the Cultural Revolution had its 'big character posters' (dazibao), and the late 1970 s and early 1980s had their 'democracy walls' (minzhu qiang), the Chinese Dream era has its own criminal poster walls (as well as bridges and all kinds of public spaces) with free ads for criminal activity. Such posters more or less dominate many cities in China today, and this kind of 'uncivil society' is allowed to spread. The walls are typically plastered with private commercial posters, job ads, and all kinds of announcements, legal and illegal alike. On many walls, recruitment posters for the army and the brothels stand side by side. The picture that accompanies this article shows several typical criminal posters, like the frequently displayed big red poster ads for recruiting male money boys and female prostitutes (concealed with inventive 'job descriptions' such as 'secretary', 'PR-consultant', 'service worker', 'housemaid' etc.). The job categories are easily recognised by the people in question as describing different forms of prostitution with promised earnings of up to sixty thousand yuan per month. 
Another poster at the bottom left of the photo pictures a beautiful twenty-nineyear-old woman accompanied by a scam story of an unhappy marriage and a rich husband's accident leading to the couple not being able to have a child. Half a million yuan (!) is promised to the person who can make her pregnant (after paying a 'small fee' of one thousand and two hundred yuan to the couple's alleged lawyer). My colleague who speaks Cantonese with a northern accent phoned the number, met a woman on the line, and set up an appointment to meet her alleged lawyer at a hotel lobby the next day. He never went, but the scam became clear to us. The 'lawyer' would disappear as soon as the fee was paid. I asked a policeman if people really buy this scam, and he confirmed that many do, and that they never receive any complaints because the betrayed 'inseminator' never dares come to the police with his foolish mistake. This type of scam has almost no chance of being targeted by the police, and this is well known among the perpetrators.

\section{Uncivil Society Out of Control}

Capitalism has come to China in the grand package of a Chinese Dream, and the crimes that follow are covered up by massively falsified crime statistics. According to data gathered a couple of years ago, in Guangzhou alone the real numbers of crime known to the police are falsified down to 2.5 percent in the official statistics, while 97.5 percent is concealed to the public (Xu 2017). The falsification of numbers concerns petty crime as well as serious violent crime. The government is no longer fully in control of crime and 'uncivil' entrepreneurialism, but they care more about controlling the alleged 'trap' of civil society. In short, petitioning is more important to control than kidnapping.
This situation recalls what Marx and Engels wrote in their Communist Manifesto about bourgeois society-that it is "like the sorcerer who is no longer able to control the powers of the nether world whom he has called up by his spells' $(2004,51)$. Both economies and norms change in this spiral of capitalist economic development (with Chinese characteristics), giving rise to 'uncivil' forms of entrepreneurialism. In such a whirlwind, the 'nether world' in Marx and Engels' account may well translate into the 'uncivil society' shown in the criminal villages in the countryside and the criminal posters on the city walls. 


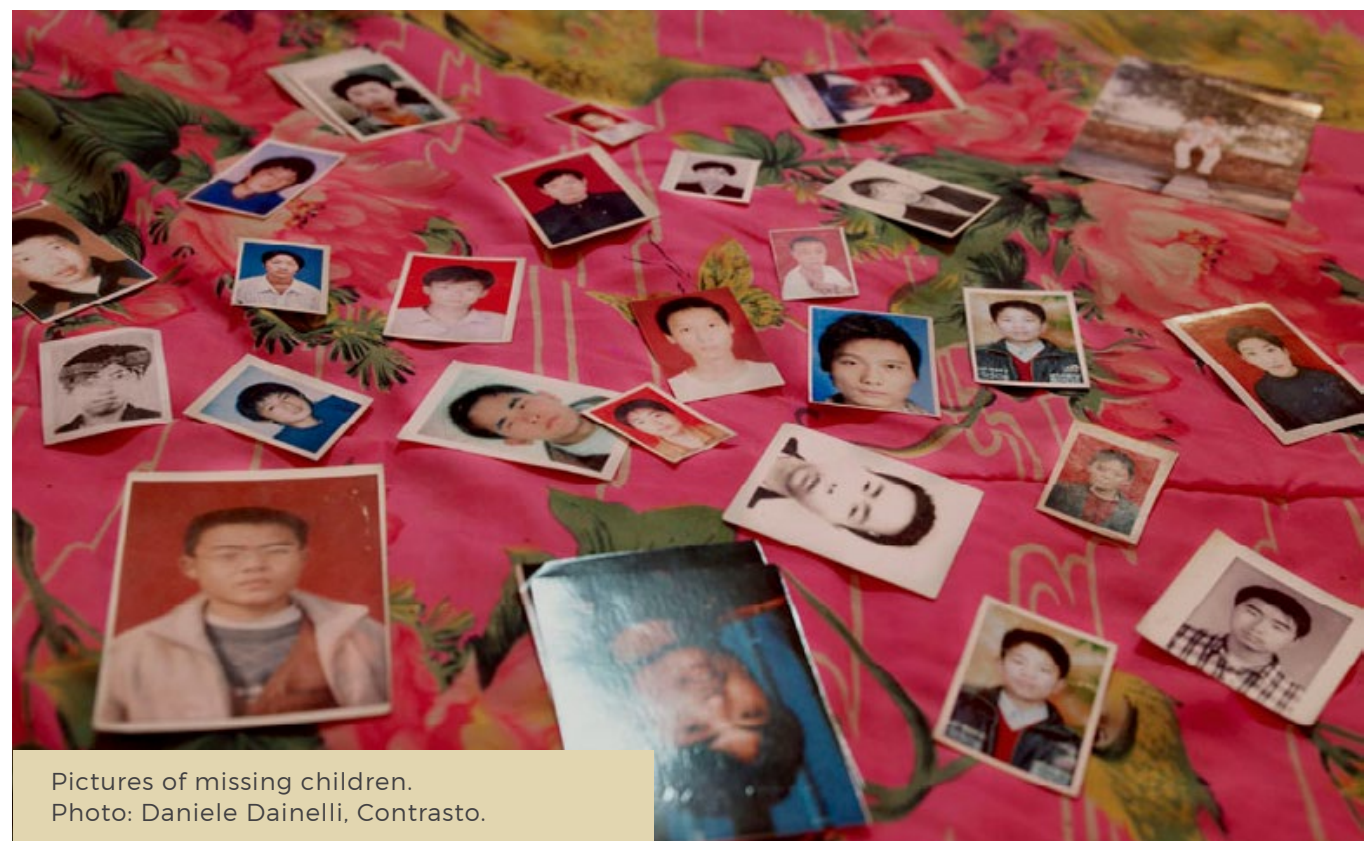

\section{Slaving Away The 'Black Brick Kilns Scandal' Ten Years On}

\section{Ivan Franceschini}

In the spring and summer of 2007, bands of aggrieved parents roamed the Chinese countryside looking for their missing children, whom they learned had been kidnapped and sold as slaves to illegal kilns. Thanks to the involvement of Chinese media and civil society, the so-called 'black brick kilns incident' became one of the most remarkable stories of popular mobilisation and resistance in contemporary China. Now that ten years have passed, are there any lessons that we can draw from this moment in history?
3,653 days, 3,653 posts. Day after day for ten years, one solitary blogger has been keeping track of the time that has passed since 28 March 2007, when fifteen-year-old Yuan Xueyu disappeared from a construction site in the centre of Zhengzhou, Henan province. Every morning, Dou Jiangming-who in his 'ordinary' life is a prominent media personality in China-posts exactly the same message on his Weibo account (https://www. weibo.com/doujiangming): 'Today it is day $x$ in the search of Yuan Xueyu. Public Security Bureau of Zhengzhou, could you please tell us what progress has been made in his case? The missing workers in the incident of the black brick kilns in Shanxi province remain missing. Netizens have donated four thousand yuan as a reward for any relevant clue. The Public Security Bureau of Zhengzhou opened the case related to Yuan Xueyu's disappearance back in 2007.'

Yuan Xueyu had arrived in Zhengzhou a couple of weeks before his disappearance to be an apprentice to a fellow villager-a worker specialising in setting up window 
frames. Like many of his childhood friends, he had been unable to resist the call of the big city, which resounded particularly strong in his remote rural village, and against the wishes of his father had dropped out of middle school. When he heard that his son was nowhere to be found, Yuan Cheng did not waste any time. He immediately went to Zhengzhou and took up a job in the same construction site. He posted leaflets with the photo of his son everywhere, but the only result was that strangers started to call him pretending to know the boy. Saying that his son had been in an accident, they asked him to wire some money and then disappeared. It was only after encountering other parents whose children had disappeared in similar circumstances, that Yuan Cheng finally found some hope. Listening to their stories, he realised that there was a good chance that his son had been kidnapped and sold into slavery in a brick kiln somewhere in the countryside. The prospects were still dim, but at least now he had an idea where to look.

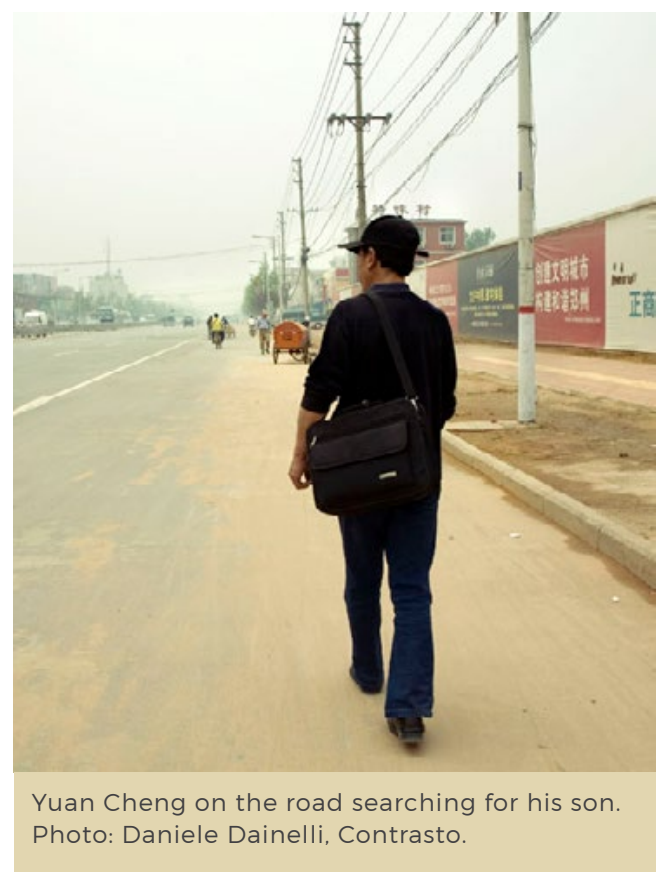

In the spring and summer of 2007-in what came to be known as the black brick kilns incident' (heizhuanyao shijian)these bands of aggrieved parents roaming the Chinese countryside looking for their missing children made for one of the most remarkable stories of popular mobilisation and resistance in contemporary China. It was a saga of unendurable pain and unprecedented camaraderie-of friendship as well as betrayal. It was a story that deserved to be told and it quickly piqued my interest and sparked my imagination. I wrote both my first book (Franceschini 2009) and one of my earliest media reports on the incident (Fang 2008). Instead of focusing on the dark side of slavery and exploitation, I decided to emphasise on the positive side of the mobilisation of Chinese civil society in support of these aggrieved parents. It was indeed an amazing display of solidarity, something that remains awe-inspiring even today. Now that ten years have passed, are there any lessons that we can still draw from this story?

\section{A Mother's Determination}

The chain of events that led to the explosion of interest in the kilns scandal began in March 2007 with Yang Aizhi, a mother whose sixteen-year old son had recently gone missing in Zhengzhou (Zhu 2007a). After covering the city with posters, Yang was contacted by another parent who told her that his two sons had just escaped from slavery in a kiln in Shanxi province. Convinced that her son had to be in a similar place, Yang immediately left for the area. There, she visited no less than one hundred kilns, finding many young slaves, some of them still wearing school uniforms. After going back to Henan, she got in touch with five other parents in the same situation through the missing people announcements 
published on the pages of a local newspaper. Together, they established what the Chinese media later termed the 'League of the Search for Children' (xunzi lianmeng). In just a couple of months they rescued more than forty children from slavery.

Realising that their task far outweighed their strength, they decided to seek help from the media. As it turned out, their stories were so difficult to believe that only one journalist, Fu Zhenzhong of the City Channel (dushi pindao), a local TV station in Henan, accepted to follow them in their search. He made the right choice. When, on the evening of 19 May 2007, the footage of young boys wearing rags and doing heavy works in kilns in Shanxi that $\mathrm{Fu}$ had shot with a hidden camera was aired on television, there was an uproar. As Fu later recalled, 'in the three days after the airing of the feature about the kilns, about one thousand parents came to the TV station looking for help' (Fu 2007). On that day, mothers and fathers that until that moment had not known where to look for their children discovered the existence of the kilns and realised that they were not alone in their plight. It was then that these parents started organising themselves in small teams to scour the Shanxi countryside.

Then, on 6 June, the aunt of a child recently rescued by the League expressed her gratitude in a tearful post on a local web portal in Henan province (Zhu 2007b). This post, which was shared by more than three hundred thousand people all over the country, finally managed to attract the attention of the national media. From that moment on, 'black brick kilns' became a term of common use throughout China.

\section{The Hidden Rules of the Kilns}

For the whole summer of 2007, the coverage of the scandal on the Chinese media was impressive, with journalists and media outlets competing with each other to describe the reality of the kilns in the smallest detail. Even the Party struggled to keep up with this avalanche of information. It came out that the slaves in the kilns were not only teenagers who had been deceived with the illusion of a well-paid job or abducted with violence, but also adults with mental problems and children, a docile workforce that never raised any demands. Among the lesser-known survivor stories was that of Hao Dingpo, a fifteen-year-old boy who had spent two and a half years in the kilns after being kidnapped from Zhengzhou in March 2005. According to his mother, whom I interviewed back in May 2008, when he finally managed to escape in the summer of 2007 , he had waist-long hair and a number on his wrist. According to his testimony, names were never used in the kiln, only numbers. They had a daily production quota of ten thousands bricks and, when they were not able to fulfil it, they were savagely beaten. When a fugitive was caught attempting to escape, he was beaten to death by the guards and the body was left in the open to rot as a warning to others. Hao Dingpo claimed to have seen six people dying this way, but there was no way to verify his claim as he was never able to indicate the exact location of the kiln.

The conditions in the kilns had a dramatic impact not only on the body of the slaves, but also on their mental well-being. When I met Zhang Shanlin in May 2008, one year after the police had rescued his son from a kiln, he was worried because the boy, who once had been lively and cheerful, had lost any interest in anything, including in his dream of becoming a chef. The teenager refused to leave his house and avoided any human contact. He not only felt ashamed about what had happened to him, but he also kept dreaming about his life in the kiln and woke up screaming almost every night.

The media were relentless in eviscerating the local dynamics behind the existence of 
the kilns. It was evident that the regime of the kilns could exist only because many people benefitted from it. A Nanfang Zhoumo report quoted a former slave as saying: "[The life in the kiln] was like the food chain in the animal realm... This chain had six rings: the owner of the kiln > the baogongtou [i.e. a subcontractor in charge of all matters related to the workers] > the guards $>$ the older workers $>$ the new workers > the retards' (Chen 2007). While the owner was always a local person, the baogongtou generally came from somewhere else-usually the place where he found his victims.

The relationship between the black kilns and the local communities was also very important. Although many accounts described the geographical seclusion of these places, local people were well aware of these realities. The reason they accepted them is that the economy of the kilns had its advantages for the local community, since they stimulated local development and created new opportunities to get rich ( $\mathrm{Zhu}$ 2007 c). Support from the local community was also one of the reasons why escaping from the kilns was so hard. Since local workers were too expensive and almost impossible to exploit due to the protection coming from their familial networks, slaves were inevitably 'outsiders' (waidiren). Sometimes local people themselves contributed by supplying the kilns with the workforce they needed. This is what happened to Shen Haijun, a thirty-eightyear-old man from Jiangsu province, who ended up as a slave in a kiln while looking for his mother, a sixty-year-old widow who had been sold as a wife to an old bachelor in Shanxi by a relative (Liu 2007). Shen told the journalists that, once he had arrived in the village where his mother had been sold, he had asked an old lady for directions. Under the pretence of helping him find a well-paid job, she sold him to the local kiln owner.
The higher echelons of the Party-state did not fare any better in the media. Reports not only highlighted that the middle-level bureaucracy in Shanxi province was fully aware of the existence of the kilns, but that some officials were even complicit in perpetuating slavery. One of the most unbelievable stories of all was that of $\mathrm{Zhu}$ Guanghui, a young boy from Henan (Zhu 2007 d). Rescued by the police from a kiln on 27 April 2007, he was immediately sold back to another kiln by a local labour inspector, who even deducted an 'intermediation fee' (zhongjiefei) of three hundred yuan from the back salary of the boy. Zhu was rescued again during another police operation at the end of May. In the following days, a local TV station managed to record a confrontation between him and the labour inspector who had sold him. Nobody could have imagined that on that same afternoon the labour inspector would deceive the boy once again, selling him to yet another kiln. Finally, on 18 June 2007, Zhu Guanghui was rescued for a third time and managed to get back home safely.

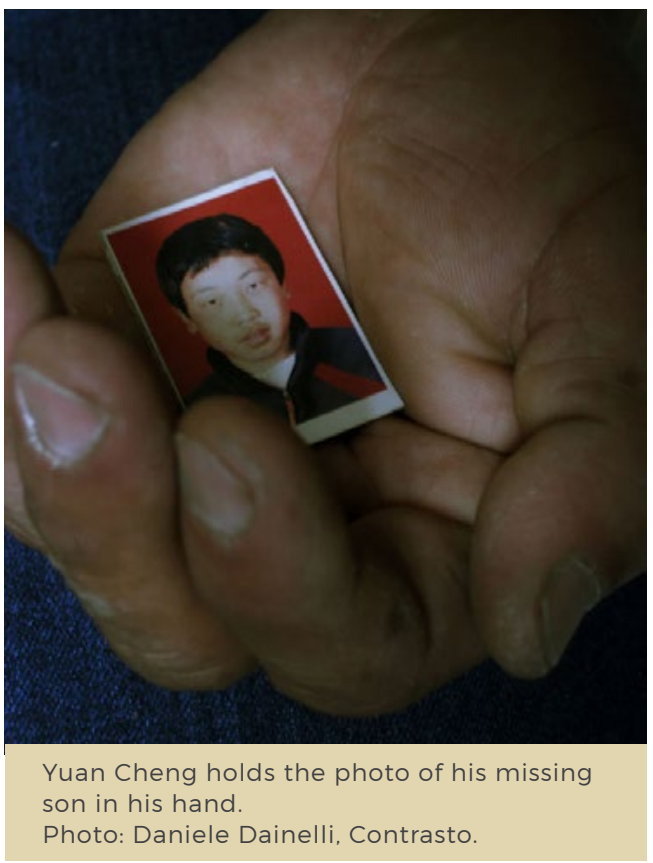




\section{The Response of the Authorities}

The stories told by families of the missing children were filled with desperation and highlighted the indifference of the local authorities. Back in May 2008, Wang Xiaoli, the mother of a boy who had gone missing in 2006 in Gongyi county, Henan province, told me: 'When I went to the police to report that my son was missing, they declined to even open the case. They said that such situations are too common to be taken into consideration.' At the moment of his disappearance, her seventeen-year-old son was studying for the university admissions exam (gaokao). He was one of the best students in his school and had a very good chance to be accepted to a top university-a remarkable achievement for a boy from a poor rural area. Yet, on 26 October 2006, he went missing without a trace: he was supposed to spend a few days at a friend's house, but somehow disappeared before reaching his destination.

The media storm triggered by the aggrieved parents changed everything, at least for a few weeks. In June 2007, the central authorities reacted launching a provincial investigation into the Shanxi kilns. The numbers involved were impressive, the outcome less so. According to official data, the police checked 86,395 employers, discovering that 36,286 (forty-two percent) of them were operating without any formal permission; 4,861 brick and tile kilns were inspected, among which 3,186 (63.3 percent) were found to be lacking any registration; in total, the workers in the kilns numbered eighty-one thousand, but only seventeen kilns were found to have severe problems (Xinhua 2007). Among them, thirteen had incidents of child labour. On the whole, 359 workers were rescued, including 121 mentally disabled adults and fifteen children. In the meantime, the top echelons of the Party launched a campaign to 'sweep' the ranks of the local bureaucracy, with ninety-five officials being punished for malfeasance and dereliction of duty, while President Hu Jintao and Prime Minister Wen Jiabao raised their voices asking for further investigations to reveal cases of corruption related to the kilns (Zhang 2007a).

At the same time, the Chinese leadership could not miss the opportunity to ride the publicity wave of the scandal to promote its political agenda. In particular, the media coverage of the kilns was used to accelerate the troubled legislative process that led to the passage of the Labour Contract Law, then stranded due to the emergence of a heated public debate about the advisability of introducing new guarantees for workers' rights at a stage in which economic development was still fuelled by low labour costs (Gallagher and Dong 2011). After more than three years of top-level discussions and more than a dozen blueprints, the kilns scandal was an essential factor that facilitated the ultimate approval of the Law, which was passed at the end of June right in the middle of the media storm. Xie Liangming, then Deputy Director of the Department of Legal Affairs of the All-China Federation of Trade Unions, declared: '[If the kilns scandal had not happened] I think that the debate would have continued. Since the scandal deeply moved the legislative bodies, including many committee members who felt that such situations could not be understood and that it was necessary to be more severe, the Law was pushed through' (Wang 2007).

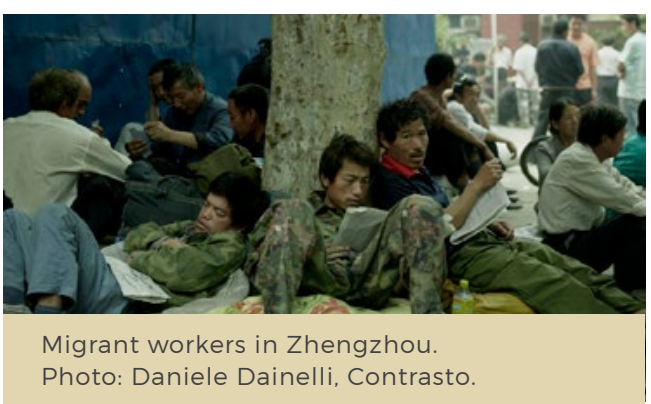




\section{The Kilns After the Kilns}

Ten years later, the kilns might not be as widespread as before, but all the signs point to their continued existence. In May 2009, Chinese media reported that in Jieshou city, Anhui province, the police rescued thirtytwo mentally disabled workers enslaved in two different kilns (Cheng 2009a). According to the available accounts, these people were deceived by a human trafficker, in this case a taxi driver, who earned two to three hundred yuan for every person that he 'introduced' to the kilns. Closely guarded by thugs who did not hesitate to resort to violence, these slaves, whose age varied from twenty-five to forty-five, lived locked in a courtyard and were forced to work ten hours a day without receiving any wage besides a few yuan for their personal expenses. The police then arrested ten people, including the baogongtou and the owners.

In June 2010, Chinese media reported that the police in Shilin county, Yunnan province, had rescued about twenty slaves from a local kiln (Huang 2010). One of the slaves, a man from Chongqing, described to the journalists the brutality of his guards who, in order to make him work seventeen hours a day, beat him with steel bars and leather belts. Similarly, in December 2010, a story of human trafficking of individuals with disabilities based in $\mathrm{Qu}$ county, Sichuan province, was widely reported in the Chinese media (Ran 2010). In that case, everything was happening with the open connivance of the local authorities, under the cover of a public shelter for disabled people. In another remarkable story, in September 2011 Cui Songwang, a reporter for a Zhengzhou television station, hung around a train station posing as a disabled man for two days, until he was kidnapped and sold to a kiln manager for five hundred yuan (Cui 2011). Cui said he was forced to work for three hours, beaten and deprived of water before he managed to escape and report the case to police. More recent media reports tell the story of slaves who managed to escape from the kilns, such as forty-threeyear old Xu Shuhe, who was a slave in black brick kilns in Guangzhou for twenty-four years (Zou 2017b); thirty-three-year old Fan Debao, who spent eleven years in slavery ( $\mathrm{Li}$ 2016); and thirty-five-year old Qi Zhaojun, who was deprived of his liberty for twentyone years in a number of kilns in Shanxi province (Gao and Zhang 2015).

Yuan Xueyu is still missing, another victim of what Børge Bakken has called China's 'uncivil society' (see the previous chapter). His father Yuan Cheng is still looking for him and in his search has, thus far, been able to save more than one hundred children (Zhang 2013). In all this, is there any lesson that can be drawn from what happened ten years ago? Looking at the latest developments in Xi Jinping's China-the taming of the critical voices in traditional and new media, the arrests and disappearances of those who speak for the weak and disenfranchised, the systematic intimidation of those who challenge the message of 'harmony' espoused by the Chinese Communist Partyone cannot but wonder whether a display of solidarity like the one that took place during that hot summer of ten years ago would still be possible today. However, the solitary blogger's daily post is a reminder that not everything is lost, that not everybody has forgotten. In the end, as they say, no matter how hard you try, paper cannot wrap up embers. 

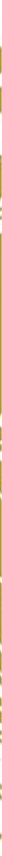
(1)
सef
-

(1)

, l... (5) (E), 1) (1) 


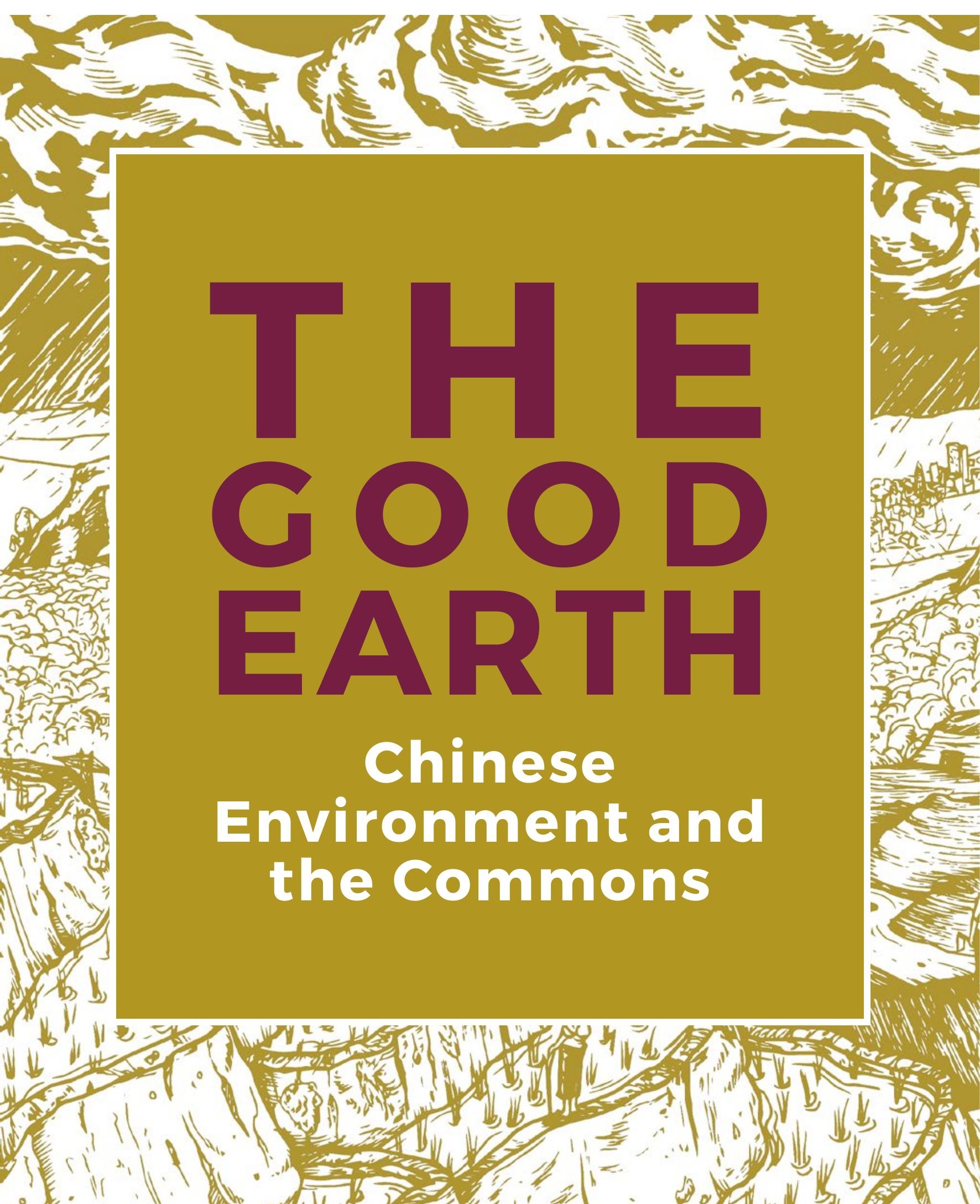




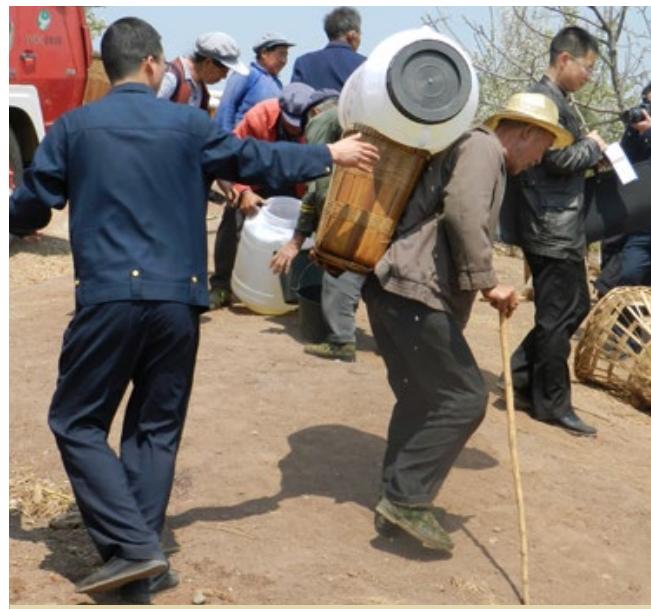

A water delivery initiative in northwest Yunnan Famers receive barrels of drinking water from the government while fresh water from local springs is impounded and diverted elsewhere. Photo: Andrea E. Pia.

\section{A Water Commons in China?}

\section{Andrea E. Pia}

The debate over China's environmental issues has given scant consideration to already existing popular alternatives to the topdown, growth-compatible governance of the country's natural resources. Forty years of Party-sanctified insistence on pursuing relentless economic development has seemingly suppressed alternative discourses in natural resource management. However, if we take closer look, we will find that at the grassroots there is no lack of alternatives. For instance, in contemporary rural China there are places where water is being managed as a commons.
As a one-time campaigner for the 2011 Italian Referendum against the privatisation of the country's domestic water services (Mattei 2013), I was excited to discover during fieldwork in Yunnan province that when briefed and asked about their views on the referendum proposals, most of my informants in the water sector were in fact sympathetic to them. They similarly hoped to protect water from marketisation and demanded the democratisation of its management.

As I write this essay, an ethnographic scene comes to mind. One day in 2012, I took part in negotiations between a village committee and a public-private enterprise regarding a water conservancy project that would have required the relocation of several of the village's households. The Committee pointed out that the proposed project mainly benefited the enterprise, which would gain access to state subsidies regardless of the efficacy of their infrastructure. The enterprise was legally required to win the Committee's assent to the project. To do so, they eventually had to accede to the local Party Secretary's request that the enterprise build a number of freeof-charge water dispensers for the newly relocated households at its own expense. Cases of political strong-arming for the sake of public access to water such as this had also been typical of Italian campaigners in the run-up to the referendum (Carrozza and Fantini 2016). But such similarities begs the question: if Chinese people involved in everyday water politics were thinking along similar lines to Italian water activists, what was pre-empting the emergence of a similar movement in China? Obviously, the two countries are characterised by divergent political traditions and conceptions of social and environmental justice (Brandtstadter and Steinmuller 2017)-for instance, a referendum is a not an option in China. 
However, in this essay I will explore whether the answer may have something to do with the thus far poorly theorised question of the commons in China.

In what follows I will argue that in contemporary rural China there are places where water is already being managed as a commons. Making fresh water a commonly held resource entails breaking with global practices of water management in three ways. First, water has to lose its status as a commodity and be re-defined as a flowing component of the environment. When water is reconceptualised as a commons, the continuous local availability of its nurturing flow gains prominence over the market-mediated relationship between its supply and demand (Helfrich and Bollier 2015). Second, from the point of view of its management, water services cease to be run for profit, return on capital invested in water infrastructure lowers to zero, and ownership is reframed as a shared obligation to universal and sustainable provision. Finally, water services are opened up to public participation with a view to preserving the life-nurturing qualities of the water flow over generations.

\section{Techno-Political Frames}

So far the debate about China's current environmental issues has given little consideration to already existing popular alternatives to the top-down, growthcompatible governance of the country's endangered natural resources. Forty years of Party-sanctified insistence on pursuing relentless economic development has seemingly muffled the few dissenting voices and suppressed alternative discourses in natural resource management-such as those concerned with stewardship, care, maintenance, or even rejuvenation of the Chinese environment (He 2015).
Instead, the language of techno-politics is holding sway. This is a mix of legal tweaks and engineering innovations-for instance, those behind the introduction of tradable water permits and huge water diversion schemes (Ray 2013; Walker 2014b)-which, by preaching the appealing fantasy of the harmonious coexistence of China's present capitalist mode of development with nature, have slowly won over many of China's most belligerent environmentalists ( $\mathrm{Ma}$ 2017). Surprisingly, the case for the coexistence of continuous growth and sustainability has arguably found a favourable, if unlikely, currency for its propagation in the political doctrine of 'Ecological Civilisation' (shengtai wenming). While proposing a re-orientation of China's current model of growth-hailed by a felicitous start and some early success stories (Geall 2015; Xinhua 2017b)-in the sanitised version currently peddled by the Chinese government, Ecological Civilisation actually seems to be working to reinforce a chauvinistic and system-preserving distrust in local people's ability to redress the imbalance between efficiency in resource use and equity in allocation. What gets de-emphasised in the institutionalisation of Ecological Civilisation is the potential offered by empowering communities to democratically take environmentally sensitive decisions for themselves (Gare 2012).

\section{Distributing the Sensible}

The dominance of the techno-politics of sustainability in China renders local people incapable of articulating and implementing alternatives. That does not mean to say that local people have no interest in developing alternative ways of dealing with environmental crises. Indeed, a good deal of empirical work has recently suggested that concrete local alternatives to business-as- 
usual are, if anything, in very high-demand, especially for those at the periphery of contemporary Chinese society. Citizens at the losing end of economic developmentincluding rural resettlers, ethnic minorities, and others-are all aware that environmental degradation is impacting them first. For instance, those who have to figure out how to fetch their clean water everyday usually seek out workable alternatives more pressingly than environmentallyblind urbanites. The analytical problem is, therefore, one of recognising the political agency of those who are elaborating viable counter-practices.

While the people directly engaged with the governance of natural resources may themselves ignore the extent to which the alternatives they put to work can be identified as sustainable or even counterparadigmatic within China's institutional architecture, the problem at stake here is one of visibility-or as Rancière would put it, one of the 'distribution of the sensible' (Rancière 2006). Rancière suggests that political fault lines are perceivable only to the groups who are sitting by them-in our case disenfranchised farmers living in water dispossessed communities-while their capacity to effectively overcome common predicaments in any political consequential way is publicly denied to them by their very proximity to such fault lines. Thus, counter-practices and counter-enunciation are rendered unintelligible to anyone, their supporters included.

Up until now, the multifarious sustainability proposals championed by the Chinese government have taken the lion's share of the public debate on sustainability in the country, so much so that the very people who are concretely engaging with political practices of responsible, equitable, and un-marketed stewardship of common resources in contemporary China are not able to call them for what they are. Even worse, they struggle to see them as being in discontinuity from the demonstrably short-term solutions ushered in by those who consider the environmental question a technical problem requiring nothing more than the tools available within the imaginative horizon of capitalism.

\section{Canal Managers of Erstwhile}

Between 2011 and 2013, I spent eighteen months working with water bureaucrats and farmers as they went about implementing changes in the provision of irrigation and drinking water in their county. During this time, the price of drinking water doubled and the two local water agencies in charge of tax collection, infrastructure upkeep, and water development were transferred to hard budget accounts. Meanwhile, state and private funds were being diverted towards nearby cities. Farmers were also asked to reinvent themselves as members of Water Users' Associations (WUAs), alien organisations handed down to villagers by Mandarin-speaking university-trained officials aimed at making the service more responsive to local needs and, most importantly, cheaper. Farmers were suddenly told to become familiar with the new norms that regulated the use, control, and exchange rights over water. They were warned that the government would hold them responsible for mismanaging the service they were now instructed to provide. During inaugural WUA meetings, the language of techno-politics was extensively used. While most of what was said would make direct reference to the science of the commons, the farmers understood that they would now have to work for free as canal managers (guanzhang).

Prior to the advent of WUAs, being a canal manager had, in fact, been something everyone in this part of Yunnan was quite familiar with. It was a democratic and 
collectively financed position to which farmers were appointed on a rotating basis, according to a broader system of rules on local water management (Pia 2016b). Farmers appointed canal managers on every single portion of a canal adjoining a field or a house. They entrusted neighbouring members of this infrastructural community with reporting any misdelivery of water nearby. If managers were found guilty of mismanagement, a democratically appointed middleman-backed by the local village committee-would identify a different manager for that portion of the canal until the next incident. A similar system of distributed responsibility and participation in monitoring existed for a network of privately-built, but collectively-used, water wells widely accessible throughout the community. In essence, people from this area of Yunnan were managing the local water supply as a common resource and were doing it effectively. This system was run as a service to the community and not for profit. Rules to punish overdrawing had also been in force at some point, but were later abandoned as state officials took charge over environmental issues.

\section{Activating Ineluctability}

What is most surprising is not that local people had extensive experience of cooperating on water management, but rather that local farmers were willing to accept the co-optation of their distributed and equitable mechanism of organised water delivery. This, at the hands of a system that promised nothing except increased levels of corruption, higher overall running costs, and dwindling state support (Pia 2016b).Indeed, the language of technopolitics is successful because it activates a particular explanatory framework that resonates among the people-that of the moral superiority of scientific management.
Farmers would assert that countryside life was bound to disappear in China and that rural dwellers had to adjust to a different lifestyle or migrate elsewhere. In their opinion, the previous system was backward and not keeping pace with more scientific forms of management represented by the WUAs. While a few younger informants held the view that locals should collectively resist the government or businesses whenever water was taken away or polluted, in general the water sector reformers had been quite successful in framing the problem of sustainability exclusively as one of science and supervision. The idea of governing water 'the old way' (laoguiju) was thereby made redundant-a survival component of an important, but now technically disposable, condition of pre-scientific Chinese water management. As mentioned above, one key idea of the notion of the commons is that of inclusive participation in the decision-making process concerning the management of natural resources. As this power seemingly fades away from north-east Yunnanese communities, so is the sense of meaningfully being part of one's community and the capacity to care for it. The Rancierian gesture I resorted to here was to acknowledge the unrecognised capacity of local Chinese people to challenge the tacit ordering and distribution of the things we have in common in counter-paradigmatic ways. As one Italian water referendum campaigner used to say during activists' assemblies: 'They want to convince us we don't care about how water gets delivered.' My ethnography shows that it is about time we start to re-convince ourselves of the contrary. 


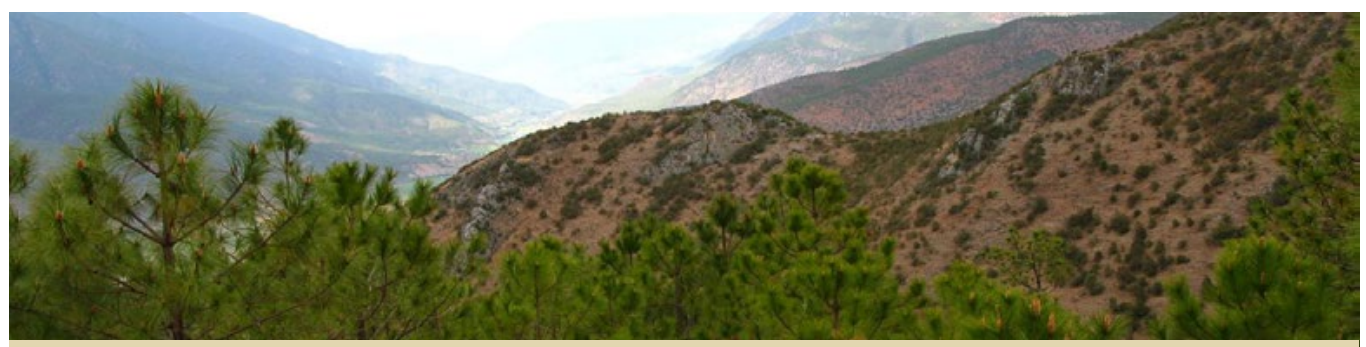

Reforestation on the Way Back to Lijiang. Photo: Vincent Liu.

\section{Amateurism and Our Common Concern for Biodiversity}

\section{Timothy McLellan}

Treating the environment as a common resource often implies not only local, but also supra-local, even global, collectives of concerned stakeholders. While engaging with local actors, these stakeholders frequently insist on the need for a 'professional' approach. Examining an international project aimed at introducing biologically diverse agroforestry in a county in southwest China, this essay describes a more 'amateur' approach adopted by one international organisation. It argues that this amateurism demonstrates that, even withinglobal professional organisations, there is an appetite for a new, more spontaneous, approach that values local knowledge and practices.

This article is based upon work supported by the National Science Foundation under Grant No. 1357194, The Cornell East Asia Program, and Cornell's Mario Einaudi Center for International Studies. To ensure the anonymity of the research subjects, pseudonyms were used for all institutional, personal, and place names
Treating the environment as a common resource often implies not only local, but also supra-local, even global collectives of concerned stakeholders. The Convention on Biological Diversity, for example, asserts that 'the conservation of biological diversity is a common concern of humankind'. An agroforestry project in Qingshan township, Yunnan province, was one such effort to establish the environment and biodiversity as a common concern for a global community of actors.

A Western cosmetics company, Metelli, sponsored the project. Launched about a decade ago, the project's goal was to introduce ecologically complex, biologically diverse agroforestry to Qingshan. According to a Metelli corporate social responsibility officer, since the company's products depend on nature for their ingredients, Metelli has a responsibility to give back to the environment. Here, Metelli sees itself as a responsible stakeholder alongside local communities, and attempts to insert itself as a collaborator in the management of Qingshan's environmental commons.

This article is based on two years' participant observation at the Institute for Farms and Forests (IFF), an international agricultural research organisation who participated in the project. Inspired by critiques of academic professionalisation, and associated explorations of the virtues of amateurism, I describe the amateur engagement that IFF attempted to bring to this project. I argue that this amateurism 
demonstrates that, even within global professional organisations like IFF, there is an appetite for what Anna Tsing calls 'creat[ing] scenes that exceed or escape professionalization.'

\section{Pursuing Amateurism}

To implement Metelli's vision for Qingshan, several organisations were recruited. First, a Western NGO with experience in agroforestry, Arboreus, and a local NGO called Shehui. Several years into the project, Metelli and Arboreus had become concerned by Shehui's lack of agri-environmental expertise. IFF was therefore recruited to the project, bringing with it its experience in agroforestry and soil management. In contrast to the other project partners, IFF's involvement was rather informal. IFF had a lucrative contract with Metelli to facilitate laboratory research on local medicinal plants with the potential for use in cosmetics. As such, when they offered assistance to Metelli's Qingshan project, IFF asked only for funds to cover travel expenses. The resulting absence of the kind of formal deliverables that ordinarily tie IFF's funding promised IFF scientists an unusual degree of latitude.

Having provisionally devised soil management practices for Qingshan, and established participatory principles according to which these ideas should be communicated, the IFF team (of which I was a member) ran several workshops in Qingshan. While IFF's enthusiasm for 'participation' embraced a central tenant of contemporary development professionalism, IFF's designs for the project were out of sync with certain contemporary trends. First, Qingshan workshops were each designed from scratch and as unique events. Workshops did not adhere to a previously established protocol, nor did IFF staff imagine their workshops to be replicable on a wider scale.
This contrasted with certain other projects where IFF employed protocols or 'toolkits' that had been designed to be transferable across time and space.

Second, IFF scientists envisioned the process of learning from Qingshan farmers and getting to know the landscape over which they sought to establish a common concern as a slow and gradual process. Workshops were organised sporadically, and in response to the project as it unfolded. Each visit was approached as a further opportunity to learn. This contrasts with certain iterations of participatory rural appraisal (PRA) delivered as rapid, one-off workshops. In such versions of PRA, Terry Rambo suggests, development professionals 'claim to understand everything important by sponsoring a three-or-four-day rapid rural appraisal exercise' (2015, 795). Here, participation is co-opted by the very forms of professional 'arrogance' Robert Chambers intended for it to address.

In the Qingshan case, far from the 'understanding [of] everything' promised by certain PRA toolkits, IFF scientists' ad hoc workshops created a degree of anxiety. Whereas transferable toolkits often imply a certainty in what should be done, the IFF team were at each stage anxious as to whether their ad hoc activities would perform as hoped: Had we really generated a space for dialogue, or were farmers simply telling us what we wanted to hear? Would the proposed soil management strategies really benefit Qingshan? In this respect, whereas scientists are often accused of adopting 'technologies of hubris', the anxieties generated by IFF's ad hoc approach suggest the seeds of what Sheila Jasanoff calls 'technologies of humility' (2013).

If contemporary research and development professionalism is characterised by replicability, scalability, transferability, rapidness, and self-confidence; I am going to describe the ad hoc, single-site, one-off, 
slow, anxiety-inducing, and often deeply personal engagement that IFF pursued as a form of amateurism.

\section{The Project Falls Apart}

A soil management plan developed at an early workshop was for winter cover crops to be planted in-between the rows of notyet-harvested primary crops. Susanna, an IFF soil scientist, had proposed this early planting strategy as a solution to the farmers' experience that cover crops did not survive Qingshan's dry winters. When it came to the appropriate time to sow cover crops, however, we discovered via Shehui's local project manager, Xuejian, that the farmers had decided to delay planting until after harvest. According to Xuejian, since the rains in Qingshan had begun very late that year, farmers expected that rains would also finish later than usual. As such, the farmers reasoned, they could afford to postpone cover crop planting until after harvest.

When this message was relayed to Susanna she was dismayed. She feared that the rains might not continue late, and having persuaded Qingshan farmers to give cover crops another try, she did not want them to fail. Susanna and her colleagues, moreover, were frustrated that Shehui had taken several weeks to inform IFF of the farmers' new approach. In this respect, IFF's attempt to situate itself within a larger collective was challenged by the fact of its exclusion from a significant decision-making process. In a sense, this exclusion denied IFF's implicit claim on Qingshan's biodiversity as an object of common concern.

IFF's response was to organise a further workshop in Qingshan. The difficulties in making this workshop happen, however, came from beyond Qingshan. IFF had initially arranged a workshop directly with a community leader in Qingshan, but Xuejian contacted IFF to cancel the workshop. Shortly thereafter, we received a communication from Arboreus explaining that all IFF activities in Qingshan must be pre-approved by both Shehui and Arboreus. The workshop did eventually go ahead, but following the workshop, wrangling continued amongst Shehui, Arboreus, and IFF. Whereas IFF scientists had anticipated and embraced the practical and ethical challenges of establishing relations with Qingshan farmers, the unexpected labour of maintaining relationships with extralocal partners emerged as an impossible headache.

Some IFF colleagues attributed the project's failure to the incompetence of their project partners. In one instance, Xuejian explained to IFF scientists that Arboreus's training in Qingshan had attempted to impress upon farmers the importance of three metre spacing between trees-a guideline, Xuejian told us, that took no account of tree species or location. For IFF scientists, this absurdly global approach to tree propagation confirmed Arboreus's ignorance. The failure of the collaboration, however, can also be attributed to an incongruity between the approaches of IFF and its project partners. As well as their incompetence, Arboreus's tree-spacing guidance showed their professionalism: it reflected their understanding of environmental sustainability as a global, scalable process.

Embracing development professionalism, Arboreus were constantly contemplating how their activities might be replicated across ever-larger scales. Indeed, this was part of the reason they wanted not only prior notification of IFF's activities, but also written reports after each visit to Qingshan. On one occasion, impressed by a soil management booklet Susanna had produced specifically for Qingshan farmers, Arboreus asked whether IFF might create a similar set of booklets for them to use globally. 
IFF, by contrast, approached the project much more narrowly: as a project in Qingshan. We were seldom distracted by the question of how to replicate or upscale activities in Qingshan. This is not to say that IFF is not ordinarily subjected to such imperatives. At a recent regional planning meeting, for example, an IFF communications officer described how the organisation must learn from marketing professionals and build a global brand for itself. Many IFF staff members were uncomfortable with such demands. Indeed, part of the Qingshan project's appeal to IFF staff was perhaps that it presented an opportunity to work outside of this global scale and the accompanying imperatives of professional research for development. In this sense, the Qingshan project promised the chance to play the amateur.

By drawing attention to IFF's amateurism I do not mean to imply that, unimpeded by their supra-local partners, IFF would inevitably have made the project a resounding success, or that amateurism escapes the contradictions and tensions inherent in efforts to make biodiversity a common concern in a world that is fundamentally unequal. Nevertheless, like China Scherz's account of a Catholic charity's refusal to adopt the logic of development donors, IFF's all too brief flirtation with what I have called amateurism shows that, even within a prominent international organisation like IFF, there are seeds of activities that 'exceed or escape "professionalization" (Tsing 2015, 285).

\section{A Victory for Professionalism}

In this Qingshan case, however, Arboreus's professionalism won through. Shortly after the shambles of IFF's negotiations to run a workshop, Arboreus commissioned an audit of the project. One outcome of the audit was for Metelli to belatedly act upon an IFF suggestion to establish experimental agroforestry plots in Qingshan. IFF responded with a detailed proposal for the plots, but some at IFF half hoped Metelli would decline to fund the proposal, and thereby give IFF an excuse to leave the project. The headache of collaboration with supra-local partners had led to a loss of faith in the project ever running smoothly. Moreover, the professional imperatives to formalise project plans and project goals, as well as to undergo audits and manage budgets, robbed the project of the amateur quality that had initially sparked IFF staff's now fading commitment to, and hope in, the project.

Transferring on a flight back to the United Kingdom after completing fieldwork, I spotted photos of farmers planting trees in Qingshan displayed at a Metelli airport concession. As an example of Metelli's corporate social responsibility, the display invited consumers to share in Metelli's concern for global biodiversity. In effect, the invitation to purchase Metelli cosmetics was also an invitation to join the collective the company had established with Qingshan farmers, and to thereby participate in the sustainable management of environmental commons. Of course, from the point of view of IFF scientists, this collective and its management of Qingshan's biodiversity had been no great success. Metelli's marketing strategy, however, may serve as a reminder that just as challenging as it can be to establish meaningful collaborations around environmental commons, constructing the façade of a global collective can be rather easy. Indeed, in an era where organisations like IFF are turning to marketing in their efforts to professionalise, we should perhaps wonder if environmental commons would be better off in the hands of amateurs. 


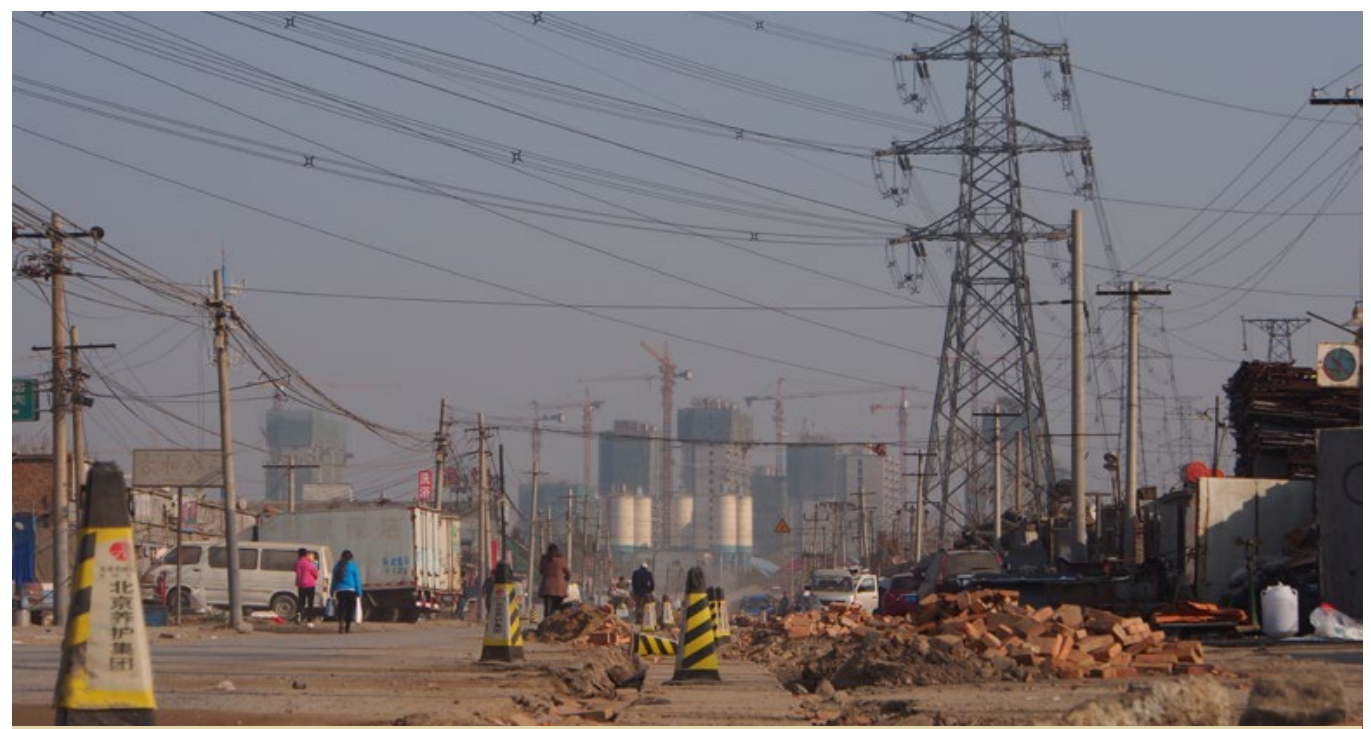

Urbanisation on the outskirts of Beijing. Dongxiaokou, late 2014. Photo: Carlo Inverardi-Ferri.

\section{Commons and the Right to the City in Contemporary China}

\section{Carlo Inverardi-Ferri}

This essay outlines the development of Dongxiaokou, an urban village on the outskirts of Beijing. Until urban redevelopment projects accelerated its demolition in recent years, this informal settlement was home to a massive population of migrant workers, who had made this place their base for entering the capital's labour market. The story of Dongxiaokou provides interesting insights into the process of commodification of land in contemporary China. In particular, it highlights the tension between land used as a common resource by migrants, and land utilised as a way to produce economic profits for real estate development.
This short essay tells the story of Dongxiaokou, an urban village in the northern outskirt of Beijing, infamously known in the press as the 'waste village' (feipincun). Until urban redevelopment projects accelerated its demolition in recent years, this informal settlement had been one of the biggest in the metropolis. Situated between the fifth and sixth ring road, around ten kilometres from the city centre, it hosted a massive population of migrant workers, who had made this place their home and used it as a base to enter the Chinese capital's labour market.

The story of Dongxiaokou provides interesting insights into the process of commodification of land in contemporary China. The article engages with this issue and highlights, in particular, the tension between land used as a common resource by migrant workers and land utilised as a way to produce economic profits for real estate development. There are at least two good reasons why this story is worth tellingone related to the status of land use rights in China; the other to the nexus between labour and migration in the country. This 
account of Dongxiaokou reasserts the centrality of an old question (Harvey 2008): in a geography where capitalism brings about a growing commodification of space, who owns the right to the city? In other words, if we consider the urban space as a common resource, who has the right to use it and under what conditions?

\section{Land Rights and Migrant Labour}

Surprisingly enough, while in the last decades China has undergone a number of subsequent shifts towards economic liberalism, land somehow remains a conundrum for the country's 'socialist market economy'. While land has certainly been subjected to the effect of the marketisation of the economy, it has also remained strictly tied to the Party-state. Today there are two main types of land property rights in China. While urban land is formally owned by the state, rural residents exercise collective ownership in the countryside. In theory, rigid regulations control the use of this resource; in practice, however, ambiguity in the legislation has resulted in an empowered Party-state, which has ended up holding sway on land-related decisions in both cities and countryside (Lin 2015).

A common practice in many rural villages involves the development of collectivelyowned land into urban and commercial functions as a way for local administrations to create new streams of revenue. While some localities have been more successful than others, this phenomenon has appeared almost everywhere in the country. In particular, these practices have multiplied in border areas between the city and the countryside, where many rural villages have been completely transformed in their geographies. This rural-urban friction has also led to another phenomenon driven by the increasing marketisation of the economy and the process of commodification of land. The sprawling of metropolises into suburban areas has resulted in the recurrent inclusion of rural villages into urban districts. Rural land is thus subjected to a two-fold process of commodification. First, it is informally developed into urban and commercial functions as a means to make a profit for rural areas. Second, these hybrid spaces are again subsumed by urban redevelopments.

The story of Dongxiaokou, a small rural village that in a few years became one of the largest informal settlements in the Chinese capital, is particularly revealing of both dynamics. In the early 2000s, the village rented most of its land to migrant workers coming from outside the municipality of Beijing. Its proximity to the city centre made it a convenient place to settle down and find work opportunities in the metropolis. When the first migrants arrived, local cadres welcomed them and accommodated the newcomers in uncultivated fields, which were rented out as a way to drive new revenues into the village.

Wealthy migrants rented big plots of land that they then divided and sublet to less well-off migrants, who in turn established their dwellings and economic activities in Dongxiaokou. Very quickly the village population grew from little less than two thousand people into an agglomeration, according to some sources, of almost thirty thousand inhabitants (Ye 2015). Interestingly, Dongxiaokou quickly became a local hub for waste recycling activities growing in scale and scope. As one of my informants claimed in a personal communication, in few years Dongxiaokou was transformed into 'one of the biggest scrap distribution centres (feipin jisandi) in the entire country.'

A complex network of buyers and suppliers for all sort of waste materials developed in the village. During the day, local recyclers roamed the wealthy neighbourhoods of 
Beijing in search of valuable products, such as used mobile phones or old compressors. In the evenings, they came back to Dongxiaokou to resell their products to middlemen who, in turn, resold them to manufacturing companies in nearby regions. A large number of complementary businesses, such as mechanic workshops, logistics firms, groceries, and restaurants, also quickly flourished in the village.

Hundreds of family-owned enterprises dominated the landscape. They all looked more or less the same. Behind a metallic gate was a rectangular courtyard where old newspapers, waste wood, plastic bottles, used electronics, or anything else with a commercial value was stored. In one of the corners of the yard there was always a small building, usually composed of two rooms, where an entire family lived. Sometimes a dog was chained to one of the walls to guard the yard.

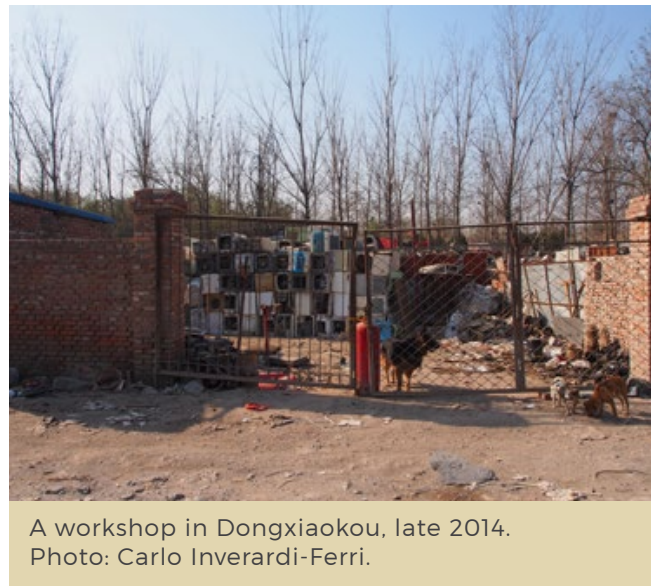

\section{A New Generation of Petty Capitalists}

Interestingly, while academia and the media have paid much attention to different generations of migrant workers in their role as wage-labourers (Lee 2016), the rise of Dongxiaokou paints a less familiar picture.
It tells the story of small family-owned firms and self-employed entrepreneurs, or in other words, petty capitalists. It is a story of what some define as the informal economy: a heterogeneous sector that crosses many different industries, and employs a large proportion of the population in contemporary China. It is not my goal to romanticise this phenomenon, which raises serious questions of occupational health and safety, as well as issues of local citizenship and environmental justice, but rather to underline what I believe to be one of its most peculiar characteristics. Migrants in Dongxiaokou-at least a good portion of them-enjoyed a relatively high level of freedom and mutual support, being part of a local society that conceived of their resources-labour and land-as means of common subsistence.

Dongxiaokou was not an isolated case. A report by the United Nations published in 2013 estimated that the informal recycling sector in China comprised twenty million people, and that it was organised in a myriad of informal settlements scattered all over the country (Wang et al. 2013). While numbers certainly cannot give an accurate account of the great variety of businesses that this industry creates, they are nevertheless useful to provide a general idea of the magnitude and impact that these activities had, and continue to have, on Chinese metropolises. This involves the creation of employment opportunities on the one side, and the production of physical landscapes on the other side.

Dongxiaokou was not a new phenomenon either. In their work on the 'Henan village' (1999), Jean-Philippe Béja and colleagues documented the emergence of these urban and economic spaces as far back as the 1990s. The authors analysed a settlement not too far from Peking University-now long demolished-in many ways similar to Dongxiaokou. They did so through the notion of desakota (desa meaning 'village' and kota 
'urban' in Bahasa), a concept that was first employed in studies on the urbanisation of Southeast Asian countries (McGee and Wang 1992). In Indonesia, the metropolitan sprawl had produced a peculiar combination of rural and non-rural activities, where areas dedicated to the production of rice were mixed with the urban landscape. Drawing a parallel with the Indonesian context, the authors described the Henan village as a peculiar Chinese desakota.

The fate of Dongxiaokou was decided in the 2000s (Tao et al. 2014). This space on the urban periphery, which had been transformed through the agency of a group of migrant workers, and which provided a fundamental service to the city-waste recycling (Inverardi-Ferri 2017)-did not resonate with the conceptions of modernity that official planners held for Beijing. When urbanisation reached the borders of Dongxiaokou, space had to be made for the new real estate projects. As a result, demolitions of the 'waste village' of Dongxiaokou accelerated in 2015. The place that previously buzzed with economic activity was again geographically transformed. Workshops that were filled with all sort of valuable products became empty fields, as their occupants had to relocate to other parts of the city. Roads were silent, except for the sounds coming from the new infrastructural works planned by the municipality. Having lost their usual clientele, shops closed down, and most dwellings were levelled.

\section{A Social Community}

As the story of Dongxiaokou suggests, two different levels of urbanisation exist in contemporary China (McGee et al. 2008). The first is a process mediated by the state that operates inside the administrative boundaries of the city; the second is an unofficial one, which goes beyond these boundaries and occurs at the margins of the metropolis or in the countryside. Here, migrant workers, attracted by the possibility of improving their material lives, enter Chinese metropolises and create particular urban economic landscapes, while suburban villages benefit economically from their presence. Yet, official planning recurrently subsumes these spaces.

These different modes of urbanisation also mirror contrasting ways of creating and living in the city. Enclaves of informalityand the specific use of land operated in urban villages-reflect the way lessprivileged groups make a livelihood, rather than a strategy to produce profits from land development. While they come from poorer rural regions and moving into metropolises, friendship and kinship networks support the adventures of these migrants who lack any basic formal right to the city. As a dweller in Dongxiaokou clearly pointed out, the social community that inhabited Dongxiakou provided important support to migrants. In his words: 'Being here is like being back home... Like this, it is easier to do our business.'

As this quote suggests, urban villages are microcosms of people and relations that represents a social community and not only economic outcomes. Here the physical and social dimensions of land are strictly intertwined with the everyday livelihoods of the people that inhabit these spaces. Their redevelopment is thus a process that brings about a destruction of these communal spaces, highlighting once more the need to ask an old-but urgent-question: who has the right to the city in contemporary China? 


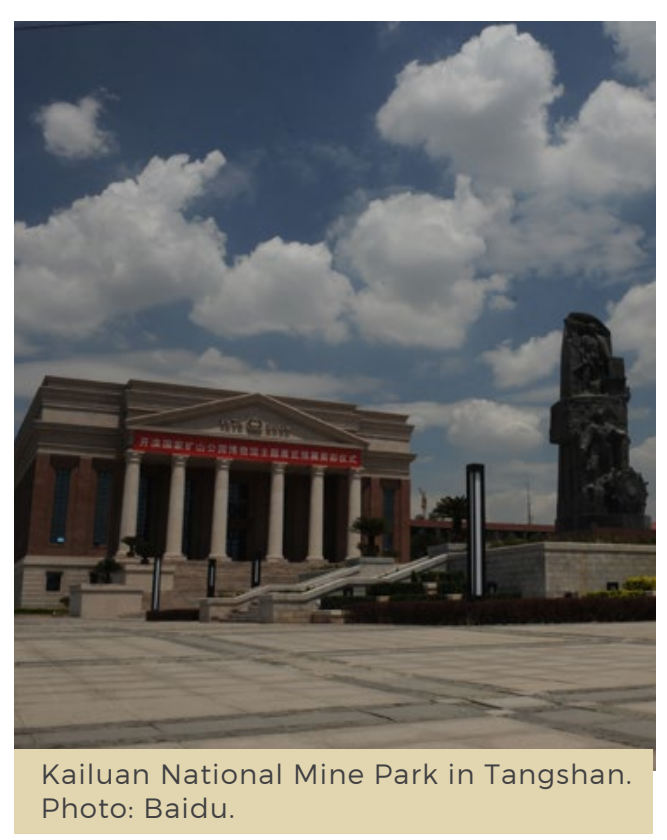

\section{Burning Coal in Tangshan Energy Resources as Commons}

\section{Edwin Schmitt}

The extraction and use of energy resources to drive modernisation has been one of the key concerns of the Chinese Communist Party. By tracing the history of coal mining in China, this essay argues that the physical characteristics of coal as a common pool resource have shaped the ways in which coal has been harvested and used, as well as the political and institutional structures that have developed around its governance.
While it is not always well recognised, energy reserves are by far the most abundant and yet most conflict-ridden common resource. In this essay, I will look at the common pool of energy resources in China, specifically coal mining and coal-fired power plants. Perhaps the most famous description of the commons comes from Garrett Hardin's deceptively simple rendition (1968): in order to prevent the ruin of common resources, society requires a set of rules for harvesting those resources so that they can be put to use. Originally the debate was about whether the most optimal rules could be found through a free market or a planned economy, the latter of which is the direction that China took. Elinor Ostrom provided a third insight into the debate, arguing that the form these rules could take was not that important as long as they were embedded into the everyday practices of a society (Ostrom et al. 1999).

Although he does not couch his argument in terms of the commons, Timothy Mitchell (2009) has recently argued that the physical characteristics of an energy resource has a strong relationship with the way these rules might develop and become socially embedded. According to Mitchell, democratic politics initially became entrenched in Europe during the Industrial Revolution as a result of the need for coal miners to collaborate together while deep underground to safely remove this energy resource from the earth. These strong collaborative relationships became essential when coal miners, as well as those responsible for transporting the coal from mine to factory, went on strike. The dense physical characteristics of coal allowed striking workers to ensure that the flow of energy, and therefore the flow of economic development, would grind to a standstill. This collaborative nature that emerged in the mines was a natural pairing with 
democratic politics when workers began to unionise and demand better conditions and pay from the capitalist owners of the mines.

\section{The Early Democracy of Chinese Miners: Anyuan vs. Kaiping}

Mitchell's history of coal begs the question: why did similar democratic principles not emerge among coal miners in China? In some ways they did, at first. One of the most famous examples comes from the Anyuan Mines, Jiangxi province during the 1920s where the Chinese Communist Party (CCP) planted the seeds of the Communist Revolution (Perry 2012). It was the collaborative nature of the miners that allowed the Party to develop Anyuan into a kind of 'worker's university' for disseminating strategies for unionising and calling worker strikes around China. Many of the principles practiced at Anyuan were rooted in democratic principles of equality while, of course, also being embedded within a Marxist-Leninist ideological call for class struggle. After attacks by the Kuomintang, the workers were forced to abandon the mine but ended up forming the First Red Army of China. As we will see, this militarisation of the workers had consequences for why China's coal miners eventually organised in a manner that does not fit Mitchell's narrative.

While the miners in Anyuan were initially democratic, workers at the Kaiping Mines in Tangshan, located in Hebei province, were suppressed by a capitalist and colonialist system of exploitation (Carlson 1971). Most of China's early industrial labour force was recruited from rural populations far from industrial centres. It was up to a group of labour contractors (batou) to bring workers and owners together, but this created an effective barrier that often prevented the British owners of the mine from ever hearing the needs of their workforce. A strict hierarchy at Kaiping ensured that the rules and decisions made for governing the mining of coal received little or no input from those labouring to remove the energy source from the earth (Wang 1947).

In late 1948, Tangshan was 'liberated' from the rule of the Kuomintang by an elite unit of the People's Liberation Army (PLA). As a first order of business, two high-ranking officers, Li Chenglong and Yan Dakai, respectively took control of the Tangshan Electric Plant and the Kailuan Coal Mine (the new name for the Kaiping mines). At that stage, it was imperative for the PLA to quickly revive the productive forces that would ensure a stable supply of weaponry to the military. Tangshan was not only a centre of energy production, but it also produced military vehicles needed to keep the PLA mobile as the CCP cemented its power across China. Since there were no CCP members at the power plant, Li Chenglong spent the first two years focussed on indoctrinating the plant workers into a socialist mode of production. While workers were considered equal 'owners' of the plant, Li installed a new hierarchy for organising decision-making, by establishing worker's brigades that had to answer to their brigade leaders, who in turn had to answer to the plant leader. This institutional hierarchy, mimicked that found within the PLA.

Moreover, scientific and engineering brigades were established, so that educated elites were integrated into the decisionmaking process of the plant. Regarding energy production, the plant leader took the input of scientists and engineers quite seriously. While the plant leader oversaw day-to-day decision-making, the amount of energy produced and supplied to the electrical grid was a decision made by the Tangshan Electrical Bureau in consultation with the goals established by the Ministry of Water Conservancy and Electric Power of 


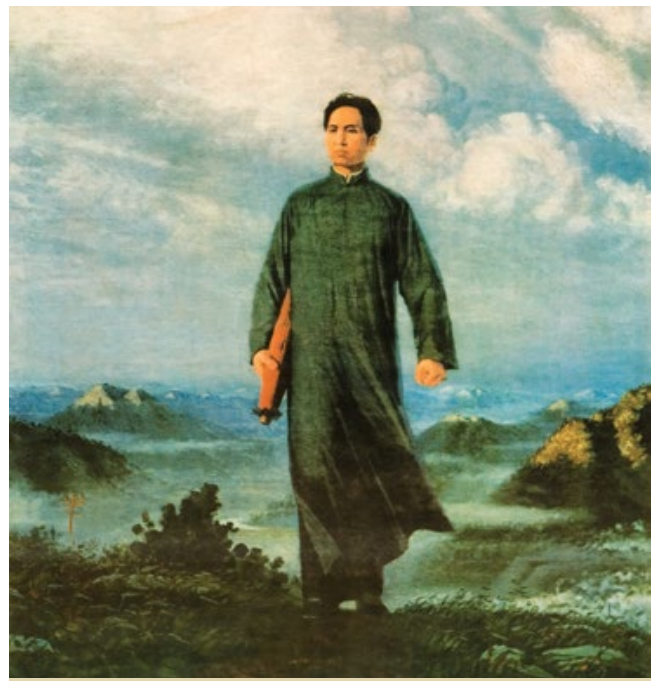

Chairman Mao goes to Anyuan.

Liu Chunhua (1968).

Hebei province and the Central Government. While this was certainly a new hierarchy, the fact that decisions on these matters were being made far away from the plant was nothing new to the workers. Similar processes were taking place at the Kailuan mine as well.

\section{The Rise of Chinese Unions}

One major difference with the hierarchy found in the older batou system was the establishment of the worker's unions. Although it was a country-wide union in name, the official All-China Federation of Trade Unions (ACFTU), was hardly a monolithic entity across China (Franceschini 2015). At the grassroots level, both the Kailuan Coal Mines and Tangshan Electric Plant established unions that represented the workers of their respective facilities. These unions allowed the voice of the workers to be heard within the Party and could be considered an outgrowth of the ideas that developed during the Party's time at Anyuan. Throughout the first thirty years of the People's Republic of China (PRC), the unions created a certain level of antagonism that required the military hierarchy described above to cooperate with the workers through their union leaders. Moreover, the transmission of Party ideology was dependent on the unions and in some cases this would result in situations beyond the control of the plant leader. For instance, during the second Anti-Rightist Campaign of 1959, the workers forced Plant Leader Li Bin to resign and heavily criticised him for his supposed rightist positions regarding electricity production. It was not until 1962 that he was forgiven, eventually becoming the plant leader for the duration of the Cultural Revolution. However, there were also times throughout the Great Leap Forward (1958-1962) and Cultural Revolution (1966-1969) when ideological shifts provided the plant leader with exceptional power and forced the workers to commit to dangerous production quotas leading to multiple accidents.

In other words, while a new hierarchy was put into place that still provided a degree of separation between the workers and decisions for harvesting and utilising energy resources, there was always a struggle between a group of decision-making experts and the workers. Perhaps the potential for a more democratic power structure did exist in early PRC history. However, we should also keep in mind that the workers' unions were isolated within their work unit. The union at Kailuan Coal Mine was strictly focussed on providing a voice for the miners and had no control over where the coal mined from Kailuan would end up. The only real connection between the Kailuan Coal Mine and the Tangshan Electric Plant unions would be when the chairperson of the union or a few worker representatives might meet at the Hebei Provincial Worker's Union Annual Conference. 
Multiple unions never collaborated, which is why the idea of a sector-wide strike preventing the flow of energy resources was unthinkable. In some ways, we might even argue that the ability of the state to ensure the flow of energy from the common pool of resources into the economy was at least as effective in this socialist military hierarchy as it ever was within the capitalist economies of Europe. Perhaps we could say that the institutionalisation of a military hierarchy for organising energy resource management that included the ability of the union to provide workers with a voice was somewhat similar to the nested institutions described by Ostrom (Ostrom et al. 1999).

\section{A Model for Energy Management}

Over the years, Tangshan's energy production was presented as an institutional model to the rest of the country, not unlike the more (in)famous Daqing Oil Fields (Taylor 2014, 70-87). Books were distributed to coal-fired power plants around the country with titles like 'The Situation of Tangshan Electric Plant Cadres Participating in Labour'. Both the Tangshan Electric Plant and the Kailuan Coal Mine regularly graced the pages of the People's Daily, with the latter being praised for its success at implementing cutting-edge technology in removing coal from the earth. More recently, the messages have begun to shift after a plan to expand the plant was accused of violating environmental policies in 2007. Today, both the Kailuan Mine and the Tangshan Electric Plant have been shut down and turned into parks, similar to those discussed by Maris Gillette in her contribution to this volume. Just a year ago, the People's Daily even published a detailed article about the successful remediation process taking place at Kailuan Coal Mine (Xu and Li 2016). Even in 'death', the mine and the power plant are being used as examples to follow as China enters the new historical phase of 'Ecological Civilisation' (shengtai wenming).

Naturally, the top-down nature of Ecological Civilisation that ensured the decision to close the plant and mine had little to do with what the workers themselves wanted. What is ironic about this story is that the top-down hierarchical political structure from which the Ecological Civilisation ideology emerged originated with the need to ensure that the Chinese military had access to highly polluting energy resources, such as coal. Regarding the commons, we can see that a top-down method can be used to prevent access to common energy resources just as it can organise the harvest of them. My focus here has not been on the effectiveness of this hierarchical structure to manage those resources over the long term-others have already argued that it did a very poor job (Smil 2003). Instead, I have been trying to show how a certain kind of social structure and political decision-making emerged from the hierarchical rules for governing common-pool energy resources in China. While some aspects of democratic decisionmaking did find their way to China's coal fields, the bonds between coal miners that Mitchell described in the European context were prevented from developing into a true political force because of the institutional structure of the CCP. In other words, the material aspects of the environment are not ineffectual when it comes to the rules we devise for governing the commons, but nor do they solely determine the structure of those rules or the political power needed to enforce them. 


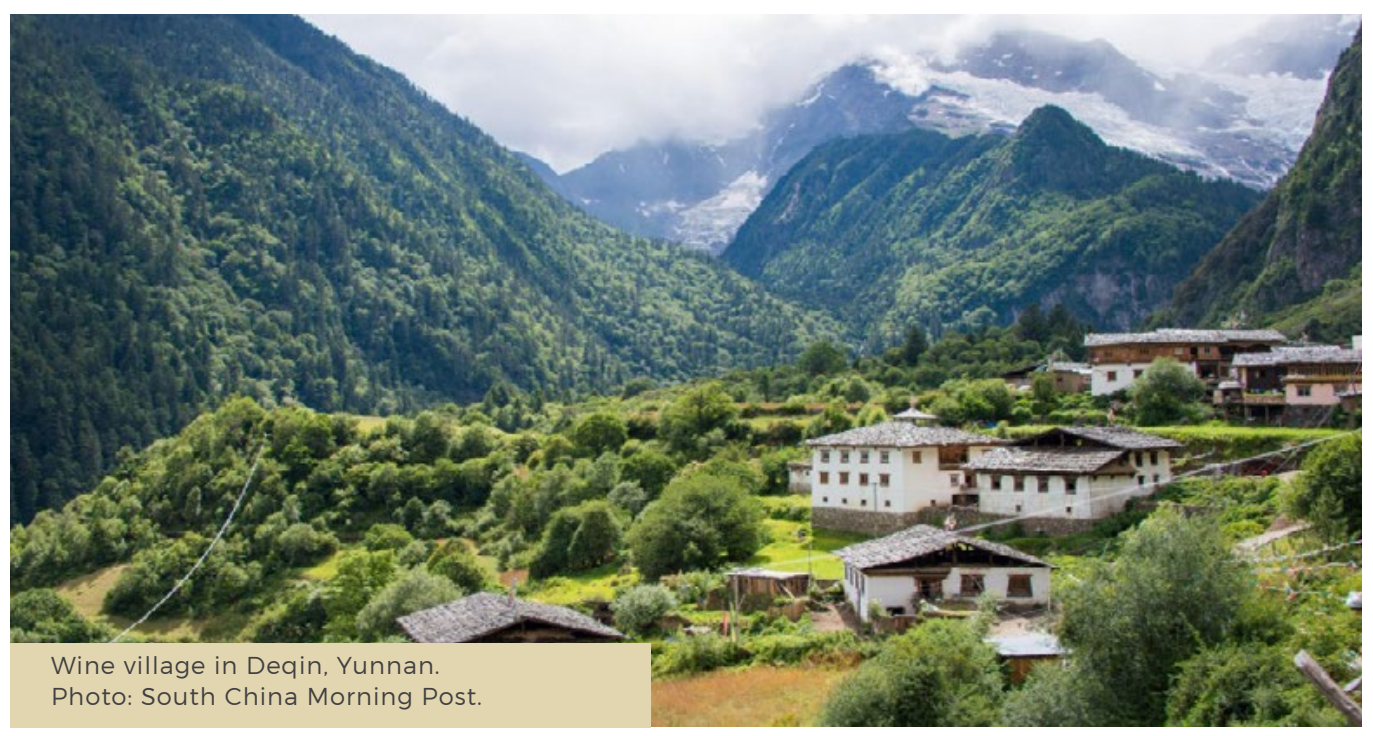

\section{Protecting}

Sacred Commons

Balancing Commodity Viticulture Economies with Ecological Health in Shangri-La

\section{Brendan A. Galipeau}

This essay explores a particular kind of local viticulture in Tibetan communities in northwest Yunnan province. While mainstream wineries emphasise modernity at any cost without much concern for the environment, the rural Tibetan grape growers examined in this article pursue an ecologically-friendly agenda meant to protect 'common' sacred landscapes. Reasons for this choice include observations of chemical degradation of the land, Buddhist ethics, and new conceptions of how ethnic representation can be exemplified by more ecologicallyfriendly forms of commodity production.
This essay explores a particular kind of local viticulture in Tibetan communities in China, which is different from mainstream wine industries within the larger Shangri-La area in northwest Yunnan province. While mainstream wineries are based on historical recreations of past missionary work and regional identities, and adopt narratives that emphasise modernity at any cost without much concern for the environment, the rural Tibetan grape growers whom I examine in this article pursue an ecologically friendly agenda meant to protect 'common' sacred landscapes. Reasons for this choice include observations of chemical degradation of the land, Buddhist ethics, and new conceptions of how ethnic representation can be exemplified by more ecologically friendly forms of commodity production. Recognition of these problems is meant to create what some villagers call a 'real Shangri-La or Shambala', that is a place of divine serenity in Tibetan Buddhism.

While government incentives aimed at supporting an emerging wine industry in Shangri-La through the promotion of new forms of agriculture and commodity schemes for growing grapes have tended 
to overlook ecological health and sustainability, awareness of such issues can be found among villagers. In some cases, these new state-based schemes are altered and challenged at the grassroots to promote ecologically sound practices and healthy living meant to protect common landscapes and resources. In Deqin county, the area where I carried out my research, some individuals interested in sustainability and ecological health further adapted viticulture and wine to indigenous cosmologies to protect common sacred lands, which they view as belonging to everyone and worthy of preservation.

Though wine from Deqin county has been marketed as 'natural', 'green', and 'ecological', the emergence of this industry has actually led to widespread use of agricultural chemicals introduced by wine companies and government officials, the effects of which are not lost on local communities. To understand how villagers perceive these changes, in what follows I will analyse how they have developed their own understandings of concepts such as 'organic' and 'ecological', and how these have been influenced by their Buddhist beliefs and their interest in preserving common sacred space.

I will tell this story through the eyes of Ani Dom, one individual in Deqin county who has become recognised locally and even nationally for his environmental and community work. Given both its local and transnational environmental and religious significance as the home of Khawa Karpo, one of the most sacred mountains in Tibetan Buddhism, Deqin has produced many local environmental activists interested in preserving local cultures and ecosystems. Among them, Ani Dom from Bu Village, the site of a major winery, has dedicated particular attention to viticulture. Over my two years in the field between 2014 and 2016, I visited him and lived in his village on multiple occasions.

\section{Of Sacred Mountains, Buddhism, and Chemicals}

I first met Ani Dom in 2014, shortly after arriving in Bu village. I planned to remain in the village for an extended period of time as it was the site of a large winery and a base for the production of sweet ice wine. On the day of my arrival, after my field assistant and I had made ourselves comfortable in a village home and were chatting with our host there, Ani Dom, an extremely talkative elderly man in a wide-brim hat with a beautiful stand of Tibetan prayer beads (mala) in his hand, appeared and explained that he had heard that a foreign visitor had arrived in the village. At that time and during many subsequent visits, I would listen to him talk about the region, the sacred mountain Khawa Karpo, Buddhism, the forest, his previous life as a hunter, and the horrible pollution that was occurring due to the chemicals used in viticulture.

In my days in Bu Village, Ani Dom spent much time telling me about local Buddhist practices and the cosmologies surrounding Khawa Karpo, which is the name of both the mountain and the god after which the place is named. As a Buddhist with a deep reverence for life, the mountain, and the local environment and culture, Ani Dom regularly shared his strong feelings about viticulture and what he perceived as excessive agricultural pollution that was killing the mountain, its spirit, and the surrounding sacred landscape. However, Ani had not always been a Buddhist: it took a near-death and highly spiritual experience to turn him into a believer. Before 1986, he was known throughout Deqin as a great hunter, perhaps the region's most famous according to his daughter Zhouma. That year, during a twenty-five-day sleepless trance brought on by a heart attack, he dreamed that the 
spirits of all the animals that he had killed had come back to exact revenge on him. In that vision, the god Khawa Karpo came to his rescue, and he then decided to devote the rest of his life to the preservation of the area. The god told him to throw his hunting dog in the river-which he did-and he also turned in his gun to the police.

Today Ani Dom's life is quite different, a matter of unending concern for his own family members and many other villagers in $\mathrm{Bu}$, including the village leaders, who find him a nuisance for interfering in their economic activities in the wine industry. As the village chief explained to me, he really does not get along with Ani Dom due to his resistance against wine companies and their chemicals. As leader of the community, the chief is primarily concerned with income and livelihood, so he does not see anything wrong with the current practices of the wine industry.

\section{A Mini-Environmental Movement in the Making}

Today Ani Dom devotes all of his time to working with both international and domestic NGOs to preserve Khawa Karpo and the village environment. He is perhaps best known for his work protecting a sacred old juniper grove in the village, where he has also built a small temple dedicated to the god Khawa Karpo. He was able to do this mostly thanks to funding that he personally collected through donations from NGOs and Buddhist monasteries, but the village as a community also contributed a significant amount to the enterprise. Much of Ani Dom's daily routine involves morning and evening walks to the temple to pray and perform circumbulations around it. These were the times when I would typically join him to discuss his ideas about Buddhist philosophy, conservation, and the changes brought to Deqin by viticulture and other forms of 'modernity'. He had many stories about his work with various environmental and cultural NGOs and his Buddhist teachings, and every day he had something new to share.

During my very first discussion with Ani Dom, he talked extensively about his various projects. He had recently set up a seniors' association to protect both the environment and the grape plantations-the Khawa Karpo Traditional Knowledge and Ecological Conservation Association. One of the goals of the group was to teach villagers to plant grapes more organically and sustainably. A Hong Kong NGO sent an expert to help Ani Dom set up the organisation and provided some training on sustainable methods to grow grapes. As Ani Dom explained to me, the excessive use of pesticides for the grapes is very bad for walnuts and other fruit trees, and the soil has progressively degraded for many years. This is the reason why he is advocating for organic wine, against the wishes of his fellow villagers. In his own words:

Pesticides are harmful for the air, earth, soil, water, and all other forms of life beyond just humans. To care about these things is what traditional Buddhist philosophies teach us; all life is sacred. Before we planted grapes, our fruit and walnut trees were much healthier and now people even get skin diseases because they don't know how to properly use the pesticides.

When I asked him what he thought about Shangri-La Wine and other local wines that were promoted and marketed as natural and as part of the Tibetan culture, he replied:

Grapes and wine are not part of the traditional Tibetan culture. This culture has been lost to the chemicals and waste 
that come with grapes. Grapes and wine are from foreigners. The grape production here in Bu village is low, but our quality is good. Buddhism promotes no-killing, so we are working to pilot grapes with no pesticides for people to enjoy.

As for the future of the link between grapes and Tibetan identity in Deqin, he said: 'If the usage of pesticides continues, things will be bad and the soil will be destroyed. I don't think the grape industry is promising for Deqin's future.'

Ani Dom's story is illustrative of a minienvironmental movement that grapes and viticulture have contributed to in Deqin. Some local people fear that most villagers in the region have fallen out of touch with Buddhism and local ecology in their pursuit of economic prosperity through chemicallyintensified grape production. Motivated by this overall concern for ecological health and Buddhist ethics, Ani Dom and a few others like him have launched their campaign against agrichemical use in viniculture. Indeed, in recent years they have worked quite actively with the Hong Kong NGO mentioned above to organise special training sessions on organic methods for grape vine care and pest management. To its credit, the NGO in its work with Ani Dom has done extensive research, even bringing experts familiar with organic methods used in Bordeaux to teach to villagers.

\section{Appeasing the Wrath of the Gods}

Ani Dom regularly portends that the pollution coming from viticulture makes the god Khawa Karpo very unhappy. Evidence of his wrath includes the retreat of the Minyong Glacier, the mountain's largest. While photo documentation shows that the glacier has been retreating for over eighty years, the rate of retreat continues to increase, which for Ani Dom is certain proof that the god is being harmed by both pollution and lack of devotion. Another example given by villagers of the dramatic consequences of failing to appease the god is a doomed attempt by Chinese and Japanese climbers to reach the summit of the mountain in 1991. Back then, an avalanche killed the entire expedition, a tragedy which was interpreted by local villagers as the response of the god Khawa Karpo to people trying to conquer his sacred domain.

Today, the quality of life and standard of living in Deqin are heavily driven by economic gains, more specifically by success in producing grapes. Major shifts have also taken place in the cultivation of crops such as wheat and barley, traditionally grown for subsistence and for religious and cultural practices. These are now being abandoned in exchange for more lucrative agricultural products. What is quite clear throughout Deqin, though, is that engagement with outside markets through agriculture and forest products is coming to redefine local perceptions of, and connections to, the Khawa Karpo landscape. In this context, the practices of Ani Dom and a few other villagers represent a form of resistance to these changes, an attempt to maintain a balance with Khawa Karpo and its spirit world to protect these sacred commons. 


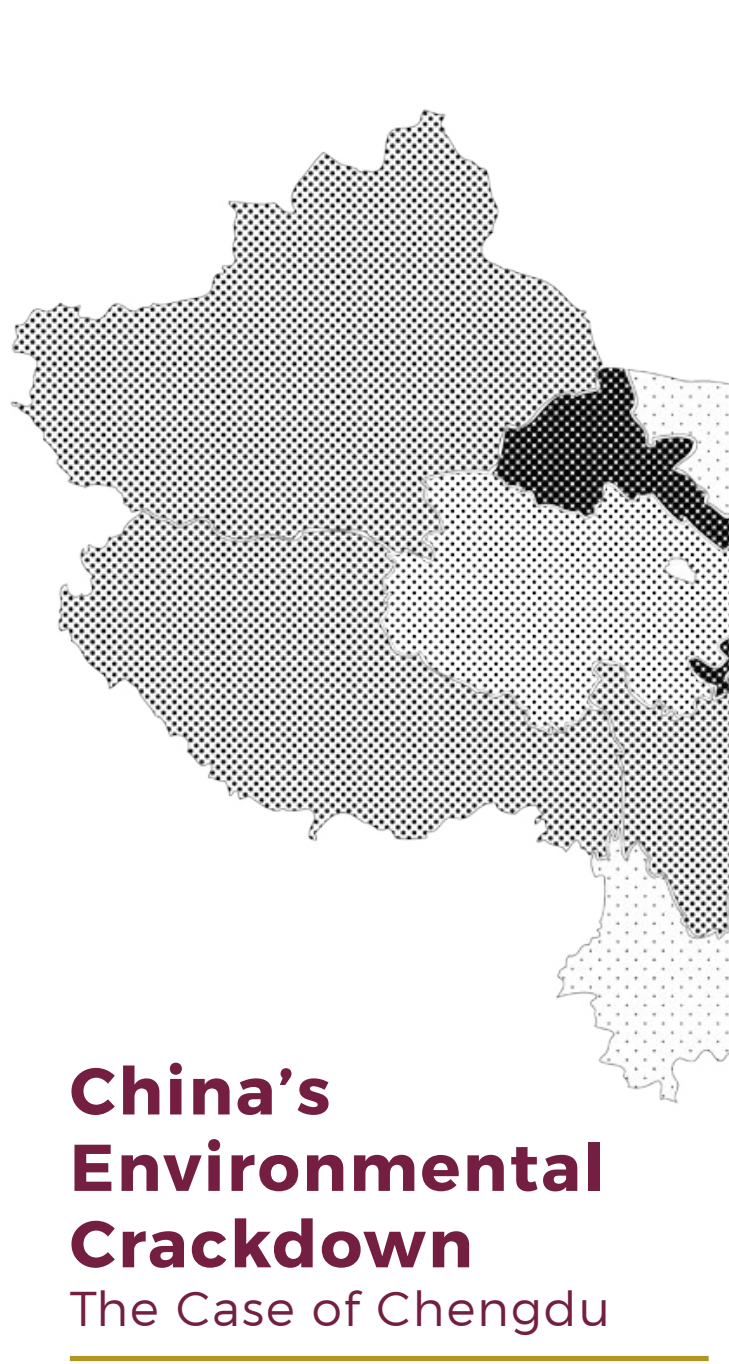

Daniel Fuchs

Edwin Schmitt

The recent Party Congress has seen an outpouring of support for strengthening environmental protections. This has come amid an intensified environmental crackdown that has seen surprise inspections of mostly smaller and older factories across the country. While these activities have received some attention in the Chinese media, at present very few reports can be found in English. To fill this gap, this essay explores the implications of the campaign for workers and business in Chengdu.

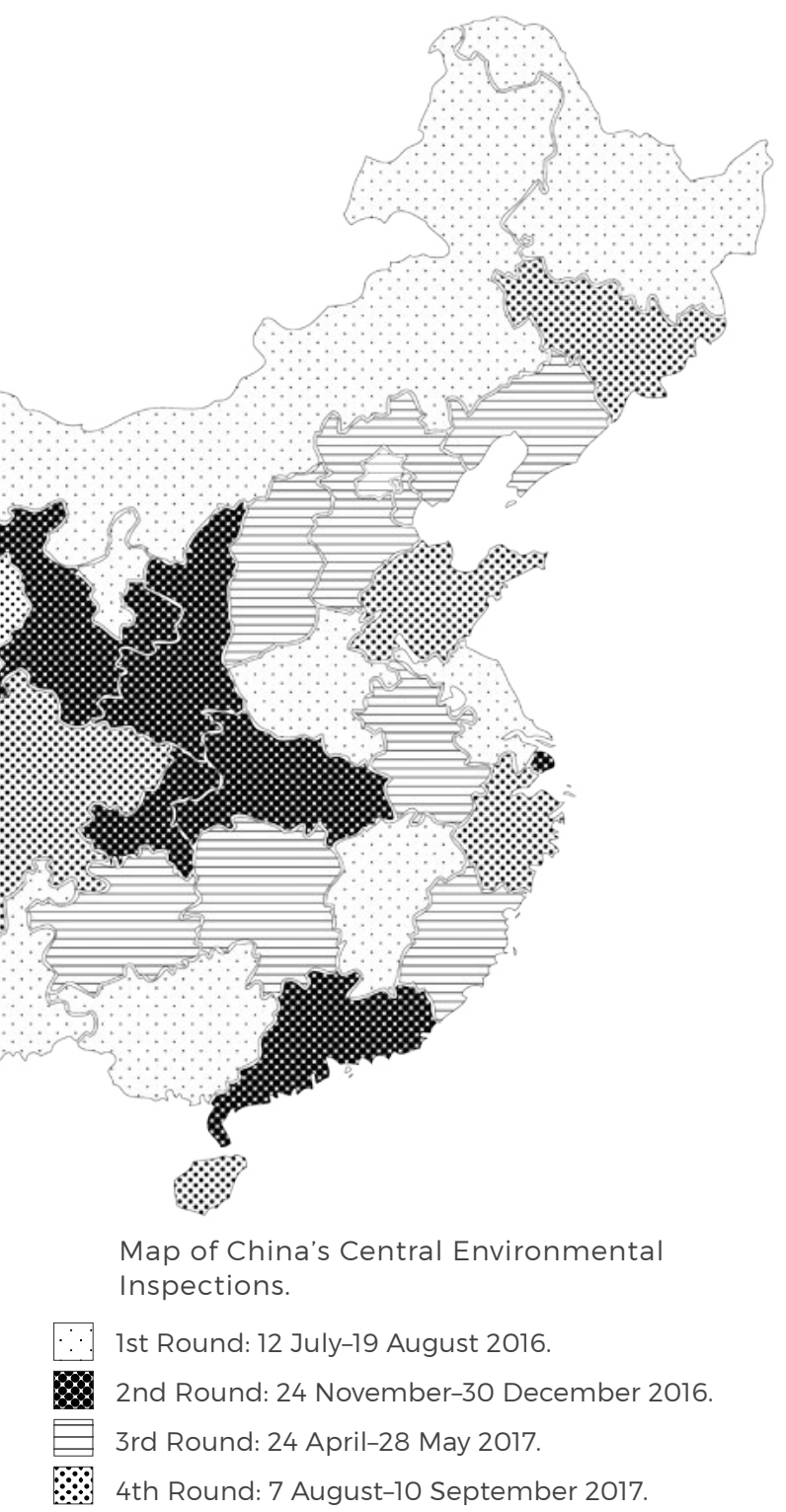

The Nineteenth Congress of the Chinese Communist Party (CCP) has seen an outpouring of support for strengthening environmental protections-a theme which was central to Xi Jinping's opening speech (Huangping Aihaozhe Wang 2017). This event comes amid an intensified 
environmental crackdown across the country. Beginning in July, drawing on the vivid metaphor of 'cutting with a single knife' (yi dao qie), the Ministry of Environmental Protection (MEP) began a surprise round of environmental inspections of factories in the Jing-Jin-Ji region, the area that encompasses Beijing, Tianjin, and Hebei province. The focus was primarily on smaller and older factories, which are recurring violators of environmental regulations. These inspections quickly expanded to all the provinces, with the MEP publishing notices in the People's Daily explaining that this protracted period of strict observation will become the 'new normal' (Liu 2017). While these activities have received some attention in the Chinese media, at present very few reports can be found in English (Schmitz 2017). In this essay we focus on the implications of this latest campaign in Chengdu. However, it is clear that this is a nationwide shift in policy implementation with implications for all of Chinese society.

\section{A Play in Four Acts}

While the past three months have seen the implementation of stricter controls, a four-stage series of routine environmental investigations began in July 2016 (Gan 2017). The real crackdown began during the third-stage, with an especially damning report of Tianjin officials on 29 July 2017 (Zhuang 2017). The critique of the typically powerful Tianjin officials resulted in an unprecedented number of follow-up environmental inspections orchestrated by local Environmental Protection Bureaus across the country. As a consequence, an increased number of factory closures occurred in provinces that had been visited by the central inspection teams over the previous months. These recent closures have already begun to impact China's export business (Knowler 2017). On 13 September, while one of us was interviewing a logistics manager for a vehicle manufacturer in the United States, the manager asked us for information about the recent factory closures in China. He had received multiple emails from suppliers in China explaining that deliveries would be delayed and prices would be increased due to the environmental inspections. Additionally, suppliers in China informed the manager that these price hikes would be permanent, as the environmental policies now in place were intended to be enforced indefinitely. Similar reports have been published on cargo shipping blogs (Vineyard 2017). Bloomberg has also recently noted that with thousands of factories suddenly closing there will be major logistical disruptions as the peak consumerist period in the US and Europe arrives before Christmas (Standaert 2017). However, as of yet very little information about what is actually happening on the ground in China has been reported.

Since we have both conducted research in Chengdu, we will draw from recent concrete examples found in that city. As we will show below, some factories were closed even before the completion of the fourth and final stage of the central environmental inspections, which began on 7 August 2017 and included Sichuan, with a heavy focus on Chengdu (Zhang and $\mathrm{Gu}$ 2017). The local authorities issued an urgent call for all government agencies to collaborate with the inspectors, but insisted that factories were not to be shut down without proof that the law had been broken (Shi 2017). Any violators were to be fined heavily and potentially forced to close. In total, the inspection team ended up disciplining 1,023 officials. According to one of our informants within the Sichuan Environmental Protection Bureau, there is a great deal of fatigue within the various local environmental protection agencies. This is due to the fact that these offices are forced to continually implement follow-up inspections with the same number of people 
and same limited resources that they had before the central inspection teams arrived. Regardless of this, as of the time of writing, the local inspections continue with no apparent end in sight.

Naturally, the business community has greeted this pressure with mixed feelings. This was evident in the circulation of many fake news reports of damages to China's economy due to the delays and price increases caused by the inspection teams. One informant who spread such information admitted the inspections had no impact on their own business, but simply felt it was important to support other business owners in China by reposting calls for the removal of the strict policies. There have also been false reports that the MEP reversed these policies in response to the outcry from business owners. One report-which is not available online any longer-construed the purpose of an MEP press conference to claim that the central authorities had never required local governments to use a 'cutting with a single knife' style in the implementation of the new policies and that factories could now return to normal operation. In fact, the conference made no mention of allowing factories to restart operations, but stressed that the crackdown would not tolerate the closure of entire economic sectors without proper evidence. As mentioned above, from the very beginning the provincial authorities in Sichuan province issued a warning to inspectors not to close factories without proof of a law violation. When the business community started complaining about 'unfair' practices during the inspections, China Environmental News sent a reporter to provide in-depth coverage of the impact of the policies on different industries (Huo 2017). The reporter claimed that not all factories or businesses of a given industry or service were being closed, but rather that environmental bureaus in Chengdu were specifically going after those companies that were in violation of the law. However, none of this reporting has paid any attention to the impact of the crackdown on the workers within the factories or businesses that have been closed.

\section{Evidence from the Footwear Industry}

To gain a better understanding of the impact these environmental inspections have had on local businesses and workers, we will now take a closer look at Chengdu's footwear industry. The local footwear sector experienced a period of successful economic development in the first decade of the 2000s. Industrial relocation from China's coastal provinces and a large, relatively cheap, skilled workforce have enabled Chengdutogether with Chongqing-to become the fourth largest footwear production base in China, behind the traditional and primary production centres in Zhejiang, Guangdong, and Fujian provinces. Footwear companies in Chengdu focus on the production of medium to low-end quality women's leather shoes. In particular, the industry cluster in Wuhou district has been officially labelled 'China's Capital of Women's Shoes' (zhongguo nüxie zhi du). The structure of the industry-consisting mainly of small and medium enterprises, and many unregulated or unregistered workshops-as well as its proximity to the city centre, has unsurprisingly made this footwear cluster a major target for environmental inspections.

According to official media reports, by 30 June 2017, 7,600 'scattered, polluting enterprises' (sanluanwu qiye) in Chengdu had been 'temporarily' closed because of environmental inspections (Zou 2017). By the end of October 2017, this number should reach a total of 9,400 firms. While we do not have access to independently verifiable figures with regards to the footwear industry, several online accounts point to a massive wave of closures. By mid-August, 
more than 90 percent of the estimated 3,000 footwear companies in Chengdu's Wuhou and Shuangliu districts had been ordered to halt production. In addition, the few remaining firms that had been allowed to stay in business were confronted with difficulties in doing so, as most of their supplier factories were also affected by production stoppages.

It is important to note that 'temporary' closures of footwear firms are in line with environmental policy, but also with broader urban planning objectives and local industrial development strategies. Since 2007, with the adoption of the so-called 'one capital, two parks' (yi du liang yuan) guideline, it has been official policy to focus on the establishment of an R\&D base as well as a trade, information, and service center for the footwear industry in Wuhou District (Huang and $\mathrm{Hu}$ 2008). Manufacturing facilities were encouraged to undergo industrial upgrading and/or to relocate to footwear industry parks in the peri-urban counties of Chongzhou and Jintang. This policy of upgrading and relocating has since then intensified with the establishment of industrial parks in rural parts of Sichuan province (for example, Anyue, Lezhi, and Santai) and the urban planning objective of transforming Wuhou District into a development hub for creative industries (Wuhou District Media Office 2017). Seen from this perspective, the recent rounds of environmental inspections highly increased the pressure on business owners who have, thus far, been reluctant to either invest in upgrading, or to move further away from Chengdu. This pressure weighs more heavily now that even the MEP has explicitly linked the environmental inspections to the broader national objective of industrial upgrading (Xiakedao 2017).

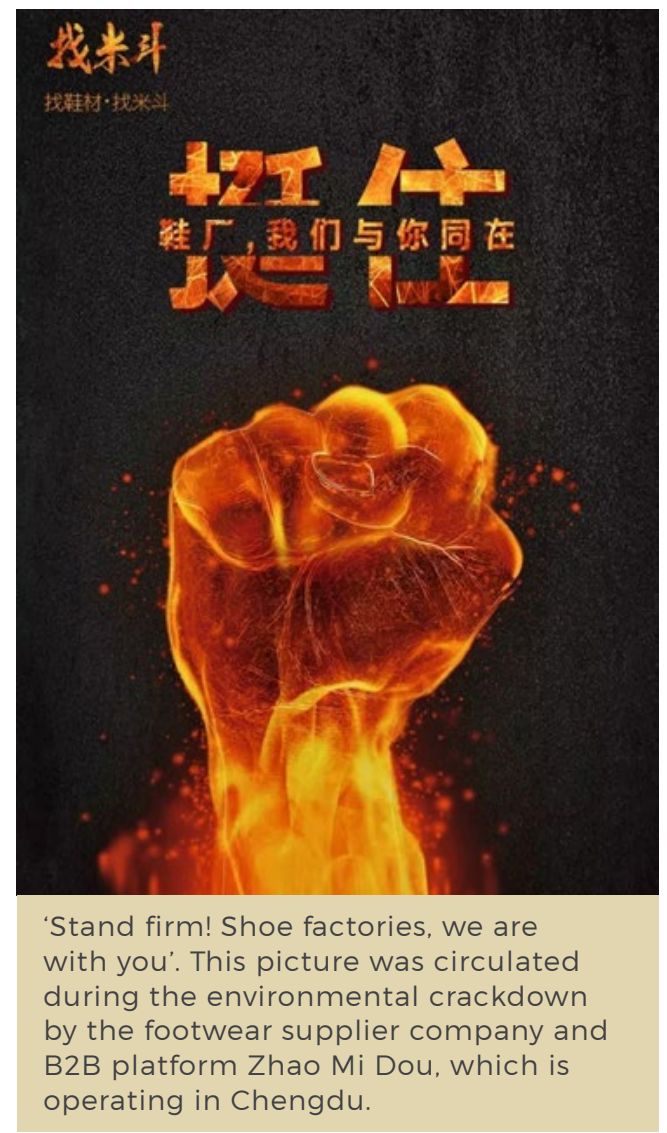

\section{Collective Resistance}

Confronted with forced production halts, business owners have organised themselves under the guidance of the so-called 'Chengdu Footwear Business Association' (chengdu xieye tongye gonghui), a platform for local footwear producers and suppliers established in 1998. The Business Association undertook an investigation across the local industry, and on 21 August sent a detailed report to the municipal authorities urging them to pay attention to the extent of the closures, the number of workers driven into unemployment, and the economic losses generated by the environmental inspections (Operational Centre of the Capital of Women's Shoes 2017a). Over the 
感谢政府的努力, 以环保之名, 化工厂停了, 塑料厂停了, 砖瓦厂停了, 沙石场停了, 铸造厂停了, 楼也停了, 矿也停了, 木板厂也停了, 养殖业也停了, 各种货物价也涨 了, 货源还断了, 货车也停了, 工人也都停工了, 做生意的也快关门了, 今年成立乡 里的空气质量达到了可食用级别了, 大家可以放心喝西北风了! 被点赞转发下去.

A frequently shared comment found in WeChat groups discussing recent factory closures.

Translation: Thanks to the hard work of the government, in the name of environmental protection, chemical plants, plastic factories, brick factories, gravel pits, steel foundries, construction sites, mines, lumber yards, and the livestock industry have all been shut down. The price of all kinds of goods have increased, sources of goods have dried up, trucks have stopped deliveries, workers have all been laid off, even business owners are about to close shop. This year's air quality in the city and the countryside has reached a 'safe to eat' level of cleanliness so everyone can relax and 'drink up' that Northwest Wind! If you like this, share it.

following weeks, several meetings between business and government representatives took place (Chengdu Footwear Business Association 2017a). While acknowledging the unavoidability of large-scale relocations out of Wuhou and Shuangliu districts, the Business Association demanded more time to prepare for the relocations and was granted permission to resume production in the meantime (Chengdu Footwear Business Association 2017b; Operational Centre of the Capital of Women's Shoes 2017b). Arguably, one of the most interesting aspects of this collective effort by business owners was how they tried to advance their position by pointing to the danger of social instability. In another report delivered on 21 August, the Business Association warned that the current situation of tens of thousands of unemployed shoe factory workers might lead to 'mass incidents' (qunti shijian) (Operational Centre of the Capital of Women's Shoes 2017a).

In fact, collective protests by workers pushed into unemployment due to recent environmental inspections have been documented in Tianjin, as well as Shandong, Hunan, and Hebei provinces (Zhang 2017). However, similar public protests could not be verified in Chengdu's footwear industry. Since the beginning of August, workers in several factories where we conducted research started to express their anger at the closure of their workplaces and the ensuing uncertainty they faced. One way of expressing their frustration was to share videos of protests by unemployed workers elsewhere. They would also share unverified accounts and rumours about physical clashes between inspection teams and workers in the area. The most widespread form of articulating dissent on social media was to write and share cynical comments and poems (See the example above) directly criticising central state policy and the 'specialists' sent to enforce environmental protection at the expense of the livelihood of the workers.

Besides expressing their frustration on social media, the immediate reaction of many shoe factory workers was to go back to their rural homes and wait there until work in Chengdu could be taken up again. Many are rural migrant workers who can easily reach their villages within hours. This has been a common strategy for local shoe production workers in recent years when there is no work available due to reduced production orders. Towards the end of August, as it became clear that most of the small- and mediumsized factories in Wuhou district would not resume production, an increasing number of 
workers began to move on to new footwear industrial parks further way from Chengdu. Whether these relocation processes succeed remains to be seen. Fieldwork conducted prior to the environmental crackdown suggested that the majority of rural migrant workers employed in the footwear industry were determined to stay in the urban area, while the younger generation (under the age of thirty) is particularly reluctant to take up these precarious factory jobs.

It should also be stressed, however, that the local government(s) in Chengdu deployed a broad range of measures to ease tensions and aid unemployed workers. According to official media reports (Zou 2017a), by the first week of August, the municipal authorities had already organised forty-nine job fairs in the districts that were most severely affected by company closures and successfully provided six thousand new job opportunities. In addition to job fairs, a special government hotline that promised to help workers find re-employment within forty-eight hours was set up. Finally, every company that agreed to employ workers affected by the recent closures has been promised subsidies of five thousand yuan per job/year over a period of three years, with the government paying the employer's share of social security contributions for the newly employed workforce.

\section{Beyond Formalism}

The recent environmental crackdown will likely have real, long-term consequences for both China's business owners and workers. While it may take some time to know for sure, we do not expect that factories will be allowed to return to business-as-usual once they restart production or move to a new peri-urban location. Reports that were issued during the central inspections in Sichuan show that while Chengdu was the initial focus of the crackdown, ultimately the whole province was strictly scrutinised (Sichuan Provincial Government 2017). The Sichuan Provincial MEP continues to collect complaints from the public and strictly enforce the law by punishing violators with fines and litigation. Moreover, all of these activities are continuously being updated online with a remarkable degree of transparency, including what appear to be full formal complaints made to local MEPs across the province, along with explanations of how the agencies have responded. Against this background, available media reports suggest that environmental inspections (including factory closures) have also taken place in the more recently established footwear industry parks (Sun and Zhu 2017). This is also referred to by a representative of the new industry park in Anyue who was quoted in the Sichuan Daily as saying: 'In the admission process [of firms intending to relocate to the park], we are also demanding that company owners upgrade with regard to production and environmental protection' (Jiang and Shi 2017).

In other words, this does not appear to be an example of local officials engaging in 'formalism' by requiring factories to close while investigators from the central government are in town. Instead, the local government appears to recognise that environmental closures are tied to larger calls for upgrading manufacturing systems and reforming economic production. While it will undoubtedly not be a perfect transition, the state is clearly attempting to pair re-employment services with strict enforcement of environmental regulations. Perhaps this is a prelude to the kind of governing strategies to expect from both the central and local governments now that the Nineteenth Congress of the CCP has concluded. In the near term, we will all need to pay closer attention to this intersection between environmental protection and industrial transformation. 


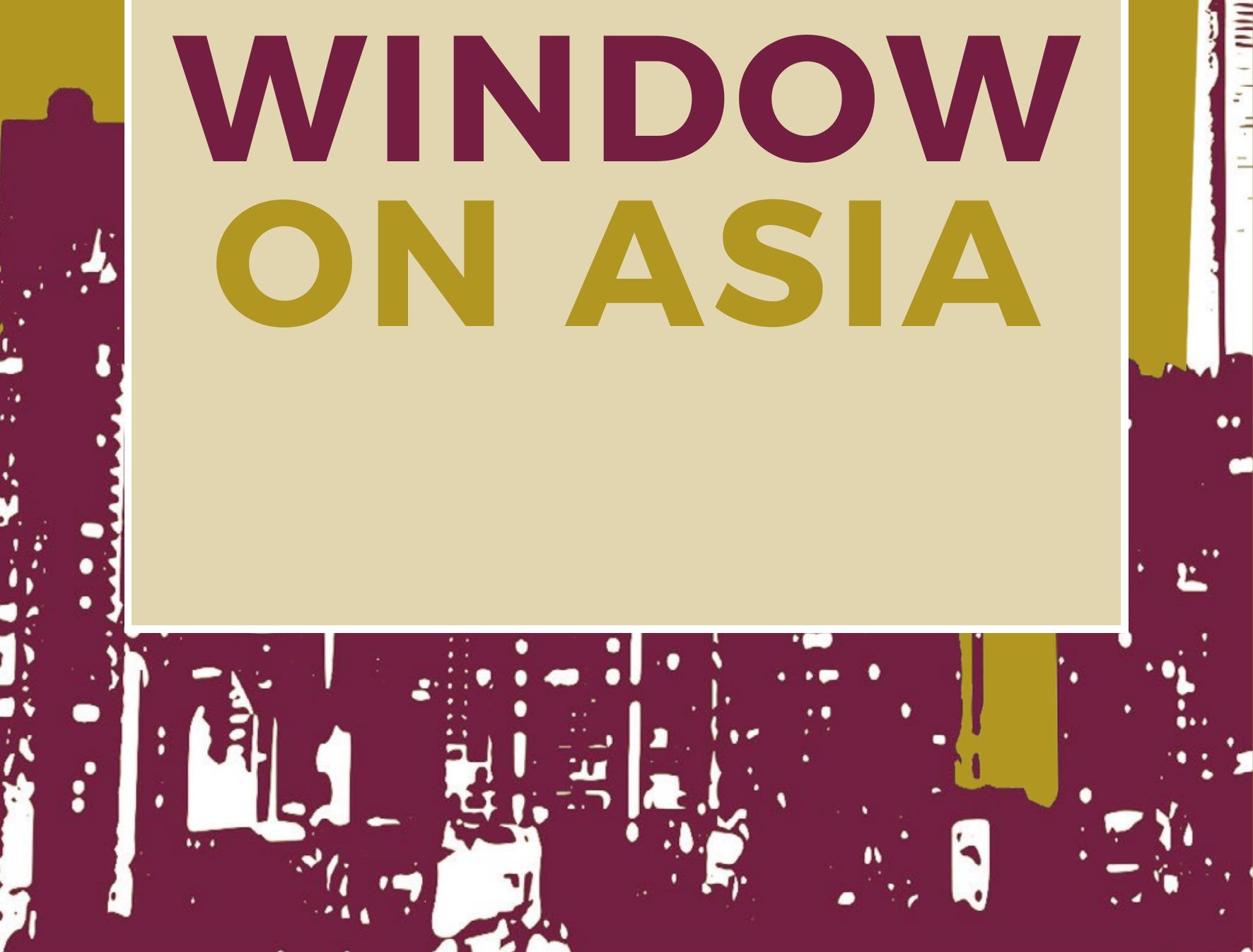




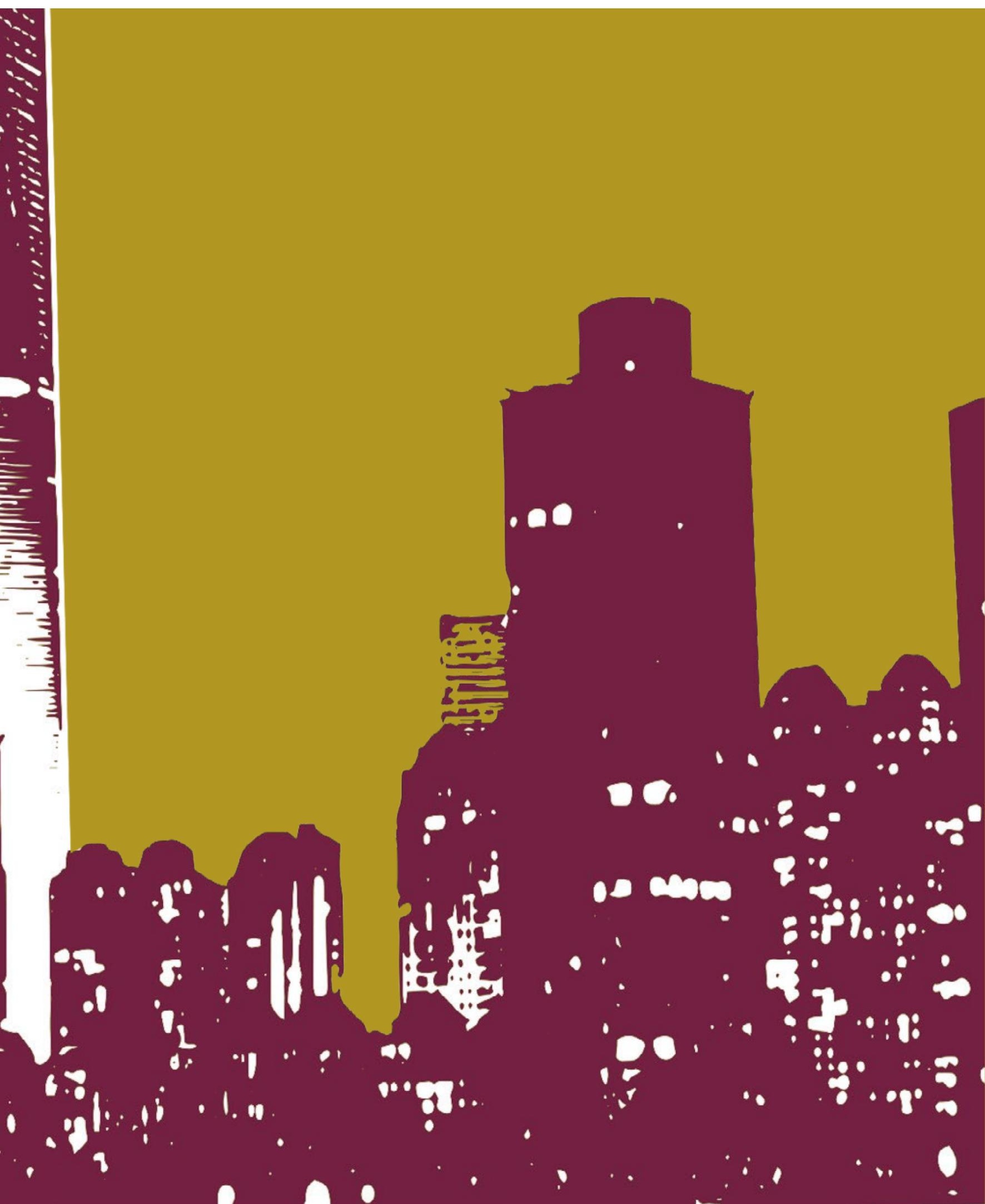




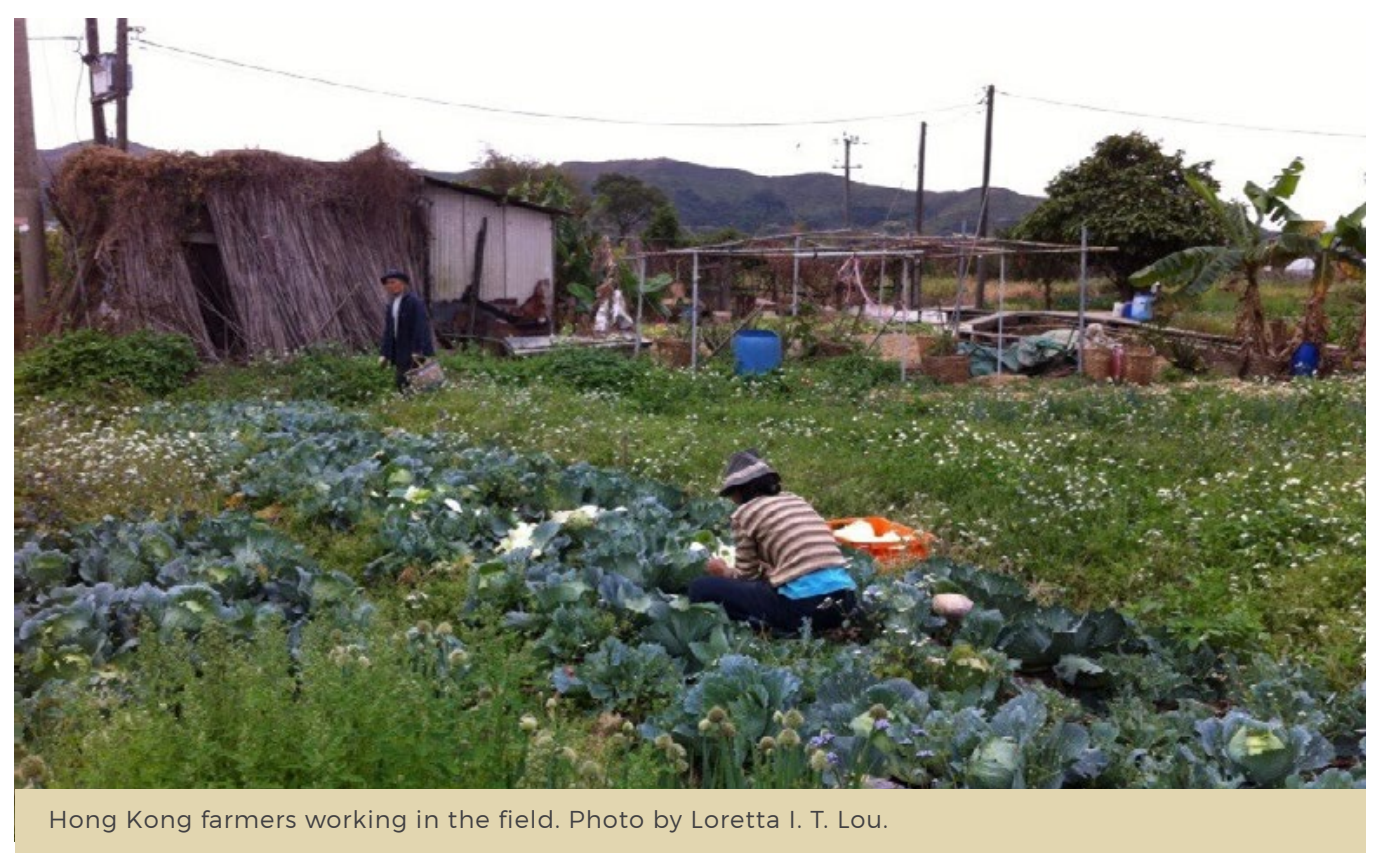

\section{In the Absence of a Peasantry, What, Then, Is a Hong Kong Farmer?}

\section{Loretta leng Tak Lou}

Given the social and political significance of 'the peasant' (nongmin) in modern Chinese history, it is surprising that the term (nongmin) is largely absent in Hong Kong, where discourses about individual farmers (nongfu) are far more prevalent. In tracing the modern etymology of Chinese peasants and the history of Hong Kong agriculture, this essay argues that the lack of 'class' consciousness makes Hong Kong farmers even more vulnerable to the unceasing wave of urban sprawl.
Given the significance of 'peasants' (nongmin) in recent Chinese history, I was surprised to find that the term nongmin is pretty much absent in Hong Kong, where I have been researching the local green living movement since 2012. In China, nongmin is an expression of social and political importance. Since the establishment of the People's Republic of China (PRC) in 1949, the term nongmin not only refers to people whose livelihoods depend on agriculture, but is also incorporated into China's administrative classification, along with other status groups such as workers (gongren) and urban residents (jumin) (Cohen 1993). In her article 'What, Then, Is a Chinese Peasant?', Mindi Schneider (2015) demonstrates that nongmin is a complex and multi-layered concept of multifarious meanings. For example, when it is a legal and administrative category, nongmin reflects the rigid separation between rural and urban hukou. As a cultural signifier, the term connotes 'low quality' and 'backwardness'. Indeed, Chinese peasants 
have been increasingly made the scapegoat for China's food security and food safety problems (Schneider 2015). As such, although the peasantry is an indispensable part of the political discourse and economic development in the $\mathrm{PRC}$, they remain one of the most socially marginalised groups in China today.

\section{In Search of a Hong Kong Peasantry}

Although the term nongmin can be found sporadically in writing, I have never heard people in Hong Kong, including those who actually engage in farming, use it in conversation. Instead, local people use 'farmer' (nongfu) to refer to individuals who plant vegetables and fruit. Depending on where, how, and why they farm, those engaging in agricultural activities in Hong Kong can be further differentiated into urban farmers (dushi nongfu), organic farmers (youji nongfu), and leisure farmers (jiari nongfu), as well as others (Cheng 2009b).

Obviously, the vastly different historical trajectories of China and Hong Kong contribute to the lack of nongmin discourses in the former British colony. One reason that the expression is not more prevalent in Hong Kong has to do with how the term was constructed and loaded with its current meanings in mainland China during the twentieth century. According to Myron Cohen (1993), nongmin was one of the many loanwords from Japan that entered China during the late nineteenth and early twentieth centuries. Like other similar linguistic imports that were borrowed to express the flood of new ideas and new social phenomena at that time (Chen 2014), nongmin was a 'modern word' that was readily available for cultural and political elites to assign new meanings to it (Cohen 1993). Before then, the word was nowhere to be found even in the most authoritative Chinese-English dictionaries. Indeed, individuals who worked in the farm were more commonly referred to as nongfu, nongding, nongjia, and nongren (translated into English as farmers, labourers, agriculturalists, etc.). As the rural population came to be known as nongmin in the mid-twentieth century, the term was constructed as a major obstacle to national development. However, under the influence of Marxism, nongmin uprisings had come to represent a major revolutionary force that had the potential to overthrow the old feudal society.

Due to Hong Kong's colonial past, local farmers (nongfu) were not subjected to this radical 'nongmin project'. It could be said that Hong Kong farmers' identities more closely resembled Chinese farmers before the mid-twentieth century, in that they were primarily tied to agricultural work and the household without the class and revolutionary referent (Schneider 2015). Indeed, archival records suggest that during the 1920s and 1930s, Hong Kong farmers' household economy, housing arrangements, and social practices differed little from their counterparts in Guangdong before the advent of the Communist's 'nongmin project' (Hayes 2006, 13). Although many traditional Chinese customs had begun to fade away in urban Hong Kong and in mainland China, especially after the Communist revolution of 1949, peasant practices were preserved in rural New Territories well into the $1970 \mathrm{~s}$ (Carroll 2007, 71).

\section{Trials and Tribulations}

Up until the 1960s, farming provided a means of livelihood for the majority of the indigenous inhabitants, as well as the thousands of mainland Chinese refugees who settled in the New Territories as rice, vegetable, and livestock farmers in 
the aftermath of World War II and the Chinese Civil War (Kadoorie Agricultural Aid Association 1982). After the wars, subsistence agriculture was actively promoted by the colonial government and the Kadoorie Agricultural Aid Association (KAAA), a charity founded in 1951 by Lawrence and Horace Kadoorie to alleviate poverty and create social stability. Working with the Agricultural and Fisheries Department, KAAA provided money and introduced various assistance programmes to Chinese refugees, such as setting them up as pig farmers and offering them interest-free or low-interest short-term loans. The Kadoorie brothers believed that philanthropy alone was not enough, so the goal of their organisation was to help the new arrivals to stand on their own feet and become self-sufficient farmers. And they succeeded. As the Chinese refugees settled in their new home and farms in the New Territories, they supplied an ever-growing percentage of the colony's food (Hayes 2006, 29). At one point during the leftist riots in 1967, the self-sufficiency rate of locally grown vegetables peaked at 48.8 percent after the PRC curtailed food supplies to Hong Kong, forcing the colonial government to rely heavily on local produce (Lau 2013, 1 and 58).

Beginning in the late 1950s, Hong Kong's subsistence agriculture came to an end when paddy rice farming went into a sharp decline (Hayes 2006, 75-79). What is interesting, though, is that following the demise of paddy rice farming, there then came what Hoi Lung Lau describes as 'the most prosperous period of Hong Kong agriculture' in the early 1970 s and early 1980s (2013, 65). In addition to the growing demand for fresh vegetables and flowers from the urban middle class, Lau believes that the superior quality of Hong Kong vegetables accounted for the agricultural boom. As his interviewee vividly recalled: 'As Chairman Mao made them put all the effort into growing grains, farmers in the mainland had gotten out of practice of growing tasty vegetables!' $(2013,69)$.

Unfortunately, this golden era of agriculture did not last long. At first, farms were hit by labour shortages as villagers in the New Territories sought higher paid manufacturing and office jobs in the city. Later, when China opened up its market in 1978, manufacturing factories were relocated to China while Hong Kong repositioned itself as Asia's financial hub with a thriving real estate market. Consequently, many farms were lost to urban sprawl and the total area of arable land continued to decrease. Meanwhile, the increased import of food from China caused Hong Kong's food self-sufficiency rate to plummet dramatically, driving local agriculture to the brink of extinction. By the 1980s, Hong Kong no longer produced rice. Although fresh vegetables are still grown in the New Territories, the total proportion of local vegetables declined from 40 percent in the 1960 s to 2.3 percent in 2013 (Lau 2013, 1; Cheung 2014, 1019). Today, 90 percent of the food supply in Hong Kong is imported, with the majority of it from the PRC.

\section{The Emergence of a New Kind of Farmer}

As incidents of food scandals soar in China, Hong Kong people have become increasingly concerned about their heavy dependence on China for their food supply. While other factors, such as the rise of local consciousness (Hung 2014), are also responsible for the Agricultural Revitalisation Movement (fugeng yundong), food safety is no doubt a major catalyst. With help from land activists, environmentalists, and local food consumers, Hong Kong farmers have joined in the movement against unbridled urbanisation and unchecked developmentalism. Even though the farmers usually prefer to take a back seat and let the 
activists do the actual organising, during the process of mobilisation, farmers in Hong Kong have learned to redefine their social and cultural identity by emphasising their contribution to sustainability and their role as defenders of Hong Kong's remaining farms.

In contrast to the nongmin in China, who continue to suffer from all kinds of stigma and discrimination, nongfu in Hong Kong seem to have overcome the bias that farming is an inferior occupation (Lau 2013, 72). Since the first mobilisation against landgrabbing in 2008 (also known as the 'Choi Yuen Village Incident', see Chang 2010), Hong Kong farmers have assumed a more dignified image. Today, farmers in Hong Kong no longer consider agriculture as an obstacle to Hong Kong's socioeconomic development-a metanarrative that has held strong until very recently. Rather, they have come to see agriculture as an indispensable element of the city, an idea that was clearly articulated during the first Hong Kong Agricultural Forum in 2013.

\section{Farmers without Class Consciousness}

Despite their new cultural identity, Hong Kong nongfu do not wield any more political power than the nongmin in the PRC. In a way, Hong Kong farmers could face extinction even sooner because they lack the class consciousness that unifies the peasantry in China. After all, it is much easier to eliminate some 4,600 farmers, most of which are tenants without land ownership, than to eliminate an entire peasant 'class' without causing some social unrest. Moreover, despite their close affinity with land activists, in reality Hong Kong farmers lack political power to influence agricultural policies. For one, their 'professional representative' in the Legislative Council is elected by a small group of elite members, who are ardent partisans of the government's pro-growth developmental strategies.

To pacify farmers and to show governmental commitment to supporting local agriculture, the government inaugurated a Hydroponic Centre in 2013 to promote the benefits of growing vegetables in a controlled environment. While vertical hydroponics appears to support local agriculture and responds to Hong Kong people's increasing demand for 'clean vegetables', the practice is highly unpopular among farmers in the New Territories, who see it as a plot to uproot them from their land, allowing the government to continue to push forward its urbanisation agenda. Speaking at the Hong Kong Agricultural Forum in 2013, TV, a farmer at the Ma Po Po Community Farm, made an analogy between farmers and vegetables on a plate of barbecued pork rice (char siu faan): 'Unorganised farmers are like the two pieces of side vegetables on the plate. Finance and real estate are the barbecued pork and we all want more of that. However, we also know that eating too much meat is no good for our health, so we add two pieces of vegetables on the side. The side vegetables are like our farmers and our local agriculture. They are good on display, but they are dispensable.' Indeed, Hong Kong farmers may have escaped the stigma and discrimination associated with their nongmin counterparts in the PRC, but in a city where an inch of land is worth an ounce of gold, they might not be able to escape being devoured by the unceasing wave of urban sprawl that is bound to happen over the next fifteen years. 


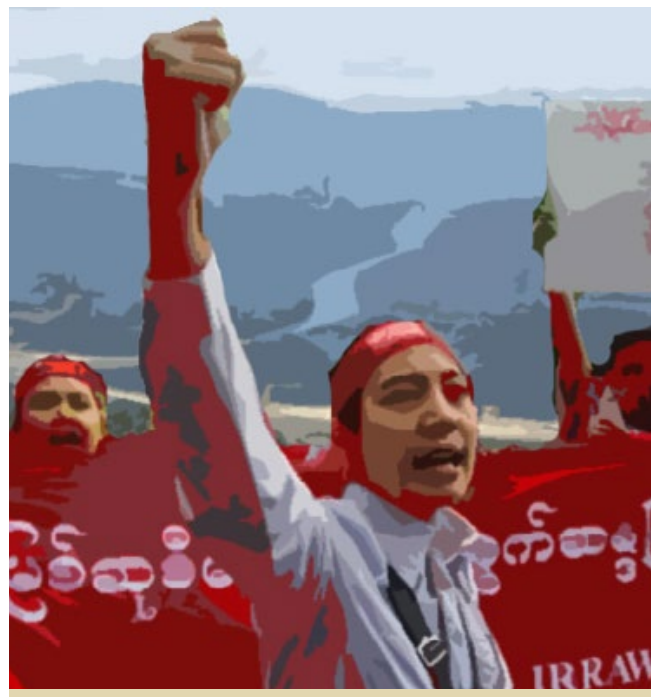

Protest against the Myitsone Dam in Myanmar. Photo: AK Rockefeller (Flickr).

\section{Burmese}

Civil Society

Challenges

China's

Development

Assistance in

Myanmar

\section{Jennifer Y. J. Hsu}

China and Myanmar have been economic partners and allies for a long time. But this partnership is now being challenged by Myanmar's democratisation process. Although nascent, Burmese civil society has shown it is ready to actively contest the legitimacy of China's various development and commercial interests in this new democracy.
The development landscape is shifting. China's emergence as a non-traditional development donor is challenging traditional donor countries that are part of the Development Assistance Committee (DAC) of the Organisation for Economic Development Cooperation (OECD), such as Australia, Canada, the United Kingdom, and the United States. After many years of ambivalence, Beijing is renewing its engagement with its Southeast Asian neighbours in trade and development cooperation, a shift predicated not only upon the need for China to secure its energy supplies as the Chinese economy continues to expand (Renwick 2014), but also on the potential economic growth of these neighbouring countries, with their cheap labour and growing middle classes. Southeast Asia represents a market of six hundred million people for Chinese goods and services-a potentially significant boon for the slowing Chinese economy. Among these countries, since its transition to a civil government, Myanmar has had one of the highest growth rates in the region, exceeding seven percent per annum, a development that has been heavily driven by foreign direct investment.

From a developmental perspective, Chinese aid and development assistance are nothing new, but over the years these instruments have shifted from being driven by ideology, as during the Maoist era, to a much more flexible and pragmatic approach. According to a recent report by the Asia Foundation (2015), Chinese development assistance currently focuses on noninterference, mutual benefit, infrastructureled growth, and demand-driven cooperation. In Southeast Asia, China has provided a full range of assistance, including soft loans, debt cancellation, and the extension of lines of traditional credit. Moreover, the Chinese state has actively assisted and invested in the infrastructure of Southeast Asian nations. In the case of Myanmar, China has 
been a long-term economic partner and ally, but this partnership is now being challenged by Myanmar's democratisation process (Toshihiro 2014). Based on fieldwork observations conducted in Myanmar in the summer of 2016, in this article I first examine the role of Chinese development assistance and investments in the country's transition, I then move on to consider how this role is perceived and challenged by an emerging but active Burmese civil society. While nascent, Burmese civil society has indeed shown that it is ready to actively contest the legitimacy of China's various development and commercial interests in this new democracy.

\section{China and Myanmar: A Strained Relationship}

China is Myanmar's most significant and largest investor to date. China's relationship with Myanmar is primarily driven by Beijing's need to secure resources for its own development, as the country offers China a wealth of natural resources and is strategically located. Gas and oil routed through the Indian Ocean into Myanmar and on to China reduce Chinese dependence on the Middle East and on the unsafe passage through the Malacca Strait. While the expansion of the Chinese economy has slowed considerably, the desire to sustain growth demands that China secure not only resources, but also a market for its goods. The Burmese economy is forecast to grow at 8.6 percent in 2016 , with similar projections for 2017 , presenting a significant opportunity for Chinese manufacturers (Asian Development Bank 2017).

For this reason, much of China's development assistance remains framed as economic cooperation, a situation that has failed to win the support of Burmese society. Large-scale projects such as the Myitisone Dam, the Letpadaung Copper
Mine, and the Kyaukphyu Gas Pipeline have drawn the attention and opposition of civil society representatives. Chinese companies, such as the China Power Investment (CPI) have been accused of not providing enough safeguards against environmental damage, nor appropriate compensation to affected communities. The Irrawaddy River, where the dam was to be located, is seen as the birthplace of the nation. Given the Irrawaddy's cultural and historical significance, the lack of consultation prior to the initiation of the dam project further strengthened the claims against CPI. In addition, accusations of land grabs and contracts that favour the Chinese have increased anti-Chinese sentiments in Myanmar (Walker 2014a).

The Chinese are seeking to make amends. The Chinese Embassy in Yangon has instructed all state-owned enterprises (SOEs) operating in Myanmar to undertake corporate social responsibility training. The China National Petroleum Corporation, the SOE responsible for the Kyaukphyu pipeline, has established a Pipeline Friendship Association in Myanmar to address local grievances that pertain to the pipeline. These types of actions have proved insufficient to address continuing concerns and the demands of Burmese civil society. For instance, a 2016 delegation from CPI that was accompanied by the Chinese Ambassador Hong Liang to Myitkyina township, Kachin state, to meet with local officials and residents attracted protests (Ye 2016); while the restarting of the Letpadaung mine elicited outcry and further protests in May 2016 (Chan and Khin 2016). The inability of the Chinese to win over Burmese support is an indication of not only a failure to address the asymmetry in its engagement with Myanmar, but also its failure to recognise the importance of the country's increasingly active civil society. 


\section{The Resistance of Local Actors}

As a long-standing partner of Myanmar during its years of international isolation, China's engagement with the country has reached a critical juncture. Now more than ever, Beijing needs to re-frame its partnership to incorporate a new development component, one that seeks to address the existing asymmetry and provides opportunities for all stakeholders to be part of the development, notably civil society groups and communities that are affected by Chinese economic interests. Indeed, Chinese involvement in Myanmar must be seen in the context of the country's political transition, which is providing new space and opportunities for local civil society.

Burmese civil society stakeholders have pushed their country's new democratic government for accountability and transparency in its deals with the Chinese, particularly considering that the Chinese authorities have in the past supported the military dictatorship. Moreover, while the Chinese government, NGOs, and investors have the capacity to deliver sustainable development and to be effective development partners with the Burmese, the asymmetrical nature of the Sino-Burmese partnership-firmly tilted in favour of China's economic, political, and strategic interests-is starting to change. In reengaging with the world and re-establishing its international connections, Myanmar is diversifying its sources of economic, social, and political support, thereby reducing its dependency on China. In addition, China's own democratic deficits are significant impediments to its overseas development assistance policies, especially considering the fact that the Chinese authorities prefer government-to-government development cooperation. This form of partnership often illuminates China's democratic deficiencies rather than hiding them and is, therefore, hardly acceptable to local Burmese civil society.

As mentioned above, the activism of Myanmar's emerging civil society has already had an impact on Chinese economic interests in the country. The Thein Sein government's decision to shelve the Chinabacked Myitsone Dam on the Irrawaddy River in late 2011 is generally attributed to opposition from Burmese civil society, based on worries about irreversible environmental damage and displacement of communities (International Rivers 2011; Kirchherr et al. 2017). Fieldwork interviews in 2016 with Burmese civil society representatives engaged across a number of fields-from corporate social responsibility (CSR) to political transition-suggest that there is a tendency to look towards the West, in particular the United States, for development assistance. This is principally out of concern for China's top-down approach to economic development cooperation. Interviews with people working in the Burmese NGO sector suggest that the Chinese state-in its various guises-is perceived as lacking the knowhow and skills to effectively engage with Burmese civil society, a perception that is also jeopardising China's legitimacy and its status as an economic and development partner. According to an NGO representative working in Myanmar's CSR sector, campaigns to improve the Chinese image and attempts to engage with Burmese civil society in the wake of large-scale protests against a number of Chinese-backed projects have, thus far, proved weak and ineffectual. For example, despite providing public access to its Environment Management Plan for the Letpadaung Copper Mine, Wanbao, the Chinese mining company that owns the site, was not able to quell protests from local villagers claiming environmental damage and inadequate compensation (Hammond 2016). 
Finally, another factor that should not be discounted in the relationship between the two countries is that Chinese economic interests in Myanmar are threatened by the ethnic conflicts taking place across the Yunnan border. For example, the conflict between the ethnic Kachin and the Burmese army threatens not only Chinese internal security-with some sixty thousand displaced people entering Yunnan since conflict intensified in early 2015 (Agence France-Presse 2015)-but also China's strategic oil and gas supply pipelines.

\section{Looking Forward}

China's political culture has always shaped the manner in which Beijing has engaged with other nations. This has entailed a strong preference for state-tostate relationships. Myanmar's reforms have opened up new space for local civil society actors and the media, all of which have become roadblocks for furthering Chinese interests in the country. China was slow to recognise the influence of civil society on domestic politics and Burmese development, and Burmese civil society representatives have grown increasingly sceptical regarding Chinese claims of mutual benefit and South-South cooperation. Still, although it has little to offer in terms of values associated with development, such as good governance and accountability, China does have a significant development experience to share, having lifted over seven hundred million people out of poverty in just two decades. And yet, in spite of this, both domestic and international civil society activists working in Myanmar question the extent to which the Chinese state and its various stakeholders will be of assistance to their country. Extrapolating further, we can also speculate that, if and when Chinese civil society stakeholders begin to play a bigger role in delivering development assistance to Myanmar, questions will surely abound as to the autonomy of Chinese civil society organisations from the Party-state (Hsu 2016). All of this is likely to continue to restrain Chinese economic and development cooperation in Myanmar.

Nevertheless, China has started to acknowledge the importance of engaging civil society actors to deepen cooperation with its neighbours. As a mechanism for building trust and cooperation at the regional level, China and the Association for Southeast Asian Nations established a high-level, people-to-people dialogue, involving civil society representatives from across the region. The first meeting was held in 2013 in the Guangxi Zhuang Autonomous Region, and was organised by the China NGO Network for International Exchange (CNIE), an umbrella organisation for China's leading non-profit social organisations (Lee and Fachir 2013). The second meeting, held in 2015 in Nusa Dua, Bali, paved the way for the establishment of an NGO network responsible for organising future rotating dialogues. Moreover, the China Foundation for Poverty Alleviation, one of China's largest NGOs, opened its second international office in Yangon in August 2016. Such measures suggest that a possible re-framing of Chinese development efforts is underway. This, in the future, may open up greater space for both Chinese and Burmese NGOs to cooperate on development projects and, thus, build trust and goodwill between the two countries. 


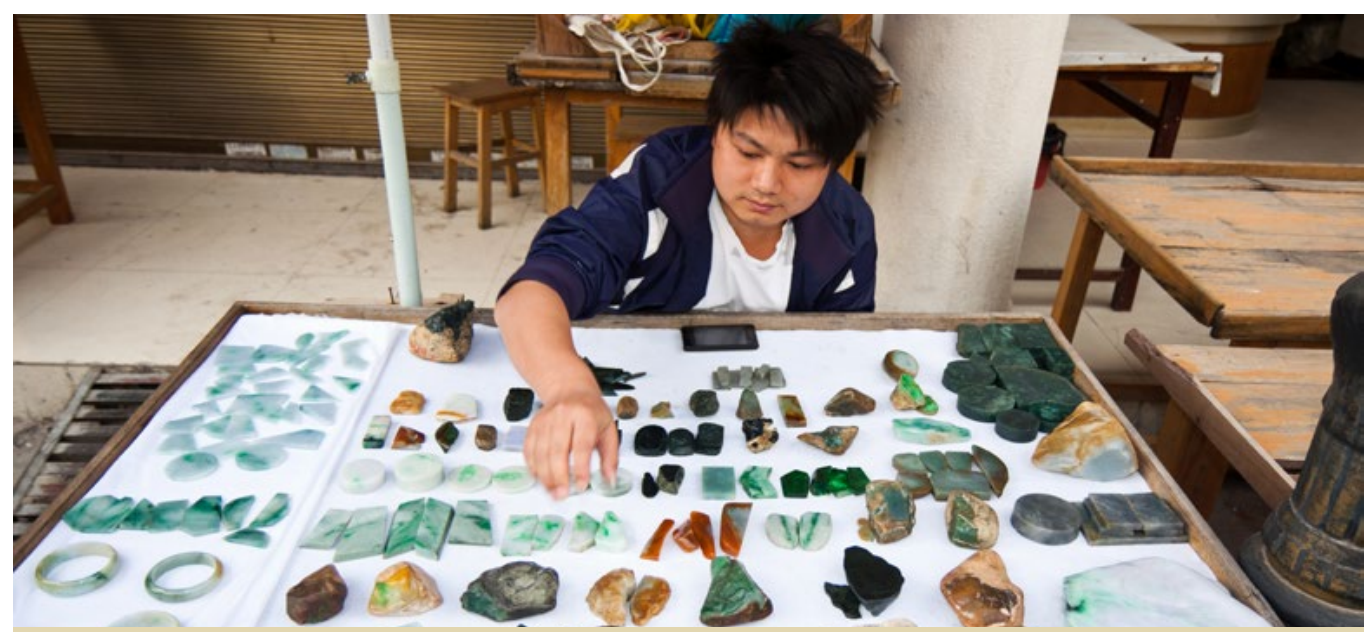

A trader sells small pieces of jadeite from Myanmar's Kachin State in the jade bazaar in Ruili, a border town in China's Yunnan province. Photo: Henrik K. Mфller.

\section{Boom or Bust in China's Jade Trade with Myanmar?}

\section{Henrik Kloppenborg M $\phi \mid l e r$}

Since 2014, declining economic growth and $X i$ Jinping's anti-corruption campaign have led to decreasing demand in certain markets for jadeite-the highest valued type of jade in China. But while institutional factors may explain these short-term fluctuations, historical continuity and cultural imaginations underpinning Chinese demand suggest that the jadeite market boom in China is not quite over yet.
In November 2015, I was seated at a tea table with a group of jade traders in an alleyway shop in Shanghai. The traders were discussing risks and opportunities of different types of investments. This was after the crash that saw the Shanghai Composite Index (SCI) fall by more than 20 percent for two consecutive months from July to August 2015, causing Chinese investors to lose about five trillion euros (Bendini 2015) The owner of the jade shop was convinced that with time his stocks would gain value. His daughter, on the other hand, had not invested in the stock market, because she felt that it was akin to gambling. 'It is much safer to invest in jade,' she said, 'Jade will always keep its value.'

As an object of economic value, jadeite (feicui)-the highest valued type of jade in China-seems subject to boom and bust cycles in China's current economy, not unlike stocks, real estate (Ulfstjerne 2015), or gold ( Wu 2017). While jadeite has seen spectacular price rises in the past three decades, parts of the industry took a blow in 2014, which Chinese traders generally ascribe to two factors: declining economic growth and Xi Jinping's anti-corruption campaign (Magnier et al. 2015; Liu 2016) 
However, institutional factors are not sufficient to understand the long-term trajectories of the markets for jadeite in the Chinese context. Jadeite is considered a sub-type of jade ( $y u)$, which in the form of nephrite has been valued in China for at least eight thousand years (Ming 2009). Over this long history, jade has assumed culturally specific connotations and properties that make it highly desirable for Chinese customers-a situation that may suggest that its markets are not likely to disappear.

\section{Jadeite Trade in the China-Myanmar Borderlands: A History}

Jadeite has reportedly trickled into China from mines in Myanmar's Kachin State since the thirteenth century (Walker 1991). Legend has it that the material was first imported into China's Yunnan province along one of the ancient caravan trade routes that linked Yunnan with Myanmar and India. Supposedly, a Yunnanese muleteer picked up a stone in Kachin state and put it in his saddlebag as a counterweight to his cargo. Back in Yunnan, the stone fell to the ground and broke into pieces, revealing a green interior (Hughes and Ward 1997). But jadeite did not leave a strong impression in China until the Qing emperor Qianlong (1735-1796)-who was obsessed with jade (Levy and Scott-Clark 2001)-started to demand large-scale imports of the stone as tribute from the Burmese King Bodawpaya in 1788. Emerald-green jadeite with high transparency and translucency was then called 'Imperial Jade' (diwang $y u$ ). Today these Qing-era criteria still function as a standard to evaluate the quality of jadeite types (Dekker 2016).

In 1860, during the Second Opium War, French and British armies sacked the Summer Palace in Beijing. On that occasion, many jade artefacts-including Burmese jadeite-were looted and brought to Paris and London. In 1863, French mineralogist A. Damour determined the chemical properties of this 'new' jade, and named it jadeite. Jadeite is chemically distinct from the more common nephrite jade, which is mined especially around Hetian, in China's Xinjiang province, but both materials are considered to be jade due to their similar observable properties (LaPorte 2004). After the communist takeover in 1949, the Myanmar-China cross-border trade withered, and the bulk of the jadeite trade was diverted to other routes. One route went through Myanmar's Shan State to markets in the northern Thai city of Chiang Mai, which catered specifically to buyers from Taiwan and Hong Kong (Zhang 2006). Alongside local ethnic groups, remnants of Chiang KaiShek's nationalist troops in Myanmar's Shan State also transported the stones, which were locally taxed by different ethnic armies (Chang 2014). Another route saw jadeite brought to Rangoon, and then shipped to Taiwan and Hong Kong. Different Kachin tribes have taxed jadeite in the Kachin State for centuries (Hughes 1999). The Kachin Independence Army (KIA), which was established in 1961, and has since fought the Burmese military for greater autonomy for ethnic Kachin in the Kachin State, took control of the mines in 1963, and centralised taxation.

With the opening of border crossings between China and Myanmar for trade in the early 1990s, increasing Chinese involvement in natural resource extraction in Myanmar, and a gradual shift in demand towards mainland China, jadeite transport shifted towards routes that run overland from the Kachin State into China (Walker 1991). The main point of entry became the border town of Ruili in Yunnan province, which since 1990 has seen the establishment of a Special Economic Zone (SEZ) for border trade, as well as upgraded infrastructure in the form of highways and a projected railway line. 
Following a ceasefire agreement between the KIA and the Myanmar military in 1994, the Myanmar military government gradually took over the most profitable jadeite mines in Kachin State, and leased mining concessions to their cronies and to Chinese investors. By 2002, the Myanmar military government had offered up to nearly onefifth of the area of Kachin state for private mining concessions, and by the mid-2000s, the government required all gemstones produced by joint ventures to be sold at annual government-organised auctions in Yangon and later Naypyidaw, as this was the easiest way to tax all sales (Woods 2016).

Total taxes in Myanmar amount to around 30 percent of the estimated sales value of a stone, and a similar import tax is officially levied at the Chinese border in Ruili. In practice, both taxes are often lowered or avoided by bribing officials, valuators, and border guards, or by smuggling the stones across the border-it is estimated that up to 80 percent of the stones that are brought to China enter the country illegally (Global Witness 2015). A report by Global Witness (2015) estimated that the value of official jade production in Myanmar in 2014 was 31 billion USD, a figure equal to 48 percent of Myanmar's official gross domestic product and 46 times the government expenditure on health for that year. The bulk of that jadeite goes to China. Meanwhile, the native Kachin people have lost crucial revenues from the jadeite mines, while facing rampant heroin addiction, HIV infection, environmental degradation, and dangerous working conditions in the mines (Beech 2017). In June 2011, the ceasefire between the KIA and the central government collapsed, and the ensuing violence resulted in the death of thousands of people and the displacement of around 100,000 civilians in the state (Project MAJE 2011).

\section{Ethnic Stratification in Ruili's Jadeite Trade}

In 2013 and 2014, I conducted fieldwork among jadeite traders and carvers in Ruili. The city's registered population was 187,000 as of 2012, comprising Han Chinese (57 percent), Dai (30 percent) Jingpo (7 percent), as well as a host of other minority groups. There are also around 35,000 unregistered Burmese, including some 15,000 Rohingya in Ruili. Around 60 percent of the Han Chinese are locals, while the rest are immigrants from cities in eastern Chinese provinces with long traditions in jade carving and trading-such as Henan, Zhejiang, Fujian, Jiangsu, and Guangdong. A local government official I interviewed in 2013 estimated that at least 50,000 people in Ruili are directly involved in the formal jadeite trade, a figure that does not include freelancers. The city hosts six major jadeite markets and around 8,000 shops. Many traders are organised in jade trade associations based on ethnic or regional affiliation.

Thanks to their broader access to investment capital and buyers in coastal China, Han Chinese control the largest companies. Some traders buy jadeite boulders at the government-organised auctions in Naypyidaw; others purchase stones in Mandalay, which are later brought into Ruili by professional transporters who take advantage of personal connections at government checkpoints. A subset of traders have stones smuggled in directly from the mines in Kachin state. People of Kachin/ Jingpo ethnicity mainly work as suppliers, while Shan/Dai peoples operate as shop owners, and the Rohingya and Bamar as cutters, polishers, and street vendors. Some Rohingya and Bamar act as middlemen, selling stones for others. Depending on profits, they usually receive 10 to 15 percent of the sales price. Others catch customers in 
the street and bring them to shops, where they receive 20 to 30 percent of the profit on deals they facilitate. Some purchase jadeite for themselves and sell it in the street.

Traders say it takes around 10,000 yuan in start-up capital to set up a small business as a mobile vendor. However, the real profits are in the trade of high-quality stones, which is much more capital intensive. In the Han trader community, operational capital usually comes in the form of informal credit between traders-often with jadeite used as security-as banks do not provide loans for this activity. As a general rule, you can borrow 50 to 70 percent of the estimated value of the jadeite you deposit with the creditor at a monthly interest rate of 3 to 5 percent.

\section{What Is the Future of China's Jadeite Trade?}

In 2013, Ruili's jadeite trade was booming. Caravans of buses arrived daily, delivering tour groups to the doorsteps of jadeite companies, which paid a percentage of their profits to the tour guides. Some traders said that jadeite prices had been rising up to 300 percent annually since 2009 , and most believed prices would continue to rise, not least because supply was diminishing due to the conflict in Kachin state, and because the mines were allegedly depleting. However, when I arrived in Ruili again in 2014, the tour buses were gone, trade was slow, and many smaller shops had closed down. Traders ascribed the market implosion to the slowdown of the Chinese economy and to Xi Jinping's anti-corruption campaign. Jadeite is a favoured form of gift and payment for illicit favours in China. As economist Thomas Naylor, who has studied illicit trade in gemstones, points out: 'In their role as financial assets, gemstones have particularly desirable characteristics.
High in value relative to bulk, they are easy to hide and to smuggle; they are universal and very liquid; and they can be sold via marketing networks whose members share an affinity for "discretion"' $(2010,132)$. In the anti-corruption era, few people dared to engage in illicit transactions using jadeite as a currency.

However, jadeite traders with enough capital to sit out the market slowdown or to divert their investments were still optimistic. While demand for mediumpriced jewellery had taken a blow, prices for high-grade jadeite were still rising. In 2013, the owner of a large jadeite company where I did parts of my fieldwork used to specialise in selling medium-priced jewellery to tourists. The following year, he closed down that company and started a new one with a Chinese man from Myanmar, who had acquired mining licenses in the Kachin state. A stone excavated from one of these mines weighed more than six tonnes and was sold to a Shanghai investor for 600 million yuan, roughly 90 million USD. Echoing other traders, the company owner said that there would always be a demand for jade in China.

This has to do with traditional Chinese beliefs regarding the function of jade in the corporeal and spiritual lives of people (Møller 2017). Jade is believed to have at least six functions: stimulate good life energy ( $q i)$, absorb bad life energy, and condition blood pressure; protect people from accidents; bring good luck; transmit spirit (ling) and karma (ye) between people, for example as gifts and inheritance objects from mother to daughter; help people contemplate the universe and their place in it; and make people feel at peace. While institutional factors may explain the slowdown in the Chinese market for medium-priced jadeite jewelry since 2014, the persistence of these beliefs suggests that China's jadeite market boom may not be over yet. 


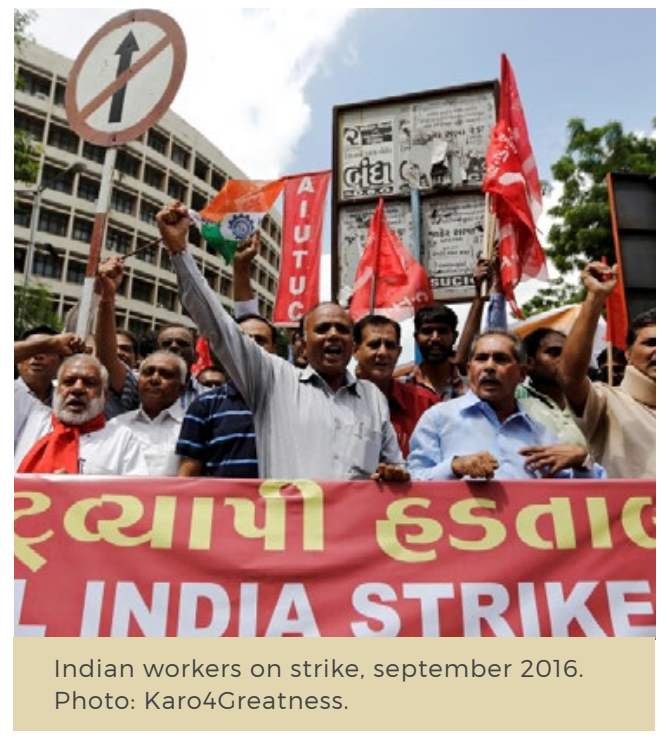

\section{Indian Labour Movements under Modi}

\section{Tom Barnes}

Indian labour politics today faces a historic paradox. On the one hand, in response to regressive changes to labour laws, India's trade unions have continued to organise what is, after China, the world's largest working-age population; on the other, massive labour protests have failed to make a dent in the political popularity of Prime Minister Narendra Modi and his right-wing Hindu nationalist Bharatiya Janata Party. To make sense of this apparent contradiction, this essay will outline the role of the Indian government in the formation of new labour law regulations since 2014, and the response of India's trade unions to this new challenge.
Indian labour politics today faces a historic paradox. On the one hand, India's vast labour movements have continued to organise what is, after China, the world's largest working-age population and to mobilise record numbers of workers in national street protests in response to regressive changes to labour laws. On the other hand, several massive labour protests have failed to make a dent in the political popularity of Prime Minister Narendra Modi and his right-wing Hindu nationalist Bharatiya Janata Party (BJP). Since 2014, the BJP has dominated government at the national level and at the local level in 13 states, including strategically-important and populous states like Uttar Pradesh and Maharashtra, as well as Rajasthan, Gujarat, and Haryana.

To explain this paradox, we need to look at the historical legacy of India's trade unions as well as the rise of the BJP, as part of a wider 'family of organisations' (Sangh Parivar), since the 1980s. Historically, the backbone of India's labour movement has been in the public sector and organised sector, which refers to all non-agricultural enterprises with ten or more employees. Despite the appearance of political strength, India's system of industrial relations never gave unions the right to collectively bargain with employers, and public sector wages and conditions were effectively fixed by the state. Unions were divided between competing federations-known as Central Trade Union Organisations (CTUOs)-each with different political party affiliations and most heavily reliant on political patronage.

Therefore, when India's economy stagnated and industrial conflict began to rise in the 1970s, the movement as a whole was poorly prepared to advance the interests of workers independently of state institutions or regional political classes. From that point onwards, the organised sector has declined as a proportion of total employment. The vast majority of new 
jobs created in the 1980s and 1990s were in small firms in the unorganised sector, which refers to enterprises with fewer than ten workers. Even when organised sector employment began to grow again in the 2000s, recruitment was increasingly dominated by the precariously employed, such as workers hired by labour contractors.

Despite the enormity of this challenge, the union movement grew significantly during the 'neoliberal' era of the 1990s and 2000s. Union membership doubled in India from 1989 to 2002 , which is the last year the national government verified trade union numbers based on complete records from all states (John 2007; Government of India 2008). Although unverified by the state, the most recent data released by the 12 officially-recognised CTUOs in 2012 and 2013 suggest that total membership may have increased by three or even four times since 2002 (Menon 2012). Much of this increase has come from informal workers.

It is on such a background that this essay will outline the role of BJP-led Governments at both national and regional levels in the formation of new labour law regulation since 2014, and the response of India's CTUOs to this new challenge.

\section{Modi's Labour Agenda}

Labour law reform is a major part of Narendra Modi's economic reform agenda, which is framed by the 'Make in India' initiative. This aims at making India the destination of choice for global manufacturing investment by continuing with previous governments' generous subsidies for large corporations and promises to cut governmental 'red tape'. Industrial conflict and union rights stand in the way of this dramatically ambitious agenda to challenge China's domination of global manufacturing.
Modi has expressed sympathy for reforms enacted by several BJP-led state governments in the areas of labour contractors and hire-and-fire flexibility. For example, the Governments of Rajasthan, Haryana, and Madhya Pradesh have made it easier for employers in organised sector firms to sack workers. This has been done by changing the rules established under the Industrial Disputes Act 1947 (IDA), making it possible for firms which employ 300 workers or more to make large-scale layoffs without state permission (previously the threshold was 100 workers). This change will be applied nationally if the Modi Government is able to pass its Labour Code, which aims to consolidate three central labour laws, including the IDA, into one simplified law. Although this code was introduced in April 2015 , its passage has been delayed by the slow pace of the Indian legislature and by opposition party control of the Rajya Sabha (upper house).

If passed, this Code would also extend the IDA's restrictions on strike action. Currently, public sector employees must give two weeks advance notice for any strike. The proposed change would extend this restriction to all workers and impose fines of 20,000 to 50,000 rupees (about 300 to 780 USD) and potential imprisonment for 'illegal' strike action (Gopalakrishnan and Sundar 2015). The Modi Government has also proposed changes to the Minimum Wage Act and the Apprenticeship Act, which would allow inter-state migrant workers to be hired as apprentices and sets their wages as a 'stipend' of 70 to 90 percent of the minimum wage, with no medical insurance.

While popular among industrialists, much of this mainstream labour law debate has focused on the small minority of regular workers employed in organised sector firms and does nothing to address the interests and rights of the majority of informal workers. Arguably, a more significant shift for informal workers involves proposed changes 
to social security. The Modi Government has already dramatically wound back the National Rural Employment Guarantee, which, since its inception in 2005, was supposed to provide 100 days of manual waged work (albeit at sub-minimum wages) for rural households. Now the government is proposing to collapse all existing social security provisions into the new unified Labour Code. If implemented, this reform would consolidate 15 separate laws into a single labour law (Gopalakrishnan 2017).

This would have a potentially dramatic impact on the rights of millions of poor informal workers. For example, labour activists have made major breakthroughs in some regions by organising workers to access entitlements through tripartite (employerunion-state) welfare boards. Many workers in informalised sectors, like construction or cigarette rolling, have benefited from death and accident insurance, maternity leave, education scholarships for their children, and funding for marriages. The new labour code threatens to undermine these hardwon rights by severely undermining these welfare boards.

\section{'Bharat Bandh'}

Since Modi's election in 2014, unionsled by the core of India's CTUOs-have periodically mobilised in large numbers to oppose the government's labour agenda. In September 2016, a massive nationwide strike caused major disruption to the economy. Some unions have claimed this was the largest general strike in history, with up to 150 million workers involved and costs to business of around 2.7 billion USD (Safi 2016). While these figures are impossible to verify, the strike was highly significant with virtually all public sector units, banks, and electricity power stations closed, in addition to insurance companies and, in many regions, trains, bus services, and schools
(Jagannathan 2016). Additionally, tens of thousands of coal miners joined the strike, along with university and college teachers (Live Mint 2016a; Reddy 2016). Many large private sector firms were also closed down or substantially affected.

This Bharat Bandh-literally 'India closed' in Hindi/Sanskrit-was the result of coordinated action by ten CTUOs who promoted a 12-point charter of demands on the Modi government (Live Mint 2016b). These demands include calls to expand subsidised food schemes, enforce existing labour laws (including minimum wages), implement universal social security, end the privatisation of public sector units, and ban foreign investment in railways and defence (Industriall Global Union 2016). The same CTUOs had organised another national strike in September 2015, which attracted a similar number of participants (Australia Asia Worker Links 2015). In February 2013, tens of millions had also joined a national strike (Australia Asia Worker Links 2013).

The scale of these successive protests demonstrates not only the sheer size of the Indian working class-the official labour force count is around 500 million, although the true figure is probably much larger-but also that CTUOs have been growing steadily in recent years. Still, in spite of these numbers and despite the BJP facing a new test in the Gujarat State elections at the time of writing, these protests have made little difference to Modi's sustained popularity as a politician and to the success of the BJP in state elections.

\section{Explaining the Paradox}

What explains the apparent contradiction between massive labour protests and a failure to change the direction of Indian politics? One reason is that India's polity and civil society is extremely diverse and 'labour politics' represent just one relatively minor 
part of it. Another is that labour politics tends to be squeezed outside mainstream debate by the country's political and media elite, who are largely hostile to unions.

A more fundamental reason relates to the BJP's historical success in appealing to a range of classes and castes, which fall between India's minority of industrialists and organised sector workers. As India's economy liberalised in the 1980s and 1990s, the BJP often succeeded in appealing to the interests of these intermediate classes' within a populist framework, while continuing to support and facilitate neoliberal economic policies (McCartney 2009). The BJP also appealed to the minority of salaried 'middle class' Indians in large cities-the well-educated, upwardlymobile sons and daughters of public sector employees and professionals who underpinned new markets for automobiles, electronic goods, and other trappings of consumer society.

This electoral appeal intersected with the rise of an immense anti-corruption movement in 2011 and 2012, which related to Indians' experience of everyday corruption. At the time, the movement severely undermined the Indian National Congressled national government. This confluence of factors meant that Modi, who cultivated an image as a 'clean', no-nonsense technocrat, was well positioned to take power in 2014, winning in a landslide.

\section{Beyond the Set-Piece}

Interestingly, many of the most significant social struggles since 2014 have occurred outside the set-piece events orchestrated by CTUOs. In the auto industry, a strike by 3,000 Honda workers in Tapukara in early 2016, 100 kilometres southwest of New Delhi, was heavily repressed by the state BJP government (Workers Solidarity Centre 2016). Over 1,000 workers were arrested,
136 workers fired, and dozens jailed. This came after the most serious conflict in the auto industry to-date, at Maruti Suzuki India Limited (MSIL) in the nearby town of Manesar. This conflict in 2011 and 2012 resulted in thousands of sackings, the tragic death of a human resources manager, and the imprisonment of dozens of workers.

Another important strike in 2016 took place in Bengaluru (Bangalore) where up to 400,000 workers emptied the city's garments factories and flooded the streets in response to government changes to state pensions (Bageshree and Bharadwaj 2016). Key features of this strike included its primarily 'wildcat' character-local CTUOs were taken by surprise, despite having organised their own, much smaller response to the changes-and that the strikers were overwhelmingly women. This massive protest succeeded in deferring the Modi government's plans (Aanchal Magazine 2016).

Given that women tend to work outside the male-dominated structures of most trade unions, another highly significant development occurred in the tea plantations of Munnar in Kerala in September 2015, when female plantation workers established a new women migrant-led union-Pembila Urumai ('Unity of Women' in Tamil)-to break with male-dominated unions (Banerji 2016).

While some of these workers may have participated in the CTUO-organised general strikes, the real challenges to the current polity have occurred in between these set-piece events, in a society in which the labour laws and social protections that have provoked such ferocious debate among industrialists, union federations, and political classes are so rarely applied. The Modi Government has signalled the intention to plough ahead with its controversial labour reform agenda, so further points of contention are likely to emerge. 


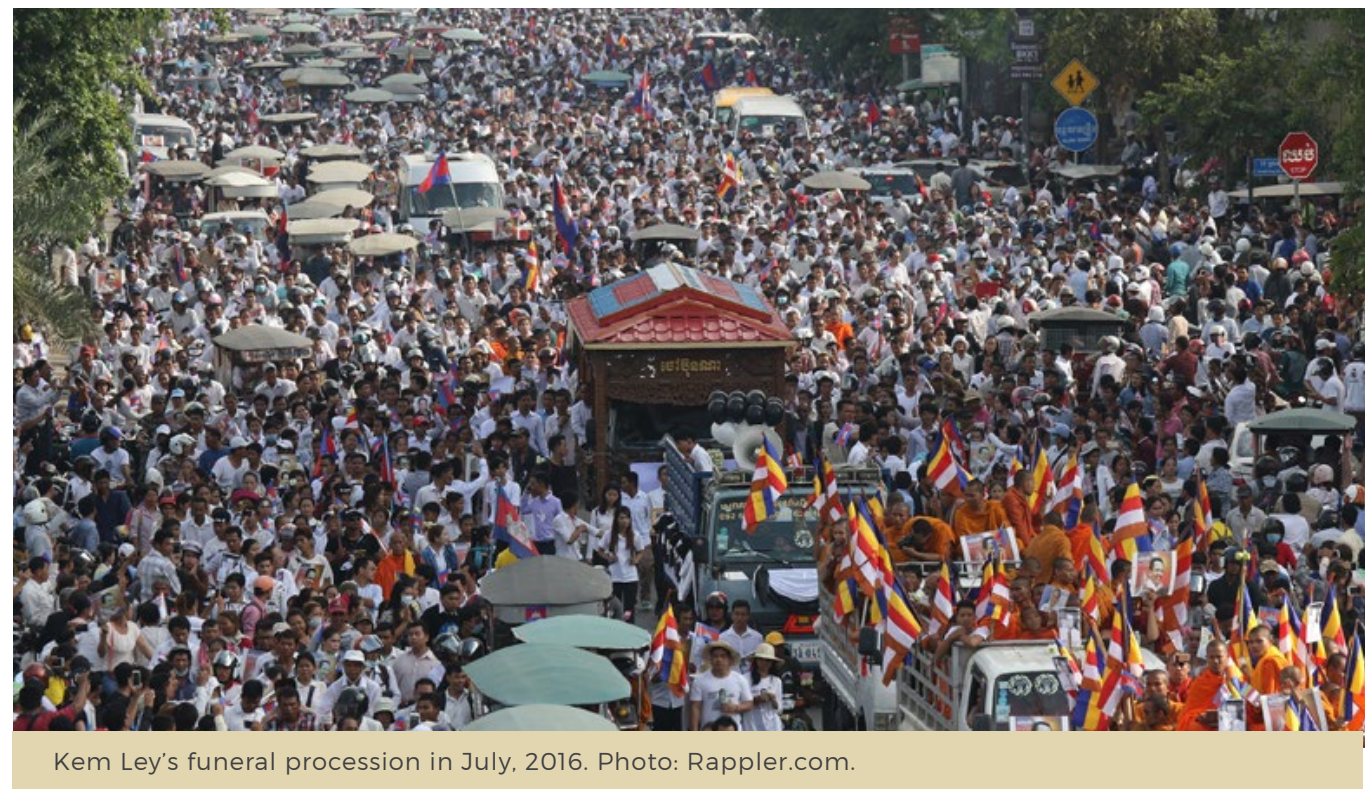

\section{In the Shadow of Kem Ley \\ Is Civil Society the Solution to Cambodia's Woes?}

\section{Astrid Norén-Nilsson}

The assassination of political analyst Kem Ley in Phnom Penh in July 2016 suggests that civil society touches a nerve of great sensibility in today's Cambodia. Cambodian democracy is currently experiencing its tensest period in two decades. If civil society plays a role in this context, it is not primarily within the traditional confines of the associational realm. Rather, in looking for a civil society challenge to party politics, we will have to shift our attention away from NGOs to the tentative emergence of social movements and to the fledgling grassroots democracy movement which Kem Ley himself spearheaded.
On 10 July 2016, independent political analyst and grassroots organiser Kem Ley was shot dead while having his morning coffee at a Caltex petrol station in central Phnom Penh (Ouch and Narim 2016). Two weeks later, an estimated two million people took to the streets to join in his funeral procession (Radio Free Asia 2016). This was the first mass social mobilisation to take place in Cambodia after the early 2014 crackdown, which had reined in the largest anti-government protests in at least fifteen years (Dara and Meyn 2013; Dara and Doyle 2014).

In 2016, Cambodian civil society played a very different role in the making of the mass mobilisations compared to previous demonstrations. In 2013, the unprecedented fearlessness with which ordinary Cambodians took to the streets seemed to be evidence that civil society was entering a new era. Though protesters were motivated by a diverse list of grievances, at that time Cambodia was marked by a sharp polarisation between the incumbent Cambodian People's Party (CPP) and the 
opposition, the Cambodia National Rescue Party (CNRP), with the latter claiming the right to interpret and represent demands for 'change'. On the contrary, in 2016, people came out to pay their respects to a civil society veteran who had sought to radically transform Cambodian politics by reforming both political parties according to civil society principles.

Kem Ley's assassination and subsequent martyrdom suggest that civil society-as an untapped potential-touches a nerve of great sensibility in today's Cambodia. Cambodian democracy is currently experiencing its tensest period in two decades: since the CNRP came within reach of an electoral victory over the CPP in 2013, the two main parties have been locked in a life and death struggle. If civil society plays a role in this context, it is not primarily within the traditional confines of the associational realm. Rather, in looking for a civil society challenge to party politics, we will have to shift our attention away from NGOs, to the tentative emergence of social movements and to the fledgling grassroots democracy movement that Kem Ley spearheaded (Henke 2011).

\section{The Limitations and Possibilities of Cambodian Civil Society}

Ever since their appearance in the early 1990s, Cambodian NGOs have taken on a large share of the functions that typically belong to the state. Still, they have always had to face serious limitations in their work. While recognising the value of the resources and services provided by NGOs for national development, the CPP has circumscribed and undermined NGOs that focus on governance and human rights issues, as well as independent youth organisations and trade unions. Most often, the relationship between the Cambodian state and civil society is understood to be competitive, with the CPP government shaping and restricting the environment in which associational activity can emerge (Feuer et al. 2014; Ly 2014). Others argue instead that the relationship is mutual, with NGOs and other civil society organisations (CSOs) confined to pursuing their objectives through manoeuvrings within the space provided by the state (Waibel et al. 2014).

Accompanying a gradual decline in foreign aid, the Cambodian state is now attempting to restrict the space available to a growing civil society. In August 2015, a highly controversial Law on NGOs and Associations was passed, restricting civil society's right to freedom of association and expression, and enabling the government to shut down organisations that criticise it (HRW 2015). Less than one year later, in April 2016, the Trade Union Law was passed, which provides protection and support to government-backed unions while undermining independent unions (Arbitration Council 2016).

In October 2014, within this stifling overall context, a number of civil society veterans, with Kem Ley at the centre, initiated the 'Khmer for Khmer' advocacy group-a network of civil society leaders and activists who pledged to promote democratic party politics by engaging citizens in the political process. The ambition of the Khmer for Khmer network was to achieve the democratising potential of civil society, not from inside the shrinking space allowed by the state, but by exporting civil society actors and principles to party politics. Their aspiration to bring forward political change via grassroots empowerment represented an extension of the international NGO discourse on empowerment (Calvès 2009).

Kem Ley and his associates reckoned that two decades of the burgeoning NGO sector had produced a huge potential for grassroots leadership-a force that had not yet been felt by the political system. 
Cambodian democratisation, they reasoned, would benefit from inserting civil society leaders into the Cambodian political system. It was with this aim in mind that in August 2015, the founders of the Khmer for Khmer network launched the Grassroots Democracy Party (GDP). The Party was meant to provide an avenue for ordinary Cambodians with good leadership skillstypically civil society leaders-to enter the political field. Significantly, it was not only the initiators and leaders of the GDP who had long-term experience working with NGOs and other CSOs, but also most party rank-and-file activists.

\section{'Grassrootism' as Party Politics?}

The movement for grassroots democracy not only reflects disillusionment with the limitations circumscribing traditional civil society work in Cambodia, but it is also an attempt to break down these constraints by entering the all-important arena of party politics. In this sense, it points to the absolute primacy of party politics for effecting change in Cambodia today. On top of the Khmer for Khmer network's agenda was the creation of microparties around the country-local development parties set up to empower those at the grassroots to become policy-makers. Though these have been slow to take off, the GDP was intended as an umbrella party for one hundred microparties that were to be established.

This suggests that the reintroduction of multi-party politics in Cambodia in 1993 has been a success, to the extent that there is a widespread belief in the country that hope for political change resides in political parties. Still, the grassroots agenda relates uneasily to party politics. Early on, the Khmer for Khmer network denied speculations that it would create its own party, claiming that its mission was only to build and strengthen grassroots political leadership. The group then subtly changed its course with the establishment of the GDP, which was set up to function as an incubator for the practice of 'intraparty democracy'. The aim was to nurture democratic leaders within the political party to work as a team, rather than rely on top leaders. In this sense, 'grassrootism' is a principle that could be emulated by other political parties. Indeed, in my interviews with GDP activists, many have stated that they envisage grassroots mobilisation being taken up by all Cambodian political parties in the future.

Yet, this all-encompassing ambition, which involved the transformation of all political parties, underscores a fundamental ambiguity in the creation of a particular political party vehicle for the grassroots agenda. Upon the creation of the GDP, Kem Ley distanced himself from the new party, only taking on an advisory role similar to the one he maintained for the CNRP. My interviews with his associates suggest that Kem Ley dissociated himself from the GDP precisely because he maintained an aspiration to change the Cambodian political landscape without participating in a specific political party. Kem Ley primarily aspired to be a coordinator among actors: his idea was to connect himself with different groups in society so as to be a focal point for the organisation of change.

Kem Ley aspired to be a charismatic leader who could reach out to, and be accepted by, all different societal groups. This would set him apart from other charismatic political leaders, such as the CNRP's Sam Rainsy and Kem Sokha, who took a partisan, oppositional stance. The ambition to apolitically or consensually represent all of society is a vestige of civil society thinking, and one that eclipses the party political avenue. 


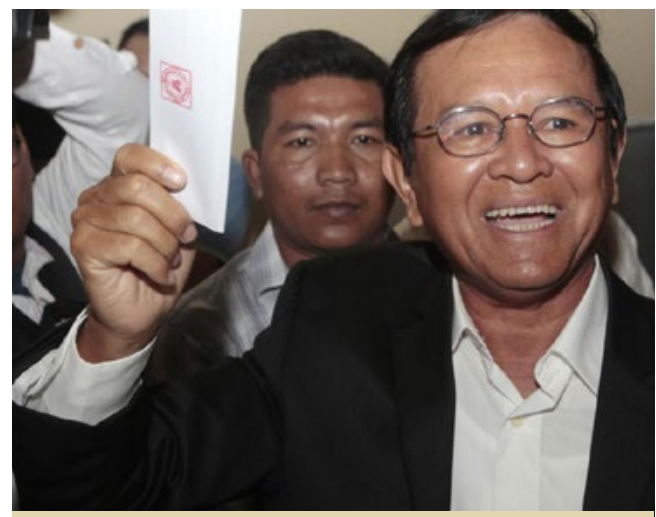

Cambodian opposition leader Kem Sokha was arrested in September 2017. Photo: Yahoo News.

\section{Roads Ahead}

Civil society as an animating idea that transcends the confines of associational life is an important force in today's Cambodia, but one that has not quite found its place. The politicisation of civil society by civil society activists themselves is an attempt to find an outlet for these grassroots energies. A grassroots model of democracy could disrupt the unequal relationships between ordinary citizens and local-level authorities that has been fundamental to the CPP's hold on power, particularly in this context where the existing pattern of local-level politics is already being undermined by demographic change (Hughes 2015). A civil society model of citizenship may be more explosive than that of political opposition.

Yet, ironically, the potential for bottom-up grassroots democracy is so intimately tied to the charismatic leader championing it-Kem Ley-that his assassination has eclipsed its prospects, at least for the time being. Whilst two million Cambodians turned out for Kem Ley's funeral in 2016, the GDP won merely five seats out of more than eleven thousand in the commune elections that took place in 2017. This is not the first time that a massive turnout of Cambodian citizens at the funeral of a beloved, charismatic leader fails to translate into political momentum. At Norodom Sihanouk's funeral procession in February 2013, about one million people poured into the streets to mourn the KingFather (Voice of America Khmer 2013). Yet, in national elections the same year, the royalist party FUNCINPEC for the first time failed to win a single seat, and the party has since all but disintegrated. The lesson is that in Cambodia today charisma is a powerful political force, but political opportunity does not outlive charismatic individuals. The CPP is acutely aware of the potential for charismatic leadership to undermine the party's authority. Since February 2017, five leaders of CNRP have been deposedthree of whom were arrested (Handley 2017). Amendments to the Law on Political Parties in July 2017 have criminalised interaction between parties and convicts, with the aim of erasing individual leaders from the political scene. This has been a largely successful strategy in that it has rendered long-time opposition leader Sam Rainsy less visible on all-important social media, with CNRP activists now afraid to interact with Rainsy's page (Nachemson and Dara 2017). A mere two months later, in September, his substitute Kem Sokha was arrested on charges of treason and now languishes in jail (Zsombor 2017). For what concerns the GDP, the unassuming profiles of its current top troika-Yang Saing Khoma, Sam Inn, and Yeng Virak-put definite limits on the prospects of the fledgling grassroots movement they now lead. Still, civil society sensibilities are evidently close to today's popular aspirations. In such a fragile and tense context dominated by political parties, the dilemma for civil society leaders will be how to rebuild a bridge of intensely felt popular ambitions in the absence of a charismatic leader. 


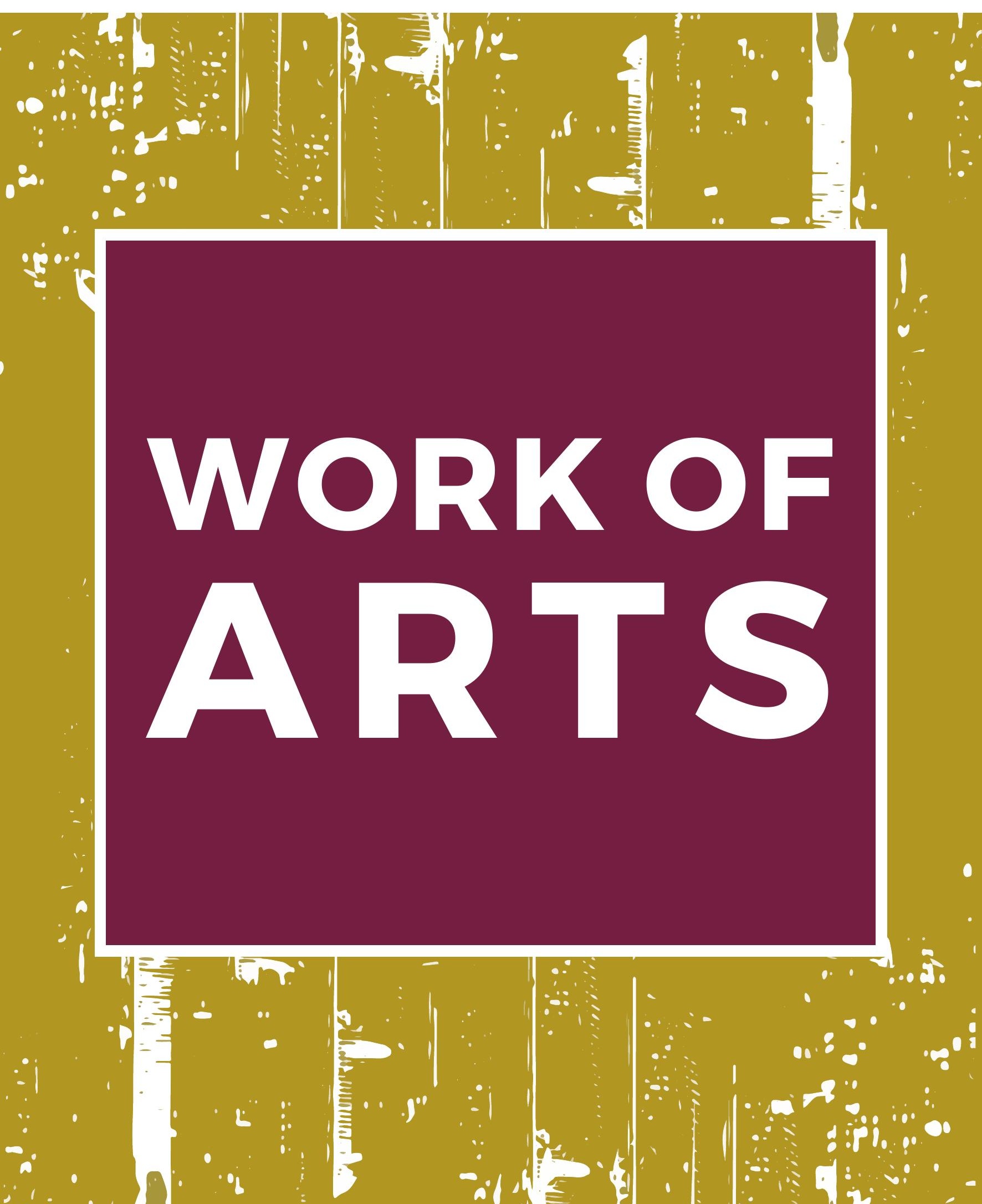




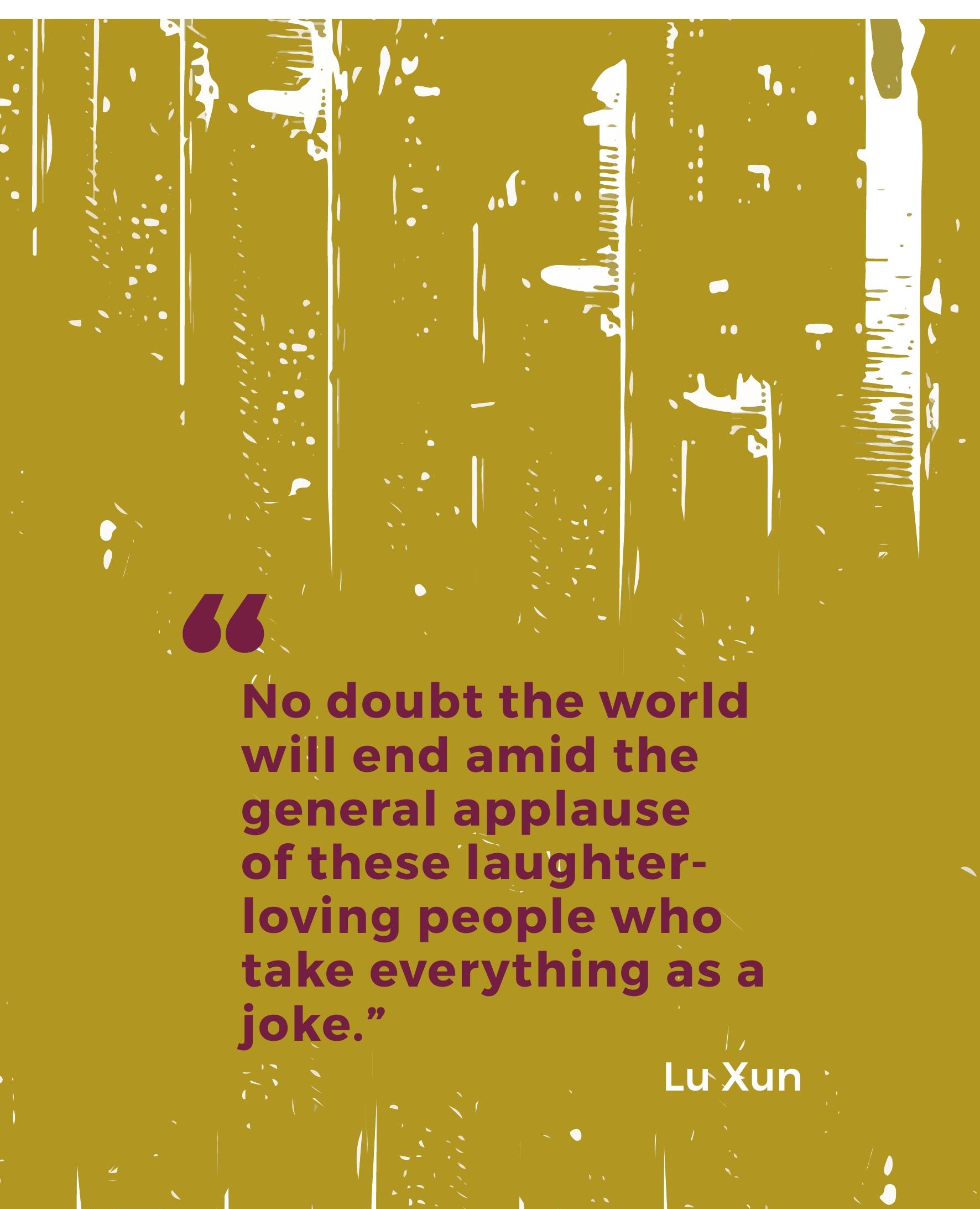




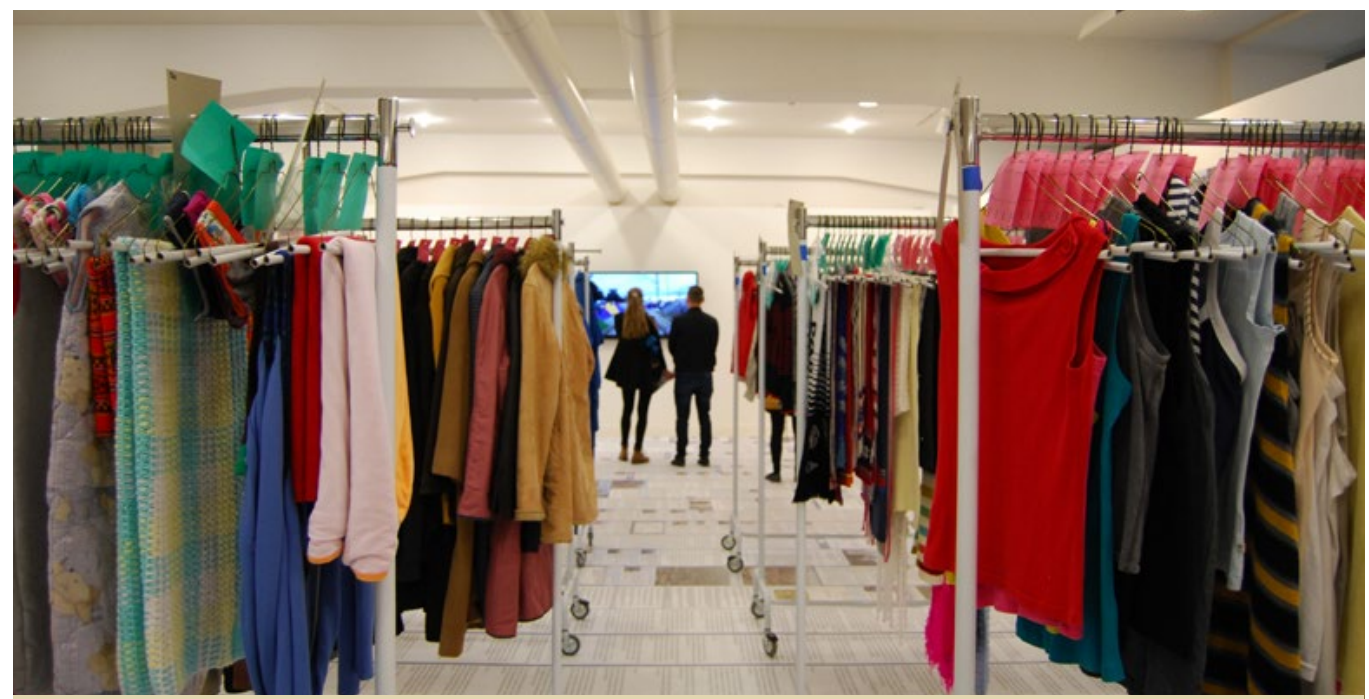

Ai Weiwei's Laundromat (2016) as currently exhibited at the National Gallery in Prague (Trade Fair Palace). Photo: Giorgio Strafella, 14 April 2017.

\section{Ai Weiwei's \#Refugees}

\section{A Transcultural and Transmedia Journey}

\section{Giorgio Strafella Daria Berg}

At least 5,079 people died in the Mediterranean Sea during 2016 while attempting to reach Europe's shores (International Organisation for Migration 2017). While many Europeans have responded to the struggle of the refugees and other migrants from the Middle East and Africa with either fear or indifference (Poushter 2016; Dearden 2017), a Chinese artiste engagé based in Berlin has employed installations, documentary filmmaking, as well as a sizeable social media presence to try and sensitise the West to this on-going tragedy (Sierzputowski 2016). Ai Weiwei represents one of the most influential figures in the global art scene and his exhibitions attract hundreds of thousands of visitors around the world (Royal Academy of Arts 2015)-since 2015 even in China, although his recent shows in Beijing do not feature his most explicitly 'political' artworks. His stature as an artist notwithstanding, it was Ai Weiwei's advocacy of human and civil rights in China-and the price he paid for his outspokenness, including eighty-one days in jail and a brain haemorrhage (Grube 2009b; Branigan 2011)-that established him as a celebrity dissident in the West at the end of the past decade. Ai Weiwei's most critical art and activism now address the condition of refugees, rather than Chinese society, putting European governments rather than the Chinese state 'on trial' while adding a 'transcultural' dimension to his work (Welsch 1999; Ai 2013). Nevertheless, as we shall argue in this essay, Ai Weiwei's most recent work stems from the same philosophy he has espoused throughout his career. 


\section{Clarity and Awakening}

Ai Weiwei states that 'freedom of speech, human rights are related to my early struggle, or my family's or the whole generation's struggle, in fighting for those basic rights' (Bloomberg 2017). As every Chinese person who has ever heard of Ai Weiwei knows, he is the son of Ai Qing (1910-1996), a famous poet imprisoned by the Kuomintang in the 1930s for his leftist activism (Gao 2012). Despite the mutual admiration between Mao Zedong and Ai Qing, the Communist Party persecuted him between 1957 and 1978, exiling his whole family from Beijing to the western provinces. At the onset of the Reform and Opening era in 1978-1979, Ai Weiwei joined an experimental artistic movement known as the Stars Group (xingxing). After the authorities shut down the Stars Group exhibition in Beijing on 1 October 1979, artists, poets, and intellectuals staged street protests demanding freedom of expression and fusing artistic creativity with political activism ( $\mathrm{Lu}$ 2014). Ai Weiwei's early encounter with Western society also contributed to shaping his political and artistic sensibilities. While living in New York between 1981 and 1993, Ai Weiwei studied the works of artists who still greatly influence his art to this day-such as Warhol, Beuys, Duchamp, and Kosuth. During this time, he also witnessed the limits of, and the struggle for, civil rights in a Western democracy (Mao et al. 2012).

Ai Weiwei's theoretical writings on art published since the mid-1990s reveal the roots of the disposition and method that one finds in his on-going exploration of the refugee crisis as well as in his earlier works. In a 1997 artistic manifesto entitled 'Making Choices' (zuochu xuanze), the artist wrote that art ought to embody a critical reflection of the human condition and the 'awakened' artist's 'vigilance on society and the crisis of humanity' (Ai 1997). Here Ai Weiwei envisages a new modernist movement founded on the liberation of humanity and the victory of the 'humanitarian spirit' (rendaozhuyi jingshen), coupling a critique of traditional definitions of art with a reflection on the existential condition that should lead to doubt, befuddlement, and finally 'awakening' (juewu). Awakened artists, he hopes, will in turn awaken the rest of society by exposing reality 'unpolished and unvarnished' and its intrinsic 'terror, emptiness, and boredom.' Rather than leading to cynicism and inaction, this stance is closely linked to Ai Weiwei's activism in that he believes artists who do so become a 'virus' of change by priming society to imagine and desire change ( $\mathrm{Ai}$ and Zeng 1995). As Ai Weiwei wrote in 2013, first 'you need people to recognize they need change. Then, you need them to recognize how to make change. Finally, change will come' (Ai 2013). Echoing the wider intellectual debate of those years, in the 1990s (Strafella 2017), Ai Weiwei already rejected both emulation of the West and nativism as inadequate standpoints, advocating instead civic engagement, creative independence, and the courage to affirm the value of human life.

Centred around the values of 'clarity' and 'awakening', the approach described above represents what we have termed 'communication activism' and permeates Ai Weiwei's art as well as his social media communication (e.g. blogging, tweeting, etc.) (Sorace 2014). Ai Weiwei designs both so that instances of oppression and injustice hit the audience with maximum brutality and effectiveness, delivering a clear message and eliciting compassion. His art documenting and mourning the death of schoolchildren in the 2008 Sichuan earthquake reflects this methodology (e.g. Remembering, 2009) (Grube 2009a), as do his recent installations in Amsterdam (\# SafePassage, 2016), Berlin (2016), Florence (Reframe, 2016), New York (Laundromat, 2016) Vienna (F Lotus, 2016), Copenhagen 
(Soleil Levant, 2017), and Prague (Law of the Journey and Laundromat, 2017), all related to the refugee crisis.

\section{Denouncing European Indifference}

In 2015, the Chinese government returned Ai Weiwei's confiscated passport. It is hard to speculate under what conditions his passport was returned, except that he promised to inform the Chinese authorities of any upcoming exhibition (Bloomberg 2017). Even though Ai Weiwei appeared to make relatively benign statements regarding the Chinese legal system to the German press (Sorace 2015), he continues to denounce censorship in China (Hantzschel 2015a; Han 2017). It is worth remembering that $\mathrm{Ai}$ Weiwei has been long critical of US and European authorities, criticising civil rights abuses in the United States and showing support for Chelsea Manning, Edward Snowden, and even Julian Assange on social media.

Shortly after Ai Weiwei relocated to Berlin looking for 'a normal life' (Hantzschel 2015b), he left on a journey around the Mediterranean Sea to document the conditions of refugees and migrants in the region. Ai Weiwei's portrayal of their lives, their odyssey, and their clashes with the European authorities have reached a global audience through various artistic mediums, a constant stream of Instagram and Twitter posts, and now also a documentary film entitled Human Flow. Furthermore, news media and online art magazines have conveyed images of that art to an audience much larger than the number of people who could see it in person (PBS 2016). It is worth noting that during the years when Ai Weiwei aimed his activism mainly at the Chinese Party-state (i.e. 2008-2014), news outlets such as The New York Times, The Guardian, and $C N N$ played a key role in establishing his celebrity status. As Chloe Preece wrote in 2015, they framed Ai Weiwei as 'a political hero/martyr' who fought for freedom of expression against a repressive regime-a narrative that provided 'reassurance of the West's ideological superiority' and thus contributed to his popularity among their audience/readership. Ai Weiwei's art and activism with regard to the plight of Middle Eastern and African refugees-a plight exacerbated by the policies of European countries, which he accuses of culpable indifference-undermines that narrative and partially recasts his media persona from one extolling the virtues of Western political systems, to one lambasting the moral paucity of their current leaders.

On the other hand, the portrayal of refugees in Ai Weiwei's photographs-and occasionally even in his artworks-tends to decontextualise its subject. Similar criticism was raised against his appropriation of the image of Alan Kurdi, a child who drowned in the Mediterranean Sea while trying to reach Greece, and his recent documentary film Human Flow (Mortensen 2017). Ai Weiwei's Mediterranean journey mainly reached us via a stream of snippets and images usually provided with little background information or references. In particular, portraits of refugees on $\mathrm{Ai}$ Weiwei's Instagram commonly lack details with regard to where they were taken, by whom, or the identity of those portrayed: Who are the men and women appearing next to Ai Weiwei in his selfies? The same questions could be asked of the photographic wallpapers in Laundromat and Law of the Journey. Moreover, on social media Ai Weiwei intertwines refugee-related fragmentsphotos, headlines, data, etc.-with equally fragmentary peeks into his professional and private life, including selfies and images of exhibitions, famous friends, press photographers, his son, and so on. Images of life in refugee camps alternate seamlessly 
with snapshots from the glamorous life of a celebrity artist. Some of the latter could be read as portraits of the artist as a celebrity, à la Warhol, the difference being that Andy Warhol posed as politically neutral while Ai Weiwei as hyper-political. When one looks at Ai Weiwei's photo-blogging as a whole, it appears to translate his preference for clarity and transparency into a one-man reality show. Drawing on Preece's analysis (2015), one may view this as the artist's 'celebritised selves' constructing and managing authenticity as a pillar of the $\mathrm{Ai}$ Weiwei brand.

Not unlike Ai Weiwei's work on the Sichuan earthquake, his artistic endeavours on the refugee crisis develop a narrative that 'unfolds across multiple media platforms, with each new text making a distinct and valuable contribution to the whole' and where 'each medium does what it does best' (Jenkins 2010). Ai Weiwei's 'transmedia' narrative on the refugee crisis unfolds beyond the artwork across platforms, such as: Instagram, where one can pore over a first-person documentation-cum-spectacle of the journey that brought about the works of art (Debord 1983); Twitter, where one can peruse the artist's own selection of news articles on the issue and thereby appreciate its importance; interviews in newspapers and magazines in which the artist expounds his vision; YouTube videos; a documentary film; etc.

\section{A Lost Battle?}

One would expect the sophisticated web of content offered by such a transmedia storytelling system' to multiply the power of Ai Weiwei's communication activism (Scott 2010). But Ai Weiwei himself appears to have identified a crack in this mode of activism (Benney and Marolt 2015). The centrepiece in one of his most recent installations, Law of the Journey, consists of a seventy-metre long overcrowded lifeboat. Currently displayed in Prague, the lifeboat is suspended in the hall of the Trade Fair Palace, which Nazi Germany utilised during the Second World War as an assembly point for Jewish prisoners before deporting them to the concentration camp of Terezín. The visitor enters the hall from the short side facing the front of the lifeboat. A series of quotes are arranged on the floor across the entire room in a way that forces the reader to walk backwards towards the opposite side, where the exit is located. One of the last quotes, right behind the stern of the lifeboat, is an extract from Letters to Olga (1988) by Vaclav Havel and it reads: 'The tragedy of modern man is not that he knows less and less about the meaning of his own life, but that it bothers him less and less.'

When addressing the scandal of the children who died when poorly built schools collapsed in the 2008 Sichuan earthquake, Ai Weiwei's adversary was a Party-state that regarded even the number of said children as a sensitive piece of information. The simple yet brave act of researching their identities through a collective effort and then hanging the list of the children's names on a wall as a piece of art-as Ai Weiwei did in the Sichuan Earthquake Names Project (Grube 2009a)-sends a clear and shocking message that compels the viewer to demand more transparency and accountability from the Chinese government. With his work on the refugee crisis, Ai Weiwei brings a method designed and honed under that regime to a continent where most citizens have access to exhaustive data and reportage on the issue, but few demand their governments to respond to it by saving as many human lives as possible. As Ai Weiwei may have realised when he added that quote on the floor of the Trade Fair Palace, European indifference and prejudice may be at least as stubborn and difficult to defeat as the Chinese Partystate. 


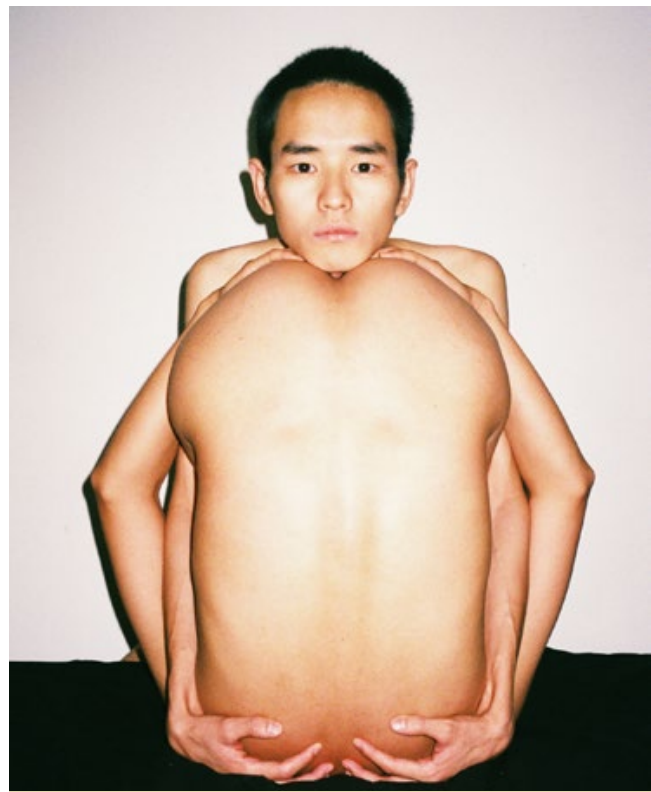

All photos in these pages are taken from Ren Hang personal website and social media.

\section{Ren Hang Bodies Without Redemption}

\section{Chen Shuxia}

On 24 February 2017, photographer Ren Hang leapt to his death from a twenty-eight-floor building in Beijing. He had not yet turned thirty, but his work had already attracted considerable international attention. This essay retraces the path of Ren's life, contextualising it within the rapidly developing field of Chinese photography. Beginning with the emergence of 'private photography' in China in the early 2000s, the article describes how a cultural industry made up of independent-publishing and photo fairs has blossomed in contemporary China.

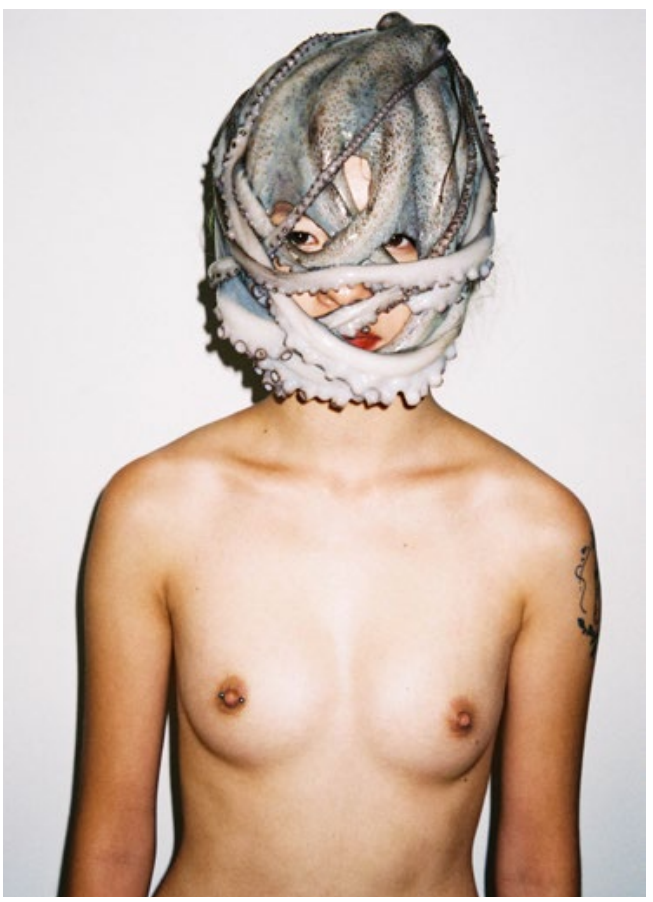

Mostly naked, friends and models of Ren Hang appear on a rooftop with skyscrapers as the backdrop, in a forest of tall trees, in a field invaded by wild grass, in a pond with budding lotuses, on a lonely rock hit by waves, or in a bathtub amongst swimming goldfish. Their naked bodies and limbs are neatly arranged as if they did not own them-an effect compounded by the deadpan expression on their young, pale faces. Labelled as 'eroticism', Ren's photography could be considered sexual, since the sexual organs of these young men and women are either subtly hidden by odd props or directly confront viewers, but Ren saw it differently. In a 2012 interview, he said: 'I don't need to try to make it classy by calling it erotica. I don't think there's anything wrong with low class' (Bernhardsson 2012).

Ren capitalised on a 'low class' approach in his early photography. Dressed in cheap bras, fish net stockings, dyed hair, and bloody red lips, his female prototypes could have just as easily been found in Yang Yong's 
early works on Shenzhen prostitutes, such as his series 'Fancy in Tunnel' (2001-2003) (Yang 2014). However, compared to Yang's seriousness in questioning the lost identity of these female migrants when facing rapid urbanisation in south China, Ren's 'low class' seemed indifferent.

Abandoning all clothes and dyed hair, Ren's natural bodies spoke for themselves. 'We were born nude... I just photograph things in their most natural condition,' Ren explained (Bernhardsson 2012). He said that he took up photography in 2007 , out of boredom, when he was studying advertising at a university in Beijing. With a Minolta point-and-shoot $35 \mathrm{~mm}$ film camera, Ren photographed everything around him. Dorm-mates walking around undressed in the heat of Beijing's summer became one of his early subjects.

\section{The Emergence of 'Private Photography' in China}

The trend of casually photographing the everyday life of friends started with the emergence of the so-called 'private photography' (si sheying) movement in China at the turn of the millennium. Influenced by pioneers of 'private photography' in the United States and Japan-such as Nan Goldin and Nobuyoshi Araki-young Chinese photographers, led by Lin Zhipeng (also known as No. 223) in Guangzhou, embraced the unique tone of film at the exact moment when the world was celebrating digital technology. They decided to capture the spontaneity of fleeting moments all around them, which they used to express their indifference to the rest of the world.

Ren picked up on the trend of 'private photography' a few years later. Like Lin, he declined the responsibility of social concern, but at the same time he also rejected both Yang and Lin's technique of casual composition of a photo. Ren's snapshots were carefully choreographed and framed. Mostly positioned in the middle of the image, the bodies in his photographs were always shown in uncanny twists and bends. By displaying the meaningless nonfunctioning bodies as props for a shot, Ren seemed to give them an alternative life. These naked young men and women looked as if they were playing hide-and-seek by climbing on trees. Pinching the skin of a neck or penis seemed childishly funny. Yet the flash from the point-and-shoot camera flattened these young faces and cast a layer of stark pallor on them. Influenced by the Japanese poet, film director, and photographer Shūji Terayama, Ren created slightly strange and ghostly atmospheres (British Journal of Photography 2017). The fact that he suffered from depression, which led him to have suicidal thoughts (Ren 2017), might also explain the absurdity and the tint of death that seeped from his images.

However, the absurd tone of his images is just right. The slender nude bodies, the young and fair faces, the out-of-context yet beautiful props form a fantasy that induces voyeuristic desire. The red lips and nails betray the 'naturalness' that Ren claimed, and hint at a formula common in fashion photography, reflecting his advertising background. If taking photographs saved him from the boredom of studying advertising, advertising came back to him in his final years. Fashion brands such as Maison Kitsuné and Gucci, as well as fashion magazines such as Purple and Libertin Dune, commissioned Ren to photograph their new collections. His stark flashed images perfectly blended 'private photography' with more staged fashion photography, giving it a brand new arty look. 


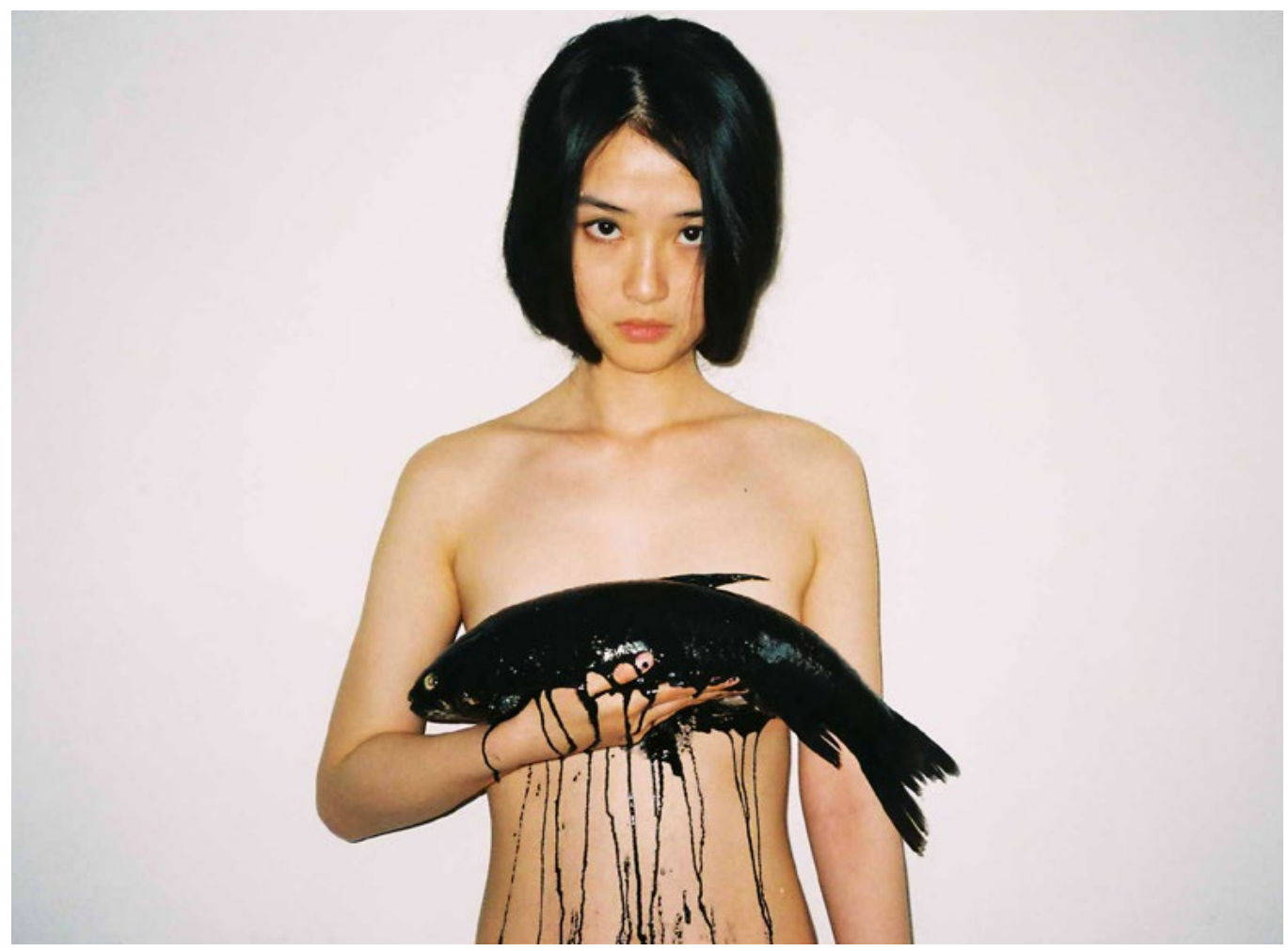

\section{Photo Books and Independent Publishing}

The nudity in Ren's photos did cause some controversy. His website and exhibitions were shut down; once he was arrested while shooting outdoors. It sounds like a precarious existence, but it wasn't. In China, this is a well-trodden path. He was no rebel willing to test the bottom line of the government or the extent of acceptance of a conservative society. Indeed, at the margins of contemporary China's controlled and moralised society, there remain many grey areas where legality is not enforced. While the police are intent to catch and suppress 'dissidents' aiming to mobilise disaffected populations, Ren was not one of them. He was just a self-made photographer. He publicised his photos on his website and social media accounts. He also self- published photo books. From 2011 until his death, he produced sixteen books, some of them with a print run of up to five hundred copies. People could buy them in art bookstores and online.

There are risks involved in this kind of self-publishing in China. All books are supposed to have a formal publisher who gets an ISSN number and goes through the censorship process. Due to the fact that the censors would have probably characterised Ren's photos as obscene, most official publishers in China would have never accepted his books. They belong to an alternative world that is teeming with life and creativity, and is often enmeshed with the new economy in ways that do not make it entirely incompatible with legality.

The cultural industry occupies a prominent position within this new economy. Listed for the first time as one of the main pillar industries by the State Council in 2009, the 


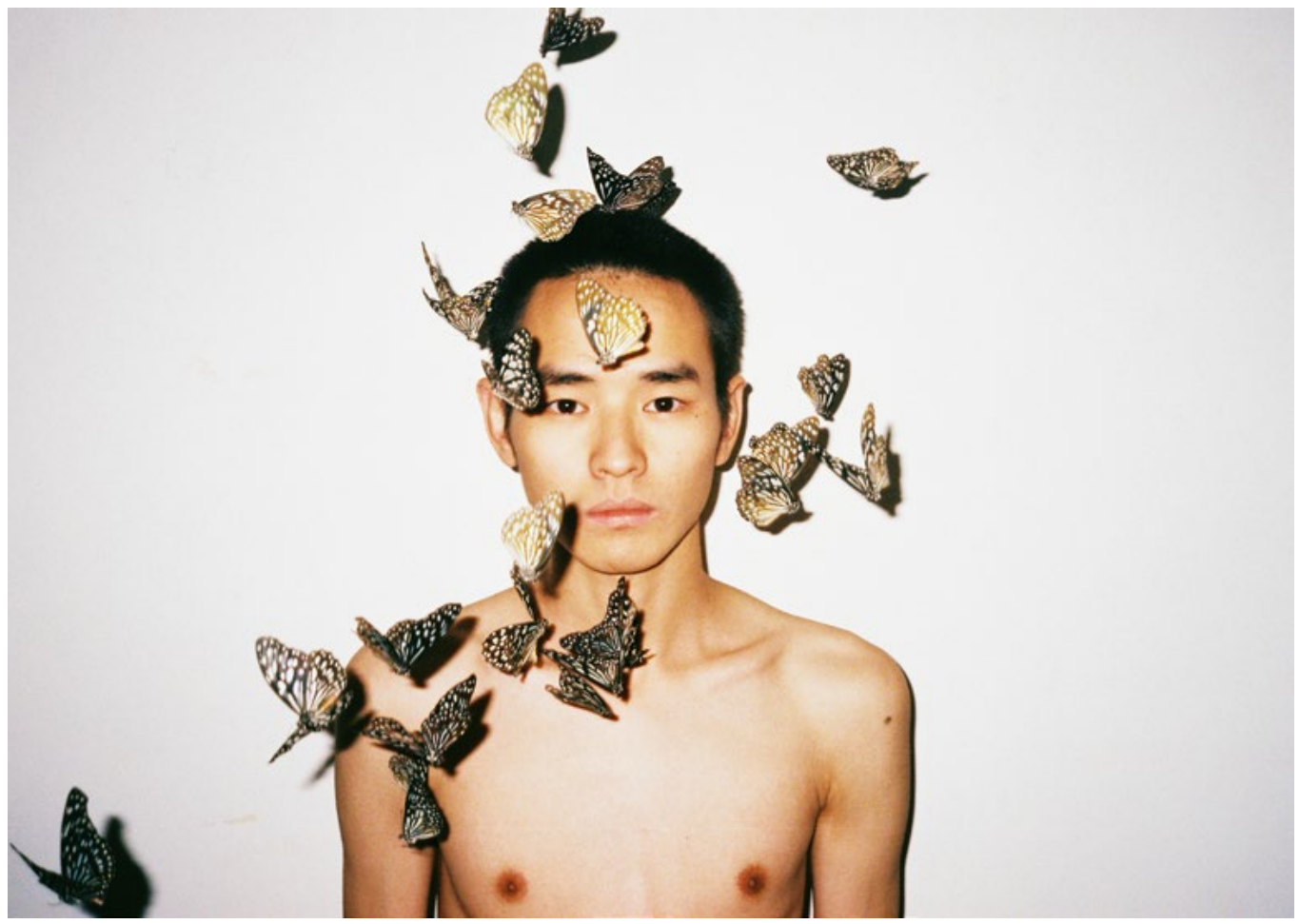

Ministry of Finance earmarked 4.42 billion yuan of special funds for its development in 2016 (Ministry of Culture 2016). This has benefited first-tier cities like Beijing, Shanghai, and Shenzhen. For example, Shenzhen has become an important base for China's cultural exports, with the value of its cultural and creative industry in 2016 estimated at 194.97 billion yuan and an annual growth rate of 11 percent (Lin 2017). The Shenzhen municipal government is also the main supporter of alternative art festivals, such as the Fringe Festival and Here is Zine, Here is Shenzhen.

Zines, short for 'magazine' or 'fanzine', are a small-run self-published medium, motivated by the need for self-expression rather than profit. Today's zines all around the world have put on a new professional and fashionable look, and have gradually attracted numerous young fans even in China. Just as Su Fei and Guan Wei, owners of the first Chinese zine store BananaFish (http://a-perfect-book-for-bananafish.com), explained: '[What we do] expresses a normal state and expectation of young people in China today... The idea of independent publishing's "speaking out for oneself", touches us.'

The photographs, poems, and diaries about his depression that Ren Hang published on his website perfectly espouse the unique spirit of zines. The fact that they come out in limited editions also gives zines some aura of hipness. 'Their freewill, extraordinariness, the feeling of sensibly fashionable exude some charm,' said Eriko Obayashi (2017), owner of POP Tame, a zine bookstore and art gallery in Tokyo. In recent years, selfpublishing photo-books has become part of this zine frenzy in China. In a time when every urban youth has a phone and is obsessed with sharing pictures of his or her life online, photography is possibly the 
most accessible and appropriate medium for zines. Photo-books now can be found online, in book stores, and especially in exhibitions, photo festivals, and photo fairs.

\section{From Shenzhen to the World}

Ren Hang caught the wave of this rising hipness. While traditional publishing venues shut their doors, independent publishers at home and abroad welcomed his new brand of talent. Self-publishing enabled him to have a specific public, more control over the printing process, and complete freedom in the selection of content. Beginning in Shenzhen, this trend of independent publishing has gradually spread to the rest of China. It seems ironic that the not-solegal self-publishing is a growing part of the new economy that is being promoted by the Chinese authorities. However, in today's

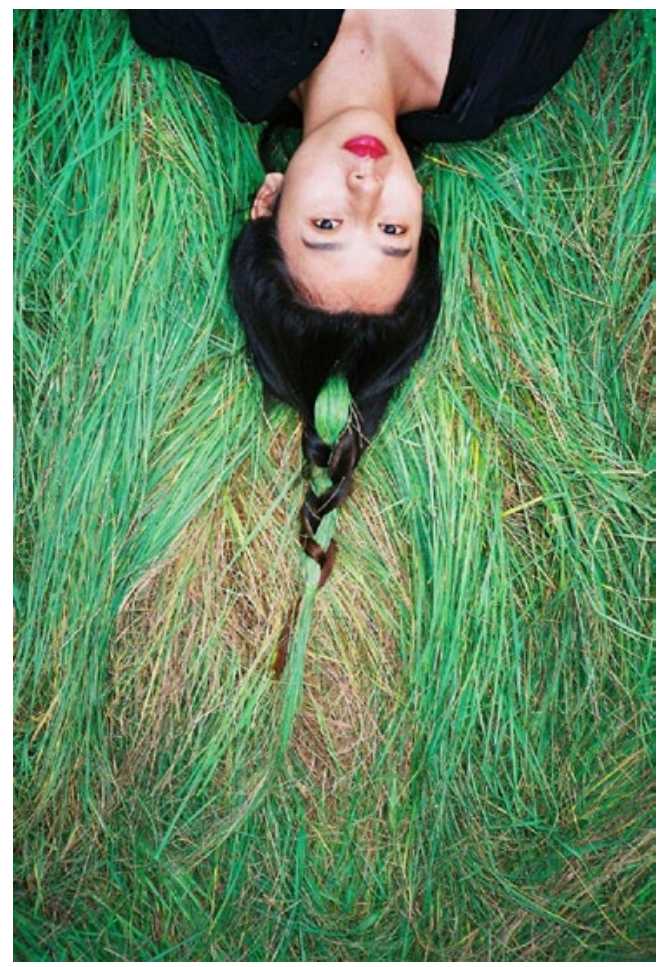

China there exists more flexibility and freedom to meet new consumer demands in the cultural industry. Most importantly, by promoting relatively niche industries, as the Shenzhen government is doing, the Chinese authorities are able to project an open and inclusive image on the international stage, thus promoting Chinese soft power across the world.

If Shenzhen leads the way with fringe festivals and zine fairs in China, Shanghai is on the frontline of photography. Besides the establishment of the Shanghai Centre of Photography in 2015, Shanghai held its third Photofairs Shanghai in September 2016, welcoming twenty-seven thousand visitors. More and more Chinese collectors are turning to photography due to the accessible price of works in limited-edition. 'The market in China has greatly matured,' said Alexander Montague-Sparey (2016), the Artistic Director of Photofairs Shanghai, 'and this has enabled us to present exciting,

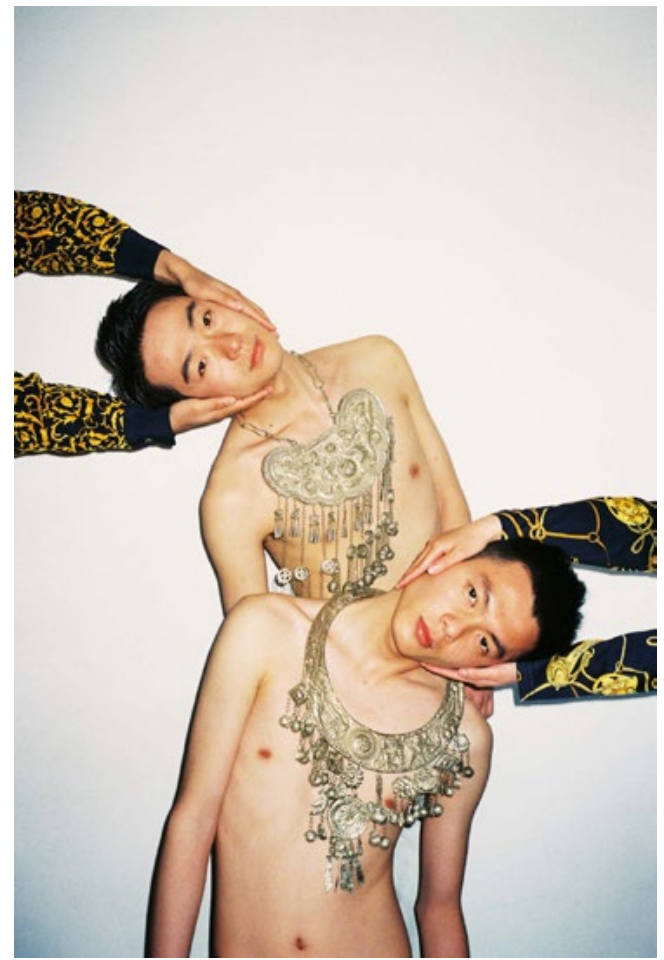


emerging artists from China and across the Asia-Pacific region.' Ren Hang was exactly this type of exciting new artist. Although there is no report of his photos being sold at the fair in Shanghai, his works are highly prized among young photographers in China. Having been shown in more than twenty solo and seventy group exhibitions around the world, Ren's art moved from gallery walls to museum walls-his two latest solos 'Naked/ Nude' and 'HUMAN LOVE' were launched earlier this year at the FOAM Museum in Amsterdam and Fotografiska Museum in Stockholm, two of the most important photo museums in Europe.

More and more young talents like Ren Hang have emerged in the last decade in China. A lot of these emerging photographers were educated in America or Europe, and are accustomed to a jetsetter lifestyle, flying between international cities for their life and work. Meanwhile, thanks to the

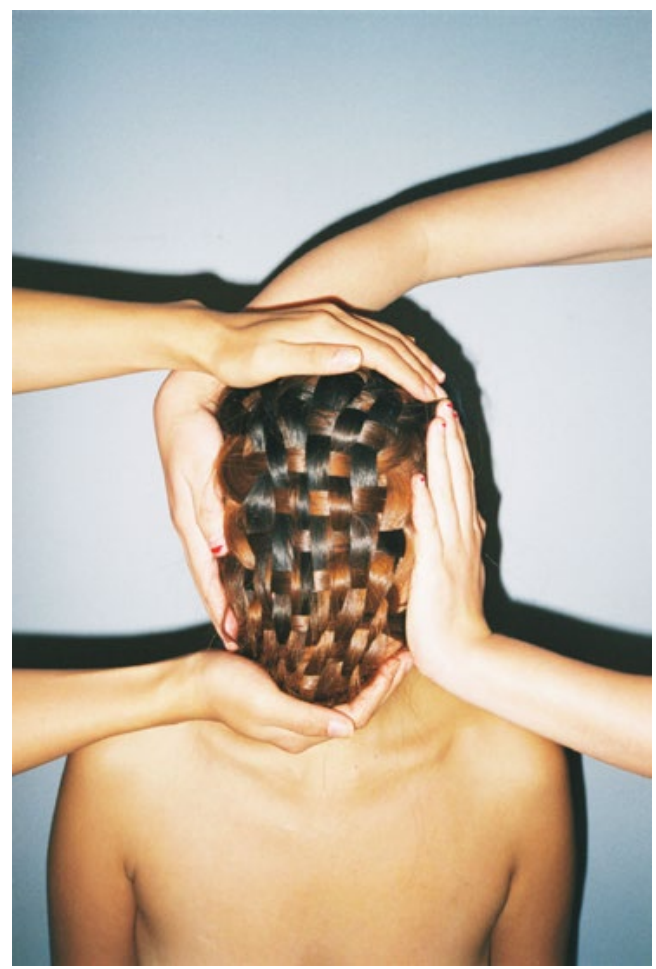

growing domestic interest in photography, international photography festivals are mushrooming across China-such as the Pingyao International Photography Festival, the Lianzhou International Photo Festival, the China Lishui International Festival, Photo Beijing, the Caochangdi Photospring, the Jimei $\mathrm{x}$ Arles International Photo Festival, etc.-each one of them attracting thousands of photo enthusiasts from home and abroad.

Ren Hang's works have attracted more attention overseas than in his home country. In February this year, Taschen published Ren Hang's first and only international collection, which covers the work of his entire career (Hanson 2017). 'The images are fresh, but also empty and superficial. They contain a deep sadness within,' commented Ai Weiwei (Genova 2017). Producing these superficial yet beautiful images with objectified young bodies might have slightly alleviated Ren's deep internal sadness. In various interviews, he remarked about the pleasure he found while taking photographs, saying that it gave him a strong sense of existence (Mocamomo 2012). Ren actively fought his depression, but his condition made him full of despair. In one of his final posts on Weibo on 27 January 2017-on the eve of the Chinese New Year-he said: 'Every year my wish is always the same: to die earlier.' On 24 February 2017, Ren leapt off a twenty-eight-floor building in Beijing, leaving behind his photos, his depression, a roaring fame, and the limelight of China's buzzing creative industry. He had not yet turned thirty. 


\section{Losing the World After the Moose Have Gone Away}

\section{Christian Sorace}

Sometimes the plans to improve people's lives end up destroying them. When the Chinese government moved the nomadic Evenki people from the forests into urban settlements and confiscated their hunting rifles, they took away their livelihood. Gu Tao's film The Last Moose of Aoluguya documents how people survive, or slowly destroy themselves, after the catastrophe of losing their world.

Man is the being through whom nothingness comes to the world Jean-Paul Sartre

Gu Tao's documentary The Last Moose of Aoluguya (an da han) (2013) follows the life of Weijia, an Evenki hunter, artist, and alcoholic who $\mathrm{Gu}$ Tao described as 'the most lonely person in the forest' (Cunliffe 2015). Traditionally, the Evenki, also known as Tungus in Russia, are a culture of nomadic hunters that span the trans-Baikal region, Siberian taiga, Mongolia, and the forests of northern China. Although mainly concentrated in Russia, in the People's Republic of China there were 30,875 Evenkis as of the 2010 population census. In the forests of China's Great Xing'an ling Mountains (daxing anling), the lives of the Evenki have revolved around moose hunting and reindeer herding.

In 2003, the Chinese government relocated the Evenki from the forest into new settlements in nearby townships as part of a broader campaign of 'ecological migration' (shengtai yimin). The relocation policy hoped to accomplish the interrelated goals of protecting nature, while providing indigenous people with new apartments and urban amenities, folded into a larger plan of accelerating regional economic development. As part of the urbanisation process, the government confiscated the Evenkis' hunting rifles and banned hunting. For this reason, Weijia asserts that the Evenki hunter lifestyle is guilty before the law that confiscated their guns and evicted them from their land: 'I heard about four young hunters who got arrested for hunting. That was the end of our culture. They put us on trial. Guilty! Just drink myself to death. We'll just have to get used to it.' Weijia's life occupies the ambivalent no man's land between dying and adaption.

Not only are the Evenkis prohibited from hunting, there are no longer any moose to hunt. The local moose population has either been killed by illegal poachers (Weijia insinuates that the poachers are mainly Han Chinese) or migrated elsewhere due to de-forestation. In the movie, Weijia and his friend Mao Xia search the forest in vain for signs of moose. All they find are sun bleached moose bones and rusted poacher traps, but no trace of living presence.

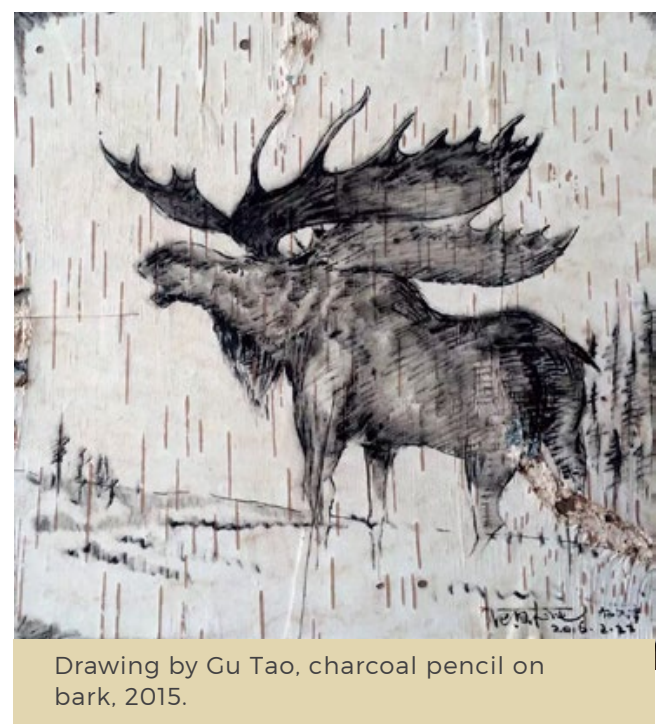


The disappearance of the moose means extinction for the Evenki. Uprooted from the forest, the Evenki culture is preserved only in the form of cultural representations and museum artefacts. In the movie, we see Weijia watching propaganda performances and television documentaries celebrating the vitality and economic development of the Evenki culture under Communist Party leadership.

\section{Blood Relatives}

We can learn about the Evenki's contemporary predicament by looking across the ocean at the history of genocide and sedenterisation of Native American nations in the United States. Despite a prevalent impulse among China watchers to blame China for all of the world's human rights violations, the destruction of indigenous culture is not particularly Chinese, Maoist, or authoritarian. The Chinese Communist Party's (CCP) tyranny of progress is only one variant of settler colonialism. In the United States, the genocide of the Native Americans was arguably more extensive, violent, and merciless than the complex and uneven histories of the CCP's policies and treatment of its minority populations, which were at least formulated under the banner of socialist equality.

The eradication of indigenous cultures also belongs to the histories of the moose in the forests of Hulunbuir and bison in the Dakota plains. In her book Dispatches from Dystopia: Histories of Places Not Yet Forgotten (2015), historian Kate Brown argues: 'The story of Custer and his defeat by Crazy Horse at the battle of Little Big Horn is well known. So, too, are his infamous trips through the plains shooting bison and leaving the stench of rotting flesh ... Custer was one of a number of Americans who felt that the extermination of the buffalo would inspire the Indians to settle down.' For pastoral nations like the Sioux, Cheyenne, and Crow, the end of the buffalo meant the end of their way of life. In the haunting words of Plenty Coup, the leader of the Crow Nation at the end of nineteenth and turn of the twentieth centuries: 'But when the buffalo went away the hearts of my people fell to the ground, and they could not lift them up again. After this nothing happened.'

In his book Radical Hope: Ethics in the Face of Cultural Devastation (2006), philosopher Jonathan Lear interprets Plenty Coup's statement to mean that life for the Crow went on after the buffalo died, but there was no longer a world in which actions could be ascribed familiar meanings. As Lear explains, the same action that meant one thing in the past (display of martial valour and courage) meant an entirely different thing on the reservation (an illegal and barbaric practice). The only bridge between these two worlds is one of memory and loss. Similarly, life for the Evenki continues in the settlements, and Weijia's life continued when he moved to Hainan to pursue a marriage based on an advertisement his mother placed in the newspaper, but it is life without a world.

The end of the world does not mean the end of state violence because new and counter-worlds will always be born from the memories of the past. As I write this essay in February 2017, the United States federal government, US Army Corps of Engineers, in tandem with oil corporations are preparing to build an oil pipeline (Dakota Access Pipeline or DAPL) through the Standing Rock Sioux Reservation's sacred burial grounds despite massive and ongoing protests and environmental concerns (NYC Stands with Standing Rock Collective 2016). At an earlier stage in the conflict in November 2016, militarised police deployed tear gas, rubber bullets, concussion grenades, and water cannons on peaceful protestors and encampments of 'water protectors' composed of over two 
hundred indigenous nations. In China, Inner Mongolian grasslands are being devastated in part due to extensive coal mining operations (Sorace 2016). Increasingly frequent protests by ethnic Mongolians over the loss of traditional grazing lands are inevitably greeted by riot police.

\section{Alcoholism}

The possibility of rebuilding a new world requires political resistance, organisation, and hope, without which there is despair. Unable to maintain their traditional livelihoods, marooned in townships with bleak economic prospects, many Evenkis became alcoholics. In an interview, Gu Tao stated that drinking was 'everywhere in the forest (Cunliffe 2015). Everybody was drinking, so much that alcohol seemed to permeate the air. I wanted to capture this aspect of their lives, and the accompanying loss of their traditional way of life. This loss caused suffering which is the reason they turned to alcohol.'

Weijia is an alcoholic because his world is over. In the film, he is clearly, and in his own words, 'drinking himself to death'. Aware that he is destroying himself, he embraces the decision as the only one available to him in lieu of a world and out of fidelity to the past. 'The guns were gone after we moved, we had nothing to do, so we started drinking. Drinking heavily. People started dying. Already eight of us have died. Eight of us have fucking died from drink. We're lost. Our culture, our guns are gone. So we drink.'

Drinking in this context is not a response to boredom. Weijia is indeed busy throughout the film. He tends to reindeer, gets married, writes poetry, half-heartedly attends an English lesson. Although being busy keeps him alive, it does not relieve him from the knowledge, which is a permanent ache and void, that his world no longer exists. It is also clear from the film that drinking does not numb the pain but in fact heightens it. Weijia confesses that if he does not drink, he is unable to speak-which is to say, drinking immerses him in reverie about the past, where speech is meaningful.

Weijia is not drinking to forget; he is drinking to remember. His drunkenness prevents him from being reconciled to the world being thrust upon him. He is frequently kicked out of the settlement for drinking; he is unable to sustain his marriage; because of drinking, his new projects are doomed to failure. In this light,

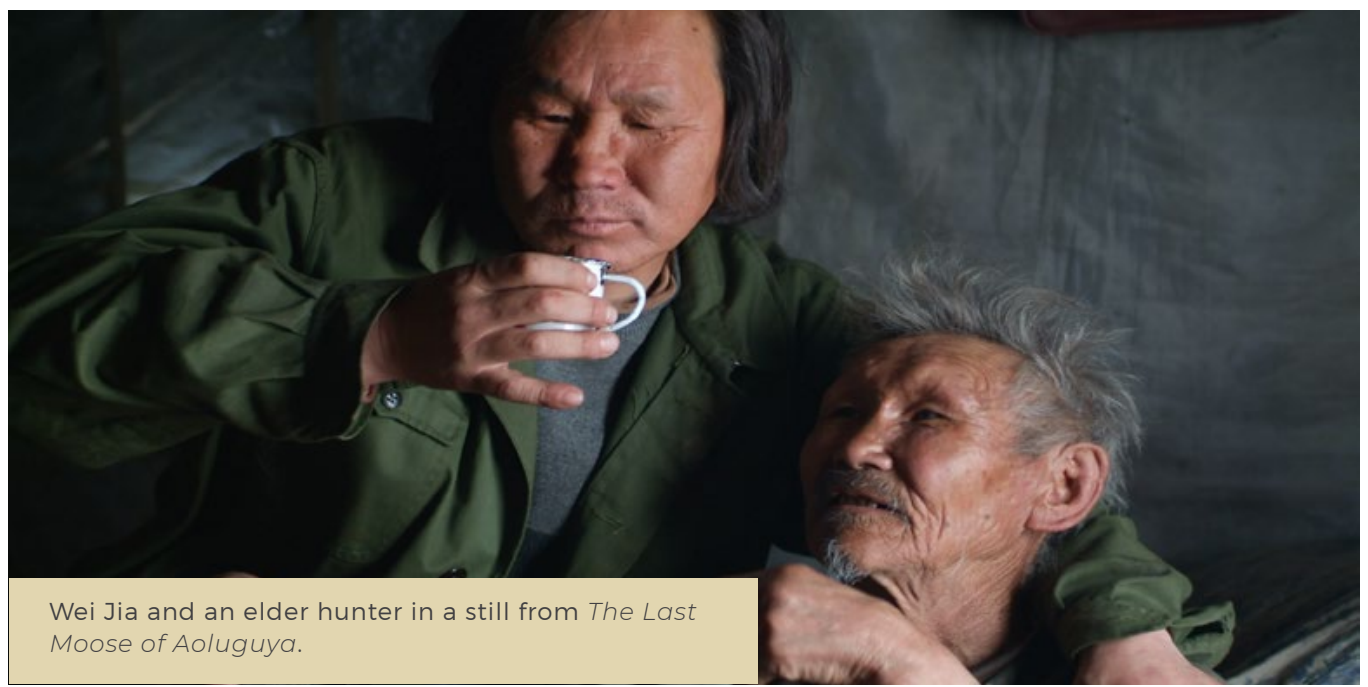


alcoholism becomes a self-conscious mode of sabotage and refusal of a world in which he is a stranger. 'To be fucking honest, it's like those Japanese samurai [author's note: he makes a cutting sound to mimic the practice of seppuku] ... Let me just say it straight, to lose your culture, it's like losing everything and so we begin to wither away. Drink! Just drink yourself to death.' These are not incoherent ramblings but clearsighted insights into the choices available to him (perhaps it is when we believe we are sober that we can trick ourselves more effectively into accepting the unacceptable). For Weijia, to stop drinking would betray the past.

Weijia's alcoholism is neither romantic nor pathological. As he puts it, 'I'm not afraid of being poisoned, that's what drinking is. If you don't get poisoned, then what's the point?' Following Lear's argument about the Crow, I suggest that Weijia's selfdestructiveness is not psychological, but an objective assessment of his (non)place in the world: 'We live in a modern society now, it's swallowed us up. Our hunting culture is disappearing. The society is becoming industrialised, and turning the world into a miserable place. If the police of a civilised world, shot at me, then I'd say, "Go ahead, shoot!" The wish to die is not a rejection of himself but of the world on offer. It seems that Weijia is not only mourning the loss of his traditional lifestyle but is also cognizant of the violence of the world promised to replace it. What kind of world is he being asked to join?

\section{On Extinction and Being Human}

Why is the fate of nomadic, reindeer people in the remote regions of Inner Mongolia so haunting? When we watch Weijia's self-destruction on the screen, we see people that we know, including our own future possibilities. Gu Tao rejects the label of being an 'anthropological filmmaker', I suspect in part because Weijia's situation of living amidst cultural collapse belongs to the human condition. Undoubtedly, the world is full of cultural plurality, textures and contexts, meanings and misunderstandings, norms and transgressions, all of which require detailed attention to, and knowledge of, the local. But details are not discrete fortresses impervious to collapse-they are fragile dwellings built on the edge of a void.

No one expects that their world will disappear. The possibility that the world can collapse is probably the kind of knowledge that Nietzsche suggested we must forget to remain alive. The cultural extinction of the Evenki is an extreme example, but collapses of different scales and intensities are happening all the time. When a factory shutters in a remote town due to capital flight and takes people's prospects at a better life along with it, is this not also a form of world collapse? When residents must permanently evacuate their villages in Alaska because of climate change, do their worlds remain intact apart from the place that held them together? When Weijia is living in China's southern island of Hainan, he remarks, 'I'm not interested in the sites here. The big hotels... that has nothing to do with me. I'm just interested in local villages' and their customs and ways of life. Perhaps his motivation to research other villages was driven by a sensibility of camaraderie through the shared experience of loss and precarity. Perhaps he wanted to find other possibilities for coping with extinction. 


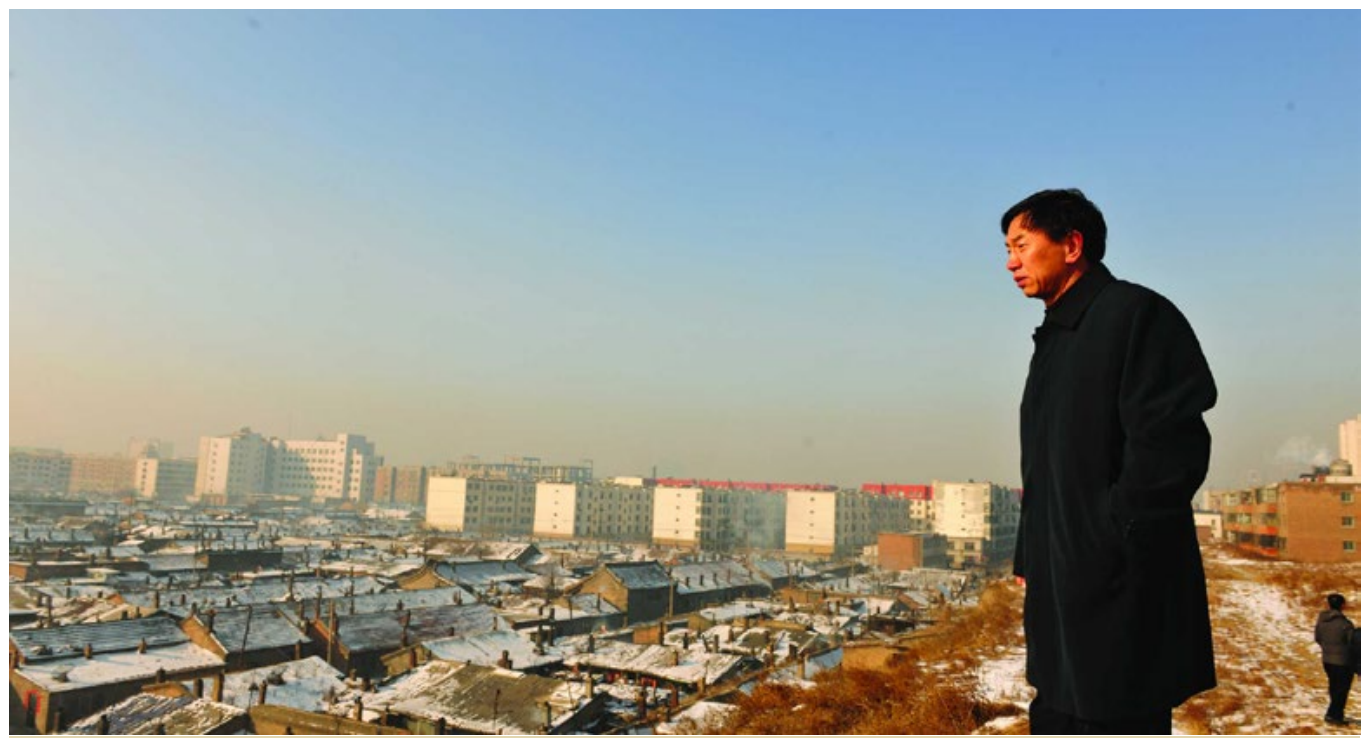

Still from The Chinese Mayor, directed by Zhou Hao, 2015.

\section{Datong, Forever in Limbo}

\section{Jonathan J. Kinkel}

The 2015 documentary The Chinese Mayor by Zhou Hao documents the story of Datong, Shanxi province, as its leaders embark on an ambitious plan to transform the city into a tourist destination. Still, although the filmmakers devote sustained attention to the relocated residents and their demolished homes, the film is no exposé: it is mostly intended to educate an international audience on the internal workings of the Chinese policy-making process.
The history of the city of Datong, Shanxi province, plays a crucial role in The Chinese Mayor, a 2015 documentary by producer Zhao Qi and director Zhou Hao. The filmmakers explain at the outset that Datong was an imperial capital sixteen centuries ago, but at the turn of the twenty-first century it had become the most polluted city in China. Under his tenure as mayor of Datong from 2008 to 2013, Geng Yanbo had an ambitious plan: transform the city into a destination for visitors and capital by rebuilding the ancient city wall, thereby restoring the city's rich cultural and historical heritage. The only catch? As many as half a million people had to be relocated from their homes in order to complete the project.

The Chinese Mayor documents the city, its leaders, and its residents as the project unfolds, and although the filmmakers devote sustained attention to the residents relocated and the homes demolished to make way for the mayor's ambitions, the film is no exposé. According to Zhao, the film primarily aimed to educate an international audience on the internal workings of the Chinese policy- 
making process and to stimulate new ways of thinking about China (McLaughlin 2015). In accomplishing these goals, the filmmakers embed themes of tradition, grievance, and desperation that colour contemporary China's complex patterns of state-society relations. This approach provides rare glimpses into contemporary China's political system-a fact to which their 2015 Sundance Special Jury Prize for Unparalleled Access attests-as well as into China's distinct political-legal tradition. The filmmakers also strive to shape their rare footage into a coherent narrative with Mayor Geng at the center and the residents of Datong, who are ultimately left in limbo by larger political machinations, in supporting roles.

\section{Concession Via Confrontation}

Unsurprisingly, the mayor's grand plan to rebuild cultural Datong's old city wall encounters fierce resistance from several residents faced with the demolition of their homes. Recounted using extensive footage of the mayor's daily life and interactions with displaced citizens, the filmmakers tell a story of demolition and displacement familiar in many parts of the world, but which takes on a different hue in the context of China's unique tradition of ruler-subject relations. Datong's culturally themed land redevelopment is the mayor's brainchild, and he supervises or intervenes when necessary in the distribution of new apartments built to replace the demolished ones. Assigning a new flat to this or that citizen becomes the mayor's preferred method of gaining individual compliance with the forced relocations.

The narrative hinges on the development of a series of characters who express direct grievances to the mayor in the street or at demolition sites. In tears, one woman confronts the mayor while falling

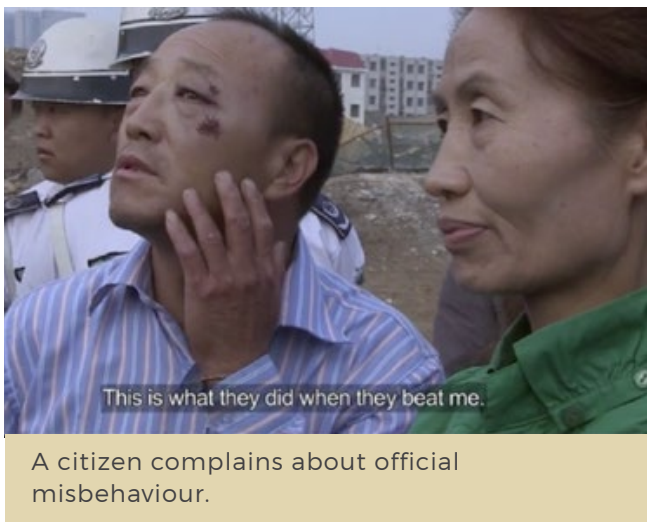

repeatedly and explains that due to her medical problems, she needs an apartment near her daughter's workplace. The mayor and his staff instruct her to wait ten days for a new apartment and assure her that they will address her concerns, on the condition that her medical situation can be confirmed. Another resident displaying facial injuries finds the mayor on the street and claims to have endured a beating from a deputy leader during the premature demolition of his home. After some squabbling, a member of the mayor's staff promises the man an apartment in what sounds like an idyllic community, 'Willow Garden'. An elderly resident, identified as 'Hua', confronts the mayor in separate scenes outside the mayoral residence (which, according to subtitles, is located in a military compound (for safety reasons'). Instead of walking past her, the mayor listens to Hua's requests for compensation for her destroyed house and her arguments that she cannot climb the stairs to the sixth-floor apartment provided by the government. Mayor Geng tells her that she is asking for too much, but once he is in his car with his staff, he discusses whether he can get her an apartment on a lower floor.

Direct, impromptu interaction between citizens and government is not unique to Datong's demolition, but is rooted in a tradition of grievance and dialogue that 
has in some form mediated the relationship between ruler and subject in China for millennia. In the influential historical narrative Zuo's Commentary (Zuozhuan), which dates back to the late fourth century $\mathrm{BC}$, a politician reasons that it is better to learn from citizens' grievances than to silence them: 'I have heard of reducing grievances by means of loyalty and kindness; I have not heard of preventing grievances by exercising power... doing so would be like trying to prevent a river from overflowing with a dike... so I listen to criticism as a remedy' (Knight 2012, 55).

The influence of this tradition was also explicitly recognised at the beginning of the Communist era, when 'the right to make written or oral complaints' (shumian konggao huozhe koutou konggao de quanli) to organs of the state was enshrined in Article 97 of the original 1954 PRC Constitution (NPC 2000). Though far from justiciable, the right to confront the state in this manner embodies the uniqueness of the Chinese political-legal system-it is among the few sections of the original Constitution of the People's Republic of China that was not lifted directly from the 1936 Soviet version.

\section{Desperation in the Narrative}

The tradition of citizens' direct confrontation of government officials also survives in today's China in part because official channels for legal grievances are either inaccessible or easily subject to elite manipulation. A prominent supporting character in the film is identified as Hui, who is distinguished by her extensive legal knowledge and litigious outlook (in one scene, she recites State Council decrees for the camera from memory). Hui questions whether the demolition of her family's home exposes broader contradictions in Chinese society: 'Should I tell [my son] to trust the law and the government, and stand up for his rights? Or should I just tell him to give up?' When she confronts the mayor directly, Hui challenges his claim that her house was constructed illegally: 'That's a problem caused by the government. How come the government wasn't supervising before but blames the fault on us now?' The mayor replies feebly: 'Who never made a mistake?' Shortly thereafter, with Hui's appeals to China's Supreme People's Court finally denied, the camera surveys the demolished ruins of her house.

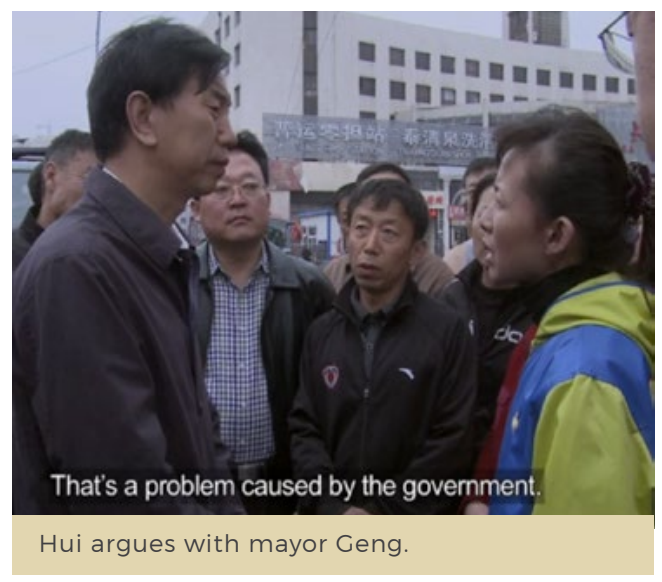

Scenes like these, in which citizens with seemingly legitimate claims cannot save their homes, build an aura of desperation that is carried forward as several characters in the film threaten suicide or indirectly reference death. One unidentified character resists the demolition of her brother's house and describes her brother and their family's forced relocation by saying: 'He ripped his belly open with a knife... I'll kill myself too... Let the corrupt rich guys live. We're not living!' The desperation of the mayor's own family also renders palpable the anxieties of people affected by the mayor's grand plans. For instance, Mayor Geng's wife confronts him at meetings and phones him repeatedly to bemoan their diminished family life: 'Have you [the mayor] had enough of living? Look at you.' In response, the mayor's calm, 
even affable demeanor comes off as ominous given the desperation of those surrounding him. When Mayor Geng tries to reassure his wife that he is not overworked, she replies: 'Are you trying to kill me?'

\section{An Unfamiliar Resolution}

As the mayor's promises of new housing add up, and with desperation rising, an unanswered question looms in the background: what will happen if these pledges of new, alternative housing go unfulfilled? Near the end of the film, the central government 'rotates' (ganbu jiaoliu) Mayor Geng to a new post as Mayor of Taiyuan, before the completion of Datong's massive relocation and construction project. For the Western audiences targeted by the film's producers, rotation of mayors is most likely an unfamiliar concept. In China, however, the rotation of mayors and other local officials to several-year stints in different localities has long been a hallmark of China's Communist nomenklatura system, a feature designed to prevent government officials from establishing parochial fiefdoms borne from close ties with local elites (Zeng 2016).

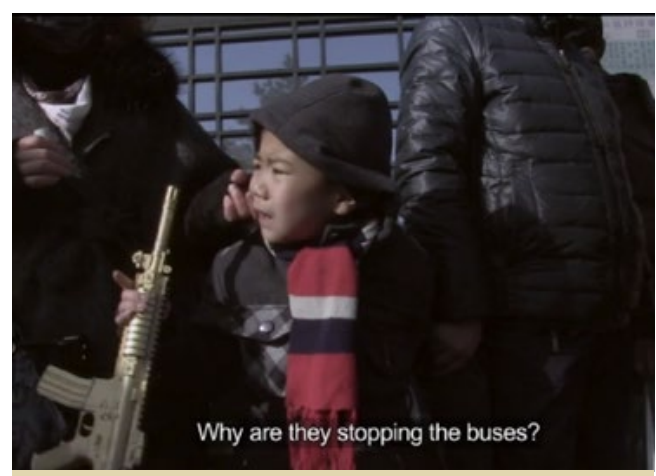

A young boy inquires about the protests that followed the mayor's abrupt departure from Datong.
To convey the import of the mayor's abrupt departure, the film employs a conversation between a young boy holding a golden toy machine gun and a woman (presumably the boy's mother). Amid large street demonstrations blocking traffic in protest at the mayor's transfer, the boy asks: 'Why are they stopping the buses?' She replies: 'They're asking for housing. No one will give them housing after Mayor Geng leaves. So, they're unhappy.' This explanation injects ambiguity into the film's resolution, as it is more cynical than the protesters' seemingly sincere chants of 'Come back, Mayor Geng!'

In these final scenes, where it is unclear whether Datong is furious over broken housing promises or distraught to lose a respected leader, the residents of Datong emerge as more sympathetic than the title character. Intriguingly, this tension is perhaps reflected in the alternative titles of the film-in some places the title is simply Datong instead of The Chinese Mayor. In contrast with the purgatory into which large, publicly financed reconstruction projects throw the relocated residents of cities like Datong-not to mention the three billion USD debt the mayor leaves behind-the rotation does not portend major consequences for Geng. In fact, the mayor ultimately plans to complete his political legacy in an even larger city, Shanxi's provincial capital Taiyuan, with a chance to dislocate even more residents: 'I wish I could have completed all my plans in Datong. But since I've been transferred, I'll create a "Cultural Taiyuan".' In the end, while the filmmakers' primary narrative intention might have been to capture the struggles faced by an idealistic mayor, they ultimately found greater success telling an historically infused story of affected residents, compelled to make sense of the debt-fuelled and politically engineered limbo thrust upon them. 


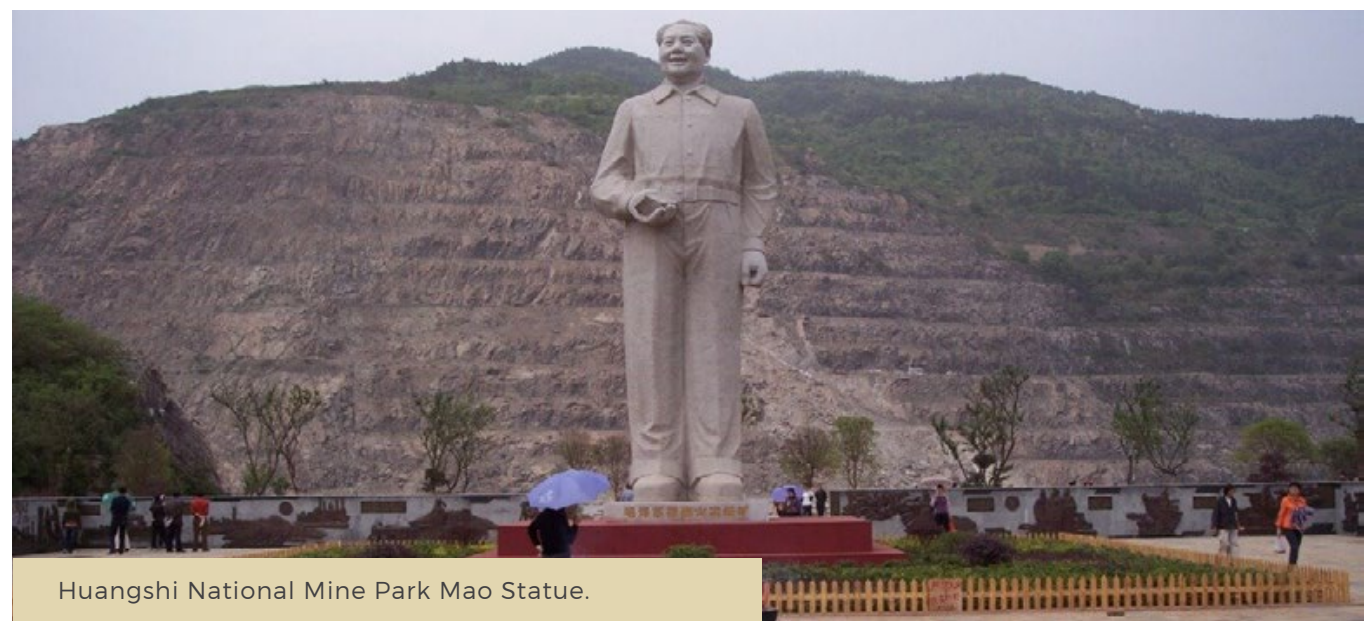

\section{China's Industrial Heritage without History}

\section{Maris Boyd Gillette}

Twenty years after the Chinese authorities decided to radically reform the country's state industry, where does public memory of the nation's socialist industrialisation reside? What aspects of the socialist path to modernity do officials or private citizens monumentalise, if any at all? To what extent does China's contemporary heritage movement encompass its socialist industrial history? This essay offers an initial attempt to answer such questions.
In the late 1990s, thousands of factories across the People's Republic of China (PRC) closed down. Most had been created as part of the Chinese Communist Party's (CCP) programme to industrialise the nation after 1949. Tens of millions of workers lost their jobs, and idle plants pockmarked thirty percent of the urban core of most cities (Frazier 2006; Hsing 2006). In Jingdezhen, the city that I have been studying since 2003, state and collective sector workers constituted 94 percent of the total employed population when these 'structural reforms' began, and the city contained approximately two hundred state and collective enterprises (Wang and Yin 1994, 443; Ding 1996, 151-152). The closures and mass layoffs profoundly shocked local residents, who experienced the 'death' of the city's porcelain factories as happening 'almost overnight' (Xiong 2012).

When China's Communist leadership decided to privatise the state and collective sector, the nation took a final step away from its socialist path to modernity. From the 1950s through to the early 1990s, the central government invested massive sums in industrial development-building new plants, inventing and purchasing new technologies, expanding the workforce, and manufacturing new products. In 
Jingdezhen, ceramics manufacturing grew from one thousand workers doing handicraft production in eight operating wood-burning kilns in 1948, into a massive porcelain industry employing over one hundred and fifty thousand workers in fifty-two mechanised sites, covering all aspects of the production process from mining to finished wares (Gillette 2016). While some outside observers and Chinese citizens recall this period primarily in terms of its political campaigns, the central government's policies nevertheless shrank income disparities between the countryside and city, provided high levels of employment and extensive job and social security, increased women's participation in the paid workforce, and raised educational levels. The decision to allow the market to drive industrial development was also a decision to relinquish most of the goals that characterised a socialist vision of the future.

Twenty years after the PRC committed China's industrial sector to the path of neoliberal capitalism, where does public memory of the nation's socialist industrialisation reside? What aspects of the socialist path to modernity do officials or private citizens monumentalise, if any at all? To what extent does China's contemporary heritage movement encompass its socialist industrial history? I offer here a first attempt to answer such questions, drawing on published sources and my fieldwork in Jingdezhen.

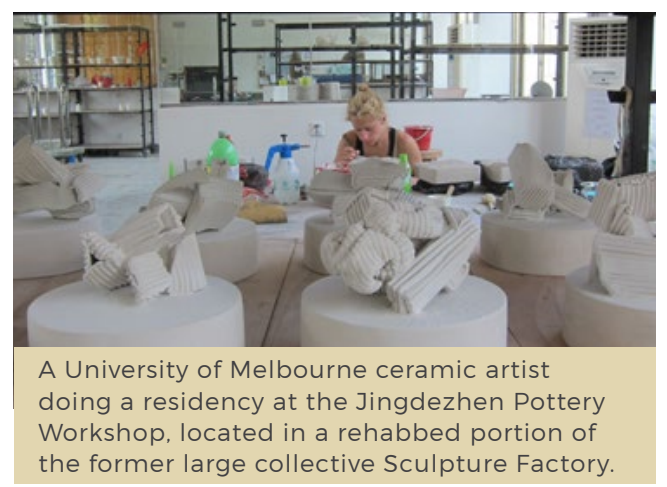

\section{Preserving Memories of Socialist Industrialisation}

Laid-off workers' narratives are the richest repository of public memory about socialist industrialisation. Former state and collective workers have repeated their stories to journalists, documentary filmmakers, and scholars-not only at the time that the state and collective sector collapsed, but for more than a decade afterwards (Williams et al. 2003; Hung and Chiu 2009; Yang 2010; Xiong 2012). In their accounts, laid-off workers testify to the meaningfulness of their membership in the socialist work unit (danwei) system in material and psychological terms. They reveal their sense of betrayal and injustice that 'the promises of the socialist ideal simply vanished' (Hung and Chiu 2009, 113). Numerous testimonies show former state and collective employees' insistent identification of themselves as 'laid-off workers' (xiagang gongren), even when they have found other work. By retaining this label, these citizens make a claim to the socialist path of modernity despite the government's rejection of it.

A more superficial form of socialist industrial history resides in the former state and collective enterprise buildings that have been preserved and adapted for new purposes. This type of architectural preservation can be said to have begun in the mid- to late 1990s, when artists in Beijing and Shanghai rented abandoned factories and warehouses to use as studios (Hee et al. 2008). In Beijing, some artists who had been evicted from the area around the old Summer Palace in 1995 moved to Dashanzi, a state enterprise built in the 1950s that was once Asia's largest military electronics plant. Factory 798 became particularly well known as an artists' community, so much so that 
international art galleries and fashionable boutiques turned the site into an 'art theme park' by the mid-2000s (Hee et al 2008, 253-256). In 2006, the State Administration of Cultural Heritage of China published its first official documents promoting the preservation and reuse of industrial heritage (Wang 2009). After this, Beijing's municipal authorities began offering funding for private developers (Chen et al. 2016, 343).

In Shanghai, private efforts to adapt socialist architecture received government support earlier than in Beijing, partly because the city had already begun preserving its semi-colonial industrial heritage in the early 1990s (Zhang 2007b). One significant early development of a former socialist enterprise was the Chunming Roving Factory on Suzhou Creek. The Shanghai municipal government began redevelopment efforts here in 1992, spurred in part by water pollution (Hee et al. 2008, 251). In 1997, Taiwanese architect Teng Kun Yen rented or purchased a Suzhou Creek warehouse built in the 1930s and made it into a design studio (Hee et al. 2008, 251; Wang 2009, 320). His redevelopment sparked other artists and designers to undertake similar renovations, leading to the preservation and adaptive reuse of not only the Chunming Roving Factory but also the socialist factories on Taikang Road that became known as Tianzifang (Yung et al. 2014). Shanghai municipal government officials quickly recognised the potential of rehabilitated socialist architecture to enhance city branding and generate revenue. In 2004 , they established a policy to promote 'creative industry clusters' which included tax concessions, special funding, and the ability to redevelop industrial land without applying for formal re-designation (Chen et al. 2016, 336, 343-344). As a result, dozens of socialist industrial sites were repurposed as creative industry clusters.

\section{A Bulldozer Approach}

Other cities were less inclined to abandon what Yung, Chan, and Xu (2014) call the 'bulldozer approach' to urban planning. In a 2016 study of twenty cities that received significant state investment for industrialisation during the $1950 \mathrm{~s}$ and 1960s, Yang (2010) shows that most municipal governments have not seen industrial heritage as a marketable resource for redevelopment and have instead removed remnants of China's socialist past. In Jingdezhen, the bulldozer approach to urban planning began in 2000, when the Bureau of Industry and Commerce bought the Jingxing Porcelain Factory, demolished it, and turned the area into a fruit and vegetable market. Other sites of socialist industry were torn down and replaced with retail storefronts and apartments.

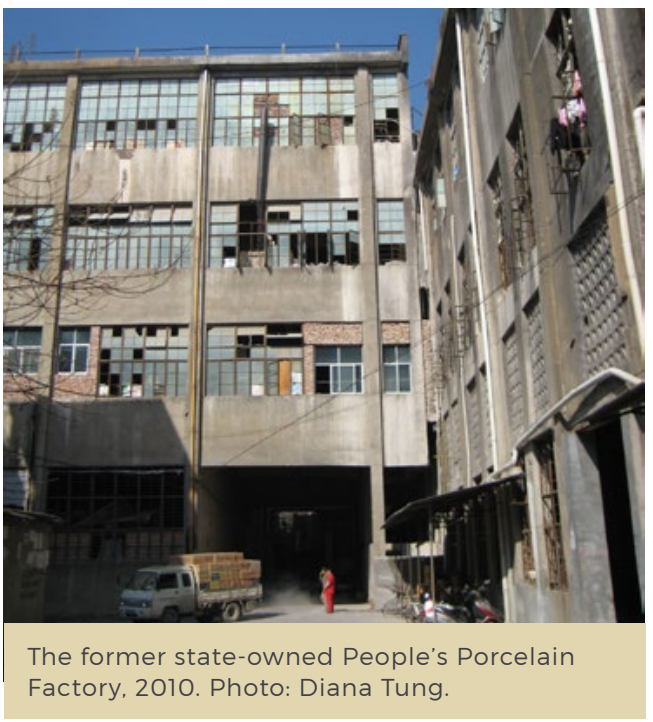

The former 'large collective' (dajiti) Sculpture Factory is Jingdezhen's primary example of adaptive reuse from the socialist period. While portions of today's Sculpture Factory bear no resemblance to the enterprise that was built in 1956, other 
parts have been preserved and adapted to serve the visiting artists and designers who participate in residencies at Carolyn Cheng's Pottery Workshop. Cheng established her Jingdezhen branch of the Pottery Workshop in the Sculpture Factory in 2005. The facility now houses gallery space, an education centre, a café, and a shop, in addition to spaces where visiting artists can design and create ceramic works.

\section{Mine Parks}

Mine parks are a third type of site that holds memories of socialist industrialisation. In 2009, the China Mining Task Force announced the government's decision to establish national mine parks at the AsiaPacific Economic Cooperation Meeting. Seven years later, officials reported that China had created seventy-two national mine parks (Tenth Mining Task Force 2016). Among them were the Jinhuagong Coal Mine Park in northern Shanxi, the Huangshi Coal Mine Park in Hubei, the Wanshan Mercury Mine Park in Guizhou, and the Haizhou Coal Mine in Liaoning. While some of the mines were put to use prior to the founding of the PRC, all received significant state resources and saw major resource extraction through to the end of the twentieth century. These 'parks' can include mine shafts, heavy machinery, historic photographs, socialist and contemporary art, and exhibits that describe the history of resource extraction and the 'lifestyles of mining communities' (China Daily 2016a).

Researchers have just begun to investigate these new industrial heritage sites, with published masters theses from urban planning and architecture programmes (Liu 2010; Meng 2011). A glimpse of how China's mine parks communicate the socialist vision of modernity is available from the reviews of visitors to the Huangshi Coal Mine Park on Trip Advisor. Many describe the former mines as visually spectacular and educational. For some, the sites produce powerful experiences of identification with the former mine workers, a visceral sense of the forward pace of socialist modernisation (jianzhengle xiandai gongye fazhang qianjinde jiaobu), and an awareness of the economic decline suffered by cities dependent on extractible resources (ganjue zhege difang gen henduo ziyuankujie chengshi yiyang, you muoluo de ganjue).

\section{A Façade of Socialist Modernity}

China's socialist industrial heritage is underdeveloped relative to its imperial and colonial pasts. Potential economic gains from tourism and commerce have driven the efforts made to date, which are almost exclusively focused on the built environment. For example, only two percent of China's cultural relics relate to industry (Xu and Aoki 2016, 80). Since at least some of these eighty-three artefacts are from industry prior to 1949, the officiallyrecognised cultural relics of socialist industrialisation represent an even smaller percentage of the total. At present, China's restored socialist structures and their creative class inhabitants preserve merely the façade of socialist modernity. Today's trendy new users largely overshadow the history of these sites' industrial development and their rapid decline. The PRC has not yet created a national inventory of its socialist industrial heritage. Nor have authorities announced plans to collect oral histories of socialist modernisation. If such trends continue, what remains of the path that China travelled toward socialist modernity will vanish, leaving only a thin veneer of industrial heritage without its rich and colourful history. 

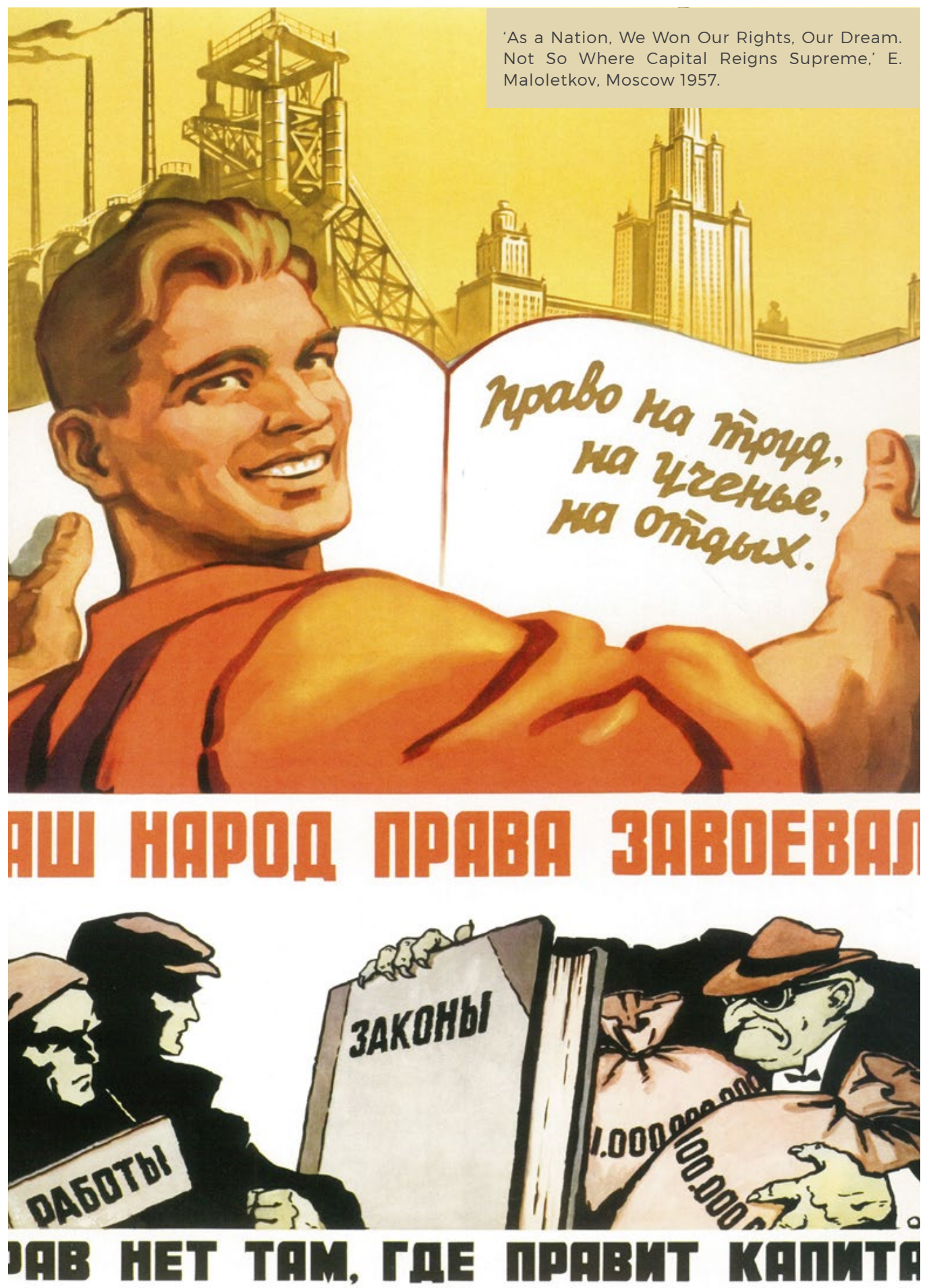


\section{Industrial}

Landscapes of

Socialist Realism

\section{Craig A. Smith}

Although industrial landscapes today appear as one of the most alien of art forms, they were once fundamental as backgrounds of socialist realist paintings. This essay examines the legacies of two masters of the genre in China and North Korea-Song Wenzhi (1919-1999) and Chōng Yōngman (1938-1999)-and demonstrates how different revolutionary histories have led to a divergence in legacy and achievement.
To many in the twenty-first century, the industrial landscape appears as one of the most alien of art forms. Yet, the billowing fumes of endless smokestacks or the web of piping from a glistening petroleum plant once made the best representatives of socialist realist painting. Socialist realist art portrayed ideal life in socialist states-anchored in communism, classconsciousness, and loyalty to the party and the people. While many Soviet works showed elements of the genre decades earlier, artists and theorists from the Soviet Union only began officially promoting socialist realism as a 'true and historically concrete depiction of reality in its revolutionary development' at the Congress of Soviet Writers in 1934, leading to its spread around the world (Gorky et al. 1977). The genre then arrived in China and Korea as an already stylised form with a long history. While in the People's Republic of China (PRC) it fell into oblivion during the reform period, it still continues to dominate in the Democratic People's Republic of Korea (DPRK) today.

In the Soviet Union, artists included industrial landscapes in the background of propaganda and artwork. The backgrounds reflected the life, and idealised the ambitions, of the working class. There was a marked emphasis on klassovost, sometimes translated as class-consciousness. Exemplars of the genre also showed partinost, loyalty to the party and its principles, and norodnost, the ambitions of the people or nation. While socialist realist industrial landscapes remained at the margins of the socialist realist genre in the Soviet Union, in the PRC and the DPRK, both of which have a long artistic tradition of landscape painting, these industrial scenes became the focus of artists' work for a short time in the mid-1970s. This essay examines the legacies of Song Wenzhi (1919-1999) and Chōng Yōngman (19381999), the most accomplished artists of industrial landscapes in the two countries, 


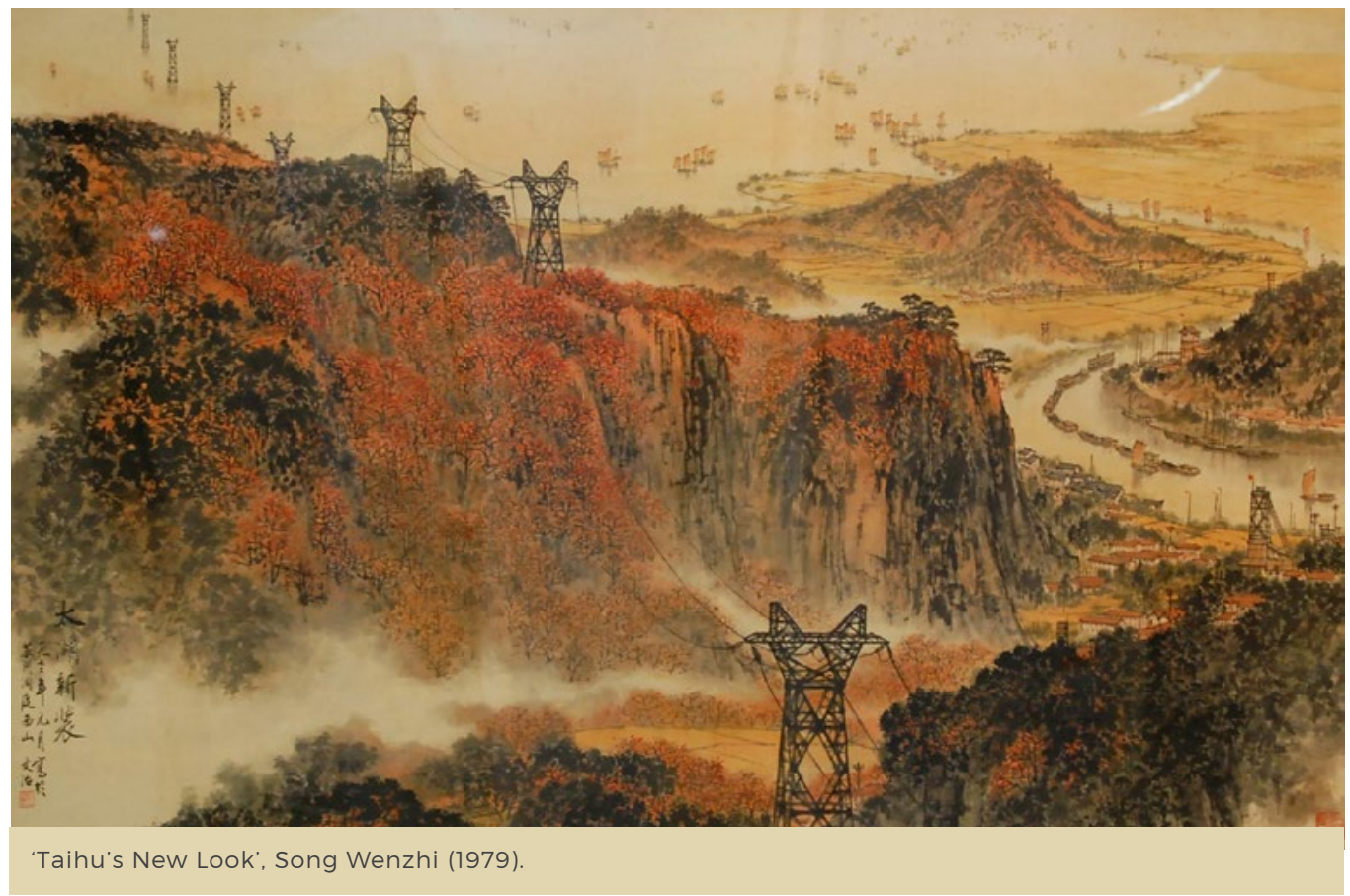

showing how different revolutionary histories have led to a divergence in legacy and achievement.

\section{Song Wenzhi and Industrial China}

In China, it was Song Wenzhi who produced the most popular examples of socialist realist industrial landscapes. Song was a classically trained artist with a strong background in landscape painting. Although he was forced to spend the first years of the Cultural Revolution (1966-1976) in a factory, he resumed painting in 1972. In 1973, he was appointed deputy director of Nanjing's Provincial Fine Arts Work Team. There, he continued to create beautiful landscape paintings. However, his art began to show elements of industrial modernity, sublimely sliding between traditional Chinese landscapes and socialist realist images of industry.
In many of Song's paintings, he introduced modern elements as a subtle but dominating feature, such as in 'Taihu's New Look' (taihu xinzhuang). Song only fully surrendered to the industrial landscape genre in a few paintings, producing images that not only stand out as excellent examples of traditional Chinese painting, but also remain iconic reminders of the time. Of these, the most memorable is his 1975 masterpiece 'Daqing Blossoms along the Yangzi River' (yangzijiang pan daqing hua). Through Song's reformed classical technique, mountains metamorphose into factories and flowers blossom as the billowing clouds from a forest of smokestacks.

Song did not continue with the genre. Whatever compelled him to create these paintings-whether it was the watchful eye of his superiors, the pull of a revolutionary 'market', or his own experiences at the beginning of the Cultural Revolution-at the end of the Maoist era he turned back to traditional landscapes. While continuing to 
sketch the occasional power line, he never returned to the subject of industrial beauty. The genre had no place in the opening up and reform period that China entered in 1978. This was not the case in the DPRK, however, where the revolution never ended.

\section{Chōng Yōngman's Depiction of History and the Workers}

In 1973, just two years before Song painted 'Daqing Blossoms', one of the most celebrated North Korean painters Chōng Yōngman produced an industrial landscape that captivated the country and led to a reconsideration of the genre of Chosōnhwa (Korean Painting) (Lee 2014b). Largely due to the historical, artistic, and ideological success of 'Evening Glow over Kangsōn Steelworks' (gangseon-ui-no-eul), Chōng later became vice-president of the
Mansudae Studio and a chairman of the central committee of the Korean Artists Federation.

The Kangsōn Steel Mill was the birthplace of the Chollima Movement, an ideologically driven productivity campaign initiated by Kim Il-sung when he visited the mill in December 1956. Unlike China's Great Leap Forward and the Stakhanovite Movement of the Soviet Union, North Korea's Chollima Movement has remained at the centre of national identity. The chollima refers to a horse of unimaginable speed in East Asian legends, indicating the astounding potential of the North Korean worker. Images of the horse are still evident everywhere in North Korea today, but Chōng's painting of the factory is just as much a symbol of this decisive period in DPRK history.

'Kangsōn Steelworks' was Chōng's most important work, marking a departure from the simple and powerful ink Chosonhwa and creating an iconic image that is still a common

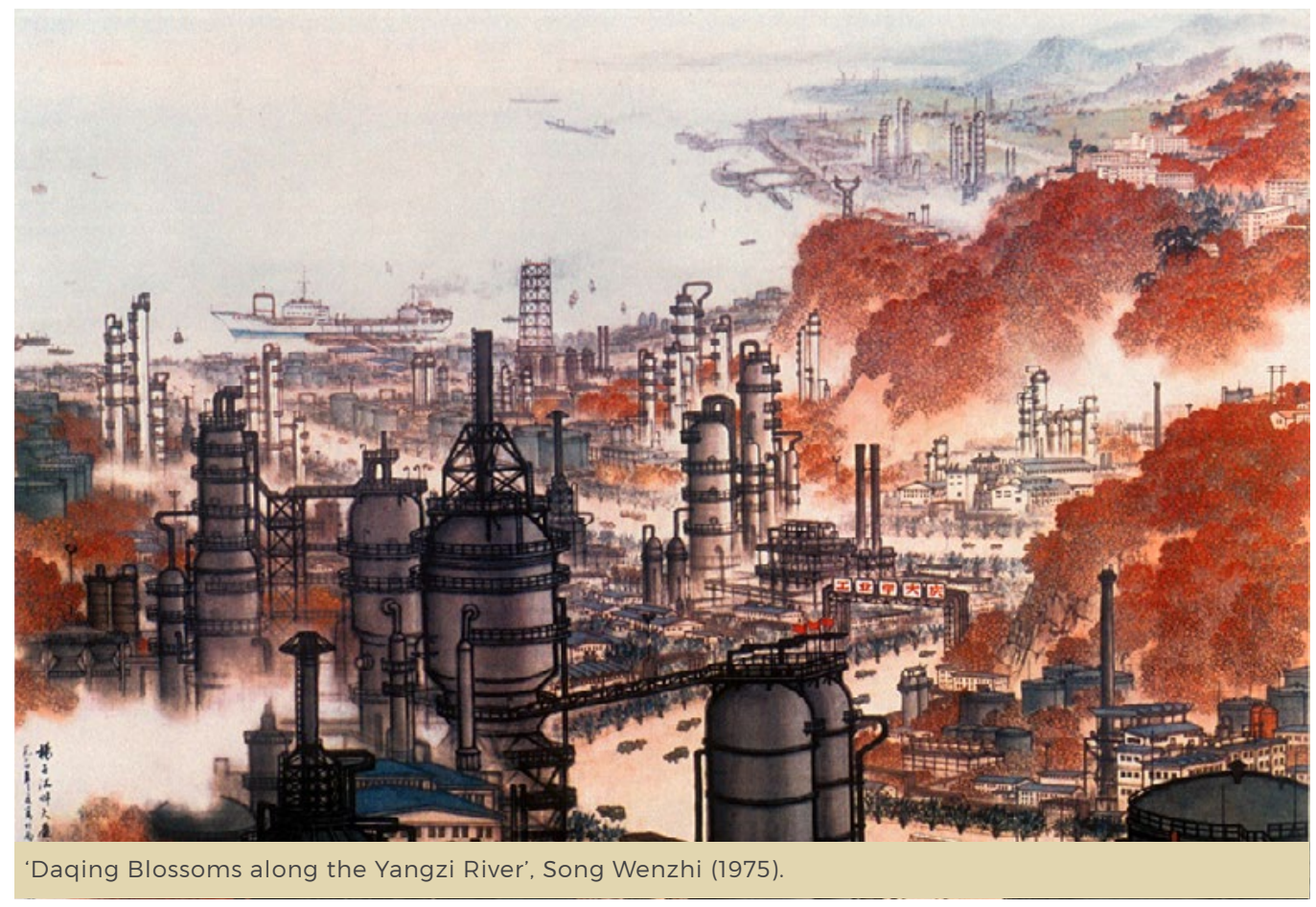



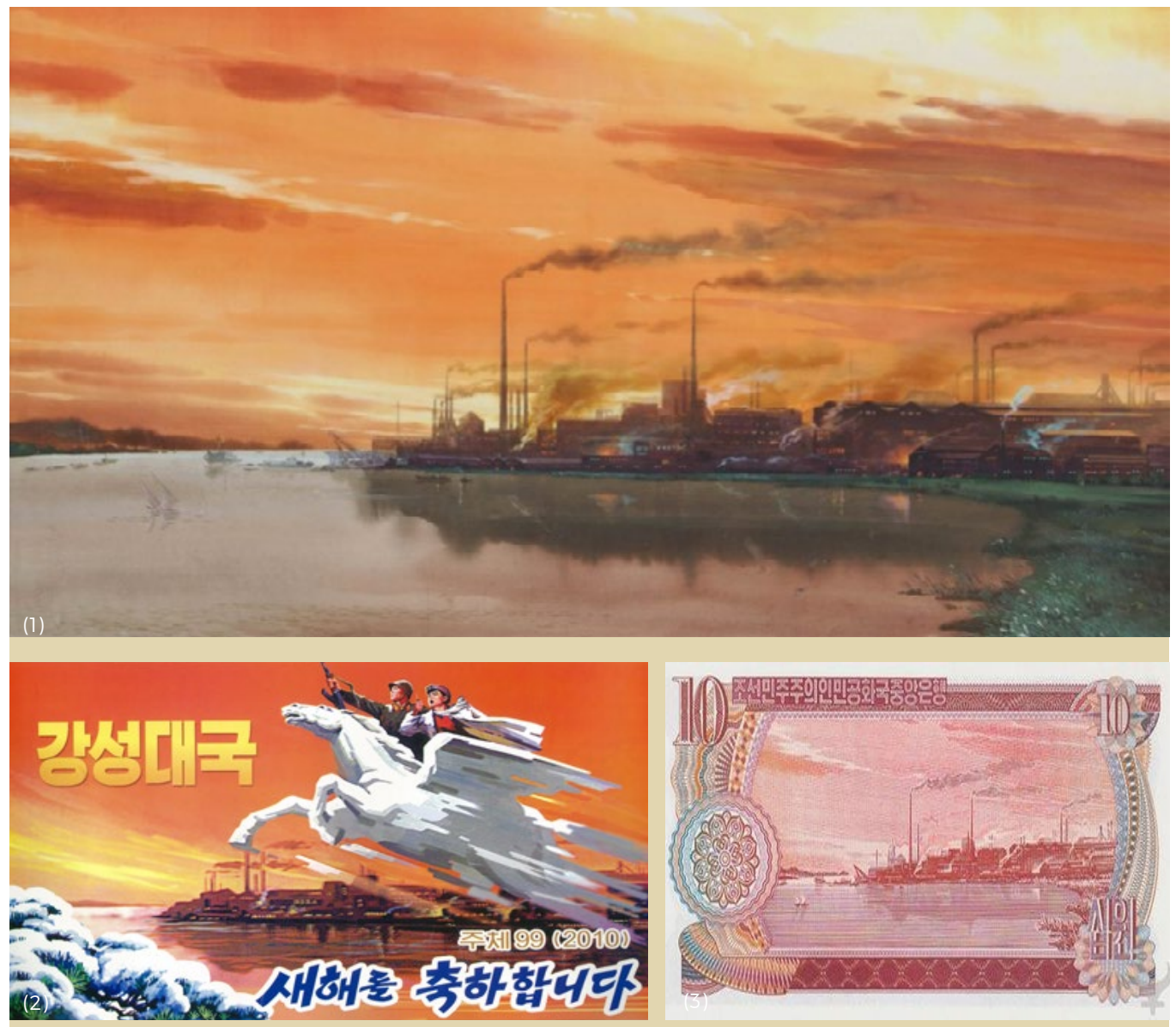

(1) 'Evening Glow over Kangsōn Steelworks', Chōng Yōngman (1973). (2) 'The worker and the soldier race forth on a chollima. A strong, great nation! Wishing everyone a Happy New Year, 2010.' (3) The ten won bill of the DPRK.

sight today. The image once featured on the ten won bill; it also serves as a backdrop for New Year's posters, and greets visitors to the Korean Museum of Art in Pyongyang. Moreover, the use of 'Kangsōn Steelworks' in official media ensures that tourists to North Korea inevitably come across this mesmerising painting in either its original form, or as the background for numerous posters that have since incorporated the classic painting in their own imagery.

\section{Real and Ideal Beauty}

Socialist realist landscapes should concentrate upon the ideal reality-rather than the real reality-for the worker, the scientist, and the farmer. Nowhere is this better achieved than in the DPRK. The socialist realist industrial landscape has long fallen out of fashion in Russia, and no longer has a place in post-socialist China, where images of smokestacks are reminders of the problems of air pollution, rather 


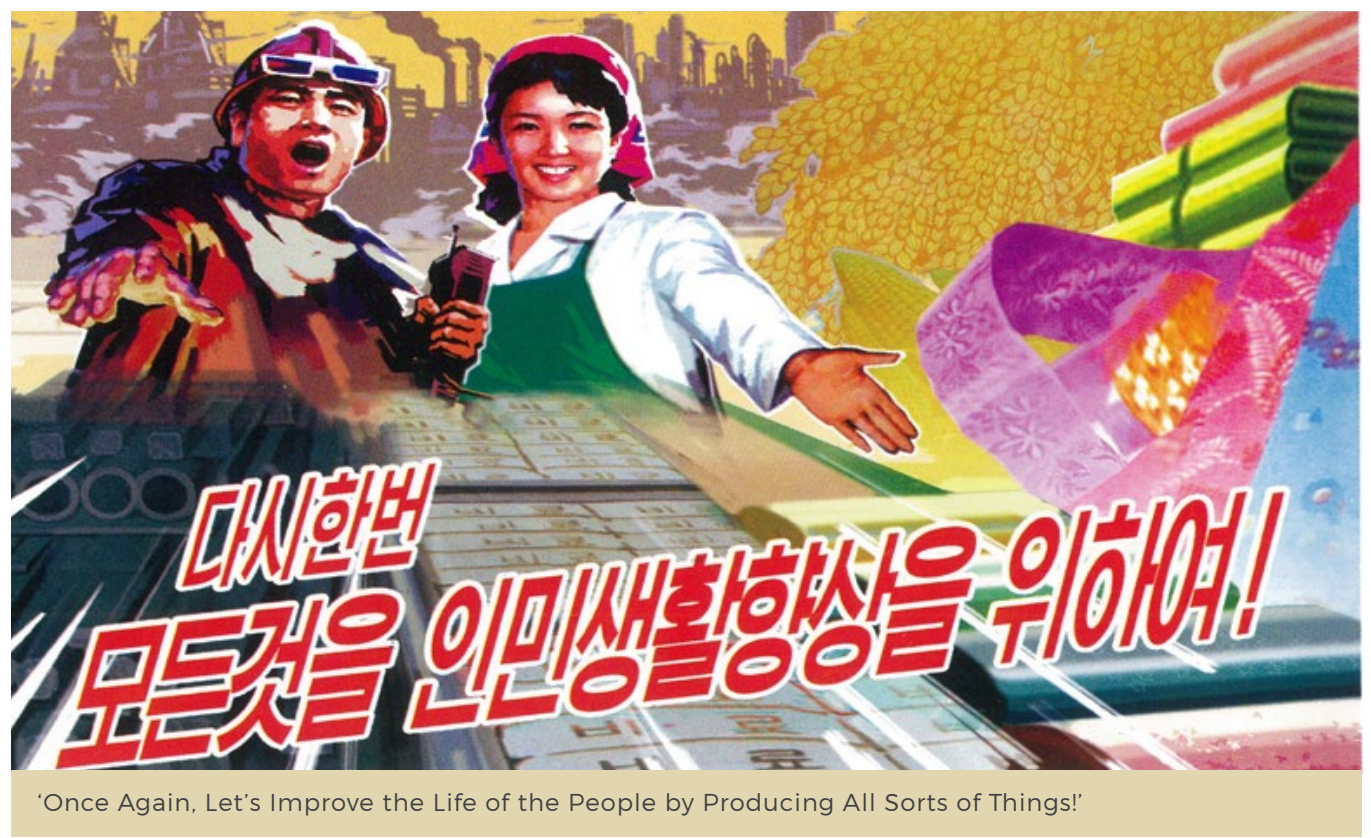

than of the glorious worker. However, the landscape still holds its symbolic value in Pyongyang, where the state glorifies the role of the worker in the continued struggle to maintain and improve the nation and the Party.

Although Song Wenzhi adapted traditional Chinese art in an innovative and a compelling fashion to produce beautiful paintings of the country's industrial accomplishments, Chōng Yōngman's 'Kangsōn Steelworks' has stood the test of time. Up to this day, it continues to captivate the people due to its vivid portrayal of industrial beauty, and finds official support due to its ideological correctness in relation to the political discourse of the ruling Party. The piece's relationship to the historical significance of the Chollima Movement cements it as an exemplar in socialist realist art-uniting the ambitions of the Party, the nation, and the working class in a way that could not be achieved in the context of China's more contentious and complicated revolutionary history.
But Chōng's achievement is not only ideological. Even before global concerns with climate change, few found beauty in images of polluting gases billowing into the air. However, those of us who have stood on concrete rooftops and watched the sun set in a torrent of colours filtered through a wall of effluvia know that these paintings are more than markers of material development. They are beautiful works of art. 


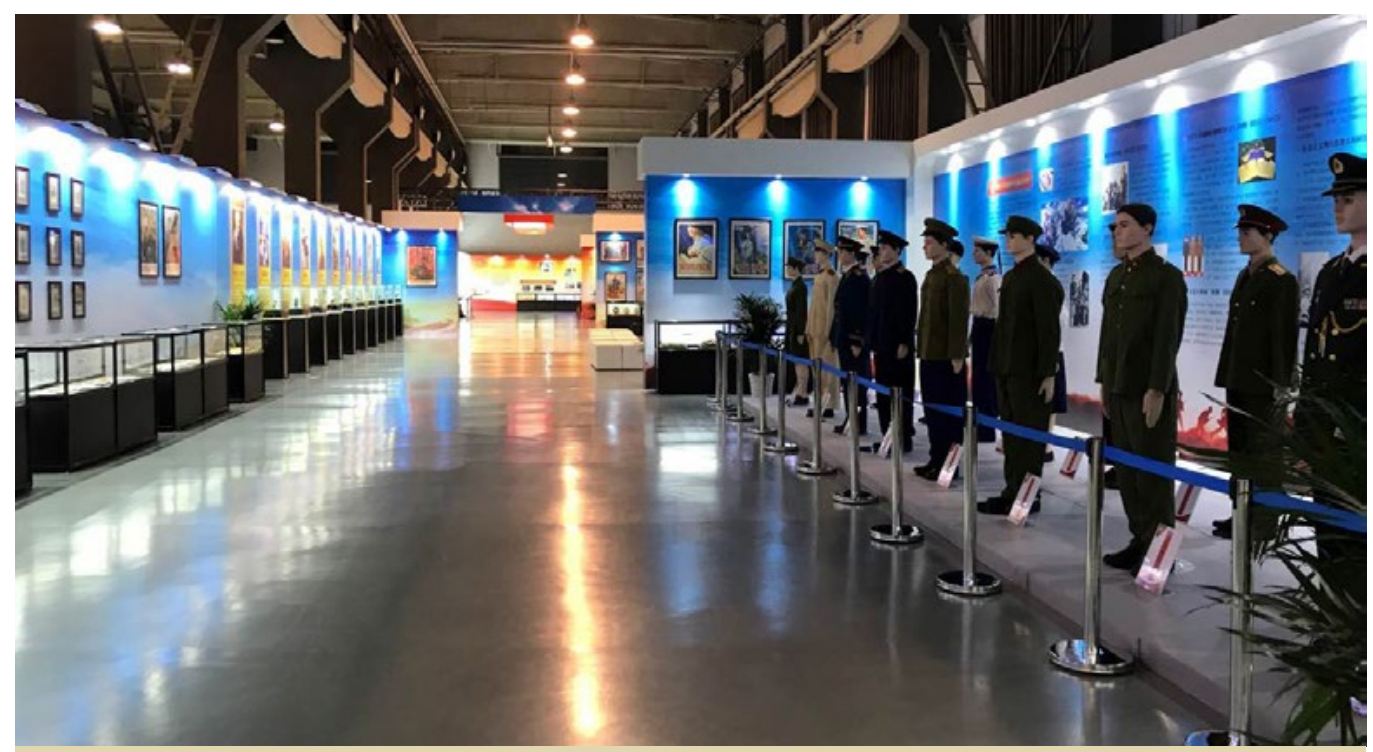

Figure 1: View of the exhibition in Chaoyang Park Beijing. August 2017. Author's photo.

\section{Collecting the Red Era in Contemporary China}

\section{Emily Williams}

Since the 1980s the Chinese Communist Party has condemned the Cultural Revolution as 'ten years of chaos'. Nevertheless, so far there has been very little discussion on the topic in the public sphere in China. This essay looks into how private collections of red relics can be used to confront this void in China's recent past. It argues that collected objects play a much more complex role in history production than we may think, as they contribute to the construction of narratives, put forth counternarratives, and fragment the very idea of historical narrative altogether.
The summer of 2017 saw the ninetieth anniversary of the founding of China's People's Liberation Army. The occasion was marked not only by a massive rally that was streamed live on television-an unequivocal display of military power overseen by President Xi Jinping (Phillips 2017)-but also by a number of exhibitions. This fact, in and of itself, is unsurprising, given the boom in museums and so-called 'red tourism' in China in recent years. One such exhibition was held at the Urban Planning Museum in Beijing's Chaoyang Park, and was significant, less for its content and curation than for its organisers: it was a collaborative effort between the government of Chaoyang 
district in Beijing, the well-known flea market of Panjiayuan, and the Red Collectors Committee of the China National Collectors Association.

The Red Collectors Association is a nationally approved body that brings together collectors of Maoist material culture. For this exhibition, they provided over 1,500 so-called 'red relics' (hongse wenwu), drawn from the private collections of association members from around the country. Somewhat peculiarly, the exhibition almost entirely excluded discussion of the objects themselves, using them as simple accessories for the broader narrative that was expounded in great detail on the walls of the exhibition. While it could be argued that in doing so the curators missed an opportunity to add an extra layer of interest to their exhibition, such a strategy is perhaps not surprising given the sensitivity that surrounds the writing of modern Chinese history. Indeed, while the curators worked hard to portray the red relics as an intrinsic part of China's 'red legacy', in reality these relics occupy a somewhat contradictory place in contemporary China.
'Red relics' are objects from the 'Red Era', a term that can indicate any period after the founding of the Chinese Communist Party (CCP) in 1921, but most often refers to the decades between 1949 and 1976. Many collections are strongest in objects from the Cultural Revolution (1966-1976), a highly controversial period that saw the production of abundant and hugely diverse material culture. Since the 1980s, the Cultural Revolution has been condemned by the CCP as 'ten years of chaos', but it continues to be the subject of both celebratory and condemnatory memories in China. These contradictory remembrances are well known, even if there is little discussion on the topic in the public sphere. For example, the Cultural Revolution was not mentioned at the Chaoyang Exhibition, except for brief mention of the country's foreign policy at that time. If we want, therefore, to understand how collections can be used to confront China's recent past, we need to look beyond public exhibitions, and consider the practices of China's red collectors.
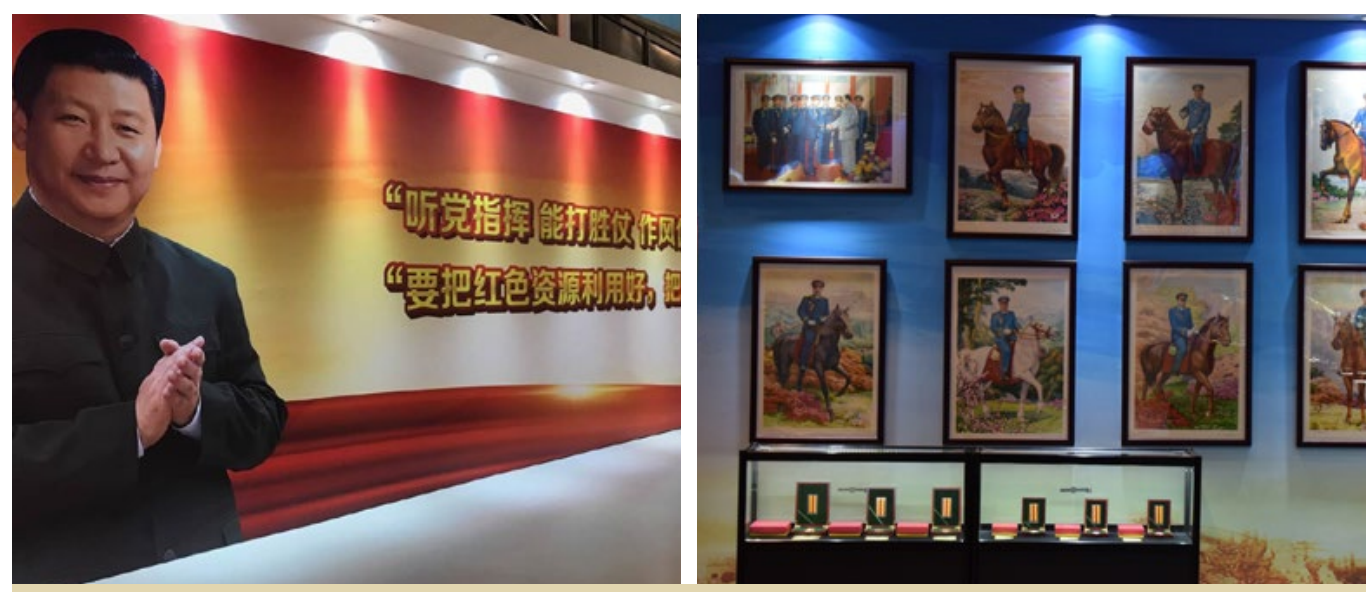

(left) Figure 2: A photograph of Chinese President Xi Jinping in the entrance hall of the exhibition. The second quote reads: 'Utilise red resources, develop the red tradition, and pass on the red gene well.' The exhibition tried to position the red relics on display as part of the 'red resources' Xi mentions. (right) Figure 3: Posters depicting some of the Ten Marshals and, below, a selection of military medals. Photos taken by the author. 


\section{Fragmented Narratives: Li Jun}

Collected objects play a much more complex role in constructing historical narratives than we may think. We might be tempted to think of a collection as a systematic accumulation of historical traces. By acquiring and then protecting these remains, the collector ensures the survival of these remnants of history, and thus ensures historical continuity. However, theorists, such as Susan Stewart (1992), problematise the relationship between history and a collection, and argue that the collected object, rather than preserving history, in fact destroys it. Indeed, the implicit search for an internal relationship between the present and the past that is embedded in the act of collecting is marked by an absolute disruption, whereby entering a collection, the object must be removed from the context from which it previously derived value and meaning. The relationship, then, is not rooted in historical reality, but rather represents an aesthetic denial of historical value. For this reason, Stewart calls a collection the 'total aestheticisation of use value' (1992, 151), and the place where history is transformed into space: a transformation that is marked most profoundly by the establishment of boundaries. According to Jean Baudrillard, a collection is defined by the establishment of a series-sets into which objects can be classified, defined by the collector, and with reference to the collector (1996, 96-97). In other words, in the classic manifestation of a collection, classification does not put forward an historical narrative, but rather fragments any such narrative through serialisation.

Cultural Revolution objects, despite their origin in perhaps the most anticapitalist period in modern Chinese history, lend themselves remarkably easily to the commodification that serialisation necessitates. For instance, Li Jun, a collector from Ningbo, Zhejiang province, began collecting Mao badges five years ago, primarily as a hobby and as a way to relieve the stress of his high-level job in a fashion company. According to an interview that I had with him in June 2016, since then he has acquired over thirty thousand Mao badges, as well as military and labour medals. He stores them in immaculately organised stacks of shelves in his spacious modern flat, organised primarily by aesthetic similarity. There are trays of young Mao on his way to Anyuan, Mao in wheat fields, Mao in every imaginable pose and in front of every imaginable background, all neatly arranged.
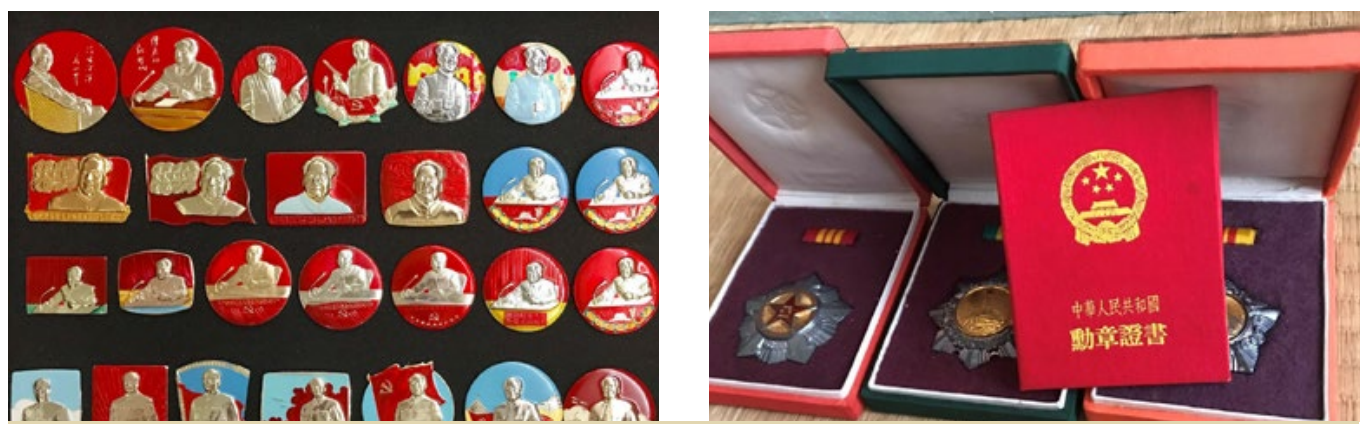

(Left) Figure 4: A selection of Li Jun's Mao badges. (Right) Figure 5: 1950s military medals and the accompanying 'meritorious medal certificate', which contains details of their original owners. Images supplied by Li Jun, 2017 

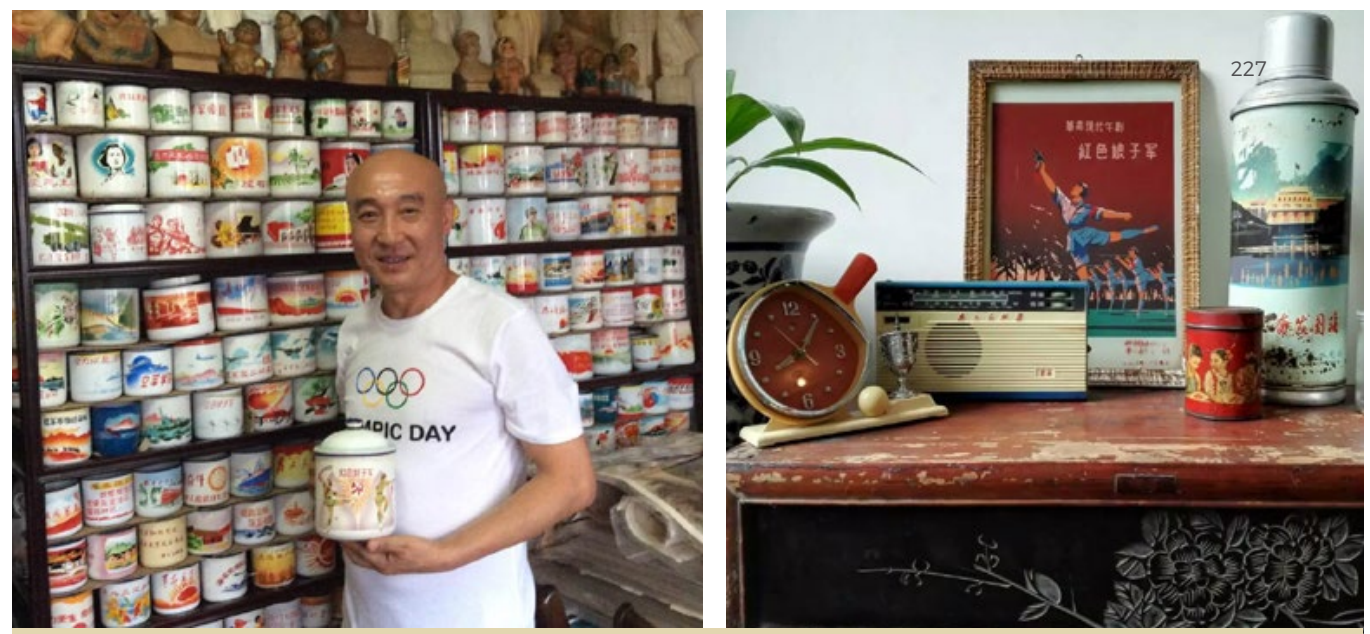

(Left) Figure 6: Beijing collector Dong Zhongchao in front of his shelf of enamel mugs, which are organised thematically. (Right) Figure 7: While Dong started off collecting posters, he now collects anything that reflects the red aesthetic of the Mao years. Image supplied by Dong Zhongchao, 2016.

Leading figures in the Collectors Association encourage members to do research on and through their objects. $\mathrm{Li}$ argues that the work units (danwei) and military units listed on the back of many badges can be a starting point for understanding cultural production during the Cultural Revolution. But, in fact, organising badges by appearance does not encourage their insertion into a historical narrative, but rather into an aesthetic series in which history is fragmented and objects gain their importance only from their appearance and their similarity (or dissimilarity) to their neighbours.

Badges have been a popular collectible in China since the early 1990s, and to be considered a collector of any merit, one must have some ten thousand unique objects. But the real way to distinguish oneself in this highly competitive field is to complement bulk objects with more rare examples. In Li's case, the pride of his collection is a small number of model worker medals and military medals, primarily from the 1950s. These are marked out by Li's attempt to historicise them: he not only collects the medals, but also tries to acquire the personal documents of each medal's former owner. In doing so, he is able to attach a personal narrative to the objects, but the process also highlights the historical distance between their original context and the present.

\section{Image-Driven Archiving: Dong Zhongchao}

Other collectors deal with the problem of historicisation in different ways. Beijing collector Dong Zhongchao-whom I interviewed in 2016 and 2017-began trading and then collecting Mao-era posters in the 1990 s, but in the 2000s he started to expand the scope of his collection. It now includes all sorts of daily life objects, such as mugs, plates, basins, teapots and thermoses, textiles and clothing, mirrors, toys, and other items that similarly share the Maoist aesthetic of the time. Alongside this, he also collects things such as Mao busts and other sculptures, editions of the Little Red Book, and Mao badges, but Dong makes no discursive or practical distinction between 

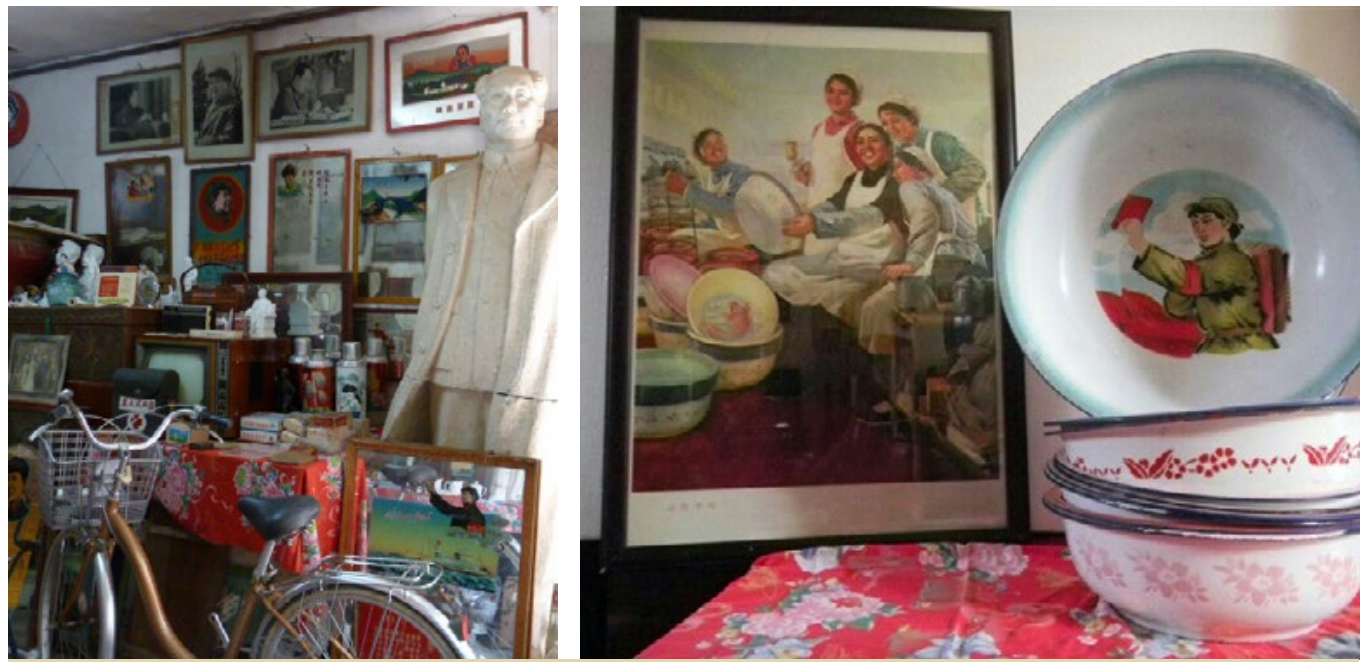

(Left) Figure 8: Dong's storeroom, containing statues, mirrors, a television, a bicycle, and myriad other objects. (Right) Figure 9: Dong's archival strategy: matching imagery from posters with objects from daily life. Photo provided by Dong Zhongchao, 2016.

these and those daily life objects, mixing them all together both on the shelves and in his conversations.

Compared to Li's ordered trays, Dong's memorabilia are stacked and heaped in an overflowing storeroom, as well as scattered throughout his home. But his collection is also meticulously digitised, and it is in his digital collection that his conception of history becomes apparent. In addition to organising his objects thematically, by place, or by period as is common in many collections, Dong takes particular pleasure in matching up his items with correspondent visual depictions in propaganda posters (see images 9 and 10).

It could be suggested that this type of archiving practice seeks to legitimise the imagery presented in the posters by demonstrating that the materiality of the life depicted in the posters can be recollected. Possessing the physical objects visible in posters seems to endorse the historicity of the poster image, suggesting the reality of the poster messages by virtue of the reality of the objects depicted in it.
But the strategy also works the other way around, as an attempt to heal the fissure in the relationship between past and present by using the poster imagery to provide the missing context for the collected objects. This strategy has a number of implications for the conceptualisation of the relationship between collected object and historical narrative.

Dipesh Chakrabarty has argued that modern historical consciousness is formed by taking objects that are contemporaneous with us and seeing them as 'relics' from the past (2008, 238-239). Doing this limits the historical object's power because it denies the possibility of a lived relation with the present-any impact the object still has is just an effect of the past. Thus, the historical object is doubly denied agency: firstly, by its removal from the context in which it originally had meaning; and secondly, by its reconceptualisation as a 'relic'. Dong's approach attempts to restore an agency to the object: combining the actual objects with their visual portrayal in posters is an attempt to construct a new, more active 

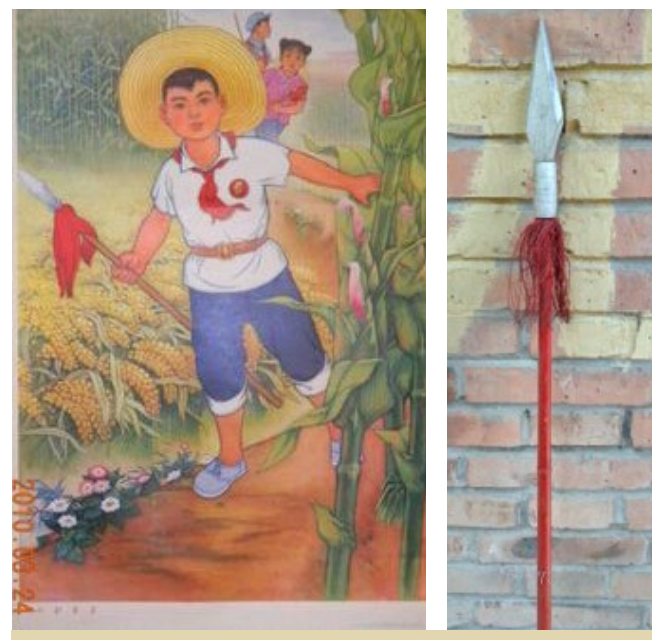

Figure 10: Dong's efforts to match poster imagery with objects goes beyond just objects of 'daily life'. Photo provided by Dong Zhongchao, 2016. way of engaging with both posters and real objects, transporting the viewer back to the Mao era, and reaffirming the validity of the values of that time, a period that he sees as characterised by greater equality compared to the corruption and individualism of contemporary Chinese society.

\section{Total Recall?}

Susan Stewart argues that the problem with trying to use relics to overcome the gap between past and present is that objects recall not the experience lived, but the experience voluntarily remembered (1992, 145). However, in today's China, where public discussion of memories of the Cultural Revolution remains limited, it is precisely memories, including those expressed through collecting practices, which are needed. While the Chaoyang Exhibition presented a clear narrative of the military's smooth rise to power and prominence, other collecting practices hold the possibility of telling more complicated stories. That these stories lack coherence is not a bad thing. Indeed, what is needed are multiple, overlapping, even conflicting narratives. If we understand the archival practices of red collectors as exercises in historical memory and as forms of historical writing, we can appreciate them for their diversity. Objects and their collections construct narratives, put forth counter-narratives, and fragment the very idea of narratives altogether. When considered collectively, they represent one of the ways in which contemporary China is attempting to deal with its difficult recent past. 


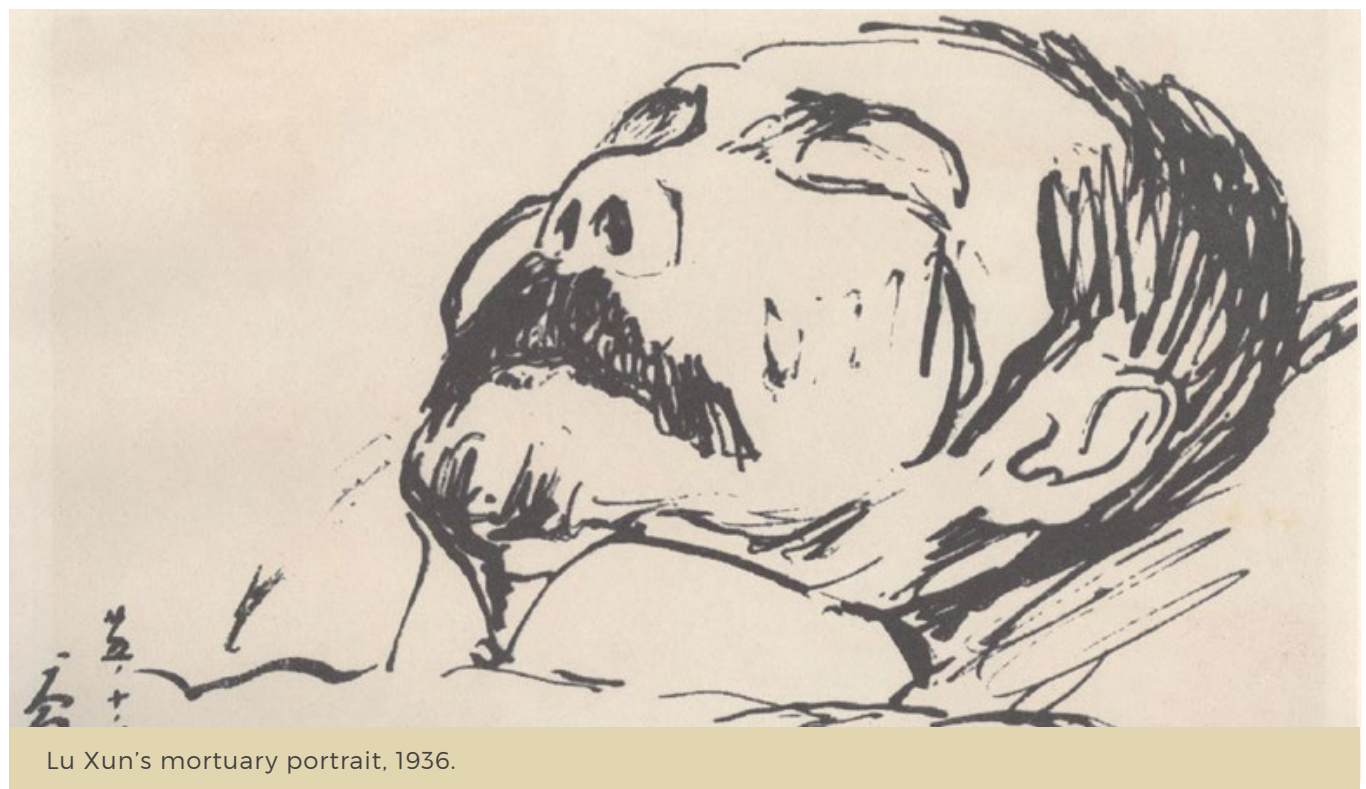

\section{Resurrecting the Dead}

\section{Ivan Franceschini}

Lu Xun today lives a new life in his homeland as well as abroad. However, given the vastness and unevenness of his oeuvre, not all his works receive the same attention. In particular, one collection of short stories stands out for their neglect: Old Tales Retold, a series of comic sketches based on ancient Chinese myths and legends published shortly before his death. This essay focusses on this semi-forgotten pearl and its relevance for today's readers.
The real misfortune suffered by men of letters lies not in being ignored and attacked in their lifetime, but comes after death when their words and conduct cease to exist; idlers pass themselves off as their confidantes spreading gossip and rumour every which way for the sake of selfpromotion. For the sake of making a little money, even a corpse becomes a tool by which they seek to secure fame and fortune, and it is this that is truly lamentable.

(Lu Xun 2017, 186-187, 94, translated by Theodore Huters)

On several occasions during his lifetime, Lu Xun (1881-1936) expressed concern over what would happen to his legacy after his death. As Eileen J. Cheng has noted, 'Lu Xun was acutely aware that after the death of the subject, texts representing the dead may take on lives of their own, as posthumous accounts can no longer be challenged by the deceased subject. Indeed, his writings selfconsciously deal with the ethics of narration and the limits of representation' (Cheng 2017, 433). Beyond the issue of people using his name for personal gain, Lu Xun worried that his writing would be distorted and manipulated to further factional and 
ideological battles. Sadly, his worst fears were to come true. In a eulogy written for the first anniversary of the writer's death, Mao Zedong hailed him as 'the sage of modern China' (xiandai zhongguo de shengren), on par with Confucius, 'the sage of feudal China'-an ironic fate for an intellectual who had spent his life attempting to break the ancient philosopher's hold on Chinese society (Mao 1939). This was the first of several speeches and articles in which Mao would appropriate $\mathrm{Lu}$ Xun for his political cause. That he was successful in this manipulation can be seen from the fact that after 1949, while the writer's former disciples and friends were falling victim to purges and violence, $\mathrm{Lu}$ Xun's name and oeuvre were used to justify a ny kind of foulness (Goldman 1982).

In spite of this, Lu Xun's legacy managed to survive and today the writer lives a new life in his homeland as well as abroad (Davies 2013a and 2013b). In China, over the past decade citations and photos of $\mathrm{Lu}$ Xun have appeared frequently on the Internet as Chinese netizens mobilised to denounce the latest injustice perpetrated by officials-be it the suppression of land protests, the muffling of critical voices, or the hypocrisy and abuses of the ruling class (Pan 2005; Henochowicz 2016). Images and characters from Lu Xun's work still appear in the conversations of ordinary people, from the 'iron house' (tiewu) where people are sleeping, unaware that they will soon be devoured by a fire raging outside, to the 'cannibalistic ethic' (chiren de lijiao) of Chinese society; from the scoundrel Ah Q, to the failed scholar Kong Yiji. I remember my surprise when, during a meeting at a women rights NGO in Beijing a few years ago, one activist referred to the 'bloody mantou' (xue mantou) - a trope from one of Lu Xun's most famous short stories, which has come to indicate the gullibility of common people, always ready to believe in the existence of absurd miraculous remedies for their problems-to complain about the obtuseness of those who refused to follow her advice.

Abroad, there has been a flourishing of new translations of $\mathrm{Lu}$ Xun into foreign languages (2010), with the latest-a collection of essays entitled Jottings under Lamplight (2017)-having been published only a few months ago. This has been accompanied by the appearance of several critical studies of remarkable breadth and profundity, such as Gloria Davies's Lu Xun's Revolution (2013), Eva Shan Chou's Memory, Violence, Queues (2012), and Eileen J. Cheng's Literary Remains (2013), to mention just a few. However, given the vastness and unevenness of the writer's oeuvre, not all his works receive the same attention. In particular, one collection of short stories stands out for their neglect: Old Tales Retold (gushi xinbian) (Lu Xun 2014), a series of comic sketches based on ancient Chinese myths and legends that Lu Xun published shortly before his death. It is on this semiforgotten pearl-and its relevance for today's readers-that this short essay will focus.

\section{The Old Tales Retold}

Old Tales Retold includes eight, short comic stories based on episodes drawn from Chinese classics. In them, we find divinities depicted as ordinary human beings, such as the goddess Nüwa, who creates mankind out of sheer boredom only to get annoyed with her creation immediately thereafter. Legendary heroes face ordinary challenges, such as an aged Hou Yi, a mythical archer who had saved the world, who has to deal with a disgruntled wife and a backstabbing disciple; or $\mathrm{Yu}$, the legendary tamer of the floods, who is confronted with the jeers of incompetent scholars and corrupt officials. Some figures come straight out of the historical annals, such as Bo Yi and Shuqi, two elders who met a tragic end because of their stubborn observance of 
Confucian morality. Others are the stuff of legends, such as Mei Jianchi, a young boy who resorts to black magic to avenge his dead father. Obviously, there is no lack of philosophers. Laozi, Mozi, and Zhuangzi appear as main characters in three of the tales. Confucius features only in an ancillary role-an absence that is far from surprising if we consider what $\mathrm{Lu}$ Xun wrote in 1926 in the afterword to his collection of essays Graves: 'As for my thinking, I have often been poisoned by Zhuangzi and Hanfeizi, at times quite casually and at others quite vigorously. I read the Confucian books earliest and most thoroughly, but they for some reason seem to have little connection with me' (Lu Xun 2017, 34, translation by Theodore Huters).

Since their publication in January 1936, Old Tales Retold never enjoyed particular renown among critics. Many were puzzled by a work so far from the realism of the writer's earlier fiction. In his preface, $\mathrm{Lu}$ Xun himself expressed scepticism about the literary value of this oeuvre: 'Most of these tales have been written in a rush, and fall short of the name 'story' as defined by literary criticism.... Moreover, having less respect for the ancients than for contemporaries, on occasions I could not avoid facetiousness' (Lu Xun 2014, 32, translation by Ivan Franceschini). Indeed, only a few months before drafting the bulk of those stories, the writer had been involved in a polemic with Lin Yutang and other proponents on the importance of 'humour' (youmo) in literature (Rea 2015, 39), going so far as to paraphrase Kierkegaard on the dangers of writing for the sheer amusement of the public:

A theatre catches fire. The clown steps to the front of the stage to announce the fact to the audience, who think it a joke and applaud. Then the clown announces again that there is a fire, but they roar with laughter and clap more loudly than ever. No doubt the world will end amid the general applause of these laughter-loving people who take everything as a joke. (Lu Xun 2003, 346-347, translated by Yang Xianyi and Gladys Yang)

While the Chinese critical debate has featured endless theoretical arguments about narrative techniques and on whether this book should be considered satire or historical fiction, discussions among the few scholars based outside China who did not dismiss this work as irrelevant have been more sanguine. In 1961, in his groundbreaking A History of Modern Chinese Fiction, C. T. Hsia described Old Tales Retold in these terms: 'In his fear of searching his own mind and disclosing thereby his pessimistic and sombre view of China at complete variance with his professed Communist faith, Lu [Xun] could only repress his deep-seated personal emotions in the service of political satire. The resulting levity and chaos... mark the sad degeneration of a distinguished if narrow talent for fiction' (1961, 46). The following year, another giant in the study of modern Chinese literature, Jaroslav Průšek, retorted: '[Lu Xun's] pictures [in Old Tales Retold] have, namely, a multiplicity of meanings, every moment relating to a number of layers of reality, their changing hues reminiscent of a winding scarf of rainbow colours. In this many-facetted iridescence lies the individuality and originality of $\mathrm{Lu}$ [Xun]'s artistic technique, which C. T. Hsia is unable to grasp...' (1962, 382). This rebuttal did not convince Hsia, however, who penned another response reiterating his opinion, citing Lu Xun's own self-deprecatory preface as evidence of the scarce value of the book (Hsia 1963).

\section{Why Read the Old Tales Retold Today?}

If even Lu Xun himself supposedly did not believe in the artistic significance of his Old Tales Retold, why rediscover this 
often overlooked book today? There are at least three reasons. First, these stories offer a glimpse into intellectual debates in Republican China that still bear relevance to China today-particularly with regard to the relationship between politics and tradition, individuals and society, and conservation and innovation. Second, by portraying ancient sages and legendary heroes not as hieratical semi-deities but as flawed human beings, Lu Xun undermines a certain kind of 'orientalist' discourse that to this day remains widespread in foreign media and academia (does this ring any Bell?). Although Ann Louise Huss (2000) hasnot without reason-associated the writer's ridicule of these figures to the physical and psychological violence against intellectuals that would be carried out during the Cultural Revolution some four decades later, the humour of Old Tales Retold undeniably provides a powerful antidote against the tendency to take the classics too seriously and to read everything related to China through pseudo-Confucian lenses. Finally, and most importantly, these tales, in their minimalism, offer a corrosive critique of any attempt at manipulating Chinese tradition for political purpose.

At its recently concluded Nineteenth Congress, the Chinese Communist Party (CCP) has amended its Constitution to include the "promotion of the creative transformation and innovative development of outstanding Chinese traditional culture' in its mission (People's Net 2017). And it is not a secret that 'Chinese traditional culture'-or at least an emasculated version of it-is at the core of the CCP's effort to promote China's soft power abroad, not least through a network of more than five hundred Confucius Institutes. In a curious assonance, in 1927, in 'The Old Tunes Are Finished', one of his most pointed essays against Chinese tradition, Lu Xun wrote of the Chinese classics as a 'soft knife' (ruan daozi), saying that the reason they are so fearsome is that readers are not alert to their danger, as they see them as being harmless (Lu Xun 2017, 173-174). Towards the end of his life, in an essay entitled 'Confucius in Modern China' published in 1935, he further elaborated on why he felt the need to attack the ancient philosopher in his writings:

Revulsion for the monk leads to distaste for the habit, and the exploitation of Confucius as an instrument to gain a certain end becoming once more transparently obvious, the desire to dethrone him grew the more potent. Therefore, when Confucius is dressed in perfect dignity, articles and works exposing his flaws are bound to appear. Confucius though he be, he must have his flaws. In normal times no one would pay them any heed, because a sage is still a man, and as such they may be forgiven him. Yet if the disciples of the Sage come forth and start prating, telling us that the Sage was this and was that, and therefore you must be likewise, people will not be able to keep from laughing out loud. (Lu Xun 2017, 186187, translation by David Pollard)

In times like these, when Chinese tradition is once again resurrected to serve dubious political purposes, it is more important than ever to rediscover the irony and sarcasm of Old Tales Retold. This is necessary not only to remind ourselves to maintain an approach to Chinese tradition devoid of dogmatism, but also to undermine the hegemonic effort of the propaganda of the CCP and the shallow authoritativeness of today's orientalists. While it is impossible to know whether by doing so we are betraying $\mathrm{Lu}$ Xun's intentions, there is a good chance that he would not have minded this opportunity 'to make the ancients out as more dead than they already are'. 


\section{CONTRIBUTOR BIOS}

\section{Børge Bakken}

Børge Bakken has worked at Oslo University, Copenhagen University, Harvard University, Ludwig Maximillian Munich University, Hong Kong University, and the Australian National University. He has written extensively on sociological and criminological issues in China. Among his books are The Exemplary Society (Oxford University Press, 2000) and Crime and the Chinese Dream (Hong Kong University Press, 2018).

\section{Tom Barnes}

Tom Barnes is an economic sociologist at the Institute for Religion, Politics, and Society at Australian Catholic University in Melbourne. His research mainly focuses on insecure, precarious, and informal work in Australia and Asia (especially India and Indonesia). He has written two books: Informal Labour in Urban India: Three Cities, Three Journeys (Routledge, 2015) and, most recently, Making Cars in the New India: Industry, Precarity and Informality (Cambridge University Press, 2018).

\section{Daria Berg}

Daria Berg, D.Phil.Oxon (1995) in Chinese Studies, is Chair Professor (Ordinaria) of Chinese Culture and Society at the University of St.Gallen, Switzerland. Her book Women and the Literary World in Early Modern China, 1580-1700 (Routledge, 2013) won the ICAS 2015 Specialist Publication Book Prize. With Giorgio Strafella, she co-edited Transforming Book Culture in China, 1600-2016 (Harrassowitz, 2016). Her current research explores China's cultural entrepreneurs and she is writing a book on China's leaders.

\section{Anita Chan}

Anita Chan is co-editor of The China Journal and a Visiting Fellow at the Political and Social Change Department of the Australian National University. She was formerly a Research Professor at University of Technology Sydney. She has published widely on Chinese workers' conditions, the Chinese trade union, labour rights, and comparative labour issues. Her ten books include China's Workers Under Assault: The Exploitation of Labor in a Globalizing Economy (2001) and, as editor, Labour in Vietnam (2011), Walmart in China (2011), and Chinese Workers in Comparative Perspective (2015). Her current research project compares the industrial relations systems of Vietnam and China.

\section{Jenny Chan}

Jenny Chan is an Assistant Professor of Sociology at Hong Kong Polytechnic University and an Advisor of SACOM. She is co-author of Dying for an iPhone (with Mark Selden and Ngai Pun, forthcoming) and La machine est ton seigneur et ton maittre [The Machine is Your Lord and Your Master] (with Yang and Xu Lizhi, 2015).

\section{Chen Shuxia}

Chen Shuxia is a PhD candidate at the Australian National University. Her research focuses on Chinese photography and its aesthetic transformation in the 1980s. Shuxia's essays have been published in Trans Asia Photography Review, Art China, artforum.com.cn, etc. Currently she is curating a series of exhibitions on photography groups active in China between the mid-1970s and late 1980s.

\section{Francesca Coin}

Francesca Coin is a lecturer in Sociology at Ca' Foscari University of Venice, where she teaches about neoliberal policies and global social movements. Her research focuses on money, labour, and subjectivity. Her latest book is Keep the Union at Bay: The Racial Dimensions of Antiunion Practices in U.S. Agriculture and the Long Fight for Migrant Farm-labor Representation (Edizioni Ca' Foscari, 2018). 


\section{Antonella Diana}

Antonella Diana is Marie Skłodowska-Curie Fellow at Sassari University. Her research interests include border governing, ethnicity, and the socio-economic effects of Chinese transnational investment, migration, and trade in mainland Southeast Asia. The author is grateful to Josto Luzzu for providing logistic support and research assistance during her fieldwork in 2015.

\section{Manfred Elfstrom}

Manfred Elfstrom is a China Public Policy Postdoctoral Fellow at Harvard University's Ash Center for Democratic Governance and Innovation. He has a doctorate from Cornell University's Department of Government. Before beginning his doctoral studies, he worked for several years with non-profit organizations supporting worker rights in China.

\section{Ivan Franceschini}

Ivan Franceschini is a Marie Skłodowska-Curie Fellow at Ca' Foscari University of Venice and at the Australian Centre on China in the World, the Australian National University. His current research mainly focuses on labour and civil society in China and Cambodia.

\section{Eli Friedman}

Eli Friedman is an Assistant Professor of International and Comparative Labour at Cornell University and the author of Insurgency Trap: Labor Politics in Postsocialist China (Cornell University Press, 2014).

\section{Fu Hualing}

Fu Hualing is a Professor in the Faculty of Law at the University of Hong Kong. His research interests include constitutional law and human rights, with a special focus on legal institutions.

\section{Daniel Fuchs}

Daniel Fuchs is a $\mathrm{PhD}$ Candidate in the Department of Development Studies at SOAS, University of London. His research focuses on migration, workers' struggles, and state-labour relations in Southwestern China.

\section{Brendan Galipeau}

Brendan A. Galipeau is the Annette and Hugh Gragg Postdoctoral Research Fellow in Transnational Asian Studies at the Chao Center for Asian Studies at Rice University. His research interests and publications focus on the Tibetan regions of southwest China, historical and contemporary wine and viticulture, Catholic missionaries in Tibet, landscapes, and the sociocultural impacts of hydropower development and agrochemical pollution.

\section{Maris Boyd Gillette}

Maris Boyd Gillette is Professor of Social Anthropology at the University of Gothenburg, Sweden. She is a sociocultural anthropologist and filmmaker who has studied porcelain workers and entrepreneurs in Jingdezhen, as well as urban Chinese Muslims in Xi'an. She works regularly with museums on exhibitionsmost recently the Campbell House Museum, the St Louis Art Museum, and the Missouri History Museum.

\section{Jennifer Y. J. Hsu}

Jennifer Y. J. Hsu is a faculty member in the Department of Political Science at the University of Alberta. Her research interests include state-society and state-NGO relations, the growth of civil society in China, and the internationalisation of Chinese NGOs. She is the author of State of Exchange: Migrant NGOs and the Chinese Government (University of British Columbia Press, 2017).

\section{William Hurst}

William Hurst is Associate Professor of Political Science at Northwestern University, where his work focuses on dimensions of Chinese and Indonesian politics including: political economy, social movements and contentious politics, labour politics, and the politics of law and legal institutions. He is the author of The Chinese Worker after Socialism (Cambridge 2009) and Ruling Before the Law: The Politics of Legal Regimes in China and Indonesia (Cambridge 2018). 


\section{Carlo Inverardi-Ferri}

Carlo Inverardi-Ferri (DPhil Oxon) is a PostDoctoral Fellow in the Department of Geography and Global Production Networks Centre at the National University of Singapore. His work is situated in the field of economic geography. The author thanks Jasnea Sarma and Andrea Pia for their valuable comments on previous versions of this short essay.

\section{Jonathan J. Kinkel}

Jonathan J. Kinkel is Assistant Director of the Center for Asian Research at Arizona State University. He received a PhD in Government from UT-Austin in 2015, and his research focusses on the development of the Chinese legal system since the Cultural Revolution.

\section{Kevin Lin}

Kevin Lin is China Programme Officer at the International Labor Rights Forum. His research interests focus on labour and employment relations in China's state sector, and China's labour movement and civil society.

\section{Loretta leng Tak Lou}

Loretta Ieng Tak Lou is Research Fellow in the Department of Sociology at the University of Warwick and a Postdoctoral Associate at Oxford's Institute of Social and Cultural Anthropology. Loretta's research interests lie in the areas of the environment, health, science and technology studies, social movements, and social changes in Greater China, the United Kingdom, and the United States.

\section{Nicholas Loubere}

Nicholas Loubere is Associate Senior Lecturer in the Study of Modern China at the Centre for East and South-East Asian Studies, Lund University. His research examines socioeconomic development in rural China, with a particular focus on microcredit and the rural financial system.

\section{Ma Tian}

Ma Tian is a dual $\mathrm{PhD}$ Candidate at Utrecht University and the University of Kent, in the Doctoral Programme in Cultural and Global Criminology. Her research explores how internal migrants are criminalised in China, with a focus on the relationship between migration and crime, punishment and governance.

\section{Nicola Macbean}

Nicola Macbean is the Executive Director of The Rights Practice, a UK-based NGO that supports those working for human rights. Nicola has worked closely with Chinese lawyers and other human rights defenders, and has implemented projects helping to combat the use of torture and the death penalty.

\section{Timothy McLellan}

Timothy McLellan is a $\mathrm{PhD}$ candidate in anthropology at Cornell University. He has a BA in Law and Chinese from The School of Oriental and African Studies, and an MSc in Law and Anthropology from The London School of Economics.

\section{Henrik Kloppenborg Møller}

Henrik Kloppenborg Møller is a PhD Candidate at the Department of Sociology, Lund University, and a visiting $\mathrm{PhD}$ candidate at Yunnan Minzu University. He has done long-term fieldwork among Chinese vendors of counterfeit goods in Shanghai and among jade carvers and traders in southwest China and northern Myanmar. His research interests include relations between materiality, knowledge, authenticity, value, and identity in China.

\section{Elisa Nesossi}

Elisa Nesossi is an Australian Research Council Fellow at the Australian Centre on China in the World, the Australian National University. Her research interests are Chinese law, criminal justice, and human rights. 


\section{Pun Ngai}

Pun Ngai is a Professor in the Department of Sociology at the University of Hong Kong. Her research focusses on labour, gender, and globalisation in mainland China and Hong Kong. She has published extensively in the areas of sociology, anthropology, labour studies, China studies, and cultural studies.

\section{Astrid Norén-Nilsson}

Astrid Norén-Nilsson is an Associate Senior Lecturer at the Centre for East and South-East Asian Studies, Lund University. Her scholarship focuses on the politics of Cambodia in the postconflict reconstruction era (1993-). She is the author of Cambodia's Second Kingdom: Nation, Imagination, and Democracy (Cornell SEAP, 2016).

\section{Fabio Perocco}

Fabio Perocco is an Associate Professor of Sociology at Ca' Foscari University of Venice. His research interests focus on inequalities, migration, labour, and racism. He is currently engaged in a project examining posted workers in Europe (Poosh).

\section{Andrea Enrico Pia}

Andrea Enrico Pia is a Fellow in the Anthropology of China at the London School of Economics since 2015. He has published a number of journal articles and book chapters on Chinese law, the environment, and the provision of public goods. As part of his teaching on contemporary Chinese society, he recently developed a digital ethnography titled The Long Day of Young Peng, which explores the journey of a young Chinese migrant to Beijing in search of employment. Actively engaged in public anthropology, he has published extensively on the web, and is a member of the editorial team of Made in China.

\section{Katie Quan}

Katie Quan is a senior labour specialist at the UC Berkeley Center for Labor Research and Education. She specialises in labour in the global economy, and was formerly Co-Director of the International Center for Joint Labor Research at Sun Yat-sen University, Guangzhou. Prior to working in academia, Katie Quan was a seamstress, organiser, and officer with the garment workers' union in the US.

\section{Taru Salmenkari}

Taru Salmenkari is an Associate Professor at Tallinn University, Estonia. Her research interests focus on civil society and other social spaces in East Asia, specifically in China and Taiwan.

\section{Edwin Schmitt}

Edwin Schmitt is a Postdoctoral Researcher at the University of Oslo. In the past, he has conducted ethnographic and survey-based research on environmental consciousness in the city of Chengdu. His current project aims to examine how the production of energy has been connected to the formation of, and changes within, the broader political power structures in recent Chinese history.

\section{Karla W. Simon}

The late Karla Simon was a Professor of Law and Affiliated Scholar at the US-Asia Law Institute, New York University School of Law. She sadly passed away while this book was in preparation.

\section{Kaxton Siu}

Kaxton Siu is an Assistant Professor at the Department of Applied Social Sciences at the Hong Kong Polytechnic University. His publications have focussed on Chinese factory workers, Hong Kong youth, social movements, and the political economy of development in China, Vietnam, and Hong Kong. He is currently researching labor politics and civil society in China and Vietnam. 


\section{Chris Smith}

Chris Smith is Professor of Organisation Studies and Comparative Management at Royal Holloway, University of London. His research interests are in labour process theory, work and employment transfer through the transnational firm, comparative analysis of work and employment, and professional labour.

\section{Craig A. Smith}

Craig A. Smith is a Postdoctoral Fellow at the Australian Centre on China in the World. His research focusses on the intellectual and social history of China in the early twentieth century, particularly with regard to the flow of intellectual concepts used in resistance to imperialism.

\section{Holly Snape}

Holly Snape is a Postdoctoral Fellow at the Research Centre for Chinese Politics, School of Government, Peking University.

\section{Dorothy J. Solinger}

Dorothy J. Solinger is Professor Emerita of Political Science at the University of California, Irvine. From 1992 to 2008, she was also a Senior Adjunct Research Scholar at the Weatherhead East Asian Institute, Columbia University. She has authored/edited seven books, a special journal issue, and nearly one hundred articles. Her current work is on urban poverty and poverty relief policies in China.

\section{Christian Sorace}

Christian Sorace is an Assistant Professor of Political Science at Colorado College. He is the author of Shaken Authority: China's Communist Party and the 2008 Sichuan Earthquake (Cornell University Press, 2017). He is currently conducting research on the urbanisation of the grasslands in Inner Mongolia, China, and ger districts in Ulaanbaatar, Mongolia.

\section{Giorgio Strafella}

Giorgio Strafella is Senior Research Fellow in Chinese Culture and Society at the University of St.Gallen and the author of Intellectual Discourse in Reform Era China (Routledge, 2017). His articles on intellectuals, artists, and political discourse in contemporary China have appeared in Asian Studies Review, China Information, and Asiatische Studien/Études Asiatiques.

\section{Jessica C. Teets}

Jessica C. Teets is an Associate Professor in the Political Science Department at Middlebury College, and Associate Editor-in-Chief of the Journal of Chinese Political Science. Her research focuses on governance in authoritarian regimes, especially sources of change such as local policy experimentation and civil society. She is the author of Civil Society Under Authoritarianism: The China Model (Cambridge University Press, 2014) and editor (with William Hurst) of Local Governance Innovation in China: Experimentation, Diffusion, and Defiance (Routledge Contemporary China Series, 2014).

\section{Emily Williams}

Emily Williams is a Research Fellow at Fudan University, Shanghai. She received her $\mathrm{PhD}$ from Birkbeck College, University of London in 2016. Her research focuses on the global impacts and legacies of Chinese Communist art and history. For more on contemporary Red Collectors, follow Emily on Instagram @Red_ Collectors_China.

\section{Roberta Zavoretti}

Roberta Zavoretti is the author of Rural Origins, City Lives: Class and Place in Contemporary China (University of Washington Press, 2017). She is interested in the entanglements of gender and class formation, and has published on family politics, care, and affective structures in post-Maoist China. Currently, she teaches social anthropology at the University of Köln, Germany. 


\section{Zheng Yu}

Zheng $\mathrm{Yu}$ is a Senior Lecturer in Asian Business and International Human Resource Management at the School of Management, Royal Holloway, University of London. Yu's research focuses on work organisation and employment relations in multinational firms, particularly those from China and Japan. 


\section{BIBLIOGRAPHY}

Aanchal Magazine, 'Provident Fund: Protests Force Govt to Ease Rules It Tightened', The Indian Express, 20 April 2016, online at: http://indianexpress.com/article/business/business-others/pfwithdrawal-norms-put-on-hold-till-july-31-following-protests/

ACFTU (All-China Federation of Trade Unions), 'AFL-CIO President Richard Trumka Visits China', 8 October 2013, online at: http://en.acftu.org/28746/201405/15/140515082037268.shtml

AFL-CIO (American Federation of Labor and Congress of Industrial Organizations), 'New AFL-CIO TPP Report Highlights Lack of Worker Protections', 16 February 2016, online at: https://aflcio.org/ press/releases/new-afl-cio-tpp-report-highlights-lack-worker-protections

Rina Agarwala, Informal Labour, Formal Politics, and Dignified Discontent in India, Cambridge: Cambridge University Press, 2013.

Agence France-Presse, 'Wealth Gap Puts China Among World's Most Unequal Nations, Survey Reveals', South China Morning Post, 30 May 2016, online at: http://www.scmp.com/news/china/ article/1102490/wealth-gap-puts-china-among-worlds-most-unequal-nations-survey-reveals

Agence France-Presse, 'Kokang Border Conflict Intensifies, Myanmar Shells Fall in China: Residents', Radio Free Asia, 20 April 2015, online at: http://www.rfa.org/english/news/china/ kokang-border-conflict-intensifies-04202015165745.html

Weiwei Ai, 'Every Day in China, We Put the State on Trial”, The Guardian, 16 April 2013, online at: https://www.theguardian.com/commentisfree/2013/apr/15/ai-weiwei-china-state-on-trial

Weiwei Ai, 'Zuochu xuanze' (Making Choices), in Weiwei Ai and Xiaojun Zeng, Huipishu (Grey Cover Book), 1997, online at: https://aaa.org.hk/en/collection/search/library/grey-cover-book

Weiwei Ai and Xiaojun Zeng eds, Baipishu (White Cover Book), 1995, online at: https://www.aaa.org. hk/en/collection/search/library/white-cover-book/view_as/grid/search/keywords:white-coverbook/page/1

Al Jazeera, 'Riot Closes China Foxconn Factory', Al Jazeera, 24 September 2012, online at: http://www.aljazeera.com/news/asia-pacific/2012/09/20129248119140129.html

Peter Alexander and Anita Chan, 'Does China Have an Apartheid Pass System?', Journal of Ethnic and Migration Studies, vol.30, no.4 (2004): 609-629.

AMRC (Asia Monitor Resource Centre), 'A Week That Shook Cambodia', 1 February 2014, online at: http://www.uniontounion.org/pdf/FFM-Cambodia-Report.pdf

Ann Anagnost, 'From "Class" to "Social Strata”: Grasping the Social Totality in Reform-Era China', Third World Quarterly, vol.29, no.3 (2008): 497-519. 
Ricardo Antunes, The Meanings of Work, Leiden and Boston: Brill, 2013.

Apple Inc., 'Apple Supplier Code of Conduct', January 2017, online at: https://images.apple.com/ supplier-responsibility/pdf/Apple-Supplier-Code-of-Conduct-January.pdf

Apple Inc., 'iPhone First Weekend Sales Top Five Million', Newsroom, 24 September 2012, online at: https://www.apple.com/newsroom/2012/09/24iPhone-5-First-Weekend-Sales-Top-Five-Million

Apple Insider, 'Riot Reported at Apple Partner Manufacturer Foxconn's iPhone 5 Plant [ux2]', Apple Insider, 23 September 2012, online at: http://appleinsider.com/articles/12/09/23/riot_reported_at_ apple_partner_manufacturer_foxconns_iphone_5_plant

Arbitration Council, 'Law on Trade Unions', 17 May 2016, online at: https://www.arbitrationcouncil. org/uploads/afca9-trade-union-law_promulgated-17may2016-eng.pdf

Kenn Ariga, Fumio Ohtake, Masaru Sasaki, and Zheren Wu, 'Wage Growth through Job Hopping in China', Institute for the Study of Labour, Discussion Paper No.7104, December 2012, online at: https://econpapers.repec.org/paper/izaizadps/dp7104.htm

Dennis Arnold, 'Civil Society, Political Society and Politics of Disorder in Cambodia', Political Geography, vol.60 (2017): 23-33.

Asia Foundation, 'China's Overseas Development Policy in a World "Beyond Aid", Roundtable Report, June 2015, online at: https://asiafoundation.org/resources/pdfs/ ChinasOverseasDevelopmentPolicyRoundTableReport2015FINAL.pdf

Asian Development Bank, 'Myanmar: Economy', 2017, online at: https://www.adb.org/countries/ myanmar/economy

Australia Asia Worker Links, 'Historical Strike in India - 150 Million Workers Strike', Australia Asia Worker Links, 6 September 2015, online at: http://aawl.org.au/content/historical-strike-india-150million-workers-strike

Australia Asia Worker Links, 'Tens of Millions of Workers Participate in General Strike in India', Australia Asia Worker Links, 24 February 2013, online at: http://aawl.org.au/content/tens-millionsworkers-participate-general-strike-india

S. Bageshree and K.V. Aditya Bharadwaj, 'Anatomy of a Leaderless Protest', The Hindu, 20 April 2016, online at: http://www.thehindu.com/news/cities/bangalore/anatomy-of-a-leaderless-protest/ article8497313.ece

Ananth Baliga and Lay Samean, 'Government Sets Minimum Wage at \$153 a Month', The Phnom Penh Post, 30 September 2016, online at: http://www.phnompenhpost.com/national/governmentsets-minimum-wage-153-month

Sabita Banerji, ‘The Anniversary of Unity’, Orumai, 13 September 2016, online at: https://orumai. org/2016/09/13/the-anniversary-of-unity/

Tom Bannister, 'NGOs Have Their Say: The 2013 China Foundation Rankings', China Development Brief, December 2014, online at: http://chinadevelopmentbrief.cn/articles/ngos-have-their-say-the2013-china-foundation-rankings 
Pietro Basso, 'Neoliberalism, Crisis and International Migration', in Lucia Pradella and Thomas Marois eds, Polarizing Development: Alternatives to Neoliberalism and the Crisis, London: Pluto Press, 2014, 86-97.

Pietro Basso, 'Politiche migratorie e precarizzazione del lavoro', in Francesca Coin ed, Gli immigrati, il lavoro, la casa, Milan: Franco Angeli, 2004, 82-117.

Jean Baudrillard (translated by James Benedict), The Systems of Objects, New York: Verso, 2006.

BBC Beijing Bureau, 'Wives of China's Human Rights Lawyers Protest in Beijing', $B B C$ News, 4 July 2016, online at: http://www.bbc.com/news/blogs-china-blog-36704380

Hannah Beech, "Battling for Blood Jade', Time, 13 March 2017, online at: http://time.com/battlingfor-blood-jade/

Jean-Philippe Béja, Michel Bommin, Xiaoshuang Feng, and Can Tang, 'Comment Apparaissent les Couches Sociales', Perspectives Chinoises, vol.52, no.1 (1999): 30-43.

Roberto Bendini, 'Exceptional Measures: The Shanghai Stock Market Crash and the Future of the Chinese Economy', Directorate General for External Policies Policy Department of European Parliament, September 2015, online at: http://www.europarl.europa.eu/RegData/etudes/ IDAN/2015/549067/EXPO_IDA(2015)549067_EN.pdf

Jonathan Benney and Peter Marolt, 'Introduction: Modes of Activism and Engagement in the Chinese Public Sphere', Asian Studies Review, vol.39, no.1 (January 2015): 88-99.

Franco ‘Bifo' Berardi, Precarious Rhapsody: Semiocapitalism and the Pathologies of the Post-alpha Generation, London: Minor Compositions, 2009.

N.E.O. Bernhardsson, 'In Conversation with Ren Hang', Vantage, 30 January 2012, online at: https:// medium.com/vantage/ren-hang-2012-eccbf96b136c

Bloomberg, 'Ai Weiwei on "Brilliant Ideas”, Bloomberg, 30 May 2017, online at: https://www. bloomberg.com/news/videos/2017-05-30/ai-weiwei-on-brilliant-ideas-video

Bloomberg, 'Anxieties about Chinese Firm's Purchase of Smithfield Foods Shown to Be Unfounded', TRIB Live, 2 July 2016, online at: http://triblive.com/business/headlines/10721664-74/smithfieldchinese-foods

Saverio Bombelli, Bruno Anastasia, and Stefania Maschio,, Il Lavoro Accessorio 2008-2015: Profili delle Aziende e dei Lavoratori, INPS and Veneto Lavoro, 2016, online at: https://www.inps.it/ docallegatiNP/Mig/Allegati/2016Lavoro_accessorio_2008-2015_profili_aziende_lavoratori.pdf

Pierre Bourdieu, 'The Social Space and the Genesis of Groups', Theory and Society, vol.14, no.6, (1985): 723-744.

Susanne Brandtstadter and Hans Steinmuller eds, Popular Politics and the Quest for Justice in Contemporary China, London and New York: Routledge, 2017.

Tania Branigan, ‘Ai Weiwei Released from Detention', The Guardian, 23 June 2011, online at: https:// www.theguardian.com/artanddesign/2011/jun/22/ai-weiwei-released-from-detention 
British Journal of Photography, 'An Interview with Ren Hang', British Journal of Photography, 27 February 2017, online at: http://www.bjp-online.com/2017/02/an-interview-with-renhang/\#closeContactFormCust00

Enda Brophy, 'System Error: Labour Precarity and Collective Organizing at Microsoft', Canadian Journal of Communication, vol.31, no.3 (2006): 619-638.

Kate Brown, Dispatches from Dystopia: Histories of Places Not Yet Forgotten, Chicago: University of Chicago Press, 2015.

Chris Buckley, 'Punches, Kicks, and the "Dangling Chair": Detainee Tells of Torture in China', The New York Times, 20 January 2017, online at: https:/www.nytimes.com/2017/01/20/world/asia/ china-lawyer-torture-xie-yang.html

Sengkong Bun and Jack Davis, 'New Expanded Minimum Wage Law Raises Concerns', The Phnom Penh Post, 29 November 2016, online at: http://www.phnompenhpost.com/national/new-expandedminimum-wage-law-raises-concerns

Jon Burnett, ‘The War on Welfare and the War on Asylum', Race and Class, vol.57, no.2 (2015): 96-100.

Anne-Emmanuèle Calvès, “ «Empowerment » : Généalogie d’un Concept Clé du Discours Contemporain sur le Développement »', Revue Tiers Monde, vol.200, no.4 (2009): 735-749.

Ellsworth C. Carlson, The Kaiping Mines, 1877-1912, Cambridge: Harvard University Press, 1971.

Beatriz Carrillo, 'Migrant Labour and the Sustainability of China's Welfare System', in Ivan Franceschini, Kevin Lin, and Nicholas Loubere eds, Made in China Yearbook 2016: Disturbances in Heaven, Canberra: ANU Press, 2017, 28-31.

John Carroll, A Concise History of Hong Kong, Landham: Rowman \& Littlefield Publishers, 2007.

Chiara Carrozza and Emanuele Fantini, 'The Italian Water Movement and the Politics of the Commons', Water Alternatives, vol.9, no.1 (2016): 99-119.

Maribel Casas-Cortés, 'A Genealogy of Precarity: A Toolbox for Rearticulating Fragmented Social Realities in and out of the Workplace', Rethinking Marxism, vol.26, no.2 (2014): 206-226.

Stephen Castles, Ethnicity and Globalization: From Migrant Worker to Transnational Citizen, London and Thousand Oaks: SAGE, 2000.

Central Committee of the CCP, 'Shibajie sanzhong quanhui jueding quanwen' (Full Text of the Resolution of the Third Plenary Session of the Eighteenth Central Committee of the CCP), 15 November 2013, online at: http://www.360doc.com/content/13/1115/21/1247204_329528606.shtml

Centro Studi e Ricerche IDOS, Dossier statistico immigrazione 2016, Rome: Edizioni IDOS, 2016.

Centro Studi e Ricerche IDOS, Dossier statistico immigrazione 2012, Rome: Edizioni IDOS, 2012.

Dipesh Chakrabarty, Provincialising Europe Postcolonial Thought and Historical Difference, Princeton: Princeton University Press, 2007.

Anita Chan ed, Chinese Workers in Comparative Perspective, Ithaca: Cornell University Press, 2015a. 
Anita Chan, 'Trade Union Elections in Foreign-Owned Chinese Factories', China: An International Journal, vol.15, no.3 (2015b): 94-113.

Anita Chan ed, Labour in Vietnam, Singapore: Institute of Southeast Asian Studies, 2011.

Anita Chan, China's Workers under Assault: The Exploitation of Labor in a Globalizing Economy, Armonk: M.E. Sharpe, 2001.

Anita Chan, Benedict J. Tria Kerkvliet, and Jonathan Unger eds, Transforming Asian Socialism: China and Vietnam Compared, Lanham: Rowman \& Littlefield, 1999.

Anita Chan, Richard Madsen, and Jonathan Unger, Chen Village: Revolution to Globalization, Berkeley: University of California Press, 2009.

Anita Chan and Irene Norlund, 'Vietnamese and Chinese Labour Regimes: On the Road to Divergence', The China Journal, no.40 (1998): 173-197.

Anita Chan and Kaxton Siu, 'Analyzing Exploitation: The Mechanisms Underpinning Low Wages and Excessive Overtime in Chinese Export Factories', Critical Asian Studies, vol.42, no.2 (2010): 167-190.

Chris King-Chi Chan and Elaine Sio-Ieng Hui, 'The Development of Collective Bargaining in China: From "Collective Bargaining by Riot” to "Party State-led Wage Bargaining”, The China Quarterly, vol.217 (2014): 221-242.

Chris King-Chi Chan and Ngai Pun, 'The Making of a New Working Class? A Study of Collective Actions of Migrant Workers in South China', The China Quarterly, vol.198 (2009): 287-303.

Jenny Chan, 'Intern Labor in China', Rural China, vol.14, no.1 (2017): 82-100.

Jenny Chan, 'Interns or Workers? China's Student Labour Regime', Asian Studies, vol.1, no.1 (2015c): 69-98.

Jenny Chan, 'iSlave', New Internationalist, 1 April 2011, online at: https://newint.org/ features/2011/04/01/islave-foxconn-suicides-workers

Jenny Chan, Ngai Pun, and Mark Selden, 'The Politics of Global Production: Apple, Foxconn and China's New Working Class', New Technology, Work and Employment, vol.28, no.2 (2013): 100-115.

Mya Htwe Chan and Su Wai Khin, 'Protesters Decry Restart to Letpadaung Copper Mine as Police Phalanx Builds', Myanmar Times, 6 May 2016, online at: https:/www.mmtimes.com/nationalnews/20160-protesters-decry-restart-to-letpadaung-copper-mine-as-police-phalanx-builds.html

Dae-oup Chang, 'From Global Factory to Continent of Labour: Labour and Development in Asia', Asian Labour Review, vol. 1 (2015): 1-48.

Derrik Chang, 'Inside Tsoi Yuen Village, the heart of the Hong Kong railway controversy', CNN, 11 January 2010, online at: http://travel.cnn.com/hong-kong/play/gallery-inside-tsoi-yuen-villageheart-express-rail-controversy-474851/

Wen-Chin Chang, Beyond Borders: Stories of Yunnanese Chinese Migrants of Burma, Ithaca and London: Cornell University Press, 2014. 
Chih-jou Jay Chen, 'Growing Social Unrest and Emergent Protest Groups in China', in Hsin-Huang Michael Hsiao, and Chengyi Lin eds, Rise of China: Beijing's Strategies and Implications for the AsiaPacific, London and New York: Routledge, 2009, 87-105.

Haijing Chen, A Study of Japanese Loanwords in Chinese, MPhil Thesis, University of Oslo, 2014.

Jiang Chen, 'Heiyao nugong de zuihou yizhan' (The Last Stop to Search for Victims at Black Brick Kilns), Wangyi Xinwen, 21 July 2007, online at: http://news.163.

com/07/0721/09/3JTQPSFB00011SM9.html

Jie Chen, Bruce Judd, and Scott Hawken, 'Adaptive Reuse of Industrial Heritage for Cultural Purposes in Beijing, Shanghai and Chongqing', Structural Survey, vol.3, no.4/5 (2016): 331-350.

Eileen J. Cheng, 'Lu Xun and the Afterlife of Texts', in David Der-wei Wang ed, A New Literary History of Modern China, Cambridge: Harvard University Press, 2017, 433-436.

Eileen J. Cheng, Literary Remains: Death, Trauma, and Lu Xun's Refusal to Mourn, Honolulu: University of Hawaii Press, 2013.

Shihua Cheng, 'Anhui Jieshou heizhuanyao shiji diaocha' (Investigation into the Black Brick Kilns Scandal in Anhui Jieshou), Zhengzhou Wanbao, 23 July 2009a, online at: http://news.sina.com. $\mathrm{cn} / \mathrm{c} / 2009-07-23 / 075415999092 \mathrm{~s} . \mathrm{shtml}$

Siu Kei Cheng, Adopting a New Lifestyle: Formation of a Local Organic Food Community in Hong Kong, MPhil Thesis, Chinese University of Hong Kong, 2009b.

Chengdu Footwear Business Association, '17 jia xiechang 1 wanyu gongren tinggong yigeyue' (17 Shoe Factories Shut Down for One Month, Affecting Over 10,000 Workers), Sohu.com, 5 September 2017a, online at: http://www.sohu.com/a/169715934_737406

Chengdu Footwear Business Association, 'Duoguan qixi, Chengdu xieye tongye gonghui tuidong xiecai jiji yingdui huanbao ducha' (Multiple Approaches: Chengdu Shoes Association Promoting New Materials for Making Shoes and Taking Positive Measures to Deal with Environmental Inspection), Sohu.com, 14 September 2017b, online at: http://www.sohu.com/a/192009497_737406

Siu Keung Cheung, 'Reunification through Water and Food: The Other Battle for Lives and Bodies in China's Hong Kong Policy', The China Quarterly, vol.220 (2014): 1012-1032.

Josh Chin, 'Meet Lu Jun, One of China's Most Wanted Social Activists', The Wall Street Journal, 6 September 2015, online at: https://www.wsj.com/articles/meet-lu-jun-one-of-chinas-most-wantedsocial-activists-1441521914

China Daily, ' Wanshan National Park Offers Insights Into Mercury Mining', China Daily, 22 November 2016a, online at: http://www.chinadaily.com.cn/china/2016-11/22/content_27457878.htm

China Development Brief, 'Special Issue: New Trends in Philanthropy and Civil Society in China', China Development Brief, Summer 2011, online at: http://chinadevelopmentbrief.cn/wp-content/ uploads/2011/09/Special-Issue-hard-copy-copy.pdf

China Foundation Center, Zhongguo jijinhui fazhan duli yanjiu baogao 2013 (The Development of Chinese Foundations: An Independent Research Report in 2013), Beijing: Shehui Kexue Wenzhai Chubanshe, 2013. 
Evan Shan Chou, Memory, Violence, Queues: Lu Xun Interprets China, Ann Arbor: Association of Asian Studies, 2012.

Clean Clothes Campaign, 'Global Living Wage Campaign for Cambodia Kicks Off', Clean Clothes Campaign, 20 November 2015, online at: https://cleanclothes.org/news/2015/11/20/global-livingwage-campaign-for-cambodia-kicks-off

Myron Cohen, 'Cultural and Political Inventions in Modern China: The Case of the Chinese "Peasant”, Daedalus, vol.122, no.2 (1993): 151-170.

Fang Lee Cooke, 'Chinese Multinationals Firms in Asia and Africa: Relationships with Institutional Actors and Patterns of HRM Practices', Human Resource Management, vol.53, no.6 (2014): 877-896.

Songwan Cui, 'Yi ge jizhe de sitian zhizhanggong heizhuanyao tiyan' (A Journalist's Fourday Experience as a Mentally Disabled Worker in a Black Kiln), 7 September 2011, online at: http://www.aboluowang.com/2011/0907/218018.html

Tom Cunliffe, 'Gu Tao: Inside and Outside the Forest', China.org.cn, 18 May 2015, online at: http://www.china.org.cn/arts/2015-05/18/content_35596397.htm

Mech Dara and Kevin Doyle, 'Police Kill 5 during Clash with Demonstrators', The Cambodia Daily, 4 January 2014, online at: https://www.cambodiadaily.com/archives/military-police-kill-5-duringclash-with-demonstrators-50081/

Mech Dara and Colin Meyn, 'CNRP Holds Biggest Demonstration in Decades', The Cambodia Daily, 23 December 2013, online at: https://www.cambodiadaily.com/archives/cnrp-holds-biggestdemonstration-in-decades-49558/

Gloria Davies, 'Lun Xun's Afterlives', The China Story, 5 April 2013a, online at: https://www.thechinastory.org/2013/04/lu-xuns-afterlives/

Gloria Davies, Lu Xun's Revolution: Writing in a Time of Violence, Cambridge: Harvard University Press, 2013b.

Alexander Day, 'The End of the Peasant? New Rural Reconstruction in China', boundary 2, vol.35, no.2 (2008): 49-73.

Lizzie Dearden, 'UN Human Rights Chief Attacks Europe's “Chilling Indifference” to Refugees as 2017 Sees Record Deaths', Independent, 8 March 2017, online at: http://www.independent.co.uk/ news/world/europe/refugee-crisis-migrants-asylum-seekers-latest-un-zeid-hussein-human-rightschilling-indifference-a7619301.html

Guy Debord, Society of the Spectacle, Detroit: Black \& Red, 1983.

Erwin Dekker, 'Exemplary Goods: Exemplars as Judgment Devices', Valuation Studies, vol.4, no.2 (2016): 103-124.

Gilles Deleuze, 'Postscript on the Societies of Control', October, vol.59 (1992): 3-7. 
Lydia DePillis, 'A Trumka-to-China Moment? He's the First Ever AFL-CIO President to Make the Trip', The Washington Post, 12 October 2013, online at: https://www.washingtonpost.com/news/ wonk/wp/2013/10/12/a-trumka-to-china-moment-hes-the-first-ever-afl-cio-president-to-make-thetrip/?utm_term=.1edc75548593

Antonella Diana, Roses and Rifles: Experiments of Governing on the China-Laos Frontier, PhD Thesis, The Australian National University, 2009, online at: https://openresearch-repository.anu.edu.au/ handle/1885/109709

Weizhi Ding ed, Jingdezhen juan (A Record of Jingdezhen), Beijing: Zhongguo Dabaikequanshu, 1996.

Yang Ding, " Quanmin faqian” de xiangfa bushi weile "yang lanhan”' (Giving Money to Everyone Is Not for the Purpose of Feeding the Lazy), Tengxun Pinglun, 7 June 2016, online at: http://view.news. qq.com/original/intouchtoday/n3549.html

(DOASLNCSEZ) Decision on the Organization and Activities of the Secretariat to Lao National Committee for Special Economic Zone No. 01/NCSEZ. 13/12/2010.

(DOALNCSEZ) Decree on the Organization and Activities of Lao National Committee for Special Economic Zone No. 517/PM, 09/12/2010.

Kevin Doogan, New Capitalism? The Transformation of Work, Cambridge: Polity Press, 2009.

Jan Drahokoupil, Rutvica Andrijasevic, and Devi Sacchetto eds, Flexible Workforces and Low Profit Margins: Electronics Assembly Between Europe and China, Brussels: European Trade Union Institute, 2016.

(DSSEZa) Decree on Special Economic Zone and Specific Economic Zone in the Lao PDR No 443/ PM. 26/10/2010.

(DSSEZb) Development Strategy for the Special Economic Zone in the Lao PDR, 2011-2020. No 188/ PM, 09/04/2012.

Cindy Fan, 'The Elite, the Natives, and the Outsiders: Migration and Labor Market Segmentation in Urban China', Annals of the Association of American Geographers, vol.92, no.1 (2002): 103-124.

Yiren Fang, 'Yiwang yu xunzhao, yinianhou de heizhuanyao' (Fading Memory and Endless Search: Black Brick Kilns after One Year), Tengxun Xinwen, 13 June 2008, online at: https://news. qq.com/a/20080613/002199.htm

Xiaoming Feng, 'China's Charitable Foundations: Development and Policy-Related Issues', The Chinese Economy, vol.48, no.2 (2015): 130-154.

Xiaoming Feng, 'China's Charitable Foundations: Development and Policy-Related Issues', Stanford Center for International Development, Working Paper no.485, October 2013, online at: http://scid. stanford.edu/sites/default/files/publications/485wp_0.pdf

Hart Feuer, Phuong Le Trong, and Judith Ehlert, 'Conclusion: The Civil Society Gaze', in Gabi Waibel, Judith Ehlert, and Hart N. Feuer eds, Southeast Asia and the Civil Society Gaze, London and New York: Routledge, 2014, 253-264. 
Leta Hong Fincher, 'China's Feminist Five', Dissent, fall 2016, online at: https://www. dissentmagazine.org/article/china-feminist-five

Jörg Flecker eds, Changing Working Life and the Appeal of the Extreme Right, Aldershot: Ashgate, 2007.

Joel L. Fleishman, The Foundation: A Great American Secret, New York: Public Affair, 2007.

Vanessa Fong and Rachel Murphy, Chinese Citizenship: Views from the Margins, London and New York: Routledge, 2006.

Michel Foucault and Michel Senellart, The Birth of Biopolitics: Lectures at the Collège de France, Basingstoke: Palgrave Macmillan, 1978-79.

Foxconn, 'Foxconn Response to Report Alleging Abuses in Internship Program', Business \& Human Rights Resource Centre, 29 July 2011, online at: https://business-humanrights.org/en/chinauniversity-report-finds-abuses-in-foxconns-internship-program

Foxconn, 'Foxconn Is Committed to a Safe and Positive Working Environment', October 2010, online at: http://regmedia.co.uk/2010/10/12/foxconn_media_statement.pdf

Ivan Franceschini, 'Meet the State Security: Chinese Labour Activists and Their Controllers', in Jane Golley, Linda Jaivin, and Luigi Tomba eds, China Story Yearbook 2016: Control, Canberra: ANU Press, 2017a, 65-72.

Ivan Franceschini, 'Revisiting Chinese Labour NGOs: Some Grounds for Hope?', in Ivan Franceschini, Kevin Lin, and Nicholas Loubere eds, Made in China Yearbook 2016: Disturbances in Heaven, Canberra: ANU Press, 2017b, 46-49.

Ivan Franceschini, 'The Broken Belt: The All-China Federation of Trade Unions and the Communist Party in the People's Republic of China', Contemporanea, vol.18, no.1 (2015): 67-90.

Ivan Franceschini, Cronache dalle fornaci cinesi. Uno dei più gravi scandali del lavoro degli ultimi anni visto attraverso gli occhi dei media cinesi, Venezia: Libreria Editrice Cafoscarina, 2009.

Ivan Franceschini and Elisa Nesossi, 'The New Foreign NGOs Management Law in China: A Compendium', in Ivan Franceschini, Kevin Lin, Nicholas Loubere eds, Made in China Yearbook 2016: Disturbances in Heaven, ANU Press, Canberra, 2017, 60-67.

Roberto Franzosi, 'One Hundred Years of Strike Statistics: Methodological and Theoretical Issues in Quantitative Strike Research', ILR Review, vol.42, no.3 (1989): 348-362.

Mark Frazier, 'State-sector Shrinkage and Workforce Reduction in China', European Journal of Political Economy, vol.22, no.2 (2006): 435-451.

Eli Friedman, 'Economic Development and Sectoral Unions in China', Industrial and Labour Relations Review, vol.67, no.2 (2014): 481-503.

Hualing Fu, 'Embedded Socio-legal Activism in China: The Case of Yirenping', University of Hong Kong Faculty of Law, Research Paper No.29, July 2012, online at: https://hub.hku.hk/ bitstream/10722/164138/1/Content.pdf?accept=1 
Zhenzhong Fu, 'Wo qinshou jiekai Shanxi heizhuanyao de neimu' (I Myself Revealed the Insights of the Black Brick Kilns Scandal), Hongwang, 6 November 2007, online at: http://china.rednet. $\mathrm{cn} / \mathrm{c} / 2007 / 11 / 06 / 1365267 . h \mathrm{tm}$

Mary Gallagher and Baohua Dong, 'Legislating Harmony: Labor Law Reform in Contemporary China', in Sarosh Kuruvilla, Ching Kwan Lee, and Mary Gallagher eds, From Iron Ice Bowl to Informationalization: Markets, Workers, and the State in a Changing China, Ithaca: Cornell University Press, 2011, 36-60.

Nectar Gan, ‘12,000 Officials Disciplined and 18,000 Companies Punished in China's Sweeping Crackdown against Pollution', South China Morning Post, 2 September 2017, online at: http://www. scmp.com/news/china/policies-politics/article/2109342/top-level-china-pollution-inspectionswrapping

Dazheng Gao and Zedong Zhang, 'Nanzi beipian heizhuanyao 21 nian yiluqitao hui Yunnan buzhi jiazaina' (Man, Trapped in Black Brick Kilns for 21 Years, Begged His Way Back to Yunnan Province, Unaware of Where His Home Is), Kunming Xinxigang, 21 August 2015, online at: http://news.sohu. com/20150821/n419397915.shtml

Ying Gao, Wo he Ai Qing (Ai Qing and I), Beijing: People's Literature Publishing House, 2012.

Arran Gare, 'China and the Struggle for Ecological Civilization', Capitalism Nature Socialism, vol.23, no.4 (2012): 10-26.

Sam Geall, 'Interpreting Ecological Civilisation (Part Three), Chinadialogue, 10 July 2015, online at: https://www.chinadialogue.net/article/show/single/en/8038-Ecological-civilisation-vision-for-agreener-China-part-three-

General Offices of the CCP Central Committee and the State Council, 'Opinion on the Reform of the Social Organization Management System and Promotion of the Healthy and Well--Ordered Development of Social Organizations', China Law Translate, 21 August 2016, online at: http://www. chinalawtranslate.com/2officessocialorg/?lang=en

Alexandra Genova, 'Ai Weiwei Reflects on the Sadness of Ren Hang's Photographs', Time, 7 March 2017, online at: http://time.com/4688548/ai-weiwei-ren-hang/

Maris Boyd Gillette, China's Porcelain Capital: The Rise, Fall and Reinvention of Ceramics in Jingdezhen, London: Bloomsbury Academic, 2016.

Global Witness, Jade: Myanmar’s “Big State Secret”, London: Global Witness Limited, 2015.

Merle Goldman, 'The Political Use of Lu Xun', The China Quarterly, vol.91 (September 1982): 446-461.

Ramapriya Gopalakrishnan, 'The Draft Labour Code on Social Security-Workers' Concerns:

Ramapriya Gopalakrishnan', Kafila, 15 May 2017, online at: https://kafila.online/2017/05/15/the-

draft-labour-code-on-social-security-workers-concerns-ramapriya-gopalakrishnan/

Ramapriya Gopalakrishnan and KR Shyam Sundar, 'Who Cares for Labour, Anyway?', Business Line, 21 May 2015, online at: http://www.thehindubusinessline.com/opinion/who-cares-for-labouranyway/article7232069.ece 
Maxim Gorky et al., Soviet Writers' Congress, 1934: The Debate on Socialist Realism and Modernism, London: Lawrence \& Wishart, 1977.

Government of India, 'Order of Verification of Membership of Trade Unions affiliated to CTUOs as of 31 December 2002', New Delhi: Ministry of Labour and Employment, 2008.

David Green, 'Getting Paid To Do Nothing: Why the Idea of China's Dibao Is Catching On', South China Morning Post, 14 April 2017, online at: http://www.scmp.com/week-asia/article/2087486/ getting-paid-do-nothing-why-idea-chinas-dibao-catching

Katherine Grube, 'Ai Weiwei Challenges China's Government over Earthquake', Art Asia Pacific, vol.64 (2009a), online at: http://artasiapacific.com/Magazine/64/ AiWeiweiChallengesChinasGovernmentOverEarthquake

Katherine Grube, 'Ai Weiwei Hospitalised after Beating by Chinese Police', Art Asia Pacific, vol.66 (2009b), online at: http://artasiapacific.com/Magazine/66/ AiWeiweiHospitalizedAfterBeatingByChinesePolice

Yingjie Guo, 'Class, Stratum and Group: The Politics of Description and Prescription', in David S. G. Goodman eds, The New Rich in China: Future Rulers, Present Lives, London and New York: Routledge, 2008, 38-52.

Jurgen Habermas, Between Facts and Norms, Cambridge: MIT Press, 1996.

Aaron Halegua, 'Chinese Workers and the Legal System: Bridging the Gap in Representation', in Ivan Franceschini, Kevin Lin, and Nicholas Loubere eds, Made in China Yearbook 2016: Disturbances in Heaven, Canberra: ANU Press, 2017, 88-91.

Peter A. Hall and David Soskice eds, Varieties of Capitalism, Oxford: Oxford University Press, 2001.

Clare Hammond, 'China Launches Local Charm Offensive', Myanmar Times, 11 May 2016, online at: https://www.mmtimes.com/business/20232-china-launches-local-charm-offensive.html

Jon Han, 'Ai Weiwei: How Censorship Works', The New York Times, 6 May 2017, online at: https:// www.nytimes.com/2017/05/06/opinion/sunday/ai-weiwei-how-censorship-works.html?mcubz=1

Erin Handley, 'Fast Raid on Kem Sokha Belies Long Prelude', The Phnom Penh Post, 4 September 2017, online at: http://www.phnompenhpost.com/opinion/fast-raid-kem-sokha-belies-long-prelude

Dian Hanson, Ren Hang, Cologne: Taschen 2017.

Jorg Hantzschel, ‘Gezeichnet von der Gangelung’, Suddeutsche Zeitung, 5 August 2015a, online at: http://www.sueddeutsche.de/kultur/ai-weiwei-im-sz-interview-gezeichnet-von-dergaengelung-1.2596038

Jorg Hantzschel, 'Ich Bitte nur um ein Normales Leben', Suddeutsche Zeitung, 5 August 2015b, online at: http://www.sueddeutsche.de/kultur/ai-weiwei-im-gespraech-ich-bitte-nur-um-ein-normalesleben-1.2594615?reduced=true

Garrett Hardin, ‘The Tragedy of the Commons', Science, vol.162, no.3859 (1968): 1243-1248. 
Jane Hardy, 'The Institutional, Structural and Agential Embeddedness of Precarity: An Engagement with Guy Standing', Warsaw Forum of Economic Sociology, vol.6, no.1 (2015): 7-25.

David Harvey, 'The Right to the City', New Left Review, no.53 (2008), online at: https://newleftreview.org/II/53/david-harvey-the-right-to-the-city

David Harvey, A Brief History of Neoliberalism, Oxford: Oxford University Press, 2007.

Vaclav Havel, Letters to Olga: June 1979-September 1982, London: Faber and Faber, 1991.

James Hayes, The Great Difference: Hong Kong's New Territories and Its People, 1898-2004, Hong Kong: Hong Kong University Press, 2006.

Huaihong He, 'Ecological Ethics Spiritual Resources and Philosophy Foundations', Social Ethics in a Changing China: Moral Decay or Ethical Awakening?, Washington, D.C.: Brookings Institution Press, 2015.

Simon Head, The New Ruthless Economy, Oxford: Oxford University Press, 2003.

Limin Hee, Thomas Schroepfer, Nanxi Su, and Ze Li, 'From Post-industrial Landscape to Creative Precincts: Emergent Spaces in Chinese Cities', International Development Planning Review, vol.30, no.3 (2008): 249-266.

Silke Helfrich and David Bollier, 'Commons', in Giacomo D'Alisa, Federico Demaria, and Giorgos Kallis eds, Degrowth: A Vocabulary for a New Era, London and New York: Routledge, 2015, 75-78.

Roger Henke, 'NGOs, People's Movements, and Natural Resource Management', in Caroline Hughes and Kheang Un eds, Cambodia's Economic Transformation, Copenhagen: NIAS Press, 2011, 288-309.

Anne Henochowicz, 'Translation: Zhao Country and the Bankruptcy of Patriotism', China Digital Times, 8 January 2016, online at: https://chinadigitaltimes.net/2016/01/translation-zhao-country/

HRW (Human Rights Watch), 'Cambodia: Joint Letter on the Draft Law on Associations and NonGovernmental Organisations', 22 June 2015, online at: https://www.hrw.org/news/2015/06/22/ cambodia-joint-letter-draft-law-associations-and-non-governmental-organizations

Chih-tsing Hsia, 'On the "Scientific" Study of Modern Chinese Literature, a Reply to Professor Průšek', T'oung Pao, vol.50, no.4-5 (1963): 428-474.

Chih-Tsing Hsia, A History of Modern Chinese Fiction, Hong Kong: The Chinese University Press, 1961.

You-tien Hsing, 'Land and Territorial Politics in Urban China', The China Quarterly, vol.187 (2006): 575-591.

Carolyn L. Hsu and Jessica C. Teets, 'Is China's New Overseas NGO Management Law Sounding the Death Knell for Civil Society? Maybe Not', The Asia-Pacific Journal, vol.14, no.4, (2016), online at: http://apjjf.org/2016/04/Hsu.html

Jennifer Y. J. Hsu, 'The Internationalisation of Chinese NGOs', China Policy Institute: Analysis, 29 September 2016, online at: https://cpianalysis.org/2016/09/29/gongos-vs-ngos-the-

internationalisation-of-chinese-ngos/ 
Jennifer Y. J. Hsu and Reza Hasmath, 'A Maturing Civil Society in China? The Role of Knowledge and Professionalization in the Development of NGOs', China Information, vol.21, no.1 (2017): 22-42.

Jintao Hu, 'Firmly March on the Path of Socialism with Chinese Characteristics and Strive to Complete the Building of a Moderately Prosperous Society in All Respects', Qiushi Journal, vol.4 no.4 (2012), online at: http://english.qstheory.cn/magazine/201204/201401/t20140121_314964.htm

Sheng Huang and Hu Xiaoxiao, 'Chengdu: Dazao xieye "yidu liangyuan”' (Chengdu: Creating "A City with Two Centres”), Chengdu Ribao, 10 October 2008, online at: http://city.finance.sina.com.cn/ city/2008-10-10/105438.html

Yanchun Huang, 'Nanzi Yunnan dangnuyao 112 tian, meitian tiebang pibian xia gan 17 xiaoshi' (A Guy, Being a Victim at a Black Brick Kiln in Yunnan Province, Worked 17 hours Daily While Being Tortured), Yunnanwang, 24 August 2010, online at: http://gb.cri.cn/27824/2010/08/24/336 5s2965996_1.htm

Huanping Aihaozhe Wang, 'Shijiuda baogao quanwen shilu (huanjing baohu fangmian neirong)' (Record of the Complete Report at the Nineteenth Party Congress: The Environmental Aspects), Huanping Aihaozhe Wang, 18 October 2017, online at: https://www.wxnmh.com/thread-1854030.htm

Caroline Hughes, 'Understanding the Elections in Cambodia 2013', Journal of Area-Based Global Studies, Special Edition 2014 (June 2015): 1-20.

Richard Hughes, 'Burma's Jade Mines: An Annotated Occidental History”, Lotus Gemology, 1999, online at: http://www.lotusgemology.com/index.php/library/articles/283-burma-s-jade-mines-anannotated-occidental-history

Richard Hughes and Fred Ward, 'Heaven and Hell: The Quest for Jade in Upper Burma', Asia Diamonds vol.1, no. 2 (1997): 42-53.

Eva P.W. Hung and Stephen W.K. Chiu., 'Voices of Xiagang: Naming, Blaming, and Framing', in Thomas B. Gold, William Hurst, Jaeyoun Won, and Li Qiang eds, Laid-Off Workers in a Workers' State, New York: Palgrave Macmillan, 2009, 95-114.

Ho Fung Hung, 'Three Views of Local Consciousness in Hong Kong', The Asia-Pacific Journal, vol.12, no.44 (2014): 1-10.

Tao Huo, 'Chengdu jiancha zhenggai jujue "yigaoqie”" (Inspection and Reform Team in Chengdu Rejected the "One-size-fit-for-all Approach"), Zhongguo Huangjing Bao, 14 August 2017, online at: http://49.5.6.212/html/2017-08/14/content_63567.htm

William Hurst, The Chinese Worker After Socialism, Cambridge: Cambridge University Press, 2009.

Ann Louise Huss, Old Tales Retold: Contemporary Chinese Fiction and the Classical Tradition, New York: Columbia University, 2000.

Athar Hussain, 'Urban Poverty in China: Measurement, Patterns and Policies', International Labour Office, Geneva, 2003.

Shannon Ikebe, 'The Wrong Kind of UBI', Jacobin, 21 January 2016, online at: https://www. jacobinmag.com/2016/01/universal-basic-income-switzerland-finland-milton-friedman-kathiweeks/ 
ILO (International Labour Organisation), 'Cambodian Garment and Footwear Sector Bulletin', January 2017, online at: http://www.ilo.org/wcmsp5/groups/public/---asia/---ro-bangkok/ documents/publication/wcms_541288.pdf

ILO (International Labour Organisation), 'Viet Nam's Trade Unions Set to Reform for Future Industrial Relations Trends', 11 May 2016, online at: http://www.ilo.org/hanoi/ Informationresources/Publicinformation/newsitems/WCMS_480825/lang--en/index.htm

IndustriALL Global Union, 'Indian Trade Unions Intensify Struggle to Win Workers' Rights', IndustriALL, 14 April 2016, online at: http://www.industriall-union.org/indian-trade-unionsintensify-struggle-to-win-workers-rights

International Organisation for Migration, 'Mediterranean Migrant Arrivals Top 363,348 in 2016; Deaths at Sea: 5,079', International Organisation for Migration, 1 June 2017, online at: https://www. iom.int/news/mediterranean-migrant-arrivals-top-363348-2016-deaths-sea-5079

International Rivers, 'Irrawaddy Myitsone Dam', 2011, online at: https://www.internationalrivers. org/campaigns/irrawaddy-myitsone-dam-0

Carlo Inverardi-Ferri, 'Variegated Geographies of Electronic Waste: Policy Mobility, Heterogeneity and Neoliberalism', Area Development and Policy, vol.2, no.3 (2017): 314-331.

Tamara Jacka, Rural Women in Urban China: Gender, Migration and Social Change, Armonk: M.E. Sharpe, 2006.

K. T. Jagannathan, 'Insurance Staff to Join Nationwide Strike on Sept. 2', The Hindu, 22 August 2016, online at: http://www.thehindu.com/business/Industry/Insurance-staff-to-join-nationwide-strikeon-Sept.-2/article14583674.ece

Sheila Jasanoff, ‘Technologies of Humility: Citizen Participation in Governing Science', Minerva, vol.41, no.3 (2013): 223-244.

Henry Jenkins, Convergence Culture: Where Old and New Media Collide, New York: New York University Press, 2010.

Junfang Jiang and Xiaolu Shi, 'Rang qiye he yuangong duo yige xuanze' (Give More Choices to Factories and Employees), Sichuan Ribao, 17 August 2017, online at: http://epaper.scdaily.cn/shtml/ scrb/20170817/171138.shtml

Jin xia shuo shenme da shihua, 'You le cishan fa, hai dei you shehui zuzhi fa' (Now We Have the Charity Law, We Still Need a Social Organization Law'), WeChat public account, 7 March 2017, online at: https://mp.weixin.qq.com/s?_ dasdbiz=MzAxOTg0NTg4MQ== \&mid=2650654487\&idx= $1 \&$ sn=bb6f8189f3b40af5b80e17669b34fo8e \&chksm = 83c9a081b4be2997a66dd889562blf57f10 2f064decc03ade95bca97052f3af dbef5a2ce782b\&scene $=0 \#$ rd

J. John, 'Overall Increase and Sectoral Setbacks: Lessons from Central Trade Union Verification, 2002.' Labour File, vol.5, no.1/2 (2007): 13-25.

Kadoorie Agricultural Aid Association, The Kadoorie Agricultural Aid Association Documentary, Hong Kong, 1982, online at: https://www.youtube.com/watch?v=WgbiDMBwVf4 
Xiaoguang Kang, Li Feng, and Gang Cheng eds, Zhongguo jijinhui fazhan duli yanjiu baogao 2011 (The Development of Chinese Foundations: An Independent Research Report in 2011), Beijing: Shehui Kexue Wenzhai Chubanshe, 2012.

Julian Kirchherr, Katrina J. Charles, and Matthew J. Walton, 'The Interplay of Activists and Dam Developers: The Case of Myanmar's Mega-dams', International Journal of Water Resources Development, vol.33, no.1 (2017): 111-131.

Sabina Knight, Chinese Literature: A Very Short Introduction, Oxford: Oxford University Press, 2012.

Greg Knowler, 'Massive Chinese Factory Closure Threatens Components', The Journal of Commerce, 6 September 2017, online at: https://www.joc.com/regulation-policy/transportation-regulations/ china-closes-down-thousands-factories_20170906.html

Gabriel Kolko, 'Vietnam since 1975: Winning a War and Losing the Peace', Journal of Contemporary Asia, vol.25, no.1 (1995): 3-49.

Tatiana Kostova, 'Transnational Transfer of Strategic Organizational Practices: A Contextual Perspective', The Academy of Management Review, vol.24, no.2 (1999): 308-324.

Keyan Lai, 'Home Country Institutions and the Internationalisation of Emerging Market Multinationals: An Ethnographic Study of the Organisational Control System in a Chinese MNC', September 2016, online at: https://orca.cf.ac.uk/97299/1/Keyan\%20Lai\%20-\%20PhD\%20thesis\%20 -\%20FINAL\%20VERSION.pdf

Joseph LaPorte, Natural Kinds and Conceptual Change, Cambridge: Cambridge University Press, 2004.

Hoi Lung Lau, Evolution of Urban Agriculture in Hong Kong: Stepping Towards Multifunctionality, MPhil Thesis, Chinese University of Hong Kong, 2013.

Jonathan Lear, Radical Hope Ethics in the Face of Cultural Devastation, Cambridge: Harvard University Press, 2006.

Ching Kwan Lee, 'Precarization or Empowerment? Reflections on Recent Labour Unrest in China', The Journal of Asian Studies, vol.75, no.2 (2016): 317-333.

Ching Kwan Lee, ‘The Spectre of Global China', New Left Review, vol.89 (2014a): 29-65.

Ching Kwan Lee, Gender and the South China Miracle: Two Worlds of Factory Women, Berkeley: University of California Press, 1998.

Danny Lee and Rif'at Syauqi Fachir , 'China-Southeast Asia People to People High-Level Dialogue Kicks Off to Realise the Common Dream and Aspiration of Its People', ASEAN Secretariat News, 4 June 2013, online at: http://asean.org/china-southeast-asia-people-to-people-high-level-dialoguekicks-off-to-realise-the-common-dream-and-aspiration-of-its-peoples/

Minna So-min Lee, In Search of Lost Time: Redefining Socialist Realism in Postwar North Korea, PhD Thesis, University of Toronto, 2014b, online at: https://tspace.library.utoronto.ca/handle/1807/43862 
Peter Nan-Shong Lee, 'The Chinese Industrial State in Historical Perspective: From Totalitarianism to Corporatism', in Brantly Womack ed, Contemporary Chinese Politics in Historical Perspective, Cambridge: Cambridge University Press, 1991, 153-179.

Guang Lei, 'Rural Taste, Urban Fashions: The Cultural Politics of Rural/Urban Difference in Contemporary China', Positions, vol.11, no.3 (2003): 613-646.

Parry Leung and Ngai Pun, 'The Radicalisation of the New Chinese Working Class: A Case Study of Collective Action in the Gemstone Industry', Third World Quarterly, vol.30, no.3 (2009): 551-565.

Adrian Levy and Cathy Scott-Clark, The Stone of Heaven: The Secret History of Imperial Green Jade, London: Weidenfeld \& Nicholson, 2001.

John Lewis, 'Tim Cook', Time, 16 April 2015, online at: http://time.com/collection-post/3822599/ tim-cook-2015-time-100/

Keqiang Li, '2017 nian zhengfu gongzuo baogao' (2017 Government Work Report), Fenghuang Zixun, 5 March 2017, online at: http://news.ifeng.com/a/20170305/50754278_0.shtml

Shenpeng Li, “'Heizhuanyao” wangshi: Bei duoqu ziyou de 11 nian' (A Past in the Black Kilns: 11 Years without Freedom), Benliu Zazhi, 26 September 2016, online at: http://news.163. com/16/0926/19/C1TN9CDK000187OR.html

Weiming Li, Shanghai diyuxing gaowei fanzui yanjiu (A Local Analysis of Highly Dangerous Crimes in Shanghai), MA Thesis, East China University of Political Sciences and Law, 2013, online at: http:// cdmd.cnki.com.cn/Article/CDMD-10276-1014154029.htm

Xiaoling Li, 'Fanzui xianyiren tunyiwu taobi zhicai Fushun jingfang duici shuobu' (Police Foiled the Suspect's Attempt to Avoid Punishment by Swallowing Weird Things), Dongbei Xingwenwang Fushun Pindao, 26 April 2016, online at: http://fushun.nen.com.cn/system/2016/04/26/019054621. shtml

Yao Li, A Zero-Sum Game? Repression and Protest in China, Cambridge: Cambridge University Press, 2017.

Zhang Li and Aihwa Ong, Privatizing China, Socialism from Afar, Ithaca: Cornell University Press, 2008.

George C.S. Lin, Developing China: Land, Politics and Social Conditions, London and New York: Routledge, 2015.

Zhoulu Lin, 'Shenzhen Wenhua chanye zouxiang neihanshi fazhan' (The Cultural Industry in Shenzhen Adopted an Intensive Approach), 10 April 2017, online at: http://ilonggang.sznews.com/ lgnews/content/2017-04/10/content_15915935.htm

Jianzhuang Liu, 'Wo wei "Shanxi heizhuanyao" deihairen daguansi' (I Represent the Victims at Black Brick Kilns on Court), Xinlang Xinwen Zhongxin, 14 September 2007, online at: http://news. sina.com.cn/c/2007-09-14/173413892982.shtml

Xiangmin Liu and Can Ouyang, 'Contingent Work in the Chinese Call Centre Sector', in Mingwei Liu and Chris Smith eds, China at Work: A Labour Process Perspective on the Transformation of Work and Employment in China, London: Palgrave Macmillan, 2016, 150-180. 
Xin Liu, '1 million Officials Probed for Graft', Global Times, 24 October 2016, online at: http://www. globaltimes.cn/content/1013265.shtml

Yi Liu, 'Zhiwu liangjian yidaoqie, huanbao shoufa caineng cheng changtai' (Only Implementing Environment Regulations Rigorously and Universally Can Lead to Better Environment and Lawabiding Behaviour), Weixin, 7 July 2017, online at: http://news.sina.com.cn/c/2017-07-07/docifyhvyie0566932.shtml

Yi Liu, Landscape Designing in Post-industrial Heritage Protection, MA Thesis, Central South University, China, 2010.

Live Mint, 'Coal India Workers Call for Nation-wide Strike on 2 September', Live Mint, 20 August 2016a, online at: http://www.livemint.com/Politics/mKqjYT4I1COFK4m5r3mgIJ/Coal-Indiaworkers-call-for-nationwide-strike-on-2-Septembe.html

Live Mint, '10 Trade Unions Firm on 2 September Nation-wide Strike', Live Mint, 19 August 2016b, online at: http://www.livemint.com/Politics/W6WR7JTaAlcwJ3w0flkQGI/10-trade-unions-firmon-2-September-nationwide-strike.html

Jiwei Lou and Shuilin Wang, Public Finance in China: Reform and Growth for a Harmonious Society, Washington, D.C.: World Bank, 2008.

Hong Lu, Zhongguo dangdai yishu shi (A History of Chinese Contemporary Art), Shanghai: Shanghai Paintings and Calligraphy Publishing House, 2014.

Lu Xun (edited by Eileen J. Cheng and Kirk A. Denton), Jottings under Lamplight, Cambridge: Harvard University Press, 2017.

Lu Xun (translated by Ivan Franceschini), Fuga sulla Luna, Milano: O Barra O Edizioni, 2014.

Lu Xun (translated by Julia Lovell), The Real Story of Ah-Q and Other Tales of China, London: Penguin Classics, 2010.

Lu Xun (translated by Xianyi Yang and Gladys Yang), Selected Works: Volume III, Beijing: Foreign Language Press, 2003.

Thim Ly, 'Mobilizing Against Hydropower Projects: Multi-Scale Dimensions of Civil Society Action in a Transboundary Setting', in Gabi Waibel, Judith Ehlert, and Hart N. Feuer eds, Southeast Asia and the Civil Society Gaze, London and New York: Routledge, 2014, 153-167.

Jun Ma, 'Ecological Civilisation Is the Way Forward', Chinadialogue, 31 October 2017, online at: https://www.chinadialogue.net/article/1440-Ecological-civilisation-is-the-way-forward

Mark Magnier, Lingling Weit, and Ian Tally, 'China Economic Growth Is Slowest in Decades', The Wall Street Journal, 19 January 2015, online at: https://www.wsj.com/articles/china-gdp-growth-isslowest-in-24-years-1421719453

Weidong Mao, Stephanie H. Tung, John Tancock, Christophe Mao eds, Ai Weiwei New York Photographs 1983-1993, Beijing: Three Shadow Press Limited, 2012.

Zedong Mao, ‘On Lu Hsun’, 19 October 1939, online at: https://www.marxists.org/reference/archive/ mao/selected-works/volume-6/mswv6_27.htm 
Christian Marrazzi, Capital and Language: From the New Economy to the War Economy, Cambridge: The MIT Press, 2008.

Karl Marx, Grundrisse: Foundations of the Critique of Political Economy, Harmondsworth: Penguin, 1973.

Karl Marx and Friedrich Engels, The Communist Manifesto, New York: Bantam Dell, 2004.

Paul Mason, Postcapitalism: A Guide to Our Future, London: Allen Lane, 2015.

Ugo Mattei, 'Protecting the Commons: Water, Culture, and Nature: The Commons Movement in the Italian Struggle against Neoliberal Governance', South Atlantic Quarterly, vol.112, no.2 (2013): 366-376.

MCA (Ministry of Civil Affairs), 'Minzhengbu guanyu "minban feiqiye danwei dengji guanli zanxing tiaoli (xiuding caoan zhengqiu yijiangao)" gongkai zhengqiu yijian de tongzhi' (Notice of Soliciting Public Opinions by the Ministry of Civil Affairs on Provisional Regulations on the Registration and Management of Private Non-Enterprises), 26 May 2016, online at: http://www.mca.gov.cn/article/ zwgk/tzl/201605/20160500000664.shtml

MCA (Ministry of Civil Affairs), 'Jijinhui Guanli Tiaoli' (Regulations on Administration of Foundations), 11 February 2004, online at: http://www.mca.gov.cn/article/zwgk/ tzl/200711/20071100003953.shtml

Matthew McCartney, Political Economy, Growth and Liberalisation in India, 1991-2008, London and New York: Routledge, 2009.

Terry McGee, George C.S. Lin, Mark Wang, Andrew Marton, and Jiaping Wu, 'China's Urban Space Development under Market Socialism, London and New York: Routledge, 2008.

Veronica McLaughlin, 'Inside the Chinese Mayor (Interview)', The 13th Floor, 8 July 2015, online at: https://www.13thfloor.co.nz/inside-the-chinese-mayor-interview/

Dan Meng, Mining Abandoned Land Construction and Environmental Regeneration Research, MA Thesis, Dalian University of Technology, China, 2011.

Sreelatha Menon, 'Indian Trade Unions are Getting Bigger, Coinciding with Slowdown', Business Standard, 6 April 2012, online at: http://www.business-standard.com/article/economy-policy/indiantrade-unions-are-getting-bigger-coinciding-with-slowdown-113040600392_1.html

Robert K. Merton, Social Theory and Social Structure, New York: Simon and Schuster, 1968.

Cecilia Milwertz and Wei Bu, 'Non-governmental Organising for Gender Equality in China', International Journal of Human Rights, vol.11, no.1-2 (2007): 131-149.

Yu Ming, Chinese Jade, Cambridge: Cambridge University Press, 2009.

Ministry of Culture, 'Caizhengbu xiada 44.2 yi yuan wenhua chanyefazhan zhuanxiang zijin' (Ministry of Finance Earmarked RMB 4.42 Dillion for Developing the Cultural Industry), 10 August 2016, online at: http://www.mcprc.gov.cn/whzx/whyw/201608/t20160810_463038.html 
Ministry of Education, 'Jiaoyubu deng wubumen guanyu yinfa "Zhiye xuexiao xuesheng shixi guanli guiding” de tongzhi' (Notice on the Issuance of Regulations on Management of Interns from Vocational Schools by the Ministry of Education and Four Other Ministries), 18 April 2016, online at: http://www.moe.edu.cn/srcsite/A07/moe_950/201604/t20160426_240252.html

Ministry of Education, 'Zhonghua renmin gongheguo zhiye jiaoyu fa' (Vocational Education Law of the People's Republic of China), 15 May 1996, online at: http://old.moe.gov.cn//publicfiles/business/ htmlfiles/moe/moe_619/200407/1312.html

Timothy Mitchell, ‘Carbon Democracy’, Economy and Society, vol.38, no.3 (2009): 399-432.

David Moberg, 'The Union behind the Biggest Campaign against Walmart in History May Be Throwing in the Towel. Why?', These Times, 11 August 2015, online at: http://inthesetimes.com/ article/18271/which-way-our-walmart

Mocamomo, 'Member Ren Hang on Phone Case Design', YouTube, 28 August 2012, online at: https:// www.youtube.com/watch?v=0ZJkanlYpb4

Henrik Kloppenborg Møller, 'The Potentials of Feicui: Indeterminacy and Determination in Human-Jade Interactions in South-West China', in Susanne Bregnbæk and Mikkel Bunkenborg eds, Emptiness and Fullness: Ethnographies of Lack and Desire in Contemporary China, New York and Oxford: Berghahn Books, 2017, 120-139.

Alexander Montague-Sparey, 'Shanghai 2016 Posts Strongest Ever Sales', Photofairs, 12 September 2016, online at https://www.artsy.net/article/photofairs-photofairs-shanghai-2016-posts-strongestever-sales

Alain Morice and Swanie Potot eds, De l'ouvrier immigré au travailleur sans papiers: Les ètrangers dans la modernisation du salariat, Paris: Karthala, 2010.

Lydia Morris, Managing Migration: Civic Stratification and Migrants Rights, London and New York: Routledge, 2002.

Mette Mortensen, 'Constructing, Confirming, and Contesting Icons: The Alan Kurdi Imagery Appropriated by \#humanitywashedashore, Ai Weiwei, and Charlie Hebdo', Media, Culture \&t Society, vol.39, no.8 (2017): 1142-1161.

Andrew Nachemson and Mech Dara, 'Hun Sen Mocks Sam Rainsy's Facebook Page', The Phnom Penh Post, 29 August 2017, online at: http://www.phnompenhpost.com/national/hun-sen-mocks-samrainsys-facebook-page

Thomas Naylor, 'The Underworld of Gemstones: Part 1: Under the Rainbow', Crime, Law and Social Change, vol.53, no.2 (2010): 131-158.

Antonio Negri, Marx beyond Marx, Massachusetts: Bergin \& Garvey, 1984.

Brett Neilson and Ned Rossiter, 'Precarity as a Political Concept, or, Fordism as Exception', Theory, Culture and Society, vol.25, no.7-8 (2008): 51-72.

Tu Phuong Nguyen, 'Labour Unrest in Vietnam and China: Insurgency or Contained Contention?', Journal of Contemporary Asia, vol.46, no.2 (2016): 345-358. 
NYC Stands with Standing Rock Collective, '\#StandingRockSyllabus', NYC Stands with Standing Rock, 2016, online at: https://nycstandswithstandingrock.wordpress.com/standingrocksyllabus/

Pál Nyíri, 'The Yellow Man's Burden: Chinese Migrants on a Civilizing Mission', The China Journal, vol.56 (2006): 83-106.

NPC (National People's Congress), 'Zhonghua renmin gongheguo minfa zongze' (General Provisions of Civil Law), 15 March 2017, online at: http://www.npc.gov.cn/npc/xinwen/2017-03/15/ content_2018907.htm

NPC (National People's Congress), '2016 Charity Law', China Law Translate, 16 March 2016, online at: http://www.chinalawtranslate.com/2016charitylaw/?lang=en

National People's Congress, 'Zhonghua renmin gongheguo xianfa (1954 nian)' (The Constitution of the People's Republic of China, 1954), Zhongguo Rendawang, 26 December 2000, online at: http:// www.npc.gov.cn/wxzl/wxzl/2000-12/26/content_4264.htm

Pál Nyíri, 'Extraterritoriality. Foreign Concessions: The Past and Future of a Form of Shared Sovereignty', EspacesTemps.net, 23 November 2009, online at: https://www.espacestemps.net/ articles/extraterritoriality-pal-nyiri/

Eriko Obayashi, Tokyo’s Constant Booksellers, Taipei: Linking Publishing, 2017.

OECD, 'International Migration Outlook 2015', OECD Library, September 2015, online at : http:// www.oecd-ilibrary.org/social-issues-migration-health/international-migration-outlook-2015_migr_ outlook-2015-en

OECD, 'International Migration Outlook 2013’, OECD Library, June 2013, online at: www.oecdilibrary.org/social-issues-migration-health/international-migration-outlook-2013_migr_outlook2013-en

Aihwa Ong, Neoliberalism as Exception: Mutations in Citizenship and Sovereignty, Durham: Duke University Press, 2006.

Aihwa Ong and Li Zhang, 'Introduction: Privatizing China: Powers of the Self, Socialism from Afar', in Li Zhang and Aihwa Ong eds, Privatizing China: Socialism from Afar, Ithaca: Cornell University Press, 2008, 1-20.

Operational Centre of the Capital of Women's Shoes, 'Chengdu xieye tongye gonghui kuaisu fanying "huanbao yidaoqie" wenti' (Chengdu Shoes Association Reacted Swiftly to Issues of the "One-sizefit-for-all Approach to Environmental Problems"), Sohu.com, 29 August 2017a, online at: http://www. sohu.com/a/168402063_206133

Operational Centre of the Capital of Women's Shoes, 'Chaoqianjia qiye huifu shengchan, "yigaoqie” tingle?' (More than 1000 Factories Resumed Production, Signalling the End of the “One-size-fit-for-all Approach”?), Sohu.com, 6 September 2017b, online at: http://www.sohu. com/a/190230486_737406

Sherry B. Ortner, 'Reading America: Preliminary Notes on Class and Culture', in Richard G. Fox eds, Recapturing Anthropology: Working in the Present, Santa Fe: SAR Press, 1999, 163-189.

Elinor Ostrom, Joanna Burger, Christopher B. Field, Richard B. Norgaard, and David Policansky, 
'Revisiting the Commons: Local Lessons, Global Challenges', Science, vol.284, no.5412 (1999): 278-282.

Sony Ouch and Khuon Narim, 'Popular Political Analyst Kem Ley Shot Dead', The Cambodia Daily, 10 July 2016, online at: https://www.cambodiadaily.com/news/popular-political-analyst-kem-leyshot-dead-115246/

Philip P. Pan, 'Chinese Evade Censors to Discuss Police Assault', The Washington Post, 17 December 2005, online at: http://www.washingtonpost.com/wp-dyn/content/article/2005/12/16/ AR2005121601709.html

PBS, '5 Times Ai Weiwei's Art Has Called Attention to the Refugee Crisis', PBS, 19 February 2016, online at: https://www.pbs.org/newshour/arts/5-times-ai-weiweis-art-has-called-attention-to-therefugee-crisis

Jamie Peck and Jun Zhang, 'A Variety of Capitalism... with Chinese Characteristics?', Journal of Economic Geography, vol.13, no.3 (2013): 357-396.

People's Net, 'Zhongguo gongchandang zhangcheng' (The Charter of the Chinese Communist Party), Renminwang, 29 October 2017, online at: http://politics.people.com.cn/nl/2017/1029/c100129614393.html

Elizabeth J. Perry, Anyuan: Mining China's Revolutionary Tradition, Berkeley: University of California Press, 2012.

Tom Phillips, 'Xi Jinping Orders Army to "Unswervingly Follow Communist Party Leadership”, The Guardian, 30 July 2017, online at: https://www.theguardian.com/world/2017/jul/30/xi-jinpingorders-army-to-unswervingly-follow-communist-party-leadership

Andrea E.Pia, 'On Chinese Pedagogical Legalism (and Its Anthropological Ghost) \#Fictions', Allegra Lab, 5 May 2016a, online at: http://allegralaboratory.net/on-chinese-pedagogical-legalism-and-itsanthropological-ghost-fictions/

Andrea E. Pia, “"We Follow Reason, Not the Law:” Disavowing the Law in Rural China', Political and Legal Anthropology Review, vol.39, no.2 (2016b): 276-293.

Frank N. Pieke, 'Introduction: Chinese and European Perspectives on Migration', in Frank N. Pieke and Hein Mallee eds, Internal and International Migration: Chinese Perspectives, Richmond: Curzon, 1999, 1-26.

Lydia Potts, The World Labour Market: A History of Migration, London: Zed Books, 1990.

Jacob Poushter, 'European Opinions of the Refugee Crisis in 5 Charts', Pew Research Centre, 16 September 2016, online at: http://www.pewresearch.org/fact-tank/2016/09/16/european-opinionsof-the-refugee-crisis-in-5-charts/

Chloe Preece, 'The Authentic Celebrity Brand: Unpacking Ai Weiwei's Celebritised Selves', Journal of Marketing Management, vol.31, no.5-6 (2015): 616-645.

Tim Pringle, 'A Class against Capital: Class and Collective Bargaining in Guangdong', Globalizations, vol.14, no.2 (2016): 245-258. 
Project MAJE, ‘The North War: A Kachin Conflict Compilation Report', 2011, online at: http://www. projectmaje.org/kachin_2011.htm

Jaroslav Průšek, 'Basic Problems of the History of Modern Chinese Literature and C. T. Hsia, a History of Modern Chinese Fiction', T’oung Pao, vol.49, no.4-5 (1962): 357-404.

Ngai Pun, Migrant Labor in China: Post-Socialist Transformations, Cambridge: Polity Press, 2016.

Ngai Pun, Made in China: Women Factory Workers in a Global Workplace, Durham and Hong Kong: Duke University Press and Hong Kong University Press, 2005.

Ngai Pun and Huilin Lu, 'A Culture of Violence: The Labor Subcontracting System and Collective Action by Construction Workers in Post-socialist China', The China Journal, no.64 (2010a): 143-158.

Ngai Pun and Huilin Lu, 'Unfinished Proletarianization: Self, Anger, and Class Action among the Second Generation of Peasant-workers in Present-day China', Modern China, vol.36, no.5 (2010b): 493-519.

Ngai Pun and Chris Smith, 'Putting Transnational Labour Process in Its Place: The Dormitory Labour Regime in Post-Socialist China', Work, Employment \& Society, vol.21, no.1 (2007): 27-45.

Radio Free Asia, 'Millions of Cambodians join Kem Ley Funeral Procession', Radio Free Asia, 24 July 2016, online at: http://www.rfa.org/english/news/cambodia/cambodia-funeral-07242016145816. html

A. Terry Rambo, 'Observations on the Role of Improved Fallow Management in Swidden Agricultural Systems', Malcolm Cairns ed, Voices from the Forest: Integrating Indigenous Knowledge into Sustainable Upland Farming, London and New York: Routledge, Washington D.C.: Resources for the Future, 2007, 780-802.

Austin Ramzy, 'Chinese Court Sentences Activist Who Documented Protests to 4 Years in Prison', The New York Times, 4 August 2017, online at: https:/www.nytimes.com/2017/08/04/world/asia/ china-blogger-lu-yuyu-prison-sentence-protests-picking-quarrels.html

Jin Ran, 'Nugong beihoude "shanren”-canjiren ziqiangdui diaocha' (The Kind People Supporting the Slaves at the Black Brick Kilns-Investigating the Self-Rescuing Team of the Disabled), Nanfang Zhoumo, 24 December 2010, online at: https://news.qq.com/a/20101224/001754.htm

Jacques Rancière (translated by Gabriel Rockhill), The Politics of Aesthetics, Edinburgh: A\&C Black, 2006.

Debika Ray, 'Water Trading Could Exacerbate Water Shortages in China', Chinadialogue, 20 May 2013, online at: https://www.chinadialogue.net/article/show/single/en/6026-Water-trading-couldexacerbate-water-shortages-in-China

Christopher Rea, The Age of Irreverence, Berkeley: University of California Press, 2015.

B. Muralidhar Reddy, 'University, College Teachers Unions Endorse Sept 2 General Strike Call', The Hindu, 9 August 2016, online at: http://www.thehindu.com/news/national/University-collegeteachers-unions-endorse-Sept-2-general-strike-call/article14560371.ece 
Hang Ren (translated by Amanda Lee Koe), 'The Last Ten Entries of Ren Hang's Depression Diary', Guernica, 26 May 2017, online at: https://www.guernicamag.com/the-last-ten-entries-of-ren-hangsdepression-diary/

Neil Renwick, 'China’s Role in Burma's Development', IDS Bulletin, vol.45 no.4 (2014): 70-84.

Reuters, 'Greek Pork Workers Strike Again over Privatization', Asia Pacific Maritime, 24 May 2016, online at: https://www.maritime-executive.com/article/greek-port-workers-strike-again-overprivatization

Graeme B. Robertson, The Politics of Protest in Hybrid Regimes: Managing Dissent in Post-Communist Russia, Cambridge: Cambridge University Press, 2010.

Royal Academy of Arts, 'Year in Review 2014-15: Highlights from the Period 1 September 2014-31 August 2015', 2015, online at: https://www.royalacademy.org.uk/page/ra-year-in-review-2014-15

Huaichuan Rui, Miao Zhang, and Alan Shipman, 'Chinese Expatriate Management in Emerging Markets: A Competitive Advantage Perspective', Journal of International Management, vol.23, no.2 (2017): 124-138.

Bill Russo, Tao Ke, and Edward Tse, 'An Inorganic Approach to Globalization: The Marriage of Geely and Volvo', BoozEtCompany, April 2010, online at: https://www.strategyand.pwc.com/media/file/ An_Inorganic_Approach_to_Globalization_en.pdf

Michael Safi, 'Tens of Millions of Indian Workers Strike in Fight for Higher Wages', The Guardian, 2 September 2016, online at: https://www.theguardian.com/world/2016/sep/02/indian-workersstrike-in-fight-for-higher-wages

Yos Santansombat eds, Impact of China's Rise on the Mekong Region, New York: Palgrave Macmillan, 2015 .

Saskia Sassen, 'The State and Globalisation', Postcolonial Interventions, vol.5, no.2 (2003): 214-248.

Saskia Sassen, Globalisation and its Discontents: Essays on the New Mobility of People and Money, New York: The New Press, 1998.

Carl-Ulrik Schierup, Peo Hansen, and Stephen Castles eds, Migration, Citizenship, and the European Welfare State, Oxford: Oxford University Press, 2006.

Carl-Ulrik Schierup, Ronaldo Munck, Branka Likić-Brborić, and Anders Neergard eds, Migration, Precarity, and Global Governance: Challenges and Opportunities for Labour, Oxford: Oxford University Press, 2015.

Rob Schmitz, 'China Shuts Down Tens of Thousands of Factories in Unprecedented Pollution Crackdown', National Public Radio, 23 October 2017, online at: https://www.npr.org/sections/ parallels/2017/10/23/559009961/china-shuts-down-tens-of-thousands-of-factories-inunprecedented-pollution-crack

Mindi Schneider, 'What, Then, Is a Chinese Peasant? Nongmin Discourses and Agroindustrialization in Contemporary China', Agriculture and Human Values, vol.32, no.2 (2015): 331-346.

Walter Schumann, Gemstones of the World (Newly Revised Fifth Edition), New York: Sterling, 1976. 
Suzanne Scott, ‘The Trouble with Transformation: Fandom's Negotiation of Transmedia Storytelling Systems', Translating Media, vol.30, no.1 (2010): 30-34.

Phetphoxay Sengpaseuth, 'Lao Workers' Rights not Upheld, Labour Official Says', Vientiane Times, 31 August 2017, online at: http://www.asianews.eu/content/lao-workers'-rights-not-upheld-labourofficial-says- 54925

Aman Sethi, '13 Guilty of Murder in 2012 Maruti Factory Riot That Killed One, 117 Acquitted', Hindu Times, 17 March 2017, online at: http://www.hindustantimes.com/gurgaon/13-guilty-of-murder-in2012-maruti-factory-riot-that-killed-one-117-acquitted/story-0OEhWKQplgDVzbkNcS008H.html

Ellen Sheng, 'China Investment in the U.S. Hit an All-time High in 2016, But Don't Expect the Same in 2017', Forbes, 18 December 2016, online at: https://www.forbes.com/sites/ellensheng/2016/12/18/ chinese-investments-in-the-u-s-hit-an-all-time-high-in-2016-but-dont-expect-the-same-in2017/\#5b40b4df5abe

Xiaolu Shi, "Chengdu xiafa jinji tongzhi mingque sange "juebu yunxu” jiaoting huanbao wenti zhenggai "yidaoqie" (Urgent Notice Issued in Chengdu, Outlining Three "Don'ts" and Suspending the One-size-fit-for-all Approach to Environmental Problems), Sichuan Daily, 12 August 2017, online at: http://epaper.scdaily.cn/shtml/scrb/20170812/170622.shtml

Shawn Shieh, 'Initiative on Philanthropy in China Same Bed, Different Dreams? The Divergent Pathways of Foundations and Grassroots NGOs in China', China Philanthropy Summit Research Center for Chinese Politics \& Business and Lilly Family School of Philanthropy, October-November 2014, online at https://philanthropy.iupui.edu/files/file/p4_shawn_shieh.pdf

Edward Shorter and Charles Tilly, 'The Shape of Strikes in France, 1830-1960', Comparative Studies in Society and History, vol.13, no.1 (1971): 66-86.

Sichuan Provincial Government, 'Zhongyang huanbao ducha zai Sichuan' (Observations from Central Environmental Inspection Teams in Sichuan Province), 11 September 2017, online at: http:// www.schj.gov.cn/ztzl/2017/zyhbdc/bdbg/dcqzxfzbqkgk/201709/t20170911_247039.html

Kate Sierzputowski, 'Ai Weiwei Wraps the Columns of Berlin's Konzerthaus with 14,000 Salvaged Refugee Life Vests', Colossal, 16 February 2016, online at: http://www.thisiscolossal.com/2016/02/aiweiwei-konzerthaus-refugee-life-vests/

Beverly J. Silver, Forces of Labour: Workers' Movements and Globalisation Since 1870, Cambridge: Cambridge University Press, 2003.

Karla W. Simon, Civil Society in China: The Legal Framework from Ancient Times to the "New Reform Era”, New York: Oxford University Press Inc, 2013.

Karla W. Simon and Holly Snape, 'Charitable Giving in China in a New Legislative Environment', Alliance Magazine, January 2017, online at: http://www.alliancemagazine.org/blog/charitablegiving-china-new-legislative-environment/

Karla W, Simon and Jessica Teets, 'Revolutionizing Social Service Delivery in China: The New Policy of “Contracting Out” to Non-Profit Organisations', International Journal of Civil Society Law, vol.12, no.2 (2014): 28-66. 
Yon Sineat and Ananth Baliga, 'Big Boost for Garment Sector Minimum Wage, Though Some See a Political Motive', The Phnom Penh Post, 6 October 2017, online at: http://www.phnompenhpost.com/ national/big-boost-garment-sector-minimum-wage-though-some-see-political-motive

Kaxton Siu, 'Continuity and Change in the Everyday Lives of Chinese Migrant Factory Workers', The China Journal, no.74 (2015): 43-65.

Kaxton Siu and Anita Chan, 'Strike Wave in Vietnam, 2006-2011', Journal of Contemporary Asia, vol.45, no.1 (2015): 71-91.

Vaclav Smil, China's Past, China's Future: Energy, Food, Environment, London and New York: Routledge, 2003.

Chris Smith and Jenny Chan, 'Working for Two Bosses: Student Interns as Constrained Labour in China', Human Relations, vol.68, no.2 (2015): 305-326.

Chris Smith and Ngai Pun, 'The Dormitory Labour Regime in China as a Site for Control and Resistance', The International Journal of Human Resource Management, vol.17, no.8 (2006): 14561470 .

Dorothy J. Solinger, 'Citizenship Issues in China's Internal Migration: Comparisons with Germany and Japan', Political Science Quarterly, vol.114, no.3 (1999a): 455-478.

Dorothy J. Solinger, Contesting Citizenship in Urban China, Berkeley: University of California Press, 1999b.

Dorothy J. Solinger, 'The Chinese Work Unit and Transient Labor in the Transition from Socialism', Modern China, vol.21, no.3 (1995): 155-183.

Christian Sorace, 'Paradise under Construction', in Ivan Franceschini, Kevin Lin and Nicholas Loubere eds, Made in China Yearbook: 2016 Disturbances in Heaven, Canberra: ANU Press, 2016, 128-131.

Christian Sorace, 'In Rehab with Weiwei', The China Story Journal, 14 October 2015, online at: https://www.thechinastory.org/2015/10/in-rehab-with-weiwei/

Christian Sorace, 'China's Last Communist: Ai Weiwei', Critical Inquiry, vol.40, no.2 (2014): 396-419.

Alexis Spire, 'Xénophobes au nom de l'Etat social', Le Monde Diplomatique, December 2013, online at: http://www.monde-diplomatique.fr/2013/12/SPIRE/49901

Anthony J. Spires, 'Organizational Homophily in International Grantmaking: US-Based Foundations and Their Grantees in China', Journal of Civil Society, vol.7, no.3 (2011): 305-331.

Nick Srnicek and Alex Williams, Inventing the Future: Post-Capitalism and a World without Work, London: Verso, 2016.

Michael Standaert, 'China Pollution Inspections Disrupting Supply Chains', Bloomberg, 18 September 2017, online at: https://www.bna.com/china-pollution-inspections-n57982088091

Guy Standing, The Precariat: The New Dangerous Class, London: Bloomsbury Academic, 2011. 
State Council, '2015 nian shehui fuwu fazhan tongji gongbao' (2015 Statistical Report on Social Services), 11 July 2016, online at: http://www.gov.cn/shuju/2016-07/11/content_5090289.htm

State Council, 'Guojia zhongchangqi jiaoyu gaige he fazhan guihua gangyao (2010-2020 nian)' (Guidelines for Mid- to Long-term National Education Reform and Development, 2010-2020), 29 July 2010, online at: http://www.gov.cn/jrzg/2010-07/29/content_1667143.htm

State Council, 'Zhonghua renmin gongheguo kanshousuo tiaoli' (Regulations for Detention Centres of the People's Republic of China), 1990, online at: https://baike.baidu.com/item/\%E4\%B8\%AD\%E5 \%8D\%8E\%E4\%BA\%BA\%Е6\%B0\%91\%Е5\%85\%B1\%E5\%92\%8C\%Е5\%9B\%BD\%E7\%9C\%8B\%E5\%A E\%88\%E6\%89\%80\%E6\%9D\%A1\%E4\%BE\%8B

Michael Stewart, 'Deprivation, the Roma and "the Underclass"', in C.M. Hann ed, Postsocialism: Ideals, Ideologies and Practices in Eurasia, London and New York: Routledge, 2002, 133-156.

Susan Stewart, On Longing: Narratives of the Miniature, the Gigantic, the Souvenir, the Collection', Durham: Duke University Press, 1992.

Giorgio Strafella, Intellectual Discourse in Reform Era China: The Debate on the Spirit of the Humanities in the 1990s, London and New York: Routledge, 2017.

Wolfgang Streeck and Philippe C. Schmitter, 'Community, Market, State-and Associations?', European Sociological Review, vol.1, no.2 (1985): 119-138.

Andrew Sturdy, Peter Fleming, and Rick Delbridge, 'Normative Control and Beyond in Contemporary Capitalism', in Paul Thompson and Chris Smith eds, Working Life: Renewing Labour Process Analysis, London: Palgrave Macmillan, 2010, 113-135.

Laichen Sun, 'From Baoshi to Jadeite: Qing-Burmese Gem Trade, c. 1644-1800', in Eric Tagliacozzo and Wenchin Chang eds, Chinese Circulations: Capital, Commodities, and Networks in Southeast Asia, Durham and London: Duke University Press, 2011, 203-216.

Zhengliang Sun and Tao Zhu, 'Huanbao buguoguan Lezhi duoge qiye bei jiaoting' (Not Meeting Environmental Standards, Many Factories in Lezhi County Shut Down), Ziyang Ribao, 16 August 2017, online at: http://www.zyrb.com.cn/2017/0816/227801.shtml

Supreme People's Procuratorate, 'Quality Standards for the Examination of Arrest Requests by People's Procuratorates', 25 August 2010, online at: http://www.lawinfochina.com/display. aspx?lib=law\&id=14811\&CGid=

Sreemoy Talukdar, 'As Narendra Modi’s Popularity Rises, Opposition Hopes May Lie with Mamata Banerjee in 2019', First Post, 19 August 2017, online at: http://www.firstpost.com/ politics/as-narendra-modis-popularity-rises-opposition-hopes-may-lie-with-mamata-banerjeein-2019-3946199.html

Dongyan Tao, Xin Tong, and Carlo Inverardi-Ferri, 'The Production of Grey Space in Rural-Urban Fringe: A Case Study of the "Waste Village" in Beijing', Urban Planning International, no.5 (2014): 8-14.

Monique Taylor, The Chinese State, Oil and Energy Security, London: Palgrave Macmillan UK, 2014. John Kuo Wei Tchen and Dylan Yeats, Yellow Peril! An Archive of Anti-Asian Fear, Brooklyn: Verso, 2014. 
Tenth Mining Task Force, 'China’s Mining Industry in 2015: Developments and Policies', Asia-Pacific Economic Cooperation Meeting, Arequipa, Peru, 9-10 May 2016, online at: http://mddb.apec.org/ Documents/2016/MTF/MTF/16_mtfl_016.pdf

E.P. Thompson, The Making of the English Working Class, New York: Vintage, 1966.

Alvin Toffler, The Third Wave, New York: Bantam Books, 1980.

Bill Toland, 'In Desperate 1983, There Was Nowhere for Pittsburgh's Economy to Go but Up', Pittsburg Post-Gazette, 23 December 2012, online at www.post-gazette.com/business/ businessnews/2012/12/23/In-desperate-1983-there-was-nowhere-for-Pittsburgh-s-economy-to-gobut-up/stories/201212230258

Kudo Toshihiro, 'China's Policy toward Myanmar: Challenges and Prospects', Institute of Developing Economies Working Paper, May 2014, online at: http://www.ide.go.jp/English/Research/Region/ Asia/201209_kudo.html

Angie Ngoc Tran, Ties That Band: Cultural Identity, Class, and Law in Vietnam's Labor Resistance, Ithaca: Cornell University Press, 2014.

Anna Lowenhaupt Tsing, The Mushroom at the End of the World: On the Possibility of Life in Capitalist Ruins, Princeton: Princeton University Press, 2015.

Michael Ulfstjerne, Un-real Estate. The Social Life of Temporary Wealth in China, PhD Thesis, University of Copenhagen, 2015.

Jonathan Unger, 'The Struggle to Dictate China's Administration: The Conflict of Branches vs Areas vs Reform', The Australian Journal of Chinese Affairs, no.18 (1987): 15-45.

USTR (United States Trade Representative), 'United States-Viet Nam Plan for the Enhancement of Trade and Labour Relations', 4 February 2016, online at: https://ustr.gov/sites/default/files/TPPFinal-Text-Labour-US-VN-Plan-for-Enhancement-of-Trade-and-Labour-Relations.pdf

Jake Van Der Kamp, 'Why Textile Trade Is Slipping through China's Fingers', South China Morning Post, 20 January 2016, online at: http://www.scmp.com/business/global-economy/article/1903487/ why-textile-trade-slipping-through-chinas-fingers

Philippe Van Parijs, 'Basic Income: A Simple and Powerful Idea for the Twenty-First Century', Politics \&t Society, vol.32, no.1 (2004): 7-39.

Carlo Vercellone, The Hypothesis of Cognitive Capitalism, London: Birkbeck College and SOAS, 2005.

Eduard B. Vermeer, 'Demographic Dimensions of China's Development', Population and Development Review, vol.32 (2006): 115-144.

Vientiane Times, 'Chinese Firms Responsible for Largest SEZ Investments', The Nation, 4 August 2017, online at: http://www.nationmultimedia.com/detail/business/30322771

Vietnam News Agency (VNA), 'Minimum Wage Increases Continue to Fall Far Short', Vietnam Plus, 18 June 2017, online at: https://en.vietnamplus.vn/minimum-wage-increases-continue-to-fall-farshort/113482.vnp 
Jared Vineyard, 'China Pollution Crackdown Shuts Down Thousands of Factories Disrupting Supply Chain', Universal Cargo, 19 September 2017, online at: http://www.universalcargo.com/chinapollution-crackdown-shuts-down-thousands-of-factories-disrupting-supply-chain/

Voice of America Khmer, Sihanouk Funeral Procession Starts With One Million Mourners, 1 February 2013, online at: https://www.youtube.com/watch?v=lWO6lqk7mQE

Loïc Wacquant, Urban Outcasts: A Comparative Sociology of Advanced Marginality, Cambridge: Polity Press, 2008.

Gabi Waibel, Judith Ehlert, and Hart N. Feuer eds, Southeast Asia and the Civil Society Gaze, London and New York: Routledge, 2014.

Andrew G. Walder and Xiaoxia Gong, 'Workers in the Tiananmen Protests: The Politics of the Beijing Workers' Autonomous Federation', The Australian Journal of Chinese Affairs, no.29 (1993): $1-29$.

Beth Walker, 'Anti-Chinese Sentiment on Rise in Myanmar', Chinadialogue, 15 May 2014a, online at: https://www.chinadialogue.net/article/show/single/en/6969-Anti-Chinese-sentiment-on-rise-inMyanmar

Beth Walker, 'Story Map: What Is the Impact of China's Mega Water Diversion Scheme?', The Third Pole, 17 December 2014, online at: https://www.thethirdpole.net/2014/12/17/story-map-what-is-theimpact-of-chinas-mega-water-diversion-scheme/

Jill Walker, 'Jade: A Special Gemstone', in Roger Keverne eds, Jade, New York: Van Nostrand Reinhold, 1991, 20-41.

Feiling Wang, 'Renovating the Great Floodgate: The Reform of China's Hukou System', in Martin K. Whyte eds, One Country, Two Societies: Rural-Urban Inequality in Contemporary China, Cambridge: Harvard University Press, 2010, 335-364.

Feng Wang, Ruediger Kuehr, Daniel Ahlquist, and Jinhui Li, 'E-Waste in China: A Country Report', StEP Green Paper Series, April 2013, online at: http://collections.unu.edu/eserv/UNU:1624/ewastein-china.pdf

Jianfeng Wang, 'Laodong hetongfa danshengji: heizhuanyao zhuqi quanpiaotongguo' (A Record of the Passing of the Labour Contract Law: Unanimous Support Thanks to the Black Brick Kilns Scandal), Jingji Ban Xiaoshi, 27 December 2007, online at: https://wenku.baidu.com/ view/9d00c7d549649b6648d7478f.html

Jianjun Wang, 'Yong guojia zhili linian mouhua shehui zuzhi gaige fazhan' (Using the Concept of National Governance in Planning Social Organization Reform and Development), China Nonprofit Review, vol.13 no.1 (2014): 1-6.

Jun Wang, 'Art in Capital': Shaping Distinctiveness in a Culture-led Urban Regeneration Project in Red Town, Shanghai', Cities, vol.26, no.6 (2009): 318-330.

Kungping Wang, Controlling Factors in the Future Development of the Chinese Coal Industry, New York: King's Crown Press, 1947. 
Zongda Wang and Chengguo Yin eds, Xiandai Jingdezhen taoci jingjishi' (Modern Economic History of Jingdezhen 1949-1993), Beijing: Zhongguo Shuji Publications, 1994.

Kathi Weeks, The Problem With Work: Feminism, Marxism, Antiwork Politics, and Postwork Imaginaries, Durham and London: Duke University Press, 2011.

Wolfgang Welsch, 'Transculturality - the Puzzling Form of Cultures Today', in Mike Featherstone and Scott Lash eds, Spaces of Culture: City, Nation, World, London and Thousand Oaks: SAGE, 1999, 194-213.

Martin K. Whyte, 'The Paradoxes of Rural-Urban Inequality in Contemporary China', in Martin K. Whyte eds, One Country, Two Societies: Rural-Urban Inequality in Contemporary China, Cambridge: Harvard University Press, 2010, 1-25.

Sue Williams, Katheryn Dietz, and Will Lyman, China in the Red, Alexandria, VA: PBS Video, 2003.

Chun Han Wong, 'China Labor Ties Fray as Grievances Rise, Economic Growth Slows', The Wall Street Journal, 9 February 2015, online at: https://www.wsj.com/articles/china-labor-ties-fray-asgrievances-rise-economic-growth-slows-1423528666

Kent Wong and Elaine Bernard, 'Rethinking the China Campaign', Colours of Resistance Archive, Fall/Winter 2000, online at: http://www.coloursofresistance.org/304/rethinking-the-chinacampaign

Kevin Woods, 'The Commercialisation of Counterinsurgency: Battlefield Enemies, Business Bedfellows in Kachin State, Burma", in Mandy Sadan eds, War and Peace in the Borderlands of Myanmar: The Kachin Ceasefire, 1994-2011, Copenhagen: NIAS Press, 2016, 114-145.

Workers Solidarity Centre, 'Report on the Ongoing Struggle and Repression at Hondo Motorcycles \& Scooters Factory Tapukara', 5 March 2016, online at: http://sanhati.com/wp-content/ uploads/2016/03/Honda-Workers-Report_WSC.pdf

Fulong Wu and Ningying Huang, 'New Urban Poverty in China: Economic Restructuring and Transformation of Welfare Provision', Asia Pacific Viewpoint, vol.48, no.2 (2007): 168-185.

Wenping Wu, 'Migrant Intra-urban Residential Mobility in Urban China', Housing Studies, vol.21, no.5 (2006): 745-765.

Yiyao Wu, 'Chinese Demand for Gold Bars and Coins Soars in First Quarter', China Daily, 5 May 2017, online at: http://www.chinadaily.com.cn/business/2017-05/05/content_29211555.htm

Zhiyuan Wu, 'Zhongguo fanzuizhixiang de ditu' (The Map of China's Criminal Towns), Daxiang Gonghui, 15 January 2014, online at: http://www.scxsls.com/a/20140115/100119.html

Wuhou District Media Office, 'Wuhouqu chanye fazhan ditu xinxian chulu' (The Map of Industrial Development Plans for Wuhou District Has Been Finalised), Sohu.com, 14 August 2017, online at: http://www.sohu.com/a/164599885_737406

Xiakedao, 'Zhe bujin shi chang huanbaozhan, yeshi chang chanye shengji de jingjizhan' (This Is a War Not Only about the Environment But Also about Industrial Upgrade), Sohu.com, 29 August 2017, online at: http://www.sohu.com/a/168375157_698856 
Xinhua, 'China Scores New Achievements in Judicial Protection of Human Rights', China Daily, 16 July 2017a, online at: http://www.chinadaily.com.cn/china/2017-07/16/content_30128773.htm

Xinhua, 'Xi Leads Ecological Civilization', China Daily, 22 March 2017b, online at: http://www. chinadaily.com.cn/china/2017-03/22/content_28634915.htm

Xinhua, 'Lianhegongzuozu tongbao Shangxi heizhuanyao shijian chachu qingkuang' (Jointinvestigation Team Reporting on the Progress of the Investigation into the Black Brick Kilns Incident), Xinlang Xinwen Zhongxin, 13 August 2007, online at: http://news.sina.com.cn/c/2007-0813/164013653720.shtml

Xuehui Xiong, 'Jingdezhen shidacichang quanjunfumo mian qutaocihuahou zhuanxingzhikun' (All Ten Porcelain Factories in Jingdezhen Were Shut Down, Leading to the Post-Porcelain Predicament), 360doc Geren Tushuguan, 18 May 2012, online at: http://www.360doc.com/ content/12/0519/09/1551506_212046032.shtml

Jianhua Xu, 'Legitimisation Imperative: The Production of Crime Statistics in Guangzhou, China', British Journal of Criminology, 12 February 2o17, online at: https://academic.oup.com/bjc/ article/2990196

Suibin Xu and Nobuo Aoki, 'Industrial Heritage Protection in the Period of Inventory Planning', Journal of Landscape Research, vol.8, no.6 (2016): 77-82.

Yunping $\mathrm{Xu}$ and Ziqiang Li, 'Tangshan shiyuanhui: hanbao yufang yongbao shiji' (Tangshan Expo: Amazing Blossom Awaiting the World), Renminwang, 20 April 2016, online at: http://paper.people. com.cn/rmrb/html/2016-04/20/nw.D110000renmrb_20160420_8-04.htm

Jie Yang, 'The Crisis of Masculinity: Class, Gender and Kindly Power in Post-Mao China', American Ethnologist, vol.37, no.3 (2010): 550-562.

Yong Yang, 'Fancy in a Tunnel', Christie’s, 23 November 2014, online at: http://www.christies.com/ lotfinder/Lot/yang-yong-b1975-fancy-in-a-5854989-details.aspx

Mon Ye, 'Chinese Ambassador Pushes for Myitsone Dam Restart', Myanmar Times, 6 June 2016, online at: https://www.mmtimes.com/national-news/20671-chinese-ambassador-pushes-formyitsone-dam-restart.html

Xiaoyan Ye, 'Changpingqu yajian liudong renkou 9.9 wan' (Mobile Residents in Changping District Reduced by 99,000), Beijing Wanbao, 25 December 2015, online at: http://bj.jjj. qq.com/a/20151225/041447.htm

Jock Young, The Vertigo of Late Modernity, London and Thousand Oaks: SAGE, 2007.

Chunsen Yu, How Do New Employment and Social Policies in Chongqing and Shenzhen Affect Rural Migrant Workers' Employment Security and Social Security?, PhD Thesis, 2017, King's College London.

Esther Hiu Kwan Yung, Edwin Hon Wan Chan, and Ying Xu, 'Sustainable Development and the Rehabilitation of a Historic Urban District: Social Sustainability in the Case of Tianzifang in Shanghai', Sustainable Development, vol.22, no.2 (2014): 95-112. 
Qingjie Zeng, 'Control, Discretion and Bargaining: The Politics of Provincial Leader Rotation in China', Chinese Political Science Review, vol.1, no.4 (2016): 623-644.

Changdong Zhang, 'Non-Governmental Organisations' Policy Advocacy in China: Resources, Government Intention and Network', China: An International Journal, vol.13, no.1 (2015): 181-199.

En Zhang, 'Hu Jintao Wen Jiabao deng dui Shangxi heizhuanyao an zuopishi' (Hu Jintao and Wen Jiabao Gave Instructions to the Handling of the Black Brick Kilns Scandal), Renminwang, 15 June 2007a, online at: http://society.people.com.cn/GB/41158/5871815.html

Li Zhang, 'Private Homes, Distinct Lifestyles: Performing a New Middle-Class', in Aihwa Ong and Li Zhang eds, Privatising China: Socialism from Afar, Ithaca: Cornell University Press, 2008, 23-41.

Li Zhang, Strangers in the City: Reconfigurations of Space, Power, and Social Networks within China's Floating Population, Stanford: Stanford University Press, 2001.

Qian Zhang, 'Yuan Cheng: xunzi zhilu jiejiu baiming shaonian heiyaogong' (Yuan Cheng's Journey to Find His Child Helped Rescue Hundreds of Teenagers from Black Brick Kilns), Beijing Qingnianbao, 29 November 2013, online at: http://news.sina.com.cn/c/2013-11-29/033928841286.shtml

Song Zhang, 'Conservation and Adaptive Reuse of Industrial Heritage in Shanghai', Frontiers of Architecture and Civil Engineering in China, vol.1, no.4 (2007b): 481-490.

Wenjin Zhang, 'The Trading Culture of Jade Stones among the Yunnanese in Burma and Thailand, 1962-88', Journal of Chinese Overseas, vol.2, no.2 (2006): 269-293.

Yi Zhang, 'Zhongguo zhengzai baofa zhangzheng "huanjing zhili” de chongtu' (In China, Conflicts over "Improving the Environment" Are Exploding), Duowei, 18 August 2017, online at: http://news. dwnews.com/china/news/2017-08-18/60007670.html

Yi Zhang and Yingxiang Liu, 'Laodongli shichang de bianhua ji "zhaogongnan” wenti diaoyan baogao' (Investigative Report on the Changes in the Labour Market and on the 'Labour Shortage'), January 2012, online at: http://www.pishu.com.cn/skwx_ps/literature/490797.html

Hongping Zhang and Peng Gu, 'Zhongyang diwu huanjing baohu duchazu ducha Sichuan sheng gongzuo dongyuanhui zai Chenghu zhaokai' (Chengdu Held the Fifth Motivational Meeting for Central Environment Inspection Teams Carrying out Inspections in Sichuan Province), Chengdu Ribao, 8 August 2017, online at: http://www.cdrb.com.cn/html/2017-08/08/content_79628.htm

Yu Zheng and Chris Smith, 'New Voyages in Search of Treasure: China Ocean Shipping Company (COSCO) in Europe', in Jan Drahokoupil eds, Chinese Investment in Europe: Corporate Strategies and Labour Relations, Brussels: European Trade Union Institute, 2017, 231-250.

Xiaohong Zhou, 'Zailun zhongchan jieji: Xianshi yihuo huanxiang' (Further Discussion on the Middle Class: Reality or Illusion), Tianjin Shehui Kexue, no.2 (2006): 60-66.

Xiaohong Zhou, 'Zailun zhongchan jieji: Lilun, lishi yu leixingxue jianji yizhong quanqiuhua de shiye' (Further Discussion on the Middle Class: Theory, History, Typology, and a Global Perspective), Shehui, vol.25, no.4 (2005a): 1-24.

Xiaohong Zhou, Zhongguo zhongchan jieji baogao (Report on China's Middle Class), Beijing: Shehui Kexue Wenxian Chubanshe, 2005b. 
Hongjun Zhu, 'Shanxi heizhuanyao neimu' (Insights into the Black Brick Kilns of Shanxi), Nanfang Zhoumo, 14 June 2007a, Al-A2.

Hongjun Zhu, 'Shanxi heizhuanyao fengbao bei ta dianran' (The Storm of the Black Brick Kilns of Shanxi Was Triggered by Her), Nanfang Zhoumo, 12 July 2007b, online at: http://www.infzm.com/ content/trs/raw/21662

Hongjun Zhu, 'Hongdong heizhuanyao shenshi diaocha' (Investigation into the Black Brick Kilns in Hongdong), Xinlang Xinwen Zhongxin, 21 June 2007c, online at: http://news.sina.com.cn/c/2007-0621/150712066580s.shtml

Hongjun Zhu, 'Beizaici zhuanmaihou shaonian Zhu Guanghui huijiale' (Having Been Trafficked Another Time, Teenager Zhu Guanghui Went Back Home), Nanfang Zhoumo, 21 June 2007d, online at: http://news.sohu.com/20070621/n250696001.shtml

Pinghui Zhuang, 'China's Environment Watchdog Reads Riot Act to Megacity over Litany of Pollution Failures', South China Morning Post, 31 July 2017, online at: http://www.scmp.com/news/ china/economy/article/2104793/chinas-environment-watchdog-reads-riot-act-megacity-over-litany

Yue Zou, 'Butiao buxuan, 48 xiaoshi songni shanggang' (With No Selection Criteria, Get Your Ready for Your Position within 48 Hours), Chengdu Shangbao, 7 August 2017a, online at: http://e.chengdu. $\mathrm{cn} / \mathrm{html} / 2017-08 / 07 /$ content_602656.htm

Xiaohua Zou, 'Nanzi beipianru heizhuanyao he chuanxiao, shisan 24 nian hou pingkoupin xunqin' (Tricked into Black Brick Kilns and Pyramid Schemes, Man, Being Lost for 24 Years, Reunited with Family Thanks to His Accent), Jiangxi Ribao, 12 April 2017b, online at: http://www.dzwww.com/ xinwen/shehuixinwen/201704/t20170412_15760093.htm

Peter Zsombor, 'Arrest of CNPR President Sokha Puts Party on the Brink', The Cambodia Daily, 4 September 2017, online at: https://www.cambodiadaily.com/news/arrest-of-cnrp-president-sokhaputs-party-on-the-brink-134268/ 


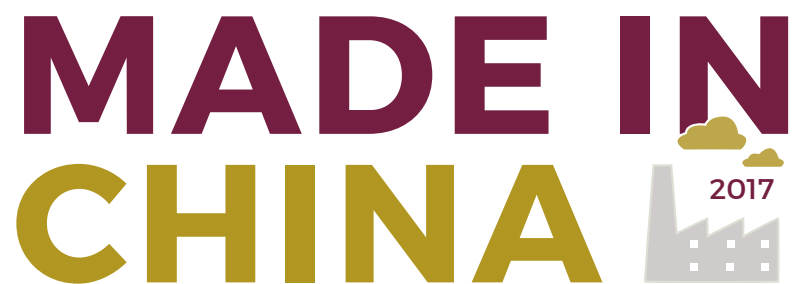

A Quarterly on Chinese Labour, Civil Society, and Rights

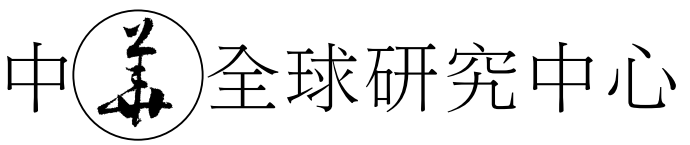

AUSTRALIAN CENTRE ON

CHINA IN THE WORLD

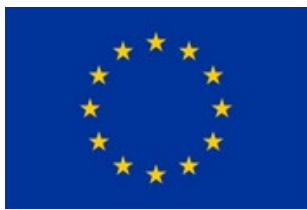

CHIN OSRESIE

mismatched shards of China

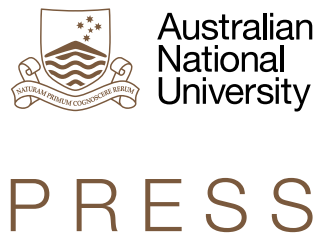

